Errol Babacan

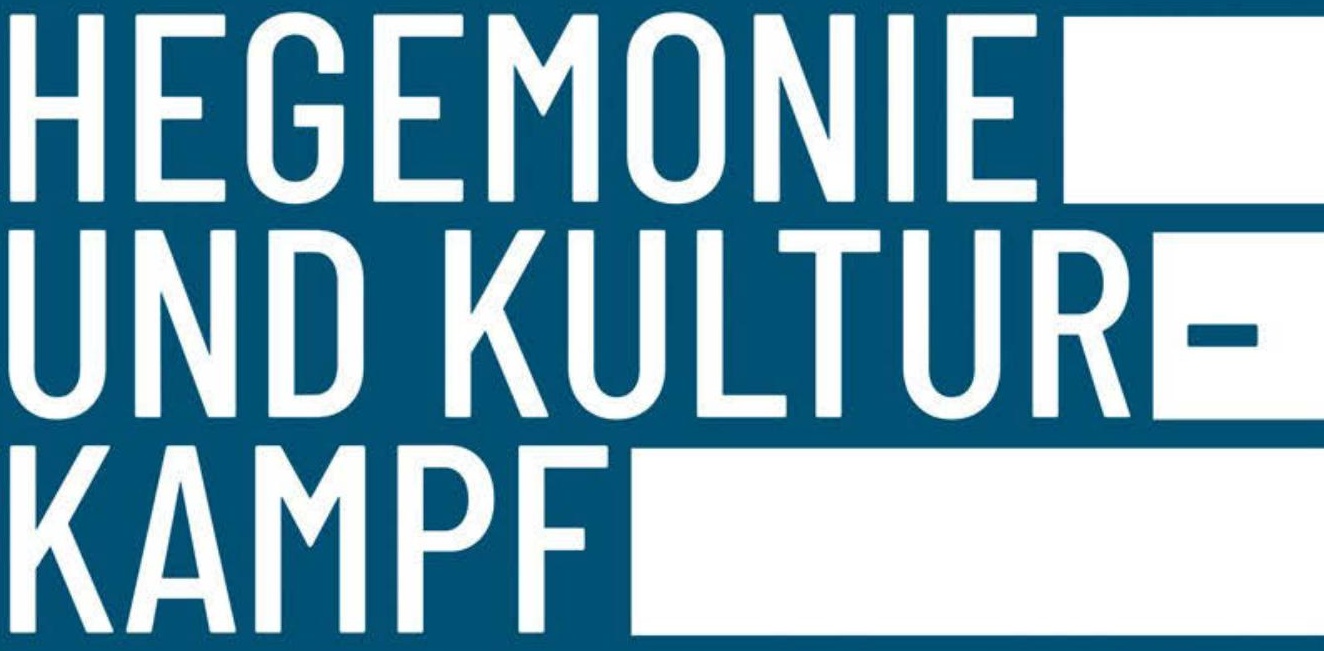

Verknüpfung von Neoliberalismus und Islam in der Türkei

[transcript] EditionPolitik 
Errol Babacan

Hegemonie und Kulturkampf

Edition Politik | Band 101 
Die freie Verfügbarkeit der E-Book-Ausgabe dieser Publikation wurde ermöglicht durch den Fachinformationsdienst Politikwissenschaft POLLUX

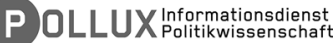

und ein Netzwerk wissenschaftlicher Bibliotheken zur Förderung von Open Access in den Sozial- und Geisteswissenschaften (transcript, Politikwissenschaft 2020)

Die Publikation beachtet die Qualitätsstandards für die Open-Access-Publikation von Büchern (Nationaler Open-Access-Kontaktpunkt et al. 2018), Phase 1 https://oa2020-de.org/blog/2018/07/31/empfehlungen_qualitätsstandards_oabücher/

\begin{tabular}{|c|c|}
\hline Karl-Franzens-Universität Graz | Universität & Landesbibliothek Münster (University \\
\hline Wien Bibliotheks- und Archivwesen | & of Munster) | Universitätsbibliothek \\
\hline Bergische Universität Wuppertal | Carl & Bielefeld (University of Bielefeld) | \\
\hline von Ossietzky-Universität (University & Universitätsbibliothek der Bauhaus- \\
\hline of Oldenburg) | Freie Universität Berlin & Universität Weimar (University of Weimar) \\
\hline (FU) (Free University of Berlin) | Georg- & | Universitätsbibliothek Erlangen- \\
\hline August-Universität Göttingen | Goethe- & Nürnberg (FAU University Erlangen- \\
\hline Universität-Frankfurt/M (University of & Nürnberg)| Universitätsbibliothek \\
\hline Frankfurt am Main) | Gottfried Wilhelm & Hagen (Fernuni Hagen) (University of \\
\hline Leibniz Bibliothek - Niedersächsische & Hagen) | Universitätsbibliothek Kassel | \\
\hline Landesbibliothek | Gottfried Wilhelm & Universitätsbibliothek Koblenz-Landau | \\
\hline Leibniz Universität Hannover | Humboldt- & Universitätsbibliothek Konstanz (University \\
\hline Universität zu Berlin | Justus-Liebig- & of Konstanz) | Universitätsbibliothek \\
\hline Universität Gießen (University of Giessen) | & Leipzig (University of Leipzig) | \\
\hline Ludwig-Maximilians-Universität München & Universitätsbibliothek Mainz (University \\
\hline (LMU) | Martin-Luther-Universität & of Mainz) | Universitätsbibliothek \\
\hline Halle-Wittenberg | Max Planck Digital & Marburg | Universitätsbibliothek \\
\hline Library | Ruhr-Universität Bochum (RUB) & Osnabrück (University of Osnabrück) \\
\hline | Sächsische Landesbibliothek Staats- und & | Universitätsbibliothek Passau \\
\hline Universitätsbibliothek Dresden (SLUB) | & | Universitätsbibliothek Siegen | \\
\hline Staatsbibliothek zu Berlin (Berlin State & Universitätsbibliothek Würzburg | Zentral- \\
\hline Library) | ULB Darmstadt | Universität & und Hochschulbibliothek Luzern (ZHB) \\
\hline Bayreuth | Universität Duisburg-Essen | & (Central and University Library of Lucerne) \\
\hline Universität Hamburg (UHH) | Universität & | Zentralbibliothek Zürich (Central Library \\
\hline Potsdam (University of Potsdam) | & of Zurich) | Bundesministerium der \\
\hline Universität Vechta | Universität zu Köln| & Verteidigung | Landesbibliothek Oldenburg \\
\hline Universitäts- und Landesbibliothek & (State Library of Oldenburg) | Leibniz- \\
\hline Düsseldorf (University and State & Institut für Europäische Geschichte | \\
\hline Library Düsseldorf)| Universitäts- und & Stiftung Wissenschaft und Politik \\
\hline
\end{tabular}

Errol Babacan (Dr. phil.), geb. 1976, ist wissenschaftlicher Mitarbeiter am Institut für Soziologie der Universität Münster. Er forscht zu Fragen der Migration sowie zur Politischen Soziologie und Ökonomie mit besonderem Schwerpunkt auf dem Politischen Islam und der Türkei. 
Errol Babacan

\section{Hegemonie und Kulturkampf}

Verknüpfung von Neoliberalismus und Islam in der Türkei

[transcript] 


\section{Bibliografische Information der Deutschen Nationalbibliothek}

Die Deutsche Nationalbibliothek verzeichnet diese Publikation in der Deutschen Nationalbibliografie; detaillierte bibliografische Daten sind im Internet über http://dnb.d-nb.de abrufbar.

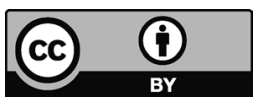

Dieses Werk ist lizenziert unter der Creative Commons Attribution 4.o Lizenz (BY). Diese Lizenz erlaubt unter Voraussetzung der Namensnennung des Urhebers die Bearbeitung, Vervielfältigung und Verbreitung des Materials in jedem Format oder Medium für beliebige Zwecke, auch kommerziell. (Lizenztext:

https://creativecommons.org/licenses/by/4.o/deed.de)

Die Bedingungen der Creative-Commons-Lizenz gelten nur für Originalmaterial. Die Wiederverwendung von Material aus anderen Quellen (gekennzeichnet mit Quellenangabe) wie z.B. Schaubilder, Abbildungen, Fotos und Textauszüge erfordert ggf. weitere Nutzungsgenehmigungen durch den jeweiligen Rechteinhaber.

Erschienen 2020 im transcript Verlag, Bielefeld

\section{(C) Errol Babacan}

Umschlaggestaltung: Maria Arndt, Bielefeld

Druck: Majuskel Medienproduktion $\mathrm{GmbH}$, Wetzlar

Print-ISBN 978-3-8376-5316-8

PDF-ISBN 978-3-8394-5316-2

EPUB-ISBN 978-3-7328-5316-8

https://doi.org/10.14361/9783839453162

Gedruckt auf alterungsbeständigem Papier mit chlorfrei gebleichtem Zellstoff. Besuchen Sie uns im Internet: https://www.transcript-verlag.de

Unsere aktuelle Vorschau finden Sie unter www.transcript-verlag.de/vorschau-download 


\section{Inhalt}

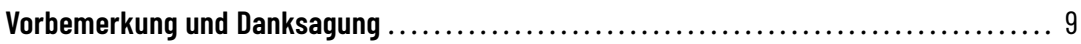

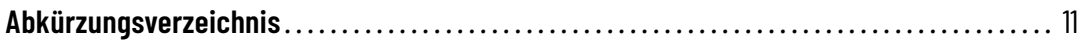

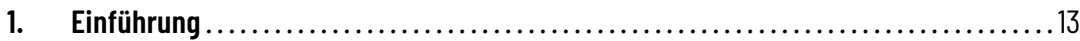

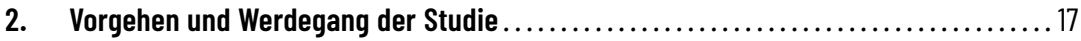

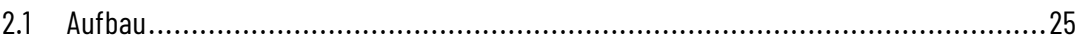

\section{Teil I - Stand der Forschung}

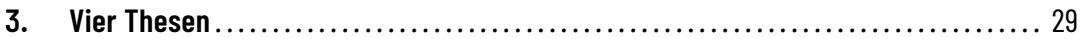

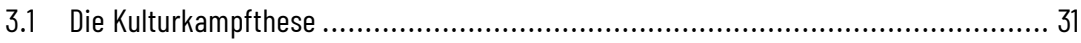

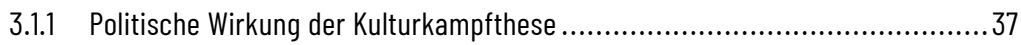

3.1.2 Autoritäre Rückverwandlungsthese ....................................................... 41

3.1.3 Kritik der Kulturkampfthese.................................................................. 43

3.1.4 Exkurs zum theoretischen Unterbau der Kulturkampfthese:

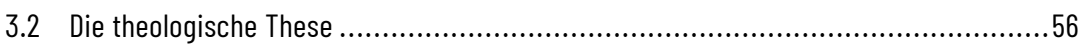

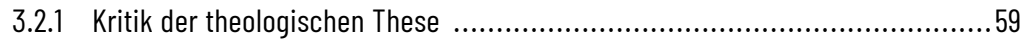

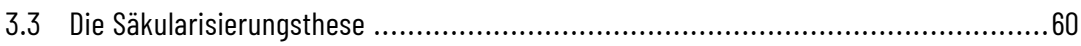

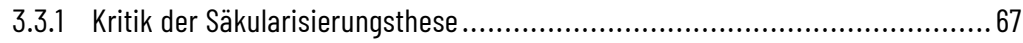

3.3.2 Erste Definition von Religion in Hegemonieprojekten: Was ist Islamismus? ?.......72



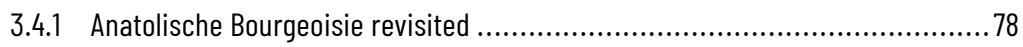

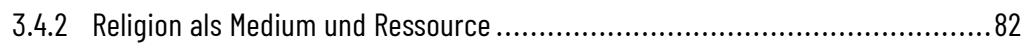

3.4.3 Religion als Herrschaftstechnik und Kohäsionsmittel ..................................... 84



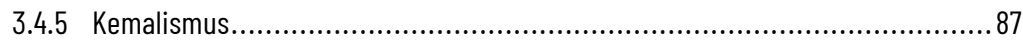

3.4.6 Islamismus als eigenständige Klassenbewegung ....................................... 88 


\section{Teil II - Theoretische Perspektive}

4. Vorgehen ...................................................... 97

4.1 Hegemonietheorie als methodische Doppelperspektive.......................................98

4.1.1 Politische Artikulation, Parteibildung und Intellektuelle ............................ 104

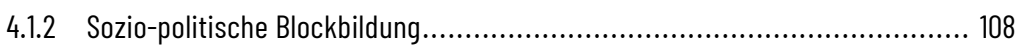

4.2 Ressourcentheoretische Erweiterung ...................................................... 112



\section{Teil III - Entwicklungsgeschichte und Konstitutionsmerkmale des islamistischen Hegemonieprojekts}

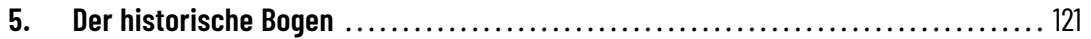

5.1 Ablösung - Einschränkung der zivilgesellschaftlichen und reproduktiven Macht der religiösen Intellektuellen ................................................................ 125

5.2 Wiederanbindung und Re-Formation: Aufbau kulturpolitischer Institutionen der Religion und Entwicklung des türkisch-islamischen Hegemonieprojekts .................. 140

5.2.1 Die Türkisch-Islamische Synthese ..................................................... 147

5.2.2 Klassenbasis der religiösen Infrastruktur im Aufbau ................................ 149

5.3 Verselbständigung: Formierung der islamistischen Bewegung und ihre Abspaltung als eigenständige Partei ............................................................................ 152

5.4 Vorrücken ins ideologische Zentrum: Der 1980er Putsch und die Entwicklung einer programmatischen Ökonomie ................................................................... 157

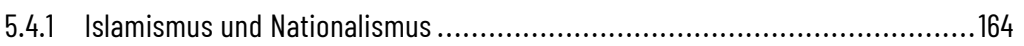



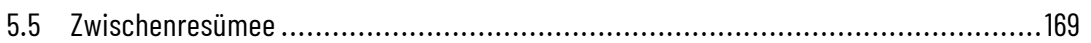

5.6 Schrittweise Monopolisierung der Staatsapparate - Die AKP-Periode ....................... 170

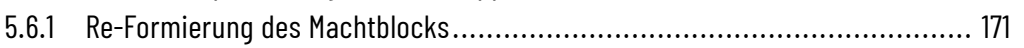

5.6.2 Hegemonie und paternalistisches Armutsregime................................... 177

5.6.3 Kulturkampf in der AKP-Periode .................................................... 187

\section{Teil IV - Religiöse Infrastruktur und Praxis}

6. Religiöse Wirkungsstätten ....................................... 205








6.1.2 Relative Autonomie und Demokratieverständnis der Diyanet ...................... 220

6.1.3 Intellektuelle Führungspraxis - Diyanet im Alltag ................................ 223

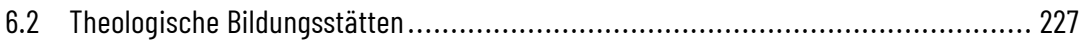

6.2.1 Entwicklung des islamistischen Kollektivwillens................................. 232

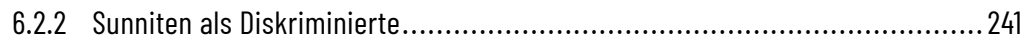

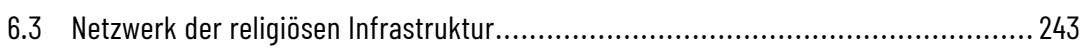

6.3.1 Verlagerung des islamistischen Netzwerks in den Staat.......................... 246

6.4 Materielle Attraktivität der religiösen Infrastruktur ............................................ 248

6.5 Zwischenresümee: Privilegienstruktur und Gruppeninteresse............................. 252

6.6 Private islamistische Institutionen - Islamische Gemeinschaften.......................... 254

6.6.1 Intellektuelle Führungs- und Distinktionspraxis.................................. 259

6.6.2 Kompromissbildung und Integration .................................................... 270

6.7 Grenzen des Kollektivs und integrative Mechanismen an seinen Rändern............... 274

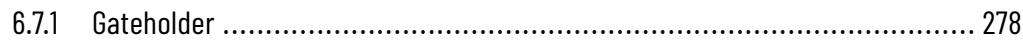

6.7.2 Bewegungsgeschichtliche Bindung ................................................281

6.7.3 Gemeinschaftsbildende Praxis......................................................... 282

6.7.4 Resümee der Integrationsmechanismen.............................................. 286

6.8 Resümee der Konstitutionsmerkmale der intellektuellen Führungsgruppe .............. 286

7. Fazit: Hegemonie, Kulturkampf und

sunnitische Privilegien - Was ist Islamismus? ....................... 289

Literatur- und Quellenverzeichnis ..................................... 297

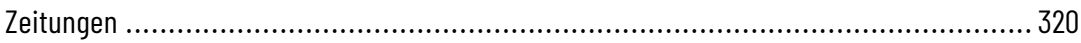

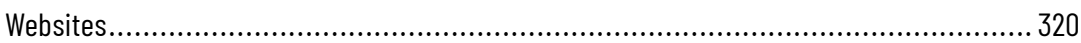





\section{Vorbemerkung und Danksagung}

Noch in der Nacht des gescheiterten Putschversuchs im Juli 2016 erklärte der türkische Präsident Recep Tayyip Erdoğan, dieser sei ein Segen Gottes. Er liefere Rechtfertigung und Legitimation für die höheren politischen Ziele seiner Gerechtigkeitsund Entwicklungspartei (AKP), die in der »Restrukturierung des Staates und der Gesellschaft « bestünden. In der Tat findet in der Türkei eine tiefgreifende »Restrukturierung« statt. Der Putschversuch lieferte den willkommenen Anlass, die Repression gegen einstige Verbündete ebenso wie gegen Oppositionelle auszuweiten und den politischen Systemwechsel zum autoritären Präsidialsystem weiter voranzutreiben. Der gesellschaftliche Wandel, den Erdoğan und seine Partei verfolgen, hat indes eine sehr viel weiter zurückreichende Geschichte. Die AKP und der Autoritarismus sind ihrerseits der Ausdruck einer langfristig betriebenen Islamisierung, die in der Förderung sunnitisch-konservativer Ideen und Praktiken im gesellschaftlichen Zusammenleben besteht. Sie hat eine stetig wachsende Schicht religiöser Akteure hervorgebracht, die der AKP Stabilität verleihen und gesellschaftliche Zustimmung für das von ihr verfolgte neoliberale Projekt organisieren. Gegenstand des vorliegenden Buchs ist, die Geschichte dieser Förderung mit Blick auf die tragenden Akteure und bestimmenden Dynamiken aus einer hegemonietheoretischen Perspektive zu rekonstruieren. Auf der Basis einer in Izmir und Diyarbakır durchgeführten Feldstudie werden gegenwärtige Ausprägungen untersucht und Entwicklungstendenzen bestimmt.

Das Buch ist die geringfügig überarbeitete Fassung meiner Dissertationsschrift, die ich am Fachbereich Gesellschaftswissenschaften der Universität Frankfurt a.M. eingereicht habe. Ohne die Förderung, Unterstützung und Geduld von vielen Einzelnen über eine lange Zeit wäre es nicht geschrieben worden. Mein allererster Dank geht an die Interview-, Gesprächs- und InteraktionspartnerInnen, die mir den Zugang zu ihren sozialen Welten öffneten und ihr Wissen mit mir teilten. Vor allem möchte ich denjenigen danken, die mir ihr Vertrauen schenkten, mir ihre Häuser öffneten und halfen, mich im Geflecht von Politik und Religion zurechtzufinden.

Ermöglicht wurde die Studie durch ein Promotionsstipendium der HansBöckler-Stiftung. Betreut wurde sie von Alex Demirović, dem ich insbesondere 
für seine Ermunterung danke, "mit Gramsci« das Wagnis der Feldforschung einzugehen. Seine kritischen Einwendungen haben meinem Vorhaben Orientierung verliehen und dazu verholfen, die Diskussion des empirischen Falls im theoretischen Feld zu verorten. Besonderer Dank gebührt auch Andreas Nölke für seine fachliche Expertise, unkomplizierte Unterstützung und Hilfestellung in einer kritischen Phase. John Kannankulam hat die ersten Schritte dieser Arbeit begleitet und war schließlich auch zur Stelle, als die letzte Hürde zu nehmen war. Die Diskussionen in seinem Forschungskolloquium an der Universität Marburg haben den Werdegang dieser Arbeit maßgeblich beeinflusst. $\mathrm{Zu}$ den frühen Begleitern gehören auch Thomas Höhne und Martina Sproll. Von ihnen habe ich erste konzeptuelle Hinweise, vor allen Dingen aber den wertvollen Rat erhalten, so früh wie möglich eine Sondierungsreise ins Feld zu starten. Danken möchte ich ihnen darüber hinaus für die freundschaftliche Unterstützung angesichts einiger Unwägbarkeiten, die mir im Laufe der Arbeit begegneten. Kritische Reflektion und fruchtbare Diskussion ermöglichten mir die Tagungen und Zusammenkünfte im Rahmen der Assoziation für kritische Gesellschaftsforschung. Der Austausch mit assoziierten Kollegen und Kolleginnen war für mich ein zentraler Anker im wissenschaftlichen Feld.

Eine Brücke zwischen wissenschaftlicher Arbeit und gesellschaftspolitischem Engagement schlug der Infobrief Türkei. Der Infobrief ermöglichte, erarbeitetes Wissen mit einer interessierten Öffentlichkeit zu teilen und so dem ursprünglichen Beweggrund für diese Arbeit nachzukommen, aktuelle Übersicht mit fundierter Analyse zu einer politischen Einschätzung der turbulenten Geschehnisse in der Türkei zu verbinden: »aus herrschaftskritischer Perspektive und in solidarischer Verbundenheit mit allen politischen Kräften, die sich für eine demokratische und sozial gerechte Gesellschaft einsetzen«, wie es in der Zielsetzung des Infobriefs heißt. Das Buch hat von der Zusammenarbeit und Auseinandersetzung im Redaktionsteam enorm profitiert. Dafür möchte ich den Mitgliedern im Einzelnen danken: Murat Çakır, Axel Gehring, Özgür Genç, Ismail Karatepe, Anne Steckner und Fitnat Tezerdi. Danken möchte ich in diesem Zusammenhang auch der RosaLuxemburg-Stiftung, die Mittel und Wege zur Verfügung stellte, um politische und wissenschaftliche Arbeit miteinander zu verbinden.

Für ihre Unterstützung und ihr Interesse an meiner Arbeit bei den vielen Aufs und Abs, die zu bewältigen waren, geht mein Dank an meine Familie und FreundInnen. Der größte Dank geht an Andrea Neugebauer. Sie war mir die wichtigste Stütze in allen Phasen und Belangen dieser Arbeit von der fachlichen Diskussion über den beharrlichen Zuspruch, das Begonnene zu Ende zu führen, bis zu den letzten Überarbeitungen, wenngleich ich für den Inhalt des Buches selbstverständlich allein verantwortlich bin. 


\section{Abkürzungsverzeichnis}

AKP: Adalet ve Kalkınma Partisi (Gerechtigkeits- und Entwicklungspartei)

ANAP: Anavatan Partisi (Mutterlandspartei)

AP: Adalet Partisi (Gerechtigkeitspartei)

CHP: Cumhuriyet Halk Partisi (Republikanische Volkspartei)

CKMP: Cumhuriyetçi Köylü Millet Partisi (Republikanische Bauern-Volkspartei)

DBP: Demokratik Bölgeler Partisi (Partei der Demokratischen Regionen)

DP: Demokrat Partisi (Demokratische Partei)

DSP: Demokratik Sol Parti (Demokratische Linkspartei)

DTP: Demokratik Toplum Partisi (Partei der Demokratischen Gesellschaft)

DYP: Doğru Yol Partisi (Partei des Rechten Weges)

FP: Fazilet Partisi (Tugendpartei)

HDP: Halkların Demokratik Partisi (Demokratische Partei der Völker)

IHS: Imam Hatip Schulen

MGV: Milli Gençlik Vakfi (Stiftung Nationaler Jugend)

MHP: Milliyetçi Hareket Partisi (Partei der Nationalistischen Bewegung)

MNP: Milli Nizam Partisi (Nationale Ordnungspartei)

MSP: Milli Selamet Partisi (Nationale Heilspartei)

MTTB: Milli Türk Talebe Birliği (Verein Nationaler Türkischer Schüler)

MÜSİAD: Müstakil Sanayici ve İşadamları Derneği (Verein Unabhängiger Unternehmer und Industrieller)

PKK: Partiya Karkerên Kurdistanê (Arbeiterpartei Kurdistans)

RP: Refah Partisi (Wohlfahrtspartei)

SHP: Sosyaldemokrat Halkçı Parti (Sozialdemokratische Populistische Partei)

TIS: Türkisch-Islamische Synthese

TOBB: Türkiye Odalar ve Borsalar Birliği (Kammern- und Börsenunion der Türkei) TÜRK-İs: Türkiye İşçi Sendikaları Konfederasyonu (Dachverband der Türkischen Industriegewerkschaften)

TÜSİAD: Türk Sanayicileri ve İşinsanları Derneği (Vereinigung Türkischer Industrieller und Geschäftsleute)

TUSKON: Türkiye İşadamları ve Sanayiciler Konfederasyonu (Dachverband von Geschäftsleuten und Industriellen der Türkei) 



\section{Einführung}

Die Gründung der Gerechtigkeits- und Entwicklungspartei (AKP) im Jahr 2001 markiert eine Zäsur in der Geschichte des politischen Islam. Eine Gruppe von »Erneuerern" unter der Führung von Recep Tayyip Erdoğan spaltete sich von einem »traditionalistischen« Flügel der islamistischen Milli Görüş Bewegung ab. Mit Erdoğan wechselte ein großer Teil der Bewegung in die neue Partei und brachte die über Jahrzehnte akkumulierten Organisierungs- und Mobilisierungsressourcen und das in den Kommunen erworbene Regierungswissen mit. Die neue Partei stand dadurch von Anfang an auf einem breiten Sockel. Ihr erster Wahlerfolg von 2002 war bedingt durch eine vom neoliberalen Regime verursachte schwere politische und ökonomische Krise. Die Wähler quittierten die mit der Krise verbundenen harten sozialen Einschnitte, indem sie der regierenden Parteienkoalition ihr Vertrauen entzogen. Mit nur 34 Prozent der Wahlstimmen erreichte die aus der Opposition gestartete AKP aufgrund des türkischen Wahlsystems nahezu eine Zweidrittelmehrheit im Parlament. Sie konnte eine Regierung bilden, ohne Koalitionen eingehen zu müssen. In der Folge gelang ihr eine Stabilisierung des neoliberalen Regimes, sie konnte ein Hegemonieprojekt aufbauen und dieses schrittweise in ein Staatsprojekt überführen.

In den ersten zehn Jahren ihrer Regierungszeit verbanden sehr viele mit der AKP die Erwartung einer politischen Liberalisierung. Die politischen Islamisten, so die Annahme, hatten sich unter der transformativen Wirkung des »freien Marktes « und des Parlamentarismus in konservative Demokraten verwandelt. Die Partei wurde als Projekt einer gläubigen Mittelklasse begriffen, die die kulturellen Werte der Mehrheitsbevölkerung repräsentiere und den neoliberalen Entwicklungspfad mit demokratischen Zielen verknüpfe. Die Rede war von einer konservativen Revolution von unten, die von der Zivilgesellschaft, bestehend aus der neuen Mittelklasse und assoziierten Intellektuellen, angeführt werde. Konzepte wie »Normalisierung«, »Westernisierung«, »Vermählung des Neoliberalismus mit dem Islam« und »Säkularisierung des Islam« spiegelten die Erwartung eines Epochenbruchs in der Geschichte der Türkei.

Als politischer Widerpart der AKP wurde eine kulturell marginale, autoritäre Staatselite ausgemacht, die sich im Militär und der Justiz verschanzt hatte und in 
Verteidigung ihrer Privilegien gegen die neoliberale Öffnung stemmte. Die Staatselite verkörperte aus dieser Transformationsperspektive volksfremde und elitäre Werte, sie führte zur Verteidigung ihrer Machtposition einen Kulturkampf auf der Grundlage des Laizismus. Durch die Frontenbildung wurde dem Geschehen eine höchst dramatische Note verliehen. Die »konservativen Demokraten« sollten die in der Geschichte der Türkei unvollständig gebliebene bürgerliche Revolution vollenden, indem sie der in den Gründungsprinzipien der Republik ausgemachten »autoritären Staatstradition« ein Ende bereiteten.

Die Niederschlagung des Aufstands im Sommer 2013, der im Istanbuler Gezi-Park begann und sich sukzessive auf das ganze Land ausbreitete, bereitete der Erwartung einer politischen Liberalisierung ein Ende. In der Folge vollzog sich ein bemerkenswertes theorie-politisches Manöver. Die prominente These von der neuen demokratisierenden Mittelklasse, die als Trägerin der Transformation bestimmt worden war, wurde stillschweigend fallengelassen. Unversehens wurde davon ausgegangen, die AKP habe sich verselbständigt, von ihrer gesellschaftlichen Anbindung gelöst und quasi über Nacht in eine autoritäre Partei verwandelt.

In meiner Studie werde ich die These vertreten, dass es keine autoritäre Verwandlung, sondern eine kontinuierliche Entwicklung gegeben hat. Die Erwartung einer Demokratisierung stellte ein theoretisch angeleitetes Missverständnis dar. Es wurde zur Basis für die wohlwollende Begleitung und Förderung der ohnehin großen gesellschaftlichen Unterstützung des Projekts der AKP, mit dem das politische System von einer parlamentarischen Demokratie in ein autoritäres Präsidialsystem überführt wurde. Als - aufgerüttelt durch den landesweiten Aufstand - die Entwicklungstendenzen auch von den Verfechtern einer Liberalisierung erkannt wurden, war das Projekt schon sehr weit fortgeschritten.

Das Missverständnis beruhte maßgeblich auf zwei Irrtümern, deren Aufrechterhaltung auch die Analysen der gegenwärtigen Kräftekonstellation noch prägt. Zum einen wurde das Verhältnis zwischen der AKP und den gesellschaftlichen Klassen auf fehlerhafte theoretische Annahmen gegründet. Die die AKP konstituierende gläubige Mittelklasse, hinter der sich ein bestimmter Teil der Unternehmerschaft des Landes verbarg, war zu keiner Zeit Vertreterin bürgerlicher Werte wie »Freiheit« oder »Gleichheit«. Sie kann eher als gesellschaftliche Trägerin eines neoliberalen Armutsregimes beschrieben werden, das eine große Masse der Bevölkerung in einen Status der Unmündigkeit drängt. Der politische Autoritarismus der AKP findet einen breiten gesellschaftlichen Nährboden in diesem Armutsregime. Zum zweiten wurde die Rolle der Religion im politischen Projekt der Partei nicht adäquat erfasst. Die Religion stellt keinen authentischen kulturellen Wert dar, sondern eine moralisch-ethische Kraft, mit der der Status der Unmündigkeit legitimiert und auf Dauer gestellt werden soll.

Einsetzend mit dieser Kritik wird die vorliegende Studie die Forschungsfrage aufnehmen, welche Rolle die Religion im politischen Projekt der AKP im Ver- 
hältnis zu den gesellschaftlichen Klassen erhielt. Sie wird an theoretische Konzepte anknüpfen, die das politische Projekt der AKP als neoliberalen Autoritarismus bestimmen und Religion als kulturelles Mittel in der Regulierung der Beziehungen zwischen den gesellschaftlichen Klassen begreifen. Auf der empirischen Grundlage einer ethnographischen Feldstudie wird sie in Weiterführung dieser Konzepte die Rolle der Religion neu bestimmen. Die primäre These wird sein, dass die religiöse Trägerschaft dem politischen Projekt eine besondere Dynamik verleiht. Im Zuge einer genaueren Bestimmung der kulturellen und sozialen Merkmale der Trägerschaft wird die Studie eine religiöse Privilegienstruktur offen legen, die sich in Form von öffentlichen Institutionen wie der staatlichen Religionsbehörde und theologischen Bildungsinstitutionen in Verschränkung mit privaten religiösen Netzwerken realisiert. Die Studie wird aufzeigen, dass die Struktur von Akteuren getragen wird, deren Affiliation mit der Religion sie auch zu Nutznießern ökonomischer Privilegien macht.

In Auseinandersetzung mit Religionskonzepten, durch die die besondere Leistung der AKP als »Säkularisierung des Islam« charakterisiert wird, wird diese Studie schließlich eine Definition von Islamismus vorschlagen. Islamismus wird als Doppelbewegung zwischen Regulierung der Beziehungen zwischen den Klassen und Etablierung einer Privilegienstruktur auf der Grundlage religiöser Ideen und Praktiken bestimmt. Der Kulturkampf wird als Modus Operandi re-konzeptualisiert, über den die religiöse Trägerschaft ihre Privilegien politisch ausficht. Indem die Religion als kulturelles Zentrum einer Privilegienstruktur bestimmt wird, kann die Islamisierungsdynamik in der Türkei als umfassender Ausgrenzungsprozess säkularer und der dominanten Auslegung des Islam widersprechenden Praktiken und Wissensbestände aus der gesellschaftlichen Partizipation begriffen werden.

Im Zuge der Begründung dieser Thesen wird auch eine Antwort auf die Frage entwickelt, warum die AKP trotz aller Turbulenzen immer noch standhalten kann. Nach inzwischen 17 Jahren an der Regierung hat die Partei etliche Krisen und interne Querelen überstanden, an denen viele andere Parteien wahrscheinlich gescheitert wären. Trotz substanzieller Verluste beim Führungspersonal - von den prominenten Parteigründern ist einzig Tayyip Erdoğan übrig geblieben - und trotz eines Putschversuchs ehemals verbündeter Kräfte im Jahr 2016 ist die Partei nicht auseinandergebrochen. Selbst über schwere ökonomische Krisen hinweg konnte die AKP große Teile der Bevölkerung an sich binden und ein Zersplittern des rechten Lagers verhindern. Ihre gesellschaftliche Stärke, so das Argument dieser Studie, bezieht die Partei aus der Fähigkeit, die Beziehungen zwischen den Klassen zu moderieren. Ihre Besonderheit liegt im Aufbau der erwähnten Privilegienstruktur, mit der die Reproduktion einer wachsenden Schicht religiöser Intellektueller verknüpft ist, die der Partei Orientierung und Zusammenhalt verleihen. 



\section{Vorgehen und Werdegang der Studie}

Die Bearbeitung der Forschungsfrage erfolgt auf dem Wege der Theorierekonstruktion. Die Vorgehensweise bei der Theorierekonstruktion besteht in der Überprüfung einer existierenden Theorie anhand eines empirischen Falls (Burawoy 1998). Die zu überprüfende Theorie dieser Studie ist die auf Antonio Gramsci zurückgehende Hegemonietheorie. Als ich 2008 mit der Konzipierung der Studie begann, war die Favorisierung eines hegemonietheoretischen Zugangs dadurch begründet, dass der AKP eine zentrale Rolle in der konsensualen Stabilisierung des neoliberalen Projekts zuzukommen schien. Die Partei wurde in der Forschungsliteratur als Bündnis charakterisiert, das disparate gesellschaftliche Kräfte unter der Führung einer Fraktion der Bourgeoisie integrierte und eine Entwicklungsperspektive vorbrachte, die Zusammenhalt in einer gespaltenen Gesellschaft organisierte. Es erschien sehr ungewöhnlich, dass ausgerechnet diese Partei, deren in der islamistischen Bewegung verwurzeltes Personal über Jahrzehnte den Umsturz der demokratischen und laizistischen Ordnung verfolgt und dabei etliche politische Krisen provoziert hatte, sich dem Laizismus, der Demokratie und einer pluralistischen Erneuerung verpflichtet haben sollte. Die vermeintliche Annäherung an die laizistische Demokratie deutete auf einen Wandlungsprozess, der sich in hegemonietheoretischen Begrifflichkeiten als eine Form der passiven Revolution hypothetisch fassen ließ. Die hiervon ausgehende Frage war, ob und wie dieser Wandlungsprozess, der nahezu die gesamte islamistische Bewegung mit der AKP erfasst und sich mit einem Expansionsprozess durch Integration bewegungsferner Kräfte verbunden zu haben schien, hegemonietheoretisch genauer bestimmt werden könnte.

Eine zweite Ungewöhnlichkeit bestand darin, dass die AKP breite Zustimmung von den im Zuge neoliberaler Politik sozial entrechteten und verarmten ArbeiterInnen erhielt, obwohl sie sich nachdrücklich der Fortführung neoliberaler Politik verschrieben hatte. Der Sachverhalt forderte die hegemonietheoretische Annahme heraus, dass die Hegemonie herrschender Klassen auf der Grundlage materieller Konzessionen, zumindest an Teile der beherrschten Klassen, beruht. Die konkrete Herausforderung der Theorie anhand des Falls Türkei war gerahmt von Bedenken in der Forschungsliteratur bezüglich der räumlichen und zeitlichen Reichweite von Hegemonietheorie. Sie wurden sowohl mit Blick auf die Übergänge innerhalb der 
kapitalistischen Produktionsweise vom Fordismus zum Neoliberalismus (Demirović 2006a; Hirsch 2005: 197ff.) als auch hinsichtlich der Anwendbarkeit von $\mathrm{He}$ gemonietheorie auf Gesellschaftsformationen der kapitalistischen Peripherie vorgebracht (Becker 2008). Vor diesem Hintergrund verband ich das Vorhaben der Theorierekonstruktion mit dem Ziel, einen Beitrag zur Frage nach der räumlichen und zeitlichen Reichweite von Hegemonietheorie zu leisten.

Um Einblicke in die Wandlungs- und Expansionsprozesse sowie Generierung von Zustimmung für das Projekt der AKP zu gewinnen und damit eine empirische Grundlage für die Theorierekonstruktion zu legen, nahm ich mir vor, die Zusammensetzung und gesellschaftliche Verankerung dieser Partei anhand von zwei lokalen Fallbeispielen zu erforschen. Für die Feldstudie bestimmte ich zwei Großstädte, in denen der expansive Integrationsanspruch der AKP an erkennbare Grenzen stieß: Izmir und Diyarbakır. Die AKP erzielte dort Ergebnisse unter dem landesweiten Durchschnitt. Die Metropole Izmir mit etwa drei Millionen EinwohnerInnen an der ägäischen Küste im Westen des Landes wurde von der Republikanischen Volkspartei (CHP) regiert. Die Großstadt Diyarbakır mit etwa 650.000 EinwohnerInnen im kurdischen Südosten der Türkei wurde hingegen von der Partei der Demokratischen Gesellschaft (DTP) regiert. Beide Parteien befanden sich auf nationaler Ebene und in fast allen anderen Großstädten in der Opposition. Die Untersuchung in diesen beiden Städten durchzuführen, erschien mir aus zwei Gründen sinnvoll. Zum einen standen Kommunalwahlen an und es hieß, die AKP richte ein besonderes Augenmerk auf diese beiden Städte und werde dort einen besonders engagierten Wahlkampf führen. Ich nahm an, dass hiermit intensive Aktivitäten verbunden sein würden, die mir auch den Zugang zum Feld erleichtern könnten. Zum anderen erschien es mir aufschlussreich, sich dem Untersuchungsgegenstand gewissermaßen von seinen Grenzen her anzunähern. Izmir galt als politische Hochburg des Kemalismus und Diyarbakır als eine der kurdischen Bewegung. Zugleich bestand die Erwartung, dass die AKP mit ihrem expansiven Integrationsanspruch auch diese beiden Städte erobern werde (vgl. Doğan 2009b). Umso mehr stand für mich die Frage im Raum: Warum war es der AKP, deren Personal sich von seiner historischen Verbindung zur islamistischen Bewegung emanzipiert und einem pluralistischen Projekt zugewandt haben sollte, bisher nicht gelungen, in diesen Städten Mehrheiten zu generieren?

Mein erster Feldaufenthalt fand im März 2009 statt und war auf drei Wochen begrenzt. Das hauptsächliche Ziel bestand darin, den noch relativ unerforschten Untersuchungsgegenstand explorativ zu erschließen. Mit Exploration ist das Sammeln von Informationen über einen Untersuchungsgegenstand gemeint, das die erste Überprüfung vorhandener Hypothesen und eventuell die Formulierung neuer Hypothesen vorbereitet (Bortz/Döring 2006: 356). Zu dieser Zeit gab es außer journalistischen Recherchen noch keine profunde Literatur über den Parteiapparat und seine gesellschaftliche Einbettung. Auf eine bestimmte Datenerhebungs- 
methode hatte ich mich zu diesem Zeitpunkt noch nicht festgelegt. Ich wollte zunächst sondieren, ob ich überhaupt einen Zugang zum Feld erhalten würde. Ins Auge gefasst hatte ich, Experteninterviews zu führen und Dokumente $\mathrm{zu}$ erheben. Die Experteninterviews sollten mir das Wissen professioneller Beobachter der Parteienlandschaft zugänglich machen und dazu verhelfen, meine Ausgangshypothesen zu hinterfragen. Sofern möglich, sollten sich teilnehmende Beobachtungen und halbstandardisierte Interviews mit Parteifunktionären anschließen, wofür ich einen Leitfaden vorbereitet hatte.

Die Aufnahme erster Kontakte mit Funktionären erfolgte rascher, als ich erwartet hatte. Im Vorfeld hatte ich eine sich kurzfristig ergebende Chance ergriffen, als Dolmetscher für eine Reisegruppe deutscher GewerkschafterInnen zu arbeiten, zu deren Programm auch ein Besuch der AKP-Zentrale in Istanbul gehörte. Dort knüpfte ich meinen ersten Kontakt, der mir wiederum einen Kontakt in Izmir vermittelte. Durch die Verlegung des Aufenthalts in die Zeit des Kommunalwahlkampfs waren die Akteure tatsächlich leicht zu erreichen. Schon nach wenigen Gesprächen in Wahlkampfbüros, die es in jedem Stadtviertel gab, knüpfte ich Bekanntschaften zu Funktionären und durfte an einem Treffen der Parteijugend teilnehmen. Aus ihnen ergaben sich alle weiteren Interview-, Gesprächs- und Beobachtungsgelegenheiten, auch im weit entfernten Diyarbakır.

Nachdem die Sondierung abgeschlossen war und die ersten Daten vorlagen, hatte ich den Eindruck gewonnen, dass Elemente der AKP-Politik, die ich für wichtig erachtet hatte, weniger bedeutsam waren, während andere nach vorne rückten. Die ersten Interviews lieferten nur sehr begrenzte Einsichten. Professionalisierte Politiker pflegten einen eingeübten Diskurs, von dem sie kaum abwichen. Sie sprachen im sichtlichen Bemühen, ein weltoffenes, liberales, pluralistisches Bild zu transportieren. Ich wurde als Botschafter adressiert, der dieses Bild in die Welt tragen sollte. $\mathrm{Zu}$ den häufigeren Sätzen zählten: »Wir sind für alle da«, »Wir kleben nicht an unseren Sesseln so wie diejenigen vor uns«, »Unsere Politik ist transparent«, »Wir stehen für Frieden und Konsens in der Gesellschaft«. Der Einfluss professionalisierter Rhetorik erschien mir groß. Die Durchführung der Interviews während des Wahlkampfs erwies sich an diesem Punkt als Nachteil.

Als ergiebig stellte sich die teilnehmende Beobachtung heraus, durch die sich ein Einblick in die gesellschaftliche Einbettung der Partei und ihre Praktiken eröffnete. Der teilnehmenden Beobachtung liegt die Annahme zugrunde, dass durch Teilnahme an Interaktionen und Situationen Aspekte von Praktiken beobachtbar und erfahrbar werden, die in Gesprächen und Dokumenten über diese Situationen nicht zugänglich sind (Breidenstein u.a. 2015: 71ff.). So fiel mir bereits im Zuge erster Beobachtungen eine deutliche Repräsentation des türkischen Islamismus im Umfeld der Partei auf, der in der theologischen Ausbildung der Parteijugend und deren Verbindungen zu religiösen Netzwerken verankert war. Mein Blick wurde auf einen Aspekt gelenkt, den ich in der Planung der Studie zwar berücksichtigt, 
aber nicht für zentral gehalten hatte. Dass das Personal der AKP nicht nur fromm, sondern zu einem erheblichen Teil in der Tradition des politischen Islam verwurzelt war, war mir selbstverständlich bewusst. In der wissenschaftlichen Literatur und den Medien wurden jedoch im Einklang mit prominenten Parteimitgliedern ein klarer Bruch mit dieser Tradition und ein Wandel des türkischen Islamismus behauptet. Meine ersten Beobachtungen vor Ort widerlegten die Behauptung dieses Bruchs zwar nicht eindeutig, sie stellten jedoch eine Irritation dar, die durch weitere Ereignisse, die dem vorherrschenden Bild über die Partei widersprachen, verstärkt wurde.

Eine Irritation war bereits während meiner ersten Begegnung mit einem Parteifunktionär entstanden, den ich im Rahmen meiner Dolmetscher-Tätigkeit in der Istanbuler AKP-Zentrale getroffen hatte. Nach einem einführenden Vortrag des Vorstandsmitglieds für die gewerkschaftliche Reisegruppe über Charakter und Ziele der Partei folgte eine Fragerunde, bei der die Antwort immer wieder auf den breiten Repräsentationsanspruch der Partei hinauslief. Auf eine Frage, wie seine Partei zur in jüngerer Zeit vermehrt diskutierten "Armenier-Problematik« stehe und wie sie die Vertreibung der Armenier des Osmanischen Reichs bewerte, antwortete der Funktionär:

Es war Krieg und wir waren von allen Seiten umzingelt. Im Osten haben wir gegen die Russen gekämpft. In einem Krieg müssen alle zusammenstehen. Um den Feind bekämpfen zu können, muss das Hinterland ruhig sein. Der Rücken muss frei sein. Stellt euch vor, ihr kämpft gegen jemanden. Da ist eine Front und euch gegenüber steht der Feind. Doch plötzlich kommt jemand von hinten und will euch erschießen. Stellt euch das vor. Was würdet ihr tun? Ihr würdet euch verteidigen, nicht wahr? Ihr würdet das nicht hinnehmen. So war das mit den Armeniern. Sie sind uns in den Rücken gefallen. Es war Krieg und das konnte nicht hingenommen werden. Es musste etwas getan werden. Was mit den Armeniern passiert ist, hängt damit zusammen.

Nachdem ich die Antwort für die Reisegruppe übersetzt hatte, herrschte beklommenes Schweigen. Das war nicht die AKP, die in deutschen Zeitungen unisono für ihr Einstehen für Völkerverständigung und eine demokratische Erneuerung von Unten gelobt wurde, die sich in Distanz zur bisher dominierenden türkischen Geschichtsthese für eine gemeinsame Historikerkommission mit Armenien einsetzte und eine »ergebnisoffene Untersuchung des Verschwindens armenischen Lebens" aus Anatolien versprach. Stattdessen waren wir mit der klassischen Dolchstoßlegende konfrontiert worden, die den Genozid als einen Akt der Selbstverteidigung im Rahmen von Kriegshandlungen rechtfertigte.

Mit zahlreichen Eindrücken und einigen Irritationen im Gepäck trat ich die Rückreise nach Deutschland an. Ich stand vor der Frage, wie ich weitermachen sollte. Ich entschied, den erkundenden Zugang der teilnehmenden Beobachtung 
beizubehalten und die Spuren, die sich gezeigt hatten, weiterzuverfolgen. Unterdessen wurde ich in der Zeit bis zur zweiten Reise mit einer Reihe neuer Veröffentlichungen zu meinem Forschungsgegenstand konfrontiert. Ab 2009, kurz nach Beginn meiner Arbeit, erschienen erste umfangreiche wissenschaftliche Veröffentlichungen zur AKP. Es mag nicht erwähnenswert, weil erwartbar erscheinen, dass im Laufe einer Studie neue Literatur über den Forschungsgegenstand veröffentlicht wird. Doch war ich mit einer außergewöhnlichen Häufung konfrontiert, neue Studien stapelten sich in kurzer Zeit auf meinem Schreibtisch. Mit einem Abstand von sieben Jahren schlug sich die außerordentliche Aufmerksamkeit, die der AKP seit ihrem ersten Wahlsieg von journalistischen Medien entgegengebracht wurde, auch in wissenschaftlichen Publikationen nieder. Auf Fragen, die ich verfolgen wollte, wurden differenzierte Antworten geliefert, neue Thesen zur AKP kamen auf. Gemeinsam mit meiner ersten Sondierung löste die Literatur einen Reflektionsprozess aus, der mich veranlasste, den Raum, den meine Studie eruieren sollte, neu zu bestimmen. Meine zweite Forschungsreise nach Izmir im Herbst 2009 leitete einen Wandel meiner Forschungsfrage ein, weg von der allgemein gehaltenen Fokussierung der gesellschaftlichen Einbettung der AKP hin zur Frage nach der Bedeutung der Religion und der religiös geprägten Netze in Verbindung mit der Partei.

Im Laufe des zweiten Aufenthalts verdichteten sich die Hinweise, dass es dem Gegenstand angemessen sein würde, die eingegrenzte Frage zu verfolgen. Ich verlegte den Schwerpunkt auf die Erkundung des religiösen Netzes und beschäftigte mich mehr und mehr mit der Frage, wie ich eine empirische Grundlage für das Wissen über dieses Netz legen könnte. Um verlässliche Daten zu erhalten, hielt ich es für notwendig, das Netz selbst zu erkunden. Der Eintritt in dieses Feld gestaltete sich jedoch erheblich schwieriger als der Zugang zum Parteiapparat. Das religiöse Netz erstreckte sich weit über den Raum der Partei hinaus in halb-öffentliche und private Räume. Um Daten zu sammeln, musste ich weitere Kontakte knüpfen und bestehende vertiefen, um das Vertrauen zu gewinnen, das mir den Zugang erlauben würde. Nach einiger Zeit, während der ich mich häufig mit einzelnen Akteuren traf und Beziehungen zu ihnen entstanden, öffneten sich mir weitere Türen. Gegen Ende des zweiten Aufenthalts wurde ich zu immer mehr Aktivitäten eingeladen. Ich nahm das Angebot an, in ein Zimmer einer Wohngemeinschaft mit islamistischen Studenten einzuziehen, und erhielt auf diesem Weg auch einen Einblick in deren Alltag.

Ebenfalls gegen Ende des zweiten Aufenthalts reiste ich zum ersten Mal nach Diyarbakır, wo ich durch Vermittlung meiner Bekanntschaften aus Izmir sogleich Kontakt zur Partei und zu religiösen Akteuren erhielt. Die Feldforschung in Diyarbakır gestaltete sich holprig. Viele Akteure waren nicht bereit, Interviews zu geben. Die Bereitschaft war so gering, da eine Repressionswelle in den kurdischen Gebieten eingesetzt hatte. Durch lancierte Abhörprotokolle und Diffamierungs- 
kampagnen, die von AKP-nahen Medien betrieben wurden, sowie durch anlaufende Gerichtsprozesse wurde offenkundig, dass schon seit längerer Zeit eine konzertierte Aktion geplant war. Geheimdienste, Staatsanwaltschaften und Polizei hatten eine große Bandbreite an legalen Aktivitäten ins Visier genommen, die sukzessive kriminalisiert wurden. Zwar war dies in den kurdischen Gebieten, wo seit über 25 Jahren Krieg herrschte, an sich nicht neuartig. Doch hatte eine beinahe zehnjährige Phase relativer Waffenruhe für eine gewisse Entspannung gesorgt. Mit dem Verbot der »kurdischen« Partei DTP und den anschließenden Verhaftungswellen rückte die Repression schlagartig wieder in den Alltag der Bevölkerung der Region und auch in das mediale Rampenlicht. Das Feld war noch relativ offen, ich konnte mich ohne größere Einschränkungen bewegen, doch mein Bewusstsein für die Gefahr, auf die eine oder andere Art durch das Überwachungsnetz erfasst und durch meine Forschung andere zu gefährden oder selbst Repressionen ausgesetzt zu werden, stieg. Im Spätherbst 2010, bei meinem dritten Feldaufenthalt, reiste ich ein zweites Mal nach Diyarbakır. Zu dieser Zeit hatte ich aber schon entschieden, von einer Vertiefung der Feldforschung in Diyarbakır abzusehen, um keine unnötigen Risiken einzugehen. Die sich in Izmir eröffnenden Möglichkeiten erschienen mir ergiebig genug, um der inzwischen präzisierten Forschungsfrage nachzugehen.

In Izmir nahm ich an mehreren Treffen der AKP-Jugend, an mehr oder weniger stark ritualisierten religiösen Konversationsrunden sowie an Stammtischrunden teil, aus denen weitere Kontakte hervorgingen. Ich wurde in religiöse Vereine mitgenommen, besuchte politische Veranstaltungen und Kundgebungen. Auf diese Weise konnte ich empirisches Material über Aktivitäten, Weltauffassungen, Organisierungs- und Interaktionsweisen sammeln. Die meisten meiner Beobachtungen fanden in Gruppensituationen statt, bei denen ich nicht im Mittelpunkt stand. In ihnen entwickelte sich oft eine Dynamik, durch die sich Adhäsions- und Fliehkräfte und ebenso der Umgang der Gruppe mit diesen zeigten.

Ich besuchte nicht nur Aktivitäten, die sich in meinem engeren Forschungsgebiet der AKP abspielten, sondern suchte auch den Kontakt zu anderen Parteien und Gruppen, forschte in den alevitischen und kurdischen Vierteln von Izmir. Manchmal beobachtete ich anonym, manchmal suchte ich das Gespräch, stellte in Vereinen und Treffpunkten mich und mein Forschungsvorhaben vor, woraufhin sich spontan Diskussionen entwickelten. Ich holte Meinungen von verschiedenen politischen Akteuren zu meinem Vorhaben und zu meinen Beobachtungen ein, führte mit ihnen Experteninterviews, gab Teile meines Wissens ins Feld zurück und stellte meine Reflektionen und Analysen zur Diskussion. Diese Aktivitäten halfen mir, das politische Feld, vor allem die Relationen im Feld zwischen der AKP und außerhalb von ihr stehender Gruppen aus der Nähe zu erschließen.

Die Dimensionen meines Vorhabens haben sich im Laufe der Feldforschung erweitert. Dass sich viele religiöse Aktivitäten im privaten Bereich abspielen und der Zugang durch kulturelle Grenzziehungen erschwert ist, ferner Repressionser- 
fahrungen und Rivalitäten dazu beitragen, dass die islamistische Bewegung in der Türkei wenig transparent ist, wird als zentrales Hindernis benannt, Daten über sie zu sammeln (Ozgur 2012: 17ff.). Die Rede ist von einer unsichtbaren Mauer, die von »Meinungsführern« durch die Produktion von Berührungsängsten gegenüber kulturell Fremden aufrechterhalten wird. Balaban zum Beispiel führt an, dass auch die Bedeckung des Körpers, Ernährungs-, Sexualitäts- und Hygieneregeln an bewusst hergestellte Ängste vor Verunreinigung (im übertragenen Sinne) gekoppelt seien (Balaban 2013: 51). Nach insgesamt sechs Monaten im Feld kann ich bestätigen, dass es Mauern gibt, sie sind jedoch nicht unüberwindbar. Sie erscheinen hoch, weil in der Türkei miteinander verfeindete oder konkurrierende kulturelle Kollektive existieren, in denen Fremdheit häufig ohne Begegnung hergestellt und eingeübt wird und die mehr oder weniger stark an politische Parteien angebunden sind. Ich stellte viel Trennendes zu meinen Kontakten aus dem religiösen Umfeld fest, es gab aber immer genug Verbindendes, um Beziehungen einzugehen, aufrechtzuerhalten, zu erweitern und zu vertiefen.

Dass ich Izmir als Einstieg für den Zugang zum Feld gewählt hatte, erwies sich als Glücksfall. Der Einfluss des Laizismus war in Izmir stark, die AKP und religiös geprägte Akteure waren dort in der Minderheit. Dies bedingte zum einen, dass sie mit einem großen Bevölkerungsanteil konfrontiert waren, dessen Lebensweise nicht durch religiöse Vorgaben geprägt war. Sich von ihnen abzukapseln, hätte eine Zementierung des Status quo als Minderheit bedeutet und der politischen Aktionslogik widersprochen, die Bevölkerung zu adressieren, um Mehrheiten zu generieren. Zum anderen waren viele der religiös geprägten Akteure in gewisser Weise selbst fremd in Izmir, zumindest in der Öffentlichkeit des Stadtzentrums. Einige waren aus ländlichen oder kleinstädtischen Regionen Anatoliens zum Studieren nach Izmir gekommen und trugen Spuren von Fremdheit und Befremdung selbst nach vielen Jahren noch mit sich. Gemeinsam mit anderen, die schon länger in Izmir lebten, teilten sie signifikante, zur Politik geronnene kulturelle Praktiken der Mehrheit nicht. In Izmir waren wir in bestimmten Situationen kollektive Außenseiter. Wenn wir beispielsweise gemeinsam in ein Straßencafé gingen, dann immer in eins, das keinen Alkohol ausschenkte, während in den Nachbarcafés getrunken, musiziert und gesungen wurde. Ich, als ein aus Deutschland angereister Fremder in Izmir, stand allerdings immer noch ein Stück weiter außen als die anderen. Ich gehörte keiner der lokalen Welten ganz an. Nicht nur mein Forscherdasein, auch mein »Türkischsein« stand durch meine aktuelle Herkunft, mein Äußeres, meine Verhaltensweisen und Sprache, in die fremdartige Spuren eingewoben waren, unter Beobachtung. Die Fremdheit nahm mit der Zeit ab, doch bekam ich immer wieder eine Befremdung gespiegelt, die wohl daraus resultierte, dass ich in kein Raster eindeutig eingeordnet werden konnte. In gewisser Weise bewegte ich mich als doppelt Fremder unter Fremden. Ich vermute, dass diese Kombination verwickelter Umstände es mir ermöglichte, in relativ kurzer Zeit Kontakte aufzubauen 
und zu vertiefen, während unter anderen Umständen die Mauern möglicherweise höher gewesen wären.

Alfred Schütz machte auf einen Vorteil des Fremden aufmerksam, der darin besteht, dass er auf unbekannte Phänomene stößt, die sich mit seinen Wissensbeständen nicht erschließen lassen und ihn somit dazu zwingen, ihre ihm unbekannte Bedeutung zu rekonstruieren (Schütz 1972). Die soziale Welt, in die ich eintrat, war mir vertraut genug, um mich in ihr bewegen und selbst verständigen zu können. Doch umfasste sie zugleich Wissen, Praktiken, Symbole und Codes, die ich mir erst erschließen musste, vieles war nicht selbstverständlich. Interaktionen schon die Begrüßung - folgten oftmals mir unbekannten Regeln, in Kommunikationen stieß ich auf ein Nebeneinander für mich nicht zu vereinbarender Elemente. Etliche Interaktionspartner verfügten als Absolventen theologischer Schulen über Wörter, Metaphern, Geschichten und historische Referenzen, deren Inhalte sich nur für diejenigen erschlossen, die sie vor einem geteilten Bildungshintergrund verstehen konnten. Schon die Sprache meiner Bekanntschaften aus dem religiösen Umfeld orientierte sich stärker am Arabischen, kam zum Teil dem Osmanischen nahe, das in der Türkei seit 80 Jahren keine Bildungssprache mehr war und für einen "normalen« Schulabgänger wie mich eine Herausforderung darstellte. Da ich für eine deutsche Leserschaft schreiben wollte, musste ich für meine Feldnotizen eine doppelte Übersetzung - zunächst für mich zum Verstehen und dann in die deutsche Sprache - leisten. Der Anspruch, sowohl die Eigenheit und den Sprachwitz zu erhalten, als auch möglichst nah am Gesprochenen zu bleiben, um Inhalte nicht zu verfälschen, forderte eine behutsame Übersetzung des Materials für die Darstellung. Da Sprache einen wichtigen Aspekt der Hegemoniebildung ausmacht - über Sprache wird eine Weltauffassung ausgedrückt, es wird Gemeinsamkeit und Differenz hergestellt und es werden Identitäten gebildet -, war es wichtig, die Hinweise durch die Übersetzung nicht unkenntlich zu machen.

Ich habe 12 Interviews mit AKP-Mitgliedern und weitere 9 mit religiösen und oppositionellen Akteuren, darunter 4 Gruppeninterviews, sowie unzählige Gespräche geführt, an mehreren formellen und informellen Treffen der Parteijugend und Bildungsseminaren der AKP teilgenommen. Ich habe ein Forschungstagebuch geführt, Mitschriften und Gedächtnisprotokolle angelegt, bei öffentlichen Veranstaltungen Bild- und Tonaufzeichnungen gemacht, Nachrichten und Debatten in Zeitungen und im Fernsehen verfolgt und dokumentiert. Eine Grenze für den Feldzugang und die teilnehmende Beobachtung bestand darin, dass meine Identität als Forscher zumeist offen lag. An vielen Aktivitäten wie Sitzungen und Konversationsrunden konnte ich nur temporär, oft auch nur einmalig teilnehmen. Schließlich sind diese Aktivitäten, die im Privaten stattfinden, nicht darauf ausgelegt, permanente Gäste und schon gar nicht Forscher zu empfangen, die beobachten. Sofern meine Beobachtungen in nicht-öffentlichen Räumen stattfanden, habe ich die Daten anonymisiert. Eine Ausnahme bilden meine Beobachtungen in der AKP-Jugend 
und im Heim einer islamischen Gemeinschaft. Dort befand ich mich erklärtermaßen als Forscher, mein Aufenthaltszweck war bekannt. Ich verzichte dennoch zumeist darauf, Namen zu nennen und genauere Orte anzugeben. Ich wandte mich den Personen ohnehin nicht aufgrund eines Interesses an ihrer Persönlichkeit, sondern mit der Frage zu, welche Rolle sie im Feld einnehmen, welche gesellschaftlichen Verhältnisse sich in ihren Interaktionen ausdrücken und verdichten.

Die Auswertung des Materials begann, wie erwähnt, zeitgleich mit der Erhebung. Angeleitet durch den hegemonietheoretischen Zugang formulierte ich auf der Grundlage der Daten eine Reihe von Thesen. Zur Vertiefung und Verdichtung der Thesen zog ich Sekundärmaterial in Form von Dokumenten und Datensätzen quantitativer Art heran, kontrastierte die Thesen mit den Befunden und Ergebnissen anderer qualitativer Untersuchungen, die sich auf den gleichen Forschungsgegenstand richteten, und setzte meine Beobachtungen im lokalen Maßstab ins Verhältnis zu Entwicklungen im nationalen Maßstab. Eine Kernthese zur Bedeutung der Religion in den gesellschaftlichen Kämpfen kristallisierte sich heraus, die mir eine neuerliche Ordnung des Materials und der Literatur ermöglichte. Mit einer empirisch zwar noch nicht gesättigten aber klar konturierten These wandte ich mich der theoretischen Reflektion zu. Aus ihr folgte eine Anpassung des theoretischen Interpretationsrahmens. Die Kernthese ließ sich mit den vorhandenen hegemonietheoretischen Begrifflichkeiten nicht vollständig erfassen, wodurch eine die Theorie modifizierende Perspektive provoziert und die Suche nach ergänzenden theoretischen Konzepten ausgelöst wurde.

Obgleich die Feldstudie die Rekonstruktionsarbeit anleitete und der Studie ihre Richtung verlieh, strukturieren die erhobenen Daten nicht die gesamte Diskussion. Indem der Schwerpunkt der Feldstudie sich auf die Konstitution einer bestimmten kulturellen Trägerschaft des politischen Projekts der AKP verlagert hat, ermöglicht sie nur eine partielle Antwort auf die Frage nach der Rolle der Religion für den Prozess der Hegemoniebildung. Insbesondere die Frage der Zustimmung, die anfänglich im Mittelpunkt des Forschungsinteresses stand, kann konzeptuell bedingt nicht mit den Daten aus der Feldstudie beantwortet werden. Um diesen zentralen Aspekt der Hegemoniebildung dennoch ausleuchten zu können, habe ich Sekundärforschung herangezogen. Durch sie wird es möglich, die Rolle der Religion und ihrer Träger umfassender im Rahmen eines Hegemonieprojekts zu diskutieren und einen Beitrag zur Frage nach der räumlichen und zeitlichen Reichweite von Hegemonietheorie $\mathrm{zu}$ formulieren.

\subsection{Aufbau}

Im Aufbau der Studie ist der skizzierte Erkenntnisprozess - die Pendelbewegung zwischen empirischer Auswertung und theoretischer Reflektion - nicht mehr ab- 
gebildet. Zu erkennen ist aber noch der starke Dialog mit der Forschungsliteratur, deren Darstellung in Kapitel 3 auch deswegen ausführlicher ausgefallen ist, um Bezugsquellen, die nur in türkischer Sprache vorliegen, deutschsprachigen LeserInnen zugänglich zu machen. ${ }^{1}$ Zur strukturierten Darstellung der Literatur entlang der Frage, wie die Rolle der Religion für das politische Projekt der Partei im Verhältnis zu den gesellschaftlichen Klassen begriffen wird, wird eine Unterteilung in vier Thesen vorgenommen. Die kritische Diskussion dieser Thesen leitet in die Begründung der Eingrenzung des Forschungsgegenstands über. Die Frage nach der Rolle der Religion im politischen Projekt der AKP wird präzisiert und eingegrenzt auf die Entwicklungsgeschichte der intellektuellen Träger der islamistischen Bewegung unter dem Aspekt ihrer gesellschaftlichen Reproduktion. Kapitel 4 stellt den theoretischen Zugang vor, der in Auseinandersetzung mit dem empirischen Material herangezogen und modifiziert wurde. Es wird argumentiert, dass ein hegemonietheoretischer Zugang eine integrierende Perspektive auf die Rolle der Religion für das Projekt eröffnet, es aber einer ressourcentheoretischen Erweiterung bedarf, um die Reichweite und Dauerhaftigkeit des Projekts und die Reproduktionsmechanismen der intellektuellen Trägerschaft besser erfassen zu können. Kapitel 5 stellt auf der Grundlage der kontemporären Verfasstheit des Islamismus eine Rekonstruktion seiner Entwicklungsgeschichte und Konstitutionsmerkmale mit dem Schwerpunkt auf der Reproduktion seiner Intellektuellen dar. Die Rekonstruktion wird nachvollziehen, wie die islamistische Bewegung sich zusammensetzt, wofür und wogegen sie seit Gründung der Republik streitet und welche Strecke sie zurückgelegt hat. Die kontemporäre Phase wird bestimmt als Monopolisierung der Staatsapparate durch die AKP. In dieses Kapitel fließen bereits empirische Daten aus der Feldforschung ein, die dann den Ankerpunkt für Kapitel 6 bilden, in dem der Aufbau einer religiösen Infrastruktur en détail analysiert wird. Vorgestellt werden die institutionellen Wirkungsstätten der Intellektuellen sowie die sozialen Praktiken, über die sie sich reproduzieren. Diskutiert wird in diesem Kapitel auch die eigenartige Auslegung von Laizität in der Türkei und wie sie zur Entwicklung der religiösen Privilegienstruktur beigetragen hat. In Verschränkung mit ihren Grenzen werden in diesem Kapitel ferner integrative Mechanismen der islamistischen Bewegung thematisiert, die verhindern, dass sie an ihren Rändern auseinanderläuft. In Kapitel 7 werden die Ergebnisse schließlich unter der theoretischen Perspektive zusammengefasst und abschließend diskutiert.

$1 \quad$ Alle Zitate in dieser Studie, die aus türkischsprachigen Quellen stammen, wurden von mir übersetzt. 


\section{Teil I - Stand der Forschung}





\section{Vier Thesen}

Die Forschungsliteratur über die AKP wird im Folgenden entlang der Frage diskutiert, wie die Rolle der Religion für das politische Projekt der Partei im Verhältnis zu den gesellschaftlichen Klassen begriffen wird. Zur strukturierten Darstellung wird eine Unterteilung in vier Thesen vorgenommen, die im Kern auf zwei theoretische Ansätze zurückgeführt werden können. Innerhalb des ersten Ansatzes, den ich unter dem Sammelbegriff »Staatszentrismus« diskutieren werde, wird die AKP im Rahmen eines Kampfes zwischen Staat und Gesellschaft interpretiert. Der "Staatszentrismus « stellt den leitenden theoretischen Ansatz in der Türkeiforschung dar. Die zentralen Annahmen basieren darauf, den Staat als eine autonome Entität zu begreifen, die der Gesellschaft als Ganzes oder einzelnen gesellschaftlichen Gruppen gegenübersteht. Innerhalb des zweiten Ansatzes, der unterschiedliche Ausprägungen des historischen Materialismus umfasst, wird die AKP im Rahmen eines Kampfes zwischen gesellschaftlichen Akteuren interpretiert.

Im Rahmen der ersten These wird die AKP mit einer konservativen Revolution der "Zivilgesellschaft« - bestehend aus einer neuen Bourgeoisie und zivilen Eliten - assoziiert, die sich gegen den »autoritären Staat« auflehnt. Die Partei wird als Trägerin eines neoliberalen Entwicklungspfads in Verknüpfung mit liberal-demokratischen Zielen und zugleich als Repräsentantin der kulturellen Werte der Mehrheitsbevölkerung beschrieben, die in erster Linie als islamisch gekennzeichnet werden. Den Antagonisten der AKP bildet im Rahmen dieser Konzeption eine Staatselite, die eine »laizistische« oder »säkulare« Kultur repräsentiert. Laizismus oder Säkularismus werden als »volksfremde« und »elitäre« Kultur konzipiert, ihre sozialen Träger als Staatseliten bezeichnet. Als historisches Anhängsel der Staatseliten wird eine von ihnen geschaffene Bourgeoisie vorgestellt, die die kulturellen Werte ihrer Erschafferin teilt und sich in Verteidigung ihrer etablierten Position gegen die neoliberale Demokratisierung und die aufkommende Bourgeoisie stemmt. Als Modus Operandi des Kampfes zwischen Staat und Gesellschaft, Elite und Volk, etablierter und aufkommender Bourgeoisie wird ein Kulturkampf identifiziert. Die Bewertung der AKP als kulturelle Repräsentantin der Gesellschaft, die ein demokratisierendes Projekt gegen die kulturell fremde Staatselite verfolgt, lässt mich diese Interpretation als Kulturkampfthese bezeichnen. Vor dem Hintergrund 
des Ausbleibens der diagnostizierten Demokratisierung hat die Kulturkampfthese eine Verwandlung durchlaufen. Ohne den Interpretationsrahmen zu verlassen, wird eine autoritäre Rückverwandlung der konservativen Demokraten in Islamisten behauptet. Die AKP wird nun der Seite des Staates zugerechnet und als autoritär oder totalitär bezeichnet. Im Anschluss an die Diskussion dieser zeitlich aufeinanderfolgenden Varianten der Kulturkampfthese erfolgt eine Rekonstruktion und Kritik der theoretischen Grundlagen des staatszentristischen Ansatzes und seiner Verankerung in der Türkeiforschung.

Die zweite These zur AKP ist die theologische These. Sie befindet sich in theoretischer Nähe zur Kulturkampfthese, unterstreicht die Einschätzung der AKP als Trägerin des politischen Projekts einer aufkommenden Bourgeoisie, die als konservativ und religiös charakterisiert wird, obgleich sie die Verbindung zwischen Religion, Politik und Ökonomie aus der Gegenperspektive konstruiert. Die theologische These behauptet einen transformierenden Effekt der Religion auf Ökonomie und Politik. Sie stellt einen theoretischen Anschluss an Max Webers Protestantismusthese her, indem sie dem Aufkommen der anatolischen Unternehmerklasse das Entstehen einer puritanisch-asketischen Arbeitsethik vorausgehen sieht, deren Ursprung sie in einer bestimmten Form des Islam verortet.

Aus Sicht der dritten These wird die AKP als eine der liberalen Demokratie verpflichtete und säkulare Partei beschrieben, die von vornherein der Seite des Staates zugerechnet wird. Die Partei wird im Rahmen einer Attacke des Staates auf den Islam beziehungsweise den »radikalen Islamismus« interpretiert, der säkularisiert worden sei. Diese Variante, die ich als Säkularisierungsthese bezeichne, baut ebenfalls auf staatszentristische Annahmen auf, bringt zugleich aber eine originelle Interpretation und neue Konzepte vor, für die eine abgegrenzte Diskussion angemessen ist. Im Unterschied zur Kulturkampfthese wird als historische Leistung der AKP die Rekonstitution der »säkularen Hegemonie«, begriffen als ein gesellschaftlicher Konsens für staatliche Herrschaft und Kapitalismus, betont.

Im Widerstreit zu diesen Interpretationen der AKP im Rahmen der Dichotomie zwischen Staat und Gesellschaft steht die vierte These. Sie umfasst Studien der historisch-materialistischen Theorietradition. Die Partei und die von ihr repräsentierten Gruppen werden ebenso wie ihre Gegenspieler als gesellschaftliche Akteure begriffen, die um die Vorherrschaft im Staat kämpfen. Religion wird nicht primär als kulturelle Form, sondern als politisiertes Mittel thematisiert. Infolgedessen wird in diesem Ansatz auch die Bezeichnung "politischer Islam « verwendet. Als treibende Dynamik der politischen Entwicklung werden Klassen- und Fraktionskämpfe beziehungsweise Akkumulationsstrategien identifiziert. Kultur - im konkreten Fall Religion - wird als Instrument zur Beherrschung subalterner Klassen, als ideologisches Mittel zur Überbrückung von Klassenspaltungen oder - als Sonderfall als kapitalbildendes Produktionsmittel begriffen. Die kämpfenden Gruppen werden als Funktionsträger oder Fraktionen der herrschenden Klasse identifiziert und 
ihr politisches Projekt als neoliberaler Autoritarismus bestimmt. Diese These bezeichne ich als Klassenkampfthese.

Bevor zur Diskussion übergegangen wird, ist vorauszuschicken, dass in der Darlegung der Forschungsliteratur Interpretationen, die keine theoretisch begründete Verbindung zwischen der AKP und den gesellschaftlichen Klassen herstellen, nicht systematisch berücksichtigt werden. Es handelt sich um politikwissenschaftliche und soziologische Ansätze, die den Schwerpunkt der Betrachtung auf politische oder soziale Akteure legen, die durch ideologische Motive angetrieben werden, ohne dass eine Verbindung zu den gesellschaftlichen Klassen hergestellt wird. Diese Eingrenzung ist der hegemonietheoretischen Fragestellung geschuldet, die anhand des empirischen Falls »Hegemoniebildung in der Türkei« nach der Verbindung zwischen politischen Akteuren, kulturellen-ideologischen Mitteln und den gesellschaftlichen Klassen fragt.

\subsection{Die Kulturkampfthese}

Stellvertretend für die Kulturkampfthese sollen aus einer Fülle an wissenschaftlicher Literatur, die dieser Ansatz über die AKP hervorgebracht hat, drei Autoren herausgegriffen werden, deren Schriften zentrale Thesen versammeln. Diese Autoren sind Ahmet Insel, der die Begriffe "Normalisierung « und »Westernisierung« für die beginnende AKP-Periode eingebracht hat; Yıldız Atasoy, die den Begriff »neoliberal-islamische Synthese « geprägt hat; sowie Hakan Yavuz, Autor einer langen Reihe von Monographien und Artikeln über die AKP und den politischen Islam, der die Begriffe »Neue Türkei« und »muslimische Demokratie« geprägt hat.

Bereits im Anschluss an den ersten Wahlsieg der AKP im November 2002 argumentierte Insel: »Die AKP repräsentiert eine neue Stufe in der Westernisierungsbewegung der Türkei - die Stufe, in der die Gesellschaft involviert wird." (Insel 2003: 305, Übersetzung E.B. $)^{1}$ Nach Insel lag in der Türkei eine Trennung zwischen Staat und Gesellschaft in Form einer kulturell artikulierten Hierarchie zwischen politischen Eliten, die einer säkularen Kultur anhingen, und dem »Volk«, das gläubig und konservativ sei, vor. Während diese Beziehung schon im Osmanischen Reich die Form eines Widerspruchs angenommen habe, indem die Eliten das »Volk« aus dem Staat ausgeschlossen hätten, sei sie im »Westen« von kultureller Harmonie geprägt. Als »Westernisierung « fasst Insel die Anpassung an eine idealtypische Entwicklungslogik der bürgerlichen Gesellschaft, mit der eine »Normalisierung der Demokratie« durch Aufhebung des kulturellen Widerspruchs erreicht werde. Mit der AKP verband Insel die »historische Chance«, die Aufhebung 
des Widerspruchs, dadurch die Integration der Bevölkerung in den »Westernisierungsprozess « zu erreichen. Mit Blick auf das politische System erkannte Insel in der AKP die Chance, aus dem "autoritären Regime«, das mit der 1982er Verfassung nach dem Militärputsch von 1980 etabliert wurde, auszusteigen. Als Kern des Autoritarismus bestimmte er die Verschiebung des administrativen Zentrums von der zivilen zur militärischen Bürokratie. Die 1982er Verfassung heilige das Konzept Staat, was Insel als »radikalen Etatismus« bezeichnete. Die Architekten der Verfassung hätten eine politische Sphäre mit dem Staat im Zentrum und der Gesellschaft an seiner Peripherie vorgesehen. Sein Befund verweist auf die Einführung der Zehn-Prozent-Sperrklausel bei Parlamentswahlen und die Stärkung des Nationalen Sicherheitsrats, in dem die Generäle eine Stimmenmehrheit erhielten, wodurch sie eine politische Richtlinienkompetenz gegenüber der gewählten Regierung erhielten. Insel bezeichnete dies als die Etablierung eines »Vormundschaftsregimes« durch das Militär (ähnlich Atasoy 2009: 80ff.). Politische Parteien hätten den Autoritarismus akzeptieren müssen, da sie sich unter Anpassungsdruck befanden, um ihre Legitimation zu erhalten. Einzig der konservative Politiker Turgut Özal, der bei der ersten Parlamentswahl nach dem Militärputsch von 1980 zum Ministerpräsidenten gewählt wurde, habe mit einem Liberalisierungsprogramm die engen Grenzen des Systems überschreiten können. Nach 1983 habe Özal eine ökonomische Liberalisierung in Gang gebracht, die vom Militär »zähneknirschend« als »Tribut an moderne Zeiten« (Insel 2003: 295) akzeptiert worden sei. Auf eine kurze Liberalisierungsphase zwischen 1983 und 1985 sei jedoch die Konsolidierung des Systems durch den verhängten Ausnahmezustand im eskalierenden Konflikt mit der Arbeiterpartei Kurdistans (PKK), die einen bewaffneten Kampf führte, gefolgt. Insel nannte dieses System, in dem er eine Peripherie einem autoritären Zentrum entgegengestellt sah, in Anlehnung an den Tag des Putsches von 1980 das »12. September-Regime«. Die AKP situierte er schließlich in der Kontinuität Özals, da dieser derselben »modernizationist conservative world as today's AKP« (ebd.) angehöre. Mit der Parlamentswahl von 2002, bei der die AKP eine absolute Mehrheit errang, sah Insel das System in die selbst gestellte Falle tappen. Während etablierte Parteien an der Zehn-Prozent-Sperrklausel scheiterten, errang die neu gegründete AKP als die Partei, die sich aufgrund ihrer »wertebasierten« Verfasstheit - konservativ-religiös, nationalistisch und liberal - in größter Distanz zum »Staat« - identisch gesetzt mit der Bürokratie - befunden habe, eine Mehrheit im Parlament. Die AKP hegte nach Insel anders als die herrschende republikanisch-autoritäre Elite, die den Staat besetzt hielt, kein Misstrauen gegenüber dem »Volk«. Sie schöpfe ihre Kraft aus der Gewissheit, Repräsentantin der kulturellen Mehrheit zu sein, womit der Weg für eine demokratische Transformation der Türkei frei geworden sei (ebd.: 303). Der Religion im AKP-Projekt maß Insel eine positive Bedeutung zu: Sie bilde ein Set moralischer Werte als Basis eines toleranten Nationalismus, der ähnlich wie der US-amerikanische Konservatismus eine Liebe zum Land ausdrücke und Diffe- 
renzen zulassen könne, im Gegensatz zum säkularen, autoritären Nationalismus der Eliten, der eine Liebe zum Staat ausdrücke und Differenzen unterdrücke.

Während Insel die gesamte Geschichte der Türkei unter dem Blickwinkel einer vorgestellten kulturellen Übereinstimmung nach westlichem Vorbild interpretierte, hob Yıldız Atasoy das Element der Liberalisierung stärker hervor. Auch sie ging davon aus, dass die AKP das Volk repräsentiere und die Installierung eines politischen Modells nach westeuropäischem Muster auf der Grundlage universeller Menschenrechte und Gerechtigkeit anstrebe (Atasoy 2009: 7ff., 109ff.). Opposition zur AKP wertete sie als kemalistische Reaktionen und verteidigte die AKP gegen den Verdacht des Islamismus als der Demokratie verpflichtete und »islam-sensible Partei« (ebd.: 5). Zu einem ganz ähnlichen Schluss gelangte Hakan Yavuz, der in Auseinandersetzung mit den Thesen von Samuel Huntington (1993) und Bernhard Lewis (1961), die im Islam ein generelles Hindernis im Übergang zur Demokratie sahen, die Frage formulierte, ob es islamisch inspirierten politischen Bewegungen gelingen kann, zu Agenten der Demokratisierung und Modernisierung zu werden (Yavuz 2009; vgl. Atasoy 2009: 25). In Auseinandersetzung mit dem Argument, das Christentum sei eine kulturelle Bedingung von Demokratie, entwickelte er die modernisierungstheoretische These, dass der Islam zu einer Quelle liberaler Demokratisierung und Modernisierung werden und Islamisten sich zu Demokraten entwickeln könnten, wenn zwei Bedingungen erfüllt seien, die seiner Auffassung nach auch für westliche Demokratien gelten: die Existenz eines liberalen Markts und eines Parlaments beziehungsweise einer öffentlichen Sphäre, in der um Werte und Identitäten gestritten werde (Yavuz 2009: Preface). Diese Bedingungen sah Yavuz durch die Bildung der AKP gegeben. Auch aufgrund der selbst erfahrenen staatlichen Repression hätten ehemalige Islamisten, die für die Scharia und gegen die Demokratie mobilisierten, Demokratie und Pluralismus internalisiert und seien zu moderaten Konservativen geworden, die den Islam in Konformität zu liberalen Werten auslegten (ebd.: XI). ${ }^{2}$ Yavuz identifizierte eine konservative Revolution, die von einer Zivilgesellschaft, getragen von Intellektuellen und einer neuen Unternehmerklasse, ausgehe (ebd.: 4).

Mit der Westernisierungsthese ging also die Definition einer Norm einher, die in der Herstellung kultureller Übereinstimmung zwischen Staat und Gesellschaft beziehungsweise den Eliten und dem Volk bestehen sollte. Die AKP wurde als konservativ-demokratische Bewegung, als Bewegung einer Peripherie begriffen, die eine Gegenbewegung zu einem autoritären staatlichen Zentrum bilde- 
te. ${ }^{3}$ Auch Atasoy lokalisierte den Beginn des Konflikts im Osmanischen Reich. Sie sah eine Modernisierungsbewegung islamischer Intellektueller, die die überlegene westliche Technologie übernehmen und die islamischen Werte beibehalten wollte, seit dem 19. Jahrhundert einer zweiten Bewegung gegenüberstehen, die Islam und Fortschritt für unvereinbar hielt und aus diesem Grund sowohl die Technologie als auch die Werte des Westens übernehmen wollte (Atasoy 2009: 44ff.; vgl. Yavuz 2009: XI). Aus der zweiten Bewegung sei der Kemalismus hervorgegangen, in dessen Mittelpunkt Atasoy den Laizismus situierte, den sie als eine Zusammensetzung aus säkularem Nationalismus, Militarismus und Etatismus definierte (Atasoy 2009: $3,26)$. Aus ihrer Perspektive entstanden und reproduzierten sich die Kemalisten in der Bürokratie, standen zu Beginn ihres Wirkens in keiner Verbindung mit irgendeiner gesellschaftlichen Gruppe oder Partei und handelten allein zum Zweck des Selbsterhalts und damit zum Erhalt des Staates. Im Laufe der Zeit erschufen sie eine Bourgeoisie nach ihrem Ebenbild, die Atasoy im Unternehmerverband TÜsİ$\mathrm{AD}^{4}$ repräsentiert sah, der sein Dasein bis in die Gegenwart in Abhängigkeit von der Bürokratie friste. Das kemalistische Projekt belegte sie mit dem Begriff »Privilegienzirkel«, der die muslimische Bevölkerung, die die Gesellschaft ausmache, ausschloss (ebd.: 9). Diesem »Privilegienzirkel« ordnete sie schließlich eine Reihe politischer Parteien zu, die über die gesamte Republikzeit unter verschiedenen Namen existierten. In den 2000 er Jahren waren dies die Republikanische Volkspartei (CHP) und die Partei der Nationalistischen Bewegung (MHP), die die hauptsächlichen politischen Rivalen der AKP waren. In Opposition zu dieser realiter recht breiten Allianz, die von Atasoy dennoch weiterhin als »Privilegienzirkel« einer kleinen Elite konzipiert blieb, situierte sie »liberale« Kräfte. Deren Parteiengeschichte ließ sie mit der Bildung der konservativen DP (Demokratische Partei) im Jahr 1946 beginnen (ebd.: 9ff.). Insels Auffassung wich nur in der Benennung der initialen Partei ab. Bei ihm setzte die Tradition mit der konservativen AP (Gerechtigkeitspartei) ab 1960 ein und mündete über die ANAP (Mutterlandspartei) und die DYP (Partei des Rechten Weges) schließlich in der AKP. Obgleich die genannten Parteien des konservativen Spektrums seit mehr als einem halben Jahrhundert nahezu ununterbrochen alle Regierungen anführten, schätzten beide Autoren deren Bedeutung gering: Sie seien nie wirklich herrschend gewesen, die autoritär-republikanische Elite (Bürokratie) habe immer die Macht im Staate gegen die gewählten Regierungen innegehabt.

Für frühere Interpretationen des politischen Islam aus dieser Perspektive siehe Cöle (1997), Keyder (1997), Yavuz (1997) und Gülalp (2005).

4 Die Abkürzung steht für Türk Sanayicileri ve Işsinsanları Derneği (Vereinigung türkischer Industrieller und Ceschäftsleute). Im Verband sind die älteren und großen Unternehmen des Landes organisiert, die oftmals in der Form von Konglomeraten organisiert sind und in etlichen Produktions-, Handels- und Finanzbereichen Monopolstellungen einnehmen. 
Neben einer demokratisierenden Wirkung der Politik auf die sozialen Träger der Religion durch Lernen aus Repression, parlamentarische Aushandlungsprozesse und Streit im öffentlichen Raum wurde eine demokratisierende Wirkung insbesondere der Beziehung zwischen Religion und Ökonomie unterstellt. Insel begriff den ökonomischen Liberalismus als befreienden Gegenpart zum elitären »Etatismus«, ein Zusammenhang, den Yavuz und Atasoy noch deutlicher ausformulierten. Atasoy interpretierte Neoliberalismus als einen freiheitsfördernden Prozess, da er für mehr Markt und weniger Staat sorge, somit die staatliche Unterdrückung einer genuin pluralen Gesellschaft beende (Atasoy 2009: 20ff.). Die liberalisierende Kraft des Neoliberalismus hatte ihrer Auffassung nach einen Wandel islamistischer Akteure, im Besonderen der Milli Görüş Bewegung, aus der die AKP hervorging, herbeigeführt. Mit der Abwendung von Industrieförderprogrammen, die sie als ein staatlich gelenktes ökonomisches Entwicklungsmodell fasste, das in den 1970ern auch von der Milli Görüş Bewegung noch favorisiert worden war, hätten sich diese Akteure vom Staat ab- und dem Liberalismus zugewandt.

Alle drei Autoren identifizierten als treibende Kraft hinter der AKP eine neue Mittelklasse oder Bourgeoisie, ohne eine genauere begriffliche Unterscheidung zwischen diesen beiden Kategorien vorzunehmen. Diese neue gesellschaftliche Gruppierung, die auch als »anatolische Bourgeoisie« (Yavuz 2009: 14) bezeichnet wurde, da sie aus den anatolischen Provinzen stamme, benannten sie als eigentliche Trägerin der Demokratisierung oder der »stillen Revolution« (ebd.: 10). Vertreten wurde diese Gruppe durch den Unternehmerverband MÜSİAD ${ }^{5}$, der »authentische« Werte, unter denen die Autoren die ihrer Einschätzung nach in der Bevölkerung vorherrschende Kultur verstanden, und Modernität, als die sie den kapitalistischen Entwicklungsweg nach westlichem Vorbild fassten, miteinander verband. Anders als die ältere Bourgeoisie, vertreten durch den Unternehmerverband TÜSİAD, habe sich die der AKP unterliegende neue Bourgeoisie ohne staatliche Unterstützung entwickelt, sei in ihrer Entwicklung von der Staatsbürokratie sogar behindert worden (Atasoy 2009: 114).

Neben dem Neoliberalismus sollte die Anbindung an liberale EU-Normen die Heranführung der Türkei an die EU durch die »anatolische Bourgeoisie« - den demokratischen Wandel garantieren (Yavuz 2009: 14). Den Wandlungsprozess bezeichnete Atasoy plastisch als »Vermählung des Neoliberalismus mit dem Islam« oder als »neoliberal-islamische Synthese« (Atasoy 2009: 109). Damit verlasse die Türkei den Pfad der für osteuropäische Staaten typischen autokratischen Entwicklung, die keine kapitalistische Klasse hervorbrachte, die für Freiheit und Bürgerrechte einstand. Die Türkei biege nun in den westlichen Pfad demokratischer Ent- 
wicklung unter der Führung der neuen Bourgeoisie ein, die sich, von der staatlichen Bevormundung befreit, anschicke, eine liberale Demokratie zu installieren (ebd.: 39, 114ff.). Zugleich sah sie die religiösen Unternehmer ein »kommunitaristisches", auf Gemeinschaftlichkeit beruhendes Gesellschaftsmodell entwerfen, das ein moralisches Gegengewicht zum »kapitalistischen Egoismus« (ebd.: 130) bilde. Einen Ausgleich zur Neoliberalisierung, zu deren Effekten Atasoy wachsende soziale Ungleichheit und Entrechtung von Arbeitern zählte, schaffe dieses Modell dank Bindungskraft einer islamischen Moral, die eine gerechtere und gleichere Gesellschaft entwerfe und von den im Verband MÜSİAD organisierten Unternehmern internalisiert worden sei. In der islamischen Moral erkannte Atasoy auch einen Ausgleich zur Gewerkschaftsfeindlichkeit dieser Unternehmer (ebd.: 131ff.).

Das »Historische« an der AKP sah Atasoy also in der Überwindung einer Repräsentationsbeziehung, die einen »Privilegienzirkel« geschaffen hatte, dem kemalistische Eliten (Bürokraten) und der Unternehmerverband TÜSİAD angehörten und der auf Kosten der »anatolischen « und »muslimischen « Bevölkerung errichtet worden war. Säkularismus oder Laizismus wurden als volksfremde und elitäre Werte begriffen, ihre Träger als Staatseliten bezeichnet, die Kultur als Mittel zur Verteidigung ihrer Machtposition einsetzten. Wie schon die Begriffe "anatolisch « und »muslimisch« andeuten, führte sie die Unterstützung für die AKP auf die Überwindung der kulturellen Unterdrückung zurück, die der »Privilegienzirkel« fortgesetzt habe. Atasoy griff in diesem Zusammenhang die Aufhebung des Verbots des Tragens eines Kopftuchs in öffentlichen Einrichtungen und die Aufhebung von bestimmten Restriktionen gegenüber der kurdischen Sprache auf, die in den ersten Regierungsjahren der AKP ergriffen worden waren. Vor dem Hintergrund der Annahme, dass die Bevölkerung überwiegend einer Form des islamischen Glaubens anhänge, zu der das Tragen eines Kopftuchs gehörte, wertete sie das Kopftuch-Verbot als Ausdruck eines pauschalen Ausschlusses der Bevölkerung aus dem Staat. Dergleichen brachte sie für die kurdische Bevölkerungsgruppe vor, die vom Kemalismus unterdrückt, von der AKP jedoch anerkannt werde. Der von ihr eingebrachte Begriff »cross-class-coalition« (ebd.: 109, 131) folgte ebenso wie der von Yavuz eingebrachte Begriff »hybrid class-coalition« (2009: 106) diesem Verständnis, wonach die AKP vermittels kultureller Inklusion dafür sorgte, dass auch MuslimInnen und KurdInnen im Staat repräsentiert würden. ${ }^{6}$ Der unter dem kemalistischen Projekt homogenisierend und autoritär wirkende Laizismus sollte unter der AKP zu einem liberalen und pluralen Projekt des toleranten Miteinanders verschiedener eine einzigartige klassenübergreifende Synthese (Karakas 2007: III) reihen sich ein, ebenso der Begriff »catch-all party« (Tröndle 2007: 89), der den Umstand umreißt, dass die Partei Mehrheiten trotz mannigfaltiger Spaltungslinien, von denen die Gesellschaft durchzogen ist, aggregierte. 
Identitäten werden (Atasoy 2009: 9). Die von den Kemalisten in den Bereich des Privaten gedrängte Religion fand demzufolge unter der AKP den Weg zurück in die Öffentlichkeit und wurde zum Mittelpunkt eines neuen Liberalismus, während die laizistischen Fundamente des Modernisierungsprojekts unangetastet bleiben sollten (ebd.: 19, 32).

Vor dem Hintergrund dieser Analysen wird die nachdrückliche Diagnose eines »epochalen« Umbruchs, die Entstehung einer »Neuen Türkei« (Yavuz 2006), die mit der AKP verbunden wurde, verständlich. Wurde eine beinahe hundertjährige Vormundschaft der Kemalisten gegenüber der Bevölkerung, in Fortsetzung eines Gegensatzes aus der osmanischen Zeit, angenommen, erschien deren Beendigung als Befreiung. Opposition zur AKP ebenso wie zum Neoliberalismus wurde als kemalistische Reaktion interpretiert, der es um die Aufrechterhaltung des Etatismus - begriffen als staatliche Unterdrückung gesellschaftlicher Pluralität - ging. Alle drei Autoren beschrieben einen kemalistischen Kulturkampf, ohne diesen Begriff explizit zu benutzen. Im Zusammenhang mit den historischen Parteien des politischen Islam sahen sie die Religion noch als kulturkämpferisches Gegenstück zum Kemalismus, als autoritäres Element eines politischen Projekts an. Die AKP repräsentierte nach Ansicht der Autoren eine Loslösung von dieser Tradition zugunsten einer Fortsetzung der konservativ-liberalen Parteientradition. Mit der AKP verwandelte sich die Religion in eine kulturelle Inspirationsquelle für die Demokratie (Yavuz), eine Verantwortungsethik von Unternehmern (Atasoy) oder in eine Form des Patriotismus (Insel), der »Volk« und Staat versöhnte. In allen drei Formen war mit der Religion in Zeiten der AKP nicht mehr der Anspruch auf politische Gestaltung verbunden, sie wurde - hauptsächlich unter Einwirkung der Ökonomie - in den vermeintlich a-politischen Bereich der Kultur gerückt. Im Kampf zweier Modernisierungsprojekte, so das Fazit, ging mit der AKP die »muslimische Demokratie« gegenüber dem »autoritären Laizismus« als Siegerin hervor.

\subsubsection{Politische Wirkung der Kulturkampfthese}

Die Rückführung einer verhinderten Demokratisierung auf den autoritären Kemalismus, der den Staat repräsentiert und die Gesellschaft unterdrückt, stellte eine theoretische Perspektive auf die AKP her, die ein Parteiergreifen für ihre Anliegen beförderte. Angeführt von Persönlichkeiten und Gruppierungen aus den Bereichen der Wissens-, Medien- und Kulturproduktion wurden Stellungnahmen verfasst und Kampagnen organisiert. Kennzeichnend war, dass die TrägerInnen maßgeblich weder der Tradition des politischen Islam noch dem konservativen Spektrum zuzurechnen waren. Als exemplarisch für diese Aktivitäten kann die Kampagne »Ja, aber nicht genug« (»Yetmez Ama Evet«) herangezogen werden, mit der sich ein Unterstützernetzwerk für die von der AKP vorangebrachte Verfassungsreform im Jahr 2010 formierte. MenschenrechtlerInnen, eine trotzkistische Vereinigung, 
eine große Zahl liberaler JournalistInnen und WissenschaftlerInnen, unter ihnen zahlreiche ehemalige Mitglieder kommunistischer Parteien und linker Studentenorganisationen der 1970er und 1980er Jahre, sowie prominente Persönlichkeiten wie der Literaturnobelpreisträger Orhan Pamuk, die Schriftstellerin Elif Shafak und die Pop-Künstlerin Sezen Aksu schlossen sich der Kampagne an und trugen zu ihrer Popularisierung bei. ${ }^{7}$

Zwischen der AKP und den Trägern der Kampagne bestand Übereinstimmung, dass die Justiz und das Militär als Bastionen des Kemalismus bezwungen werden mussten. Diese Sichtweise war unterlegt durch die Auflösung des in den ersten Regierungsjahren der AKP bestehenden parlamentarischen Konsens mit der Oppositionspartei CHP in Bezug auf Verfassungsreformen. Waren diese Reformen im Zuge des Heranführungsprozesses an die EU-Mitgliedschaft noch gemeinsam beschlossen worden, so folgte eine zunehmende Polarisierung, die ihren ersten Höhepunkt 2007 erreichte, als die Wahl eines neuen Staatspräsidenten anstand und die AKP einen ihrer prominenten Parteigründer, ihren ersten Ministerpräsidenten Abdullah Gül, zum Kandidaten ernannte. Die Wahl von Gül galt als sicher, da die AKP über die notwendige Mehrheit im Parlament verfügte. Der amtierende Präsident, der noch von einem Parlament mit kemalistisch-säkularer und sozialdemokratischer Mehrheit gewählt worden war, hatte seiner Kontrollfunktion über die Legislative nachkommend etliche Gesetze der AKP mit einem aufschiebenden Veto belegt oder dem Verfassungsgericht zur Prüfung vorgelegt. Die im Parlament vertretene republikanische Opposition befürchtete, dass die AKP mit einem Präsidenten aus den eigenen Reihen einen autoritären und islamistischen Kurs einschlagen würde. Sie organisierte Großdemonstrationen, bei denen auch das Militär zur Verteidigung der Republik und des Laizismus gegen die »islamistische Gefahr « aufgerufen wurde, obgleich das übergeordnete Motto »Weder Putsch noch Scharia« lautete. Als einer der Organisatoren trat der »Verein für Atatürkistisches Denken« ADD (»Atatürkçü Düşünce Derneği«) auf, der eine nationalistische Strömung in der CHP repräsentiert. ${ }^{8}$ Der Verein sah nicht nur den Laizismus gefährdet, sondern auch den Bestand der Republik Türkei aufgrund einer Regierungspolitik, die in einer Sezession des Südostens über die Anerkennung der kurdischen Identität, einer Aufgabe des türkischen Protektorats in Zypern im Zuge der EU-Reformen und in

Innerhalb des sozialistischen und liberalen Spektrums fand diese Kampagne Verbreitung durch die Zeitung Taraf, die ehemalige Kommunisten, Trotzkisten, Liberale und weitere Personen, die offenbar aus Ceheimdienst- und Polizeiquellen gespeist wurden (Aladağ 2013), unter ihrem Dach versammelte. In Teilen wurde die Kampagne auch durch die populär-wissenschaftliche Zeitschrift Birikim gestützt, in der Ahmet Insel regelmäßig publiziert. Siehe hierzu beispielhaft die Birikim-Ausgabe 163/164, die nach dem ersten Wahlsieg der AKP 2002 erschien, sowie die Ausgabe 256/257, die vor dem Verfassungsreferendum 2010 gedruckt wurde.

$8 \quad$ Zur Geschichte der ADD siehe Erdoğan (2001a). 
einer kompletten Erosion der türkischen Identität durch die Aufnahme eines Dialogs mit Armenien über die Frage des Genozids an der armenischen Bevölkerung des Osmanischen Reichs münden würde (Baran 2008).

Während die AKP in den aufgeführten Fragen Verhandlungsbereitschaft signalisierte, stellte sie sich anders als ihre Vorläuferinnen aus dem Spektrum des politischen Islam nicht offensiv gegen den Laizismus, einzelne Vertreter wiesen bisweilen sogar jeden Bezug zum Islam zurück (Çavdar 2006). Sie präsentierte sich als konservativ-demokratische Kraft (Akdoğan 2004), die die Glaubensfreiheit für alle verteidige, insbesondere aber das Primat der politischen Regierung gegen einen »tiefen Staat « durchzusetzen versprach, woraus sie auch internationales Ansehen bezog. ${ }^{9}$ Mit dem »tiefen Staat « wurde die Existenz eines verdeckten Netzwerks in den staatlichen Institutionen behauptet, das parallel zur politischen Regierung bestehen sollte, deren legitime und legale Machtausübung es sabotierte. ${ }^{10}$ Tatsächlich gab es Hinweise auf das Bestehen eines solchen Netzwerks, doch die Verbindungen zwischen den einzelnen Akteuren aus Militär, Wissenschaft und Medien, die diesem Netzwerk angehören sollten, wurden nie stichhaltig belegt. Die Auffassung, dass die Massendemonstrationen in Verbindung zu diesem Netzwerk stehen und den Boden für einen militärischen Sturz der Regierung vorbereiten sollten, war nicht nur unter den liberalen Unterstützern der Regierung, sondern auch bei vielen neutralen Beobachtern, die einen kemalistischen Faschismus aufkommen sahen, verbreitet (Tuğal 2007). Mit der Veröffentlichung eines Memorandums vor der Präsidentschaftswahl, in dem allgemein zur Wahrung des Laizismus aufgerufen wurde, schien der Generalstab dem Ruf der Demonstrierenden zu folgen. ${ }^{11}$ Der Aufruf wurde als Ultimatum an die Regierung interpretiert, von der Aufstellung Güls abzusehen und sich auf einen gemeinsamen Kandidaten mit der Opposition zu einigen. Die AKP beharrte auf ihrem Kandidaten Gül. Die von Tumulten im und dem demonstrativen Auszug der CHP-Abgeordneten aus dem Parlament begleitete Wahl Güls fand statt. Eine juristische Auseinandersetzung schloss unmittelbar an. Die CHP reichte eine Klage beim Verfassungsgericht gegen die Rechtmäßigkeit

9 Bis ins Jahr 2013 wurde die AKP auch in der internationalen Presse nahezu uneingeschränkt als demokratische Hoffnungsträgerin präsentiert (vgl. Berlinski 2017).

10 Der Begriff »tiefer Staat« wurde inflationär verwendet, um eine Verstrickung zwischen der nationalistischen und laizistischen Opposition, dem Militär, der Justiz und einem paramilitärischen Netzwerk anzuzeigen, das für die Ermordung kritischer Intellektueller wie Hrant Dink verantwortlich gemacht wurde. Die Auffassung prägte auch die internationale Berichterstattung zur Türkei. Siehe exemplarisch Niels Kadritzke (Kopftücher, Ceneräle und türkische Demokratie, 14.12.2007) und Wendy Kristianasen (Die Türkei denkt sich neu, 12.2.2010) in Le Monde diplomatique.

11 Das Memorandum wurde als »elektronisches Memorandum « (E-Memorandum) bekannt, da es auf der Website des Generalstabs veröffentlicht wurde. Siehe das Memorandum im Wortlaut bei Saraçoğlu und Yeşilbağ (2015: 924). 
der Wahl ein. Das Gericht erklärte die Wahl für ungültig und schuf mit seiner Begründung einen umstrittenen Präzedenzfall. Es schrieb die Anwesenheit von mindestens zwei Dritteln der Abgeordneten im Parlament bei einer Abstimmung als zwingend für die Beschlussfähigkeit vor, womit eine parlamentarische Sperrminorität geschaffen wurde, die durch den Auszug der Abgeordneten der CHP gegeben war. In Reaktion hierauf rief die AKP Parlamentswahlen aus, erlangte erneut eine parlamentarische Mehrheit und konnte ihr 2002er Wahlergebnis von 34 auf 46 Prozent erheblich steigern. Neben der CHP zog diesmal auch die Partei der Nationalistischen Bewegung MHP, die einen fanatischen türkischen Nationalismus pflegt, ins Parlament ein. Eine erneute Blockade der Präsidentschaftswahl war nicht mehr möglich, zusammen mit der MHP, die signalisierte, der AKP beizustehen, verfügte die Regierung über die vorgeschriebene parlamentarische Zweidrittelmehrheit. Gül wurde zum Präsidenten gewählt. Die Auseinandersetzung war damit aber noch nicht ausgefochten. Ein Staatsanwalt erhob Anklage gegen die AKP wegen Verstoßes gegen das laizistische Prinzip in der Verfassung und forderte ein Verbot der Partei und die Verhängung politischer Betätigungsverbote gegen prominente Vertreter der Partei: Strafmaßnahmen, von denen vier historische Vorläuferparteien der AKP bereits betroffen gewesen waren. Die Klageführung bezog als Beweismittel für einen Verstoß gegen den Laizismus auch ein Gesetz ein, das die Aufhebung des Kopftuchverbots an den Universitäten vorsah. Die AKP hatte nach der Präsidentschaftswahl im Jahr 2007 dieses Gesetz mit den Stimmen der MHP verabschiedet, das mit Bestätigung durch den Präsidenten Gül in Kraft trat. Hintergrund war die im Jahr 1997 erfolgte Intervention des damals noch von Generälen dominierten Nationalen Sicherheitsrats gegen ein regierendes konservatives Parteienbündnis, an dem eine Vorgängerpartei der AKP - die Wohlfahrtspartei RP - beteiligt war. Zur Bekämpfung der »anti-laizistischen Gefahr« wurde damals neben einer Reihe von Maßnahmen (Dufner 1998), die die öffentliche Förderung des Islam beschnitten, auch das Tragen eines Kopftuchs an Universitäten verboten. Das Verfassungsgericht verhängte 2008 eine Geldstrafe gegen die AKP wegen »anti-laizistischer Umtriebe«, aber kein Verbot. Bereits zuvor hatte das Gericht das Gesetz zur Aufhebung des Kopftuchverbots durch ein gesondertes Urteil wieder aufgehoben. Neben dem Memorandum der Armee und den juristischen Ermittlungen gegen die AKP wurde die Auffassung, es existiere ein »tiefer Staat«, der einen Putsch gegen die Regierung plane, durch die im Jahr 2007 aufgenommenen staatsanwaltlichen Ermittlungen gegen ein verdecktes Netzwerk bestärkt, das unter dem Namen Ergenekon bekannt wurde. Der damalige Ministerpräsident Erdoğan verbürgte sich persönlich für die Ermittler, die im Laufe von zwei Jahren zahlreiche Armeeoffiziere und Zivilisten wegen Planung eines Putschs verhaften ließen.

Die Frontstellung zwischen Teilen der CHP, des Militärs und der Justiz auf der einen und der Regierung auf der anderen Seite wurde als Bestätigung der These gesehen, dass in der Türkei ein Demokratiedefizit vorliege, dessen Beseitigung 
zuallererst eine Abrechnung mit dem Kemalismus und dem »tiefen Staat « notwendig mache (vgl. Ciddi 2011; Saraçoğlu/Yeşilbağ 2015: 914ff.). Die Initiatoren der Kampagne »Ja, aber nicht genug " nahmen an, dass die Verfassungsreform einen Schritt in diese Richtung darstelle. Als konkretes Zeichen führten sie eine im Paket enthaltene Gesetzesänderung an, mit der es möglich werden sollte, Armeeangehörige vor Zivilgerichten anzuklagen und den Generalstabschef des Putschs von 1980, Kenan Evren, persönlich vor Gericht zu stellen. Das Referendum wurde mit einem positiven Ergebnis für die Verfassungsänderungen entschieden. Die Regierung erhielt neue Befugnisse, die ihren Einfluss auf die höheren Justizbehörden ausweitete. ${ }^{12}$ Eine trotzkistische Gruppe in den Reihen der Kampagnenträger hatte diese Einschränkung der Gewaltenteilung gar als erstrebenswert ausgelegt, da es der Demokratisierung diene. ${ }^{13}$

\subsubsection{Autoritäre Rückverwandlungsthese}

Der präsentierte geschichtliche Ausschnitt liefert einen Einblick in die ereignisreiche politische Entwicklung, auf deren Grundlage sich ein beträchtlicher Teil der liberalen Öffentlichkeit, darunter viele WissenschaftlerInnen, die Überzeugung bildete, die Regierung verfolge demokratische Absichten, die von den »etatistischen« Kräften sabotiert würden. Frühen Reformen im Zuge der EU-Annäherung wie der Rekonfiguration des Nationalen Sicherheitsrats und der partiellen Liberalisierung von Minderheitenrechten - in erster Linie Anerkennung der kurdischen Sprache -

12 Zu der Auffassung, dass die AKP mit der angestrebten stärkeren Kontrolle über die Behörden auch eine Liberalisierung erzielen werde, trug bei, dass sie zuvor die Eröffnung eines Strafverfahrens wegen »Herabsetzung der Republik und des Türkentums« auf der Crundlage des Paragraphen 301 an die Erlaubnis des Innenministeriums gebunden hatte. Staatsanwälte hatten den Paragraphen immer wieder herangezogen, um die Hinterfragung der offiziellen Staatsideologie, zu der insbesondere die Leugnung des Cenozids an der armenischen Bevölkerung des Osmanischen Reichs gehört, der juristischen Verfolgung auszusetzen. Die politische Kontrolle über die Verfahrenseröffnung wurde als Aussetzung eines Mittels zur Unterdrückung der Meinungsfreiheit interpretiert. Doch aus rechtsstaatlicher Perspektive bedeutete diese Reform eine Kompetenzverschiebung von der Judikative zur Exekutive: Anstatt die Straftat per Gesetz aufzuheben und somit der Staatsanwaltschaft die Rechtsgrundlage zu entziehen, wurde die Aufnahme von Ermittlungen an den politischen Willen der Regierung gebunden.

Im August 2010 veröffentlichte die trotzkistische Partei DSIP (»Devrimci Sosyalist İşçi Partisi« - Revolutionäre Sozialistische Arbeiterpartei), die zu den entschlossensten Verfechtern der Kampagne gehörte, eine Erklärung mit dem Titel »Auf den Müll mit der Verfassung des 12. September « (gemeint war die Verfassung von 1982). Darin hieß es: »Wir werden Ja sagen bei dem Referendum, weil die Diktatur der Richter des Verfassungsgerichts und des Hohen Rats der Richter und Staatsanwälte mit diesen Veränderungen verhindert wird « (Übersetzung des Autors aus dem elektronischen Dokument »12 Eylül Anayasası Çöpe«vom 08.08.2010 im Archiv des Autors, das im Internet nicht mehr aufzufinden ist). 
wurden ein hohes demokratisierendes Gewicht beigemessen. In Wirklichkeit verlief die politische Entwicklung in eine andere Richtung, die von der Unterstützergemeinschaft der AKP erst nach den Massenprotesten gegen die AKP im Sommer 2013, ausgelöst durch die Bebauungspläne für den Gezi-Park in Istanbul, wahrgenommen wurde. Die Regierung reagierte mit harten Polizeieinsätzen und repressiven Kampagnen gegen die Protestierenden. In der Folge wich die Erwartung einer Demokratisierung der These einer »autoritären Wende« (Özbudun 2014; Öniş 2015; Kalaycıŏlu 2015; Esen/Gumuscu 2016), die durch eine qualitativ neuartige Eskalation des Krieges mit der PKK ab 2015 bestärkt wurde, womit auch die Erwartung einer friedlichen Beilegung dieses Konflikts schwand. Von den besprochenen Vertretern der Kulturkampfthese ist Ahmet Insels Interpretation beispielhaft für die staatszentristische Reaktion auf diese Entwicklungen. Im Interpretationsrahmen Staat versus Gesellschaft verbleibend nahm Insel eine Umkehrung der Vorzeichen vor. Die AKP verkörperte nun alle autoritären Attribute, die zuvor dem Staat zugeschrieben waren. Die Partei sei etatistisch geworden, unterdrücke die Gesellschaft und sorge für die Kontinuität der autoritär-laizistischen Institutionen der Republik. ${ }^{14}$ Die »autoritäre Wende« der AKP auf dem Weg in einen »Totalitarismus« erklärte er mit der Machtkonzentration beim inzwischen zum Staatspräsidenten gewählten Erdoğan. Entsprechend nannte er die neue Regimeform personifizierend »Erdoğanismus«. Die konservative Mehrheitsbevölkerung sehe in Erdoğan einen Beschützer gegen die kemalistische Tradition, weshalb sie ihn weiterhin unterstütze. Die Religiosität dieser Bevölkerung, die er 2003 als eine Form des religiösen Patriotismus gefasst hatte, thematisierte er nun als einen exkludierenden und unterdrückerischen sunnitischen Nationalismus, dessen Wurzeln er im Osmanischen Reich liegen sah. Die AKP sah Insel auf dem Weg, die gesamte Gesellschaft $\mathrm{zu}$ islamisieren (İnsel 2014; 2015; 2016a; 2016b).

Damit entstand eine Interpretation, die bedeutet, dass etwa 85 Prozent der wahlberechtigten Bevölkerung, die bei den Parlamentswahlen im Jahr 2015 für die CHP, die MHP oder die AKP stimmten, sich auf der Seite des Staates gegen die Gesellschaft positioniert hatten, da die CHP und die MHP schon zuvor dem Staat zugerechnet worden waren. Der Staat expandierte und umschloss nun auch die AKP, die bis dahin für das Volk oder die Gesellschaft gestanden hatte; die Gesellschaft, die als reale Größe konzipiert eine unterdrückte Majorität - das >Volk « darstellte, schrumpfte zu einer unterdrückten Minorität. Gleichzeitig wendete sich der nahezu hundert Jahre alte Kulturkampf, den die Kemalisten gegen das >Volk«

14 Der Schwenk von Insel ist exemplarisch für eine ganze Reihe von Autoren, darunter auch Cizre (2017), die eine Absorption der AKP in den Kemalismus behauptet. Siehe kritisch Deniz Yıldırım: Yoksa liberaller Kemalist mi? [Sind die Liberalen etwa Kemalisten?], in: İleri Haber, 06.11.2014, https://ilerihaber.org/yazar/yoksa-liberaller-kemalist-mi-30399.html (Abruf am 11.10.2018). 
geführt hatten, auf einmal gegen sie. Von den besprochenen Autoren wendete sich Yavuz ähnlich wie Insel der Person Erdoğan zu und fokussierte den Machtkampf mit dem Gülen-Netzwerk als Austragung einer inner-islamistischen Rivalität (Yavuz/Koç 2016). Die AKP hatte nach einem Putschversuch im Juli 2016, der mutmaßlich durch das lange Zeit mit ihr verbündete Netzwerk angeführt wurde, dauerhaft den Ausnahmezustand über das gesamte Land verhängt. Mit dem Ausnahmezustand wurde der Präsident ermächtigt, per Dekret zu regieren, womit die nachfolgende Einführung des Präsidialsystems per Referendum, mit dem die weitgehende Gewalteneinheit in der Verfassung verankert wurde, vorweggenommen wurde. ${ }^{15}$

Die einst prominente These einer demokratisierenden Wirkung des Neoliberalismus und des Parlamentarismus, mit der der Autoritarismus zurückgedrängt und der kemalistische Kulturkampf beendet werden sollten, wurde nach 2013 stillschweigend beiseitegelegt. Weshalb die normalisierenden und demokratisierenden Dynamiken, die mit Begriffen wie »Neue Türkei« und »stille Revolution« belegt worden waren, nicht gewirkt hatten, blieb unreflektiert. Die Frage, warum die Religion »wieder « zu einem kulturkämpferischen Mittel der Politik geworden war, wurde mit dem Machtwillen einer Einzelperson oder mit inner-islamistischen Rivalitäten erklärt. In Bezug auf die von dieser Arbeit verfolgte Frage besteht die auffälligste Veränderung bei der autoritären Rückverwandlungsthese darin, dass die Rolle der Religion für das politische Projekt der AKP nicht mehr im Verhältnis zur Bourgeoisie thematisiert wurde. Der Unternehmerverband MÜSİAD beziehungsweise die anatolische Bourgeoisie, die das »demokratische« Projekt der AKP begründeten, rückten mit Einsetzen der »autoritären« Phase aus dem Blickfeld.

\subsubsection{Kritik der Kulturkampfthese}

Die empirischen Auslassungen und konzeptionellen Unstimmigkeiten in der Kulturkampfthese sind so zahlreich, dass eine umfassende Kritik der eigenständigen Rekonstruktion der politischen Geschichte unter der Fragestellung nach der Rolle der Religion im politischen Projekt der AKP vorgreifen würde. Da diese Rekonstruktion erst nach der Diskussion der gesamten Forschungsliteratur erfolgen wird, werden an dieser Stelle nur einige zentrale Punkte zusammengefasst.

An erster Stelle ist anzuführen, dass der Befund einer Demokratisierung nicht an demokratietheoretisch begründeten Kriterien orientiert war (vgl. Yildızoğlu 2009). Eine Reihe von Reformen, die eine Erosion der Gewaltenteilung und von Bürgerrechten erzielten, wurden ausgeblendet. Bereits 2004 richtete die AKP mit Sondervollmachten ausgestattete Gerichte ein, 2005 verabschiedete sie ein re- 
striktives Strafrecht und 2006 verschärfte sie die »Terrorbekämpfungsgesetze ${ }^{16}$ In dieser frühen Periode, als die »Demokratisierung « auf dem Weg in die EU die vermeintlich größten Fortschritte machte, setzten der Aufbau eines »Polizeistaats « (Aydin 2012) und die Etablierung einer regierungskonformen politischen Justiz ein (Göktaş 2012). ${ }^{17}$ Auch die Massenprozesse gegen Offiziere, Wissenschaftler, Journalisten und weitere Zivilisten im Rahmen der Ergenekon- und Balyoz-Verfahren, die wegen angeblicher Putschplanungen eröffnet wurden, wurden jenseits rechtsstaatlicher Prinzipien geführt. ${ }^{18}$ Dass die AKP den harten Kern des sogenannten Etatismus - Institutionen des »12. September-Regimes« wie den Hochschulrat YÖK, der nach dem Putsch von 1980 zur Kontrolle des Personals und der Lehrpläne an den Hochschulen eingeführt worden war - unberührt ließ, sich stattdessen alle Behörden unterordnete, wurde als notwendiges Übel bei der Bekämpfung des »tiefen Staats« gerechtfertigt. Dass die AKP schon 2011 für sechs Monate die Praxis des Regierens per Dekret ausübte, womit sie das Parlament als gesetzgebende

Der damalige Innenminister der AKP-Regierung formulierte die Ausrichtung der seit Anfang 2009 enorm ausgeweiteten Repression, die als »Terrorbekämpfung « bezeichnet wurde, folgendermaßen: „Die Aktivitäten der Terrororganisation beschränken sich nicht auf hinterhältige Angriffe in den Bergen und Hügeln, den Städten, Straßen und Gassen. Sie berühren weitere Aspekte. Es gibt psychologischen Terror, wissenschaftlichen Terror. Der Terror hat einen Hinterhof. Es gibt Terrorpropaganda, die Bemühung, ihn unschuldig, vernünftig und gerechtfertigt erscheinen zu lassen. Manche sehen diesen Aufbau nicht, übersehen ihn. Wieder andere unterstützen den Terror, indem sie verdrehen, Gründe erfinden, rationalisieren, Bilder malen, Gedichte und Kolumnen schreiben. Damit nicht genug. Sie machen den Soldaten und den Polizisten, die den Terrorismus bekämpfen, zum Thema ihrer Kunst, ihres Schaffens und versuchen sie so, zu demoralisieren«. Innenminister Idris Naim Şahin, in: Radikal, Iç̧işleri Bakanı'ndan yeni terör tarifleri [Neue Terrordefinitionen vom Innenminister], 26.12.2011.

17 Die Strafrechtsreform und Änderungen der Definition von Terrorismus ebneten den Weg, oppositionelle Regungen jedweder Art mit Terrorismus in Verbindung bringen zu können. Die Einrichtung von Gerichten mit Sonderbefugnissen ermöglichte eine weitgehende Einschränkung des Rechts auf Verteidigung, parallel dazu eine Ausweitung richterlicher und staatsanwaltlicher Befugnisse. Die Justiz konnte gegen politische Gegner der Regierung nach dem Prinzip des »Feindstrafrechts« (Göktaş 2012) agieren, wonach die Angeklagten nicht als Staatsbürger ausgestattet mit bestimmten Rechten, sondern als Staatsfeinde betrachtet wurden. Massenverhaftungen von politischen Oppositionellen und Regierungskritikern, Demonstrations- und Versammlungsverbote standen auf der Tagesordnung. So wurden zwischen 2005 und 2012 insgesamt etwa 70.000 Personen vor den mit Sondervollmachten ausgestatteten Gerichten angeklagt. Der Ablauf von Strafprozessen, das Fehlen belastbarer Beweise, geheimdienstliche Ermittlungsmethoden legten nahe, dass viele »Straftaten « Erfindungen der Behörden waren (Saymaz 2013: 40ff.). Schon 2012 befanden sich in der Türkei mehr Journalisten in Cefängnissen als in China und Iran zusammen (Dani Rodrik, Turkey's miscarriage of justice, in Washington Post, 21.09.2012).

18 Siehe ausführlich zum Prozesshergang und der Rolle des Gülen-Netzwerks die WebDokumentation balyozdavasivegercekler.com des Wissenschaftlers Dani Rodrik, der auf der Grundlage akribischer Recherchen Widersprüche und Fälschungen in der Anklage offenlegt. 
Instanz, somit auch die Möglichkeiten der parlamentarischen Opposition zur Beratung und Kontrolle der gesetzgeberischen Tätigkeit außer Kraft setzte, wurde nicht reflektiert. Per Dekret entließ die Regierung missliebiges Personal aus der Verwaltung, das noch vor ihrer Regierungszeit ernannt worden war. Die Möglichkeit solchen Vorgehens wurde 1971 nach einer militärischen Intervention in die Verfassung eingeführt und nach dem Militärputsch von 1980 bekräftigt. Die AKP machte von diesem Mittel ungeachtet ihrer Kritik am Militärputsch Gebrauch (vgl. Babacan 2013). Die nicht mehr mit der Bekämpfung des Kemalismus erklärbare Blockadehaltung der AKP bei der Senkung der Zehn-Prozent-Sperrklausel, durch die die demokratische Repräsentation im Parlament eingeschränkt worden war, wurde als Schönheitsfehler interpretiert (vgl. Iğsı 2013).

Als zweiter Punkt ist anzuführen, dass die eindeutige Frontstellung, die zwischen dem Militär und der CHP auf der einen und der AKP auf der anderen Seite zu bestehen schien, gerade bei den wenigen, eine demokratische Tendenz aufweisenden Reformen nicht gegeben war. So kann die Machtverschiebung im Nationalen Sicherheitsrat, wodurch das Stimmengewicht der Generäle im Rat reduziert wurde und die gewählte Regierung eine Mehrheit erhielt, als Demokratisierung gewertet werden. Damit verfügte das Militär über keine legalen Mittel mehr, entscheidend in politische Prozesse zu intervenieren. Doch wurde diese Entscheidung aus dem Jahr 2003 wie auch die Gesamtheit der EU-Reformen bis zur Aufnahme von Beitrittsgesprächen im Jahr 2005 von der kemalistischen Opposition mitgetragen. Auch die vorsichtige Anerkennung der kurdischen Realität und die Aufhebung des seit den 1980er Jahren bestehenden militärischen Ausnahmezustands in den überwiegend kurdisch besiedelten südöstlichen Provinzen wurde vor AKP-Zeiten als Reformvorhaben erarbeitet und mit Zustimmung der CHP verabschiedet. Dass die ultra-nationalistische MHP sich bei umstrittenen Gesetzesvorhaben und politischen Kreuzungspunkten - Aufhebung des Kopftuchverbots, Wahl des Präsidenten 2007 - auf der Seite der AKP positionierte, passte ebenfalls nicht in die Zweiteilung der politischen Landschaft, in der die MHP als entschiedene Gegenspielerin der AKP dargestellt wurde. Auch in Bezug auf die politische und ökonomische Frontstellung zwischen dem Militär - identisch gesetzt mit dem Staat - und dem Neoliberalismus - identisch gesetzt mit dem Markt - wurde ein Zerrbild geschaffen. Die Installierung des neoliberalen Modells wurde vom Militär nach Aufforderungen aus der Bourgeoisie gegen den Widerstand aus den werktätigen Klassen durchgesetzt und noch in den $2000 e r$ Jahren von den vermeintlich etatistischen Parteien (DSP, MHP) vorangetrieben, die keinen programmatischen Widerspruch zum neoliberalen Modell formulierten. Einzuwenden ist schließlich, dass der sunnitische Islam wie auch die islamistische Bewegung im Verlauf der Republikgeschichte keinesfalls pauschal unterdrückt und marginalisiert wurden. Wie in der späteren Rekonstruktion der politischen Geschichte noch ausführlich darzustellen sein wird, ist der sunnitische Islam vielmehr seit Gründung der Republik 
institutionell etabliert, seine Stellung wurde insbesondere im Zuge von Militärinterventionen stetig ausgebaut.

Eine Reihe konzeptioneller Widersprüche ist als dritter Kritikpunkt anzuführen. Mit der Verschiebung der AKP auf die Seite des Staates wurde die Partei ohne Begründung von ihrer Klassenbindung gelöst. Die Bourgeoisie wurde aus der politischen Gleichung entfernt und durch den vagen Begriff Gesellschaft ersetzt, die nun die liberale Gegenseite der »autoritären« AKP bildete. Sowohl in dieser Verschiebung als auch in der vormaligen Definition der »liberalen« AKP als einzige Repräsentantin der Gesellschaft oder des Volks wird erkennbar, dass mit der Verwendung des Begriffs Gesellschaft trotz gegenteiliger Aussagen nicht das Bemühen verbunden war, eine real existierende soziale Größe zu fassen, die sich aus verschiedenen Klassen, Gruppen oder Akteuren zusammensetzt, die politisch und kulturell-ideologisch unterschiedlich verfasst sind, sondern eine normative Einheit konstruiert wurde, die gegenüber dem Staat per se als liberal gekennzeichnet wurde. Im Widerspruch zur Feststellung kultureller Pluralität, die die Türkei kennzeichne, wurde der Gesellschaft zugleich eine statische und ursprüngliche kulturelle Identität (anatolisch, muslimisch) zugeschrieben, die sich über ein Jahrhundert dem unterdrückerischen Zugriff der Politik (Kemalismus, Etatismus) widersetzt habe. Suggeriert wurde ein kultureller Stillstand Anatoliens, wo erst in jüngster Zeit unter der Einwirkung des Neoliberalismus Bewegung entstanden sei, die eine liberale Bourgeoisie hervorgebracht habe. Eine in diesem Rahmen vorgenommene Setzung des Konzepts bestand darin, den Islam als immer schon vorhandene und einheitliche kulturelle Größe anzunehmen. Die prozesshafte Entwicklung von kulturellen »Werten « oder »Identitäten « wurde durch die Benennung »anatolischer Werte« negiert. Schließlich wurde in Widerspruch zum vorausgehenden Konzept, in dem der Neoliberalismus und die politische Entwicklung unter der AKP dynamisch aufeinander bezogen wurden, der Machtwille einer Einzelperson als bestimmender Faktor in die Analyse eingeführt, um das Scheitern der zuvor vorgebrachten Demokratisierung zu begründen. Das Einführen eines Machtwillens frei von allen gesellschaftlichen Anbindungen ersetzte eine widersprüchliche Theorie durch theoretische Willkür. ${ }^{19}$

Durch das Bemühen, alle Aspekte der politischen Geschichte in einen Gegensatz zwischen autoritärem Staat und liberaler, nach Freiheit strebender Gesellschaft zu zwängen, wurde der institutionelle Aufbau eines tendenziell totalitären Regimes übersehen, bestimmte kulturelle Elemente als Repräsentationen einer kulturellen Essenz idealisiert und historische Verläufe wie die Beziehungsge- 
schichte zwischen Militär, Neoliberalismus und Religion verzerrt dargestellt. Vor diesem Hintergrund kann eine erste Schlussfolgerung gezogen werden: Die sachlichen Mängel und konzeptionellen Widersprüche der Kulturkampfthese stehen in einem Zusammenhang zur Politik der AKP. Es bedurfte eines enormen Aufwands, eine Demokratisierung vorzutäuschen, während das Gegenteil stattfand. Zur Bewältigung dieser Aufgabe gelang es der AKP, zahlreiche Intellektuelle in eine »PR-Kampagne« (Uzgel 2009) einzubinden, die auf einen Gründungsdiskurs der Partei aufbaute, der darauf ausgelegt war, Skeptiker zu überzeugen, dass sie sich von Zielen der islamistischen Bewegung abgewandt hatte, $\mathrm{zu}$ denen die Beseitigung der Demokratie, die Abkehr vom Westen und die Etablierung eines islamistischen Regimes gehörten (Saraçoğlu 2011; Yıldızoğlu 2009). Autoritäre Entwicklungen schon in den ersten Jahren der AKP wurden unter Wahrnehmung der zweckgebundenen Freiheit, Kritik am Kemalismus - insbesondere am Militär üben zu können, bagatellisiert oder übersehen (Güney 2009). Für die Reproduktion der staatszentristischen Kritik in Übereinstimmung zu ihren Zielen stellte die AKP auch materielle Möglichkeiten - bspw. zahlreiche Jobs für liberale Intellektuelle in regierungsnahen Medien - zur Verfügung (Aladağ 2013; Savran 2015). Als die kemalistischen Oppositionszentren zur AKP in den staatlichen Behörden nachhaltig geschwächt waren, nahm die Bedeutung der Kritik am Kemalismus aus Sicht der AKP ab. Die staatszentristische Kritik und ihre intellektuellen Träger wurden von der AKP fallen gelassen.

Der Befund einer »autoritären Wende« steht in der Folge dieses Fallengelassenwerdens. Entgegen der angeführten Evidenz wurde weiter darauf beharrt, dass die AKP sich einst auf dem Weg einer Demokratisierung befand. Eine Reflektion der theoretischen Überzeugungen, die die Vortäuschung einer Demokratisierung beförderten, ist damit verhindert worden. In Auseinandersetzung mit diesem theorie-politischen Manöver folgt im nächsten Schritt ein Exkurs zum theoretischen Unterbau des Staatszentrismus, mit dem dargelegt werden soll, dass die Analyse des politischen Geschehens an theoretisch angeleiteten und tief in der Türkeiforschung verankerten Irrtümern orientiert war, die die Erwartungen und Wahrnehmungen selektiv determinierten.

\subsubsection{Exkurs zum theoretischen Unterbau der Kulturkampfthese: Die Autoritäre Staatstradition}

Die der Kulturkampfthese zugrunde liegenden theoretischen Überzeugungen bildeten die Voraussetzung dafür, dass die Öffentlichkeitsarbeit der AKP greifen, die Einbindung der liberalen Intellektuellen gelingen und der Demokratisierungsdiskurs im In- und Ausland dominant werden konnte. Die politische Entwicklung wurde unter der Prämisse einer modernisierenden und liberalisierenden Wirkung der Ökonomie (Neoliberalismus, Markt) auf Politik (Staat) und Kultur (Religion) in- 
terpretiert. Diese Auffassung gründete auf einem Paradigma der Türkeiforschung, das als These von der autoritären Staatstradition (vgl. Hoşgör 2008) oder These vom starken Staat (Heper 1985 u. 1992; vgl. Dinler 2003; Güngen/Erten 2005) ausformuliert worden ist. ${ }^{20}$ Die These findet sich in den Gesellschafts-, Geschichts- und Rechtswissenschaften wieder und prägt die Diskurse verschiedener intellektueller Strömungen und Parteien des Landes. ${ }^{21}$ Sie definiert Koordinaten der nationalen Geschichte und stellt eine politische Perspektive her, an die gesellschaftliche Akteure anknüpfen können, um für ihre Ziele $\mathrm{zu}$ werben und Bündnisse $\mathrm{zu}$ schmieden. Zwei ineinandergreifende theoretische Konstruktionen liegen ihr zugrunde. Erstens wird der Staat als eine aus sich selbst heraus begründete Entität begriffen, der gesellschaftliche Akteure oder Sphären gegenübergestellt sind. Zweitens werden westliche Idealtypen konstruiert, die die Vergleichsfolie für die Analyse der Geschichte der Türkei bilden.

Eingebettet ist die These in einen auf Max Weber zurückgehenden theoretischen Ansatz (vgl. Balaban 2013). Die Vorgehensweise entspricht in ihren Grundzügen der von Theda Skocpol unter dem Begriff »staatszentristisch « zusammengefassten theoretischen Perspektive (Skocpol 1985; vgl. Dinler 2003: 32f.). Die Grundannahme ist, dass der Staat über eine eigene Rationalität verfügt und über den gesellschaftlichen Gruppen stehend eigene Ziele verfolgt. Übertragen auf die Türkei ist mit diesem Ansatz verbunden, die Geschichte in der Regel aus der Perspektive eines Kampfes zwischen dem »autoritären Staat« und den über die Produktionsmittel verfügenden Klassen $\mathrm{zu}$ interpretieren. Letztere werden mitunter in Beziehung zu zumeist nicht näher bestimmten Gruppen wie Eliten, Notabeln und religiöse Führer gestellt, die sich gemeinsam von der Unterdrückung eines staatlichen Zentrums zu befreien suchen. Gesellschaft wird in der Regel als Containerbegriff verwendet, der diese Gruppen integriert. Die Bauern- und Arbeiterschaft, auch das Kleinbürgertum werden zumeist als passive Bevölkerungsmasse - als Volk gefasst.

Aus der staatszentristischen Perspektive erscheint die gesamte Geschichte seit Bestehen des Osmanischen Reichs als fortwährende Reproduktion der »autoritären Staatstradition«. Manche Autoren führen diese gar auf das Byzantinische Reich zurück und behaupten eine 2000-jährige Tradition (vgl. Çağlar 2003: 70). In Anlehnung an Webers Typen legitimer Herrschaft wird das Osmanische Reich als patrimonialer Staat begriffen, in dem der Sultan den Staat repräsentierte und als

20 Eine qualitative Inhaltsanalyse von 173 englischsprachigen sozialwissenschaftlichen Artikeln und Konferenzvorträgen, die im Zeitraum 2002-2009 zur türkischen Politik erschienen, ergab eine deutliche Dominanz dieses Ansatzes (Hoşgör/Özel 2010).

21 Zur Verbreitung dieser These im linken politischen Spektrum der 1960er Jahre und ihrer politischen Folgen siehe Ulus (2011: 74ff.). 
alleiniger Herrscher willkürlich die ökonomischen Beziehungen dominierte. Anders als im Westen habe der osmanische Staat die Herausbildung einer Bourgeoisie und die Akkumulation von Kapital verhindert (vgl. Dinler 2003: 19ff.). Diese Struktur habe sich auch nach dem Übergang vom Osmanischen Reich zur Republik gehalten, indem die Bürokratie sich fortan an die Stelle des Sultans setzte und als eigenständige Gruppe Interessen entwickelt habe, die sie mit denen des Staates gleichsetzte (Keyder 1987). Mit Gründung der Republik wird der Kemalismus zum neuen Träger der »Staatstradition« erklärt und zur Chiffre für den Staat erhoben, der die Gesellschaft beherrscht (Kazancıgil 1981). Die Gründungsgeschichte wird als eine »Revolution von oben «, als die Etablierung eines Staatswesens durch die Nachahmung eines westlichen Entwicklungswegs unter der Führung einer einzigen Person - des Armeeoffiziers Mustafa Kemal, der später den Nachnamen Atatürk (Ahne der Türken) erhielt - und einer ihm ergebenen Bürokratie beschrieben, ohne dass es zuvor einen Wandel in den gesellschaftlichen Machtbeziehungen gegeben haben soll (Trimberger 1978).

Mit der Patrimonialismus-These eng verknüpft ist das Begriffspaar Zentrum-Peripherie, das von Şerif Mardin in den 1970er Jahren in die Türkeiforschung eingebracht wurde (Mardin 2006a). Mit dem Begriffspaar wird die Trennung von Staat und Gesellschaft in zwei voneinander geschiedene und miteinander im Konflikt stehende Sphären oder Akteure für die politische Analyse operationalisiert. Der Staat als autonomer und eigenwilliger Akteur wird als bürokratisches Zentrum vorgestellt, das die gesellschaftliche Peripherie beherrscht. Die Dominanz des Staates in der Türkei wird als derart ausgeprägt aufgefasst, dass er seine Interessen über die seiner Staatsbürger stelle und ein »social engineering « Projekt von oben ohne jegliche gesellschaftliche Legitimationsquelle verfolge. Hervorzuheben ist die entschieden vorgebrachte Auffassung einer ideengetriebenen Entwicklung. Mardin bestimmt als zentrale Triebfeder der Geschichte einen Staatsgeist, der als bürokratischer Code sich der regierenden Akteure bemächtigt und ihnen die »Stärkung des Zentrums« als Staatsziel auferlegt (ebd.: 311f.).

Andere Autoren lokalisieren den Antrieb der Geschichte in einem innerhalb der Bürokratie ablaufenden Lagerkampf um das Ziel, wie das »Staatswohl« zu verfolgen sei. Die Entstehung der Bourgeoisie und die Einführung des Kapitalismus werden als eine Notlösung beschrieben, die von einem Teil der Bürokratie im Zuge der Republikgründung ergriffen wurde, um ihr eigenes Überleben zu sichern (Keyder 1987: 59). Die Bürokratie sei gezwungen gewesen, den Kapitalismus ohne bürgerliche Revolution einzuführen, da es den genuinen Träger der Revolution die Bourgeoisie - noch nicht gegeben habe. Erst danach habe die Bürokratie eine »Ersatz-Bourgeoisie« geschaffen, die jedoch im Gegensatz zu ihren Pendants im »Westen« nicht für bürgerliche Freiheiten eintrat (ebd.: 54). Die Bourgeoisie sei korrumpiert oder schwach geblieben, habe dem Staat im Gegenzug für dessen »Geburtshilfe« Treue gezeigt und »für das Privileg, Geld zu scheffeln, auf das Recht 
verzichtet, eine Zivilgesellschaft zu gründen« (ebd.: 82, Übersetzung E.B.; ähnlich argumentiert Mardin 1980: 235). Die Hervorbringung einer Zivilgesellschaft als autonomen Bereich der Freiheiten außerhalb des Staates wird ab den 1980er Jahren als genuine Aufgabe der Bourgeoisie beschrieben (Belge 1998). Der Begriff Zivilgesellschaft betonte unter dem Eindruck des Militärputschs von 1980 das Zivile gegenüber dem Militärischen und gestattete es, nationalistische und islamistische Parteien als zivilgesellschaftliche Kräfte zu definieren. Die theoretische Definition war mit der politischen Strategie verbunden, diese Parteien als demokratische Bündnispartner gegen das Militär (Staat) zu bestimmen (vgl. Çağlar 2000: 80ff.). Dass die »künstlich geschaffene« türkische Bourgeoisie die von den Autoren einer Bourgeoisie zugeschriebenen Aufgaben nicht erfüllte, sich an verschiedenen Kreuzungspunkten - Übergang in ein Mehrparteiensystem in den 1950ern, im Zusammenhang mit dem Militärputsch 1980 - nicht für liberale und »zivilgesellschaftliche« Ziele, sondern für ihren Profit und die Bekämpfung der Arbeiterbewegung einsetzte, wird als Preisgabe der historischen Mission thematisiert (Keyder 1987: 225f.; Buğra 1994: 120f.). Im gleichen Zusammenhang wird behauptet, der »türkischen « Bourgeoisie mangele es an unternehmerischem Geist und an einem Streben nach großen Taten. Sie sei ängstlich, opportunistisch und suche immer die Nähe zur Bürokratie (Heper 1987: 103).

Ihre empirische Plausibilität bezieht diese Auffassung aus der Entwicklungsgeschichte der Bourgeoisie im Westen, von der angenommen wird, dass sie als demokratische, nach allgemeiner Freiheit und Gleichheit strebende Bewegung und »allein« durch ökonomische Aktivitäten, ohne Zugriff auf politische Mittel emporgekommen sei (Buğra 1994: 20, 132; Buğra 1998). Das Konstrukt eines freien Marktes, der außerhalb des Staates sich entwickelt, bildet in der staatszentristischen Literatur das ökonomische Pendant zur Zivilgesellschaft. Dem »patrimonialen«türkischen Staat wird vorgehalten, dass er zwecks Verfolgung eigenständiger Ziele permanent in die Ökonomie eingreife (vgl. Dinler 2003: 41f.). Das vorherrschende Grundverständnis vom »Staat im Westen« besagt, dass dieser Ausdruck eines unternehmerischen Geists, begrenzt auf eine rationale und funktionale Administration sei, deren Aufgaben rein technischer Natur seien. Entsprechend werden polit-ökonomische Entwicklungen immer aus der Perspektive einer Abweichung von der »westlichen« Norm betrachtet. Großbritannien und Frankreich werden zumeist als idealtypische Vorbilder herangezogen. Einer in diesen Ländern »aus eigener Kraft « entstandenen Bourgeoisie wird eine Dritte-Welt-Bourgeoisie gegenüber gestellt, die im Rahmen nachholender Industrialisierungsprojekte und unter dem Druck internationaler Konkurrenz durch staatliche Intervention und Protektion geschaffen wurde (Buğra 1994: 20, 132). ${ }^{22}$ Mit Referenz auf den Westen

22 Diese Auffassung über die Entwicklung von Klassen schließt an eine breitere Literatur über sogenannte Dritte-Welt-Länder an, in denen die Bourgeoisie im Gegensatz zur west-eu- 
wird schließlich eine zweite Auffassung vom Staat vorgebracht, der unter die Kontrolle der Bourgeoisie gerät und sich dabei von einer eigenständigen Macht zu einem neutralen Apparat verwandelt (Keyder 1987: 76, 118, 125ff.). Der angenommene Wandlungsprozess, der theoretisch nicht nachvollzogen wird - wie kann es sein, dass ein handelndes Wesen (bürokratisches Staatssubjekt) sich in einen neutralen Apparat verwandelt? -, wird als demokratisch-liberaler Normalzustand bürgerlicher Entwicklung vorgestellt.

Als analytischer Ausgangspunkt dieser Konzeption kann die Idee eines idealen Klassenbewusstseins ausgemacht werden, das einen spezifischen und kohärenten Inhalt aufweist, der im Fall der Bourgeoisie im Liberalismus bestehen soll. Infolgedessen werden die Etablierung von Marktliberalismus, politischem Liberalismus und Rationalismus als makelloser Ausdruck einer vollständig entwickelten, unabhängigen Bourgeoisie begriffen. Der Normalzustand einer Klassengesellschaft wird als Endprodukt eines Klassensubjekts konzipiert, das im Laufe seiner teleologischen Entwicklung bestimmte Werte und Normen hervorbringt (vgl. kritisch Poulantzas 1967). Das gleiche Entsprechungsprinzip wird auf die Kultur angewandt, die normativ von einem vorgestellten, idealen Klassensubjekt abgeleitet wird. Bürgerliche Kultur wird mit Konzepten wie Aufklärung, Rationalität, Fleiß, Individualität, Risikobereitschaft, Vermittlungs- und Kompromissfähigkeit als ideologiefrei beschrieben. Während in der Türkei ein von einer Elite aufgesetzter, künstlicher und deshalb autoritärer »Nationalismus von oben« vorherrsche, bestünden in der »Ersten Welt « ursprünglich gewachsene »Nationalismen von unten« (Keyder 1997), die als konfliktfrei vorgestellt werden.

Am staatszentristischen Ansatz sind im Hinblick auf die empirische Darstellung sowohl der Geschichte des Osmanischen Reichs und der Türkei als auch der »westlichen « Entwicklung der kapitalistischen Produktionsweise und bürgerlichen Revolution sowie ihrer Theoretisierung eine Reihe von Einwänden anzubringen. ${ }^{23}$ Ein zentraler Kritikpunkt ist, dass mit dem Beharren auf einem bürokratischen Eigensinn - in gesteigerter Form reduziert auf einen einzigen Potentaten - systematisch die gesellschaftlichen Akteure übersehen werden, die untereinander um politische Veränderung ringen. Dieser Einwand setzt bereits an der Frage nach der Verfügungsgewalt über die Produktionsmittel im Osmanischen Reich und dessen politischen Aufbau an. Entgegen der staatszentristischen Reduktion auf den alles bestimmenden Sultan stellte das Reich ein komplexes politisches Gebilde dar, in dem verschiedene Produktions- und Besitzverhältnisse nebeneinander existierten

ropäischen Geschichte keinen ökonomischen, sondern einen politischen Ursprung habe (Evans/Rueschemeyer 1985; Boone 1994).

23 Eine ausführliche Kritik dieser Literatur leisten mit unterschiedlichen Schwerpunkten Utku Balaban (2013), Gazi Çağlar (2000), Demet Dinler (2003) und Sungur Savran (1985 u. 2010). 
und in dem sich mehrere Machtzentren herausbildeten. Die schrittweise und langwierige Transformation des Reichs in einen Nationalstaat und der Übergang in die kapitalistische Produktionsweise geschah unter dem Druck einer über das Reich verteilten Händlerklasse, die zusammen mit einer ab dem 18. Jahrhundert neu entstehenden Klasse von Großgrundbesitzern auf die Zentralisierung der Staatsmacht drängte, um gegen politisch wie militärisch überlegene Gegner in der globalen Konkurrenz bestehen zu können (Aytekin 2015a: 47f.; Aytekin 2015b: 58f.; Savran 2014). Für das 20. Jahrhundert ist die Herausbildung verschiedener Fraktionen, die unterschiedliche Ideologien, Programme und Maßnahmen zur Verwirklichung ihrer Entwicklungsziele vorbrachten und auf unterschiedliche Weisen auf die Bürokratie einwirkten, aus verschiedenen Perspektiven erforscht worden (Gürel 2014). Mit Blick auf die Republikgründung kann aufgezeigt werden, dass zwischen zwei Fraktionen der besitzenden Klassen ein Disput zwischen den Polen einer Liberalisierung und der direkten Lenkung der Kapitalakkumulation stattfand, während Einigkeit bei der Frage der Herstellung der allgemeinen Bedingungen der Kapitalakkumulation unter anderem durch die Schaffung des freien Arbeiters bestand (Boratav 1987; Şener 2015: 214; Toprak 1982). Auch für die nachfolgenden Perioden können Fraktionskämpfe als Hintergrund politischer Konflikte ausgemacht werden (Ahmad 1993: 121ff.; Savran 2002).

Der staatszentristische Ansatz übersieht ferner, so ein zweiter zentraler Kritikpunkt, dass die Bourgeoisie nicht passive und mutlose Begleiterin, sondern treibende Kraft autoritärer Projekte zur Umsetzung ihrer Entwicklungsziele war, wie im Zusammenhang mit dem Militärputsch von 1980 noch ausführlicher dargestellt wird (Yalman 2002; ders. 2009: 308ff.). Der staatszentristische Ansatz sperrt sich der empirischen Evidenz, obwohl diese auch in seinen Leitwerken durchscheint (Keyder 1987: 198f., 225f.; Buğra 1994: 120f.), indem er die Verbindung zwischen politischen Projekten und Klassen auf der Basis einer Idealvorstellung herstellt. Sobald die AutorInnen feststellen, dass die Bourgeoisie autoritäre Ziele verfolgt oder unterstützt, schreiben sie dies dem verzerrenden und korrumpierenden Einfluss des Staates zu.

Ein dritter Kritikpunkt lautet, dass Kämpfe der arbeitenden mit den besitzenden Klassen - zur Intensivierung, Verbesserung oder auch Aufhebung der politischen und ökonomischen Bedingungen der Ausbeutung - ausgeblendet werden (vgl. Dinler 2003). Die empirische Blindheit gegenüber sozialen Kämpfen ist an die Perspektive gebunden, Klassen nicht in Relation zueinander, sondern zum Staat zu bestimmen (vgl. Balaban 2013). Die Reproduktionsgrundlage der Bourgeoisie wird nicht im Verhältnis zwischen Kapital und Arbeit, sondern in der Herstellung einer Zivilgesellschaft und eines freien Marktes gesehen. Da subalterne Klassen bei der Umsetzung dieser Ziele keine eigenständige Rolle spielen, sind sie in den Analysen nicht oder kaum sichtbar. Ihren Platz in der Geschichte erhalten sie nicht als Antagonisten der besitzenden Klassen, sondern unspezifisch als »Volk«, das mit den 
besitzenden Klassen in Gegenüberstellung zum Staat, der sie kulturell diskriminiert oder integriert, in einem Boot sitzt.

Schließlich stehen die kritisierten Punkte in Beziehung zu einer verzerrten Vorstellung von der Entstehung der kapitalistischen Produktionsweise und der Bourgeoisie als Ergebnis eines quasi-natürlichen Evolutions- oder Modernisierungsprozesses. Hieran sind der Reihe nach eine kapitalismus-, eine demokratie-, eine staats- und eine hegemonietheoretische Kritik anzubringen. Erstens transportiert das Bild einer Bourgeoisie, die »aus eigener $\mathrm{Kraft}$ « emporkommt ebenso wie das Bild eines »reinen« Marktes eine unrealistische Kapitalismusvorstellung, die der Lehre des fundamentalistischen Wirtschaftsliberalismus folgt. Hierbei werden Grundprinzipien der kapitalistischen Produktionsweise, die dem Ideal eines sich selbst regulierenden freien Marktes widersprechen - die Machtasymmetrie beim Tausch von Arbeitskraft gegen Lohn, die systematische Produktion von Marktungleichgewichten zwischen konkurrierenden Kapitalisten und die Tatsache marktbeherrschender Unternehmen - systematisch ausgeblendet (vgl. Dörre 2009: 30ff.). Zweitens verklärt das Bild einer Bourgeoisie, die im »Westen« als demokratische, nach allgemeiner Freiheit und Gleichheit strebende Bewegung aufgekommen sei, die Entwicklungsgeschichte bürgerlicher Demokratien. Als die jungtürkische Bewegung im Osmanischen Reich im Jahr 1908 begleitet von einem Aufstand und mit den klassischen Parolen der Französischen Revolution (Freiheit, Gleichheit, Gerechtigkeit) zur politischen Macht griff, war im westeuropäischen Bürgertum mehr als hundert Jahre nach der ersten großen bürgerlichen Revolution noch immer die Überzeugung vorherrschend, dass Kapitalismus und Demokratie unvereinbar seien. Erst nach dem Ersten Weltkrieg und in Verbindung mit Kämpfen der Arbeiterbewegung und unterdrückten Bevölkerungsgruppen, denen gleiche Bürgerrechte verwehrt wurden, wurde in manchen westlichen Ländern der minimale Kernbestand der Demokratie, das allgemeine, einkommens- und vermögensunabhängige Wahlrecht sukzessive erstritten, wobei dieser Prozess auch wieder rückgängig gemacht werden konnte (Demirović 2006b; Therborn 1977). ${ }^{24}$ Drittens vermittelt die prinzipielle Äußerlichkeit zwischen Politik und Ökonomie, die dem staatszentristischen Ansatz unterliegt, ein verzerrtes Bild, insofern das Politische schon immer konstitutiv in den Produktionsverhältnissen und ihrer Reproduktion existierte (Poulantzas 2002: 45). Während die Prinzipien der kapitalistischen Produktionsweise mit Gewalt eingerichtet und gegen

24 In einer vergleichenden Diskussion der historischen Entwicklung bürgerlicher Demokratien führt Therborn (1977) aus, dass verschiedene Ausgrenzungs- und Unterdrückungsmechanismen wie Nationalismus, Rassismus, Sexismus und die Verfolgung politischer Opponenten, so sehr sie auch bestimmten bürgerlichen Idealen widersprechen mögen, zum historischen Kernbestand bürgerlicher Praxis gehören. 
Widerstände durchgesetzt wurden, sind ihre Existenzbedingungen, die Reproduktion der Produktionsverhältnisse, immer staatlich vermittelt (vgl. Brand/Görg 2000; Demirović 2007a). Die politisch durchgesetzte Änderung von Rechtstiteln (vom Leibeigentum zur freien Bauernschaft, die Formen des Privateigentums), Steuern und physische Gewalt bei der Überführung von Gemeinschaftsgütern in Privateigentum, insgesamt die Anwendung »außerökonomischer « Zwangsmittel sind der Entwicklung der kapitalistischen Produktionsweise von Anfang an eingeschrieben. ${ }^{25}$ Die politische Lenkung der Kapitalakkumulation durch öffentliche Ausschreibungen, Vergabe von Lizenzen und Subventionen, aber auch mittelbar durch sogenannte Grundaufgaben des Staates wie Investitionen in die materielle Infrastruktur, in die Ausbildung von Arbeitskräften oder in Projekte, die dem Absatz und Transfer von Waren dienen, können der Entwicklung bestimmter Kapitalfraktionen förderlich oder auch hinderlich sein. Einen liberalen Staat aber, der nicht in die Ökonomie eingreift, kann es nicht geben. Viertens verkennt die Vorstellung einer Ideologiefreiheit der Bourgeoisie, wie auch die Bestimmung des Wirtschaftsliberalismus als genuine Ideologie der Bourgeoisie, dass bürgerliche Revolutionen mit nationalen Symbolen und Parolen geführt wurden, die Gründung von Nationalstaaten mit der Definition eines Staatsvolks einherging, mit der kulturelle Differenzen unterdrückt worden sind, bürgerliche Bewegungen auch im idealisierten West-Europa nationalistische und rassistische Inhalte transportieren (können). Sie verkennt auch, dass die Bourgeoisie andere ökonomische Ideologien als den Wirtschaftsliberalismus favorisieren kann, sofern sie sie als förderlich für ihre langfristigen Entwicklungsziele oder auch ihr Tagesgeschäft ansieht. Die Vorstellung einer Ideologiefreiheit ist ebenfalls darauf zurückzuführen, dass die Bourgeoisie nicht im Verhältnis zu anderen Klassen, sondern zu einem autoritären Staat bestimmt wird. Dass Beziehungen zwischen den Klassen auch ideologisch und kulturell vermittelt sind und die Form der Hegemonie annehmen (Candeias 2007; Demirović 2007b), liegt außerhalb des Horizonts der staatszentristischen Konzepte. $^{26}$

Das staatszentristische Konzept ist also mit der Suche nach einem Klassenkern und einem außerhalb des Staates stehenden Klasseninteresse verknüpft. Die Analyse ist an einem Hauptwiderspruch zwischen der Bürokratie und der Bourgeoisie ausgerichtet. Politische Parteien werden diesem vermeintlichen Hauptwiderspruch konzeptuell untergeordnet, indem sie entweder mit der Bourgeoisie oder

25 Den gewaltsamen Charakter dieses Prozesses zeichnet Edward P. Thompson (1987) anhand der Entstehung der Arbeiterklasse in England eindrücklich nach.

26 Der Begriff Hegemonie findet im staatszentristischen Ansatz zwar Verwendung, so zum Beispiel bei Keyder (1987: 76, 118, 125ff.). Allerdings wird er nicht zur Analyse eines Verhältnisses zwischen Klassen eingesetzt, sondern dient der Darlegung einer stufenartigen Entwicklung der Bourgeoisie, die an normativen Vorstellungen gemessen wird und sich vom Staat zu befreien sucht. 
der Bürokratie identifiziert werden. ${ }^{27}$ Im Lichte dieser theoretischen Perspektive ist die Befreiung der Gesellschaft bedingt durch die Befreiung der Bourgeoisie von der Bevormundung durch den Staat. Dementsprechend wird die wissenschaftliche Forschung an der Suche nach einem Ideal, einer vom Staat unabhängigen Bourgeoisie ausgerichtet, von der der Vollzug des idealtypisch verklärten westlichen Staatsmodells erwartet wird. Die uneingeschränkte Machtergreifung durch die Bourgeoisie, die die demokratisch-liberale Mission ausführt, ist das politische Ideal, das durch den staatszentristischen Ansatz theoretisiert wird.

Die bislang diskutierte staatszentristische Literatur zur AKP ist auf der Grundlage dieser Theorietradition geschrieben worden, die weberianische Staats- und Herrschaftstheorie mit der wirtschaftsliberalen Orthodoxie verbindet. Das Aufkommen der AKP wurde als Erfüllung der als elementar angenommenen Voraussetzung für die vollständige Entwicklung der bürgerlichen Revolution begriffen, die in der Türkei bislang vom autoritären Staat verhindert worden sei. Die AKP schien die Notwendigkeit einer Bewegung gegen den Staat für das Gelingen der Demokratisierung zu erfüllen, indem sie als Repräsentantin einer unabhängig vom Staat entstandenen »anatolischen« Bourgeoisie identifiziert wurde. Die als »Distanz zum Staat « bezeichnete Position galt als Beglaubigung der demokratischen Identität der neuen Bourgeoisie. Zugrunde lag die Auffassung, dass Neoliberalismus vollständig entwickelter Ausdruck eines reinen Marktes und einer unabhängigen Bourgeoisie sei. Die angenommene Entpolitisierung der Religion entsprach der Auffassung einer weberianisch begründeten Normalisierung, der zufolge bürgerliche Politik nach einem ideologiefreien, nach rationalen Maßstäben funktionierenden Zustand strebt. Im Gegensatz zur kemalistischen Bürokratie, die die Bevölkerung kulturell beherrscht habe, wurden der neuen Bourgeoisie »authentische« Werte in Übereinstimmung mit der Bevölkerung attestiert. Damit wurde die zweite angenommene Voraussetzung für die Vollstreckung der demokratischen Revolution - die Aufhebung des Kulturkampfs der Eliten gegen das Volk, der sich in kultureller Fremdheit und Unterdrückung manifestierte und den "normalen« Lauf der bürgerlichen Geschichte verzerrte - als erfüllt angesehen.

Mit dem offensichtlichen Scheitern der Demokratisierung, nachdem die staatszentristisch-liberale Kritik am Kemalismus ihren Zweck für die AKP erfüllt hatte, gingen die Verfechter der Liberalisierung durch die AKP dazu über, die

27 Erwähnt werden muss, aufgrund der herausragenden Bedeutung des Autors in der Türkeiforschung, eine Abweichung von dieser Zweiteilung. Heper verortet die Bourgeoisie jenseits des Kampfes zwischen Staatseliten und zivilen Eliten, die politische Parteien und Klientelnetzwerke bilden und miteinander um die Macht im Staat ringen. Beide Elitengruppen werden von ihm als freischwebend konzipiert. Ihre Verbindung zur Kultur wird als rein instrumentell zum Zwecke des Machterhalts begriffen (Heper 1985: 98ff.). 
Rückkehr des autoritär-patrimonialen Staates vorzubringen. Dass sie die anatolische Bourgeoisie nach der »autoritären Wende« aus ihrer politischen Analyse entfernten, war ein Schritt im Rahmen dieses Schwenks. Zur Erhaltung der staatszentristischen Perspektive wurde die Verbindung zwischen der Bourgeoisie und der nun autoritär gewordenen AKP gelöst und die Religion einem patrimonialen Machtwillen untergeordnet. Tatsächlich aber erklärten der Unternehmerverband MÜSİAD wie auch andere Verbände der Bourgeoisie nicht nur weiterhin ihre Unterstützung für das politische Projekt der AKP im Übergang zu einem Präsidialsystem, sie trieben es sogar voran (Yıldırım 2018).

\subsection{Die theologische These}

Die theologische These befindet sich in theoretischer Nähe zur Kulturkampfthese, konstruiert die Verbindung zwischen Religion, Politik und Ökonomie jedoch aus der Gegenperspektive, indem sie einen transformierenden Effekt der Religion auf die Ökonomie behauptet. Die Konstruktion stellt einen theoretischen Anschluss an Max Webers Protestantismusthese her und formuliert gleichzeitig einen empirischen Widerspruch gegen die auch von Weber vertretene Auffassung, der Islam bilde ein Entwicklungshemmnis für die kapitalistische Industrialisierung. In Bezug auf Anatolien brachte die theologische These in älteren Studien in Übereinstimmung mit Weber die Auffassung hervor, dass die in der Bevölkerung verbreitete mystische, sufistische Strömung des Islam, gelegentlich auch als Volksislam bezeichnet, sich durch fatalistische, passive und weltabgewandte Elemente hervortue. Der von den islamistischen Parteien der 1970er Jahre repräsentierten religiösen Strömung wurde zugestanden, puritanische Elemente $\mathrm{zu}$ enthalten, diese seien aber durch moralischen Rigorismus gekennzeichnet, der sich im Alkoholverbot, in Kleiderordnungen, der Kontrolle der Sexualität und der Forderung nach Ergebenheit gegenüber Älteren niederschlage. Der Rigorismus nehme keine organisierende und aktivierende Rolle wie der Calvinismus oder Asketismus ein, sei vielmehr Teil der patrimonialen Struktur, die schon das Osmanische Reich gekennzeichnet und keine dynamische kapitalistische Entwicklung zugelassen habe (Mardin 1991: 35, 113; vgl. Cengiz 2013: 56).

Eine knappe Skizze der Debatte um Max Webers These über die Entstehung des »industriellen Kapitalismus« und des »kapitalistischen Geistes« verhilft zu einer besseren Einordnung der theologischen These. ${ }^{28}$ Weber (1986) hatte deren Ent-

Eine ausführliche Diskussion der Protestantismusthese im Zusammenhang mit der Entstehung der anatolischen Bourgeoisie leistet Cengiz (2013: 27ff.), von dem ich die Bezeichnung »theologische These « für diesen Teil der Literatur übernommen habe. Auf seine Studie gehe ich in Kapitel 3.4.1 näher ein. 
stehung auf die protestantische Ethik zurückgeführt und als Beleg angeführt, dass die reichen Städte zum Protestantismus tendiert hätten, Unternehmer und höhere Angestellte überwiegend Protestanten gewesen seien. Er antwortete damit implizit auf eine These von Karl Marx, der lange vor ihm eine kausale Verbindung zwischen Protestantismus und Kapitalismus herstellte, indem er Religion als Widerschein der wirklichen Welt und den Protestantismus als die bürgerliche Entwicklung des Christentums bezeichnete (Marx 1977: 93f.). Was bei Marx eine beiläufige Bemerkung über die Aneignung der Religion durch die Produktionsmittelbesitzer blieb, wurde bei Weber - mit umgekehrter Kausalität - zur zentralen Aussage über die Entwicklung des Kapitalismus.

Der Protestantismus- oder Calvinismusthese ist von verschiedenen Autoren auf empirischer Grundlage widersprochen worden. Werner Sombart hob die positive Rolle der jüdischen Religion in der Entstehung des Kapitalismus hervor, revidierte dieses Argument später, bezog den Katholizismus ein, um schließlich noch später festzustellen, dass diverse Bedingtheiten zwischen Religion und wirtschaftlicher Entwicklung vorhanden seien, die Entstehung des kapitalistischen »Geistes « aber nicht aus der Religion erklärt werden könne (Fisahn 2016: 155ff.). Der Historiker Eric Hobsbawm widersprach, indem er auf katholische Regionen verwies, in denen die »industrielle Revolution« im Gange war, während zum Protestantismus übergetretene Regionen in der Nachbarschaft noch in vorindustriellen Produktionsmethoden feststeckten (Hobsbawm 1968). Weitere Autoren argumentierten, dass der Calvinismus bei Weber - gekennzeichnet durch die Einheit von harter Arbeit und religiöser Praxis, Begrenzung des Konsums aufs Notwendige und moralische Entgrenzung des Gewinnstrebens - idealisiert dargestellt wurde, die unterschiedlichen Ausprägungen des Calvinismus von ihm nicht berücksichtigt worden seien (vgl. Cengiz 2013: 33ff.). Widerspruch erhoben auch Autoren, die in Übereinstimmung mit der von Marx getroffenen Aussage argumentierten, dass die Kapitalisten sich den Protestantismus angeeignet und angepasst hätten (Hill 1961). ${ }^{29}$ Demzufolge wurde der Protestantismus als Opportunität aufgegriffen, um die Loslösung vom Katholizismus mit seinen festgefügten zentralistischen Strukturen, die eng an die feudalen Klassen angebunden waren beziehungsweise mit ihnen in eins fielen, zu betreiben. Zugespitzt formuliert wurden bestimmte Gruppen

29 Die Attraktivität des Protestantismus für Handwerker und Händler in den mittelalterlichen Städten habe darin bestanden, dass er sie von der katholischen Kirche und deren Regeln befreite. Die Abgrenzung gegenüber der katholischen Kirche über die protestantische Idee, dass Cott sich im Herzen eines jeden befinde, habe die Basis für Anpassungen an konkrete Bedürfnisse gebildet. Sie habe individuelle Freiheiten verliehen in der Interpretation, was richtig und was falsch sei, indem es die Rechenschaftspflicht gegenüber der Kirche aufhob (Hill 1961). 
nicht zu Kapitalisten, weil sie Protestanten waren, sondern sie wurden zu Protestanten, weil sie Kapitalisten waren oder sich im Entstehungsprozess zu Kapitalisten befanden.

Jedenfalls ist der These, die die Gründe für den ökonomischen Wandel oder auch für dessen Ausbleiben in der Theologie selbst, im Sinne einer von den materiellen Verhältnissen losgelösten Ideologie, verortet haben, vielfach widersprochen worden. Der Widerspruch hat nicht verhindert, dass die These weiterhin breit rezipiert und reproduziert wird, so auch im Zusammenhang mit der Entstehung der anatolischen Bourgeoisie. Basierend auf Aussagen von Unternehmern, die ihren Erfolg mit kulturellen Werten verbinden, wird Religion als Ausgangspunkt ökonomischen Erfolgs bestimmt. Als exemplarisch kann die Studie der European Stability Initiative (ESI) über Unternehmer in Kayseri mit dem Titel »Islamische Calvinisten. Umbruch und Konservatismus in Zentralanatolien « herangezogen werden (ESI 2005). Sie greift explizit Webers These auf, der zufolge die Ursachen für die Entwicklung des "westlich-modernen« Kapitalismus in einer rationalen Organisierung der »Industrie« lägen, die wiederum in der protestantischen Kultur angelegt gewesen sei. In der zentralanatolischen Provinz Kayseri sei eine solche "protestantische Arbeitsethik« in Verbindung mit konservativen Werten entstanden. Im Gleichschritt mit Urbanisierung und Industrialisierung sei der Müßiggang des traditionellen Dorflebens, in dem Arbeiten verpönt gewesen sei, den Tugenden harter Arbeit und der unternehmerischen Initiative gewichen. In der »zentralanatolischen Revolution« erkennen die Autoren ein harmonisches Nebeneinander von Islam und »Moderne«, das sich im »demokratischen Konservatismus« der AKP, die in Kayseri überdurchschnittlich hohe Wahlerfolge erzielen konnte, widerspiegele. Die im Rahmen der Studie interviewten Unternehmer und Politiker bekundeten, die Eröffnung einer Fabrik sei wie ein Gebet, auch der Prophet sei ein Händler gewesen, wodurch sie eine Deckungsgleichheit zwischen ihrem Handeln und dem Islam behaupteten. Kurzum, die Unternehmer bestätigten gegenüber europäischen Forschern Webers These, wonach die puritanisch-asketische Ethik die Grundlage der ökonomischen Rationalisierung und eines neuen beruflichen Ethos, also die Wegbereiterin für den Kapitalismus sei (ESI 2005: 26).

Weitere Studien, die im Islam Entsprechungen zum Calvinismus erkennen, argumentieren explizit theologisch, indem sie Rationalität, Individualismus, hartes Arbeiten und Sparsamkeit mit Zitaten aus dem Koran belegen (Ayengin 2005; Mutlu 1990). Ebenfalls sind Studien über die Gülen Gemeinschaft zu erwähnen, deren aktivistische Frömmigkeit, dem von Weber analysierten innerweltlichen Asketismus gleich, sich rationalisierend auf soziale Beziehungen auswirke (Özdalga 2000). ${ }^{30}$ Eine weitere Linie besteht aus Arbeiten, die über Meinungsumfragen $\mathrm{Tu}$ -

30 »Die Anatolier waren ungebildet und provinziell, arm und fromm. Motiviert durch Gülens Lehren strebten sie nun nach Bildung und wurden wohlhabend, sie blieben aber weiter 
genden oder Einstellungen zu identifizieren versuchen, die förderlich für die Akkumulation von Kapital seien. So wird beispielsweise per Befragung von erfolgreichen Unternehmern der positive Einfluss der Religion auf wirtschaftlichen Erfolg abgefragt. Solche Arbeiten demonstrieren, wie das methodische Design das Ergebnis vorwegnehmen kann. Die Bestätigung des positiven Einflusses von Religion verwundert wenig, da Mitglieder eines Unternehmerverbands befragt wurden, der sich explizit auf die Religion beruft (vgl. Cengiz 2013: 65).

Die Calvinismusthese löste unter islamischen Theologen eine kontroverse Debatte aus, während sie unter islamistischen Politikern und Unternehmern, insbesondere aber unter europäischen Rezipienten nicht zuletzt durch die ESI-Studie an Verbreitung und Zustimmung gewann. Sie ereilte das gleiche Schicksal wie die Kulturkampfthese. Die Diskussion über den islamischen Calvinismus klang mit schwindender Aussicht auf den EU-Beitritt ab und geriet mit der vermeintlich autoritären Wende der AKP in Vergessenheit. Offensichtlich war die breite Rezeption durch die damalige politische Konjunktur begründet, die durch das Bemühen gekennzeichnet war, den vermeintlichen Gegensatz zwischen Islam und unternehmerischem Erfolg zu desavouieren, die modernisierenden Kräfte der kapitalistischen Entwicklung im Zuge der EU-Annäherung hervorzuheben beziehungsweise sich gegenüber Europa (europäischen Forschern) als »modern« zu präsentieren.

\subsubsection{Kritik der theologischen These}

Eine ausführlichere Kritik der theologischen These erfolgt im Zuge der Darlegung der vierten These, der Klassenkampfthese, der hier nicht vorgegriffen werden soll. Neben der schon vorgebrachten Kritik an der methodisch fragwürdigen Vorgehensweise, aus Meinungsumfragen und Selbstauffassungen von Unternehmern Kausalketten zwischen sozio-ökonomischen Entwicklungen und ideologischen Positionen zu generieren, möchte ich an dieser Stelle anführen, dass der Entgegensetzung von moralischem Rigorismus $\mathrm{zu}$ einem unternehmerisch aktivierenden Asketismus entgeht, dass Rigorismus durchaus in der Form eines demographischen Gestaltungswillens kapitalistische Entwicklungsschritte begleiten kann. Die von der AKP zeitweise auf die Tagesordnung gehobenen Themen wie die Bestrafung des Ehebruchs, das Abtreibungsverbot oder die Aufforderung, eine bestimmte Anzahl von Kindern zu zeugen, reihen sich in diese Tradition ein, die paternalistische Verbote und Vorschriften aufstellt, ohne die kapitalistische Akkumulation kategorisch zu negieren. In der Entgegensetzung wird wie in der

fromm. Cülen brachte ihnen die Bedeutung von Bildung und unternehmerischem Erfolg nahe«, so der Journalist Rainer Hermann für die Frankfurter Allgemeine Zeitung, die als Echo der theologischen These im deutschen Sprachraum fungierte (Prediger Fethullah Gülen im F.A.Z.-Gespräch: »Islam und Moderne stehen nicht im Widerspruch«, 06.12.2012). 
Kulturkampfthese ein Denken erkennbar, das der kapitalistischen Produktionsweise bestimmte Normen und Werte zuordnet, ohne die sie sich nicht (dynamisch) entwickeln könne. Aus einer historischen, zugleich idealisierten Konstellation wird auf eine harmonische Verknüpfung von Ökonomie und Kultur geschlossen, die mit einem Höchstmaß an Rationalität - wie auch immer dies bestimmt werden kann - verbunden wird. Gegenüber den historisch-kulturell spezifischen Verknüpfungen erweist sich diese Denkweise als sehr statisch. Bestimmte Entwicklungen mögen im Rahmen spezifischer Verknüpfungen begünstigt, andere dagegen behindert werden, ohne dass gleich ein kategorischer Ausschluss vorliegen muss. Abschließend sei darauf aufmerksam gemacht, dass die Vorstellung, das Leben in Anatolien sei vor dem Aufkommen des kapitalistischen Unternehmers durch Müßiggang gekennzeichnet gewesen, eine orientalistische Behauptung darstellt, die gegenüber der Härte des vorangegangenen Arbeitslebens der Werktätigen ziemlich indifferent ist. ${ }^{31}$

\subsection{Die Säkularisierungsthese}

Eine besondere Antwort auf die Frage, wie die Stellung der Religion im AKP-Projekt begriffen werden kann, wird in Cihan Tuğals Studie »Passive Revolution. Absorbing the Islamic Challenge to Capitalism« (2009) entwickelt. Tuğal argumentiert, dass das Besondere an der AKP die Passivierung der islamistischen Bewegung sei, die sich in der Türkei als eine radikale Herausforderung des bestehenden Systems entwickelt habe. Durch die AKP sei die anti-säkulare, anti-westliche und anti-kapitalistische Bewegung zu einem stabilisierenden und vitalisierenden Element »säkularer« Ordnung mit prowestlicher und neoliberaler Politik geworden. Den Wandel dieser Bewegung, die sich außerhalb der AKP und ihrer Vorgängerparteien entwickelte, diskutiert Tuğal auf der Grundlage einer ethnographischen Studie, die er in einem Randbezirk Istanbuls (Sultanbeyli) durchführte. Im Unterschied zur Kulturkampfthese hebt er die Wiederherstellung der »säkularen Hegemonie« hervor und betont eine Absorption des Islamismus in den "Staat « und den »Kapitalismus«. Da die Studie besondere Einsichten in den Werdegang islamistischer Mobilisierung ermöglicht, eine singuläre Stellung innerhalb der Forschungsliteratur einnimmt, indem sie staatszentristische Annahmen mit hegemonietheoretischen Begriffen von Antonio Gramsci zusammenbringt, und einen hervorragenden Einstieg in konzeptionelle Fragen ermöglicht, wird sie im Folgenden ausführlicher diskutiert. prägten Kayseri/Hacılar des 20. Jahrhunderts zu keiner Zeit verpönt gewesen war (Cengiz 2013: 229). 
Als Ausgangslage konstatiert Tuğal eine nach dem Militärputsch von 1980 einsetzende umfassende Krise der »säkularen Hegemonie«. Als deren Kernelemente benennt er das Parteiensystem, das zwischen mitte-links und mitte-rechts Parteien gespalten gewesen sei, die Etablierung bürokratischer Autorität, die Konstruktion einer türkischen Nation, die Säkularisierung des Islam, die Kreation einer urbanen Identität und die Entwicklung von Korporatismus, worunter er ein populistisches Patronage-System begreift (Tuğal 2009: 36ff.). Aus Erzählungen von Bewohnern des Bezirks rekonstruiert er, wie die Krise dieser sechs Elemente der »säkularen Hegemonie« im Alltag erfahren wurde und islamistische Mobilisierung sich als Antwort entfalten konnte. Von einem kleinen Vorort Istanbuls mit wenigen Tausend Einwohnern in den frühen 1980ern entwickelte sich Sultanbeyli innerhalb von knapp 20 Jahren infolge massiver Landflucht zu einem Stadtteil mit mehr als 200.000 Einwohnern. Die rapide Binnenmigration ging mit informellen Besiedlungsformen einher, deren Regeln zwischen den Migranten, der Stadtverwaltung, den Parteien und anderen vermittelnden Instanzen (informelle Makler, Vereine) ausgehandelt wurden. In einem hohen Grade informell gestaltet waren auch die Beschäftigungsformen der lohnabhängigen Bevölkerung. Während es Gewerkschaften aufgrund der informellen Beschäftigungsstruktur und in Abwesenheit größerer Industrie- und Handwerksbetriebe erschwert war, sich zu organisieren, fanden sich andere Vereinigungen, die die Bevölkerung auf der Grundlage provinzieller Herkunft und konfessioneller Zugehörigkeit ansprachen und organisierten. Zum Zeitpunkt seines ersten Forschungsaufenthalts zu Beginn der 200oer Jahre fand Tuğal eine Bevölkerung vor, die in den 1990ern von islamistischen Aktivisten agitiert worden war. Deren Aktivitäten hätten dazu geführt, dass der Bezirk den Ruf einer islamistischen Hochburg erwarb. Tuğal zeichnet nach, wie islamistische Vereinigungen und Netzwerke in den 1980er und 1990er Jahren - organisiert über Freundeskreise, Teehäuser, Lesegruppen, Kulturzentren, Medien, Moscheen - begonnen hatten, das Leben zu regulieren, islamisch geprägte Lebensstile, Raumgestaltungen und ökonomische Beziehungen zu entwerfen. Der Islam sei im Bezirk $\mathrm{zu}$ einer verbindenden Identität für die aus allen Landesteilen zusammengewürfelte Bevölkerung geworden. Die zwischen kurdischer und türkischer Bevölkerung bestehende ethnische Grenzziehung, die eine virulente Krise der nationalen Einheit über die gesamte Republikgeschichte darstellte, sei tendenziell überwunden worden.

Das strategische Konzept der Islamisten habe »integrale Religion « gelautet. Alle Aspekte des Zusammenlebens islamisch hergeleiteten Regeln zu unterwerfen, habe dessen Radikalität ausgemacht. Darin seien das Ziel enthalten gewesen, den Nationalstaat durch eine internationale Gemeinschaft der Gläubigen zu überwinden, die Grundsätze, neben Gott keine weiteren Autoritäten wie Parteien, Parlamente oder Regierungen zu akzeptieren, sowie eine Hoheit der Religion über die Wirtschaft herzustellen. Während sie die Legitimität des Nationalstaates und die Autorität von 
Parteien und Parlamenten ablehnten, schufen die Radikalen einen Gegenentwurf zum existierenden Staat (ebd.: 60). Bemerkenswert ist die sozio-kulturelle Positionierung der Radikalen im Bezirk. Der Islamismus entwickelte sich nach Tuğals Darstellung in einem vorwiegend kleinbürgerlichen Milieu, bestehend aus Studenten und Lehrern, bezog kleine Angestellte ein und berührte am Rande proletarische Milieus. Die meisten Radikalen distinguierten sich von der großen Masse der Bevölkerung über Bildung. Sie verachteten den eklektischen »Volksglauben«, der nicht auf einem Studium des Koran und anderer religiöser Schriften beruhte, sondern - aus Sicht der Radikalen - aus verzerrten Überlieferungen bestand. Ebenfalls zeigten sie wenig Interesse an den materiellen Sorgen der Bevölkerung, teils verschmähten sie »Brotthemen« sogar naserümpfend als Oberflächlichkeit (ebd.: 67). Umgekehrt fand die umstürzlerische Interpretation des Islam wenig Anklang in der Bevölkerung, was Tuğal darauf zurückführt, dass sie keine konkreten Antworten auf alltägliche Sorgen aufbot. Doch trotz Distanz zur Bevölkerung und Ablehnung von Parteien hätten die Radikalen, obwohl nur aus kleinen Gruppen bestehend, eine starke Sogwirkung auf die Wohlfahrtspartei (RP) entfaltet. Die Ablehnung politischer Parteien habe nicht verhindert, dass sie eine Koexistenz mit der Kommunalregierung eingingen, die von der RP gestellt wurde. Tuğal legt eindrücklich dar, wie die Partei als Puffer und Schnittstelle zwischen politischen Institutionen und radikalen Islamisten fungierte, indem sie einerseits innerhalb der institutionellen Grenzen operierte, andererseits die schrittweise Islamisierung aller Lebensbereiche mit vollzog.

Eine herausgehobene Rolle in diesem Prozess misst Tuğal Führungsfiguren zu. Der Vorsitzende der Wohlfahrtspartei Necmettin Erbakan habe über eine starke Ausstrahlung auf die Anhängerschaft verfügt, auch wenn er nur symbolisch über Diskurse und Abbildungen - präsent war. Erbakan habe ein mit Atatürk, der ebenfalls symbolisch präsent war - sein Porträt sei in jedem öffentlichen Gebäude und in nahezu jedem Geschäft ausgehängt gewesen -, vergleichbares Charisma erworben. Verschiedene religiöse Netzwerke (»Gemeinschaften«) ergänzten das Feld. Während Radikale den Nationalstaat ablehnten, beispielsweise zur Verweigerung des Kriegsdienstes und von Behördenposten aufriefen (ebd.: 95), hätten Partei und Netzwerke das Gegenteil erwirkt, insbesondere indem sie die in Krisensituationen brüchig werdende Zustimmung zum Staat wiederherstellten. Während Radikale das Vertrauen in (die Lösungskapazitäten von) Behörden, Parteien und Parlamente(n) unterhöhlten, wurde dasselbige durch Erbakan und seine Partei wiederhergestellt, allerdings in Konkurrenz zu den »säkularen Eliten «, die Tuğal im Militär, der CHP und den höheren bürokratischen Rängen verortet. Ein Ausdruck dieser Konkurrenz sei gewesen, dass religiöse Autoritäten wie Imame begonnen hätten, säkulare Autoritäten wie Schullehrer zu ersetzen. Tuğal fasst diesen Vorgang als Etablierung alternativer Autoritäten und Führungsfiguren. Während unter den Radikalen ein spontaner Antikapitalismus auch in Form von Konsum- und Technolo- 
giekritik aufzufinden war, umwarb die RP die Armen mit dem Versprechen einer islamisch inspirierten »Gerechten Ordnung «, prangerte Korruption und »illegitim erworbenen Reichtum« an, womit insbesondere zinsabwerfender Geldverleih gemeint war. Die Versprechen der RP gerieten jedoch zunehmend in Widerspruch zur Realität, was umso sichtbarer wurde, desto länger sich die Partei an der Kommunalregierung befand, so Tuğal. Korruption durchzog immer stärker die Kommunalverwaltung der RP, in der Vorstellungen sozialer Gerechtigkeit gegen eine Idealisierung des freien Marktes ausgetauscht wurden und Unternehmer ihre Position sukzessive durchsetzen konnten.

Trotz solcher Tendenzen in der RP konstatiert Tuğal, dass das interagierende Sammelsurium unterschiedlicher Akteure - Partei, Netzwerke, Radikale - das bestehende »kapitalistische System « sowohl herausforderte, als auch stabilisierte, ohne dass immer eindeutig zu bestimmen gewesen sei, ob die Tendenzen der Radikalen oder der Partei überwogen. Tuğal sieht die Partei und die Netzwerke der islamischen Gemeinschaften anders als die Radikalen nicht als islamistisch an, da sie keine Überwindung des Säkularismus - der Trennung von Politik, Ökonomie und Religion - beabsichtigt hätten (ebd.: 7, 250). De facto hätten sie aber im Wechselspiel mit den Islamisten »Doppelmacht « institutionalisiert: »eine Situation, in der Keime eines zweiten Staats neben dem bestehenden gelegt wurden« (ebd.: 14, Übersetzung E.B.). Mit den Begrifflichkeiten der Islamisten bezeichnet Tuğal diesen Staat in Entstehung als "islamischen Staat «, der durch die Einheit religiöser und politischer Institutionen und Autoritäten gekennzeichnet sei. 1997 habe dann das Militär diesem Versuch auch im Bezirk Sultanbeyli ein Ende gesetzt. Das Streben nach Entwicklung eines »islamischen Staats« sei jäh beendet worden. Auf die Zerschlagung, die Tuğal als eine gewaltsame Attacke des bestehenden (alten) Staates begreift (ebd.: 23), folgte eine mehrjährige Phase der Repression, bei der auch die RP verboten wurde. Islamistische Aktivisten protestierten nach der Intervention des Militärs weiterhin auf der Straße gegen Staat und Säkularismus, während ehemalige Funktionsträger der inzwischen verbotenen RP, die sich in der Nachfolgepartei FP (Tugendpartei) organisierten, den Protesten fern blieben. Die Mobilisierung sei schwach geblieben und habe unterdrückt werden können, so dass sich auf Seiten der Aktivisten Frustration einstellte. Auf diese etwa drei- bis vierjährige Phase zwischen 1997 und 2000 folgte die ökonomische Krise der Jahre 2000/2001, die neuen Unmut der Bewohner des Bezirks hervorrief, der sich nicht mehr gegen den »säkularen« Staat, sondern gegen neoliberale Politik richtete. Während sich die islamistischen Aktivisten frustriert zurückgezogen hätten, mobilisierten kleine Ladenbesitzer, die unter der Krise litten, auf die Straße. Tuğal beschreibt, dass der Einsatz der Polizei gegen die neuen Proteste bewirkte, dass die Autorität der Polizei gegenüber den überwiegend konservativen und nationalistischen Ladenbesitzern, die die Polizei für gewöhnlich als Verbündete ansahen, zerbrechlich wurde. Die Niederschlagung habe einen zweiten Höhepunkt der Krise der »säku- 
laren Hegemonie« des Staates dargestellt. Da die Protestierenden politisch jedoch führungslos (geworden) waren, weder die Nachfolgepartei der verbotenen RP, die im Bezirk weiterhin über eine Mehrheit verfügte, noch die islamistischen Aktivisten sich an den Straßenprotesten beteiligten, sei der Protest ziel- und wirkungslos versandet.

Eine Wende habe diese Phase der Frustration gefolgt von führungslosem Protest mit der Gründung der AKP genommen. Tuğal befindet, dass die AKP das Werk der 1997er Intervention vollendete, ein Fazit, das auf den ersten Blick nicht plausibel erscheint, da sich die militärische Intervention auch gegen das Personal der $\mathrm{RP}$, das sich später in der AKP reorganisierte, richtete, sowie ein scharfer Gegensatz zwischen der neu gegründeten AKP und dem »säkularen« Militär zu bestehen schien. Das Fazit wird jedoch begreiflich, wenn die Intervention von ihrem Ergebnis her betrachtet wird, das in der Auflösung der Unentschiedenheit zwischen radikaler Herausforderung und konservativ-marktorientierter Linie der RP bestand. Mit der AKP seien die in der RP zwar sukzessive stärker werdenden aber immer noch umstrittenen Tendenzen - eine neoliberale, marktorientierte, säkulare und schließlich auch pro-westliche Ausrichtung - eindeutig dominant geworden. Der nach der Zerschlagung der Linken in Folge des 1980er Putschs einzig übrig gebliebene Widerstandsherd gegen »kapitalistische Marktbeziehungen« in Gestalt der radikalen Islamisten habe seinen Einfluss verloren. Das Gerechtigkeitsversprechen der RP sei zugunsten eines am globalen Wettbewerb orientierten Wachstumsideals aufgegeben worden. Die AKP lag so gesehen auf der politischen Linie der 1997er Intervention: Ihr Entstehen - so Tuğals Sicht - stabilisierte den »säkularen Staat«.

Während die Ausrichtung der AKP in Kontinuität zu bereits in der RP vorhandenen Tendenzen steht, sieht Tuğal das Besondere darin, dass sich viele Radikale - noch unter dem Eindruck ihrer Ohnmacht gegenüber der Repression stehend nun der Partei anschlossen. Das Ziel der Errichtung eines islamischen Staats wie auch die aus dem Koran abgeleitete Ablehnung von Zinsen sei der Zustimmung zur liberalen Demokratie und Notwendigkeit von Gesetzen, zu parteipolitischem Engagement und der Trennung von Religion und Wirtschaft gewichen. Die Ziele der Aktivisten hätten sich von der Errichtung einer »integralen Religion« hin $\mathrm{zu}$ einer »Gesellschaft der Tugend « - nach wie vor mit Verweis auf den Islam verschoben, die durch Parteipolitik hergestellt werden sollte (ebd.: 149). Tatsächlich plädierten unter der AKP ehemalige Islamisten für eine Trennung der Religion von technischen, ökonomischen und administrativen Angelegenheiten, auch in Konfrontation mit Korruptionsvorwürfen, die auf den Islam zurückfielen. Tuğal beschreibt einen Prozess, der auch von anderen Autoren wie Asef Bayat konstatiert wird, der hierfür den Begriff des »Post-Islamismus« geprägt hat (Bayat 2013). ${ }^{32}$

32 Bayat bewertet die Abkehr von der Errichtung eines »islamischen Staates« allerdings wesentlich positiver als Tuğal. Er behauptet einen länderübergreifenden »post-islamistischen« 
Während Bayat die transformative Kraft politischer Institutionen betont, betont Tuğal sozio-ökonomische Anpassungsprozesse wie die Adaption der aus ländlichen Gebieten migrierten Bevölkerung an das städtische Leben, die wachsende Involvierung islamistischer Aktivisten in unternehmerische Tätigkeiten und die Begegnung mit »liberalen « Interpretationen des Islam. ${ }^{33}$ Die Integration in die Partei- und Regierungsarbeit an der Schnittstelle zu ökonomischen Interessen habe den Wandel gefestigt. Die Partei habe den Wandel in Übereinstimmung mit den Interessen von Bauunternehmern und anderen Geschäftsleuten in eine demokratische, institutionalisierte, zivile und neoliberale Richtung kanalisiert. Religion sei - maßgeblich über die staatliche Religionsbehörde und an sie angeschlossene Moscheen, aber auch durch die verschiedenen Gemeinschaften - in den Dienst einer Unternehmergruppe gestellt worden, die ihre Kontrolle über deren inhaltliche Auslegung ausgeweitet habe. Schließlich habe die »säkulare Hegemonie«, die bis zur AKP staatlich gelenkt - etatistisch - gewesen sei und nur über eine schwache zivilgesellschaftliche Basis verfügt habe, mit dem Aufstieg der gläubigen Unternehmer und der AKP eine starke zivilgesellschaftliche Basis erhalten: Die 80-jährige Hegemonie des Staates, so die Quintessenz, sei in eine Hegemonie der Bourgeoisie transformiert worden, die durch größere Stabilität gekennzeichnet sei (Tuğal 2009: 53).

Begrifflich fasst Tuğal diesen in einer Fallstudie ausgearbeiteten Vorgang unter Rückgriff auf Antonio Gramscis Hegemonietheorie als Absorption einer radikalen Herausforderung in ein bestehendes System. Die Absorption habe zum Ergebnis, dass partikulare Interessen der Bourgeoisie universalisiert wurden, indem die Neoliberalisierung, die über zwei Dekaden immer wieder Krisen und Proteste hervorrief, unter der AKP auch von den ArbeiterInnen im Viertel - trotz zunehmender sozialer Ungleichheit - als im eigenen Interesse stehend anerkannt wurde. Den von Gramsci entlehnten Begriff passive Revolution verwendet Tuğal zur Kennzeichnung einer Eigentümlichkeit dieses Prozesses, der mit der Absicht

Trend, dem er auch die AKP zurechnet. Bayat zufolge sind»Post-Islamisten«immer noch Islamisten, sie legen den Islam aber nicht mehr autoritär und repressiv, sondern in Konformität zu demokratisch-liberalen Werten aus.

Zur Veranschaulichung des Wandels soll ein konkretes Beispiel herangezogen werden: Noch in den frühen 2000er Jahren habe unter radikalen Islamisten Konsens bestanden, das Minarett einer Moschee als Symbol religiöser Autorität habe der höchste Punkt in einem Stadtteil zu sein. Mitte der $2000 e r$ Jahre sei dieser Konsens der Anschauung einer rationalen Nutzung des Raums gewichen. Es sei mit ökologischer Vernunft und dem Verweis argumentiert worden, dass der Anschluss an die globale Entwicklung nur gehalten werde könne, wenn dem Trend, in die Höhe zu bauen, gefolgt werde (Tuğal 2009: 211). Tatsächlich wirken im Hintergrund auch ökonomische Interessen: ]e höher gebaut werden kann, desto mehr Raum für die kapitalistische Verwertung steht zur Verfügung. 
islamistischer Aktivisten, das bestehende System zu revolutionieren, einsetzte, infolge ihrer Integration jedoch das Gegenteil, eine Vitalisierung und Stärkung bestehender Herrschafts- und Ungleichheitsmuster bewirkte. Die zunehmende Islamisierung der Kultur, die auch auf die »säkulare« Elite übergegriffen habe (ebd.: 54), sieht Tuğal ebenso wie die Säkularisierung der Islamisten als Kennzeichen der passiven Revolution an. Während die Islamisten in Bezug auf ihre politischen Ziele gescheitert seien, hätten sie die Beschränkung auf kulturelles Wirken akzeptiert, wodurch das säkulare System gestärkt wurde. Unter der AKP sei die Religion symbolisch geworden, sie organisiere nicht mehr das Leben, sei aber noch immer eine politische Ressource. Allein das Profil des Personals an der Spitze des Staates habe sich ausdifferenziert: Eine gläubige Elite habe zu den Reihen der säkularen Elite aufgeschlossen. Eine weitere Eigentümlichkeit, die die passive Revolution kennzeichne, sei, dass sich in der Bevölkerung der Glaube an den Radikalismus der Aktivisten und an ihre grundlegende Opposition zum System gehalten habe, obwohl diese sich gewandelt und auf die »staatstreue«, konservativ-neoliberale Linie der AKP, identisch mit der des anatolischen Unternehmerverbands MÜSİAD, eingeschwenkt seien. ${ }^{34}$ Diese Täuschung korrespondiere mit der Selbsteinschätzung ehemaliger Radikaler: Während sie sich im pragmatischen Sog der Partei zu »staatstragenden« Befürwortern eines schrankenlosen Kapitalismus entwickelten, brachten viele die Behauptung vor, nach wie vor an ihren alten Zielen festzuhalten, es nun aber mit einem Marsch durch die Institutionen versuchen zu wollen. Tuğal kennzeichnet dies als einen Rechtfertigungsdiskurs, der die tatsächliche Entwicklung - eine vollständige Absorption des Islam in den Kapitalismus und den Staat - verschleiere.

Neben den Begriffen Absorption und passive Revolution fasst Tuğal den Wandel umstürzlerischer Islamisten zu Kapitalisten begrifflich auch als eine Rationalisierung der Religion im Sinne einer Unterwerfung unter politische und ökonomische Zwecke, nicht als Ergebnis einer welthistorischen Entwicklung, so seine Kritik an Max Weber, von dem er das Konzept Rationalisierung entlehnt, sondern als Ergebnis eines Ringens um Hegemonie (ebd.: 89). Die AKP verortet Tuğal im Hinblick auf ihre Beziehung zur Religion in einer instrumentellen Tradition: Alle relevanten politischen Akteure ab den 1940er Jahren hätten die Religion zu verschiedenen Zwecken - zur Herstellung nationaler Kohäsion, im Kampf gegen den Kommunismus und zur Glorifizierung von Kapitalismus und Moderne - benutzt, so sein Argument (ebd.: 40; vgl. Tuğal 2013). Auf die Sorgen der türkischen »Säkularisten«, die im Zeitraum von Tuğals Feldforschung Großdemonstrationen gegen eine nach ihrer Meinung von der AKP ausgehende islamistische Gefahr organisierten, formuliert er eine ähnlich beschwichtigende Antwort wie die VertreterInnen der Kultur-

34 Dass die AKP oder die assoziierte Bourgeoisie den »Säkularismus « gestärkt hätten, wurde zu einer Auffassung, die viele Autoren teilen (Ozgur 2012: 148; Yankaya 2014: 249ff.). 
kampfthese: Die AKP habe keine islamistische Agenda, sie folge einem »U.S.-style conservatism«, der die radikalen Spitzen der Religion breche und sie rationalen Zielen unterordne (Tuğal 2009: 54).

Tuğal hebt also die Absorption religiöser Mobilisierung in den Kapitalismus und den Staat hervor. Im Unterschied zur Kulturkampfthese betont er die Rekonstitution von Herrschaft und die Herstellung von Konsens für soziale Ungleichheit, die durch die Eliminierung von Gerechtigkeitsvorstellungen zementiert wurde. Angesichts der Zurückdrängung des Internationalismus der Radikalen habe auch der türkische Nationalismus eine Revitalisierung erfahren, zumal an der Basis der AKP deren partiell immer noch trans-ethnisch ausgerichteter Ansatz nicht akzeptiert worden sei. Im Bezirksalltag dominiere wieder ethnische Segregation, Kurden würden marginalisiert und stigmatisiert, die kurdische Bewegung als feindlich wahrgenommen. Vor dem Hintergrund solcher Beobachtungen identifiziert Tuğal zwei Entwicklungen, die eine Gefahr für die Aufrechterhaltung der wiederhergestellten »säkularen Hegemonie« darstellten. Erstens werde mit der Rekonstitution des ethnischen Nationalismus durch die AKP die Überwindung der türkisch-kurdischen Spaltung durch Vereinigung in einer islamischen Gemeinschaft hinfällig. Zweitens nutzten neue Radikale die unter der AKP wieder eröffneten Gestaltungsräume, um die »integrale Religion« herzustellen (ebd.: 15).

\subsubsection{Kritik der Säkularisierungsthese}

Die Studie besticht durch die minutiöse, anschauliche und gleichzeitig systematisierende Darstellung des Wandlungsprozesses islamistischer Ziele sowie durch die weitsichtige Vorwegnahme potentieller Schwachstellen (»kurdische Frage«) des von der AKP angeführten Projekts nationaler Einheit. Sie wirft jedoch auch eine Reihe inhaltlicher und konzeptioneller Fragen auf. Einen Problempunkt stellt die Benennung der AKP als liberale Partei dar. Sie ist an eine formalistische Definition von Liberalismus gebunden, die aus der Perspektive erfolgt, die Tuğal auf den Islamismus einnimmt. Die Absorption von »Islamisten« in die AKP, also in die Organisationsform Partei, die an Wahlen teilnimmt und die parlamentarische Repräsentation akzeptiert, genügt ihm, um eine Revitalisierung der liberalen Demokratie festzustellen. Eine Sensibilität für Verschiebungen im politischen Gefüge ebenso wie für Kräfteverhältnisse, die einem »illiberalen« Handeln der AKP im Sinne einer Aufhebung liberal-demokratischer Institutionen zu diesem Zeitpunkt entgegenwirkten - schließlich waren ihre Widersacher nicht nur gesellschaftlich verankert, sondern auch in den staatlichen Institutionen noch sehr stark vertreten und leisteten Widerstand -, fehlt dieser Sicht. Die schrittweise herbeigeführte Aufhebung der Gewaltenteilung durch die AKP und die systematische Anwendung repressiver Mittel 
gegen bestimmte Opponenten - in Kontinuität zur tradierten (Rechts-)Praxis bewertet Tuğal nicht. ${ }^{35}$

$\mathrm{Zu}$ diskutieren sind auch die Gründe des Wandels »radikaler Islamisten«. Tuğal hebt die Intervention von 1997 als ausschlaggebend hervor, da sie die »radikalen Islamisten « frustriert und überzeugt habe, dass Straßenprotest unwirksam sei, somit den Boden für die Anerkennung parteiförmiger Organisierung bereitet habe. In ausdrücklicher Abgrenzung von marxistischen Autoren folgert er, es sei die Politik und nicht die Ökonomie, die in letzter Instanz bestimmend für diesen fundamentalen Wandel gewesen sei (ebd.: 24). ${ }^{36}$ Diese Schlussfolgerung kann aus zwei Richtungen herausgefordert werden. Erstens stellt die Integration radikaler Islamisten in parteiförmige Politik und kapitalistische Verbandsinteressen einen kontinuierlichen Prozess dar, der die Beziehung von »Radikalen« zu den Vorgängerparteien der AKP seit den 1970er Jahren ununterbrochen kennzeichnet, wie Tuğal selbst darlegt (2009: 77ff.). Die Grundlage für Individualisierung und Streben nach Reichtum, wovon mehrere Generationen »radikaler Islamisten« aufgesogen wurden, wird offensichtlich von einer gelingenden Kapitalakkumulation gebildet. Die von Tuğal benannten sozioökonomischen Prozesse, deren Sogwirkung auf »Islamisten « schon immer stark zu sein scheint, bezeugen dies. Obwohl er den langfristigen Trend kenntlich macht, bezieht er ihn nicht in die Bestimmung von Determinanten des sozialen Transformationsprozesses ein und rückt stattdessen ein singuläres Ereignis wie die 1997er Intervention in den Vordergrund. Aus Tuğals Schilderungen geht ebenfalls hervor, dass die diffuse Unterbestimmtheit der antikapitalistischen Positionen der »Radikalen« die Absorption prädestinierte. Zwar kann die Kritik des Zinses, des Konsums und des technologischen Fortschritts eine Herausforderung für Akkumulationsstrategien darstellen. Die »islamistische« Kritik blieb jedoch graduell und hauptsächlich auf die Zirkulationssphäre begrenzt, sie bezog nicht ein, dass die kapitalistische Produktionsweise durch bestimmte Eigentums- und Ausbeutungsverhältnisse charakterisiert ist. Deutlich wird dies

35 In einer späteren Veröffentlichung erörtert Tuğal (2016) den »islamischen Liberalismus« der AKP, den er hauptsächlich durch Einwirkung externer Faktoren wie den sogenannten Arabischen Frühling für gescheitert erklärt. Unter der Bezeichnung »islamischer Liberalismus« fasst er eine Kombination aus formaler Demokratie (Politik), freier Marktwirtschaft (Ökonomie) und einem »moderaten « Islam (Ideologie). Dass die Partei sich im Rahmen relativ niedriger Standards in der Türkei an formal-demokratische Abläufe hielt, wird von ihm als politischer Liberalismus gewertet. Dagegen ist einzuwenden, dass die frühen Reformen der AKP nicht institutionell garantierte Rechte und Handlungsräume für alle politischen Akteure erweiterten, wie es dem Ideal des politischen Liberalismus nahekäme. Die Reformen, so auch die Zurückdrängung des Militärs aus politischen Entscheidungsprozeduren, dienten vielmehr der eigenen Machterweiterung. 
auch daran, dass die islamistische Seite der »Doppelmacht« keine positive Alternative zur kapitalistischen Produktionsweise aufwies. Die Kritik konnte auch aufgrund dieser mangelhaften Bestimmung in moralische Bahnen gelenkt und sogar nützlich gemacht werden. Tuğal beschreibt, wie auch unter den Radikalen das Geschäftsmodell »islamischer« Unternehmer, die auf informellen Wegen das Geld von Kleinsparern mit dem Versprechen einsammelten, es in Konformität zu »islamischen« Regeln - zinsfrei - durch Gewinnbeteiligungen zu verwerten, populär wurde. Der Glaube an die moralische Überlegenheit des »islamischen« Zinsverbots wurde von diesen Unternehmern als Lockmittel, als »moralischer « Vorteil im Wettbewerb kapitalistischer Unternehmen eingesetzt (ebd.: 141). Zweitens lässt die Zuordnung der Intervention zum Staat - mit säkularen Eliten und dem Militär gleichgesetzt - unberücksichtigt, dass der radikale Anspruch, alle Lebensbereiche religiösen Motiven zu unterwerfen, auf gesellschaftliche Widerstände stieß. Die 1997er Intervention gegen eine gewählte Regierung konnte sich auf diesen Widerstand berufen, der von einer Vielzahl von Parteien, Organisationen und Intellektuellen getragen wurde (Akça 2014: 26ff.; Buğra 1998: 525). Es gab eine soziale Basis für die Intervention, die nicht das Werk einer von der Gesellschaft entkoppelten »säkularen Elite« oder eines nicht näher bestimmbaren Staates war. Nicht zuletzt griff das Militär moderierend in ökonomische Konstellationen ein, indem es die »islamischen « Geschäftsmodelle, die zu Konkurrenten großer Konzerne aufgestiegen waren, zerschlug. Die Konzerne gehörten zu den Befürwortern des militärischen Eingriffs, das heißt, die Intervention war in die Austragung kapitalistischer Konkurrenz eingebunden (Doğan 2009a: 249ff.; Savran 2015).

An diesem Punkt kommt ein theoretisches Problem der Studie zum Tragen, deren konzeptionelle Grundannahme auf einem äußerlichen Verhältnis zwischen Politik, Ökonomie und Kultur beruht, die durch Akteure auf der Handlungsebene zusammen gebracht werden. ${ }^{37}$ In der Operationalisierung des Hegemoniekonzepts setzt Tuğal diese Grundannahme in eine Unterteilung in vier Kategorien politische Gesellschaft, Zivilgesellschaft, Staat und Ökonomie - um. Ein erfolgreiches »hegemoniales Projekt« zeichne sich durch Verlinkung dieser Bereiche aus (Tuğal 2009: 32ff.). Radikale Islamisten und die AKP konzipiert er mal als Teil der politischen Gesellschaft, mal als Supra-Akteure, die über allen Bereichen stehend an der Verlinkung arbeiten. Während sie dies tun, stoßen sie auf Widerstände des Staates, den sie gleichzeitig zu gestalten versuchen. Die methodische Unbestimmtheit, den Staat als einen Bereich, den Akteure mit anderen Bereichen zu verlinken gelöst. 
und $\mathrm{zu}$ gestalten versuchen, und zugleich als einen Akteur, der dagegen Widerstand leistet, zu konzipieren, wird durch weitere Definitionen ergänzt, wonach der Staat eine Imagination in den Köpfen der Subjekte (ebd.: 27, 158) oder ein Ensemble an Institutionen und Organisationsformen darstellt. Tuğal reproduziert mit dieser Sicht einerseits das staatszentristische Konzept, in dem der Staat als dominanter, von den gesellschaftlichen Klassen getrennter Akteur gefasst wird, der ein "autoritäres « Zivilisierungsprojekt von oben verfolgt (ebd.: 24, 40ff.). Dieser Auffassung folgt auch seine These, dass die »säkulare Hegemonie« bis zur AKP staatlich gelenkt gewesen sei und erst mit dem Aufstieg der gläubigen Unternehmer und der AKP eine starke zivilgesellschaftliche Basis erhalten habe, wodurch sie stabiler als die zuvor bestehende »säkulare Hegemonie« geworden sei (ebd.: 28ff., 36). ${ }^{38}$ Andererseits bringt er eine hegemonietheoretische Operationalisierung vor, die die Bourgeoisie und die politische Partei in den Vordergrund rückt, die die Gesellschaft dominieren. Die Zusammenfassung des Vorgangs auf der begrifflichen Ebene resultiert aufgrund dieser gegenläufigen Auffassungen in einem verwickelten Fazit: Die AKP hat die Hegemonie des Staates revitalisiert, die eine staatlich-gelenkte kapitalistische Hegemonie war, aber keine der Bourgeoisie, während sie gleichzeitig die Hegemonie der Bourgeoisie hergestellt hat, die nicht nur in allen Belangen der Hegemonie des Staates gleicht, sondern in Form einer staatlichen Attacke auch von ihm ausging. Worin besteht aber der Unterschied zwischen der Hegemonie des Staates und der Hegemonie der Bourgeoisie? Ist die Bourgeoisie unter der AKP zum Staat geworden oder hat der Staat die Bourgeoisie absorbiert?

In Tuğals Konzept existieren unausgesprochen zwei Hegemonien nebeneinander: die des Staates und die der Bourgeoisie. Indem er den Staat außerhalb der Produktionsverhältnisse stellt, unterstellt er staatlichen Institutionen selbstläufige Ziele. Dies führt zu gegenläufigen Feststellungen. Einerseits begreift er die AKP als Ausdruck einer neuen Stufe in der kapitalistischen Entwicklungsgeschichte der Türkei - die Stufe, mit der die Bourgeoisie dem Staat die Ausübung der kapitalistischen Hegemoniefunktion abnimmt. Andererseits sieht er die Hegemonie der Bourgeoisie durch den Staat, durch eine staatliche Attacke im Jahr 1997 hergestellt, die sich aber außerhalb des Ökonomischen entwickelt haben soll. Einerseits folgt er der staatszentristischen Auffassung, wonach die laizistische Weltauffassung und die bürgerliche Aufklärung im Gegensatz zur konservativen und religiösen Weltauffassung nur über eine schwache gesellschaftliche Verankerung

38 Das Stabilitätskriterium irritiert auch vor dem Hintergrund, dass zum Zeitpunkt des Abschlusses der Studie die AKP gerade einmal 6 Jahre an der Regierung war. Einen Zeitraum von 80 Jahren mit einem von 6 Jahren auf der Grundlage einer räumlich und zeitlich begrenzten ethnographischen Studie zu vergleichen, erscheint gewagt, zumal das Land in dieser Zeit die größte republikanische Protestbewegung seiner Ceschichte (2007er Proteste gegen die Wahl von Abdullah Gül zum Präsidenten) erlebte, während der Krieg mit der PKK in Verbindung mit einer grenzüberschreitenden militärischen Operation erneut eskaliert war. 
verfügten. Andererseits widerlegt er diese These schon durch die Wahl des Begriffs »säkulare Hegemonie«. Dass die »säkulare Hegemonie« 80 Jahre auf einem schwachen Konsens beruht haben soll, lässt fragen, ab wann ein Konsens stark genug ist, um Hegemonie begründen zu können. Gleichzeitig widerlegt Tuğal die These eines schwachen Konsens vor der AKP empirisch, indem er eine »säkulare« Bourgeoisie und Zivilgesellschaft, eine breite Schicht von säkularen Eliten und eine beständige - »säkulare« - parteiförmige Organisierung in mehreren Parteien benennt, die über eine messbare Resonanz in der Bevölkerung verfügten. Darüber hinaus sieht Tuğal einen Machtblock mit Gründung der Republik entstehen, der aus zwei konkurrierenden Strömungen der besitzenden Klassen bestand, deren Konkurrenz sich in der Formierung der Parteienlandschaft nach 1946 bestehend aus einem »mitte-links« und einem »mitte-rechts« Flügel niederschlug (ebd.: 36ff.). Dass er diese beiden Strömungen, die die gesamte Republikgeschichte vor der AKP politisch dominierten, nicht als gesellschaftliche Formierungen, als Hegemonieprojekte fasst, die auf unterschiedlichen Klassenallianzen und kulturellen Merkmalen beruhten, obwohl er ihre weitgefächerten und tiefgreifenden sozio-kulturellen (»zivilgesellschaftlichen«) Verankerungen im Einzelnen benennt, ist eine Inkonsequenz, die aus der prinzipiellen Separierung von Staat und Klassen folgt. Schließlich ist die These, dass der Kapitalismus vor der AKP nur über eine schwache zivilgesellschaftliche Verankerung verfügt haben soll, eine Widerspiegelung des hegemoniepolitischen Diskurses konservativer Strömungen, die in Tuğals Konzept den »mitte-rechts« Flügel innerhalb des Machtblocks bilden. In diesem Diskurs gelten Akteure des "mitte-links« Flügels - oftmals gleichgesetzt mit Kemalisten - aufgrund ihrer "säkularen« oder nicht-konservativen Weltauffassung als kulturell nicht oder schwach in der Bevölkerung verankert. Distanz zu und Kritik an konservativ-patriarchalen und religiösen Traditionen wird als Entfremdung von einer ursprünglichen Identität aufgefasst. Dem »mitte-links« Flügel kulturell nahestehende Bevölkerungsgruppen werden als staatliche, autoritär (de-)formierte Akteure beschrieben. Auf der Gegenseite platziert Tuğal eine gläubige Zivilgesellschaft, die ein scheinbar von erziehungspolitischen Prozessen unberührtes Dasein fristete und sich so eine kulturelle Identität bewahren konnte. Gerade aufgrund der informativen und systematisierenden Darlegung komplexer kultureller Formierungsprozesse in der Studie ist es erstaunlich, dass Tuğal diesen kulturalistischen Essentialismus nicht konsequent dekonstruiert. Die Dekonstruktion hätte erlaubt, beide Elemente des "gespaltenen Machtblocks« vor der AKP als ebenso gesellschaftlich wie das von der AKP repräsentierte Hegemonieprojekt zu begreifen. Wie Tuğal aufzeigt, verfügten sie über zivilgesellschaftliche Unterbauten und repräsentierten gesellschaftliche Klassenallianzen. Nicht zuletzt die Festigkeit des türkischen Nationalismus in Sultanbeyli, der nach Tuğals Darstellung an der Basis sogar fester verankert war als in der Spitze der AKP, verweist auf eine übergreifende zivilgesellschaftliche Verankerung des »Machtblocks«, insofern Nationalismus 
auch von Tuğal als eine Ideologie begriffen wird, die die Gegensätze zwischen den Klassen passiviert und somit Hegemonie festigt. Widerspruch ruft auch die Beschreibung des »Zivilisierungsprojekts des Staates« der Prä-AKP-Zeit hervor, zu dem Tuğal Technisierung, Individualisierung und Urbanisierung, die Herstellung von Akzeptanz für Schulbildung, die Durchsetzung einer bestimmten Kleiderordnung und von Verhaltensweisen, die an den Rhythmus der Stadt und der Fabrik angepasst wurden, zählt (ebd.: 90ff.). Formgleiche Vorgänge interpretiert er erst zum Zeitpunkt der Regierungsübernahme durch die AKP als Etablierung einer kapitalistischen Rationalität in Verbindung mit kulturellen Normen, als kontemporäre Prozesse bürgerlich-kapitalistischer Vergesellschaftung.

Werden die staatszentristischen Reminiszenzen aufgelöst, dann lässt sich tatsächlich folgende Aussage treffen: Die von Tuğal beschriebene Krise der Hegemonie, die von der AKP restauriert wurde, war nicht die Krise eines von den gesellschaftlichen Klassen losgelösten »säkularen Staates«, sondern eine Krise der bürgerlichen Hegemonie, die sich als eine Repräsentationskrise des bürgerlichen Machtblocks provoziert durch neoliberale Politik ausdrückte. Der Machtblock wurde nicht aufgelöst, sondern re-formiert. Mit der Bearbeitung der Krise ist der politische Islam zur dominanten Kraft des »mitte-rechts« Flügels aufgestiegen. Die Krise bestimmter Elemente des bürgerlichen Nationalstaats blieb eng begrenzt auf kleine Gruppen von Radikalen. Die »Radikalen« wurden in die AKP, die sich als eine Partei der Unternehmerklasse formierte, absorbiert. Doch bedeutet die Absorption der Radikalen auch, dass die AKP die Religion rationalisiert und die »säkulare Hegemonie « wiederhergestellt hat? Um diese Frage beantworten zu können, muss das Religionsverständnis im Zusammenhang mit der auf Max Weber zurückgehenden Rationalisierungsthese genauer betrachtet werden.

\subsubsection{Erste Definition von Religion in Hegemonieprojekten: Was ist Islamismus?}

Eine Prämisse der von Tuğal aufgegriffenen Rationalisierungsthese ist, dass es einen nicht-instrumentellen Zugriff auf Religion geben kann. Erst mit dem Übergang in die kapitalistische Produktionsweise findet nach dieser Auffassung ein Wesenswandel der Religion durch Säkularisierung oder Profanisierung statt. Zuvor wird von einem nicht-instrumentellen, interesse- oder zweckfreien Zugriff auf Religion ausgegangen. Positiv formuliert wird unterstellt, dass es einen religiösen Selbstzweck, eine »Authentizität« der Religion jenseits weltlicher Bezüge geben kann. Die Grundannahme ist daher eine Doppelte: Dass Religion von den mate- 
riellen Lebensverhältnissen losgelöst ein eigenständiges Dasein fristen kann und Rationalität erst mit dem Kapitalismus entsteht. ${ }^{39}$

Die von der AKP gleich zu Beginn ihrer Regierungszeit propagierte Aussage, dass Geld keine Religion habe (Tuğal 2009: 179), kann zur Konkretisierung des Diskussionspunkts herangezogen werden. Die Aussage widerspricht einem lange gehegten Diskurs, Geld müsse bestimmten »islamischen« Regeln, wie dem Zinsverbot, unterworfen sein. Insbesondere "radikale Islamisten « hatten die Sicht vorgebracht, aus Zinsen resultiere illegitimer Reichtum. Wie Tuğal darstellt, bewirkte die Integration der »Radikalen « in die AKP ein Verstummen der einzigen Instanz, die eine »islamische« Kritik am Zins vorbringen und an die "gläubige« Bevölkerung hätte appellieren können. Ehemalige »Islamisten« waren sogar zu Verfechtern von Zinsen geworden, trugen selbst ihr Geld auf die Bank, legitimierten dies und ihren neu erworbenen Reichtum mit göttlicher Vorsehung: „Gott hat uns dies beschieden« (ebd.: 219). »Gläubige« Unternehmer waren damit gleich von zwei moralischen Bürden befreit: Sie konnten verzinste Kredite aufnehmen, selbst Geld mit Zinsen verleihen und ihren Reichtum genießen, ohne auf nennenswerten Widerspruch seitens »islamischer« Gerechtigkeitsvorstellungen zu stoßen.

Das Beispiel untermalt eindrücklich Tuğals These einer Absorption der Radikalen in den Kapitalismus. Wird dieser Vorgang jedoch als Rationalisierung und Instrumentalisierung abgehandelt, wodurch der Zugriff »radikaler Islamisten « auf die Religion als nicht-instrumentell erscheint, wird die grundsätzliche Frage aufgeworfen, welcher Zugriff einem »wahren« oder »ursprünglichen« Inhalt der Religion entspricht. Kann beispielsweise die Positionierung zum Zinsverbot in religiösen Texten als Lackmustest für die Wahrhaftigkeit herangezogen werden? Die Konsequenzen einer solchen Herangehensweise reichen sehr weit. Sie erfordert

39 Die Rationalisierungsthese impliziert, Religion sei erst mit dem »industriellen « Kapitalismus in Berührung mit »weltlichen « Dingen gekommen. Max Weber ist der Auffassung, dass der »Geist« des Kapitalismus aus den Mönchszellen des Asketismus entrann, von dort aus begann, »die Welt umzubauen und in der Welt sich auszuwirken unternahm«, wodurch »die äußeren Güter dieser Welt zunehmende und schließlich unentrinnbare Macht über den Menschen, wie niemals zuvor in der Geschichte« gewannen (Weber 1986: 203f.). Die Auffassung, wonach die Mönche »außerhalb « weltlicher Dinge in ihren Klöstern lebten, um von dort in die Welt hinauszutreten, ist ziemlich sonderbar. Wie lässt sie sich damit vereinbaren, dass religiöse Institutionen gerade in vor-bürgerlichen Cesellschaften nicht nur auf enge und in vielfältiger Weise mit politisch-ökonomischen Institutionen verschränkt waren, sondern vielfach mit ihnen sogar in eins fielen? Kirchen, Klöster, Orden wie auch andere religiöse Zusammenschlüsse besaßen Ländereien, verfügten über Produktionsmittel, trieben Steuern ein und verpflichteten die bäuerliche Bevölkerung zu Zwangsabgaben und -diensten. Die Rationalisierungsthese rückt diese politisch-ökonomische Realität religiöser Institutionen die Verschränktheit von Religion und sogenannten »äußeren Gütern« - an den Rand oder in die Unsichtbarkeit, sofern sie sie erst mit dem Kapitalismus beginnen lässt. 
nicht nur Expertise hinsichtlich religiöser Texte, sie hebt auch die sozialwissenschaftliche Perspektive auf, indem sie sie in eine theologische überführt, in der auf der Grundlage des Koran - also text-basiert - darüber diskutiert wird, was islamisch ist und was nicht. Die wissenschaftliche Auseinandersetzung wird damit unvermeidlich Teil eines theologischen Streits über die richtige Auslegung eines Textes. Eine solche Herangehensweise misst religiösen Wahrheiten einen Stellenwert zu, der ihnen in der Praxis nicht zukommt. Hierauf verweist gerade der von Tuğal beschriebene Vorgang: Unter Heranziehung unterschiedlicher Aussagen aus demselben religiösen Text legten dieselben Akteure Zins und Reichtum erst im Widerspruch, dann in Konformität zum Islam aus. Reichtum wurde zur Gabe Gottes erklärt oder, gemäß einer weiteren Interpretation, als Belohnung für die Anhäufung von religiösem Wissen dargestellt (ebd.: 129). Hieraus kann die »Wahrheit« gewonnen werden, dass religiöse Texte unterschiedlich ausgelegt werden können. Welche Interpretation sich durchsetzt, wird nicht über das Vordringen zu einem wahren Kern, sondern in gesellschaftlichen Kämpfen im Ringen um eine Interpretationshoheit entschieden (vgl. Bayat 2007). Der Wandel bestimmter islamistischer Positionen zeigt ferner an, dass der Zugriff auf Religion immer instrumentell ist, insofern sie zur Erklärung und Begründung von weltlichen Vorgängen herangezogen wird. ${ }^{40}$ Tuğal weist diese Einsicht, dass es keinen aus dem gesellschaftlichen Kontext losgelösten, ursprünglichen Islamismus geben kann, selbst in verschiedenen Passagen ausdrücklich nach, verliert sie jedoch wieder durch den Rückbezug auf das weberianische Theoriemodell. So entsteht zumindest die Tendenz, der Religion eine Sonderrolle beizumessen, indem sie außerhalb des menschlichen Lebens gestellt wird, nicht als eine von Menschen gemachte kulturelle Form begriffen wird. Ebenfalls irritiert Tuğals Bezugnahme auf die Rationalisierungsthese, die bei Weber durch eine Hinwendung des Glaubens zum Diesseits begründet wird. Die »Radikalen« in der Türkei waren auch vor ihrer Verwandlung in Kapitalisten dem Diesseits zugewandt. Ihr Zugriff auf die Religion war ausdrücklich mit der Absicht einer umfassenden Gestaltung des gesellschaftlichen Zusammenlebens (integrale Religion) verbunden. Was ist diesseitiger als der Anspruch, das Diesseits zu verändern? Ihre Verwandlung zeichnet sich nicht dadurch aus, dass sie sich einer Welt zuwandten, der sie zuvor abgewandt waren, sondern dass sie sich schrittweise von einem sozialistisch und internationalistisch beeinflussten, diffusen Radikalismus kleinbürgerlicher Studenten und Angestellter, den Entwicklungszielen der dominanten Klassen, wie sie in der RP und später in der AKP zur Geltung kamen, annäherten. Die genaue Frage, die Tuğals Studie in Bezug auf die Stellung der Religion aufwirft, ist daher nicht, ob religiöse Ansichten dem Diesseits oder dem Jenseits 
zugewandt sind, ob sie instrumentell sind oder nicht, sondern in welcher Beziehung sie zum Diesseits stehen, mit welchen »weltlichen« Zwecken sie verbunden sind oder werden. ${ }^{41}$

Eine anschließende Frage ist, inwiefern - nach Tuğals Auslegung - nicht nur die AKP, sondern alle Vorgängerparteien nicht islamistisch sind, dagegen aber die mit radikalen Absichten verbundene Interpretation des Islam, die von kleinen Gruppen im Bezirk geteilt wurde. Tuğal verwendet das Attribut radikal gleichbedeutend mit islamistisch, so dass der Begriff »radikaler Islamismus« bei ihm eine Tautologie darstellt. Als islamistisch und folglich radikal bezeichnet er - unabhängig von den angewendeten Mitteln - »ein Projekt, das den Staat, die Ökonomie und die Gesellschaft entlang islamischer Linien gestalten will« (Tuğal 2009: 267, Übersetzung E.B.). Den Einwand gegen die Möglichkeit, eine »islamische Linie« objektiv - zeit- und raumübergreifend - bestimmen zu können, zurückstellend, kann nachvollzogen werden, warum Tuğal die Abwendung von den beschriebenen Zielen als Deradikalisierung ansieht. Doch ist der Begriff Säkularisierung für die Bezeichnung des gleichen Vorgangs ebenfalls nachvollziehbar? Die AKP hat kein theokratisches Regierungssystem und keine theologische Instanz installiert, die verbindlich jede einzelne wirtschaftspolitische Entscheidung auf ihre Konformität zum Koran hin überprüft. So gesehen steht sie für die Trennung administrativer und wirtschaftspolitischer Regierungs- und Regulierungsfragen von der religiösen Textauslegung. Nichtsdestotrotz ist ein Einwand gegen diese enge Definition von Islamismus vorzubringen, denn unter der AKP fand weder eine Trennung von politischen und religiösen Institutionen, noch eine generelle Loslösung der Religion von wirtschaftlichen Fragen statt. Der Begriff Säkularisierung verdeckt den selektiven und kontrollierten Einsatz religiöser Praktiken und Diskurse und den konsequenten Ausbau religiöser Institutionen unter der AKP, zuvorderst der Religionsbehörde und der theologischen Schulen, wie im Verlaufe der Arbeit noch auszuführen sein wird. Auch in Bezug auf die Ökonomie beschreibt Tuğal keine Trennung, sondern einen Kampf um die Reartikulation von Religion und Wirtschaft innerhalb des islamistischen Lagers, in dem sich eine bestimmte kapitalistische Rationalität durchgesetzt hat. ${ }^{42}$

41 Dass sie »Brotthemen «als diesseitig verachteten, entbindet die Radikalen nicht von der Notwendigkeit, Essen und Trinken zu müssen, um sich stofflich zu reproduzieren. Da sie nicht verhungert sind, ging ihre Verachtung offensichtlich nicht so weit, auf ihre eigene stoffliche Reproduktion zu verzichten. Wie sie hierfür gesorgt haben, bleibt im Dunkeln. Hierfür müsste eine genauere Analyse der materiellen Reproduktionsbedingungen des kleinbürgerlichen Islamismus unternommen werden.

42 Hervorzuheben ist eine Differenz von Tuğals These gegenüber anderen Interpretationen, die denselben Prozess der Deradikalisierung oder des »Moderat-Werdens « nicht etwa für radikale Islamisten, sondern für die AKP und ihre Vorgängerinnen (Çavdar 2006; Yavuz 2009), 
Zusammenfassend lässt sich konstatieren, dass die analytische Trennung von Politik, Kultur und Ökonomie zu einer prinzipiellen Trennung tendiert, indem

- Islamismus als kulturelles Phänomen gefasst wird, das Politik und Ökonomie dominiert,

- unter Etatismus die Dominanz der Politik gegenüber Ökonomie und Kultur begriffen wird,

- Säkularismus als kombinierte Domination der Kultur durch Politik und Ökonomie gefasst wird.

Der theoretische Widerspruch, den diese Trennung hervorbringt, prägt den zentralen Befund der Studie durch die Kombination von Säkularisierung und Hegemonie im Begriff »säkulare Hegemonie«. Unter Säkularisierung fasst Tuğal zwei Vorgänge: Die formelle/institutionelle Trennung politischer und religiöser Angelegenheiten und die Unterwerfung der Religion unter politische und wirtschaftliche Ziele. ${ }^{43}$ Hegemonie verweist dagegen nach Gramsci, an dessen Konzept Tuğal anschließen möchte, auf ein Führungsverhältnis zwischen Klassen. Ideologie und Kultur nehmen in diesem Verhältnis eine vermittelnde Rolle ein. Die dominanten Klassenakteure sind bestrebt, Ideen und kulturelle Praktiken in einer Gesellschaft so zu gestalten, dass sie ihre Stellung festigen und ihre Entwicklungsziele begünstigen. Tuğal belegt diesen Vorgang an zahlreichen Beispielen in Bezug auf den Islam, der unter der Führung des Unternehmerverbands MÜSİAD entlang kapitalistischer Bedürfnisse (re-)interpretiert wird. Seinen Befund formuliert er klar: Der Islam wird zum bestimmenden Merkmal in der Herstellung nationaler Einheit und fungiert als kulturelle Ressource, um kapitalistische Ziele zu vermitteln (ebd.: 245). Wenn Hegemonie aber auf ein Führungsverhältnis zwischen Klassen verweist und der Islam zu einem bestimmenden Medium wird, um bürgerliche Führung (Hegemonie) auszuüben - in Tuğals Formulierung »Konsens für Herrschaft und Ungleichheit « zu organisieren (ebd.: 24) -, dann widerspricht dieser zentrale Befund dem Begriff »säkulare Hegemonie«. Der Begriff lässt auch die Unterscheidung zwischen einer "gläubigen« und einer »säkularen« Elite gehaltlos werden, wenn doch beide für den Säkularismus stehen. Die begriffliche Zwickmühle entsteht, da Hegemonie eine Theorie der Verkopplung von Produktionsverhältnissen und ihrer ideologisch-kulturellen Vermittlung ist, Säkularisierung (nach Tuğals Verständnis) dagegen eine Theorie der Entkopplung von Institutionen oder

den Unternehmerverband MÜSIAD (Demirpolat 2002; Yankaya 2014) und die islamischen Gemeinschaften (Özdalga 2000; Yavuz 2003; Yavuz 2004) feststellen.

43 Die Kritik könnte auch an dem Punkt ansetzen, dass sich diese beiden theoretischen Ansätze widersprechen: Der eine bezeichnet die Trennung der Religion von Politik und Wirtschaft als Säkularisierung, der andere die Unterwerfung der Religion unter Politik und Wirtschaft. 
- aus rationalisierungstheoretischer Perspektive - eine der Verweltlichung von Religion im Sinne einer Unterwerfung unter politische und wirtschaftliche Ziele ist. Sofern aber der Begriff Hegemonie nach der kulturellen und ideologischen - der »zivilgesellschaftlichen« nach Gramsci - Gestaltung von Führung zwischen Klassen, nach den Medien und Inhalten, über die sich ein Konsens bildet, fragt, die Ausübung von Hegemonie maßgeblich mit Religion verkoppelt ist, dann ist es konsequent, die gesellschaftlichen Träger dieser Verkopplung - MÜSİAD, die AKP und assoziierte Intellektuelle - als Islamisten zu bezeichnen. Folglich kann die von der AKP ausgetragene bürgerliche Hegemonie gemäß ihrer zivilgesellschaftlichen Prägung als islamistisch bezeichnet werden. Der Begriff Islamismus ist deshalb nicht auf »radikale Islamisten« einzugrenzen, sondern auf alle Akteure auszuweiten, die ihren gesellschaftlichen Gestaltungsanspruch zentral über islamisch kodierte Bezüge herstellen (vgl. White 2002: 6; dies. 2008). Der Begriff Kodierung drückt an dieser Stelle aus, dass die Wahrhaftigkeit dieser Bezüge kein Gegenstand der wissenschaftlichen Bestimmung ist. Ausschlaggebend ist die Herleitung aus Quellen, die dem »Glaubenssystem« Islam zugerechnet werden beziehungsweise sich auf dieses berufen. Islamismus ist dann die Bezeichnung für eine politische Ideologie als integraler Bestandteil eines Hegemonieprojekts. Der Gegenstand islamistischer Praxis ist die Gestaltung von Weltauffassungen und kulturellen Praktiken durch religiöse Bezüge. Der Begriff politischer Islam bezieht sich auf den konkreten Gestaltungswillen, diese Bezüge allgemeinverbindlich zu machen. Diese Definition schließt nicht aus, zwischen verschiedenen islamistischen Strategien und Projekten bei der Umsetzung dieser Ziele zu unterscheiden, Differenzierungen sowie die Heterogenität islamistischer Akteure innerhalb eines nationalen Raums oder im internationalen Vergleich zu berücksichtigen (vgl. Bayat 2013).

\subsection{Die Klassenkampfthese}

Aus einer vierten Perspektive wird die AKP als Trägerin eines kapitalistischen Herrschaftsprojekts begriffen. Die Perspektive unterscheidet sich grundlegend von staatszentristischen Ansätzen, indem sie den Staat nicht als eigenmächtigen und von den gesellschaftlichen Klassen losgelösten Akteur behandelt sowie die Konfliktachse nicht zwischen einem homogenen Staat und einer (Zivil-)Gesellschaft verlaufen sieht. Die von der AKP fortgeführte neoliberale Politik wird als eine Rücknahme parlamentarisch-demokratischer Entscheidungsmechanismen und sozialer Rechte subalterner Klassen bestimmt. Im Gegensatz zum staatszentristischen Ansatz, der der politischen Dynamik einen über die autoritäre Staatstradition vermittelten Kulturkampf zugrunde legt, werden Klassen- und Fraktionskämpfe beziehungsweise Akkumulationsstrategien als treibende Dynamik der politischen Entwicklung analysiert. Kapitalismus wird nicht als 
ein a-historischer, dem bürgerlichen Subjekt entspringender Normenkatalog, sondern als eine Produktionsweise begriffen, die mit strukturellen Machtverhältnissen verbunden ist. Ideologie/Kultur - im konkreten Fall Religion - wird eine hegemoniebildende, legitimatorische, organisierende Rolle in der Durchsetzung kapitalistischer Entwicklungsinteressen oder - als Sonderfall - eine kapitalbildende Funktion beigemessen.

\subsubsection{Anatolische Bourgeoisie revisited}

Eine Vielzahl von Veröffentlichungen aus dieser Theorietradition, die unterschiedliche Ausprägungen des historischen Materialismus umfasst, untersucht den Unternehmerverband MÜSİAD oder die »islamische Bourgeoisie« und deren Rolle bei der Formierung des politischen Islam (Balkan/Balkan/Öncü 2015; Çoşar/Yücesan-Özdemir 2012; Köse/Öncü 1998; Uzgel/Duru 2009). Wie auch von der staatszentristischen Literatur vorgebracht, wird eine Korrespondenz zwischen dem Aufstieg des politischen Islam und dem Aufstieg einer Gruppe kapitalistischer Unternehmen seit den 1970er Jahren festgestellt, für die die populären Bezeichnungen »anatolische Bourgeoisie« und "anatolische Tiger« - letztere stellte eine Parallele zur Erfolgsgeschichte südostasiatischer Firmen her - in Umlauf kamen. Weitere populäre Bezeichnungen waren »islamisches« und "grünes« Kapital. Die Farbe Grün sollte auf den religiösen Aspekt aufmerksam machen, sie gilt als Symbol des Islam.

Kritisiert wird die Trennung zwischen einer kleinen bis mittleren »anatolischen « und einer großen »westlichen « oder »Istanbuler « Bourgeoisie mit dem Hinweis, dass diese Trennung hinter die Dynamik der Kapitalakkumulation zurückfällt. So startete fast die gesamte große Bourgeoisie der Türkei in »Anatolien« und verlagerte ihre Investitionen erst im Laufe ihrer Entwicklung in westliche Regionen, da sie dort bessere Verwertungsbedingungen vorfand. Etliche Unternehmen, die der Fraktion der »anatolischen Bourgeoisie« zugeschlagen wurden, hatten die gleiche Entwicklungsdynamik durchgemacht und erwirtschafteten einen Großteil ihres Profits inzwischen im Großraum Istanbul (Sönmez, M. 2009: 180ff.). Als irreleitend kritisiert wird auch, kleine und mittlere Unternehmen pauschal der islamischen Bourgeoisie zuzuschlagen. Weitere Verbände von kleinen und mittleren Unternehmen, die sich nicht durch die Adaption einer religiösen Ideologie auszeichnen, gerieten aus dem Blick (Öztürk 2015). ${ }^{44}$ Grundlegend ist der Widerspruch zur Auffassung, wonach die etablierten Unternehmen im Verband TÜSİAD durch den Staat entstanden seien, dem sie ihre Monopolstellungen verdankten und dessen autoritäre Eigenschaften sie übernommen hätten, die »anatolische Bourgeoisie«

44 Zu nennen ist der 2003 gegründete Verband TÜRKONFED, der einen Zusammenschluss regionaler Verbände kleiner und mittlerer Firmen bildet, die mit TÜSIAD kooperieren. 
bestehend aus mittelständischen Unternehmen dagegen »aus eigener Kraft« oder gegen den Staat entstanden sei und deshalb liberale und demokratische Eigenschaften aufweise. Wie in der Besprechung des staatszentristischen Ansatzes angeführt, ist die Herstellung der allgemeinen Bedingungen der Kapitalakkumulation immer auch ein politischer Prozess. Verschiedene Studien konkretisieren dieses Argument, indem sie im Einzelnen aufzeigen, welche politischen Mittel eingesetzt wurden, um die Entwicklung der Bourgeoisie in Anatolien zu fördern (Boratav 2003; Cengiz 2013; Doğan 2009a; Ercan/Tuna 2006; Hoşgör 2015; Öztürk 2010 u. 2015). Sie zeigen auf, dass die Entwicklung der Unternehmerschaft in Abhängigkeit zur nationalen und internationalen Konjunktur verlief. So herrschte in den 1970ern ein investorenfreundliches politisches Klima vor, die Zahl neugegründeter kapitalistischer Unternehmen nahm rasant zu (Cengiz 2013: 204ff.; Tuna/Güneş 2012: 111) ${ }^{45}$ Der öffentliche Sektor bediente die Nachfrage der Privatindustrie nach bestimmten Vorleistungen zu einem Beschaffungspreis, der zumeist unter den Herstellungskosten lag. Wechselkursgarantien des Staates bei ausländischen Krediten ermöglichten Unternehmern einen Schutz gegen die hohe Inflation, Kursverluste der Lira wurden aus dem öffentlichen Haushalt beglichen (Boratav 1987: 90).

Aufgrund der Assoziation zahlreicher neu entstandener Unternehmen mit der islamistischen Bewegung und der Irreführungen, die mit der Bezeichnung »anatolisch" einhergehen, wird in der historisch-materialistischen Forschungsliteratur die Bezeichnung »islamisch« für diese Bourgeoisie bevorzugt. Allerdings wird mit dieser Bezeichnung nicht eine Vorrangigkeit religiöser Motive gegenüber unternehmerischem Handeln, wie sie in der theologischen These hergestellt wird, verbunden. Verschiedene Studien widerlegen die These, dass der Islam oder eine bestimmte Form des Islam eine entscheidende Rolle spielte, insofern er die Unternehmerschaft in besonderem Maße motiviert und die Herausbildung eines »islamischen Calvinismus" (ESI 2005) befördert haben soll. Über den Vergleich zwischen der jüngeren kapitalistischen Entwicklungsgeschichte verschiedener Städte wird aufgezeigt, dass die Bourgeoisie sich auch in säkular geprägten Städten im gleichen Zeitraum auf der Grundlage vergleichbarer Bedingungen ohne religiöse Motive entwickelte (Tok 2011). Doğan legt indes dar, dass von wenigen konservativ-islamischen Firmen abgesehen, deren Gründung vor die 1980er Jahre zurückreicht und die schon länger zu den etablierten Unternehmen gehörten, mehr als die Hälfte der »islamischen « Unternehmen erst im Zusammenhang mit der Neoliberalisierung entstanden, die durch Liberalisierung und Deregulierung von grenzüberschreitendem Handel und Investitionen sowie Privatisierung öffentlicher Unternehmen gekennzeichnet ist. Sie fingen häufig im exportorientierten Textilsektor

45 Eine ausführlichere Besprechung der politisch-ökonomischen Bedingungen für die Entwicklung dieser Unternehmen in Verschränkung mit der Religion erfolgt in Kapitel 5.4. 
an, um von dort in neue Sektoren sowie ins Ausland zu expandieren. Die Verwertung des städtischen Raums und die Privatisierung kommunaler Dienstleistungen bildeten demzufolge weitere herausragende Mittel zur Kapitalakkumulation, die ab den 1980er Jahren dem Unternehmertum auch in den islamistisch regierten Kommunen ein schnelles Wachstum ermöglichte. Die Wahlsiege der Wohlfahrtspartei in den Großstädten Istanbul und Ankara 1994 fielen schon in eine Phase, in der die größeren Firmen, die für den globalen Markt produzierten, innerhalb von MÜSİAD tonangebend geworden waren (Doğan 2009a: 289ff.; Ders. 2011: 73). Weitere Studien zeigen auf, dass unter der AKP insbesondere die Förderung des Bausektors vielen dieser Firmen ein enormes Wachstum ermöglichte. Sie erhielten günstige Kredite von den staatlichen Banken, profitierten von den relativ günstigen internationalen Krediten und der tieferen Integration in den Weltmarkt (Sönmez, M. 2009: 183; Ertuğrul 2009). In den besonders schnell gewachsenen Stadtbezirken organisiere sich ferner über die AKP eine lokale Bourgeoisie, die das Führungspersonal der Partei stelle. Diese Bourgeoisie, die zu einem erheblichen Teil älteren Generationen von Binnenarbeitsmigranten entstamme, nutze die Opportunitäten, die die Partei biete, wie den Zugang zur kommunalen Infrastruktur, Beziehungen in Behörden und zur nationalen Regierung (Balaban 2013: 45ff.; Doğan 2016: 258f.).

Eine Studie zur mittelanatolischen Stadt Kayseri, die als Vorzeigemodell für den »islamischen Calvinismus« fungierte, setzt sich systematisch mit der theologischen These, die eine motivierende Rolle der Religion für die Unternehmer behauptet, auseinander (Cengiz 2013). Die Studie demonstriert, wie schematisch verkehrt die Vorstellung von einem unterentwickelten anatolischen Hinterland ist, das vom Kemalismus vernachlässigt wurde. Nach Cengiz war Kayseri an der Wende vom 19. zum 20. Jahrhundert eine kosmopolitische und ökonomisch dynamische Metropole. Der Genozid an der christlichen Bevölkerung Anatoliens setzte dem Kosmopolitismus ein Ende, der Erste Weltkrieg und die Weltwirtschaftskrise lähmten die wirtschaftliche Entwicklung. Doch schon 1934 wurde im Rahmen des ersten Fünfahresplans der Republik die größte Baumwollspinnerei des Landes in Kayseri gegründet. 1927 wurde die Stadt an das Schienennetz angeschlossen, dadurch der Transport von Rohstoffen und Waren erheblich erleichtert. Die Gründung staatseigener Betriebe $a b$ den 1930er Jahren ermöglichte in verschiedenen technischen Bereichen die Ausbildung von Fachkräften, die zwei bis drei Jahrzehnte später zu Gründern derjenigen Unternehmen gehören sollten, die der staatszentristischen Legende nach ohne staatliche Unterstützung emporgekommen waren. Ohne die hohen Zölle in der Phase der Importsubstitution wären die ersten Fabrikanten, die in den 1950ern Textilproduktionsstätten mit veralteter Technologie gründeten, nicht konkurrenzfähig gewesen. Der industriellen Entwicklung zum endgültigen Durchbruch verhalf die Özal-Periode nach 1980. Die späteren »anatolischen Tiger« aus Kayseri überstanden die schwere Schuldenkrise Ende der 1970er und erhielten öffentliche Förderkredite zu Sonderkonditionen. Anlaufschwierigkeiten der 
1970er bedingt durch Engpässe in der Rohstoff- und Energieversorgung wurden auf nationaler Ebene behoben. Wie auch in der ESI-Studie angeführt, waren es in der Landwirtschaft ebenso wie in der Industrieproduktion öffentliche Kredite für Investitionen, andere Subventionsformen, Zölle und der öffentliche Ausbau von Infrastrukturen (Straßen, Schienen, Depots, Warensammel- und Verteilungsnetze, Produktionsstätten etc.), mit denen die private Kapitalakkumulation gefördert wurde. Schließlich zogen diese Unternehmen Vorteile aus der 1996 in Kraft getretenen Zollunion mit der EU (vgl. ESI 2005: 15).

Ihren gegenwärtigen Status als industriell entwickelte Region verdankt die Stadt Kayseri, die als beispielhafte Entwicklungsstätte der anatolisch-muslimischen Bourgeoisie und des islamischen Calvinismus gehandelt wurde, also einer 80-jährigen Förderung. Cengiz betont, dass hierbei die Religion erst in der jüngeren Phase, nach 1980, eine Rolle zu spielen begann. Demzufolge fand keine Verwandlung von mit religiösen Motivationen ausgestatteten Akteuren zu Kapitalisten statt, vielmehr griffen ehrgeizige Unternehmer auf die Religion, auf religiös durchwirkte Organisations- und Beziehungsformen zu, um ihr Wirken in einen breiteren Rahmen zu stellen und ihre gesellschaftliche Position zu legitimieren. Weitere Einblicke in die industrielle Entwicklungsgeschichte stellen die aus Selbstdarstellungen von Unternehmern gewonnene These infrage, dass dem Aufstieg der »anatolischen Tiger« die Bildung von Netzwerken horizontaler Solidarität in nach 1980 neu entstandenen Produktionsnischen zugrunde lag. Demzufolge hatte die »anatolische Bourgeoisie« sich gegenseitig gestützt, um gegen die etablierte Bourgeoisie zu bestehen (Buğra 1998), der Islam habe den in die urbanen Zentren wandernden Unternehmern mit ländlichen Wurzeln in einer »fremden und feindlichen Welt« dazu verholfen, Verbindlichkeit herzustellen und gegenseitiges Vertrauen aufzubauen, wodurch ökonomische Aktivitäten erleichtert oder erst ermöglicht worden seien (Kuran 1995). Cengiz rekonstruiert eine Geschichte gegenseitigen Betrugs unter den Fabrikanten, deren Beziehungen untereinander durch Konkurrenz und Neid geprägt gewesen sei. Von wenigen Ausnahmen solidarischen Handelns abgesehen, die auf individuelle Initiativen zurückgingen und keine regelhaften Muster erkennen ließen, habe ein Prozess des Aussiebens stattgefunden, an dessen Ende einige wenige der ursprünglichen Unternehmer übrig geblieben seien. ${ }^{46}$ Während nach außen ein Bild vermittelt

46 Detailliert nachgezeichnet wird dies anhand der Ceschichte einer Kabelfabrik (HES), die 1974 als Kollektivgründung von 832 Partnern - allesamt Einwohner des Dorfes Hacılar - startete, bis zuletzt nur noch zwei Haupteigentümer übrig blieben, die die anderen mit allerlei Tricks hinausgedrängt hatten. Bei näherer Betrachtung entpuppt sich der kapitalistische Erfolg des Unternehmens als ein Verdrängungswettbewerb, bei dem niemand dem anderen etwas gönnt (Cengiz 2013: 280ff.). 
werde, wonach der Prozess der Industrialisierung durch unternehmerische Solidarität gekennzeichnet war, gäben Einblicke hinter die Fassade zu erkennen, dass das solidarische Ideal nicht der Realität entsprach (Cengiz 2013: 280ff.).

\subsubsection{Religion als Medium und Ressource}

Die Thematisierung der Beziehungen zwischen den Klassen bildet in historisch-materialistischen Ansätzen eine zentrale Differenz $\mathrm{zu}$ weberianischen Ansätzen, in denen Ethik als ein Kampf des Kapitalisten mit sich selbst, innere moralische Schranken oder kulturelle Hemmnisse zu überwinden, thematisiert wird, die Rolle von Ethik in den Beziehungen zwischen den Klassen - im Prozess der Aneignung der Mehrarbeit - dagegen unterbelichtet bleibt. Historisch-materialistische Studien beschreiben, wie die Religion in diesen Beziehungen als Medium zur Erzeugung kultureller Hegemonie fungiert. Untersuchungen $\mathrm{zu}$ kleinen und mittleren Betrieben zeigen auf, dass Unternehmer wie Arbeiter im persönlichen Kontakt auf religiöse Weltanschauungen zugreifen, um Arbeitsangelegenheiten zu verhandeln. Der Griff zur Religion verhindere die Thematisierung struktureller Hierarchien zugunsten eines »utopischen Kompromisses (Durak 2011: 128), in dem Unternehmer und Arbeiter als Gleiche erscheinten. Anderweitig hergestellte kulturelle Nähe, die Abstammung vom gleichen Ort, nicht selten auch verwandtschaftliche Beziehungen bildeten ein Netz gegenseitiger Verpflichtungen aus (Cengiz 2013: 332). Als Grundlage für die Aktivierung dieser Medien oder Vermittlungsinstanzen wird in diesen Ansätzen die Desorganisierung der ArbeiterInnen durch massenhafte Verfolgung ihrer Intellektuellen begleitet von restriktiven Gesetzen gegen gewerkschaftliche Organisierung mit dem 1980er Militärputsch thematisiert, der die Zurückdrängung kollektiver Handlungsfähigkeit der ArbeiterInnen erwirkte. Informalität wird als zentraler Faktor für den Bedeutungsgewinn der Religion in der Regulierung der Beziehungen zwischen den Klassen identifiziert. Auf diesen Zusammenhang werde ich in der späteren Diskussion zur Bestimmung der Rolle der Religion im Projekt der AKP näher eingehen.

Zum historisch-materialistischen Ansatz gehört auch die Bestimmung von Religion als organisationelle Ressource, die eine netzwerkbildende Funktion für Unternehmer erfülle. Cengiz sieht die Attraktivität der in den 1990er Jahren an Popularität gewinnenden islamischen Gemeinschaften für die Unternehmer in der Bildung von sozialen Netzwerken (Cengiz 2013). Über den religiösen Aspekt hinaus seien die Gemeinschaften in die Organisation politischer und ökonomischer Aktivitäten involviert und böten eine Plattform oder Börse für geschäftliche Kontakte. Diese Form könne bis zur Symbiose zwischen Gemeinschaften und politischen Funktionären reichen. Dargelegt wird somit, dass sich die Bourgeoisie parallel zu ihrem ökonomischen Aufstieg nicht nur in Verbänden und politischen 
Parteien, sondern auch in anderen Formen wie informellen Gemeinschaften und formellen Vereinen organisiert, die ihr weitere Möglichkeiten der Einflussnahme auf das politische und kulturelle Leben eröffnen. Insbesondere im Zuge der neoliberalen Privatisierungspolitik träten die Finanzierung von Schulen, Moscheen, Gesundheitszentren, die Vergabe von Stipendien und Organisierung von Armenhilfe hervor, wodurch sie ihren gesellschaftlichen Einfluss festigen könne (Doğan 2009a). Ferner wird ein psychologischer Faktor hervorgehoben. Die Spenden, die die Gemeinschaften einsammeln, und die Einbettung von Handlungen in religiöse Deutungen verschafften den gläubigen Unternehmern eine gewisse Erleichterung angesichts der täglichen Konfrontation mit Geldgeschäften, die ihnen moralische Probleme bereiteten. Religiöse Handlungen verschafften ihnen das Gefühl von Tugendhaftigkeit und Anständigkeit in einer »schmutzigen « Geschäftswelt, die sie $\mathrm{zu}$ Handlungen zwinge, hinter denen sie moralisch zumindest teilweise nicht stehen konnten. Sie fungierten ebenso wie andere religiöse Instanzen als Mittler, die Widersprüche zwischen religiösen Überzeugungen und zuwiderlaufenden alltäglichen Praktiken befriedeten. Dies könne durch eine Fatwa oder eine Billigung geschehen, die von einer religiösen Autorität ausgesprochen werde, so zum Beispiel zwecks Legitimierung verzinster Kredite (Cengiz 2013: 362ff.). Die Verbindung religiöser Gemeinschaften zur Bourgeoisie wird vor diesem Hintergrund begriffen als ideologische und organisationelle Ressource, die auch eine psychologische Bedeutung einnehmen kann.

Die Netzwerkthese knüpft an eine ältere Studie von Ayşe Buğra ${ }^{47}$ an, die mit Blick auf MÜSİAD das Entstehen einer islamischen Subökonomie konstatierte, zu der sie auch Marketingstrategien zählte, die mit Bezug auf die Religion die Vorzüge bestimmter Waren anpriesen. Neben der »muslimischen « Kleidung und den nach bestimmten Regeln zubereiteten »halal« Lebensmitteln umfasse die Palette alle erdenklichen Konsumgüter, die mit islamischen Symbolen versehen wurden. Der Slogan, dass »auch Muslime es verdient haben, gut zu leben«, untermauere das Bemühen, eine Kompatibilität zwischen Glauben und kapitalistischer Lebensweise herzustellen. Buğra hebt den exkludierenden Charakter dieser Verschränkung von Marketing und islamischer Identitätsbildung hervor:

»Der Islam erscheint als eine wichtige Ressource, um den Marktanteil der Mitgliedsunternehmen von MÜsiAD zu erhöhen [...] Die Mobilisierung dieses Typs von Kapital basiert signifikant auf personalen, informellen Beziehungen, die weitgehend auf kulturellen Identitäten beruhen, die daran ausgerichtet sind,

47 Ayşe Buğra war eine der ersten, die eine Studie über MÜsiAD veröffentlichte. Sie verfolgt keinen historisch-materialistischen, sondern einen staatszentristischen Ansatz. Ihre Arbeit wird trotzdem an dieser Stelle unter Bezug auf ihre empirischen Ergebnisse angeführt. 
die Nicht-Religiösen auszuschließen wie auch die Religiösen einzuschließen.« (Buğra 1998: 532, Übersetzung E.B.)

\subsubsection{Religion als Herrschaftstechnik und Kohäsionsmittel}

Eine weitere Position im Rahmen des historisch-materialistischen Ansatzes begreift das AKP-Projekt als neoliberalen Populismus, konzipiert als eine Herrschaftstechnik, die das Lokale (Islam) über die AKP mit dem Globalen (Neoliberalismus) verbindet. Die AKP erscheint in diesem Licht als lokale Vertreterin der globalen Partei des Neoliberalismus. Ähnlich wie in der Säkularisierungsthese diskutiert, wird der Zugriff auf islamische Muster als instrumentell gewertet, um Herrschaft $\mathrm{zu}$ begründen (Yıldırım 2009). Religion wird als Instrument zur Beherrschung subalterner Klassen, als identitätsbildendes Mittel zur Überbrückung von Klassenspaltungen und Herstellung nationaler Einheit sowie als hegemonialer Diskurs konzipiert. Diese Perspektive schließt an das Argument an, wonach die neoliberale Transformation nach dem Militärputsch von 1980 eine strukturelle Begrenzung von Politik auf ein Mittel zur Generierung von Zustimmung für die Dominanz des Kapitals (Güveloğlu 2004; Türk 2004) und eine Verschiebung politischer Auseinandersetzungen auf das außer-ökonomische Feld der Identitätspolitiken anstrebte (Akça 2014; Yalman 2002).

Aus den Arbeiten, die die Religion als Mittel zur Kohäsion begreifen, sticht die Interpretation von Cenk Saraçoğlu hervor, der das Nichtaufgreifen des islamistischen Diskurses durch die AKP in ihren Anfangsjahren als taktisches Manöver einschätzt, um Skeptiker zu überzeugen, dass sie sich von den islamistischen Zielen der Milli Görüş Bewegung abgewandt hatte (Saraçoğlu 2011). Die AKP habe Vertrauen zu den internationalen Bündnispartnern aufbauen und die nicht nur im Inland vorhandenen Bedenken zerstreuen müssen, die Partei könnte insgeheim eine islamistische und antidemokratische Agenda verfolgen und die von der Milli Görüş Bewegung Mitte der 1990er Jahre bereits einmal ausgelöste Krise innerhalb des bürgerlichen Machtblocks erneut provozieren, als die mit ihr assoziierten Kapitalgruppen die Dominanz des etablierten Finanzkapitals infrage stellten (vgl. Doğan 2009a). Saraçoğlu thematisiert das Scheitern des Kemalismus an der Artikulation eines tragfähigen Hegemonieprojekts als Voraussetzung für den Erfolg der AKP, die bewusst nur bestimmte Aspekte der diskursiven Strategie der Milli Görüş Bewegung fortsetzte. Sie kanalisierte die in Krisenzeiten stärker werdende Unzufriedenheit mit dem bestehenden System gegen die angeblich volksfremde und egoistische Elite, mit der der Kemalismus und die CHP identifiziert wurden. Das Anprangern eines unmoralischen Materialismus des Finanzkapitals gehörte ebenfalls dieser Strategie an. Als qualitative Neuerung der AKP sieht Saraçoğlu die Artikulation eines islamischen Konservatismus an, der die Definition der Nation von einer ethnischen $\mathrm{zu}$ einer religiös-konservativen Fundierung verschiebt und 
dabei auf eine "glorreiche« osmanische Vergangenheit rekurriert. Durch die Hervorhebung einer gemeinsamen Unterdrückungsgeschichte durch den Kemalismus und den Rekurs auf eine verbindende islamische Identität solle die ethnische Spaltung zwischen Türken und Kurden überwunden werden. Die Religion ist aus dieser Sicht ein ideologisches Mittel zur Herstellung nationaler Einheit und Einhegung der säkularen kurdischen Bewegung und ihrer Autonomieziele.

\subsubsection{Faubourgeoisie}

Einen besonderen Weg in der Bestimmung des Verhältnisses zwischen politischem Islam und den gesellschaftlichen Klassen beschreitet Utku Balaban, der den politischen Islam in Verbindung zu einer relativ eigenständigen Klasse bringt, die er über eine theoretische Explikation des Akkumulationsprozesses bestimmt (Balaban 2013). Die informelle und dezentralisierte Produktionsstruktur in der Türkei bedinge, dass eine Mittelklasse zwischen der Bourgeoisie und dem Proletariat entstanden sei, die Kontrolle über einen erheblichen Teil der Arbeitskräfte ausübe. Diese Klasse, die Balaban mit Referenz auf Henri Pirenne als Faubourgeoisie bezeichnet und auf der gleichen Ebene mit dem Kleinbürgertum und der Technokratie als eine dritte Mittelklasse ansiedelt, definiert er über ihre Funktion im globalen Kreislauf der Kapitalverwertung. ${ }^{48}$ Die Faubourgeoisie nehme in der Verwandlung von produktivem Kapital zu Warenkapital eine entscheidende Stellung ein. Als Mitglieder dieser Klasse bestimmt Balaban anhand empirischer Erhebungen in Istanbul vornehmlich Handwerksbetriebe, kleine Händler, Ladenbesitzer, Haus- und Wohnungsvermieter. $\mathrm{Zu}$ ihr gehörten aber auch informelle Arbeitskraftvermittler, die dafür sorgten, dass Arbeitskräfte dort eingesetzt werden können, wo sie aktuell gebraucht werden. Als typische Wirkungsstätten dieser Vermittler führt er die zahllosen Ateliers in der Textilproduktion an, die je nach Auftragslage zehntausende Arbeitskräfte kurzfristig »einstellen« und wieder »entlassen« könnten. Ähnliches gelte im Bausektor und im kleinsten Maßstab für Heimarbeit, die in einer Art Verlagssystem organisiert sei (ebd.: 35f.). Nach Balaban zieht diese Klasse

48 Balaban referiert Pirenne, der die mittelalterliche Stadt als historische Entwicklungsstätte der Bourgeoisie untersuchte. Demzufolge bezog die Bourgeoisie ihre Bezeichnung aus dem französischen Wort »bourg«, also dem mittelalterlichen »Städtchen«. Die »ursprüngliche« Bourgeoisie habe sich als die Klasse konstituiert, die innerhalb der Stadt(mauern) angesiedelt war. Eine nähere Betrachtung der proto-industriellen Entwicklung dieser Städte liefere Hinweise, dass sich im Laufe der Zeit eine »Vorstadt« - »faubourg« - herausbildete, in der sich Händler und Handwerker ansiedelten, die Produktion und Handel organisierten, während die Bourgeoisie in den Städten den Finanz kontrollierte (Balaban 2013: 39f.). Die Bezeichnung Faubourgeoisie folgt dieser Beschreibung, die sie für die Gegenwart nutzbar zu machen versucht. 
einen besonderen Vorteil aus ihrer Stellung im Prozess der Kapitalverwertung, insofern ihre Mitglieder sich in unmittelbarer räumlicher und biographischer Nähe zu den ArbeiterInnen, die zum größten Teil aus BinnenmigrantInnen bestehen, befänden. Die Mitglieder der Faubourgeoisie lebten in den Arbeitervierteln und die meisten könnten als soziale Aufsteiger identifiziert werden. Sie gehörten früheren Generationen von ArbeitsmigrantInnen an, die die Lebensgestaltung der späteren Generationen - ihre Wünsche, Sorgen und Nöte - noch aus eigener Erfahrung gut kennten. ${ }^{49}$ Die Nähe bedinge Präsenz im gesamten Alltag, nicht nur in der Produktionsstätte, sondern auch an den Orten der Reproduktion (Freizeit, Konsum, Wohnen), wodurch das Netz der Kontrolle über die Arbeiter(-viertel) sehr dicht gewoben sei (ebd.: 45ff.). Der politische Islam gebe dieser Kontrolle nicht nur ihre ideologische Gestalt, vielmehr habe diese Klasse den Diskurs des politischen Islam adaptiert, um ideologische Kontrolle über das Proletariat beziehungsweise die sich im Proletarisierungsprozess befindlichen Millionen an BinnenmigrantInnen aus der Bauernschaft herzustellen. Aus dieser Kontrolle beziehe sie die Macht, mit der Bourgeoisie über einen größeren Anteil am Mehrwert verhandeln zu können. Die Bourgeoisie definiert Balaban in Abgrenzung zur Faubourgeoisie über die Fähigkeit, den Preis der produzierten Ware auf dem globalen Markt bestimmen zu können.

In gewisser Weise konzipiert Balaban die Faubourgeoisie also als subalterne Bourgeoisie, während er gleichzeitig eine Analogie zur Fraktionierung zwischen Finanzkapital und anderen Kapitalfraktionen herstellt. Zur Faubourgeoisie zählt er auch größere Fabrikanten, die als Auftragsfertiger (Contract Manufacturer) an einem Ende der globalen Wertschöpfungskette stehen. Nach Balaban ist die Faubourgeoisie eine Klasse, die im globalen Maßstab überall dort auftaucht, wo eine ähnlich dezentralisierte und informelle Produktionsstruktur, die eine große Masse an Arbeitskräften einschließt, existiert. Explizit verweist er auf das Entstehen und Wirken dieser Klasse in China, die dort einen chinesischen Nationalismus adaptiert habe, während sie in den früh entwickelten Industrieländern nicht mehr oder kaum präsent sei. Letzteres bedinge, dass die Formierung dieser Klasse bisher theoretisch nicht erfasst wurde. Sie wurde verkannt, weil nach wie vor die frühen

49 Cengiz kommt in seiner Studie über die Entwicklung der Bourgeoisie in Kayseri zu einem ähnlichen Befund. Insbesondere die ältere Generation der Unternehmer kenne die Abläufe des Produktionsprozesses, die Arbeitsbedingungen, Sorgen und Nöte, Gefühle und Denkweise der Arbeiter aus eigener Erfahrung. Es gelinge ihnen deshalb, die Arbeiter besser zu kontrollieren und zu motivieren. Zugleich hätten sie ein scharfes Bewusstsein im Hinblick auf ihre neue Klassenposition entwickelt. Ungleichheit verteidigten sie als natürliche Ordnung, die sie wortreich mit Allegorien aus dem alltäglichen Leben unterlegten, ohne ihre Klassenposition zur Schau zu tragen. Ihre Kleidung, Rede- und Verhaltensweisen befänden sich in Nähe zur Arbeiterschaft (Cengiz 2013: 311ff.). 
Industriezentren die empirische Grundlage für die klassentheoretische Wissensproduktion bildeten. Schließlich sei die spezifische und konjunkturelle Prägung des politischen Islam in der Türkei durch die Bedürfnisse dieser Klasse bestimmt, deren Entstehen zwar im globalen Maßstab beobachtet werden könne, deren unmittelbare Reproduktionsbasis aber der Nationalstaat sei. Infolgedessen sei der politische Islam auch keine internationale beziehungsweise länderübergreifende Bewegung, die Klassengrundlage des politischen Islam müsse für jeden nationalen Raum im Einzelnen bestimmt werden. Dass der politische Islam die Ideologie der Faubourgeoisie in der Türkei bilde, bedeute nicht, dass dies auch in anderen Ländern der Fall sein müsse.

Der Verhandlungsprozess und die Entwicklungsdynamik der Faubourgeoisie, von der einige Mitglieder nach und nach zur Bourgeoisie aufgestiegen seien, bestimmen nach Balaban seit geraumer Zeit die politischen Kämpfe des Landes. Parallel zu ihrem Kampf mit der Bourgeoisie ringe die Faubourgeoisie auch mit dem Kleinbürgertum, der historischen Trägerin bürgerlicher Hegemonie, das inzwischen erheblich geschwächt und von der Faubourgeoisie abgelöst worden sei. Nach Balaban präge der Kemalismus die Ideologie des Kleinbürgertums, das sich aus klassischen Intellektuellen - Akademiker, Künstler, Journalisten, Werbefachleute zusammensetze und deren Rolle im Kreislauf des Kapitals darin bestehe, den Verwandlungsprozess von Warenkapital in Geldkapital zu ermöglichen. Balaban stellt also eine Korrespondenz zwischen ideologischen Friktionen, Klassenakteuren und Berufsgruppen her. Abweichend von der bisher besprochenen Literatur sieht er die hauptsächliche Konfliktachse nicht innerhalb der Bourgeoisie, also zwischen zwei Fraktionen der Bourgeoisie repräsentiert durch MÜSİAD und TÜSİAD verlaufen, sondern zwischen zwei relativ eigenständigen Klassen. Die Innovation seines Ansatzes besteht darin, Zwischenklassen in die historisch-materialistische Analyse einzuführen, die in Bezug auf die Türkei dazu tendiert, in der Analyse von Kräfteverhältnissen nur zwei antagonistische Hauptklassen zu kennen: die Bourgeoisie und das Proletariat.

\subsubsection{Kemalismus}

Der politische Islam wird also in der Regel als eine Bewegung der Bourgeoisie oder einer mit ihr assoziierten beziehungsweise konkurrierenden Mittelklasse begriffen. Im Gegensatz zur staatszentristischen Literatur bemerkenswert vernachlässigt wird in historisch-materialistischen Ansätzen die Auseinandersetzung mit dem Kemalismus in Verbindung zu den gesellschaftlichen Klassen. Während in manchen Arbeiten der Kemalismus mit dem Staat identifiziert wird (Cengiz 2013: 165), allerdings ohne eine tragende theoretische Rolle zu erhalten, oder wie bei Saraçoğlu auf der ideologischen Ebene als gescheitertes Hegemonieprojekt der Bourgeoisie begriffen wird, thematisieren nur wenige Autoren seine Verbindung zu den 
Klassen mit der gleichen Bestimmtheit wie beim politischen Islam (Oğurlu/Öncü 2015; Öztürk 2015). Neben Balaban, der den Kemalismus dem Kleinbürgertum zurechnet, gehört zu diesen Autoren Sungur Savran, der den Kemalismus so wie in den staatszentristischen Ansätzen mit einer »westlich-laizistischen« Fraktion des Kapitals zusammenbringt. Allerdings fasst er diese Verbindung nicht als Ausdruck einer sa-normalen k kapitalistischen Entwicklung, in der der Kemalismus den Staat symbolisiert, sondern als Folge einer sich bereits im 19. Jahrhundert herauskristallisierenden strategischen Entscheidung der Bourgeoisie, einen Anschluss an die europäischen Akkumulationszentren herzustellen. Nicht die Bourgeoisie ist hier dem Kemalismus untergeordnet, sondern der Kemalismus wird als eine Bewegung der Bourgeoisie gesehen, die zur Verwirklichung ihrer Entwicklungsziele ein umfassendes kulturelles Reformprogramm durchsetzte, das auch eine Entscheidung für den Laizismus beinhaltete (Savran 2015).

\subsubsection{Islamismus als eigenständige Klassenbewegung}

Eine Abweichung von diesen Auffassungen, die den politischen Islam über die Vermittlung zu den besitzenden Klassen begreifen, stellt eine zweite besondere Herangehensweise dar, die von Ergin Yıldızoğlu vorgebracht wird, der den politischen Islam unabhängig von der islamischen Bourgeoisie oder Mittelklasse als eigenständige Klasse definiert, die keine materiellen, wohl aber symbolische Produktionsmittel besitze (Yıldızoğlu 2016: 121f.). Das symbolische Mittel dieser Klasse bestehe aus der Kontrolle über religiöses Wissen, über das sie sich Zugang zur gesellschaftlichen Mehrarbeit beziehungsweise zu materiellen Mitteln verschaffe. Dass die Kontrolle über die Religion mittelbar die materielle Reproduktionsgrundlage dieser Klasse bilde, ohne selbst materiell zu sein, bedinge, dass sie das Bewusstsein einer Klasse entwickele. Um ihre Reproduktion zu sichern, versuche die die Klasse anführende Fraktion, die Yıldızoğlu als muslimische Intelligenzija bezeichnet, die Regulation der gesellschaftlichen Produktions- und Reproduktionsbeziehungen in Übereinstimmung zur Reproduktion ihres symbolischen Mittels - der Religion zu bringen. Die AKP sei die Vollzieherin dieses Prozesses oder Programms, der sich als Kulturkampf realisiere und dessen Kern aus dem Aufbau eines biopolitischen Regimes bestehe. Darunter falle die biologische Reproduktion durch Kontrolle der Familie, der sexuellen Praktiken, der Ästhetik der Körper (Kleiderordnungen) sowie der Raum-Zeit-Koordinaten durch Festlegung von Gebetsstunden und Orten. Diese Klasse bringe zudem Netzwerke und Organisationen hervor, die über verschiedene Wege - öffentliche Subventionen und Aufträge, Steuererleichterungen, private Spenden - sich die gesellschaftliche Mehrarbeit aneigneten. Die Originalität dieser Überlegung, die nicht in theoretisch ausgearbeiteter Form vorliegt, besteht darin, die Dynamiken des kulturellen Projekts der AKP - eine sukzessive Islami- 
sierung aller Lebensbereiche - als von eigenständigen Klasseninteressen getrieben zu erfassen.

\subsubsection{Kritik der Klassenkampfthese}

Der historisch-materialistische Ansatz fragt nach der materiellen Reproduktionsgrundlage gesellschaftlicher Akteure. Für die Bourgeoisie wird diese Grundlage in der Aneignung des gesellschaftlichen Mehrwerts ausgemacht, verbunden mit der Verfügungsgewalt über die Produktionsmittel, die ihre Vormachtstellung begründet. Die Frage, wie die Rolle der Religion für das politische Projekt der AKP im Verhältnis zu den gesellschaftlichen Klassen begriffen werden kann, beantworten historisch-materialistische Ansätze unter dieser Voraussetzung damit, dass sich die AKP der Religion bedient, um die Vormachtstellung der Bourgeoisie ideologisch zu festigen. Religion wird nicht primär als a-politische kulturelle Form wie im staatszentristischen Ansatz, sondern als politisiertes Mittel zur Überbrückung von Klassenspaltungen und Herstellung von Hegemonie begriffen. Konzeptuell kommt der Religion eine nachgeordnete Rolle zu, sie verfügt über keine eigenständige Dynamik, fungiert nicht als Motivatorin oder Modifikatorin unternehmerischer Initiative. Ihre Bedeutung gewinnt sie durch den Wert, den ihr die Mitglieder der herrschenden Klassen in der Erfüllung der Aufgabe der Hegemoniebildung sowie hinsichtlich organisationeller und psychologischer Bedürfnisse beimessen. Diese Auffassung impliziert eine einseitige Beziehung zwischen den herrschenden Klassen und der Religion. Nahegelegt wird, dass die herrschenden Klassen die Religion jeder Zeit wieder fallen lassen können, es in ihrer Hand liegt, über den gesellschaftlichen Stellenwert der Religion zu bestimmen. Der Gegebenheit, dass die Religion institutionell verankert ist und von realen Akteuren getragen wird, deren materielle Reproduktion an die Reproduktion der Religion beziehungsweise ihrer gesellschaftlichen Bedeutung gekoppelt ist, wird kein oder nur ein geringes Gewicht beigemessen. Dass die Religion für eine große Zahl von Akteuren selbst ein Reproduktionsmittel darstellt, sie also eine relativ eigenständige ökonomische Seite aufweist, wird in der Erfassung ihrer Rolle kaum berücksichtigt. Die gesellschaftliche Tragweite der Auseinandersetzung zwischen Islamismus und Kemalismus, die sich in der Form eines Kulturkonflikts äußert, bleibt damit unterbelichtet.

Einen assoziierten Diskussionspunkt stellt die Trennung zwischen dem Globalen (Kapitalakkumulation oder Neoliberalismus) und dem Lokalen (Kultur) dar. Einzuwenden ist erstens, dass der Begriff lokal zur Entnennung des Nationalen beiträgt, die dem neoliberalen Globalisierungsdiskurs entspringt, der die Auflösung des Nationalen propagiert. Da der Bezugspunkt für die diskutierten Ansätze aber explizit der nationale Raum ist, der bestimmte, durchlässige, konfigurierbare aber doch vorhandene Grenzen für die analysierten Prozesse - Kapitalakkumulation, Formierung von Klassen und ihrer Kämpfe - absteckt, ist auf dem Begriff 
National zu insistieren. Zweitens schwingt in dem Begriff eine statische und homogene Vorstellung von Kultur mit: Der Islam erscheint als ein kulturelles Fundstück, das die herrschenden Klassen für sich entdecken und instrumentalisieren. Diesen Einwand berücksichtigt zwar der Ansatz, den sunnitischen Islamismus als lokalen Signifikanten einer neuen Fraktion der Mittelklassen - der Faubourgeoisie - zu bestimmen. Nichtsdestotrotz irritiert die Verwendung des Begriffs lokal zur Charakterisierung des Islam als Ideologie oder Diskurs.

Balaban identifiziert einen spezifischen Klassenakteur, der sich über den politischen Islam politische Geltung verschafft. Anzumerken ist in diesem Zusammenhang zunächst, dass die in Abgrenzung zur Faubourgeoisie vorgenommene Definition der Bourgeoisie über einen speziellen Marktzugang (Bestimmung des Preises von Waren) wie auch die Zurechnung von Arbeitskraftvermittlern, Ladenbesitzern und Fabrikanten zu ein und derselben Klasse nicht hinreichend begründet ist (vgl. Arslan 2014). Sofern der politische Islam tatsächlich mit distinkten Klassenakteuren assoziiert sein sollte, die über ihre Stellung im Akkumulationsprozess identifiziert werden können, stellt sich ferner die Frage, in welcher Beziehung dieser Befund zur kulturellen und politischen Polarisierung steht, die sich in der Türkei auch räumlich durch die Herausbildung regionaler Schwerpunkte einzelner Parteien niederschlägt. Balaban übergeht diese Tatsache, wenn er eine Korrespondenz zwischen ideologischen Friktionen und den Fraktionen der Mittelklassen herstellt. Besondere Relevanz für diese Arbeit erlangt dies bei der Abgrenzung der Faubourgeoisie vom Kleinbürgertum. Die von Balaban angeführte Korrespondenz zwischen ideologischer und ökonomischer Position bei der Bestimmung dieser Fraktionen der Mittelklassen steht einerseits im Widerspruch zur Begebenheit, dass der politische Islam durchaus die von Balaban dem Kleinbürgertum zugerechneten Typen von Intellektuellen - Akademiker, Künstler, Journalisten, Werbefachleute - integriert. Andererseits steht die Zurechnung im Widerspruch dazu, dass der Kemalismus in bestimmten Bezirken großer Metropolen wie auch in etlichen Provinzen von Akteuren getragen oder unterstützt wird, die Balaban der Faubourgeoisie - Händler, Ladenbesitzer, Bauunternehmer etc. - zuschlägt. Dieser Einwand betrifft auch die kurdische Bewegung und ihre Parteien sowie die vierte größere Partei, die proto-faschistische MHP, die in bestimmten Gebieten stark vertreten sind oder sogar Mehrheiten bilden und dabei maßgeblich von kleinen Händlern und Ladenbesitzern unterstützt werden (vgl. Uysal/Topak 2010). Wird der Klassenbestimmung von Balaban Folge geleistet, so lässt sich im Widerspruch zu seiner These konstatieren, dass Mitglieder der Faubourgeoisie je nach Lokalität kemalistische, kurdisch-säkulare wie auch andere ideologische Positionen einnehmen können. Dies steht einerseits im Einklang mit der These, dass es sich um eine globale Klasse handelt, die unterschiedliche ideologische Erscheinungen auf nationalstaatlicher Ebene annehmen kann, verweist andererseits aber innerhalb der nationalstaatlichen Ebene auf Diskrepanzen zwischen Klassenpositionen, wie 
sie von Balaban über den Kapitalverwertungsprozess definiert werden, und politisch-ideologischen Positionen. Damit erodiert das Konzept, den politischen Islam als Ideologie der Faubourgeoisie zu bestimmen.

Von der bisherigen Kritik ausgenommen ist der Ansatz von Ylldızoğlu, den politischen Islam unabhängig von der islamischen Bourgeoisie als eigenständige Klasse, die keine materiellen, sondern symbolische Produktionsmittel besitzt, zu definieren. Ylldızoğlu reflektiert, dass die Religion für eine große Zahl von Akteuren ein Reproduktionsmittel darstellt, sie also eine ökonomische Seite aufweist. Die vorliegende Studie wird einen ähnlichen Ansatz entwickeln, für dessen Präzisierung die Kritik an Yıldızoğlus Ansatz behilflich sein wird. In Yıldızoğlus Ansatz wirft die Bestimmung dieser Akteure als Mitglieder einer Klasse theoretische Probleme auf. $\mathrm{Zu}$ fragen ist, inwiefern die Verfügung über immaterielle Produktionsmittel eine Klasse begründen kann und wie das dazugehörige Produktionsverhältnis begriffen werden soll, sofern Arbeitskräfte und Besitzer (»Intelligenzija«) des Produktionsmittels (Religion) sich nicht gegenüber stehen, sondern in eins fallen. Abstrahiert vom konkreten Gegenstand wird nahegelegt, Netzwerke und Kultur generell als Produktionsmittel in den Händen ihrer Mitglieder oder Träger zu fassen. Konsequenterweise müssten dann alle Akteure, die vermittelt über ihre kulturschaffende, ideologie- oder wissensproduzierende Kerntätigkeit irgendeine Form des Einkommens erzielen, als Mitglieder einer eigenständigen Klasse gefasst werden. Akteure, die solchen Tätigkeiten nachgehen aber nicht dem politischen Islam angehören oder ihm nicht zuarbeiten, müssten als weitere Fraktionen oder Klassen definiert werden. Ideologische Unterschiede und Nähe zu politischen Projekten und nicht die Stellung im Produktions- oder Akkumulationsprozess bildeten dann die Grundlage für die Bestimmung dieser Klasse(n). Im Zuge einer solchen Bestimmung müsste ein genauer Begriff zur Bezeichnung dieser Klasse(n) gefunden und ihre Beziehung zu den anderen Klassen, zur Bourgeoisie, zum Proletariat, zur Bauernschaft und möglichen anderen (Mittel-)Klassen, geklärt werden. Eine derartige Expansion des Klassenbegriffs in die Sphäre der Kultur- und Ideologiearbeit birgt das Risiko einer Erosion des Klassenbegriffs. Sie wirft gleichzeitig aber eine wegweisende hegemonietheoretische Frage bezüglich der Position von Kulturschaffenden und Ideologieproduzenten auf, die Gramsci als Intellektuelle fasste: Wie kann die Position und Bedeutung der intellektuellen Träger eines Hegemonieprojekts, sofern sie nicht als Mitglieder der Bourgeoisie bestimmt werden können, begriffen werden, ohne den Klassenbegriff überzustrapazieren? 


\subsection{Resümee des Forschungsstands und Präzisierung der Forschungsfrage}

An dieser Stelle sollen nun die Forschungsstränge mit Blick auf die Forschungsfrage, wie die Rolle der Religion für das politische Projekt der AKP zu begreifen ist, pointiert resümiert werden. Die Diskussion der Literatur zeigt, dass die Beantwortung der Frage sehr voraussetzungsvoll ist. Sie ist mit gesellschaftstheoretischen Grundsätzen verknüpft und eingebettet in kontroverse, diametral auseinanderlaufende Interpretationen der politischen Geschichte des Landes. Im Hintergrund der Kontroverse geht es um die generellere Frage, wie das Verhältnis zwischen politischen und bürokratischen Akteuren zu den gesellschaftlichen Klassen begriffen werden kann und welche Rolle Ideologien und kulturelle Praktiken in der Gestaltung dieses Verhältnisses spielen.

Im Wesentlichen konnten zwei widerstreitende Ansätze identifiziert werden. Der erste, der als staatszentristischer Ansatz gekennzeichnet wurde, diskutiert alle Fragen aus der Perspektive eines Kampfes zwischen dem Staat und der Gesellschaft. Im Rahmen der Kulturkampfthese, die dieser Ansatz hervorgebracht hat, wird die AKP mit einer konservativ-islamischen Bourgeoisie identifiziert, die die kulturellen Werte der Mehrheitsbevölkerung repräsentiert und einen neoliberalen Entwicklungspfad verfolgt, der als emanzipatives Element thematisiert wird. Den Gegenpart zur AKP bildet eine »kulturell marginale«, säkulare Elite, die sich in Verteidigung ihrer Privilegien gemeinsam mit einer von ihr protegierten Bourgeoisie gegen die neoliberale Demokratisierung stemmt. Die Interpretation wurde von der politischen Entwicklung nachdrücklich überholt und verwandelte sich in die Autoritarismusthese, ohne dass die Urheber sich dem theoretisch angeleiteten Scheitern ihrer Analysen stellten. Die AKP wurde stillschweigend von der Bourgeoisie gelöst und auf einen von der Gesellschaft isolierten Willen eines Potentaten reduziert. Die theologische These kann dem Staatszentrismus zugeordnet werden, obgleich sie der Religion ein größeres Gewicht verleiht, indem sie ihr eine rationalisierende Wirkung auf die Ökonomie und vermittelt darüber auf die Politik zuschreibt. Der historisch-materialistische Ansatz, der unter dem Sammelbegriff Klassenkampfthese diskutiert wurde, rückt Klassen- und Fraktionskämpfe ins analytische Zentrum. Als treibende Dynamik der politischen Entwicklung wird eine langfristig angelegte Erosion der parlamentarischen Demokratie und sozialer Rechte im Zuge neoliberaler Politik, die von der AKP fortgeführt wurde, bestimmt. Während der staatszentristische Ansatz Kultur als Marker für den ewigen Kampf zwischen Staat (autoritäre Kultur) und Gesellschaft (liberale Kultur) einsetzt, wird Kultur im zweiten Ansatz als politisiertes Mittel begriffen. Ihr wird eine hegemoniebildende, legitimatorische, organisierende Rolle in der Durchsetzung kapitalistischer Entwicklungsinteressen oder - als Sonderfall - eine kapitalbildende Funktion beigemessen. Zwischen den beiden Ansätzen bewegt sich die 
als Säkularisierungsthese gekennzeichnete Interpretation, die säkulare und gläubige Eliten identifiziert, die unterschiedliche kapitalistische Entwicklungswege in Nähe zum Staat die ersteren, in Nähe zur Bourgeoisie die letzteren - mit jeweils unterschiedlichen ideologischen und kulturellen Präferenzen organisieren.

Aus der kritischen Diskussion der Ansätze können folgende vorläufige Schlüsse für diese Arbeit gezogen werden:

- Das politische Projekt der AKP kann als ein Hegemonieprojekt bestimmt werden, das in den Beziehungen zwischen den Klassen und ihren Fraktionen begründet liegt und in Konkurrenz zu mindestens drei weiteren Hegemonieprojekten steht, deren politische Zentren von der CHP, der MHP und der kurdischen Bewegung gebildet werden.

- Islamismus bezeichnet eine politische Ideologie als integralen Bestandteil eines Hegemonieprojekts. Den Gegenstand islamistischer Praxis bildet die Gestaltung von Weltauffassungen und kulturellen Praktiken durch religiöse Bezüge. Der Begriff politischer Islam betont den organisierten Willen, religiös hergeleitete Auffassungen und Praktiken allgemeinverbindlich zu machen.

- Die politische Partei ist eine zentrale, organisierende Trägerin des Projekts, sie ist jedoch nicht die einzige. Verbände, Institutionen, kulturelle Organisationen, Netzwerke und soziale Gruppen treten in Verschränkung mit der Partei als Hegemonieträger auf. Sie nehmen intellektuelle Aufgaben wahr und bestimmen mit über die Reichweite des Projekts.

Quer zu den theoretischen Ansätzen konstatieren verschiedene Autoren einen Islamisierungsprozess. Im Rahmen des staatszentristischen Ansatzes wird dieser Prozess erst nach Dominantwerden des islamistischen Kulturkampfs als Problem erkannt. Zuvor bestimmen essentialistische Interpretationen den Ansatz, durch die die Islamisierung als natürliche Entfaltung eines ursprünglich-kulturellen Kerns der Gesellschaft erscheint, der sich gegen den vermeintlich von außen oktroyierten, "fremdartigen« Kemalismus durchsetzt. Nachfolgend dominieren instrumentalistische Interpretationen, die zu einer Bagatellisierung der Islamisierung tendieren, insofern sie sie als Oberflächenphänomen begreifen, hinter dem der Machtwille eines Potentaten steckt. Aus der Perspektive historisch-materialistischer Ansätze wird die Islamisierung dagegen vorwiegend als nebensächliche Begleiterscheinung im Zuge der Herstellung bürgerlicher Hegemonie begriffen.

Die Kritik an den Auffassungen zur Islamisierung lautet zusammengefasst, dass der Umstand, wonach die Religion ein zentrales Reproduktionsmittel für eine signifikante Anzahl an Akteuren geworden ist, die das Hegemonieprojekt der AKP tragen, durch die Fixierung auf einen Potentaten oder die Bourgeoisie ebenso unberücksichtigt bleibt wie die Tatsache, dass diese Akteure ihre gesellschaftliche Stellung sukzessive ausgebaut und gefestigt haben. Dies hat politisch zur Folge, 
dass der Anpassungs- und Assimilationsdruck, der vom konservativen Islamismus ausgeht, ebenso gering geschätzt wird wie die längerfristigen erzieherischen und bildenden Auswirkungen der islamistischen Agenda. Folglich bleibt in allen Ansätzen auch der Modus Operandi der Islamisierung - der Kulturkampf - unterbestimmt.

Die Dynamik hinter dem Phänomen »Islamisierung« ist bislang unzureichend bestimmt und erfasst worden. Auf der konzeptuellen Ebene stellt sich das Problem als Frage nach der Verbindung zwischen Religion, Politik und Ökonomie. Indem instrumentalistische Ansätze eine prinzipielle Äußerlichkeit konstruieren, können sie den spezifischen Charakter der Verbindung dieser Elemente nicht adäquat erfassen. Zur Bearbeitung des Problems muss die organisatorische und intellektuelle Entwicklungsgeschichte des Islamismus in der Türkei aus einer eigenständigen theoretischen Perspektive, die die materielle Reproduktion der Hegemonieträger berücksichtigt, rekapituliert werden. Die Frage nach der Rolle der Religion im politischen Projekt der AKP kann vor diesem Hintergrund präzisiert und eingegrenzt werden auf die Entwicklungsgeschichte von Hegemonieträgern unter dem Aspekt ihrer gesellschaftlichen Reproduktion. Im nächsten Kapitel erfolgt die Begründung der Wahl beziehungsweise der Beibehaltung der hegemonietheoretischen Perspektive, die zunächst nur heuristisch ergriffen worden war. 
Teil II - Theoretische Perspektive 



\section{Vorgehen}

Verschiedene Autoren haben darauf hingewiesen, dass der fragmenthafte, unabgeschlossene Charakter von Gramscis Werk, das zum größten Teil unter den schwierigen Bedingungen der faschistischen Haft entstand, eine besondere Offenheit für Interpretationen aufweist (Candeias 2007; Demirović 2007b; Opratko 2012; Thomas 2009). Die gleichen Begriffe erhalten in neuen Zusammenhängen neue Bedeutungen. Manche Begriffe werden ausformuliert und weiter entwickelt, andere liegen gelassen. Dies vorausgeschickt, sei betont, dass der folgende Abschnitt keine werkkritische Rekonstruktion leisten, sondern in erster Linie die von Gramsci eingenommene methodische Perspektive aufgreifen wird. In diesem Zuge werden unter Berücksichtigung ihrer Entstehungsbedingungen zentrale Begriffe und Konzepte, die in der Auseinandersetzung mit dem empirischen Gegenstand dieser Arbeit herangezogen wurden und mit denen die Theorierekonstruktion begonnen wurde, systematisch erörtert.

Im Anschluss an die Darstellung und Diskussion der methodischen Perspektive und der herangezogenen Konzepte wird die aus der Pendelbewegung zwischen Empirie und Theorie hervorgegangene Modifikation der Hegemonietheorie diskutiert, die ein genaueres Erfassen des Untersuchungsgegenstands dieser Studie ermöglichte. Dies bedeutet, dass es sich bei den nachfolgenden Abschnitten schon um einen theoretischen Ausblick auf die aus der Theorierekonstruktion gewonnenen Ergebnisse dieser Studie handelt. Dass diese Fassung der empirischen Diskussion vorangestellt ist, bedeutet nicht, dass zuerst die Theorie entwickelt und dann die Empirie in sie eingepasst wurde. Das Voranstellen erfolgt, da die Trennung der theoretischen von der empirischen Diskussion eine strukturiertere Darstellung ermöglicht: in Auseinandersetzung mit der aktuelleren hegemonietheoretischen Diskussion, wie sie schon im Abschnitt zur Säkularisierungsthese begonnen wurde. Nichtsdestotrotz werde ich in der nachfolgenden Darstellung in Grundzügen auf die im vorangegangenen Abschnitt bereits skizzierte Forschungsproblematik eingehen und bei der späteren Diskussion des empirischen Falls kenntlich machen, wie ich zu meinen theoretischen Ergebnissen gelangt bin. 


\subsection{Hegemonietheorie als methodische Doppelperspektive ${ }^{1}$}

Als grundlegend für den Ansatz von Gramsci erachte ich die Fragestellung, in welcher Beziehung eine bestimmte gesellschaftliche Gegebenheit zur Produktion der materiellen Lebensbedingungen, infolgedessen $\mathrm{zu}$ den Verhältnissen, in die die Produktion eingelassen ist, steht. Diese Fragestellung verbindet die Begriffe, die Gramsci für die politische Analyse rund um das Konzept Hegemonie entwickelt. Aspekte der Kultur und der Ideologie, allgemeiner der Lebensweise werden unter der Perspektive betrachtet, wie sie mit der konkreten Organisation der Produktionsweise(n) verknüpft sind (vgl. Lauggas 2007). ${ }^{2}$ In Gramscis Hegemonie-Verständnis ist es immer eine in der Anordnung der Produktionsverhältnisse bestimmbare Klasse, die eine führende Rolle in der Organisierung von Hegemonie einnimmt (vgl. Demirović 2007b). Der Begriff Hegemonie bringt das Bestreben zum Ausdruck, eine freiwillige Gefolgschaft anderer Klassen für die Reproduktion oder Transformation bestehender Produktionsverhältnisse zu erreichen. Für die herrschenden Klassen bildet die in den Produktionsverhältnissen begründete Verfügungsgewalt über die Mittel zur materiellen Reproduktion einer Gesellschaft das Fundament ihrer Vormachtstellung. Eine die kapitalistische Produktionsweise charakterisierende Form dieser Verfügungsgewalt ist das Privateigentum an den Produktionsmitteln, die der Bourgeoisie den Zugriff auf die gesellschaftliche Mehrarbeit - die Ausbeutung der Arbeitskraft - ermöglicht. Auf die Mittel und Wege der Absicherung dieser Vormachtstellung aus der strategischen Perspektive ihrer Überwindung richtet sich das Hauptaugenmerk von Gramsci.

Die Überlegungen Gramscis zur historischen Entwicklung und Expansion einer Klasse gewähren einen geeigneten Einstieg in seine Begriffswelt. Gramsci unterscheidet zwischen der ökonomisch-korporativen Phase, in der das Bewusstsein einer Interessensolidarität zwischen den Mitgliedern einer Klasse vorhanden aber auf die ökonomische Sphäre begrenzt ist, von der politischen Phase, in der sie die korporativen Interessen überschreitet und beginnt, die politischen Institutionen nach ihren allgemeinen Bedürfnissen zu organisieren. In der politischen Phase bewirkt die aufsteigende Klasse »über die Einheitlichkeit der ökonomischen und politischen Ziele hinaus auch die intellektuelle und moralische Einheit « und stellt »alle Fragen, um die der Kampf entbrannt ist, nicht auf die korporative, sondern auf eine >universale< Ebene« (Gramsci 1991ff.: 1561). Sie universalisiert ihr Projekt, indem sie einen klassenübergreifenden Block über intellektuelle und moralisch-ethische

Der Abschnitt 4.1 (S. 98-103) enthält Formulierungen und Überlegungen, die auf einen zusammen mit Axel Gehring geschriebenen Artikel zurückgehen (s. Babacan/Gehring 2013). Ideologie begreife ich als ein Set zusammenhängender Ideen, die bestimmte Deutungszusammenhänge herstellen. Den Begriff Kultur verwende ich umfassender, er bezieht alle Praktiken tätiger Auseinandersetzung mit Welt ein und verweist auf die Art und Weise dieses Tätigseins. 
Führung herstellt, auf deren Grundlage politische und ökonomische Kompromisse gebildet werden.

Dem Bürgertum stellte sich die Einbindung und Mobilisierung subalterner Klassen zuerst im Kampf gegen die feudalen Klassen als politische Aufgabe (Adolphs/Karakayali 2007: 123). Fortan entwickelte es seine Erfahrung zu einer steten Führungspraxis, die als ein »Prozess der Verallgemeinerung von Interessen in einem instabilen Kompromissgleichgewicht « (Demirović 1992: 154) zusammengefasst werden kann. Hegemonie ist nach Gramsci expansiv, molekular und langfristig angelegt. Sie durchdringt die Erziehung, die Bildung, die Sprache, die Literatur, die Architektur usw. Der herrschenden Klasse gereicht es dabei zu einem strukturellen Vorteil, dass sie, indem sie über die materiellen Produktionsmittel verfügt, auch über die Mittel zur geistigen Produktion verfügt, »so dass ihr damit zugleich im Durchschnitt die Gedanken derer, denen die Mittel zur geistigen Produktion abgehen, unterworfen sind « (Marx/Engels 1981: 46).

Einer der prominentesten und zugleich missverständlichsten Begriffe, der bei Gramsci auf die verschiedenen konsensualen Einbindungsweisen subalterner Klassen über die Organisierung der Ideologie und der Kultur verweist, ist der der Zivilgesellschaft. Davon unterschieden ist die politische Gesellschaft, die den Bereich institutionalisierter Herrschaft fasst, die Gramsci durch Zwang charakterisiert sieht. Zusammen bilden sie den integralen Staat, der Konsens und Zwang umschließt. Missverständlich ist der Begriff aufgrund der gelegentlichen Verwechselung des gramscianischen Ansatzes mit liberalen Konzepten, in denen der Zivilgesellschaft ebenfalls eine herausgehobene Bedeutung zukommt. In liberalen Konzepten wird Zivilgesellschaft als eine Sammlung privater Akteure oder als ein freiheitlicher Ort begriffen, den das Bürgertum in Gegenüberstellung zum Staat, der die Herrschaft organisiert, errungen habe. ${ }^{3}$ Wie bereits angeführt, hat sich in der Türkei nach dem Putsch von 1980 eine Theorieströmung aus den Reihen der sozialistischen Bewegung herausgebildet, die den Zivilgesellschaftsbegriff entdeckte und mit der Idee verknüpfte, dass die Demokratisierung aufgrund der autoritären Staatstradition ausgeblieben sei, die jegliche autonome Entwicklung der Gesellschaft - explizit der Klassen - unterdrückte. Die Entwicklung einer normativ als freiheitlich definierten Zivilgesellschaft wurde unter Berufung auf Gramsci zur primären Bedingung für Demokratisierung erklärt, wofür die Organisationen der Bourgeoisie wie auch alle anderen Akteure, die als nicht-staatlich galten, in einer popularen Front vereinigt werden sollten (Belge 1983 u. 1998; Küçükömer 1994). Ein wichtiger theoretischer Grundstein der späteren Parteiergreifung liberaler Intellektueller für die AKP wurde zu dieser Zeit gelegt, als reaktionäre 
und faschistische Kräfte des Bürgertums - darunter auch die damaligen islamistischen Parteien - als Bündnispartner der Linken bestimmt wurden, da sie alle gleichermaßen vom Staat beziehungsweise dem Militär unterdrückt würden. Dass dieselben Kräfte seit den frühen 1960er Jahren die gewaltsame Bekämpfung sozialistischer und sozialdemokratischer Akteure im Rahmen antikommunistischer Kampagnen austrugen, verschwand hinter der Theorie (Çağlar 2000: 61ff.; Savran 1986). ${ }^{4}$ Die Botschaft dieser im politischen Diskurs der Türkei als »links-liberal« gekennzeichneten Strömung, die sich auf Gramsci berief, lautete in der Konsequenz, die durch den Putsch gestärkte Bourgeoisie und ihre Parteien noch mehr zu stärken. Die praktische Zerschlagung der Arbeiterbewegung im Zuge des Putsches wurde so durch die »links-liberale« Konfusion der Begriffe - folglich der mit ihnen verbundenen politischen Strategie - mit Theorie untermauert. In Auseinandersetzung mit diesem liberalen Zivilgesellschaftsverständnis bestimmten materialistische Theoretiker die Zivilgesellschaft ebenfalls als einen Ort des Bürgertums, aber nicht als einen der Freiheiten, sondern der Reproduktion bürgerlicher Herrschaft in Form »kapitalistischer Ideologie« (Türkay 1998). Die Zivilgesellschaft verstärkt dieser Auffassung nach Klassenherrschaft, ihre Herausbildung wird für jede Form der Demokratisierung als nachteilig erachtet (Savran 1986).

Gramscis Konzeption unterscheidet sich von beiden Auffassungen, die die Zivilgesellschaft als einen vom Staat geschiedenen bürgerlichen Ort - entweder freiheitlich geprägt oder herrschaftlich durchzogen - begreifen. Gramsci kritisiert die Identifizierung der Begriffe mit einem Ort oder einem Akteur als Verdinglichung einer methodischen Unterscheidung. Der Begriff, der die Realität begreifen helfen soll, legt sich über die Realität und wird mit ihr identisch gesetzt. Folgende Passage reflektiert das Problem:

»Der Ansatz der Freihandelsbewegung beruht auf einem theoretischen Irrtum, dessen praktischer Ursprung unschwer zu erkennen ist: nämlich auf der Unterscheidung von politischer Gesellschaft und Zivilgesellschaft, die aus einer methodischen Unterscheidung zu einer organischen gemacht und als solche dargestellt wird. So wird behauptet, die ökonomische Tätigkeit gehöre in die Zivilgesellschaft und der Staat dürfe nicht in ihre Regulierung eingreifen. Aber da in der Wirklichkeit der Tatsachen Zivilgesellschaft und Staat ein und dasselbe sind, ist festzuhalten, dass auch der Liberalismus eine `Regulierung`staatlicher Natur ist, eingeführt und aufrechterhalten auf dem Wege der Gesetzgebung und des Zwanges: er ist eine Tatsache des sich der eigenen Ziele bewussten Willens und nicht der spontane, automatische Ausdruck der ökonomischen Tatsache.« (Gramsci 1991ff.: 1566f.) 
Die Passage gibt den Hinweis, dass Begriffspaare wie politische Gesellschaft/Zivilgesellschaft, Zwang/Konsens Bestandteile einer methodischen Perspektive sind, darauf ausgelegt, die inhaltliche und formale Gestalt von Klassenherrschaft zu analysieren (vgl. Gramsci 1991ff.: 399; Haug 2004). Mit anderen Worten, die Begriffspaare betrachten den gleichen Gegenstand, nur unter zwei verschiedenen Perspektiven. Diesem Ansatz folgend ist von einer idealtypischen Trennung, die bestimmte Bereiche dem Konsens und andere dem Zwang zuordnet, Abstand zu nehmen (vgl. Opratko 2012: 39ff.; Thomas 2009: 159ff.). Andernfalls müssten ein Parlament, eine Regierung oder eine Armee als Teile der politischen Gesellschaft ausschließlich als zwangsbestimmt oder -ausübend gedacht werden, während Rassismus und $\mathrm{Pa}$ triarchat ihren Zwangs- und Gewaltcharakter verkennend als kulturelle Elemente der konsensbestimmten oder -ausübenden Zivilgesellschaft zugeschlagen werden müssten. Nicht das Objekt, sondern die Perspektive, die auf das Objekt eingenommen wird, ist ausschlaggebend: Ein Parlament kann unter dem zivilgesellschaftlichen Aspekt als Ort der Organisierung von Konsens betrachtet, in seiner Funktion als Legislative dagegen der politischen Gesellschaft zugerechnet werden. Das Militär kann ebenso wie eine politische Partei Konsens organisieren, gleichzeitig die Regierung stellen und Gewalt ausüben. Nochmals zu betonen ist, dass die Begriffe nicht identisch mit der Realität zu setzen, sondern als Werkzeuge zu begreifen sind, um die Durchsetzungsformen klassenförmiger Vergesellschaftung als historisch und kulturell spezifische, umkämpfte Bedingungsverhältnisse zu analysieren (vgl. Adolphs/Karakayali 2007). Eine weitere Passage aus den Gefängnisheften hebt diesen konzeptionellen Grundsatz hervor:

»Ein anderer festzumachender und zu entwickelnder Punkt ist derjenige der >Doppelperspektive im politischen Handeln und im staatlichen Leben. Verschiedene Ebenen, auf denen die Doppelperspektive auftreten kann, von den elementarsten bis zu den komplexesten, die sich aber, entsprechend der tierischen und menschlichen Doppelnatur des Machiavellischen Zentauren, theoretisch auf zwei grundlegende Ebenen reduzieren lassen, des Zwangs und des Konsenses, der Autorität und der Hegemonie, der Cewalt und der Kultur, des individuellen Moments und des universellen (der \Kirche und des `Staates ), der Agitation und der Propaganda, der Taktik und der Strategie usw. Manche haben die Theorie der >Doppelperspektive` auf etwas Beschränktes, Banales reduziert, auf nichts weiteres nämlich als auf zwei Formen von >Unmittelbarkeit‘, die mechanisch mit größerer oder geringerer > Nähe in der Zeit aufeinander folgen. Statt dessen kann es vorkommen, dass, je mehr die erste >Perspektive` sam unmittelbarsten<, am elementarsten ist, desto >ferner ( (nicht in der Zeit, sondern als dialektisches Verhältnis), komplexer, höher die zweite sein muss, das heißt, es kann wie im menschlichen Leben vorkommen, dass ein Individuum, je mehr es die eigene unmittelbare körperliche Existenz zu verteidigen gezwungen ist, um so mehr alle komplexen und höchs- 
ten Werte der Kultur und der Menschheit verficht und sich auf ihren Standpunkt stellt.«(Gramsci 1991ff.: 1553f.)

Die Einnahme dieser Perspektive bedingt, Zwang und Konsens nicht als äußere Grenzen eines Herrschaftsmodus zu begreifen, die sich gegenseitig aufheben können, sondern stets aufeinander zu beziehen. An die zitierte Passage anschließend heißt dies, dass struktureller Zwang, Diktatur und massive Gewalt nicht unbedingt auf eine »begrenzte Hegemoniefähigkeit« (Becker 2008) oder das Fehlen von Hegemonie verweisen, wie es für Gesellschaften der kapitalistischen (Semi-)Peripherie, zu denen die Türkei gezählt werden kann, geltend gemacht wird (Öncü 2003; Yalman 2002). Gerade die besondere Dichte eines Konsenses kann massive Gewalt ermöglichen, zudem auf strategische Schwächen derjenigen Kräfte verweisen, die der Gewalt ausgesetzt sind. ${ }^{5}$

Jedenfalls lässt die Ausübung von Gewalt die theoretische Perspektive, die zivilgesellschaftlichen Ankerpunkte von Klassenherrschaft in ihren historisch-kulturell spezifischen Ausprägungen aufzuspüren und in Verbindung zur konkreten Organisation der Produktionsweise zu analysieren, nicht von vornherein obsolet werden. Dass der »zivilgesellschaftlich« verankerte Konsens eine Möglichkeitsbedingung der Aufrechterhaltung des Zwangsapparats des bürgerlichen Staates und der militärischen Niederschlagung von Aufständen ist, ist für Gramsci vielmehr eine strategische Problematik, vor die er die kommunistische Bewegung gestellt sah. Sich des "stummen Zwangs der ökonomischen Verhältnisse« und der strukturellen Gewaltförmigkeit bürgerlicher Vergesellschaftung bewusst, stellt er sich dem Problem kollektiven Handelns innerhalb konkret vorfindlicher Gesellschaftsformationen (Scherrer 1998: 167). Seinen Reflektionen liegt die Erfahrung der westeuropäischen Arbeiterbewegung zugrunde, die den »revolutionären Moment« unmittelbar nach dem Ersten Weltkrieg nicht nutzen konnte und eine Niederlage erlitt (Buci-Glucksmann 1981: 179ff.). Offensive Strategien, die auf die Eroberung der Staatsmacht, also des Machtzentrums der »politischen Gesellschaft« zielten, misslangen, da die Hegemonie des Bürgertums zwar Risse bekommen hatte, aber nicht gebrochen war. Das Bürgertum vermochte es, eine Revolution, wie sie in Russland bereits im Gange war, zu verhindern. In der Schrift Einige Gesichtspunkte der Frage des Südens umreißt Gramsci (1986), wie das Bürgertum gegen die kommunistische Initiative, Proletariat und Bauern auf der Klassengrundlage zu vereinigen, die selbigen mit Folklore und Romantisierungen umgarnte, auf imperialistische und nationalistische Versprechen setzte und auf rassistisch geprägte Spaltungen und religiöse Weltauffassungen zugriff. Das Bürgertum kämpfte nach Gramsci jedoch son (1979) sowie bei Ranajit Guha (1997), einem Mitbegründer der Subaltern Studies Group (vgl. Babacan/Gehring 2013). 
nicht nur an der ideologischen Front, es ging darüber hinaus ökonomische und politische Kompromisse mit der Sozialdemokratie ein. Der kommunistischen Strategie griff es mit einer klassenübergreifenden Blockbildung, die politische, kulturelle und ökonomische Elemente umschloss, vor.

Der politische Gehalt der begrifflichen Trennung liegt also in einer die revolutionäre Strategie betreffenden Prioritätensetzung. Bevor die politischen Institutionen gestürmt werden konnten, von Gramsci als Bewegungskrieg bezeichnet, hätten die sozio-kulturellen Praktiken transformiert, ein Stellungskrieg in der "Zivilgesellschaft« zur Zersetzung des bürgerlichen Konsenses geführt werden müssen. Hierfür bedurfte es - im von Gramsci bemühten Militärjargon verbleibend - einer genauen Kenntnis der Schützengräben und Kasematten des Bürgertums, die in jedem Land auf historisch-kulturell spezifische Weise gestaltet waren. Im Westen, um auf die strategische Problematik zurückzukommen, verfügte das Bürgertum anders als in Russland über eine weitverzweigte »ideologische Struktur (Gramsci 1991ff.: 373). Hierunter begreift Gramsci eine materielle Organisation, die sich auf das gesamte Land erstreckt - bestehend aus Bibliotheken, Schulen, Zirkeln, Clubs, Sport- und Kulturvereinen, Architektur, Straßenanlagen etc. - und die darauf gerichtet ist, die theoretische und ideologische Front zu verteidigen und zu entfalten. In diesem Zusammenhang schreibt Gramsci, die Zivilgesellschaft in Russland sei »in ihren Anfängen und gallertenhaft" gewesen (ebd.: 874). Zwar lässt diese Aussage auch die Interpretation zu, wonach eine Zivilgesellschaft erst mit dem Bürgertum entsteht, die Einhaltung der methodischen Perspektive erfordert aber, sie in Beziehung zur Führungsfähigkeit der herrschenden Klassen zu setzen. Wenig entwickelt war so gesehen nicht die Zivilgesellschaft als ein vom Staat geschiedener Bereich, sondern die Zivilgesellschaft bürgerlichen Typs, also die ideologische Struktur, die das Bürgertum aufgebaut oder sich angeeignet/angepasst hatte, währenddessen die Führungsfähigkeiten des Feudaladels am Schwinden waren. Für diese Interpretation spricht ferner, dass Gramsci auch die feudalen Verhältnisse unter der Perspektive eines integralen Staates analysiert, mit der Betonung, dass die »zivilgesellschaftlichen « Funktionen im Feudalismus stärker monopolisiert gewesen, nämlich weitgehend von den »Kirchenmännern« ausgeübt worden seien, die »einige wichtige Dienstleistungen monopolisiert hatten: die religiöse Ideologie, das heißt die Philosophie und die Wissenschaft der Epoche, einschließlich der 
Schule, des Bildungswesens, der Moral, der Justiz, der Wohltätigkeit, der Fürsorge usw.« (ebd.: 1498). ${ }^{6}$

\subsubsection{Politische Artikulation, Parteibildung und Intellektuelle}

Hegemonie gründet nach Gramsci auf der Fähigkeit einer Klasse, ihre partikularen Interessen $\mathrm{zu}$ einem Allgemeininteresse $\mathrm{zu}$ formieren (vgl. Jessop 1982: 58, 100f., 131), indem sie ihre korporativen Interessen überschreitet und eine hegemoniale Verknüpfung zwischen ökonomischen, politischen und kulturellen Elementen herstellt. Für die Bezeichnung dieses Prozesses der Verknüpfung haben Ernesto Laclau und Chantal Mouffe den Begriff der Artikulation geprägt. Die Verknüpfung zwischen den Elementen ist ihnen zufolge nicht Ausdruck eines gemeinsamen Grundwesens wie der Klassenidentität, sondern das Resultat politischer Konstruktion durch Integration disparater Positionen (Laclau/Mouffe 1985: 108ff.). Kompromissbildung und Artikulation können diesem Verständnis folgend als zwei Seiten einer Medaille bestimmt werden. Artikulation ist immer vorläufig, so wie ein Kompromiss immer instabil ist und die Kämpfe nie still stehen. Artikulation wendet sich zugleich gegen die Vorstellung, dass der Gang der Politik mehr oder weniger bereits durch die soziale Struktur vorgeschrieben ist. Artikulation besagt, dass es einen Gestaltungsraum für Akteure gibt, Hegemonie zu organisieren, auch unter Bedingungen eklatanter sozio-struktureller Ungleichheiten innerhalb eines Landes, beispielsweise bedingt durch ein Nebeneinander verschiedener Produktionsweisen oder starke regionale Unterschiede. So kann strukturelle Ungleichheit sozialdemokratisch artikuliert werden, die Ursachen können der kapitalistischen Entwicklungslogik zugeschrieben und die Überwindung als staatliche Aufgabe formuliert werden. Sie kann liberal artikuliert und als ein Mechanismus des kulturellen Ausschlusses gedeutet werden, für die der Staat, dessen Zurückdrängung zugunsten des Marktes gefordert wird, verantwortlich gemacht wird.

Indes geschieht das Aufgreifen des Konzepts der Artikulation unter dem Vorbehalt, dass Hegemonie nach Gramsci nicht auf Bewusstseinsformen, Ideologie oder Diskurse zu reduzieren ist. Subalterne Gruppen entwickeln ein reales Interesse an der Aufrechterhaltung ihrer Position objektiver Unterwerfung, sie erwarten »reale Vorteile« (Candeias 2007: 19). So kann die in den Gefängnisheften von Gramsci thematisierte Verknüpfung zwischen Amerikanismus und Fordismus als eine spezifische Artikulation bestimmt werden, die mit der industriellen Massenfabrik einen

6 Dass die Doppelperspektive von Gramsci epochenübergreifend in Anschlag gebracht wird, schlägt sich auch in seinen religionsbezogenen Überlegungen nieder. Religion taucht in den Gefängnisheften auf unterschiedliche gesellschaftliche Konstellationen und Epochen bezogen »als Konsens stiftendes, auf Überzeugung setzendes, die Zustimmung der Beherrschten förderndes Moment im Ringen um kulturelle Hegemonie in der Zivilgesellschaft auf« (Steckner 2012: 12). 
bestimmten Arbeitertyp in Verbindung mit bestimmten kulturellen und sozialen Verhältnissen hervorbrachte (Haug 2007). Der sozialdemokratisch institutionalisierte Klassenkompromiss in der BRD kann ebenfalls als eine spezifische Artikulation bestimmt werden, in der die subalternen Klassen Bewusstseinsformen ebenso wie Organisationsweisen ausbildeten, die die kapitalistische Produktionsweise als Grundordnung akzeptierten (Röttger 2007).

Für die Analyse politischer Projekte und ihrer Träger bedarf es indes einer weiteren Operationalisierung des Konzepts der Artikulation, die durch die Konzepte "politische Artikulation« und »Hegemonieprojekt« erreicht werden kann. »Politische Artikulation« (De Leon/Desai/Tuğal 2009) besagt, dass es die Politik beziehungsweise miteinander streitende Politiken sind, die verschiedene Zusammenhänge zwischen Ökonomie, Politik und Kultur herstellen. Hierin ist auch der Hinweis enthalten, dass Hegemonie in verschiedene "Hegemonieprojekte zerfallen kann, die sich durch unterschiedliche Medien und Inhalte der Vermittlung von Konsens und Kompomissen auszeichnen sowie sich tendenziell in größerer oder geringerer Nähe zu bestimmten Klassen(-fraktionen) und ihren Entwicklungszielen befinden können. Tendenziell bedeutet, dass die Nähe nicht strategisch-bewusst hergestellt sein muss, sie kann auch einen spontanen Charakter aufweisen, indem sie wie selbstverständlich sich innerhalb eines bestimmten Möglichkeitsraums bewegt (Kannankulam/Georgi 2012: 34). ${ }^{7}$

In bürgerlichen Nationalstaaten nehmen politische Parteien eine zentrale Stellung bei der Artikulation von Hegemonieprojekten ein (vgl. De Leon/Desai/Tuğal 2009). Gramscis Reflektionen über die Bildung von Parteien setzen indes an einem vorgeordneten Punkt an. Bestimmend ist wiederum die Doppelperspektive: Parteibildung wird als die Herausbildung eines Kollektivwillens, der sich wie ein Netz grundlegender Übereinkünfte in der Gesellschaft verästelt und an dessen Formierung unterschiedliche Akteure beteiligt sind, sowie als die Formierung einer politischen Partei, die sich als spezifisch bürgerlicher Organisationstyp auf der Grundlage des Kollektivwillens erhebt, betrachtet. So rückt die organisierende und bildende Funktion von Parteien unter dem Aspekt der Reorganisation und Neubildung vorhandener »Kollektive« in den Vordergrund (vgl. Elfferding 1983: 24). Dieser Ansatz lässt Gramsci Parteien vor allen organisatorischen und institutionellen Grenzen untersuchen. Eine Zeitung, wissenschaftliche Einrichtungen, einzelne Intellektuelle können ebenso Partei sein - im basalen Sinne des Ergreifens eines Stand-

Ich greife den Begriff »Hegemonieprojekt« aus der Studie von Kannankulam und Georgi (2012) auf. Hierbei beziehe ich mich in erster Linie auf die begriffliche Abgrenzung zum in der gramscianischen Literatur gebräuchlicheren Begriff des »hegemonialen Projekts«. Letzterer impliziert eine erfolgreich etablierte Vorrangstellung eines Projekts, während der Begriff »Hegemonieprojekt« betont, dass das Ausmaß, in dem ein Projekt sich etabliert hat, variieren kann. Für eine weitergehende historisch-materialistische Fundierung des Begriffs siehe Buckel u.a. (2017: 16ff.). 
punkts auf dem Boden bestimmter gesellschaftlicher Verhältnisse - wie die juristische und organisatorische Form der Partei selbst. Ihre Plausibilität gewinnt die Doppelperspektive zum einen dadurch, dass die verschiedenen Kanäle und Netze der »Zivilgesellschaft« ebenso Hegemonie artikulieren wie eine politische Partei. Zugleich ist letztere in der Regel selbst eine komplexe Einrichtung mit zahlreichen Verästelungen. So zeigt schon ein Blick auf das Personal einer Partei die Verschränkung verschiedener gesellschaftlicher Funktionen oder Rollen: Kaum eine Partei und erst recht keine Massenpartei besteht aus reinen Funktionären, ihr Personal setzt sich aus verschiedenen (Berufs-)Gruppen zusammen, die parallel zur Parteitätigkeit verschiedene gesellschaftliche Aufgaben wahrnehmen. Zum anderen ist die Perspektive unterfüttert durch Untersuchungen zum Aufstieg der bürgerlichen Klasse. So griff beispielsweise die italienische Bourgeoisie beim Fehlen einer breiten Massenbasis und einer mächtigen Vereinheitlichung auf "Quasi-Parteien « wie die Freimaurer-Logen zurück, um die Kirche - »den Hegemonie-Apparat der vorangegangenen Gesellschaft « (Buci-Glucksmann 1981: 101) - zu bekämpfen. ${ }^{8}$ Als ein anderes Beispiel für »Quasi-Parteien« thematisiert Gramsci die Bewegung um den Philosophen Benedetto Croce, der eine liberale kulturelle Bewegung anführte, indem er maßgeblich eine Weltauffassung formulierte, die verschiedene bürgerliche Gruppen vereinte (ebd.).

Schließlich steht die Doppelperspektive auf den Parteibildungsprozess im $\mathrm{Zu}$ sammenhang mit der Prämisse, dass Führung zugleich politisch und intellektuell sein muss. Die führende Gruppe muss, um führend zu werden, sich in allen Bereichen organisieren, sie muss ihre Führung verallgemeinern. Für die Verallgemeinerung von Führung bedarf es einer großen Masse an aktiven Trägern, die Gramsci unter dem Begriff des Intellektuellen zusammenfasst. Zwar sind nach Gramsci alle Menschen Intellektuelle, denn jede Tätigkeit bedarf des Denkens, es erfüllen aber nicht alle Menschen die Funktion des Intellektuellen. Von ihrem gesellschaftlichen Sein, ihrem Platz in den Produktionsverhältnissen aus betrachtet, ordnen sich die Intellektuellen einer gewissen Arbeitsteilung ein, sie üben Funktionen aus:

»]ede gesellschaftliche Cruppe schafft sich, während sie auf dem originären Boden einer wesentlichen Funktion in der Welt der ökonomischen Produktion entsteht, zugleich organisch eine oder mehrere Schichten von Intellektuellen, die ihr Homogenität und Bewusstheit der eigenen Funktion nicht nur im öko-

8 Zur Rolle der Katholischen Kirche schreibt Cramsci im Zusammenhang mit der Herausbildung von traditionellen Intellektuellen: »Verknüpft mit diesen Erscheinungen ist die Entstehung und Entwicklung des Katholizismus und der kirchlichen Organisation, die für viele Jahrhunderte den größten Teil der intellektuellen Tätigkeiten absorbiert und das Monopol der kulturellen Führung ausübt, mit strafrechtlichen Sanktionen für den, der sich widersetzen oder auch das Monopol umgehen will.«(Gramsci 1991ff.: 1507). 
nomischen, sondern auch im gesellschaftlichen und politischen Bereich geben.« (Gramsci 1991ff.: 1497)

Diese Kategorie nennt Gramsci die organischen Intellektuellen. Mit Blick auf die herrschenden Klassen sieht es Gramsci als eine historische Notwendigkeit an, dass eine Elite der Unternehmer entweder selbst die Fähigkeiten als Organisatoren der Gesellschaft innehat oder zumindest die Fähigkeit besitzt, »die >Gehilfen` (spezialisierte Angestellte) auszuwählen, denen diese Tätigkeit des Organisierens der außerbetrieblichen allgemeinen Verhältnisse anvertraut werden kann« (ebd.). Die allgemeine Aufgabe dieser Intellektuellen besteht darin, die günstigsten Bedingungen für die Ausdehnung der eigenen Klasse in allen Bereichen einer Gesellschaft $\mathrm{zu}$ schaffen: »den Techniker der Industrie, den Wissenschaftler der politischen Ökonomie, den Organisator einer neuen Kultur, eines neuen Rechts usw. usf.« (ebd.). Von den organischen Intellektuellen, die mit der Entstehung einer Produktionsweise aufkommen, unterscheidet Gramsci die traditionellen Intellektuellen, die auf eine epochenübergreifende Tradition zurückblicken können. Mit Blick auf den Feudalismus stellt Gramsci fest, dass es auch in dieser historischen Phase an die politische Herrschaftsausübung gebundene nicht-kirchliche Typen gab, die die Dominanz der Kirchenmänner einschränkten. Dieser traditionelle Typ könne auf eine in die Antike zurückreichende Tradition der nicht-kirchlichen Wissenschaft - insbesondere der Philosophie - zurückblicken, in deren Kontinuität er sich stellte. Er existiere trotz radikaler »Veränderungen der gesellschaftlichen und politischen Formen « (ebd.: 1498) fort, da er für die politische Herrschaftsausübung notwendige, epochenübergreifende Aufgaben erfülle. Die Selbstpositionierung der Gesamtheit der Intellektuellen als autonom und unabhängig von der herrschenden gesellschaftlichen Gruppe steht nach Gramsci in Verbindung mit dieser Wahrnehmung, die die Intellektuellen als eigenständige Klasse oder unabhängige Elite auffasst. Intellektuelle bilden nach Gramsci aber weder eine Klasse, noch sind sie unabhängig, sie sind prinzipiell »Gehilfen« einer gesellschaftlichen Klasse bei der Ausübung der subalternen Funktionen der gesellschaftlichen Hegemonie in der »Zivilgesellschaft « und der politischen Regierung in der »politischen Gesellschaft» (vgl. Solty 2009).

Gramsci stellt ferner fest, dass die Entwicklung der kapitalistischen Produktionsweise eine massive Expansion der Intellektuellenfunktion hervorbringt, die die Intellektuellen schon durch ihre schiere Masse zu einem politischen und ökonomischen Faktor werden lässt. Die Besonderheit dieser Perspektive besteht darin, dass unterschiedliche Berufsgruppen wie Lehrer, Wissenschaftler, Journalisten, Juristen, Angestellte von Verbänden, Kammern und Gewerkschaften, sowie eine Vielzahl an Akteuren, die im Bereich der Kulturproduktion tätig sind - Priester, Sportler, Popstars, Schauspieler - in Abhängigkeit von ihrer konkreten Tätigkeit ebenso den Intellektuellen zugeordnet werden können wie politisches und bürokratisches 
Personal. Die Aufgabe der politischen Partei in Bezug auf die Intellektuellen sieht Gramsci schließlich darin, die organischen Intellektuellen einer gegebenen Gruppe mit den traditionellen Intellektuellen zu verschmelzen. Die Partei entwickelt politische Intellektuelle, die fähig sind, alle Aufgaben eines integralen Staates - ökonomische, politische und kulturelle - zu erfüllen. Sie führt politisch qualifizierte Intellektuelle, Führer, Organisatoren aller Aktivitäten und aller Funktionen, die der Entwicklung eines integralen Staates inhärent sind, zusammen (Gramsci 1991ff.: 1505).

\subsubsection{Sozio-politische Blockbildung}

In diesem Zusammenhang kann die Hegemonieproblematik folgendermaßen re-formuliert werden: Gesellschaftliche Hegemonieträger fallen mit Klassen, die auf der Grundlage bestimmbarer Produktionsverhältnisse entstehen, nicht in eins. Mit der Hegemonie der herrschenden Klasse ist eine Konstellation gemeint, in der alle anderen Klassen und alle Aspekte des gesellschaftlichen Lebens unter der Vormachtstellung der herrschenden Klasse verbunden sind. Alles, was diese Konstellation bewusst oder unbewusst mit organisiert, gehört zur gesellschaftlichen Partei der herrschenden Klasse. An der Schnittstelle zwischen politischen Institutionen, organisierten Interessen und intellektueller Führung übt die politische Partei eine integrierende Funktion aus, die verschiedenen Gruppen einen Kollektivwillen und ein Zielbewusstsein verleiht (ebd.: 1535; vgl. Jäger 2007). Der Ansatz unterscheidet sich von Zugängen, die politische Parteien als einen Reflex präexistenter Spaltungen und Identitäten begreifen (vgl. kritisch De Leon/Desai/Tuğal 2009), wie sie auch in der staatszentristischen Literatur zur AKP zum Tragen kommen. Vielmehr stellen Parteien spezifische Verbindungen zwischen ökonomischen, kulturellen und politischen Positionen her, die sie zu einem Kollektivwillen artikulieren. Die Frage, wer kämpft, lässt sich auf dieser Ebene folgendermaßen beantworten: Es sind spezifisch zusammengesetzte und -gehaltene Kollektive, die sich in den Kämpfen konstituieren, reproduzieren, neu zusammensetzen und möglicherweise auch wieder zerfallen (Elfferding 1983: 30).

Die Bildung eines Kollektivs im Prozess der politischen Artikulation umschließt die Bildung von Identitäten sowie die Abgrenzung und Definition einer auf ein bestimmtes Territorium bezogenen Nation, die aber nicht nur als diskursive Integration wie bei Laclau und Mouffe (1985) oder »imaginierte Gemeinschaft« wie bei Anderson (1993) zu begreifen ist. Die hegemonietheoretische Annahme besteht darin, dass zumindest Teilen der subalternen Klassen und Fraktionen, über die Hegemonie ausgeübt wird, materielle Konzessionen gewährt werden:

»Die Tatsache der Hegemonie setzt zweifellos voraus, dass den Interessen und Tendenzen der Gruppierungen, über welche die Hegemonie ausgeübt werden 
soll, Rechnung getragen wird, dass sich ein gewisses Gleichgewicht des Kompromisses herausbildet, dass also die führende Gruppe Opfer korporativ-ökonomischer Art bringt, aber es besteht auch kein Zweifel, dass solche Opfer und ein solcher Kompromiss nicht das Wesentliche betreffen können, denn wenn die Hegemonie politisch-ethisch ist, dann kann sie nicht umhin, auch ökonomisch zu sein, kann nicht umhin, ihre materielle Grundlage in der entscheidenden Funktion zu haben, welche die führende Cruppe im entscheidenden Kernbereich der ökonomischen Aktivität ausübt.«(Gramsci 1991ff.: 1566f.)

Wie schon bei der Frage des Zwangs und der Gewaltanwendung hat der Begriff der materiellen Konzessionen Bedenken am Konzept Hegemonie aufkommen lassen: Die herrschenden Klassen in (semi-)peripheren Gesellschaftsformationen verfügten über beschränkte materielle Möglichkeiten für Zugeständnisse, weshalb bestenfalls Projekte einer begrenzten Hegemonie möglich seien (Becker 2008). Mit der Aufkündigung des fordistischen Kompromisses in den kapitalistischen Zentren und des Rückbaus sozialer Errungenschaften subalterner Klassen wird gefragt, ob es nicht denkbar sei, dass das Bürgertum sein Verhältnis zur eigenen Führungsfähigkeit ändert und seine Herrschaft in einer anderen als der Form der Hegemonie ausüben könne (Demirović 2007b: 38; vgl. Jessop 1990: 211). Ohne diese Möglichkeit grundsätzlich auszuschließen, stellt sich die Frage, ob sich diese Bedenken nicht zu stark an einer fordistischen Bedingungskonstellation und einem sozialdemokratisch institutionalisierten Kompromiss orientieren, in dem materielle $\mathrm{Zu}$ geständnisse die Form verbriefter Rechte und kontinuierlicher Reallohnerhöhungen angenommen haben (vgl. Candeias 2004: 9). Die schrittweise Zerschlagung dieses Kompromisses im Übergang zum neoliberalen Akkumulationsregime ist in vielen Ländern zweifellos durch kurzfristig verstärkte Gewaltanwendung geschehen. Doch war die Anwendung von Gewalt nicht voraussetzungslos, sie bedeutete nicht, dass die Bourgeoisie keinerlei Konsens mehr herzustellen vermochte. Hieran schließt eine zweite Überlegung an, nämlich die Formierung von Interessen und Tendenzen nicht dem Hegemoniebildungsprozess vorauszusetzen. Verbriefte Rechte haben sich im Zuge von Kämpfen als spezifisches Interesse herausgebildet, sie sind in einen historischen Kompromiss eingegangen, der in Kämpfen wieder aufgelöst werden kann. Folglich sollte jeweils konkret bestimmt werden, wie Interessen sich artikulieren und formieren.

Übertragen auf Kollektive bedeutet dies, dass sie nicht nur durch Ideologie, sondern auch durch materielle Konzessionen geformt werden, deren Form für die einzelnen Bestandteile des Kollektivs konkret bestimmt werden muss. Bevor ich auf diese These im nächsten Abschnitt näher eingehe, möchte ich in Abgrenzung zum Kollektiv den Begriff des sozio-politischen Blocks in die hegemonietheoretische Begriffsbildung einführen. Der Begriff des Kollektivs soll reserviert sein für die aktiv organisierte Gruppe eines Hegemonieprojekts, die diesem seine kultu- 
relle und politische Prägung verleiht. Mit dem Begriff sozio-politischer Block soll dagegen ein gesellschaftliches Bündnis gefasst werden, das auch passive Elemente, also die »Geführten« eines Hegemonieprojekts einschließt. Als soziale Größe sind sozio-politische Blöcke unterhalb eines historischen Blocks anzusiedeln, der bei Gramsci eine das Denken und Fühlen umfassende Einheit einer die Klassen übergreifenden Lebensweise bezeichnet (Demirović 2001: 61), die mit einer Kapitalakkumulationsstrategie korrespondiert (Jessop 1990). Ein historischer Block stellt die widersprüchliche Einheit von Führenden und Geführten auf der allgemeinsten Ebene eines Führungsverhältnisses zwischen den Klassen dar. Er ist nicht $\mathrm{zu}$ verwechseln mit einem Machtblock, der »eine von inneren Widersprüchen gekennzeichnete Einheit von politisch herrschenden Klassen und Fraktionen « (Poulantzas 1978: 239, Übersetzung E.B.) bezeichnet. Als Repräsentationen einer Seite des Widerspruchs zwischen Führenden und Geführten können einem Machtblock Kapitalgruppen, die Spitzen von Parteien, Gewerkschaften und Verbänden angehören, was jeweils konkret bestimmt werden muss (Candeias 2007: 20). Ein sozio-politischer Block rekurriert hingegen auf Spaltungen innerhalb eines historischen Blocks, die sich in der Formierung verschiedener Parteien ausdrücken, die auf dem Boden bestehender Produktionsverhältnisse unterschiedliche Hegemonieprojekte artikulieren. Einen sozio-politischen Block als Ergebnis politischer Artikulation zu begreifen, der in der Regel, aber nicht zwangsläufig von einer politischen Partei angeführt wird, bedeutet auch, dass der Block flexibel und offen gegenüber Modifikationen ist. Auf diese Weise kann beispielsweise die Flexibilität in der Artikulationsfähigkeit neoliberaler Politik mit verschiedenen bereits vorhandenen Blöcken, deren Konstitution im Rahmen eines prä-neoliberalen Akkumulationsregimes begann, erfasst (vgl. Candeias 2004: 333; ders. 2008), wie auch die kleinteiligere, konjunkturbedingte Manövrierfähigkeit eines sozio-politischen Blocks auf der ideologischen Ebene berücksichtigt werden.

Schließlich kann in diesem begrifflichen Rahmen zwischen verschiedenen Hegemonieprojekten anhand charakteristischer Medien und Inhalte der Herstellung von Konsens und Vermittlung von Kompromissen unterschieden werden. Ferner kann zwischen den einzelnen Konstituenten eines sozio-politischen Blocks differenziert und danach gefragt werden, wie der spezifische Nexus zwischen Ökonomie, Politik, Kultur/Ideologie, der den sozio-politischen Block charakterisiert, gebildet und zusammengehalten wird. Je nach Untersuchungsperspektive kann die Differenzierung unterschiedlich stark ausfallen. Eine allgemeine Unterteilung wird berücksichtigen müssen:

- die gesellschaftlichen Klassen und gegebenenfalls Fraktionen, deren Führung organisiert wird;

- die Gruppe der Intellektuellen, die die politische und kulturelle Führung organisieren; 
- die subalterne Anhängerschaft, die in parlamentarischen Demokratien mehr oder weniger mit der Wählerschaft korrespondiert.

Auf dieser Grundlage kann die Geschichte der AKP als die Geschichte der Formierung eines Hegemonieprojekts und eines sozio-politischen Blocks geschrieben werden, dessen kulturelle und ideologische Prägung von einer spezifischen Sorte Intellektueller hervorgebracht wird, die den zivilgesellschaftlichen Konsens für ein neoliberales Akkumulationsregime organisieren. Es wurde bereits angesprochen, dass die hegemonietheoretische Rekonstruktionsarbeit an dieser Stelle an eine Grenze gestoßen ist, die eine Erweiterung notwendig machte. Die Grenze liegt darin, dass die Ausübung von Führung über die Artikulation partikularer ökonomischer Interessen zu einem Allgemeininteresse und die instrumentelle Verknüpfung von Diskursen und Praktiken mit ökonomischen Projekten hinausgeht. Ein instrumentalistischer Ansatz lässt sowohl die Rolle dieser Intellektuellen als auch die treibende Dynamik der Islamisierung, die sich als Kulturkampf äußert, unzureichend bestimmen. Um die Tragweite der Tatsache, dass Religion ein Reproduktionsmittel der intellektuellen Träger des Blocks darstellt, in einem Wechselverhältnis zur Reproduktion der kapitalistischen Produktionsverhältnisse zu erfassen, ohne die Intellektuellen als eigenständige Klasse oder Elite zu konzipieren, bedarf es eines erweiterten Modells. Das Konzept Artikulation bahnt den Weg, sozio-politische Blockbildung als gegenseitige Durchdringung politischer, ideologischer, kultureller und ökonomischer Elemente zu begreifen.

An dieser Stelle gilt es die These zu den Intellektuellen zusammenzufassen: Indem sie die Führungsbeziehungen zwischen den Klassen kulturell und ideologisch gestalten, sind sie "Gehilfen« der herrschenden Klassen in der Ausübung von Hegemonie. Als Konstituenten eines sozio-politischen Blocks organisieren sie dessen Führung, die sie kulturell und ideologisch prägen. Die Erweiterung besteht darin, dass sie zugleich objektiv einen eigenständigen Zweck verfolgen, denn die Reproduktion der Hegemonie ist auch die Reproduktion ihrer eigenen Existenzbedingungen und Organisationsformen. Sie partizipieren am Prozess der Ausbeutung über die Wahrnehmung der kulturellen und ideologischen Aufgaben der Hegemoniebildung, die ihnen einen Zugang zum gesellschaftlichen Mehrwert vermitteln. Hieran knüpft eine zweite gegenstandsbezogene These der Studie an, die in den Folgekapiteln dieser Arbeit empirisch ausgeführt wird. Die religiöse Prägung der Hegemonie schlägt sich in einem Islamisierungsprozess nieder, der über die Herstellung der Reproduktionsgrundlagen für die mit dem Projekt affiliierten Intellektuellen hinaus eine materielle Seite aufweist. Die Aneignung der Religion ist mit der Aussicht auf ökonomische Vorteile für die Aneignenden verknüpft. Diese Vorteile prägen die Konstitution des sozio-politischen Blocks und stehen in einem Wechselverhältnis zur Islamisierung beziehungsweise Reproduktion der Intellektuellen. Um diese beiden miteinander verknüpften Thesen zu begründen und die 
Mechanismen des Partizipations- und Assoziationsprozesses im Rahmen des hegemonietheoretischen Ansatzes begreifen zu können, um zu verstehen, worin der gesellschaftliche Effekt und ökonomische Einsatz von Führungspraktiken besteht, ist es erforderlich, die materiellen Reproduktionsgrundlagen der Intellektuellen, damit auch die Ebene zu bestimmen, auf der ihre Kämpfe in Bezug zu den Produktionsverhältnissen erfasst werden können. Eine solche Bestimmung wird im Folgenden durch Bezugnahme auf die Kapitaltheorie von Pierre Bourdieu erfolgen, mit der die Grundlage für eine ressourcentheoretische Erweiterung gelegt wird.

\subsection{Ressourcentheoretische Erweiterung}

Unter Kapital begreift Bourdieu alle »Teilungsprinzipien der sozialen Welt, die Austauschverhältnisse regulieren und als Machtressourcen wirken können« (Hillebrandt 2009: 382). Kapital kann nach Bourdieu auf drei grundlegende Arten und in drei Formen - in objektivierter, institutionalisierter und inkorporierter Form auftreten. Ökonomisches Kapital ist nach Bourdieu die dominierende Kapitalform, es ist unmittelbar und direkt in Geld konvertierbar, eignet sich besonders zur Institutionalisierung in der Form des Eigentumsrechts und ist als Rationalitätsprinzip inkorporiert. Kulturelles Kapital liegt objektiviert in kulturellen Gütern, Artefakten vor, ist unter bestimmten Voraussetzungen in ökonomisches Kapital konvertierbar, wird als Bildung, Geschmack und kulturelles Vermögen inkorporiert und als schulische Titel institutionalisiert (Bourdieu 1987: 204ff.). Soziales Kapital zeigt sich inkorporiert als soziale Verpflichtungen, Ansehen und Beziehungen, ist unter bestimmten Voraussetzungen ebenfalls in ökonomisches Kapital konvertierbar und eignet sich besonders zur Objektivierung in Form von Ehrentiteln, »oder, anders ausgedrückt, es handelt sich dabei um Ressourcen, die auf der Zugehörigkeit zu einer Gruppe beruhen« (Bourdieu 1983: 190f., Hervorhebung im Original). In welcher Gestalt Kapital jeweils auftritt, ob es an Tauschwert gewinnt oder verliert, hängt von dem jeweiligen Anwendungsbereich sowie den mehr oder weniger hohen Transformationskosten $\mathrm{ab}$, die Voraussetzung für sein wirksames Auftreten sind (Bourdieu 1987: 227f.).

Es kann etwas vereinfachend gesagt werden, dass Bourdieu eine Theorie des Tauschs entwickelt, in der Kapitalien Tauschmittel sind, die sich sowohl durch die Beteiligung an Praxis entwickeln, als auch ihr vorausgesetzt sind. Die kategorische Trennung zwischen Ökonomie, Politik und Kultur, die nach Bourdieu eine Erfindung der Wirtschaftstheorie ist, die die gesellschaftlichen Austauschverhältnisse auf den Warentausch reduziert, möchte er durch soziale Vermittlungsverhältnisse aufheben. Dies ermögliche, den ökonomischen Charakter künstlerischer und intellektueller Praktiken, die nicht im Warentausch in einem engeren Sinne bestehen, $\mathrm{zu}$ fassen (Bourdieu 1983: 184f.). Zugleich wird ein differenziertes Erfassen sozialer 
und kultureller Praktiken - Fähig- und Fertigkeiten, Zeugnisse, Titel, soziale Beziehungen, Ansehen - möglich, durch die Klassenunterschiede reproduziert werden. Denn nach Bourdieu halten diese Praktiken im Regelfall die Klassengrenzen aufrecht, nur im Ausnahmefall verhelfen sie zu ihrer Überwindung.

Für die Bestimmung der Rolle der Religion in den sozialen Kämpfen ermöglicht die Auseinandersetzung mit Bourdieus Konzept, Religion nicht allein als Mittel zur Ausübung von Hegemonie, sondern zugleich in Assoziation mit einem Set von sozialen und kulturellen Praktiken zu begreifen, die einen objektiv ökonomischen Charakter tragen. Soziale und kulturelle Praktiken gewinnen so einen neuen Stellenwert. Ihre Träger erscheinen nicht mehr als einfache Funktionsträger einer Klasse, für die sie stellvertretend kämpfen, indem sie bestimmte kulturelle Positionen einnehmen, vielmehr kämpfen sie auch für die Reproduktion ihrer eigenen Positionen. Indes sind diesem Rückbezug auf die Kapitaltheorie Bourdieus theoretische Grenzen gesteckt, die aus grundlegenden Differenzen zum hegemonietheoretischen Konzept hervorgehen. Kapital basiert bei Bourdieu nicht auf einem mehrwertbildenden Ausbeutungsverhältnis, sondern auf Aushandlungen zwischen Akteuren, die in hierarchisch strukturierten sozialen Feldern stattfinden, in denen die Akteure in ein Tauschverhältnis treten. Zwar finden sich prägnante Formulierungen in Bourdieus Werk, in denen er Ausbeutung benennt, er führt aber nicht aus, was diese ausmacht. Praxis wird als Aushandlungsprozess über den Tauschwert von Kapitalien konzipiert, deren Akkumulation Akteure im sozialen Raum (potentielle) Positionen in einem hierarchischen Verhältnis zueinander einnehmen lässt. Obgleich er Kapital als »akkumulierte Arbeit« (Bourdieu 1983: 183) bezeichnet, wird diese Arbeit, mit der nicht Lohnarbeit, sondern jede Tätigkeit gemeint ist, die Kapitalien hervorbringt, nicht in Verbindung zu einem Ausbeutungsverhältnis begriffen. Gemeint ist offenbar nicht die Aneignung fremder Arbeit. Dem in dieser Studie verwendeten Kapitalbegriff liegt ein anderes Verständnis zugrunde. Generell werden Klassenunterschiede in einem auf Marx zurückgehenden Verständnis nicht als Ungleichheitsbeziehungen, sondern als Ausbeutungsverhältnisse thematisiert. Kapital bildet sich nach Marx, an den Gramscis Hegemonietheorie anschließt, durch die Enteignung der Mehrarbeit der Produzenten in der Form des Mehrwerts durch eine Klasse von Enteignern. Als angeeigneter Mehrwert ist ihm ein gesellschaftliches Verhältnis zwischen Produzent und Expropriateur vorausgesetzt und eingeschrieben. Über die Aufhebung des Verhältnisses vermittels Kämpfen würde mit diesem Verhältnis auch das Kapital selbst - als mehrwertsch(r)öpfend eingesetztes Produktionsmittel - nicht weiter existieren. Das lässt sich für die von Bourdieu eingeführten, für die Analyse gesellschaftlicher Klassen und ihrer Fraktionen bedeutsame Elemente wie Bildung, Ansehen oder Titel nicht behaupten. Ihre Konvertibilität in ökonomisches Kapital, allgemein ihr Tauschwert und damit ihre Vermittlung zur Praxis kann neu ausgehandelt, verschoben und überholt werden. Für diesen Tauschprozess, in dem Positionen ausgehandelt werden, bedarf 
es keiner Ausbeutung und keines Mehrwerts, so dass auch Kämpfe zur Aufhebung von Ausbeutung theoretisch nicht erfasst werden können. Zudem werden soziale und kulturelle Kapitalien im Tauschprozess eingesetzt oder angewendet, aber nicht unbedingt verausgabt, anders als die Arbeitskraft (vgl. Zander 2003). Folglich tritt ein Vermittlungsproblem zwischen den beiden Theorien auf, für das nachfolgend eine pragmatische Lösung vorgeschlagen wird, die eine Abweichung von Bourdieus Theorie darstellt. Die Lösung sieht folgendermaßen aus: Erstens wird Bourdieus Kapitalbegriff durch den Begriff der Ressourcen ersetzt, um die Differenz zum marxschen Begriff nicht zu verwischen. Zweitens wird eine Redefinition vorgenommen: Ressourcen sind nach meiner Definition dem Produktions- und somit auch dem Kapitalverhältnis nachgeordnet. Sie stehen in Beziehung zum Produktionsverhältnis, sie konstituieren es jedoch nicht, sondern werden selbst erst auf der Grundlage von Produktionsverhältnissen als Ressourcen konstituiert. Sie regulieren die Produktionsverhältnisse, indem sie zum einen die »feinen Unterschiede« bei der Reproduktion von Klassen ausmachen, in selteneren Fällen dazu verhelfen können, Klassengrenzen zu überwinden, wie es Bourdieu auch im Blick hatte. Entscheidend für diese Arbeit ist aber, zum anderen, die These, Ressourcen als »Reproduktionsmittel« von Arbeitskraft- und Kapitalbesitzern anzusehen, die die Verwertungsbedingungen beziehungsweise den Tauschwert modifizieren, dadurch die Verteilung der gesellschaftlichen Mehrarbeit beeinflussen können. Eine weitere Differenz besteht darin, dass es bei der Operationalisierung des Ressourcenkonzepts im Rahmen dieser Arbeit nicht darum geht, die Bedeutung der Religion feldimmanent $\mathrm{zu}$ bestimmen, sondern in ihrer politisch-ökonomischen Einbettung, das heißt in ihrer Beziehung zu den gesellschaftlichen Klassen und deren Praxis. ${ }^{9}$ Die ressourcentheoretische These dieser Arbeit besteht darin, dass die Modifikation des Tauschwerts von Ressourcen im gerade ausgeführten Sinne nicht auf Kämpfe innerhalb bestimmter Felder und deren innere Logiken begrenzt ist, sondern an Kämpfe um Hegemonie gebunden ist, mit denen sie artikuliert sind. ${ }^{10}$ Die Frage nach den materiellen Reproduktionsgrundlagen der Intellektuellen, die die kulturellen Träger des politischen Islam bilden, kann so als Frage nach dem Tauschwert der mit der Religion artikulierten sozialen und kulturellen Ressourcen auf einem spezifischen Kampffeld, das das der Hegemonie ist, gestellt werden. Im nächsten Abschnitt soll nun die theoretische Begründung des Verteilungsmechanismus erfolgen, die durch diese Rekonzeptualisierung von Ressourcen als Repro-

9 Auf dem religiösen Feld geht es nach Bourdieu um die Heilung der Seelen, ausgetragen werden Kämpfe um das Monopol auf die Verwaltung heilsrelevanter Güter.

10 Eine ähnliche argumentative Stoßrichtung verfolgt Cihan Tuğal in einem Artikel über den Wandel des »türkischen Subproletariats « unter der AKP (Tuğal 2011), indem er feststellt, dass die Bildung und Konversion von (religiösen) Kapitalien nicht feldimmanent, sondern in Beziehung zu politischen Kämpfen geschieht. 
duktionsmittel, die die Verteilung der gesellschaftlichen Mehrarbeit beeinflussen, notwendig geworden ist.

\subsection{Verteilungsverhältnisse}

Um die Bedeutung von Ressourcen bei der Verteilung der gesellschaftlichen Mehrarbeit zu begründen, bietet eine Studie von Korkut Boratav über die gesellschaftlichen Klassen in der Türkei ein geeignetes theoretisches Grundgerüst (Boratav 2005). Boratav unterscheidet zwischen Verteilungsverhältnissen ersten Grades und Verteilungsverhältnissen zweiten Grades. Verteilungsverhältnisse ersten Grades bestehen zwischen den gesellschaftlichen Klassen, die sich in einem Produktionsverhältnis gegenüberstehen, im kapitalistischen Produktionsverhältnis zwischen der Bourgeoisie und dem Proletariat. ${ }^{11}$ Über die Verteilungsverhältnisse zweiten Grades, die auch als Re-Distributionsverhältnisse bezeichnet werden, bestimmt Boratav sowohl Fraktionen der herrschenden Klassen als auch gesellschaftliche Gruppen oder Schichten. Demzufolge wird in jeder Gesellschaftsformation die über die Ausbeutung angeeignete Mehrarbeit über marktförmige und nicht-marktförmige Mechanismen weiter-verteilt und weiter-geleitet. Diese Verteilung verläuft über die wirtschaftspolitische Ausrichtung, sie kann durch Subventionen, Steuervorteile, Dienstleistungen, Zins- und Geldpolitik, Festlegung von Preisen, erleichterte oder erschwerte Marktzugänge für bestimmte Fraktionen und Gruppen geschehen. Die Bourgeoisie sieht Boratav in fünf Untergruppen aufgeteilt: die Industrie- und Agrarbourgeoisie, die Handels- und Finanzbourgeoisie sowie Rentiers. Für diese Studie von besonderem Interesse ist, dass mittels regelhafter und voneinander unterscheidbarer Formen der Re-Distribution, die aus der Perspektive der Akteure verschiedene Formen des Einkommens darstellen, auch gesellschaftliche Gruppen oder Schichten bestimmt werden können. Die hauptsächlichen Gruppen, die Boratav für die Türkei benennt, sind: Angehörige der Bürokratie; Mitglieder der freien Berufe (»professionals«, d.h. Anwälte, Architekten, Ingenieure, Ärzte etc.); Handwerker; Kleinhändler und kleine Ladenbesitzer; urbane Marginale. ${ }^{12}$

Boratav unterscheidet zwischen drei voneinander abgrenzbaren Produktionsweisen in der Türkei der 1980er Jahre. Diese sind die kapitalistische, die halb-feudale und die einfache Warenproduktion. Der Reihe nach stehen sich Bourgeoisie und Proletariat, vertraglich gebundene Bodenpächter und Bodenbesitzer sowie für den Markt produzierende bäuerliche Kleinproduzenten und Händler gegenüber.

Boratav betont die Schwierigkeit der theoretischen und empirischen Bestimmung solcher Gruppen. Jede Definition werde Lücken aufweisen und bestimmte Mechanismen nicht adäquat berücksichtigen können. In der Realität können einzelne Individuen mehreren Klassen oder Cruppen gleichzeitig angehören, auch Wechsel in zeitlich enger Abfolge sind möglich (bspw. vom Subunternehmer zum Arbeiter oder vom Kleinbauern zum Tagelöhner). Die Be- 
Anders als die sozialen Klassen, die zur ersten Kategorie gehören, beruht die Existenz dieser Gruppen nicht prinzipiell auf einem dialektischen Verhältnis, das ein bestimmtes Gegenüber benötigt. ${ }^{13}$ Sie hängt dennoch von der Ausbeutung der unmittelbaren Produzenten ab, da hier die Mehrarbeit entsteht, die angeeignet und umverteilt werden kann. Dies bedeutet, dass der Tauschwert sozialer und kultureller Ressourcen für die in den Blick genommene Gruppe der Intellektuellen auf der Ebene der Verteilungsverhältnisse zweiten Grades gebildet wird.

Das Schema ermöglicht, Bevölkerungsgruppen systematisch in die Analyse einzubeziehen, die in der primären Gegenüberstellung von ausbeutenden und ausgebeuteten Klassen nicht vorkommen, weil sie weder der einen noch der anderen Seite zugerechnet werden können. Hierdurch können die Rolle und das Gewicht dieser Gruppen und ihrer Organisationen für politische Dynamiken diskutiert, von ihnen angenommene kollektive Bewusstseinsformen und Haltungen in einen $\mathrm{Zu}$ sammenhang mit der Verteilung der gesellschaftlichen Mehrarbeit, an die ihre materielle Reproduktion gekoppelt ist, gestellt werden. ${ }^{14}$ Auf die Problematik des Partizipationsmechanismus der Intellektuellen zurückkommend, lässt sich zunächst feststellen, dass unter den Gruppen, die Boratav aufzählt, keine Intellektuellen erwähnt sind. Dies liegt jedoch allein daran, dass er keine gramscianische Terminologie verwendet. Eine differenzierte Betrachtung der Intellektuellen des politischen Islam, um die es in dieser Arbeit geht, wird aufzeigen, dass sie quer zu den genannten Gruppen liegen, zu einem großen Teil einer der genannten Gruppen zugeordnet werden können und zu einem eher kleineren Teil der Bourgeoisie angehören. Es wird dann darum gehen, einen Einblick in die kulturellen und sozialen Praktiken zu gewinnen, über die diese Gruppen an der Verteilung der Mehrarbeit partizipieren und die Mechanismen zu identifizieren, über die sich der »Tauschwert « ihrer sozialen und kulturellen Ressourcen bildet. Vorausgreifend ist nochmals hervorzuheben, dass sich der »Tauschwert« in Beziehung zur Hegemonieausübung,

stimmung bleibe daher notwendigerweise schematisch, dennoch sei dies besser, als gar keine Bestimmung vorzunehmen und die Begriffe frei und assoziativ zu werden.

13 Unbestritten ist aber, dass es historisch zu einer quantitativen Expansion und Ausdifferenzierung einiger dieser Cruppen - wie der Bürokratie und der freien Berufe - erst mit der kapitalistischen Produktionsweise kam.

14 Andere marxistische Autoren haben die gleichen Gruppen, die Boratav definiert, hauptsächlich dem Kleinbürgertum zugerechnet. Nicos Poulantzas nimmt beispielsweise die Reproduktion der gesellschaftlichen Arbeitsteilung von intellektueller und manueller Arbeit zur Grundlage der Bestimmung von Klassenstellungen der Bürokratie (Poulantzas 2002: 185f.). Boratavs Schema weicht ab, da er die Reproduktionsgrundlage der Bürokratie nicht allein im kapitalistischen Produktionsverhältnis liegen sieht und ihre Klassenstellung nicht vermittelt über die Arbeitsteilung definiert. Allerdings betont auch Boratav, dass das kapitalistische Produktionsverhältnis die hauptsächliche Crundlage des Staates Türkei bildet, und benennt verschiedene Wege der Assoziation der Bürokratie mit der Bourgeoisie, die er jedoch wesentlich konkreter und weniger grundsätzlich darlegt als Poulantzas. 
die an die Religion gekoppelt ist, bildet. Sofern diese These zutrifft, kann auch von einer relativen Autonomie dieser Gruppe gegenüber den besitzenden Klassen gesprochen werden, da der Erhalt und die Steigerung des Werts ihrer Ressourcen als ein objektives Gruppeninteresse bestimmt werden kann. Als Mechanismus dieser »Tauschwertbildung« tritt der Kulturkampf auf, der in der Verdrängung anderer Hegemonieträger besteht. Mit anderen Worten, es sind die Einbettung in Hegemonieprojekte und folglich die politischen Kämpfe um Führung, über die sich kulturelle und soziale Ressourcen konstituieren und die entscheidend zu ihrer Aufund Abwertung beitragen. 



\section{Teil III - Entwicklungsgeschichte und}

Konstitutionsmerkmale des islamistischen Hegemonieprojekts 



\section{Der historische Bogen}

Über mehrere Dekaden stand das Kopftuch im Mittelpunkt des Streits zwischen Islamisten und Laizisten. Für Islamisten symbolisierte es religiöse Identität, die es von der laizistischen Unterdrückung zu befreien galt. Laizisten hielten das Kopftuch für eine Vorbotin der Scharia, es aus den staatlichen Institutionen zu verbannen, erhoben sie zur zentralen Abwehrstrategie. Während die Fixierung auf das Kopftuch viele Frauen aus der gesamten öffentlichen Verwaltung und allen Bildungsinstitutionen ausschloss, damit einige der Phänomene produziert wurden, auf die die Kulturkampfthese sich bezieht, wurde dem längst laufenden Marsch, den islamistische Männer durch die Institutionen angetreten waren, weit weniger Aufmerksamkeit zuteil. Als die AKP Ende 2002 zum ersten Mal eine Regierung bildete, hatte dieser Marsch schon weite Strecken zurückgelegt. Eine der ersten Institutionen, deren Leitung die AKP Anfang 2003 mit einem türkischen Islamisten besetzte, war die Generaldirektion für Stiftungen - im Folgenden abgekürzt als Stiftungsbehörde. Der neue Behördenleiter Yusuf Beyazıt empfahl sich mehrfach für diesen Posten. In der Istanbuler Kommunalverwaltung hatte er unter dem Oberbürgermeister Recep Tayyip Erdoğan verschiedene Funktionen bekleidet. Ausgestattet mit den sozialen Ressourcen, der Vernetzung mit der islamistischen Partei, brachte er kulturelle Ressourcen mit, die ihn auf besondere Weise qualifizierten: Neben der Verwaltungserfahrung hatte er eine theologische Bildungslaufbahn mit einem Abschluss an einer theologischen Fakultät vorzuweisen. Unter seiner Leitung wurde die Behörde, die bis dahin in erster Linie die Aufsicht über Kirchen und Synagogen führte, in ein Instrument kultureller Restauration umgestaltet. ${ }^{1}$

Auf die Behörde aufmerksam wurde ich durch einen Zufall. In den ersten Tagen meiner Sondierungsreise, als ich noch als Dolmetscher für die deutsche Reisegruppe tätig war, zappte ich durch das abendliche Fernsehprogramm. Entnervt von der zunehmend um sich greifenden staatlichen Zensur, die jedes vermeintlich unanständige Wort durch einen Piepton ersetzte, Zigaretten und nackte Körperteile, die mit weiblicher Geschlechtlichkeit assoziiert werden konnten, unkenntlich, milchig 
intransparent gemacht hatte, landete ich beim Staatsfernsehen. Es lief eine Sendung mit einem islamischen Gelehrten, der aus dem Koran und dem Leben des Propheten Mohammed erzählte. Seine gelehrsam-souveräne Art zu reden, ungestört von Pieptönen, ließ mich verweilen. Vom Leben des Propheten und seiner Zeitgenossen leitete seine Erzählung über zu den Prinzipien des »osmanisch-islamischen Stiftungswesens«:

Stiften bedeutet im Islam gleichzeitig karitativ und unternehmerisch tätig zu sein. [...] Das Stiftungsprinzip wurde nahezu 100 Jahre nicht beachtet. Immobilien, die für Waisenkinder gespendet worden waren, wurden für öffentlichen Besitz gehalten, sie wurden von irgendwem besetzt und bebaut. Seit 2003 haben wir 27.000 Immobilien inventarisiert, auch im Zentrum von Istanbul, wo Immobilien so wertvoll sind wie in Manhattan. Wir haben sie ausfindig gemacht und führen sie wieder ihrem eigentlichen Zweck zu. [...] Wir arbeiten wie eine Holding. Im Sinne des Stifters verwerten wir sie, wir betreiben sie gewinnbringend. ${ }^{2}$

Der Sprecher führte aus, die Behörde betreibe Parkhäuser, Tankstellen, Hotels und Einkaufszentren, baue Hochhäuser und vermiete Wohnungen. Private Investoren könnten im öffentlichen Besitz befindliche historische Stätten aus der osmanischen Zeit restaurieren, betreiben und nach einer gewissen Zeit der Behörde rückübertragen. Seit 2003 habe die Behörde jährlich 750 Objekte, darunter viele Moscheen, restaurieren lassen, davor seien es gerade mal 12 pro Jahr gewesen. Nachdem das in der Tradition des türkischen und islamischen Wohlfahrtsgedankens stehende Stiftungswesen 100 Jahre brach gelegen habe, nehme die Behörde die moralische Verpflichtung im Sinne der ursprünglichen Stifter wieder wahr: Vom erwirtschafteten Geld verteile sie Lebensmittelhilfen, vergebe monatliche Renten für Bedürftige, Behinderte und Waisenkinder, bevorzugt an Kinder gefallener Soldaten.

Erst gegen Ende der Sendung wurden der Name des Gelehrten und seine Funktion eingeblendet. Vor mir saß, durch einen Bildschirm getrennt, der Behördenleiter Yusuf Beyazıt, der mir das Thema meines Forschungsprogramms für die kommenden Jahre skizzierte: Die Verbindung von Gewinnstreben und Investitionsgeist mit kultureller Restauration und einem paternalistischen Armutsregime unter der intellektuellen Führung von theologisch ausgebildetem Personal.

Die Rede des Behördenleiters, auf die ich in den folgenden Abschnitten immer wieder Bezug nehmen werde, enthielt auch den ersten Fingerzeig für diese Studie, an welchem historischen Punkt die Rekonstruktion der Entwicklungsgeschichte des politischen Islam ansetzen sollte. In der Klage über die Vernachlässigung des islamischen Stiftungswesens und der mit ihm verbundenen moralisch-ethischen

2 Die Sendung lief im Staatsfernsehen am 09.03.2009. Ich gebe die Worte des Sprechers anhand meiner Mitschrift wieder. 
Verpflichtung seit »nahezu 100 Jahren« war enthalten, dass der politische Islam sich als eine Bewegung begreift, die einen Anschluss an das osmanisch-islamische Erbe herstellen möchte, um eine vor-republikanische Ordnung wiederherzustellen. Dies führt zu der Frage, wie diese Ordnung, die der politische Islam herbeisehnt, ausgesehen hat.

Eine Beschäftigung mit dieser Thematik birgt sogleich die Gefahr, den Bogen $\mathrm{zu}$ weit $\mathrm{zu}$ spannen, sich in den Weiten der osmanischen Geschichte zu verlieren, gar, dem Behördenleiter gleich, das Leben des Propheten zum historischen Ausgangspunkt machend eine Geschichte über 1000 Jahre zu rekapitulieren. Tatsächlich besteht in diesem Zusammenhang eine Forschungslücke, nicht in der islamischen Theologie, die dieses Feld ausgiebig beackert, sondern aus historisch-materialistischer Perspektive. Das hegemonietheoretisch perspektivierte Wissen über die alte, vor-republikanische Ordnung hinsichtlich ihrer ideologischen Strukturen - nach Gramscis Verständnis als materielle Organisationen - ist begrenzt. Über die Religion ist wenig mehr als die pauschale Feststellung zu erfahren, dass sie die Beziehungen zwischen den Klassen regulierte, in der Regel die Ideologie der herrschenden Klassen bildete. Zur Aufrechterhaltung des knappen Wissensstands trägt auch die theoretische Setzung bei, vor-kapitalistische Herrschaftsverhältnisse seien allein durch Zwang charakterisiert gewesen. Hegemonietheoretische Fragen, die sich für Kultur und Ideologie interessieren, rücken dadurch ins Abseits. Wie die weitgreifenden Apparate der Religion, die Gramsci als »die kolossalste Utopie, das heißt die kolossalste >Metaphysikı, die in der Geschichte erschienen ist, da sie der großartigste Versuch ist, in mythologischer Form die wirklichen Widersprüche des geschichtlichen Lebens zu versöhnen « (Gramsci 1991ff.: 1475), bezeichnete, in die »zivilgesellschaftliche« Regulierung der Klassenverhältnisse eingebettet waren, ist nicht systematisch erforscht.

Der Verzicht auf eine hegemonietheoretische Perspektive auf die Geschichte der Religion hat Konsequenzen für die Gegenwart. Er trägt zur Entstehung eines Übergewichts ideengeschichtlicher Analysen bei, die die materielle Grundlage der Religion ignorieren, sie nicht in Beziehung zu den Klassen und ihren Kämpfen begreifen. Wie im Kapitel zur Säkularisierungsthese diskutiert, bezeugt der Begriff Verweltlichung, wie die religiöse Metaphysik sich in der Wissenschaft in Form einer Trennung zwischen weltlichen und nicht-weltlichen Sphären reproduziert. Die angenommene Inkompatibilität von Religion und bürgerlicher Vergesellschaftung beziehungsweise kapitalistischer Entwicklung bildet eine Parallele zu dieser Auffassung, die Religion als ein irrationales, von den materiellen Verhältnissen losgelöstes Gebilde begreift. Auf der Gegenseite steht die Frage nach den konkreten Bedingungen des Aufkommens bürgerlich-säkularer Bewegungen im Osmanischen Reich. Sie ist bislang ebenfalls kaum aus einer historisch-materialistischen Perspektive gestellt worden. Die Ansicht, Säkularisierung bilde einen welthistorischen Trend, ließ die Reflektion ihrer Entstehungsgeschichte lange Zeit überflüssig, weil 
für die gegenwärtigen und zukünftigen Auseinandersetzungen irrelevant erscheinen.

In Bezug auf die Republik Türkei kommt hinzu, dass die Trennung zwischen Staat und Religion unter dem Begriff der Laizität in der Verfassung verankert wurde, die kemalistische Überzeugung dies als Wahrheit etablierte, während es doch nur einen Ausschnitt wiedergab. Statt einer Trennung von öffentlichen und religiösen Institutionen, wie es im laizistischen Frankreich, das als Vorbild diente, weitgehend und doch nicht komplett durchgesetzt wurde, wurde mit Gründung der Republik die Religion sowohl institutionell eingehegt als auch konserviert. ${ }^{3}$ Einerseits fanden einschneidende Veränderungen in der Rolle der Geistlichen und ein politisch vorangetriebener Säkularisierungsprozess statt. Andererseits wurde insbesondere mit Gründung der Religionsbehörde Diyanet der Grundstein gelegt für die spätere Expansion der öffentlichen religiösen Institutionen, die eine maßgeblich organisierende und bildende Funktion für die islamistische Bewegung einnehmen sollten.

Infolgedessen öffnet sich ein neues Untersuchungsfeld, dessen Bearbeitung den Rahmen dieser Studie sprengen würde. Zur Bewältigung der Aufgabe werden die folgenden Ausführungen sich auf die Rolle der sunnitischen Geistlichen in der Spätphase des Osmanischen Reichs, in der der Niedergang der alten Ordnung bereits in vollem Gange war, beschränken. Die Einschränkung auf diese Gruppe lässt sich auch dadurch begründen, dass der politische Islam in seiner gegenwärtigen Gestalt sich auf die Stellung dieser Gruppe sunnitischer Geistlicher bezieht, die auf besondere Weise in das soziale Gefüge integriert und mit verschiedenen Aufgaben befasst waren. Von der historischen Betrachtung ausgenommen sind religiöse Institutionen und Intellektuelle anderer Glaubensgruppen, sowohl der alevitischen als auch der jüdischen und christlichen Gruppen. Mit Aleviten werden heterodoxe Glaubensgruppen bezeichnet, die in der heutigen Türkei mit 10 bis 20 Prozent der Bevölkerung die größte Gruppe stellen, die sich vom Sunnitentum unterscheidet. ${ }^{4}$

Laizität bezeichnet für gewöhnlich die Loslösung staatsbürgerlicher Rechte und Freiheiten von religiösen Auslegungen und Bekenntnissen. In der Praxis wurde dieses Prinzip verschiedenartig umgesetzt, die Trennung zwischen staatlichen und religiösen Institutionen wurde in vielen Ländern, die als laizistisch gelten, mehr oder weniger strikt vollzogen. In der BRD zum Beispiel genießen Kirchen Privilegien in öffentlichen Bildungs-, Erziehungs- und Cesundheitssystemen sowie Sonderrechte im Steuer- und Arbeitsrecht und sind gleichzeitig der öffentlichen Kontrolle entzogen (Cavuldak 2013). Traunmüller schlägt angesichts der »in rechtswissenschaftlichen oder politisch-theoretischen Konzepten üblichen Konzentration auf differences in kind - welche etwa idealtypisch eine strikte Trennung von Staat und Kirche von einem etablierten Staatskirchentum einerseits, sowie einem Kooperationsmodell andererseits, unterscheiden - «, eine Wende zur »Anerkennung von differences in degree« (2012: 209) vor, um die realen Verflechtungen erfassen zu können.

4 Meines Wissens gibt es keine belastbaren Zahlen zur Größe der alevitischen Cruppe im Osmanischen Reich. Auch zur Türkei fehlen genaue Zahlen. Da offiziell keine verschiedenen 
Erst in Relation $\mathrm{zu}$ ihnen könnte die Rolle der sunnitischen Geistlichen vollständig erfasst und ein annähernd realistisches Bild religiöser Strukturen für das ins Visier genommene Feld gewonnen werden. Doch wird es auch ohne ein derartiges Aufrollen des Feldes hilfreich und möglich sein, Teileinsichten und Schlussfolgerungen zu präsentieren, im Zuge dessen die Frage, wofür die heutige islamistische Bewegung streitet, nachvollziehbarer beantworten und die Tiefe der Auseinandersetzung zwischen politischem Islam und kemalistischem Laizismus besser begreifen zu können.

\subsection{Ablösung - Einschränkung der zivilgesellschaftlichen und reproduktiven Macht der religiösen Intellektuellen}

Die wissenschaftliche Geschichtsschreibung zur Rolle der sunnitischen Geistlichen, die unter dem Titel »Ulema« firmierten, stand lange Zeit unter der Perspektive eines Kampfes zwischen Moderne und Tradition, zwischen Fortschritt und Reaktion. Diese Form der Thematisierung korrespondiert mit der angesprochenen, bis ins späte 20. Jahrhundert verbreiteten Vorstellung, dass Religion und religiöse Institutionen sich auf dem Rückzug befinden und Säkularisierung einen welthistorischen Trend bildet (vgl. Calhoun u.a. 2011). Ab den 1980er Jahren wurde diese Perspektive nicht mehr nur durch reale Entwicklungen wie im Iran, sondern auch durch eine alternative Geschichtsschreibung herausgefordert, die den Widerspruch zwischen Religion und materiellem Fortschritt relativierte oder negierte. In der Türkei setzte eine sukzessive sichtbar werdende Beschäftigung mit der Thematik ein, die von Absolventen inzwischen wieder etablierter theologischer Schulen vorangetrieben wurde. Während die bis dahin mit den Geistlichen sympathisierende Literatur durch Anekdoten, Romane und journalistische Arbeiten geprägt war, schrieben theologisch geschulte Akademiker die Geschichte der osmanischen Geistlichen, als deren Erben sie sich zumeist begriffen, neu. Im Zuge dessen etablierte sich ein zweiter Pol, der die bis dahin vorherrschende Darstellung der Geistlichen in der akademischen Geschichtsschreibung als obskurant und fortschrittsfeindlich konterkarierte und sie stattdessen als Opfer einer jungtürkisch-positivistischen Verschwörung darstellte (Bein 2006: 26f.).

Beide Pole sparen Ambivalenzen in der Geschichte der Geistlichen und ihrer Institutionen im Osmanischen Reich sowie der Nachfolgerepublik aus. Sunniti-

Konfessionen des Islam anerkannt sind, gibt es keine behördlichen Statistiken. Es gibt nur Umfragen, bei denen die Angaben stark schwanken (Akşit u.a. 2012; Çarkoğlu/Toprak 2000). Ein Problem von Umfragen sehe ich darin, dass die Diskriminierung von Alevitlnnen in der Türkei ihnen nahelegt, falsche Angaben zu machen beziehungsweise ihre Identität zu verbergen. 
sche Geistliche nahmen die bereits in der Mitte des 19. Jahrhunderts innerhalb intellektueller Kreise bestehende Überzeugung, dass die Aufklärungsbewegung in Westeuropa Vorbotin einer der kapitalistischen Entwicklung eingeschriebenen Logik sei, nahezu einhellig als Bedrohung ihrer besonderen Stellung wahr. Jedoch entwickelten sie unterschiedliche Abwehr- und Anpassungsstrategien. Tendenziell bildeten sich zwei Strategien heraus: eine proaktive, die eine Reformierung der eigenen Institutionen befürwortete, um Geistliche besser zu wappnen für den kapitalistischen Fortschritt, und eine defensive, die die Konservierung der bestehenden Institutionen als besten Weg ansah, den eigenen Status zu erhalten. Die konservativ-defensive Strömung, mit dem vom Sultan ernannten Scheichülislam, der obersten religionsrechtlichen Autorität, an ihrer Spitze hielt am traditionellen Bildungssystem in den Medrese fest. Die Medrese waren mit den Moscheen eng verbundene theologische Schulen, in denen die sunnitische Lehre des Islam tradiert wurde. Reformierungsbemühungen der Medrese, deren Curricula erweitert und den neuen Erfordernissen angepasst werden sollten, stießen auf Widerstand seitens der defensiven Strömung, die sich gegen Neuerungen sperrte, weil sie ein Nachgeben als Anstoß für einen nicht mehr aufzuhaltenden Säkularisierungsprozess auffasste. Die defensive Haltung verursachte eine negative Rückkopplung. Das Ansehen der Medrese sank gegenüber den säkularen Schulen, auf denen der Nachwuchs für die Administration eines sich ausdifferenzierenden Staatswesens erzogen wurde. Die Zurückdrängung der Kirche vor Augen bildete sich in der proaktiven Strömung dagegen die Bemühung heraus, den Islam als offen gegenüber Neuem auszulegen. Der Islam sei mit dem reformunfähigen Christentum nicht zu vergleichen, ein Widerspruch zwischen Islam, Logik und Wissenschaft bestehe nicht, so die von dieser Strömung vertretene Position (ebd.: 81ff.). Das Problem des aufkommenden Nationalismus und des Nationalstaats nahmen die Geistlichen ebenfalls durch die Brille eines Vergleichs mit der »westlichen« Entwicklung wahr. Die Gründung des Nationalstaats taucht bei ihnen thematisch als Notwendigkeit auf, das Überleben »islamischer« Gesellschaften gegenüber westlicher Dominanz zu gewährleisten (Bora 1998: 105).

Die von den Geistlichen als von außen kommend thematisierte Bedrohung war indes Ausdruck von Kämpfen um Hegemonie, die innerhalb der Reichsgrenzen stattfanden. Wie in der Diskussion des staatszentristischen Ansatzes angeführt, avancierte bereits in der Tanzimat-Periode (Periode der Neuordnung) ab 1838 die Integration in den globalen Akkumulationsprozess unter der Führung einer Handelsbourgeoisie zu einer politischen Priorität (Aytekin 2015a; Boratav 1987). Entgegen der staatszentristischen Annahme, vor Gründung der Republik habe keine Bourgeoisie existiert, waren die Tanzimat-Reformen bereits Ausdruck des Aufstiegs einer Bourgeoisie und nicht Ausdruck der Initiation eines kapitalistischen 
Entwicklungswegs durch die Bürokratie. ${ }^{5}$ Eingebettet war die Entwicklung der osmanischen Bourgeoisie in eine langwierige Formationskrise des Reichs. Der historisch aus dem Kapitulationssystem - frühneuzeitliche Handelsprivilegien - entstandene Freihandel, in den das Osmanische Reich unter der Dominanz der kapitalistischen Zentren eingebunden wurde, wies der osmanischen Ökonomie die Rolle einer Rohstofflieferantin und Abnehmerin für komplexe industrielle Fertigwaren $\mathrm{zu}$, wodurch Bemühungen einer industriellen Entwicklung untergraben wurden und handwerkliche Produzenten unter einen verstärkten Konkurrenzdruck gerieten (Babacan/Gehring 2013; vgl. Quataert 2006). Bedingt durch ihre ökonomische und militärische Überlegenheit nahmen europäische Staaten zunehmend Einfluss auf die Innenpolitik des Reichs, tätigten selbst Investitionen im großen Maßstab und etablierten eine Praxis der Protektion nicht-muslimischer Bevölkerungsgruppen. Von der Protektion und sich vertiefenden Integration in globale Handels- und Finanzkreisläufe profitierte insbesondere eine Handelsbourgeoisie, die durch Assoziation mit den miteinander konkurrierenden europäischen Staaten Privilegien wie die Befreiung von Zöllen erwarb. Die dominante Fraktion der osmanischen Bourgeoisie formierte sich unter diesen Bedingungen als eine vorwiegend nicht-muslimische, die den Außenhandel, aber auch die trotz widriger Bedingungen sich entwickelnde industrielle Produktion dominierte, während das staatliche Personal weiterhin überwiegend aus den muslimischen besitzenden Klassen rekrutiert wurde, die - gegenüber der Handelsbourgeoisie - in eine ökonomisch subalterne Position gedrängt wurden (Aytekin/Uslu 2015: 97ff.). ${ }^{6}$ Eine Folge dieser Entwicklungen war ein zunehmendes Auseinanderdriften ökonomischer und

Die Entwicklung einer Bourgeoisie lässt sich auch an der Zunahme von Ateliers und Manufakturen mit der beginnenden Industrialisierung im 19. Jahrhundert in küstennahen Regionen und großen Städten ablesen (Akkaya 2002; Çağlar 2003: 93ff.; Kasaba 1988). Fragwürdig ist auch die staatszentristische Auffassung, politische Macht und Eigentum seien in den Händen des Sultans konzentriert gewesen, der despotisch über alle Untertanen herrschte. Nach Çağlar war das Privateigentum an Boden in der Entstehungsphase des Reichs sogar die vorherrschende Eigentumsform. Ab dem 15. Jahrhundert wechselten sich juristische Mischformen an Privateigentum miteinander ab. Es existierten Privatländereien und Eigentum religiöser Orden (2003: 88ff.). Daneben wird eine formalistische Interpretation der Eigentumsverhältnisse im Osmanischen Reich vorgenommen, die den Blick auf die tatsächliche Verfügungspraxis über den Boden verstellt. Der Sultan galt zwar formal als Eigentümer großer Ländereien, das lebenslängliche Recht auf Steuererhebung lag jedoch bei Vasallen, die dieses Recht de facto an ihre Nachfahren weitergaben, auch wenn eine erbrechtliche Regelung fehlte. Der Sultan fungierte in diesen Fällen als eine formale Anerkennungsinstanz. In zentralen Regionen des Reichs war ab dem 16. Jahrhundert ein Lehenswesen etabliert, wie es prinzipiell auch aus westeuropäischen Feudalstaaten bekannt ist (vgl. Aytekin 2015a). Dass sich die Handelsbourgeoisie überwiegend christlich konstituierte, bedeutet nicht, dass die christliche Bevölkerung des Reichs als solche den besitzenden Klassen angehörte. Der allergrößte Teil der christlichen Bevölkerung setzte sich so wie die Gesamtbevölkerung aus kleinen Bauern zusammen, die aber im Unterschied zur muslimischen Bevölkerung Sonder- 
politisch-militärischer Macht entlang ideologisch-kulturell (ethnisch und/oder religiös) definierter Linien, die den politischen Aufbau destabilisierte. In der christlichen Bevölkerung entwickelte sich zuerst ein eng mit der Handelsbourgeoisie assoziiertes Bildungsbürgertum, das die Hierarchie zwischen den auf religiöser Grundlage, in einem hierarchischen Verhältnis zueinander stehenden Gruppen des Reichs - den sogenannten Millet bestehend aus muslimisch-sunnitischen, christlichen und jüdischen Gruppen, unter denen die ersten eine privilegierte Stellung einnahmen - herausforderte (vgl. Göçek 1993). Die Idee einer ethnisch begründeten Nation nahm Einzug in die Vorstellungswelt der osmanischen Intellektuellen. In den Städten entstand zuerst eine an die Handelsbourgeoisie gekoppelte, »zivilgesellschaftliche« Struktur in Form von Schulen, Clubs, Zeitungen und Zeitschriften, politischen Organisationen, Gewerkschaften, Freimaurerlogen, bürgerlicher Literatur und Dichtung. Die Entwicklung einer nationalen Kultur wurde zur neuen Hegemoniestrategie kulturell voneinander geschiedener Bourgeoisien, die Führung über eine Bevölkerung mit ähnlichen kulturellen Merkmalen zu organisieren (Çağlar 2000: 483ff.).

In Reaktion auf die stärker werdenden Fliehkräfte, die in nationale Abspaltungen an den Peripherien des Reichs mündeten, entwickelten sich als Alternativen zu den ethnischen-nationalen - zuerst auf dem Balkan, dann in den arabischen Teilen des Reichs und schließlich in Anatolien auf der Grundlage einer armenischen Identität - ein osmanisches und ein islamistisches Hegemonieprojekt. Das osmanische Hegemonieprojekt versuchte, dem unterschiedlichen Religionen und Sprachgemeinschaften angehörenden Bürgertum das Bewusstsein eines gemeinsamen »osmanischen « Interesses zu vermitteln, behielt jedoch auf widersprüchliche Weise die Priorisierung des sunnitischen Elements gegenüber liberalen Staatsbürgerrechten jenseits religiöser Differenzen bei. In Abgrenzung zum Osmanismus, der die nationalen Abspaltungen auf dem Balkan nicht aufzuhalten vermochte und dadurch geschwächt wurde, setzte das islamistische Hegemonieprojekt allein auf das sunnitische Element. Welche gesellschaftlichen Kräfte genau dieses Projekt trugen, ist eine Frage, der in der Literatur nicht systematisch nachgegangen wird. Da die sunnitischen Geistlichen traditionell mit den Kleinhändlern, handwerklichen Produzenten und Grundbesitzern verwoben waren (Mardin 2006a: 307), die unter einem starken Konkurrenzdruck ihre Position zu halten oder zu verbessern suchten, liegt nahe, dass es sich in Verbindung mit diesen Gruppen entwickelte. Jedenfalls mobilisierte das islamistische Projekt gegen die mit den Tanzimat-Reformen eingeleitete politische Liberalisierung und staatsbürgerliche Gleichstellung, die das Millet-System ablösen sollten. Die Säkularisierung des Rechts- und Bildungssystems und eine massive Expansion der Verwaltung, die die ökonomische Entwick-

steuern und -abgaben entrichten mussten, also härteren Ausbeutungsbedingungen ausgesetzt waren. 
lung begleiteten, stellte die Vorherrschaft der sunnitischen Geistlichen - der Ulema - auf diesen Gebieten als Richter und Lehrer infrage (Çağlar 2000: 479ff.). Die Reformen wurden allerdings nur schleppend umgesetzt, da sie auf vielfältige Widerstände stießen (Zürcher 2004: 52ff.). Die mehr als 30-jährige Herrschaft von Sultan Abdülhamit II. (1876-1909) unterbrach schließlich den an der Stellung der Geistlichen rüttelnden Reformprozess der Tanzimat-Periode. Die für kurze Zeit in Kraft getretene Staatsverfassung, die die Säkularisierung des Rechtssystems und Gleichstellung anderer Religionsgemeinschaften festschrieb, wurde außer Kraft gesetzt, die Reformkräfte wurden ins Ausland vertrieben, Opposition wurde unterdrückt und ein Ausbau sunnitischer Institutionen gefördert. Den sunnitischen Geistlichen wurde in Konfrontation mit der Transformation religiöser Gruppen in nationale Gemeinschaften wieder ein größeres Gewicht verliehen (Zürcher 2004: 79ff.). Ulema wurden verstärkt auch in die Provinzen außerhalb der Hauptstadt entsandt, gleichzeitig wurde die Kontrolle über die gesamte religiöse sunnitische Struktur verstärkt, die über die Ulema hinaus lokale Orden und religiöse Logen umfasste, die wiederum mit den Gilden verschränkt waren. Abdülhamit inszenierte seine Rolle als Kaliph, führte Zeremonien und Symbole ein, die seine Legitimation als glorreichen muslimischen Herrscher untermauern sollten. Mit der Gründung der nach ihm benannten Hamidiye-Regimenter, hauptsächlich aus Mitgliedern sunnitisch-kurdischer Clans bestehend, wurde eine para-militärische Truppe gebildet, die gegen Russland und armenische Organisationen eingesetzt wurde und zugleich der Kontrolle und Integration der sunnitisch-kurdischen Bevölkerung dienen sollte. Die Regimenter wurden schließlich zu Instrumenten von Clans, die in den Jahren 1894-1896 den Genozid einleiteten, indem sie Massaker an der armenischen aber auch der alevitischen Bevölkerung begingen, deren Besitz sie beschlagnahmten (Kieser 2000). ${ }^{7}$ Eine mobilisierende und legitimierende Rolle bei der Ausübung der Massaker nahmen Medrese-Studenten sowie sunnitisch-kurdische Scheichs ein, die mit religiöser Autorität ausgestattete Grundbesitzer waren. Das Ineinanderfallen von religiöser Autorität und Grundbesitz in Kurdistan gibt einen weiteren Hinweis auf die Klassengrundlage des damaligen Islamismus (vgl. Aydınkaya 2015; Aytekin/Uslu 2015: 152). ${ }^{8}$

Wird unter Cenozid die systematische Vernichtung einer Cruppe begriffen, die bestimmte kulturelle Merkmale trägt, so sind die Jahre 1915/1916 ein Kulminationspunkt, der in einer Kontinuität von Vernichtungs- und Vertreibungsaktionen steht, die in den vorangehenden wie auch nachfolgenden Jahrzehnten auf dem Boden des Osmanischen Reichs bzw. des Nachfolgestaats Türkei durchgeführt wurden.

8 Zur Geschichte religiöser Organisierungsweisen in Kurdistan kann exemplarisch die Arbeit von van Bruinessen (1992) herangezogen werden, der aufzeigt, dass geistliche Führung und die Verfügung über Land und Boden häufig in einer Person oder Familie zusammenfielen. Siehe auch bei Mardin (2006a: 307), der schreibt, dass Cutsbesitzer gleichzeitig geistliche Führungsfiguren waren. 
Resümierend lässt sich festhalten, dass das islamistische Projekt als eine repressive Reaktion entstand, um inmitten massiver territorialer Verluste sowie sich verstärkender Fliehkräfte die politische Zentralisierung durch eine kulturelle Zentralisierung zu untermauern. Obgleich die Abdülhamit-Periode nicht per se »vormodern « war, wie es in der kemalistischen Geschichtsschreibung mit einem abwertenden Zungenschlag heißt, die Zentralisierung der Verwaltung, der Ausbau der Infrastruktur und die Investitionen in die Produktivkraftentwicklung fortgeführt, neue Schulen gegründet wurden, die konservativ-sunnitische Auffassungen mit »modernem« Verwaltungswissen vereinbaren sollten, um die ökonomische Entwicklung zu fördern (Aytekin 2015b: 75), vertiefte der Islamismus dieser Periode die gesellschaftliche Spaltung zwischen Reformern und Bewahrern innerhalb des Reichs. Hierzu trug auch die Befreiung der Ulema vom Militärdienst bei, deren privilegierte Behandlung Distanz zu anderen zentralen Institutionen wie dem Militär herstellte, in dem sich säkulare Reformkräfte organisierten (Bein 2006: 52ff.).

Der an der Stellung der Geistlichen rüttelnde Reformprozess, dem sich ein gewichtiger Teil der Ulema durch den Versuch einer Konservierung ihrer Institutionen entgegenstellte oder zumindest zu entziehen versuchte, war also in politische und ökonomische Entwicklungen eingebettet. Ein Blick auf die religiösen Stiftungen, die in der Rede des Leiters der Stiftungsbehörde zu Beginn dieses Kapitels als karitative Institutionen thematisiert wurden, lässt eine Präzisierung der dem Beharrungsvermögen zugrunde liegenden Motive zu. Die Stiftungen stellten, über die Gruppe der an die Zentralverwaltung des Reichs gebundenen Ulema hinaus, eine Existenzgrundlage für Geistliche dar. Sie waren von den besitzenden Klassen abhängige Institutionen, die der Legitimation der Besitzverhältnisse und der Bereitstellung gesellschaftlich notwendiger, reproduktiver Versorgungsleistungen dienten. Sie unterstanden der Jurisdiktion von Scharia-Gerichten und verwalteten Land und Immobilien - Straßen, Brunnen, Basare, Produktionsstätten wie Manufakturen und Mühlen -, die sie zwecks Bewirtschaftung weiterverpachten konnten. Mit ihren Einnahmen wurde eine langfristige ökonomische Basis für die Bereitstellung der durch den Stifter festgelegten religiösen und sozialen Dienste gelegt. Das konnte eine Moschee oder eine Loge, eine Schule oder Pflegeeinrichtung, eine Suppenküche, ein Gasthaus oder eine Karawanserei sein. Manche Einrichtungen waren der Versorgung der assoziierten Familie oder Glaubensgemeinschaft vorbehalten, andere waren Teil einer kulturell übergreifenden sozialen Infrastruktur. Sie waren jedoch zugleich eine Reproduktionsgrundlage für die Verwalter und Organisatoren der Stiftungen: die Geistlichen.

Im Osmanischen Reich waren die Stiftungen kontinuierlich expandiert, ganze Dörfer beziehungsweise die Abgaben dieser Dörfer wurden ihnen überschrieben 
(Barnes 1987). ${ }^{9}$ Die Motive für Individuen und Familien, einen Teil ihres Besitzes in Stiftungsbesitz umzuwidmen und einen Verwalter zu ernennen, erscheinen vielfältig. An vorderer Stelle stand die Legitimation des restlichen Besitzes und der herrschenden Ordnung. Die StifterInnen erschienen als gerechte, gütige, vermittels des Glaubens mit der Bevölkerung verbundene WohltäterInnen. Die Kontrolle des reproduktiven Systems, darunter auch der Bildung, kam als Beweggrund hinzu (Isik 2014; Kuran 2001; Singer 2000). ${ }^{10}$ Ab dem Ende des 18. Jahrhunderts war die relative Autonomie der Stiftungen beschnitten worden, ihre Verwaltung war schrittweise zentralisiert und unter die Aufsicht eines Ministeriums gestellt worden. Auslösend waren Forderungen seitens europäischer Staaten, die den Stiftungsbesitz für private Investoren zugänglich machen wollten, die Suche nach neuen Finanzmitteln, um eine stehende Armee finanzieren und Schulden an europäische Staaten zurückzahlen zu können, sowie die Zentralisierung der Administration, um die wirtschaftliche Entwicklung stärker steuern zu können (Kuran 2001: 887ff.; Zencirci 2015). Im Zuge dessen war ein Konflikt mit den Verwaltern der Stiftungen und den Geistlichen entstanden, die als Überwacher und Angestellte an die Stiftungen gebunden waren. Sie hatten gegen Steuerreformen opponiert oder deren religiöse Legitimation verweigert, auf die die tragenden Akteure des einsetzenden kapitalistischen Transformationsprojekts angewiesen waren, da die Erhebung von Steuern auf der Basis des islamischen Rechts gerechtfertigt wurde.

Die Schlussfolgerung, dass die Blockadehaltung von Geistlichen auf der Gegenseite den Befürwortern einer Säkularisierung Auftrieb verlieh, liegt nahe (Duzgun 2012). Offenbar befanden sich die Geistlichen inmitten eines Richtungsstreits innerhalb der besitzenden Klassen. Die institutionell eingebetteten Gruppeninteressen der Geistlichen müssen dem Flügel des Machtblocks, der die Reformen antrieb, als Hemmschuh in der Verfolgung seiner Entwicklungsziele erschienen sein. Es

$93 / 4$ des urbaren Landes in Anatolien soll nach offiziellen Dokumenten aus dem Jahr 1923 der Verwaltung von Stiftungen unterlegen haben, schreibt Kuran (2001). Andere Quellen sprechen von der Hälfte des Staatsbesitzes, das sich unter der Verwaltung von Stiftungen befunden haben soll. Solche Angaben sind allerdings schwer nachzuvollziehen. Was es im Einzelnen heißt, ein Stück Land habe unter der Verwaltung einer Stiftung gestanden, ist nicht immer klar. Skepsis ist auch gegenüber statistischen Erhebungsmethoden von vor 100 Jahren angebracht, die in einem bis heute nicht vollständig katastriertem Land wie der Türkei Besitzanteile an urbarem Land bestimmen. Doch wie hoch auch immer der tatsächliche Anteil war, nachvollziehbar ist, dass die Reproduktion von Geistlichen auch an die Stiftungen gebunden war.

10 Barnes (1987) bezeichnet die »vakıf« oder »vaqf« als ein Äquivalent zum Kirchenbesitz im Christentum, da er theoretisch nicht veräußert werden konnte. Die Unveräußerlichkeit wurde als Überführung in Cottesbesitz ideologisiert. Dass Stiftungsbesitz zumindest auf dem Papier dem Handel entzogen wurde, begründet die Wortbedeutung von »vakıf«: Stilllegen, aus dem Verkehr ziehen. In der Praxis gab es jedoch durchaus Besitzwechsel und Umwidmungen (Singer 2000). 
liegt nahe, dass nicht nur europäische Staaten, sondern auch interne Akteure ein Auge auf den Stiftungsbesitz geworfen hatten, der ein Hindernis für die mittels verschiedener Reformen in die Wege geleitete Privatisierung der Produktionsmittel darstellte (vgl. Kuran 2001: 887ff.). Die vorsichtige Formulierung resultiert aus dem Umstand, dass es sich hierbei um kein gesichertes Wissen handelt, sondern um eine Hypothese, die aus der schlussfolgernden Interpretation parallel stattfindender Entwicklungen gewonnen wurde. $\mathrm{Zu}$ diesem Komplex lässt sich keine genauere Aussage ohne erhebliche eigenständige historische Forschung treffen, $\mathrm{da}$, wie schon angesprochen, die themenbezogene Literatur zumeist Ideen oder ökonomische Daten untersucht und vergleicht, ohne ihre gesellschaftlichen Träger und deren materielle Reproduktionsgrundlagen genauer in den Blick zu nehmen. Die Wissenslücke hinsichtlich der wirkenden Interessen oder Kräftekonstellationen wird oft mit abstrakten Akteuren wie Staat, Zentrum oder Peripherie gefüllt.

Die Gegenbewegung, die aus der Abdülhamit-Periode, die den Zerfall des Reiches ebenfalls nicht aufhalten konnte, hervorging, waren die Jungtürken, die 1908 eine politische Revolution vollzogen, mit der der im frühen 18. Jahrhundert beginnende Aufstieg der bürgerlichen Klasse politisch abgeschlossen wurde (Savran 1985). Die vorausgehende islamistische Repression und das Versprechen, eine republikanische Verfassung und Bürgerrechte im Rahmen einer osmanischen Identität einzuführen, mobilisierten Vertreter verschiedener Religionszugehörigkeit und Ethnizität für das jungtürkische Ziel, den Zerfall des Reichs aufzuhalten. Gleichwohl setzte sich eine türkistische Strömung innerhalb der Jungtürken immer stärker durch und dominierte $a b$ 1913, sodass das anfangs integrative Hegemonieprojekt der Jungtürken die bereits vorhandenen Tendenzen ethnisch-nationaler Spaltung noch stärker vorantrieb (Zürcher 2004: 110).

Die Jungtürken beendeten die Abdülhamit-Periode und fanden in der konservativen Strömung der Ulema harte Opponenten, die eine eigene Organisation gründeten, die sich aktiv in das politische Geschehen einmischte und gegen die jungtürkische Regierung Partei ergriff, die sie als existenzielle Bedrohung wahrnahm. 1909 schloss sich ein großer Teil der Studenten an den Medrese in Befürchtung einer Abschaffung ihrer Privilegien und ihrer beruflichen Möglichkeiten einer Konterrevolution gegen die Jungtürken an, die jedoch scheiterte (Bein 2006: 70). Eine zweite Gruppe stellte sich dagegen auf die Seite der Jungtürken, auch weil sie davon überzeugt war, dass sie am ehesten den Zerfall des Osmanischen Reichs aufhalten könnten. Die Jungtürken reformierten die Medrese, führten Naturwissenschaften und west-europäische Sprachen als Lehrfächer ein. Dass sie die Geistlichen komplett verdrängen wollten, wie in der islamistischen Literatur häufig behauptet wird, ist aber nicht nachvollziehbar. Erst mit den Entwicklungen nach dem Ende des Ersten Weltkriegs wurde die Spaltung zu einem Bruch. Mit der Niederlage der Jungtürken und der teilweisen Restauration des Sultanats gewannen die konservativen Ulema wieder die Überhand. Reformen wurden rückgängig ge- 
macht und die mit den Jungtürken verbündeten Ulema verfolgt. Der Bruch mit den Jungtürken und ihrer politischen Nachfolgebewegung - den Kemalisten - wurde durch weitere einschneidende Ereignisse vertieft. Nach der Niederlage im Ersten Weltkrieg stellten sich der wiedereingesetzte Scheichülislam, hochgestellte Ulema und ihre Organisationen in Istanbul auf die Seite der Kapitulationsregierung und gegen die nationale Widerstandsbewegung, die sich in Anatolien gegen die Siegermächte des Ersten Weltkriegs zu organisieren begann und unter der Führung des Armeeoffiziers Mustafa Kemal den »Unabhängigkeitskrieg « einleitete (ebd.: 218). Etliche Ulema nahmen hohe Posten in der von den Siegermächten bewilligten neuen Regierung ein, erhofften sich eine Restauration ihrer traditionellen Macht gegen säkulare Reformen. Der Preis, den sie zu zahlen bereit waren, war die Akzeptanz der Kapitulationsbedingungen, die das Osmanische Reich auf ein kleines, unter alliierter Kontrolle stehendes Gebiet begrenzte, das zudem durch den Einmarsch griechischer Truppen sich vollkommen aufzulösen drohte. Sie bekämpften die unter Mustafa Kemal gebildete Parallelregierung in Ankara und diskreditierten sich dadurch in den Augen der Widerstandsbewegung als Kollaborateure der Siegermächte (ebd.: 263f.).

Die neue politische Führung, die sich schließlich gegen das Sultanat in Istanbul durchsetzte, einen neuen Friedensvertrag aushandelte und die Republik gründete, entschied vor dem Hintergrund dieser Entwicklungen, die Organisationen der Ulema zu zerschlagen, auch um eine Situation der Doppelmacht, die in den Kämpfen zuvor mehrfach aufgeschienen war, zu unterbinden (vgl. Gözaydın 2009: 26f.). Durch den Zusammenbruch des Osmanischen Reichs und das Schrumpfen des Staatsgebiets auf Anatolien war der Anspruch obsolet geworden, die geistliche Führung aller Muslime auf der Welt zu stellen. Religiöse Institutionen, die diesen Anspruch repräsentierten, wurden abgeschafft. Die Abschaffung der Institution des Scheichülislam und des Kaliphats, durch das der Sultan zum legitimen Nachfolger des Propheten erkoren wurde, hob die zentrale Stellung der Religion auf. Das religiöse Zivilrecht wurde in ein allgemein verbindliches bürgerliches Zivilrecht überführt, womit religiöse Richter (Kadı) ihre aus der islamischen Rechtsauslegung hergeleiteten Kompetenzen wie das Recht auf Eheschließung und die Auslegung des Erbrechts, sowie die Erbringung religiöser Dienstleistungen wie bei Geburten verloren (Mardin 2006b: 233ff.). Das Bildungssystem wurde säkularisiert, die Ausbildungsstätten mit islamischem Schwerpunkt (Medrese) geschlossen und alle Moscheen staatlicher Aufsicht unterstellt. ${ }^{11}$ Mit dem Verlust ihrer ideologischen und politisch-rechtlichen Funktionen verloren viele Geistliche ihre materiellen Reproduktionsgrundlagen. Mit dem Verbot und der Enteignung religiöser Logen, Orden 
und Bruderschaften (»tekke«, »zaviye« und »tarikat«) wurden religiöse Organisierungsweisen und Netzwerke illegalisiert, womit das Band zur Bevölkerung durchtrennt werden sollte (Çağlar 2003: 172).

Eine Reihe weiterer politischer Ereignisse ließ die »Bekämpfung der religiösen Reaktion« zu einem zentralen Motiv der frühen Republik werden. Im Zuge des »Unabhängigkeitskriegs« nach dem Ersten Weltkrieg wurde von der nationalen Widerstandsbewegung, die von Mitgliedern der besitzenden Klassen angeführt wurde, noch eine »Gemeinschaft der Muslime« angerufen (Gürel 2014: 318). Über ideologische Agitation hinaus waren die Aussicht auf eine armenische Staatsgründung im Osten Anatoliens und die Rückkehr der vertriebenen christlichen Bevölkerung, die den Genozid überlebt hatte, deren Besitz aber beschlagnahmt und umverteilt worden war, maßgebliche Mobilisierungsfaktoren (Çağlar 2000: 505).

Um die Bedeutung des Genozids für die Hegemoniebildung einschätzen $\mathrm{zu}$ können, ist an dieser Stelle ein Einschub erforderlich. Der Genozid ging nicht nur der Formierung des bürgerlichen Machtblocks, sondern auch der Formierung sozio-politischer Blöcke in der Republik Türkei voraus. Die Ermordung und Vertreibung der christlichen Bevölkerung, die ihren Höhepunkt im Ersten Weltkrieg unter der politischen Führung der Jungtürken erreichte, wurde unter Beteiligung verschiedener Gruppen in allen Reichsteilen durchgeführt. Die Neuverteilung des Eigentums der Vertriebenen und Ermordeten bildete die materielle Basis für eine "muslimische« Bourgeoisie, deren Förderung von den Jungtürken in Kontinuität zur Abdülhamit-Periode schon vor dem Krieg betrieben worden war (Boratav 1987: 29; Gerlach 2002; Özçelik 2015). Zugleich wurden noch während des Krieges verlassene Gehöfte und Werkstätten der Vertriebenen von der lokalen Bevölkerung wie auch von den bereits vor dem Krieg aus den abgespalteten Reichsgebieten des Balkan und Kaukasus vertriebenen Millionen muslimischer Flüchtlinge in Besitz genommen und als Mittel der Subsistenz oder für warenförmige Produktion im kleineren Maßstab benutzt (Çağlar 2000: 505; Keyder 1987: 81f.; Zürcher 2004: 171f.). ${ }^{12}$ Die theoretische Diskussion zur Frage materieller Konzessionen bei der Hegemoniebildung aufnehmend lässt sich argumentieren, dass die Verteilung der Kriegsgewinne als eine historisch spezifische Form eines materiellen Gründungskompromisses zwischen verschiedenen Klassen und Gruppen betrachtet werden kann. Die Verteilung stellte keinen sozialdemokratischen Kompromiss zwischen einer organisierten Arbeiterklasse und einer Bourgeoisie dar, vielmehr formierte sich die materielle Basis eines klassenübergreifenden Kompromisses auf der Grundlage einer

12 Eine spätere Enteignungswelle der nicht-muslimischen Bevölkerung wurde durch eine Vermögenssteuer 1942 erwirkt. Die nicht-muslimische Bevölkerung wurde gezwungen, ihr Kapital und ihren Grundbesitz zu liquidieren, um die schlagartig auferlegte Steuer zu begleichen. Durch den Zwangsverkauf zu niedrigen Preisen wurden erneut »anatolischen Muslimen«Vermögen transferiert (Boratav 1987: 69). 
Enteignung und Umverteilung, die bis heute - aufgrund der aktiven wie passiven Verwicklung eines erheblichen Teils der Bevölkerung quer zu den Klassenlagen ein die sozio-politische Blockbildung prägendes Element darstellt.

Die Einbindung kurdischer Gruppen beziehungsweise kurdisch-sunnitischer Geistlicher in die nationale Widerstandsbewegung basierte zum einen auf ihrer Mitwirkung am Genozid, zum anderen bedingte sie, dass zu dieser Zeit noch eine Restauration des Kaliphats auf der Grundlage einer sunnitischen Identität verhandelt wurde. Bis 1922 wurde die »osmanische Nation« beschworen, die auf den Islam als vereinheitlichendes Element aufbaute (Özdalga 2006). Die frühen 1920er markieren folglich eine Zwischenphase, in der das Neue noch in alten Kleidern auftrat. Deutlich zu erkennen ist dies an der aus dem Jahr 1921 stammenden und bis heute gültigen Nationalhymne, die keinen ethnischen Bezug enthält, dafür aber eine ausnehmend kriegerische Gottesverehrung mit einem islamistischen Nationalismus verbindet. Eine Wende zur Formierung eines kemalistisch-säkularen Hegemonieprojekts markieren die Jahre 1924-25. 1924 erfolgte die generelle Untersagung von Parteigründungen außerhalb der CHP, nachdem sich eine parteiförmige Opposition formiert hatte, die auch mittels eines religiös aufgeladenen Diskurses mobilisierte, der die Regierung in Ankara als anti-religiös darstellte. Religiöse Intellektuelle artikulierten Opposition, die sich auf Mustafa Kemal (Atatürk) als »Ungläubigen « und die Bürokratie als Trägerin einer fremden Lebensart einschoss und die republikanische Staatsform zu einem Synonym für Verwestlichung und Entfremdung von einem kulturellen Selbst erhob. Ein Zitat des islamistischen Intellektuellen Mehmet Akif Ersoy (1873-1936), dem Verfasser der Nationalhymne, gibt den kulturkämpferischen Ton der Anklage gegen republikanische Reformen auf prägnante Weise wieder:

》Clieder einer Nation, deren Religion ein Abklatsch, deren Welt ein Abklatsch, deren Sitten ein Abklatsch, deren Kleidung ein Abklatsch, deren Reden ein Abklatsch, die im Ganzen ein Abklatsch, also auch ein Abklatsch des Menschen sind, sind nicht fähig, eine echte Cemeinschaft zu bilden, können deshalb auch nicht überleben.« (zit.n. Yücekök 1977: 90, Übersetzung E.B.) ${ }^{13}$

Als 1930 von der CHP-Führung die Bildung einer Oppositionspartei initiiert wurde, um inmitten der Weltwirtschaftskrise eine kontrollierte Opposition zuzulassen, die die Unzufriedenheit mit der wirtschaftlichen Situation absorbieren sollte, dominierten islamistische Intellektuelle in kurzer Zeit den Diskurs dieser Partei, wie schon 1924, mit ihrer anti-säkularen Agitation. Die Partei gewann rasch an Popularität, drohte zu einer ernsthaften Herausforderung für die CHP zu werden, sodass

13 Das Zitat wurde so wie alle anderen türkischsprachigen Zitate in dieser Arbeit von mir übersetzt. 
das politische Manöver zur Absorption der Unzufriedenheit mit der wirtschaftlichen Situation beendet und die Partei wieder geschlossen wurde. In diese Zeit fällt auch die Untersagung der Benutzung religiös aufgeladener Sprache für politische Zwecke (Toprak 2005).

Die über Jahrhunderte tradierte Macht religiöser Autoritäten schlug sich in der frühen Republik auch darin nieder, dass sie eine führende Rolle in Bewegungen einnahmen, die für lokale Autonomie, in Kombination mit der Wiedereinführung des Kaliphats wie beim kurdischen Scheich Said Aufstand, mobilisierten. Die Regierung ging rigoros gegen solche Bewegungen vor, versuchte, jede potentielle Form der Doppelmacht militärisch zu zerschlagen. Mit der Niederschlagung des Scheich Said Aufstands im Jahr 1925 setzten die kategorische Leugnung der kurdischen Ethnie und der Schwenk zum eindeutig ethnischen Nationalismus - dem Türkismus - ein, der eine Assimilation der kurdischen Ethnie vorsah (Bora 1998: 17ff.; Bozarslan 2003 u. 2008; van Bruinessen 1989). ${ }^{14}$ Unterdessen zeigt das Massaker an der alevitischen Bevölkerung in der Provinz Dersim (1937-38) an, dass der politische und soziale Charakter von Bewegungen, die von Geistlichen mit angeführt wurden, entgegen der kemalistischen Geschichtsschreibung sich nicht auf den Begriff reaktionär reduzieren lassen. Vielmehr trat der kemalistische Topos »Bekämpfung der religiösen Reaktion« auch als Chiffre zur Legitimation der Zentralisierung der Staatsgewalt sowie der ethnischen Homogenisierung auf, um das ambitionierte republikanische Entwicklungsprogramm umzusetzen (vgl. van Bruinessen 2000).

Sowohl die 1924 als auch die 1930 gegründete und kurz darauf verbotene Partei adaptierte ein wirtschaftsliberales Programm. Da beide Parteien keine Chance erhielten, ihr Programm umzusetzen, lässt sich nicht beurteilen, ob sich ihre Wirtschaftspolitik in der Praxis tatsächlich von der Politik der CHP unterschieden hätte. Es lässt sich aber festhalten, dass die Verbindung zwischen Wirtschaftsliberalismus und Islamismus kein neuartiges Phänomen ist, das erst mit der AKP aufkommt. Eine weitere Parallele zur späteren islamistischen Bewegung besteht darin, dass der islamistische Diskurs der 1920er Jahre die »Bürokratie« für die Umwälzung der Produktions- und Lebensweisen verantwortlich machte, damit die Position der Großgrundbesitzer und der Handelsbourgeoisie kaschierte, die bis in die 1950er Jahre die dominierenden Klassenfraktionen in Anatolien waren. Die Herstellung günstiger Bedingungen für die Reproduktion dieser Fraktionen, für ihre Eingliederung in den globalen Warentausch war langfristig mit negativen Folgen für Kleinbauern, Handwerker, Kleinhändler wie auch Landarbeiter und Subsismenhang, der in der Literatur als »kurdische Frage« diskutiert wird. Auf diese Frage wird im späteren Verlauf der Arbeit gesondert eingegangen. 
tenzbauern verbunden, die dem Wettbewerb nicht standhalten konnten und unter einen Proletarisierungsdruck gerieten (Yücekök 1977: 90f.). Unter der Ägide religiöser Intellektueller, die durch die schrittweise Zurückdrängung ihrer jahrhundertelangen Vormachtstellung mit einem Statusverlust konfrontiert waren, wurde die Identifikation der Bürokratie als verantwortliche Täterin mit einer kulturellen Denunziation verbunden, die die Bürokratie als verwestlicht und gottlos anzeigte. Der denunziatorische Diskurs verbarg, dass die religiösen Intellektuellen selbst zu einem erheblichen Teil der Bürokratie als Ulema angehört hatten beziehungsweise für sich einen bürokratischen Status reklamierten.

Zusammenfassend kann festgehalten werden, dass die Säkularisierung in Verschränkung mit der Zentralisierung der politischen Verwaltung unter einem ökonomischen Druck von außen wie von innen verlief. Der historische Abriss gibt zu erkennen, dass die Zurückdrängung der Ulema nicht als ein evolutionär-logischer Prozess aufgefasst werden sollte, den die bürgerliche Vergesellschaftung - häufig im Begriff der Modernisierung als neutraler Prozess gefasst - automatisch mit sich bringt. Sofern Geistliche mit der alten, dezentralen Ordnung verbunden waren und deren Beharrungsvermögen repräsentierten, wurden sie zu einem Hindernis in der Reformierung des Finanz- und Steuerwesens im 19. Jahrhundert. Sofern ihre Reproduktion an Stiftungsbesitz gebunden war, den sie verteidigten, standen sie der Privatisierung der Produktionsmittel im Wege. Sofern sie sich einer Anpassung der Schulbildung an reproduktive Erfordernisse einer kapitalistischen Entwicklung verweigerten, disqualifizierten sie sich als organische Intellektuelle dieses Entwicklungswegs. Sofern sie sich gegen die Jungtürken, anschließend gegen die nationale Unabhängigkeitsbewegung auf der Seite der Kapitulationsregierung positionierten, danach lokale Aufstände und Widerstände gegen die neue Zentralregierung anführten, diskreditierten sie sich als regierungstreue Intellektuelle.

Der säkulare, evolutionistische und mechanisch-materialistische Kollektivwille, eine Republik nach westeuropäischem Vorbild aufzubauen, formierte sich schon in der ersten Hälfte des 19. Jahrhunderts insbesondere in den Militärschulen unter dem Einfluss der europäischen Aufklärungsbewegung (Aytekin/Uslu 2015: 185). Die Entschlossenheit der politischen Führung unter Mustafa Kemal, die Vorherrschaft religiöser Weltauffassungen zurückzudrängen, erscheint als letzte Abrundung dieses Willens, der unter der Hegemonie westeuropäischer Akkumulationszentren Reformen in Gang setzte, die das kulturpolitische Gegenstück zur »Bekämpfung der Reaktion«bildeten. Die Einführung von Familiennamen, der lateinischen Schrift und »moderner" Kleidungsvorschriften, die rechtliche Gleichstellung der Geschlechter, das Verbot von Polygamie, die Entfernung der Klausel, die den Islam als "Religion des Staates" festschrieb und andere Reformen unter dem Topos des »Erreichens des Niveaus der kontemporären Zivilisation« können so als Bestandteile einer Kulturrevolution zur Bildung eines neuen nationalen Bewusstseins, als kemalistisch-säkulares Hegemonieprojekt gefasst werden. 
Unabhängig von der sozialen Herkunft ihrer Mitglieder waren die Jungtürken ihren Inhalten und Zielen nach eine bürgerliche Organisation, auf die die Kemalisten folgten (Savran 2010; Reyhan 2008). In politischer Kontinuität zu den Jungtürken führten die Kemalisten eine Politik fort, die die sozio-kulturellen Grundlagen einer nachholenden kapitalistischen Entwicklung bereitstellen, die nationale Bourgeoisie fördern und die ökonomischen Aktivitäten im Rahmen eines nationalen Marktes zusammenführen sollte (Savran 2015; Toprak 1982). Begünstigt von wirtschaftspolitischen Entscheidungen wurden inländische Produktionsmittelbesitzer gefördert. Der Etatismus der frühen Republikperiode, der im staatszentristischen Ansatz als Primat des Staates interpretiert wird, war ein kapitalistisches Entwicklungsprogramm, das unter den Bedingungen der Weltwirtschaftskrise 1928/29 das Hauptaugenmerk auf die Stärkung einer nationalen Bourgeoisie legte. Mit der Gründung öffentlicher Banken und staatlicher Betriebe in kapitalintensiven Sektoren sowie der Koordinierung knapper Investitionsmittel ab den 1930er Jahren wurde ein Industrialisierungsprogramm eingeleitet, das auf den Akkumulationsprozess der Privatunternehmen abgestimmt war. Die staatlichen Betriebe agierten nicht nur als Lieferanten eines günstigen Produktionsinputs, sondern auch als wichtige Absatznehmer für die Privatunternehmen. Diese Komplementärbeziehung, die als »Etatismus« bezeichnet wird, blieb noch weit über die dreißiger Jahre hinaus ein wichtiges Merkmal staatlicher Politik. Noch bevor die Konturen dieses Projekts klar zu Tage getreten waren, hatten die Kemalisten Anfang 1921 die politische Führung einer sich formierenden sozialistischen Bewegung, die vor dem Hintergrund der Oktoberrevolution im benachbarten Russland an Ausstrahlungskraft gewonnen hatte, verhaften oder ermorden lassen (Aytekin/Uslu 2015: 171ff.). Mit der offensiven Negierung der Existenz von Klassen wurde die Unterdrückung der Organisierung der Arbeiterbewegung legitimiert (Boratav 1987: 30ff., 51; vgl. Boratav 2005).

Orientiert an Gramscis Gliederung von Entwicklungsstadien lässt sich formulieren, dass die Republikgründung die Überführung der Bourgeoisie aus einem korporativen in ein politisches Stadium abschloss (Yalman 2002). Die CHP bildete die organisatorische Struktur, in der die besitzenden Klassen politisch zusammengeführt wurden. Die Erziehung der intellektuellen Träger des kapitalistischen Entwicklungsprogramms geschah maßgeblich über die Säkularisierung und Vereinheitlichung des im Osmanischen Reich fragmentierten Bildungs- und Erziehungswesens, mit der eine kulturelle Vereinheitlichung der Nation erreicht werden sollte (vgl. Şener 2015). Der heute noch aktive Topos vom »Erreichen des Niveaus der kontemporären Zivilisation « rekurrierte auf die Frage eines neuen nationalen Bewusstseins. Erziehungspolitische Maßnahmen, die das Leitbild eines an der urbanen west-europäischen Lebensweise ausgerichteten »modernen« Menschen etablierten, standen in Verbindung mit einem ökonomischen Programm, für das die Zentralisierung der Staatsgewalt fortgeführt und mit dem - auch über Gesetze - 
das Bewusstsein eines gemeinsamen nationalen, „türkischen «Interesses unter der Führung des sich etablierenden Bürgertums geschaffen werden sollte. Vor diesem Hintergrund kann die Politik der CHP als Organisierung einer "programmatischen Ökonomie« bestimmt werden, mit der Gramsci die intensivierte Abstimmung von Produktions- und Lebensweise begrifflich fasste (Gramsci 1991ff.: 2063).

Die offizielle Türkische Geschichtsthese konstruierte ab der zweiten Hälfte der 1920er Jahre die nationale Identität als Synthese von Türkischsein und Zivilisation. Das Islamische, das sukzessive mit dem Arabischen gleichgesetzt wurde, war hiervon ausgeschlossen (Özdalga 2006). Das Territorium und die Staatsbürgerschaft, die Rasse und die Ethnie wechselten sich als dominante Elemente des kemalistischen Nationalismus ab. In allen Formen wurde die Nation aber als eine säkulare, nicht-religiöse Entität definiert, die mit Ausnahme der frühesten Phase der Republik als organisch-kulturelle Einheit konzipiert wurde. Das Türkentum sollte einen Schmelztiegel bilden, um nicht-türkische muslimische Gruppen in der Türkei zu assimilieren und in eine einheitliche türkische Nation $\mathrm{zu}$ integrieren (Saraçoğlu 2011). Der ethnisch-säkulare Nationalismus, zu dem die CHP heute noch tendiert, wurde in den 1930er Jahren durch das Prinzip des Populismus ergänzt, worunter die kulturelle Verbreitung der republikanischen Ideale begriffen wurde (vgl. Koçak 2001; Odman 2006).

Das Parteienverbot und andere Restriktionen wie das Verbot der Orden und Bruderschaften zwang viele Islamisten in die außerparlamentarische Opposition, die sie über verschiedene Medien fortsetzten (Savran 2015: 70). Die Spaltung der Geistlichen in zwei Lager hielt auch in der Republik an: Während eine Strömung aus der Niederlage die Lehre zog, dass eine offene und radikale Opposition gegen die Säkularisierung schädlich, graduelle Anpassung notwendig ist, um eine totale Niederlage abzuwenden, beharrte eine zweite Strömung auf der radikalen Ablehnung der Republik und machte die Anpassungsbereiten für die Niederlage mitverantwortlich. Mitglieder der letzten Generation der osmanischen Ulema überwinterten bis in die 1950er Jahre in den republikanischen Institutionen, bekleideten Positionen im Bildungs- und Justizbereich (Bein 2006: 294). Mit Gründung der Diyanet İşleri Başkanlığı (Amt für Religiöse Angelegenheiten, im Folgenden nur Diyanet) im Jahr 1924 blieb der Religion eine institutionelle Grundlage erhalten. Ulema, die sich auf die Seite der Jungtürken gestellt hatten, nahmen leitende Positionen in der lange Zeit relativ kleinen Diyanet ein, auf deren Rolle und Entwicklung an späterer Stelle ausführlicher eingegangen wird.

Im Rahmen des staatszentristischen Ansatzes wird im Anschluss an den von Max Weber theoretisch bestimmten patrimonialen Herrschaftstyp die These vertreten, die Ulema seien nicht frei gewesen, sie hätten in der Ausübung ihrer Tätigkeit und der Auslegung des Koran den Befehlen des Sultans gehorchen und damit dem Primat des Staates folgen müssen (Inalcik 1969). Die skizzierte Geschichte der sunnitischen Geistlichen in der Endphase des Osmanischen Reichs bis in die frühe 
Republik hinein zeigt auf, dass sie keine opportunistischen Bürokraten waren. Sie konnten abwägen, ob sie Vorgaben Folge leisten wollten, auch wenn es sie möglicherweise ihren Status oder mehr kostete. Sie vertraten divergierende Positionen zu den politischen Entwicklungen ihrer Zeit, insbesondere zu den ihre eigenen Privilegien betreffenden Angelegenheiten, organisierten sich auch in Parteien und agierten nicht bloß als treue Anhänger des Sultans. Auch wenn die ideologische Legitimation wechselnder und sich widersprechender Vorgaben zu ihren Aufgaben gehörte, machte die Wahrnehmung dieser Aufgabe sie nicht zu Erfüllungsgehilfen ohne eigenen Willen, sondern zu Verfolgern ihrer qua gesellschaftlicher Funktion eingenommenen Position. Sie können als organische Intellektuelle der osmanischen Gesellschaftsformation bezeichnet werden, die in den Machtblock integriert waren. In der von ihnen ausgeübten Funktion waren politische und zivilgesellschaftliche Aufgaben mit reproduktiven Aspekten im doppelten Sinne - sowohl gesellschaftliche als auch gruppenspezifische - miteinander verschmolzen. Im historischen Übergang zur kapitalistischen Produktionsweise erlitt die Mehrzahl von ihnen eine Niederlage, durch die sie ihre privilegierte Stellung bei der Vermittlung der Hegemonie der besitzenden Klassen und zugleich ihre materiellen Reproduktionsgrundlagen als organische Intellektuelle verloren. Die Entkopplung der reproduktiven von der religiösen Struktur bedeutete eine Entwertung sozialer und kultureller Ressourcen, über die sie als Schriftgelehrte, Juristen, Erzieher und Mitglieder einer vernetzten Struktur verfügten. Die Säkularisierung beziehungsweise der kemalistische Laizismus führten dazu, dass ihre Ressourcen in diesen Praxisfeldern, die sich in Verschränkung mit der Vermittlung von Hegemonie ausgebildet hatten, nicht mehr ausreichten, um die entsprechenden Praktiken ausüben zu können.

\subsection{Wiederanbindung und Re-Formation: Aufbau kulturpolitischer Institutionen der Religion und Entwicklung des türkisch-islamischen Hegemonieprojekts}

Die Rekonstruktion der gesellschaftlichen Stellung, die die religiösen Intellektuellen einnahmen, lässt besser begreifen, weshalb die osmanische Ordnung für sie eine zentrale historische Referenz bildet. Die Elemente dieser Stellung waren die institutionalisierte Einbindung in die Verwaltung des Reichs über die Rechtsprechung, das Bildungssystem und die Verfügung über Produktionsmittel in Verbindung mit relativ autonomen Institutionen, die reproduktive und religiöse Dienstleistungen erbrachten. Artikuliert waren sie mit der Aufgabe, die Hegemonie der besitzenden Klassen auszuüben. Die republikanische Revolution besiegelte einen tiefen Einschnitt in ihrer gesellschaftlichen Stellung, die unter anderem an das Stiftungswesen gebunden war. Die Restauration osmanischer Artefakte und des 
Stiftungswesens, die der zu Beginn des vorangegangenen Abschnitts zitierte emsige Behördenleiter Beyazıt im Jahr 2009 betrieb, ist aus ihrer Perspektive nicht nur die Wiederherstellung einer symbolischen Ordnung, sondern auch einer gesellschaftlichen Stellung. In den $2000 e r$ Jahren hatten die religiösen Intellektuellen schon einen beträchtlichen Weg zurückgelegt. Inzwischen waren sie eingebettet in eine soziale Bewegung, die verschiedene Organisationen und Parteien ausgebildet hatte und auf einen bemerkenswerten Geländegewinn zurückblicken konnte: Die kemalistischen Kräfte waren zunehmend aus den mittelanatolischen Regionen in die Küstenregionen verdrängt worden. Die Türkei der $2000 e r$ Jahre war Schauplatz eines stark zugespitzten Kulturkampfs konkurrierender Hegemonieprojekte, bei dem alle symbolischen Waffen ins Feld geführt wurden, die die sozialen Träger der Projekte über Jahrzehnte akkumuliert hatten. Doch wie kam es, dass die Religion beziehungsweise ihre Träger nach ihrer Zurückdrängung wieder einen derartigen Bedeutungsgewinn verzeichnen konnten?

Bereits in den 1940er Jahren wurde damit begonnen, das Rad der Säkularisierung zurückzudrehen. Ab Mitte der 1940er Jahre wurde massiv und systematisch in den Ausbau der religiösen Institutionen investiert, die Religionsbehörde Diyanet, die bis dahin ein Schattendasein fristete, wurde ausgebaut. 1949 wurde Religion als Wahlfach in Schulen wieder eingeführt, das Verbot von Wallfahrten zurückgenommen (Keyder 1987: 122). Die unter den Jungtürken reformierte Medrese, in denen allgemeine Schulbildung mit religiöser Unterrichtung kombiniert worden war, fungierte als Vorbild der theologischen Schulen, die nun schrittweise eingeführt wurden (Bein 2006: 289). In der Forschung wird dieser Vorgang als Nachgeben gegenüber der religiösen Reaktion nach dem Übergang in ein Mehrparteiensystem im Jahr 1946 unter dem Druck der neu gegründeten DP (Demokratische Partei), eine Abspaltung aus der CHP, thematisiert (Aytekin/Uslu 2015: 371). Die Gründe für die Renaissance der Religion als Nachgeben zu thematisieren, lässt außen vor, dass die CHP an der Restauration der Stellung der Religion aktiv mitwirkte. Şemsettin Günaltay, der Ende der 1940er Jahre Ministerpräsident einer CHP-Regierung war, brachte die Idee vor, Nation und Religion bedingten sich gegenseitig, die Türken hätten dem Islam am besten gedient. Der prominente Schriftsteller und CHP-Abgeordnete Yahya Kemal erhob den Authentizismus, das Bei-Sich-Selbst-Sein zum zentralen Motiv des Daseins. Er betonte die Bedeutung praktizierter Religion als Zusammenkunft in der Gemeinschaft, in Abgrenzung zum Katechismus, der unbedingten Überzeugung oder dem Bekenntnis, deren Dogmatismus er ablehnte. ${ }^{15}$

15 Damit nahm er die zentrale Idee auf, dass Religion zuallererst eine Form der Cemeinschaft darstellt, einzelne Glaubensgemeinschaften Instrumente sind, die Legitimation und Wahrhaftigkeit der Religion zu reproduzieren und auf Dauer zu stellen, dass religiöse Rituale und Bindung bedeutsamer als die Gläubigkeit an sich sind, eine Auffassung, die in der lateinischen Herleitung des Wortes religio aus dem Verb religare sich wiederfindet, das »aneinander binden« heißt und in Abgrenzung zum Wort superstitio benutzt wurde, das individuelle, 
Nicht zuletzt wurden auf Initiative eines CHP-Abgeordneten 1949 die türkistischen Vereine »Türk Ocakları (Türkenwiege) wieder eröffnet, die zu einer Plattform wurden, die Vorteile der Religion als ethische Kraft und vereinheitlichendes Moment anzupreisen. Beklagt wurden der Verlust der Ideale und die Dominanz des Materiellen, dem die moralische Erziehung des Volkes entgegenzusetzen sei, die nur über die Religion geschehen könne (Bora 1998: 68ff., 84ff., 93).

In der CHP gab es keine einheitliche Position zur Restauration der Stellung der Religion. In der Partei fand angesichts der Zunahme kommunistischer Staaten nach dem Zweiten Weltkrieg eine Auseinandersetzung über die Frage der Förderung der Religion statt, in der ein Flügel die Vorzüge der Religion für die Aufrechterhaltung der bürgerlichen Ordnung hervorhob, ein zweiter dagegen befürchtete, die Religion könne außer Kontrolle geraten. Das vermehrte Aufkommen »reaktionärer« Ideen nach dem Zweiten Weltkrieg war verbunden mit der Wahrnehmung einer »kommunistischen Gefahr«, die die CHP als genuine Partei der besitzenden Klassen nicht weniger umtrieb als die DP (Akpınar/Araman 2011: 82). Die pauschale staatszentristische These, die rasche Entwicklung konservativer und religiöser Weltauffassungen rühre von einem Versagen des Kemalismus her, die kulturelle Distanz zur Bevölkerung durch die Etablierung eines "Sozialethos « und einer "popularen Kultur« außerhalb der Religion zu überbrücken (Bora 1998: 42ff., 125; Mardin 2006c: 252f.), ignoriert dagegen die »zivilgesellschaftlichen« Ankerpunkte des kemalistischen Projekts in einer kulturell heterogenen, aus langen Kriegen, Migrationsbewegungen und Zwangsumsiedlungen heraus entstandenen Gesellschaftsformation. Kriegsflüchtlinge aus dem Balkan und dem Kaukasus sowie Gruppen, die nach dem Ersten Weltkrieg aus ehemaligen Gebieten des Reichs in die Türkei zwangsumgesiedelt wurden, nahmen die vom Kemalismus offerierte nationale Identität ebenso an wie Gruppen, für die die kemalistischen Reformen Befreiung von konservativer Enge und sunnitischer Kontrolle bedeuteten (vgl. Erden 2004). Die Reformen hatten eine intellektuelle Schicht geschaffen, die die kapitalistische Fortschrittsorientierung angenommen hatte. Die Einparteienherrschaft der CHP, die bis 1946 die besitzenden Klassen und ihre Intellektuellen $\mathrm{zu}$ integrieren vermochte, stieß an andere Grenzen. Die negativen Auswirkungen des Zweiten Weltkriegs auf die Wirtschaft, bedingt durch den Zusammenbruch der globalen Nachfrage nach landwirtschaftlichen Exportgütern, die das wichtigste Handelsgut der damaligen türkischen Volkswirtschaft stellten, riefen Unmut innerhalb der zu drei Vierteln noch bäuerlich wirtschaftenden Bevölkerung hervor. Die CHP initiierte eine Agrarreform, mit der Land an besitzlose Bauern verteilt werden sollte, erhob zugleich eine neue Steuer auf landwirtschaftliche Erträge, auch um die Kriegsgewinnler, die mit Grundnahrungsmitteln spekulierten, zu besteuern (Boratav 2003:

institutionell nicht geregelte Spiritualität bezeichnete und die Bedeutung von Aberglaube annahm (Bora 1998: 58). 
90f.). Ein Teil der relativ mächtigen Fraktion der bereits kapitalistisch wirtschaftenden Großgrundbesitzer opponierte gegen diese Vorhaben (Uslu 2015: 351). Ihre Opposition fiel zeitlich zusammen mit einer bildungspolitischen kemalistischen Offensive, mit der die bis dahin vernachlässigten Dörfer erreicht werden sollten. Ab 1940 waren Bildungsinstitute (»Köy Enstitüleri« - »Dorfinstitute«) mit dem Ziel eröffnet worden, ausgewählte Dorfkinder mit landwirtschaftlichen und handwerklichen Fertigkeiten ausgestattet zu Lehrern für ihre Dörfer zu erziehen. Ein von den Urhebern der Institute willkommen geheißener Effekt war die gleichzeitige Vermittlung kemalistischer Entwicklungsideale. Grundbesitzer und mit ihnen assoziierte konservative Intellektuelle, die sich bis dahin in der CHP organisiert hatten, nahmen dies als Bedrohung wahr, da die Institute unter dem Einfluss der aufklärerischen Strömung in der CHP konservative Praktiken wie die Geschlechtertrennung untergruben. Jungen und Mädchen lernten gemeinsam. Das Selbstbewusstsein der partizipierenden Kinder beziehungsweise Jugendlichen wurde durch kollektives Arbeiten und Lernen in den Instituten gestärkt. Die Institute vermittelten keine feindliche, wohl aber aufgeklärte bis kritische Haltung zur Religion (vgl. Karaömerlioglu 1998). Dies hatte zur Folge, dass die Grundbesitzer, die ihre Hegemonie weiterhin vermittels konservativer und religiöser Weltauffassungen organisierten, ihre Stellung in Gefahr sahen. Sie führten eine antikommunistische Kampagne, bis die Institute nach wenigen Jahren wieder geschlossen wurden.

Die DP formierte sich vor diesem Hintergrund als Abspaltung einer Gruppe der besitzenden Klassen unter der Führung opponierender Großgrundbesitzer von der CHP. Aus staatszentristischer Perspektive wird die DP als eine »Graswurzelbewegung « (White 2008: 361) begriffen, die aus der Peripherie kommend sich der CHP, die das Zentrum besetzt haben sollte, widersetzte. Eine Graswurzelbewegung war die DP mit Sicherheit nicht. Sie setzte sich aus (ehemaligen) federführenden Politikern der CHP zusammen, nahm ferner zahlreiche hochrangige Offiziere und Bürokraten auf (Ahmad 1993: 9, 123). Mit dem Auseinanderbrechen des Bündnisses der besitzenden Klassen in der CHP und dem Übergang in ein Mehrparteiensystem wurden die Auseinandersetzungen zwischen den Klassen und Klassenfraktionen nicht mehr innerhalb der CHP, sondern im Rahmen eines parlamentarischen Mehrparteiensystems zwischen zwei dominanten Hegemonieprojekten geführt. Die Spaltungen, Ungleichzeitigkeiten und Differenzen, die durch die kapitalistische Entwicklung hervorgerufen oder verstärkt wurden, wurden zum zentralen Politikum konkurrierender Parteien. ${ }^{16}$ Mit der Abspaltung zeigte sich wie schon im Zusammenhang mit der Gründung der Oppositionspartei im Jahr 1930, dass innerhalb der CHP neben dem kemalistischen ein zweites Hegemonieprojekt 
fortexistierte, das sich in Anbindung an Grundbesitzer und Händler über konservative und religiöse Auffassungen reproduzierte. Die Auffassungen kamen nicht neu auf, sie erhielten stärkere Sichtbarkeit durch eine parteiförmige Organisation, die Mehrheiten für die entwicklungspolitischen Ziele derjenigen Teile der Bourgeoisie zu generieren versuchte, die sie repräsentierte (Atılgan 2015a: 415).

Mit der DP fand auch der islamistische Diskurs nach dem Parteienverbot von 1924 seinen Weg zurück in die parlamentarische Politik. Ein Wahlslogan von Adnan Menderes, der Vorsitzender der DP wurde und selbst zu den mächtigsten Großgrundbesitzern des Landes gehörte, lautete: »Wir werden Istanbul zu einem zweiten Mekka, die Eyüp Sultan Moschee [in Istanbul] zu einer zweiten Kaaba machen.« (zit.n. Yücekök 1977: 153) Eine der ersten Reformen der DP, die zwischen 1950 und 1960 regierte, bestand darin, den Gebetsruf wieder auf Arabisch ausrufen zu lassen. Der Koran durfte wieder im Radio rezitiert werden, religiöse Gemeinschaften konnten sich wieder freier und sichtbarer organisieren. Die DP war jedoch keine islamistische Partei, in ihrer weltanschaulichen Ausrichtung dominierten konservative Themen, über die Reaktionen auf die kapitalistische Umwälzung mit Begriffen wie Entfremdung und Entartung gegen die Aufklärung, den Kommunismus im Besonderen und die Linke im Allgemeinen kanalisiert wurden (Bora 1998: 68ff.). Die DP präsentierte sich als Bewahrerin einer Authentizität und Unveränderlichkeit, deren permanente Auflösung sie durch Vorantreiben der kapitalistischen Entwicklung zugleich organisierte. Sie kann als erste politische Trägerin eines konservativen Hegemonieprojekts bestimmt werden, dessen ideologisches Repertoire in der Sakralisierung der Gemeinschaft, der Nation, der Tradition, der Geschichte und der (patriarchalen) Familie bestand. Die Religion trat als ein Element auf, jedoch nicht unbedingt als vorgeordnetes Element, das zur Aufrechterhaltung der Ordnung und der Autorität herangezogen wurde. In der Realität waren die Grenzen zwischen Konservatismus und Islamismus fließend. Dennoch war der Konservatismus eine relativ eigenständige Strömung, die in Gestalt der DYP (Partei des Rechten Weges) und der ANAP (Mutterlandspartei) die politische Landschaft bis zur Gründung der AKP maßgeblich prägte.

Die Popularität bestimmter religiöser und konservativer Auffassungen, die zum Bestandteil des Parteiprogramms der DP wurden, kann nicht aus ihren ökonomischen wie politischen Zusammenhängen losgelöst - rein ideologisch - ermessen werden. Sie müssen als Bestandteil eines Hegemonieprojekts, die Führung bestimmter Fraktionen der Produktionsmittelbesitzer zu organisieren, untersucht werden. Ihren ersten Wahlsieg 1950 verdankte die DP hauptsächlich Versprechen, die sie der zu dieser Zeit noch überwiegend unter kleinbäuerlichen Verhältnissen lebenden Bevölkerung machte, die unter dem Wirtschaftseinbruch und dem Nachfragerückgang auf landwirtschaftliche Produkte infolge des Zweiten Weltkriegs litt. Den Kleinbauern versprach sie Subventionen und Aufhebung von Kontrollen durch die Gendarmerie, den Arbeitern Streikrecht und Organisierungs- 
freiheit. Ihre Versprechen popularisierte sie als Befreiung von der etatistischen Unterdrückung der Bürokratie, sich selbst präsentierte sie als Partei des Volkes. Die hohe Zustimmung zur DP um die 58 Prozent bei ihrem zweiten Wahlsieg 1954 wurde durch eine günstige wirtschaftliche Entwicklung befördert. Die globale Nachfrage nach landwirtschaftlichen Gütern war angestiegen, im Rahmen des Marshallplans waren US-amerikanische Kredite an die Türkei vergeben worden, die die kapitalistische Entwicklung förderten, zugleich eine enge Anbindung der Türkei an die USA bewirkten, die politisch durch den NATO-Beitritt untermauert wurde (Atılgan 2015a: 485ff.). Von den günstigen wirtschaftspolitischen Rahmenbedingungen abgesehen, die Subventionen und Kredite für landwirtschaftliche Produzenten ermöglichten, löste die DP ihre Versprechen an die subalternen Klassen nicht ein. Sozialdemokratische und sozialistische Organisationen der Arbeiterbewegung blieben verboten, die zunehmende Mechanisierung in der Landwirtschaft erhöhte den Konkurrenzdruck auf die Landarbeiter. Die Kleinbauern konnten mit den großen und mittleren Grundbesitzern, die am stärksten von der Wirtschaftspolitik profitierten, nicht Schritt halten. Als inmitten eines ökonomischen Engpasses, hoher Inflation und steigender Auslandsverschuldung die Zustimmung zur DP in der zweiten Hälfte der 1950er Jahre abnahm, erhöhte sie den Druck auf die Arbeiterschaft durch weitere Verbote ihrer Organisationen, setzte auf Repression gegenüber der politischen und gesellschaftlichen Opposition wie auch gegenüber Teilen der Beamtenschaft und Armeeoffiziere, deren Forderungen nach einem höheren Sold sie ignorierte, erpresste große Industrielle, sich von der CHP zu lösen. Die Ära der DP, die sich auf dem Weg der Errichtung einer Diktatur befand, dabei jedoch die Unterstützung der aufsteigenden Industriebourgeoisie sowie an Popularität verloren hatte, wurde 1960 durch den ersten Militärputsch in der Republikgeschichte beendet. Der Putsch erhielt die Unterstützung verschiedener gesellschaftlicher Gruppen aufgrund autoritärer Bestrebungen der DP (ebd.: 485ff., 545).

Der Putsch stellt eine ambivalente Zäsur in der politischen Geschichte dar. Einerseits wurde das Militär nach dem Putsch über den neu in der Verfassung verankerten Nationalen Sicherheitsrat in den politischen Entscheidungsprozess einbezogen. Mit der gleichzeitig erwirkten ökonomischen Einbindung des Militärs wurde der kapitalistische Entwicklungsweg als Orientierung für die Offiziere festgelegt. Die Offiziersgehälter wurden erhöht, junge Offiziere stiegen in mittlere Einkommensklassen auf, für Generäle wurden Luxusvillen gebaut, Offiziere im Ruhestand wurden in die Bürokratie rekrutiert und in den Vorstand von Privatfirmen berufen. Durch die Gründung eines bis heute bestehenden, weit verzweigten Konsortiums (OYAK), das Offizieren Privilegien wie verbilligte Kredite und Konsumgüter verschafft sowie Dividenden an Offiziere im Ruhestand auszahlt, wurden die Offiziere zu Rentiers gemacht. Durch die Anbindung an OYAK, das mit staatlicher Förderung in kurzer Zeit zur aus der Industriebourgeoisie her- 
vorgegangenen Gruppe der transnational verflochtenen Konglomerate des Landes aufstieg, wurde im Militär ein starkes Interesse geschaffen, in die gesellschaftlichen Kämpfe zugunsten der Konglomerate einzugreifen (Ahmad 1993: 130ff.; Ulus 2011: 15). ${ }^{17}$ Neben diesen antidemokratischen Maßnahmen initiierte der Pusch andererseits eine neue Verfassung, die bürgerliche Freiheiten auch der Arbeiterschaft zuerkannte, vielmehr den konstitutionellen Rahmen für eine sozialdemokratisch geprägte Blockbildung zwischen den Konglomeraten, der Industriearbeiterschaft, den Angestellten der öffentlichen Verwaltung, Teilen des Kleinbürgertums und der Kleinbauern bildete. Erste Tendenzen dieser Blockbildung auf der Grundlage eines semi-peripheren Fordismus hatten schon in den 1950ern bestanden. Von der Etablierung einer fordistischen Politik in Form einer importsubstituierenden Wirtschaftspolitik kann ab 1962 gesprochen werden. Sie war darauf ausgerichtet, das Wachstum der inländischen Industriebourgeoisie, die für den Binnenmarkt produzierte, durch selektive Zölle zu fördern, Subventionen und (knappe) Devisen in Projekte zu lenken, die ihrer Entwicklung dienten. Der Fordismus in der Türkei entwickelte zwar nicht die gleiche Expansivität wie in den kapitalistischen Zentren, er bestimmte nichtsdestotrotz die Akkumulationsdynamik und die Organisation der Arbeitsteilung bis in die späten 1970er Jahre (Aydın, Z. 2005: 209f.). Stetige Reallohnerhöhungen für die Industriearbeiterschaft und der Aufbau wohlfahrtsstaatlicher Elemente kennzeichnen diese Periode. Die Verbesserung der Ausbildungsund Reproduktionsbedingungen der Arbeitskräfte durch formale Arbeitsverträge und soziale Leistungen und die Erhöhung ihrer Kaufkraft komplementierten die Entwicklung der Industriebourgeoisie und sorgten für den Absatz produzierter Waren (Boratav 1987: 108f.; Odman 2000: 451f.). Der an die industrielle Entwicklung gekoppelte fabrikzentrierte, den öffentlichen Sektor umfassende Kompromiss, der soziale und politische Rechte für die Werktätigen enthielt, blieb begrenzt, da er nur einen Teil der Werktätigen integrierte und die industrielle Entwicklung in bestimmten Teilen des Landes konzentrierte. Er wies ferner einige Besonderheiten auf, so die informellen Siedlungen (»Gecekondu«) der aus ihren bäuerlichen Reproduktionszusammenhängen in die Industriezentren gelockten Arbeitskräfte. Er bestimmte dennoch die Lebensverhältnisse eines großen Teils der Bevölkerung und entwickelte eine Ausstrahlungskraft über die tatsächlich integrierten Werktätigen hinaus. gen ausgeführt, die sich nach dem Putsch in zwei Flügel spalteten: Einen links-kemalistisch sozial-reformerischen, der in der kurzen Zeit der Militärregierung eine Landreform zugunsten von Kleinbauern initiierte und wohlfahrtsstaatliche Regelungen zugunsten der subalternen Klassen auf die Agenda hob, und einen rechten Flügel, der eine alsbaldige Übergabe der Regierungsgeschäfte an zivile Kräfte mit dem Kalkül forderte, dass diese die Landreform rückgängig machen würden. Der rechte Flügel setzte sich durch und die Landreform wurde tatsächlich zurückgenommen (Ulus 2011: 199f. Fn. 20). 


\subsubsection{Die Türkisch-Islamische Synthese}

Die DP-Regierung scheiterte an der damaligen Kräftekonstellation. Doch wurden in ihrer Regierungszeit die infrastrukturellen Voraussetzungen für die Entwicklung der islamistischen Bewegung gelegt, die sie bis in die Gegenwart charakterisieren. Die detaillierte Darstellung dieser Infrastruktur, die die Diyanet und die theologischen Ausbildungsstätten umfasst, erfolgt in einem separaten Kapitel, nachdem die Entwicklungsstadien der islamistischen Bewegung im Verhältnis $\mathrm{zu}$ den gesellschaftlichen Kämpfen nachgezeichnet worden sind. Unter der Förderung der DP-Regierungen entstand eine große Zahl Akademiker, Schriftsteller, Journalisten, Agitatoren und Polemiker, die sich in verschiedenen Vereinen zusammenschlossen, Netzwerke bildeten und fortan daran arbeiteten, den konservativen Islamismus mit dem völkischen Türkismus in einem türkisch-islamischen Hegemonieprojekt zusammenzubringen. Die Entwicklung des konservativen Islamismus als distinkte Ideologie in Gestalt der Türkisch-Islamischen Synthese setzt in dieser Phase ein. Die Synthese ist im Rückblick das wichtigste Deutungsangebot, das die türkische Rechte im Laufe des 20. Jahrhunderts entwickelt hat. Sie stellt eine Kombination der sich schon im Osmanischen Reich herausbildenden Ideologien des Osmanismus, Türkismus, Islamismus und Konservatismus dar. In ihr finden sich türkistische und islamistische Motive, eine Sakralisierung vermeintlich vorkapitalistischer Werte und Ideale, Antikosmopolitismus, eine grundskeptische Weltanschauung und ein ausgeprägter Opferdiskurs. Sie ist als eine Begleiterscheinung der Türkisierungs- und Islamisierungspolitik anzusehen, die in historischer Kontinuität zum Genozid, mit dem die nicht-muslimische Bevölkerung aus Anatolien entfernt wurde, betrieben worden ist (Aç1kel 1996; Çoban 2015).

Der Grundthese der Türkisch-Islamischen Synthese ist, dass Türkentum und Islam sich gegenseitig bedingten. Die »Türken« hätten dem Islam am besten gedient, indem sie seine Expansion anleiteten und mit missionarischem Eifer neue Gebiete eroberten. Die Orden der Sufi hätten sich dabei als besonders zuverlässig herausgestellt, indem sie nicht in Kontemplation verharrten, sondern mit dem Schwert in der Hand den Heiligen Krieg bestritten und zugleich loyal zum Staat geblieben seien. Ausformuliert wurden diese Ideen maßgeblich von Akademikern, die sich 1962 im Verein »Aydınlar Kulübü« (»Klub der Intellektuellen«, 1970 umbenannt in »Wiege der Intellektuellen«) zusammenschlossen. Auch die zur gleichen Zeit (1963) gegründeten Vereine zur Bekämpfung des Kommunismus wurden maßgeblich von islamistischen Intellektuellen und Netzwerken getragen (Atılgan 2015b: 590; Özdalga 2006). Sie argumentierten, dass das Wesentliche im Sufismus nicht im Rückzug vom Weltlichen, sondern im kriegerischen Missionierungsgeist bestand. Hervorgehoben wurde damit ein aktivierendes Element von Religion, das im Gegensatz zum passivierenden Rückzug aus dem Weltlichen, zur Konzentration der Befreiung auf ein Jenseits steht, wie es häufig mit Religion verbunden wird. Aus 
der Perspektive der Türkisch-Islamischen Synthese ist das Weltliche nicht etwas, das auszuhalten ist (Açıkel 1996). Die akademischen Urheber der Synthese sahen sich in den 1960ern mit einer aufkommenden sozialistischen und anti-imperialistischen Arbeiter- und Studentenbewegung konfrontiert, zu deren Bekämpfung sie alternative Deutungsangebote entwickelten. Sie machten als Ursache für Armut und Unterdrückung eine angebliche Unterwürfigkeit gegenüber dem Westen durch kulturelle Verwestlichung aus und behaupteten, dass durch die Zurückdrängung von Aufklärung und Säkularisierung bei gleichzeitiger Begeisterung für technologische Entwicklung die Unterlegenheit gegenüber dem Westen, damit auch Armut und Unterdrückung überwunden werden könne.

Ein weiterer Ausdruck stärker werdender islamistischer Aktivitäten in dieser Periode ist die Entwicklung der »idealistischen Bewegung«, die ursprünglich einen säkularen und völkisch-rassistischen Türkismus ausgebildet hatte, der in den 1960er Jahren sunnitisch-islamistischen Interpretationen $\mathrm{zu}$ weichen begann. ${ }^{18}$ Die politische Repräsentantin dieser Strömung war die Republikanische Bauern-Volkspartei (CKMP), die 1969 in Partei der Nationalistischen Bewegung (MHP) umbenannt wurde und die mit den faschistischen Grauen Wölfen - eine paramilitärische Organisation zur Bekämpfung linker Strömungen - assoziiert war (At1lgan 2015b: 592f.; Ulus 2011: 125). Die idealistische Bewegung, die mit dem Kleinbürgertum und kleinen Firmen assoziiert war, entfernte sich von den Nicht-Sunniten, den Aleviten, die sie zuvor als »Türken« integriert hatte. Trotz dieser frühen und über die Jahrzehnte fortgeschrittenen Annäherung an den Islamismus wirkt in der idealistischen Bewegung bis heute eine pan-türkistische Strömung fort, die stärker gen Osten orientiert ist und eine Einheit aller »Turkvölker« imaginiert, in der der Islam keine vorgeordnete Rolle spielt. Die Verbindung der Bewegung mit Kleinbürgern und kleineren Unternehmern, die in bestimmten Regionen der Türkei Schwerpunkte gebildet haben, lässt sie als ein türkistisches Hegemonieprojekt bestimmen, das ideologisch-kulturelle Schnittmengen zum konservativ-islamischen wie auch zum kemalistischen Hegemonieprojekt aufweist.

Mit dem Verbot der DP führte deren Nachfolgepartei AP das konservative Hegemonieprojekt fort. Sie nahm den Diskurs auf, der den durch die kapitalistische Umwälzung hervorgerufenen Unmut gegen die »kulturelle Verwestlichung« lenkte, für die die CHP und der Kemalismus verantwortlich gemacht wurden. Für die mit der Industrialisierung und Mechanisierung der Landwirtschaft einhergehende Auflösung des kleinen Handwerks und der kleinbäuerlichen Produktion, für die Proletarisierung von Handwerkern und Bauern wurden Institutionen und kulturelle Formen verantwortlich gemacht, die als westlich und volksfremd kodiert 
wurden. Die konservativen Parteien präsentierten sich als permanente Opposition, obgleich sie nahezu ununterbrochen die Regierungen stellten. Sie beschwerten sich über "westliche« Institutionen, obwohl sie die Einbindung in den Welthandel unter der Dominanz westlicher Akkumulationszentren und Bündnisse (NATO) maßgeblich beförderten. Sie beschwerten sich über »westliche« Werte, mit denen sie die Kleinfamilie, den Zins und den Kapitalismus anzeigten, obwohl sie die kapitalistischen Verhältnisse politisch durchsetzten. Während sie die permanente Umwälzung von Lebensweisen und kulturellen Formen organisierten, damit auch die Existenzbedingungen der Großfamilie untergruben, stellten sie sich als Bewahrer der »kulturellen Werte des Volkes« - der »nationalen« Kultur - gegen seine Unterdrücker dar.

\subsubsection{Klassenbasis der religiösen Infrastruktur im Aufbau}

Die Periode zwischen 1946 bis etwa Mitte der 1960er Jahre markierte den beginnenden Wiederaufstieg der Geistlichen nach ihrer Zurückdrängung. In dieser Zeit fand der erste Anlauf statt, die gesellschaftliche Stellung der religiösen Intellektuellen wiederherzustellen und ihre bis dahin stark eingegrenzte Stellung im Machtblock auszubauen. Die Formierung sozio-politischer Blöcke und der Kulturkampf wurden auf eine parteiförmige Ebene gehoben und der Islamismus begann, sich als eine nationale Bewegung zu reformieren. Während der Kemalismus die kapitalistische Entwicklung mit einer Ausrichtung an der bürgerlichen Aufklärungsbewegung verbunden, Emanzipationsangebote mit Zwangselementen vereint hatte, artikulierte der türkische Konservatismus die gleiche Entwicklung nach 1946 als Befreiung konservativ-religiöser Praktiken. Beide Strömungen artikulierten einen bevölkerungspolitischen Gestaltungsanspruch, der im Kemalismus explizit als Veränderung - werden wie der Westen - und im Konservatismus als Bewahrung - bei sich selbst bleiben - artikuliert wurde. Das kemalistisch-säkulare Hegemonieprojekt versprach eine Befreiung von konservativ und religiös geprägter sozialer Kontrolle. Für laizistische Kräfte stellte das mit der Gründung der Republik in der Verfassung verankerte Prinzip der Laizität die Befreiung von der Herrschaft sunnitischer Geistlicher dar, wodurch auch der alevitischen Bevölkerung eine staatsbürgerliche Gleichstellung ermöglicht wurde (White 2008). ${ }^{19}$ Die Zwangselemente im kemalistischen Reformeifer, der der Bevölkerung die Übernahme von Kleidungsformen, Musikgeschmäckern, Freizeitgewohnheiten, einer neuen Schrift und Sprache etc. auferlegte, bot dem konservativen Hegemonieprojekt Ansatzpunkte und verlieh der konservativen Artikulation Plausibilität.

19 Allerdings wurde diese Gleichstellung nie vollkommen eingelöst, da sunnitische Institutionen bestehen blieben, wie in nachfolgenden Kapiteln noch auszuführen sein wird. 
Da beide Projekte maßgeblich den kapitalistischen Akkumulationsprozess organisierten, über dessen Ausrichtung gen Westen grundsätzliche Einigkeit bestand, den sie jedoch durch unterschiedliche kulturelle Formen $\mathrm{zu}$ vermitteln suchten, können sie auf einer analytischen Ebene als zwei konkurrierende kulturpolitische Strategien der herrschenden Klassen bezeichnet werden, Hegemonie auszuüben. Der Kulturkampf tritt als Modus Operandi auf, über den sich beide Hegemonieprojekte in Konkurrenz zueinander reproduzierten.

Die Phase ist also gekennzeichnet durch eine stärker sichtbar werdende Reorganisation islamistischer Intellektueller, deren Vorgänger nach dem Ersten Weltkrieg mit den Siegermächten kooperiert hatten. Dass sie sich mit der DP, der CKMP und der AP verbanden, sich gegen sozial-reformerische Bewegungen richteten, die als Kommunisten und Volksfremde markiert wurden, und dass sie die kapitalistische Entwicklung in Gestalt eines neutralen technologischen Fortschritts zum unverzichtbaren Element erhoben, zeigt an, dass sie sich in Assoziation zu den besitzenden Klassen entwickelten. Um einen genaueren Einblick in die soziale Trägerschaft der islamistischen Bewegung in dieser Periode zu gewinnen, erfolgt an dieser Stelle ein Vorgriff auf die Entwicklung der religiösen Infrastruktur. Der Aufbau der religiösen Infrastruktur wurde hauptsächlich von Vereinen initiiert, deren Wachstum in den 1950er Jahren bemerkenswert steil nach oben ging. Nach der Liberalisierung des Gesetzes für Vereinsgründungen 1946 wurden zunehmend Vereine mit religiösen Zielsetzungen gegründet. 1946 entstanden 8 Vereine zur Förderung des Moscheebaus, 1961 dann schon 5.000 und 19688.400 neue Vereine. Nach 1960 flachte der Anstieg auf einem hohen Niveau ab, dafür stieg die Zahl von Vereinen mit anderen religiösen Zielsetzungen wie dem Bau theologischer Schulen (Yücekök 1977: 131ff.). Auch Vereine zum Betreiben ehrenamtlich geführter Korankurse, die nicht an die Diyanet angeschlossen waren, sprossen aus dem Boden. Allerdings konnten ehrenamtliche Korankurse anders als religiöse Vereine schon vor 1946 gegründet werden. Zwischen 1932 und 1949 stieg deren Zahl von 9 Kursen mit 232 Schülern auf 127 Kurse mit 8.706 Schülern (Ozgur 2012: 34ff.). 1951 gab es dann schon 237 und 1968 2.510 Korankurse. $\mathrm{Zu}$ den ehrenamtlichen Kursen kamen 954 Kurse der Diyanet hinzu, die etwa 40.000 Schüler und Schülerinnen unterrichteten. Eine weitere statistische Angabe lässt eine Gewichtung zu: Der Anteil von Vereinen mit religiösen Zielsetzungen an allen neu gegründeten Vereinen stieg zwischen 1946 und 1959 von 1,3 auf 31,9\% und stabilisierte sich danach bei etwa 28 \% bis ins Jahr 1968 (Yücekök 1977: 131ff.). Die Zahlen sind beeindruckend, insbesondere weil die Kosten für den Bau der Moscheen, der Schulen und das Betreiben ehrenamtlicher Kurse hauptsächlich durch private Spenden gedeckt wurden. Sie zeigen den Beginn des Wiederaufbaus der religiösen Struktur an, durch den die materiellen Reproduktionsmöglichkeiten der Theologen sukzessive ausgebaut wurden. 
Die einzige auffindbare Studie, die eine differenzierte Untersuchung der Vereine vornimmt, liefert eine Vorschau auf die islamistische Bewegung der Folgezeit, indem sie exemplarisch zum Vorschein bringt, dass die soziale Trägerschaft sich hauptsächlich aus drei Gruppen zusammensetzte (Yücekök 1977). In einem städtischen Gebiet initiierten überwiegend Kleinhändler und Handwerker die Gründung, in ländlichen Gebieten waren es hauptsächlich Kleinbauern. In beiden Gebieten befanden sich als dritte Gruppe unter den Gründern ausgebildete Theologen, die teils zu der kleineren Gruppe von Beamten gehörten (ebd.: 211ff.). Aus der Zusammensetzung lässt sich schließen, dass die unmittelbare Klassenbasis der religiösen Struktur im Aufbau in den 1950er und 1960er Jahren aus dem Kleinbürgertum und der kleinen Bourgeoisie hervorging. Nach Yücekök war dies ein Teil des Kleinbürgertums, das zu den »Verlierern« (1977: 80) der kapitalistischen Umwälzung gehörte, die sie mit den Institutionen der laizistischen Republik und dem Westen gleichsetzten. Seine Befragung der Vereinsgründer ergab in Übereinstimmung mit den Kernthesen des konservativen Islamismus, dass 70 Prozent die Aufhebung des »Religionsstaats« mit Gründung der Republik als einen großen Fehler ansahen und der Nachahmung des Westens und dem Sittenverfall die Schuld an den größten Übeln der Gesellschaft gaben.

Yücekök führt an, dass das Kleinbürgertum aufgrund der beschleunigten kapitalistischen Entwicklung nach dem Zweiten Weltkrieg einem Konkurrenzdruck ausgesetzt gewesen war, angesichts dessen zumindest ein Teil das »Alte« herbeisehnte (1977: 102). Boratav stellt fest, dass das Kleinbürgertum in der gleichen Phase expandierte, insgesamt von der kapitalistischen Entwicklung profitierte (1987: 77ff.). Beide Feststellungen - zunehmender Konkurrenzdruck und Expansion - schließen sich nicht unbedingt gegenseitig aus. Wenn aber das Kleinbürgertum als »Verliererin« bezeichnet wird, wie von Yücekök, überdeckt dies seine gesellschaftliche Stellung und politische Positionierung. Nachvollziehbar ist, dass sich das Kleinbürgertum durch Liberalisierungen politisch in Parteien und zivilgesellschaftlich in Vereinen reorganisieren konnte. Das "Alte« war nicht mehr antikapitalistisch oder feudal artikuliert: Auch die Grundlage der kleinbürgerlichen Reproduktion bestand in der Aufrechterhaltung der kapitalistischen Akkumulation. Das ausgeprägte antikommunistische Element im konservativen Islamismus, der auch in den Vereinen zum Tragen kam, bringt zum Ausdruck, dass es sich gegenüber den subalternen Klassen auf der Seite des Großgrundbesitzes und der Handelsbourgeoisie positionierte, die sich vorwiegend in der DP organisierten.

Resümierend lässt sich festhalten, dass sich die islamistische Bewegung ab den 1950er Jahren auf den Großgrundbesitz und die Handelsbourgeoisie stützen konnte, während sie zugleich im Kleinbürgertum Wurzeln schlug und über Vereine eine rapide anwachsende intellektuelle Schicht ausbildete, die fortan das türkisch-islamische Hegemonieprojekt weiterentwickeln sollte. 


\subsection{Verselbständigung: Formierung der islamistischen Bewegung und ihre Abspaltung als eigenständige Partei}

$\mathrm{Ab}$ den 1950er Jahren erreichte die Ausdifferenzierung der Bourgeoisie eine neue Schwelle. Lange Zeit bildeten die kapitalistischen Großgrundbesitzer und die Handelsbourgeoisie die dominanten Fraktionen der besitzenden Klassen. Mit der Entwicklung der industriellen Produktion gewann die Industriebourgeoisie an Gewicht. Sie bildete sehr rasch monopolistische Strukturen aus und brachte ihre Interessen erfolgreich voran. ${ }^{20}$ Verschiedene Autoren bringen vor, dass der Konkurrenzdruck, den kleinere Produzenten in der Landwirtschaft und im produzierenden Gewerbe durch die Industriebourgeoisie spürten, die Suche nach einer eigenständigen politischen Repräsentation auslöste, die sich durch eine Abspaltung von der konservativen Partei AP bildete, die wiederum auf die DP gefolgt war (Buğra 1998; Gülalp 1999; Keyder 1987; Yücekök 1977). Mit der Abspaltung eines Flügels der kleineren Unternehmer nahm der Islamismus die Form einer eigenständigen sozialen Bewegung an, die sich wenig später auch parteiförmig organisierte. Aufgrund der eigenständigen parteiförmigen Organisierung wird insbesondere in der historisch-materialistischen Literatur ab diesem Zeitpunkt der Begriff politischer Islam verwendet. Die Tatsache der parteiförmigen Organisierung sollte jedoch nicht verdecken, dass der Islam - genauer formuliert eine sunnitisch geprägte Auslegung - auch zuvor schon politisch artikuliert war.

Der Abspaltung von der AP ging ein Konflikt über die Ausrichtung der Wirtschaftspolitik und die Verteilung öffentlicher Subventionen voraus, worin die Größe der Unternehmen eine wichtige Rolle spielte. Konkreter Austragungsort des Konflikts war der zur damaligen Zeit wichtigste Unternehmerverband, die Kammern- und Börsenunion der Türkei (TOBB). Vorsitzender des Verbands war der Ingenieur Necmettin Erbakan, der kleineren Unternehmen, die eine Stimmenmehrheit stellten, eine für sie günstigere Verteilung staatlicher Subventionen versprach, wogegen die größeren Unternehmen opponierten. Auf Betreiben der Handelskammern von Istanbul und Izmir, in denen die großen Unternehmen dominierten, wurde Erbakan 1969 von der AP-Regierung abgesetzt. Die Rolle der AP bei diesem Vorgang widerlegt die in den $2000 e r$ Jahren prominent gewordene

20 Die Organisierung der großen Unternehmen der Türkei in Form von Holdings oder Konglomeraten, die auf den Feldern der Produktion, des Handels und der Finanzen gleichermaßen aktiv sind, ermöglicht ihnen, produktives Kapital und Celdkapital innerhalb der gleichen Organisationsstruktur zu halten. Sie können dadurch stärkere Kontrolle über die verschiedenen Formen des Mehrwerts (Zins, Profit, Handelsgewinne) ausüben und einen größeren Mehrwert abschöpfen. Manche Autoren verwenden den Begriff Finanzkapital für die Holdings, andere Autoren nennen sie großes Kapital, große Bourgeoisie oder einfach nur Monopole, da sie jeweils bestimmte Bereiche der Produktion dominieren (Ercan 2002; Öztürk 2010 und 2015). 
staatszentristische These, wonach die großen Unternehmen traditionell durch die CHP vertreten worden seien. Die großen Unternehmen hatten sich in den 1960er Jahren unter den Regierungen der AP und der CHP etabliert.

Der Konflikt forcierte die Abspaltung des politischen Islam als eigenständige Partei. Der Parteibildung ging zunächst jedoch die Formierung der Milli Görüş Bewegung (Nationale Sicht), ebenfalls unter der Führung von Erbakan, ab Mitte der 1960er Jahre voraus. Mit der Milli Görüş Bewegung nahm der affirmative Bezug auf das Osmanische Reich und die sunnitische Auslegung des Islam in Verbindung mit dem Kleinbürgertum und der kleinen Bourgeoisie einen programmatischen Charakter an. Erbakan, der sich bei der AP vergeblich für eine Nominierung bei den Parlamentswahlen beworben hatte und zugleich seines Postens als Vorsitzender der TOBB enthoben worden war, trat schließlich als unabhängiger Kandidat an. Er wurde 1969 mit Unterstützung der Händler und Gewerbetreibenden der mittelanatolischen Stadt Konya, die sich nachfolgend zu einer Hochburg des politischen Islam entwickeln sollte, als unabhängiger Kandidat ins Parlament gewählt. Die 1970 aus der Milli Görüş Bewegung hervorgegangene erste eigenständige Partei des politischen Islam in der Türkei war die Nationale Ordnungspartei (MNP), die von Politikern gegründet wurde, die zuvor hauptsächlich in der AP aktiv gewesen waren (Akpınar/Araman 2011: 84). Sie stellte einen Zusammenschluss kleinerer Gewerbetreibender, Händler und Agrarier dar, die Korruption, Habgier und Sittenverfall anprangerten, die sie durch die richtige ethische Haltung, gewonnen aus der Religion, zu reparieren versprachen. Die MNP rückte die Wiedereinführung der sunnitischen Institutionen des Osmanischen Reichs ins Zentrum ihres Programms (Yücekök 1977: 101f.). Kleinere Kapitalbesitzer, die später als »anatolische Bourgeoisie « bezeichnet werden sollten, adaptierten einen Diskurs, durch den sie sich in eine Reihe mit den unter einem zunehmenden Proletarisierungsdruck stehenden kleinbäuerlichen Produzenten und ihren eigenen Arbeitern stellten, die schweren Ausbeutungsbedingungen zu sehr geringen Löhnen ausgesetzt waren.

Infolge einer neuerlichen militärischen Intervention im Jahr 1971, die sich in erster Linie gegen die erstarkende Arbeiterbewegung richtete, wurde die MNP wegen Aktivitäten gegen die Laizität verboten. Dennoch ebnete die Intervention dem türkisch-islamischen Hegemonieprojekt den Weg (Ulus 2011: 16). Mit der Intervention wurde ein fünfjähriges politisches Betätigungsverbot für Mitglieder verbotener Parteien verhängt, das für Politiker der sozialistischen Arbeiterpartei der Türkei (TiP) umgesetzt, für Politiker der MNP aber umgangen wurde. Im direkten Anschluss an die MNP wurde mit gleichem Personal und programmatischer Ausrichtung die Nationale Heilspartei (MSP) gegründet, die Kundgebungen veranstaltete, auf denen zum Dschihad aufgerufen und die Einführung der Scharia propagiert wurde. Die 1971er Intervention leitete eine massive Förderung sunnitisch-islamistischer und türkistischer Kräfte ein, die para-militärische Einheiten bildeten, die mit dem Militär und der Polizei kooperierten, aus denen linke und 
links-kemalistische Kräfte schrittweise entfernt wurden. Gegen die Arbeiter- und Studentenbewegung sowie gegen AlevitInnen wurde in den 1970ern eine »Bürgerkriegsstrategie« (Çağlar 2003: 188) verfolgt, die hauptsächlich von Kräften ausgeführt wurde, die mit der Partei der Nationalistischen Bewegung (MHP) assoziiert waren und Rückendeckung aus den Sicherheitsapparaten erhielten. Politisch getragen wurde die »Bürgerkriegsstrategie « aber von den Regierungen der sogenannten Nationalistischen Front, die von der konservativen AP, der türkistisch-islamistischen MHP und der islamistischen MSP gemeinsam gebildet wurden (Ozan 2015: 724ff.). ${ }^{21}$

Während die MSP die Förderung der Industrialisierung zugunsten kleinerer Kapitalbesitzer forderte und gegen die etablierten Großunternehmen agitierte, die sie als Teil einer »westlich-jüdischen Allianz« anklagte, hatte die 1971er Intervention Bedingungen geschaffen, die für alle Kapitalfraktionen Vorteile boten. Die in den 1960ern angestiegenen Reallöhne wurden gesenkt, das links-kemalistische Personal wurde sukzessive aus der Bürokratie entfernt, sozialdemokratische und sozialistische Bewegungen, die parallel zur globalen Konjunktur sich ab Mitte der 1960er Jahre in einem starken Aufwind befanden, wurden einer massiven Repression ausgesetzt (vgl. Alpkaya 2001; Boratav 1987: 100ff.). Dennoch wurde die linke Bewegung über die gesamten 1970er Jahre stärker. Sie war in der Industriearbeiterschaft verankert, die kämpferische Gewerkschaften wie die DİSK ${ }^{22}$ hervorbrachte, deren Mitgliederzahlen von 30.000 im Jahr 1967 auf 700.000 im Jahr 1980 anwuchs, umfasste die Bauernschaft und das Kleinbürgertum, was nicht zuletzt in der Bildung der linken Lehrergewerkschaft TÖB-DER ${ }^{23}$ mit 200.000 Mitgliedern und der Formierung einer studentischen Linken zum Ausdruck kam (Çağlar 2003: 189).

Unter dem Druck der sozialistischen Bewegung wurde ein sozialdemokratischer und links-reformerischer Flügel in der CHP gestärkt, der sogar die Frage einer Agrarreform zugunsten von Kleinbauern nach 1940 ein zweites Mal auf die politische Agenda rückte. Bis zur Linkswende in den 1970ern gehörten industriell unterentwickelte Regionen des Landes zu den politischen Hochburgen der CHP. In den 1970ern stieg die CHP auch in den Gecekondu, den durch Binnenmigration rapide angewachsenen Arbeitervierteln in den industriell entwickelten Großstädten, zur stärksten Kraft auf (Ahmad 1993: 160). Beide Umstände - zunächst die Verankerung der CHP in unterentwickelten Regionen, dann ihr Stimmengewinn unter

Gegen Ende der 1970er Jahre häuften sich die Anschläge auf sozialistische und links-kemalistische Akteure. Zwar gab es auch linke militante Cruppen, die auf die »Bürgerkriegsstrategie«mit gleichen Mitteln antworteten, Gegenanschläge verübten, sich teils auch gegenseitig bekämpften. Das Ausmaß des rechten Terrors überschritt jedoch die von links ausgehende Gewalt und die antifaschistische Gegenwehr um ein vielfaches, die rechten Kräfte waren militärisch gesehen überlegen und besser ausgestattet (Çağlar 2003: 190).

22 Konföderation Revolutionärer Arbeitergewerkschaften der Türkei. Verein für den Zusammenschluss und die Solidarität aller Lehrer. 
den BinnenmigrantInnen - entkräften die These, wonach die bäuerliche Lebensweise beziehungsweise die soziale Entwurzelung aus der bäuerlichen Lebensweise - die Konfrontation der »Tradition« oder der »schwarzen Türken« mit der »Moderne« oder den »weißen Türken « - ausschlaggebend für die Hinwendung der in die Städte migrierenden Bevölkerung zum Konservatismus und späteren Islamismus waren (Göle 2004; White 2008: 361f.). Sie stützen vielmehr das Argument, dass sozio-politische Blöcke nicht als Ausdruck einer kulturellen Statik oder Reaktion begriffen werden sollten, sondern als (immer vorläufiges) Ergebnis eines Hegemoniebildungsprozesses. In der starken politischen Polarisierung der 1970er bildete die sozialdemokratische Perspektive - mit den zahlreichen sozialistischen Initiativen interagierend - einen große Teile der Werktätigen überzeugenden Gegenpol zu den kulturkämpferischen Strategien der Hegemoniebildung (Ozan 2015: 676ff.).

Vor diesem Hintergrund ist eine Differenzierung bezüglich der kemalistischen Bewegung vorzunehmen. Die Bewegung brachte im Laufe der Zeit unterschiedliche Flügel hervor, die etwas schematisch in links und rechts unterteilt werden können. Der eher linke Flügel war an der Philosophie der Aufklärung und einem bürgerlichen Entwicklungsprogramm orientiert, das sozialistische und sozialdemokratische Elemente aufnahm und einen institutionalisierten Kompromiss zwischen den Klassen herzustellen suchte. Er bildete anti-imperialistische Auffassungen aus, konnte kulturelle Differenz zulassen und neigte zur Aktivierung einer kritischen Massenbasis. Der eher rechte, sich mit der türkistischen Bewegung überschneidende und über die gesamte Zeit betrachtet dominante Flügel geriet in den 1970ern in die Defensive. Er war wesentlich pragmatischer an der Förderung der privaten Kapitalakkumulation zugunsten der Monopolbildung ausgerichtet, strebte eine kulturelle Homogenisierung der Bevölkerung an, betrieb einen Personenkult um Atatürk, beargwöhnte die subalternen Klassen und setzte auf autoritäre, gewaltförmige Lösungen.

Nachdem das politische Feld, in dem sich die islamistische Bewegung formierte, skizziert worden ist, kann nun auf deren Entwicklung zurückgekommen werden. Der politische Islam führte in den 1970er Jahren die schon bei der Wahl des noch parteilosen Erbakan lancierte Kampagne, wonach alle anderen Parteien unecht, nicht-national seien, weiter. Ein zentraler Slogan der Milli Görüş Bewegung in den frühen 1970ern lautete, dass materieller Fortschritt durch ideelle Entwicklung zu erreichen sei. Die Bewegung behauptete einen kausalen Zusammenhang zwischen wirtschaftlicher Unterentwicklung und dem Verfall moralisch-ethischer Werte unter dem Einfluss "fremder « Ideen aus dem Westen. Das Auseinanderklaffen zwischen Staat, der eine westlich-säkulare Kultur adaptiert habe, und Volk, das im Islam verwurzelt sei, wurde beklagt und die Idee vorgebracht, dass die Wiederbelebung der authentischen Kultur des Landes, die in einer islamischen Tradition bestehen sollte, den Verfall aufhalten und den materiellen Entwicklungsrückstand aufholen werde. Von Anbeginn war diese Vorstellung mit Großmachtambitionen 
und einer nationalistischen Geschichtsauffassung verbunden. Die Bewegung trat als Begründerin einer wiedererstarkten Türkei auf und drückte diese Vision mit dem Slogan »Von Neuem Große Türkei« (»Yeniden Büyük Türkiye«) aus. Das Osmanische Reich bildete den historischen Bezugspunkt, an dessen Stärke angeknüpft, die mit seinem Zusammenbruch verlorene Einheit von Staat und Volk wiederhergestellt, damit die Führung der »islamischen Welt« übernommen werden sollte (vgl. Toprak 2005; Yavuz 2005).

Der sich abspaltenden Bourgeoisie ging es jedoch nicht nur um den Erhalt einer gesellschaftlichen Position, sondern auch um einen größeren Anteil am gesellschaftlichen Mehrwert. Dieser Zusammenhang drückte sich in den 1970ern in der Artikulation einer spezifischen Wachstumsstrategie aus, die zum zentralen Programmpunkt der MSP wurde. Sie bestand in der Forderung einer staatlich geförderten Entwicklung der Schwerindustrie. Die Idee einer Förderung der Schwerindustrie war keine türkische Besonderheit, sie wurde zu dieser Zeit in vielen Ländern der kapitalistischen Peripherie diskutiert. Die Grundidee war, kleine Kapitaleigner zu Anteilshaltern staatlich geförderter Gesellschaften zu machen, wodurch ihnen ein Entwicklungssprung ermöglicht werden sollte. Mit anderen Worten, die MSP wurde zur nationalen Trägerin einer international bestehenden Bewegung aufholender Entwicklung (Gülalp 1999). Die MSP nahm 1973 und 1977 an Parlamentswahlen teil, bei denen sie zuerst 11,8 dann 8,5 Prozent erzielte und dabei in den östlichen Provinzen am erfolgreichsten war. Der Erfolg in den östlichen Provinzen, die wirtschaftlich gesehen unterentwickelt waren, zeigt ebenfalls die Anbindung der Bewegung an die kleine Bourgeoisie an, die ihre Stellung im kapitalistischen Wettbewerb zu verbessern suchte.

Bemerkenswert ist, dass bei den Parlamentswahlen von 197757 \% der Bewerber für eine MSP-Kandidatur einen religiösen beruflichen Hintergrund aufwiesen, gefolgt von Industriellen (18\%) und Ingenieuren (17\%). Unterstützt wurde die Partei von verschiedenen religiösen Orden der Nakschibendi, Nurcu und Kadiri. Auf das Wirken der Orden (Gemeinschaften) wird an späterer Stelle ausführlicher eingegangen. An dieser Stelle sei bemerkt, dass über ihre damalige Funktionsweise und tatsächliche Verbreitung nicht viel bekannt ist. Im Zusammenhang mit der Entwicklung der islamistischen Partei traten sie als informelle Zusammenschlüsse von Kleinaktionären in Erscheinung. Mehmet Zahid Kotku, ein Nakschibendi Scheich, der in der Literatur als Mentor von Erbakan auftaucht, führte eine lokale Zelle des Ordens an, dessen Mitglieder Anteile an einer Fabrik besaßen, in der Necmettin Erbakan als Manager angestellt war (Akpinar/Araman 2011: 84ff.; Ozgur 2012: 118f.). Das Beispiel gibt den Hinweis, dass die Orden sich den kapitalistischen Gegebenheiten schon in den 1960ern angepasst hatten. Tauchten sie im Osmanischen Reich im Zusammenhang mit Grundbesitz auf, waren sie in der Republik in Konkordanz zur Umwälzung der Produktionsweise in den Betrieb kleinkapitalistischer Unternehmen involviert. Wenngleich aus den wenigen journalistischen 
Recherchen nicht hervorgeht, in welchem Umfang sich dieses Engagement bewegte, können die Träger dieser Aktivitäten als Element des Machtblocks bestimmt werden, das sich mit Gründung der Milli Görüş Parteien politisch eigenständig machte (vgl. Doğan 2009a). Die starke Repräsentation von Theologen in der MSP und die Assoziation mit den Orden zeigen ein verstärktes Wirken von religiösen Intellektuellen an, für die die politische Partei - neben den Vereinen zum Aufbau einer religiösen Infrastruktur, die im vorangegangenen Abschnitt vorgestellt wurden - zu einer wesentlichen Wirkungsstätte wurde.

\subsection{Vorrücken ins ideologische Zentrum: Der 1980er Putsch und die Entwicklung einer programmatischen Ökonomie}

Ihren dritten historischen Entwicklungsschritt machte die islamistische Bewegung mit dem 1980er Putsch. Im konservativ-islamischen Narrativ der 2000er Jahre taucht der Putsch in der Regel als negativer Bezugspunkt auf. Einer meiner Interviewpartner im Jahr 2009 aus der AKP beschrieb die Kräfteverhältnisse folgendermaßen:

H: Die größte Hürde vor der Demokratie in der Türkei ist das Militär. Wegen der Fehler, die in der Vergangenheit gemacht wurden, glaubte ich nicht daran, dass mit der Demokratie etwas erreicht werden könnte. Obwohl wir politisch eine Regierung stellen, obwohl das Volk uns wählt, kommt einer, zieht uns eins über die Rübe und stürzt uns. Das haben wir 60, 71, 80 und 97 im 28. Februar-Prozess erlebt. Das hat uns immer fern gehalten von der Politik, auf diese Weise konnten wir nichts erreichen. Bis Tayyip Erdoğan uns die Idee vermittelte, dass wirklich etwas verändert werden kann.

$1^{24}$ : Wen meinst du mit wir?

$H$ : Damit meine ich uns als Volk, wir Menschen.

Das Memorandum der Militärführung und das eingeleitete Verbotsverfahren gegen die AKP (vgl. S. 40f.), sowie eine rechts-kemalistische Mobilisierung, die das Militär als eine zuverlässige Bastion gegen den Islamismus kennzeichnete, verstärkten die Wahrnehmung, dass es einen unversöhnlichen Gegensatz zwischen dem Militär und der AKP gab, die mein Interviewpartner im vorliegenden Ausschnitt mit dem Volk gleichsetzte. Obwohl sich die antagonistischen Lager - die Kemalisten auf der einen und die Islamisten auf der anderen Seite - einig über die Stellung des Militärs waren, allerdings mit gegensätzlichen Wertungen, handelte es sich um eine der größten Täuschungen in der politischen Geschichte der Tür-

24 Mit dem Kürzel »l« wird bei Interview- und Gesprächsausschnitten im gesamten Buch der Autor gekennzeichnet. 
kei, die mit einem staatszentristischen Begriffsapparat einherging, durch den das Militär außerhalb gesellschaftlicher Kräftekonstellationen platziert wurde.

Die 1970er Jahre waren durch eine sich zuspitzende Hegemoniekrise gekennzeichnet. Wie dargestellt, umschloss der Kompromiss zwischen der Industriearbeiterschaft und den öffentlichen Angestellten mit der Industriebourgeoisie zu Beginn der 1960er Jahre eine Reihe bürgerlicher Freiheiten und sozialdemokratischer Rechte. Eingebettet in und beeinflusst durch den globalen Aufwind für linke Bewegungen entwickelte die Aktionsbereitschaft organisierter ArbeiterInnen eine Dynamik, die alsbald den sozialdemokratischen Kompromissrahmen sprengte. Die Abhängigkeit der ökonomischen Entwicklung von Importgütern - technologischer Input, Investitionsgüter und Rohstoffe -, der Devisenmangel und der Griff nach internationalen Krediten sowie die trotz militärischer Intervention von 1971 weiterhin starke Arbeiterbewegung, die höhere Löhne und bessere Arbeitsbedingungen erstritt, hatten das importsubstituierende Entwicklungsmodell schon Mitte der 1970er Jahre in eine Krise gebracht (Ercan 2002). Die Fragmentierung der rechten Parteienlandschaft als Ausdruck unterschiedlicher Akkumulationsstrategien verschiedener Kapitalfraktionen vertiefte die Hegemoniekrise. Sie erschwerte die politische Kompromissfindung innerhalb des bürgerlichen Machtblocks erheblich. Vor diesem Hintergrund wurde der Ruf aus der Bourgeoisie nach dem Militär zur nachhaltigen Zerschlagung der Arbeiterbewegung und mit ihr der linken Bewegung sukzessive lauter. Schließlich provozierte das an eine strukturell bedingte Grenze stoßende Akkumulationsmodell eine Schuldenkrise, durch die der IWF auf den Plan gerufen wurde, mit dem im Januar 1980 ein Strukturanpassungsprogramm vereinbart wurde. Gegen den massiven Widerstand aus der Industriearbeiterschaft, Teilen des Kleinbürgertums und der Kleinbauern putschte das Militär im September 1980 zur Durchsetzung dieses Programms, das der gesamten Bourgeoisie Vorteile auf Kosten sozialer Errungenschaften der subalternen Klassen zusicherte (Boratav 2005: 73; Ozan 2012). Die unter der faktischen Führung von Turgut Özal vom Militär eingesetzte Regierung vereinte die wesentlichen Stoßrichtungen des Putschs zur Überwindung der Hegemoniekrise: Neoliberalisierung, Islamisierung und Behebung der Fragmentierung der Rechten (Ahmad 1993: 182; Akça 2014: 14ff.; Yalman 2009: 235ff.). ${ }^{25}$ dung sowohl mit der islamistischen Partei MSP und dem Nakschibendi-Orden als auch mit der Weltbank, den Monopolen sowie dem Arbeitgeberverband der Metallindustrie, deren Fabriken über Jahre von Streiks betroffen waren. Eine der ersten Entscheidungen, die nach dem Übergang in eine zivile Regierung 1983 getroffen wurde, war die Öffnung des Bankensektors für sogenanntes islamisches Kapital aus Saudi-Arabien, bei dessen Management der Bruder von Turgut Özal eine prominente Rolle spielte. 
Der Aufbau neuer Produktionssektoren und -kapazitäten, gekennzeichnet durch die importsubstituierende Entwicklungspolitik, rückte zugunsten einer tieferen Integration in den Weltmarkt und einer schrittweisen Finanzialisierung in den Hintergrund. Massive Lohnkürzungen, Streichung von Subventionen insbesondere in der Landwirtschaft und die Ausrichtung der Produktion am Export bildeten die erste Phase der Neoliberalisierung, mit der eine stärkere Öffnung des nationalen Marktes für Importgüter und internationales Kapital, das infolge der Überakkumulationskrise in den kapitalistischen Zentren neue Verwertungsfelder suchte, erzielt wurde (Sönmez, S. 2009). Um der türkischen Bourgeoisie bei gleichzeitiger Liberalisierung und Deregulierung von Handel und Investitionen eine konkurrenzfähige Stellung zu erhalten, wurde der fabrikzentrierte Kompromiss zwischen der Industriearbeiterschaft und den großen Fabrikanten, in den auch die Angestellten im öffentlichen Dienst und die freien Berufe eingebunden waren, aufgekündigt. Die radikale Kürzung von Löhnen und Gehältern bewirkte, dass deren Anteil am Bruttosozialprodukt zwischen 1979 und 1988 von 33 auf 14 Prozent sank (Çağlar 2003: 193). Im selben Zeitraum fiel der Reallohn um 32 Prozent (Boratav 2003: 164). Linke Gewerkschaften blieben bis Ende der 1980er verboten, gewerkschaftliche Organisierung wurde durch restriktive Hürden nachhaltig erschwert. Die Streichung von landwirtschaftlichen Subventionen und die fortschreitende Mechanisierung der Landwirtschaft verstärkte die Migration in die urbanen Zentren, die Migranten und Migrantinnen wurden allerdings nur noch in Teilen von den Fabriken absorbiert. Zusammen mit der Deregulierung von Arbeitsverhältnissen wurde nahezu die Hälfte der Werktätigen dauerhaft in informelle Beschäftigungsformen gedrängt. Die massive Expansion prekärer und informeller Beschäftigungsformen untergrub die Organisationsmacht der in der Massenfabrik verankerten Gewerkschaften zusätzlich. ${ }^{26}$

Der 1980er Putsch beendete und vollendete zugleich die von konservativen, türkistischen und islamistischen Kräften getragene »Bürgerkriegsstrategie« der 1970er Jahre, indem er die linke Arbeiter- und Studentenbewegung nachhaltig zerschlug. ${ }^{27}$ Tuğal gibt in seiner Studie (2009: 81ff.) über den Bezirk Sultanbeyli in Istanbul detailliert wieder, wie das politische Vakuum, das durch die Zerschlagung

26 Informelle Arbeit ist arbeits- und sozialrechtlich ungeschützt, sie ist nicht staatlich reguliert und registriert. Der Anteil informeller Arbeitskräfte an der Cesamtzahl der Beschäftigten lag nach Angaben der türkischen Statistikbehörde in den 1990er Jahren bei bis zu $50 \%$ und im Jahr 2016 bei etwa 33 \% (Turkish Statistical Institute: Results of Household Labour Force Survey-tuik.gov.tr).

27 Das Ausmaß dieser Zerschlagung war immens. Innerhalb eines Jahres wurden mehr als 100.000 Verhaftungen, in Folge des Putschs insgesamt 650.000 Festnahmen durchgeführt. 30.000 Richter, Staatsanwälte, Polizisten und Lehrer wurden entlassen, 14.000 Personen aus politischen Gründen ausgebürgert, alle Parteien, 23.000 Vereine, Studentenorganisationen, oppositionelle Gewerkschaften, Zeitungen und Zeitschriften verboten (Çağlar 2003: 30). 
der Linken entstand, von der islamistischen Bewegung gefüllt wurde. ${ }^{28}$ Doch trotz enormer Durchschlagkraft des Putsches erfolgte die Auflösung des sozialdemokratischen Kompromisses nicht auf allen Ebenen zeitgleich. Auf der Ebene der Kommunen kam es gegen Ende 1980er Jahre auch in mittel- und ostanatolischen Städten sowie in den großen Metropolen auf der Basis eines Bündnisses zwischen der formellen Arbeiterschaft, Angestellten und Teilen des Kleinbürgertums zu einem Wiederaufleben sozialdemokratischer Regierungen, die von der 1985 gegründeten SHP (Sozialdemokratische Populistische Partei) gebildet wurden. Die Sozialdemokraten machten Versprechen wie demokratische Bürgerbeteiligung, Ausbau kommunaler Dienstleistungen, Verbesserung der Reproduktionsbedingungen auch für die informelle Arbeiterschaft, die sie nicht einlösten. Stattdessen blähten sie das kommunale Personal auf, wurden in Korruptionsskandale verstrickt, verschuldeten die Kommunen mit Großprojekten und brachen schließlich unter dem Druck der ökonomischen Krise von 1994 zusammen (Doğan 2004 u. 2007). Die erheblich geschwächte SHP, die auch an einer nationalen Regierung beteiligt gewesen war, die nach jeder Krise neue Austeritätsmaßnahmen beschlossen, schloss sich 1995 der erst 1992 wieder gegründeten CHP an. ${ }^{29}$

Auf die nicht eingelösten sozialdemokratischen Versprechen folgten ab 1994 Wahlsiege der RP (Wohlfahrtspartei), der damaligen islamistischen Partei, deren Personal bis in die Gegenwart in der AKP organisiert ist und seitdem vielerorts mit 50-70 Prozent Zustimmung durchgehend regiert. Die RP war 1982, nach einer zweijährigen Unterbrechung parteiförmiger Organisierung aufgrund eines allgemeinen Verbots politischer Parteien nach dem Putsch, gegründet worden. Mit ihrer Gründung setzte der Aufstieg des politischen Islam von einer Splitterpartei des konservativen Spektrums zu einer Massenpartei ein, deren Wahlerfolge sich von mittelanatolischen Städten schrittweise in die westlichen Metropolen ausdehnten. Den politischen Erfolgen lagen die wirtschaftspolitischen Maßnahmen im Rahmen des Putschs zugrunde. Die Senkung der Reallöhne und die langfristige Unterbindung einer selbständigen Organisierung der Arbeiterschaft zur Gewährleistung der internationalen Konkurrenzfähigkeit türkischer Firmen in einem liberalisierten Umfeld waren begleitet von der Verlagerung arbeitsintensiver Produktion in die inneren Peripherien der Türkei. ${ }^{30}$ Eine messbare Folge dieser Politik war die

28 Die Zerschlagung der Linken verhalf den Islamisten in vielen Bereichen zum Durchbruch, so auch in der gewerkschaftlichen Organisierung. Entsprechend begrüßte der islamistische Gewerkschaftsdachverband HAK-iş so wie viele andere islamistische Akteure den Putsch. Die führende links-kemalistische Partei der 1990er war allerdings die vom ehemaligen CHP-Vorsitzenden Bülent Ecevit geleitete DSP. Die CHP blieb in den 1990ern marginal. 
Neugründung von Industriezonen, in denen tausende kleine und mittelständige Betriebe zusammengefasst wurden. Zwischen 1987 und 1996 entstanden 30 neue Industriezonen in verschiedenen Provinzen, während es davor lediglich sechs gab (Akpinar/Araman 2011). In diesem Zusammenhang stehen das Wachstum und die Entstehung von Firmen, die mit der Bezeichnung "anatolische Bourgeoisie« versehen wurden (vgl. Sönmez, M. 2009: 180ff.). Sie profitierten von der Verlagerung arbeitsintensiver Produktion in die inländische Peripherie und konnten auf relativ billige und wenig organisierte Arbeitskräfte zugreifen. Insbesondere bei Unternehmen kleiner und mittlerer Größe - mit weniger als 10 respektive bis zu 250 Beschäftigten -, die den größten Anteil an den jungen Unternehmen ausmachten, bildeten sich informelle Beschäftigungsverhältnisse ohne Versicherungsschutz, die Vorenthaltung von Löhnen, kurzfristige Entlassungen und Wiedereinstellungen zur Vermeidung von Dauerbeschäftigung, die mit Rechten wie Abfindungszahlungen verbunden war, als regelhafte Praxis heraus (Özuğurlu 2008). Die staatliche Förderung von Industriezonen, die von Steuern und Zöllen befreit wurden, kam hinzu. Ein erheblicher Teil der kleinen und mittleren Firmen, die im Textil, Bau- und Nahrungsmittelsektor konzentriert waren, schloss sich 1990 im Verband MÜsİAD zusammen, der fortan das unternehmerische Rückgrat der islamistischen Bewegung bildete.

Parallel zur Entwicklung der kleinindustriellen Bourgeoisie, die politisch von der RP repräsentiert wurde, war die Periode nach 1980 gekennzeichnet durch intensive Bemühungen, einen ethischen Rahmen für die Beziehungen zwischen Unternehmern und Arbeitern zu formulieren. Die RP ergänzte nach 1980 die Ideologie der MSP um das Element der »Gerechten Wirtschaftsordnung «, die einen Dritten Weg zwischen Kapitalismus und Sozialismus propagierte. Eine Arbeitsmoral, die die ArbeiterInnen - dem Vorbild des aufsteigenden Unternehmers gleich - zu Strebsamkeit, Fleiß und Disziplin anhielt, wurde entwickelt. Die sogenannte islamische Ethik basierte auf dem Idealbild eines fleißigen, großzügigen, gerechten, tugendhaften Unternehmer, dem homo islamicus, der den egoistischen homo economicus, dessen Entstehen im kapitalistischen Westen verortet wurde, ersetzen sollte. Die islamische Ethik wurde als allgemeine Garantin für Gerechtigkeit beworben, die religiöse Identität des Unternehmers für die Verbindlichkeit des Gerechtigkeitsversprechens hochgehalten. Eine gerechte Gesellschaft werde sich durch das Praktizieren des Glaubens von selbst herstellen, so die Behauptung, die sich im

lichten. Die Intensivierung der Konkurrenz zwischen den ArbeiterInnen verschiedener Länder bereitete auch in der Türkei den Weg für die schrittweise Aufkündigung des sozialdemokratisch geprägten Kompromisses. Die Umstellung der industriellen Produktion auf den Export und eine tiefere Eingliederung in globale Produktionsketten waren begleitet von einer schrittweisen Liberalisierung des Waren- und Kapitalverkehrs unter Anleitung des IWF und der Weltbank (Akçay 2012: 147; Sönmez, S. 2009: 41). 
Slogan der Milli Görüş Bewegung, »Der Muslim klaut nicht, betrügt nicht und ist gerecht «, niederschlug (Yavuz 2005). Der Verdienst, der von Gott in höchstem Maß wertgeschätzt werde, so eine häufig zitierte (vermeintliche) Aussage Mohammeds, sei der Verdienst, den sich ein Arbeiter durch den Respekt gegenüber seinem Arbeitgeber erwerbe (Buğra 1998: 533).

Die »Gerechte Ordnung« bildete die islamistische Artikulation der Aufkündigung des sozialdemokratischen Kompromisses. An die Stelle formalisierter Rechte wurde das vage Versprechen gesetzt, den Kapitalismus mit der islamischen Moral, die die Grundlage gegenseitigen Vertrauens zwischen Unternehmern und Beschäftigten bilden sollte, zu bändigen. Aus einer hegemonietheoretischen Perspektive stand die »Gerechte Ordnung « für den Schwenk von einem engen wirtschaftspolitischen Programm der Förderung von kleinen Industriellen zu einer »programmatischen Ökonomie«, die die Re-Artikulation von Produktionsweise und Lebensweise unter neoliberalen Bedingungen vorbereitete. Wie sich diese Re-Artikulation in den 1980er und 1990er Jahren entwickelte und sich auf die Beziehungen zwischen den Unternehmern und den ArbeiterInnen auswirkte, habe ich im Kapitel zur Klassenkampfthese auf der Grundlage der Forschungsliteratur zur »anatolischen Bourgeoisie« andiskutiert. Ich werde das Thema in den nächsten Abschnitten wieder aufnehmen und ausführen.

Einzuführen ist an dieser Stelle, dass die ANAP in den 1980er Jahren eine Form des materiellen Kompromisses in den rapide anwachsenden suburbanen Vierteln systematisierte, der der Entwicklung von Klassen eine besondere Dynamik verlieh, die bis in die AKP-Periode weiterwirkte. Die ANAP erließ sogenannte Bauamnestien für die illegalen Wohnviertel (Gecekondu), die von den auf der Suche nach Arbeit in die Städte strömenden BinnenmigrantInnen seit den 1950er Jahren selbsttätig auf Grundstücken errichtet worden waren. Die Gecekondu waren zu einem integralen Bestandteil des importsubstituierenden Entwicklungswegs geworden. Die Kommunen sparten Kosten für die Errichtung von Wohnmöglichkeiten und deren infrastrukturelle Versorgung, die von den BinnenmigrantInnen in selbsttätiger Arbeit übernommen wurden. Die Unternehmer konnten geringe Wohnkosten der ArbeiterInnen bei den Löhnen einsparen, erhielten zugleich Zugriff auf informelle, nicht organisierte Arbeitskräfte, die unter einem starken Existenzdruck standen. Die Gecekondu blieben stark umkämpft, Vertreibungen und der Abriss mühsam errichteter Wohnstätten stellten ihre BewohnerInnen immer wieder von neuem vor Nöte. Nichtsdestotrotz wurden durch Bauamnestien viele bäuerliche BinnenmigrantInnen sukzessive zu Grundstückseigentümern gemacht, von denen einige durch spätere Gentrifizierungswellen in die Reihen der besitzenden Klassen aufstiegen. Ihre Grundstücke wurden infolge des anhaltenden Zustroms der Bevölkerung in die Städte teils enorm aufgewertet (Eğilmez 2010: 617ff.). Eine mit diesem Vorgang assoziierte Form des materiellen Kompromisses - die insbesondere in Gang gesetzt wurde, um im Vorfeld von Wahlen für Wählerstimmen zu werben - 
bestand darin, die Gecekondu-Viertel schrittweise in die öffentliche Infrastruktur - Wasser- und Stromversorgung, Straßenbau etc. - zu integrieren (Boratav 2003: 153; Eder 2010: 161f.). Dass 1950 noch drei Viertel der Bevölkerung in ländlichen Gebieten lebte, 1980 diese Zahl auf 56 Prozent und 2010 auf 23 Prozent gesunken war, vermittelt einen Eindruck, welches Gewicht diesem informellen Mechanismus zukam beziehungsweise in abgeschwächter Form bis in die AKP-Periode zugekommen ist (Saraçoğlu 2015: 769). Die Bauamnestien und die schrittweise Integration trugen nach dem Putsch von 1980 auch dazu bei, dass sozialistische Initiativen weniger Gehör bei den BewohnerInnen der Gecekondu-Viertel fanden.

Mit dem Putsch von 1980 rückte die Türkisch-Islamische Synthese ins ideologische Zentrum vor und löste schrittweise die Türkische Geschichtsthese, durch die in den 1920er Jahren das Türkentum als Schmelztiegel bestimmt worden war, als dominante Ideologie ab. Die Junta nahm den Islam in die offizielle Ideologie als konsolidierendes Element auf (Adas 2003: 66f.). ${ }^{31}$ Wie sind vor diesem Hintergrund die fortbestehenden laizistischen Bekenntnisse des Militärs zu begreifen? Die Junta versuchte, größtmögliche Zustimmung zum Putsch herzustellen, und präsentierte sich als überparteilich, im allgemeinen Interesse handelnd. Sie appellierte an alle Kräfte, sich nicht auf der Seite der Linken zu positionieren. Der Appell war auch an das linkskemalistisch-sozialdemokratische und liberale Kleinbürgertum gerichtet. In deren Reihen fand er Anklang, da eine Erholung von der ökonomischen Krise, die in den späten 1970er Jahren Warenknappheit, Hyperinflation und Schwarzmarktbildung hervorgebracht hatte, und ein Ende der bürgerkriegsähnlichen Zustände in Aussicht gestellt wurden. Die Verhaftung einiger militanter Faschisten nach dem Putsch verlieh dieser Aussicht Glaubwürdigkeit. Unterdessen behielt die Junta einen affirmativen Bezug auf Atatürk und die kemalistischen Prinzipien, denen sich erhebliche Teile der Bevölkerung verbunden fühlten. Während der sunnitische Religionsunterricht als Pflichtfach in den Schulen eingeführt und die Türkisch-Islamische Synthese gefördert wurde, wurde zugleich die Popularisierung des Atatürkismus verstärkt. ${ }^{32}$ Der Personenkult konnte bei oberflächlicher Betrachtung, zusammen mit dem laizistischen Bekenntnis des Militärs, den Eindruck vermitteln, die längst unterhöhlte und weiter erodierende Laizität, auf deren Konstitutionsmerkmale im Zusammenhang mit dem Aufbau der religiösen Infrastruktur noch ausführlicher eingegangen wird, bestehe fort (Özdalga 2006: 559ff.). Auf der anderen Seite war sich die Junta bewusst, dass das primäre Motiv

Zu erwähnen sind die mit Koranversen gespickten Reden des Ceneralstabschefs Kenan Evren, der aus dem Figurenmeer des reaktionären Putschs nur aufgrund seiner Position, nicht jedoch aufgrund irgendeiner besonderen Leistung herausragt (Mertcan 2012: 221). in Schulbücher, aber erst in den $1980 e r$ Jahren wird sie in Schulbüchern massiv aufgebauscht (Copeaux 2000: 61f.). 
des Putschs, die Arbeiterbewegung zu zerschlagen und die Kräfteverhältnisse zugunsten der Bourgeoisie zu verschieben, die Integration der türkistischen und islamistischen Kräfte erforderte (vgl. Taşkın 2001: 571). Ihnen war es bereits gelungen, den Einfluss der Linken in den Arbeitervierteln zu begrenzen, und sie vermochten es auch, in diesen Vierteln Zustimmung zum Putsch zu organisieren (Balaban 2013: 46). ${ }^{33}$ Die Intellektuellen der Türkisch-Islamischen Synthese kämpften auf der Seite des Militärs gegen die kurdische Bewegung und die Arbeiterbewegung. Sie konnten ihre Vorstellungen von Bildungsreformen und einer kulturellen Restauration ins Zentrum rücken. Der Putsch ist daher auf der politischen Ebene als Ausdruck einer Allianz zwischen rechts-kemalistischen, türkistischen und islamistischen Kräften zu bewerten, die sich schon beim 1971er Eingriff des Militärs angekündigt hatte.

\subsubsection{Islamismus und Nationalismus}

Die ideologische Artikulation der islamistischen Bewegung verlief nach dem Putsch in Abhängigkeit zum Verlauf des Krieges mit der PKK (Arbeiterpartei Kurdistans), die ab 1984 einen kurdisch-nationalen Befreiungskampf auf der Grundlage sozialistischer Auffassungen einleitete. Nachdem das islamistische Element zunächst ein Übergewicht erhielt, rückte mit der Verschärfung des Krieges in den 1990ern der Türkismus in den Vordergrund. Dass Islam und türkische Nation zusammengehören, gehörte in den 1990ern zum Mantra führender Islamisten. Ahmet Davutoğlu, der später zum Chefideologen der türkischen Außenpolitik unter den AKP-Regierungen wurde, versicherte in Auseinandersetzung mit der rechts-kemalistischen Bewegung, die den nationalistischen Charakter der Islamisten anzweifelte und sie so zu schwächen versuchte, dass Islam und Nation organisch miteinander verbunden seien, dass das Militär die Religion gerade in Kriegszeiten benötige, da der Soldat mit Gebeten in den Krieg geschickt werde (Bora 1998: 132). Den Islam als Vehikel anzusehen, mit dem die Ordnung, die Stabilität und eine harmonische Gesellschaft zementiert werden sollen, bildete auch die Leitidee von Fethullah Gülen, der zu den Gründern der Vereine zur Bekämpfung des Kommunismus gehört und den 1980er Putsch euphorisch begrüßt hatte. $^{34}$

33 Balaban bezeichnet den 1980er Putsch vor dem Hintergrund dieses Wirkens als Putsch der Faubourgeoisie, die er als Klassenbasis des politischen Islam bestimmt, wie in Kapitel 3.4.4 diskutiert.

34 In der Tradition des Sufismus sich verortend gilt Said Nursi als Begründer der Nurcu Bewegung, zu der der Cülenismus gehört. Während Nursi noch zwischen negativem (türkistischen, republikanischen) und positivem (islamistischen) Nationalismus unterschied, verschob sich diese Wertung bei Fethullah Gülen zugunsten der Unterstützung des türkischen Konservatismus. Der türkische Muslim ist im Cülenismus ein besonders reiner Muslim, der 
In der Diskussion zur Säkularisierungsthese wurde auf der Grundlage von Tuğals Studie erörtert, dass sich in den 1970ern eine islamistische Kritik am Nationalismus entwickelt hatte. Diese Kritik rückte desto stärker in den Hintergrund, je weiter die Wohlfahrtspartei ins politische Zentrum vorrückte, ein Prozess, der sich in den Beobachtungen Tuğals im Sultanbeyli der frühen 2000 er anhand der AKP fortgetragen hat. Obgleich der islamistische Internationalismus mit Schlagwörtern wie "Panislamismus« und »Islamische Nation« zum Vokabular der Wohlfahrtspartei (RP) gehörte, blieb diese immer türkeizentriert. Die Türkei wurde imaginiert als einzige potentielle Option der Einheit aller Muslime. Der Internationalismus blieb gefangen in einer politischen Utopie, die die Türkei als aufstrebende Großmacht imaginierte. Der Pan-Islamismus, der sich auf eine transethnische Identität gründet und jeglichen Bezug auf ethnische Identitäten zurückweist, erlangte in der Türkei keine Beständigkeit. Alle relevanten Bewegungen, die über den Islam mobilisierten, wiesen einen nationalistischen Charakter auf. Auch daran zeigt sich, dass der türkische Islamismus in ein Hegemonieprojekt einzubetten ist, dessen ökonomische Basis im Nationalstaat Türkei liegt. Die politische Trägerin des Projekts beherrscht die strategische Ausrichtung des Islamismus, sie ist in der Lage, den transethnischen Moment der Religion zu kontrollieren.

Doch gibt die Beziehung des türkischen Islamismus zum Nationalstaat Anlass, die These zu diskutieren, dass Islamismus als ein post-nationales Phänomen zu begreifen sei (Gülalp 1997). Wird Islamismus als post-nationales Phänomen begriffen, entsteht die sonderbare Diagnose, Bewegungen, die sich maßgeblich auf die Religion berufen und deren Wirken auf die Verbreitung religiöser Praktiken und Weltauffassungen zielt, zu attestieren, dass sie »eigentlich « nicht religiös seien. Die Diagnose resultiert aus der Auffassung, Nationalismus könne sich einzig auf ethnischer Grundlage bilden. Nationalismus als besondere Ideologie zeichnet sich jedoch nicht dadurch aus, dass er sich (ausschließlich) auf Ethnizität gründet, sondern durch die Berufung auf ein Volk oder eine Nation, deren Interessen von politischen Akteuren zu verfolgen sind. Die Berufung auf das Authentische, das Immer-Schon-Vorhandene, das keiner besonderen Begründung bedarf, weil es ganz einfach da ist, und die Sakralisierung nationaler Interessen bilden den ideologischen Grundstoff des Nationalismus, der die Einzigartigkeit und Überlegenheit einer Nation behauptet (vgl. Anderson 1993). Die Konstruktion einer nationalen Identität legt das Fundament für den Nationalismus und für die Formulie-

türkische Staat steht über allem. Die nationalistische und obrigkeitshörige Weltanschauung kommt im missionarischen Eifer und den obersten Prinzipien, dem Staat dienen, Disziplin und Gehorsam - zusammengefasst in der Chiffre »hizmet«, die wörtlich nur»dienen«, im gegebenen Kontext »dem Islam dienen« bedeutet - zum Ausdruck (Bora 1998: 132ff.; Özdalga 2006: 559ff.). 
rung nationaler Interessen, die die Interessen von einzelnen Mitgliedern, Klassen oder Gruppen übersteigen. Eine nationale Identität basiert auf der Zuschreibung von bestimmten konstanten und harmonisierenden Eigenschaften an eine Bevölkerung, die Nation oder Volk genannt wird und der ein Besitzanspruch auf ein bestimmtes Territorium zugesprochen wird (Saraçoğlu 2011). Auf einer konkreteren Bestimmungsebene setzt sich eine nationale Identität aus einer Kombination verschiedener, realer und/oder imaginierter kultureller Elemente zusammen. Islamistische Bewegungen unterscheiden sich von ethnizistischen Bewegungen nicht dadurch, dass sie nicht nationalistisch sind oder sein können, sondern durch die ideologischen Parameter und kulturellen Merkmale, die sie zur Definition der nationalen Identität heranziehen. Sie stellen die Religion als vereinigendes Element in den Mittelpunkt ihrer Definition und nicht die Ethnizität. Nationalismus kann daher als Form begriffen werden, die mit kulturellen Elementen - maßgeblich religiöse und ethnische in der Türkisch-Islamischen Synthese - ihren Inhalt erhält. Der konstruierte Charakter bedingt, dass die Anordnung verändert, Elemente hinzugefügt und entfernt werden können. ${ }^{35}$

\subsubsection{Die 1997er Intervention}

Nachdem sich Mitte 1996 eine konservative Koalitionsregierung unter der Führung der islamistischen Wohlfahrtspartei (RP) gebildet hatte, lösten die Islamisten eine Krise innerhalb des bürgerlichen Machtblocks aus. Das Militär ergriff am 28. Februar 1997 über den Nationalen Sicherheitsrat mit Unterstützung verschiedener oppositioneller Parteien und Verbände Maßnahmen, die das Ende der von der RP angeführten Koalitionsregierung bereiteten. Zum ersten Mal in der Beziehungsgeschichte des Militärs mit dem politischen Islam schlug das Pendel für eine länger anhaltende Periode zuungunsten des Letzteren aus. Ein weiteres Mal stellt sich die Frage nach den Gründen für die militärische Intervention.

Als zentrales Motiv für den Eingriff tritt die Zerschlagung von Kapitalgruppen - der sogenannten Anatolischen Holdings - hervor, die in MÜSİAD organisiert waren. Die Holdings hatten sich Wettbewerbsvorteile bei der Kapitalakkumulation durch illegale Methoden erworben, indem sie Devisen im Ausland eingesammelt, ditionen entwickelten, verweist darauf, dass die Religion ähnlich wie der Nationalismus der Vereinheitlichung eines bestimmten Raums nach innen durch Abgrenzung nach außen diente, und dass die Religion erst in Bezug zu realen Akteuren Bestandteil einer wirklichen Bewegung wird (vgl. Bora 1998: 97ff.). 
in die Türkei geschmuggelt und auf diese Weise einen schnell wachsenden Kapitalstock gebildet hatten, den sie insbesondere durch Produktwerbung mit islamischen Motiven verwerteten. Sie entwickelten sich zu potentiellen Konkurrenten der in TÜSİAD organisierten großen Unternehmen, als sich ihre Chancen, bei öffentlichen Ausschreibungen von Großprojekten an Filetstücke zu gelangen, durch ihre Nähe zur Wohlfahrtspartei erhöhten (Doğan 2009a: 294ff.; Öztürk 2015). Neben dieser entstehenden Konkurrenz sorgte das von der Wohlfahrtspartei offensiv propagierte Projekt, die Türkei zur führenden Kraft sogenannter islamischer Länder zu machen, trotz geringer Aussicht auf Umsetzung für Verunsicherung auf allen Ebenen und spaltete sogar das islamistische Lager. Das Projekt stellte die Eingliederung in die Europäische Union (EU) infrage, mit der Anfang 1996 die Zollunion in Kraft getreten war. Die Eingliederung wurde von den großen Unternehmen betrieben, von vielen kleineren Unternehmen, die die Wohlfahrtspartei unterstützten, jedoch abgelehnt, da sie sich dem Konkurrenzdruck aus der EU nicht gewachsen sahen. Neben diesen politisch artikulierten ökonomischen Friktionen ist umstritten, welcher tatsächliche Stellenwert der von militanten islamistischen Gruppen in den 1990ern ausgehenden Gewalt gegen vorwiegend links-kemalistische und alevitische Gruppen sowie dem wachsenden Konformitätsdruck auf »nicht-islamische« Lebenspraktiken - durch Gendersegregation, Alkoholverbote, Angriffe auf »westlich gekleidete« Frauen und auf republikanische Symbole - beizumessen ist. ${ }^{36}$ Dieses Motiv tritt nach meiner Einschätzung nur in Kombination mit den beiden ersten als ein tragendes auf. Es wurde vom Militär und dem Unternehmerverband TÜSİAD, der die militärische Intervention maßgeblich unterstützte, aber zum Hauptmotiv erkoren, da es die Mobilisierung gesellschaftlicher Unterstützung für die Intervention ermöglichte. Obwohl die Wohlfahrtspartei darauf bedacht war, keine offene islamistische Agenda zu propagieren, hielten sich etliche prominente Parteimitglieder bei öffentlichen Auftritten nicht an diese Richtlinie. Erbakan selbst setzte Zeichen, indem er Ordensführer und andere Islamisten im Ministerpräsidentenamt empfing, während seine Partei versuchte, non-konforme Richter durch parteinahes Personal zu ersetzen, um dadurch den legalen Handlungsspielraum für die Islamisierung auszuweiten (White 2008: 367f.). Gleichzeitig förderte die Wohlfahrtspartei massiv die theologischen Schulen und die Korankurse, die nach dem Putsch von 1980 einst vom Militär gefördert worden waren und in der Zwischenzeit das Mobilisierungspotential der islamistischen Partei stark erweitert hatten. Die Artikulation der islamischen Bildungsinstitutionen mit den Friktionen innerhalb 
des Machtblocks ließ sie nun zu einer Bedrohung der Dominanz der Großunternehmen beziehungsweise des von ihnen eingeschlagenen Entwicklungswegs der EU-Integration werden.

Vor diesem Hintergrund setzte sich im Militär ein in der Forschungsliteratur nach wie vor nicht eindeutig bestimmter Flügel durch, der rechts-kemalistische und türkistische Erkennungszeichen aufwies, um die mit 21,4 Prozent der Stimmen aus den Wahlen von 1995 als stärkste Kraft hervorgegangene Wohlfahrtspartei, die eine Koalitionsregierung anführte, in Schranken zu verweisen. Am 28. Februar 1997 beschloss der von Generälen dominierte Nationale Sicherheitsrat ein Memorandum, in dem von der Regierung die Ergreifung von Maßnahmen gefordert wurde, die die soziale Basis der Wohlfahrtspartei schwächen sollten, darunter die Schließung der Mittelstufen der theologischen Schulen, die staatliche Kontrolle der islamischen Gemeinschaften und der Korankurse und die Durchsetzung des Kopftuchverbots an Universitäten. Mitte 1997 fiel schließlich unter dem Druck des Nationalen Sicherheitsrats die von der Wohlfahrtspartei angeführte Regierungskoalition auseinander. Ein Jahr später verbot das Verfassungsgericht die Wohlfahrtspartei wegen Verstoßes gegen das laizistische Prinzip. Politische Betätigungsverbote und Haftstrafen gegen islamistische Politiker wurden verhängt, die theologischen Schulen wurden entwertet, ein allgemeines Kopftuchverbot an Universitäten verhängt (Dufner 1998).

Das Militär griff in dieser Situation auf den kemalistischen Laizismus als nach wie vor wirksame Ideologie $\mathrm{zu}$, die es als unerschütterlich lancierte. Im dialogischen Widerspruch zu dieser Propaganda entwickelte sich eine neo-kemalistische Reaktion, die den Kemalismus als längst unterhöhlt in der Defensive sah. In den von der Wohlfahrtspartei regierten Kommunen, darunter auch die Metropolen Istanbul und Ankara, hatten religiös begründete Eingriffe in das öffentliche Leben wie Alkoholverbote, die Verbreitung religiöser Symbole in der Öffentlichkeit und der offensive, auf Eroberung ausgerichtete islamistische Diskurs die Einschränkungen säkularer Freiheiten stetig breiter werden lassen. Ein konservativ-islamischer Konformitätsdruck hatte sich in öffentlichen und privaten Räumen entfalten können (Cengiz 2013: 280, 349; Doğan 2007: 210; Toprak u.a. 2009; Tuğal 2009: 106). Der Neo-Kemalismus teilte vor diesem Hintergrund das politische Feld in zwei antagonistische Lager: Laizisten gegen Anti-Laizisten, Republikaner gegen Feinde der Republik, Fortschrittliche gegen Reaktionäre, Nationalisten gegen Separatisten und Kollaborateure des Imperialismus. Der Neo-Kemalismus weist auffallende Strukturgleichheiten zur Türkisch-Islamischen Synthese auf: Die Überzeugung, Opfer einer imperialistischen Verschwörung zu sein, die das Land wie schon nach dem Ersten Weltkrieg von innen - mithilfe von Islamisten und Kurden - spalten wolle; ein starker Rückbezug auf eine glorreiche Vergangenheit (symbolisiert im Nationalen Unabhängigkeitskrieg und Atatürks Lebenszeit); Sehnsucht nach einer starken Führung; die Einheit von Staat und Volk (vgl. Erdoğan 2001b). Be- 
dingt durch die Schwächung der Linken und der Arbeiterbewegung wurde nach 1997 die Teilung des politischen Feldes in zwei rechte Hegemonieprojekte des Bürgertums - ein islamistisch-türkistisches und ein kemalistisch-türkistisches - mit der kurdischen Bewegung als gemeinsame Feindin prägend. Der Sog dieser Lager auf andere Strömungen, verstärkt durch die Wirkkraft der politischen Repräsentations- und Machtverteilungsmechanismen, prägte die politische Konstellation der beginnenden $2000 e r$.

\subsection{Zwischenresümee}

Die Darlegung der Entwicklungsgeschichte und Konstitutionsmerkmale der islamistischen Bewegung begann in Anlehnung an den Leiter der Stiftungsbehörde mit der Benennung eines Forschungsprogramms, das die Verbindung von Gewinnstreben und Investitionsgeist mit kultureller Restauration und einem paternalistischen Armutsregime unter der intellektuellen Führung von theologisch ausgebildetem Personal ergründen wollte. Auf dem Wege der Rekonstruktion der Beziehungsgeschichte der islamistischen Bewegung zu den besitzenden Klassen aus einer hegemonietheoretischen Perspektive konnte eine erhebliche Teilstrecke zurückgelegt werden. Vier Stationen der Beziehungsgeschichte wurden ausgemacht. Sie verlief von der Ablösung über die Wiederanbindung und die Verselbständigung bis zum ideologischen Vorrücken ins politische Zentrum.

Bis in die 1950er Jahre war die islamistische eine nachgeordnete Bewegung des Großgrundbesitzes und der Handelsbourgeoisie, deren gesellschaftliches Gewicht danach stark abgenommen hat. Zeitgleich re-formierte sich der Islamismus als Bewegung des Kleinbürgertums, die von kleinen Händlern, Handwerkern und Grundbesitzern getragen wurde und ein »zivilgesellschaftliches« Netz aufbaute. Allen wirtschaftspolitischen Differenzen zum Trotz ließ der Antikommunismus den sich in den 1960er Jahren mit der kleinen Bourgeoisie verbindenden Islamismus zu einem subalternen Partner der aufsteigenden Industriebourgeoisie werden, die rasch monopolistische Strukturen aufbaute. In den 1960er und 1970ern stellte die Bewegung ihr Mobilisierungspotential gegen die Linke und die Sozialdemokratie, die generell als kommunistisch (miss-)begriffen wurde, auch durch die Formierung militanter Kräfte unter Beweis. Mit dem 1980er Putsch ebnete das Militär auf Zuruf aus der Bourgeoisie dem türkisch-islamischen Hegemonieprojekt den Weg ins ideologische Zentrum. Fünfzehn Jahre bevor 1996 mit der Wohlfahrtspartei zum ersten Mal eine islamistische Partei eine nationale Regierung anführte, und mehr als zwanzig Jahre bevor die AKP das politische Zentrum besetzte, wurden unter den ANAP-Regierungen eine neo-osmanische Vision entwickelt und die Türkisch-Islamische Synthese propagiert. Die Verbindung zur arbeitsintensiven kleinindustriellen Produktion beziehungsweise massenhaften manufakturellen Auftragsfertigung 
begleitete den rapiden Aufstieg des Islamismus nach 1980. Die der kleinen Bourgeoisie und dem Kleinbürgertum angehörenden Islamisten stiegen schrittweise in die Industriebourgeoisie auf. In den Produktions- und Wohnstätten der expandierenden Städte entstand die Basis für die Hegemonie über die Arbeiterschaft, die mit einem neoliberalen Schulden- und Armutsregime der AKP-Periode verknüpft wurde, um die es im letzten Abschnitt der Entwicklungsgeschichte gehen wird, die durch die Besetzung des politischen Zentrums gekennzeichnet ist.

\subsection{Schrittweise Monopolisierung der Staatsapparate - Die AKP-Periode}

Die fünfte Station der Entwicklungsgeschichte der islamistischen Bewegung, die die Gegenwart kennzeichnet, ist die der Monopolisierung der Staatsapparate durch die Träger des islamistischen Hegemonieprojekts. Mit der AKP ist die islamistische Bewegung sukzessive zur dominanten politischen Kraft im Machtblock aufgestiegen, die zwischen den bürgerlichen Klassen moderiert. Seit den Wahlen von 2002 stellte sie, wie in der Diskussion der Kulturkampfthese bereits angeführt (vgl. S. 43f.), schrittweise Kontrolle über die staatlichen Institutionen her. Die politische Form, die diese Kontrolle angenommen hat, ist das Präsidialsystem, das exekutive und legislative Kompetenzen mit einer ausgeprägten Kontrolle über die Justiz beim Präsidenten bündelt. Gesellschaftlich verankert ist diese politische Form in der Regulierung der Klassenverhältnisse auf der Grundlage des neoliberalen Akkumulationsregimes.

Im Folgenden diskutiere ich zuerst die Re-Formierung des Machtblocks unter der AKP und die wirtschaftspolitischen Entwicklungen, die diese Re-Formierung ermöglicht haben. Hiervon leite ich über zur Frage der sozio-politischen Blockbildung in der AKP-Periode und thematisiere die Lage der ArbeiterInnen im Verhältnis zum islamistischen Hegemonieprojekt. Damit greife ich Führungsmechanismen und materielle Integrationsformen des Projekts auf, zu denen auch die Verteilung von Armenhilfe gehört, die in der Rede des Leiters der Stiftungsbehörde Yusuf Beyazıt zu Beginn dieses Kapitels als türkisch-islamische Stiftungspraxis thematisiert wurde. Ich werde argumentieren, dass die Etablierung eines neoliberalen Schulden- und Armutsregimes erheblich zur Breitenwirkung des islamistischen Hegemonieprojekts beiträgt. Im Anschluss erfolgt, gestützt durch empirische Beobachtungen aus meiner Feldstudie, eine Beschreibung des Kulturkampfs, durch den sich das islamistische Hegemonieprojekt in der AKP-Periode gegenüber konkurrierenden Hegemonieprojekten behauptete. 


\subsubsection{Re-Formierung des Machtblocks}

Der Gründung der AKP ging die ökonomische Krise von 2000/2001 voraus, die den Kulminationspunkt einer Reihe von Krisen in den 1990er Jahren bildete, die durch die Liberalisierung der Finanzmärkte ausgelöst worden waren. Die Türkei hatte sich nach 1989 im Vollzug des Strukturanpassungsprogramms des IWF zu einem attraktiven und zugleich krisenhaften Anlagemarkt für internationales Finanzkapital entwickelt (Yeldan 2007: 7). Die Attraktion von Finanzkapital vertiefte das chronische Leistungsbilanzdefizit, dessen strukturelle Ursache in der Unterlegenheit der Produktionsstruktur in puncto Produktivität und technologischer Entwicklung gegenüber den kapitalistischen Zentren lag. Von der Liberalisierung der Finanzmärkte profitierten ausländische Investoren ebenso wie die großen inländischen Konzerne über Finanzgeschäfte sowie durch Arbitrage-Gewinne, die durch die Ausnutzung von Preis- und Zinsunterschieden zwischen Ländern zustande kamen (Boratav 2003: 198). Die Lohnabhängigen litten dagegen unter den hohen Inflationsraten, die zwischen 1993 und 2002 im Durchschnitt bei 70 Prozent lagen, und den Devaluationen, die ihre Einkommen und Ersparnisse ruckartig abwerteten (Saraçoğlu/Yeşilbağ 2015: 898).

Bei den Ende 2002 abgehaltenen Wahlen wurde die von der links-kemalistischen DSP, der konservativen ANAP und der türkistischen MHP gebildete Koalitionsregierung, die unter der Aufsicht des IWF ein weiteres Strukturanpassungsprogramm umsetzte, von den WählerInnen abgestraft. Die Koalitionsparteien scheiterten an der Zehn-Prozent-Sperrklausel ebenso wie die konservative DYP, die zu den tragenden Parteien des neoliberalen Akkumulationsregimes gehört hatte. Die DSP rutschte von 22,2 auf 1,2 \%, die ANAP von 13,2 auf 5,1\%, die DYP von 12 auf 9,5\% und die MHP von 18 auf 8,4\% ab. Die Krise beschleunigte die Absorption der konservativen Parteien in die islamistische Partei, die zu diesem Zeitpunkt selbst eine Re-Formierung durchlief. Noch vor den Wahlen hatten sich Abgeordnete der DYP und der ANAP der AKP angeschlossen, die eine parlamentarische Fraktion aus Abgeordneten gebildet hatte, die die islamistische FP (Tugendpartei) verlassen hatten. Eine Gruppe von »Erneuerern« hatte sich von der Führung durch Necmettin Erbakan losgesagt, der die FP nur noch durch Mittelspersonen leiten konnte, da er selbst einem politischen Betätigungsverbot unterlag. Zum ersten Mal existierten zwei Parteien der Milli Görüş Bewegung. Mit Recep Tayyip Erdoğan wechselte ein großer Teil der Bewegung in die AKP und brachte die über Jahrzehnte akkumulierten Organisierungs- und Mobilisierungsressourcen, das in den Kommunen erworbene Regierungswissen und ein soziales Netzwerk mit, wodurch die Partei von Anfang an auf einem breiten Sockel stand.

Der erste Wahlerfolg von 2002 mit 34,3 Prozent ermöglichte die Bildung einer Regierung, ohne Koalitionen eingehen zu müssen. Seitdem ist die AKP aus jeder Wahl als stärkste Partei hervorgegangen. Es ist einmalig in der Geschich- 
te der Türkei, dass eine mit Wahlen an die Regierung gekommene Partei sich so lange behaupten konnte. Mit Ausnahme der Parlamentswahl vom Juni 2015, die unter Bedingungen eines erneut eskalierten Bürgerkriegs mit der PKK sowie Bombenanschlägen auf Friedenskundgebungen wiederholt wurde, konnte sie aufgrund des türkischen Wahlrechts parlamentarische Mehrheiten bilden, auch wenn sie weniger Stimmen erhalten hatte als die Oppositionsparteien zusammen. Hervorzuheben ist, dass nach dem Juni 2015 Wahlen nicht mehr unter fairen und gleichen Bedingungen für alle Parteien stattgefunden haben. Zudem hat die AKP nach 2016 wegen angeblicher Unterstützung der PKK alle Bürgermeister der von der kurdischen Partei DBP (Demokratische Partei der Regionen) regierten Kommunen zusammen mit einigen Parlamentsabgeordneten ihrer kurdisch-linksliberalen Schwesterpartei HDP (Demokratische Partei der Völker) absetzen beziehungsweise verhaften lassen. Indem sie an deren Stelle an die Zentralregierung gebundene Verwalter ernannte, hat die AKP die Kontrolle über die Staatsapparate auf die kommunale Ebene ausgeweitet. ${ }^{37}$

In den ersten Jahren stand die AKP vor der Aufgabe, die schwelenden Krisendynamiken des Landes in den Griff zu bekommen. Hierfür musste die Zustimmung der von der neoliberalen Umwälzung und den ruckartigen Krisen am stärksten betroffenen Arbeiter- und Bauernschaft und des Kleinbürgertums wiedererlangt, der seit Jahrzehnten bestehende Konflikt zwischen den Kapitalfraktionen moderiert und die vom Staat entfremdete kurdische Bevölkerung - verstärkt durch die in den 1990er Jahren geführten Militärkampagnen gegen die PKK - zurückgewonnen werden. Zugleich musste Vertrauen zu den internationalen Bündnispartnern aufgebaut und Bedenken zerstreut werden, die Partei könnte eine islamistische und anti-westliche Agenda verfolgen und die fünf Jahre zuvor von der Wohlfahrtspartei provozierte Krise des Machtblocks erneut auslösen. In der Auseinandersetzung mit der Kulturkampfthese wurde schon ausgeführt, dass die Partei diese Herausforderungen im Rahmen der Forcierung der EU-Beitrittsgespräche bewältigte. Die Einhaltung und Umsetzung des mit dem IWF nach der Krise 2000/2001 vereinbarten Reformprogramms sicherte der Partei weitere Unterstützung. Der AKP gelang die

37 Obgleich ebenso einige Bürgermeister CHP-regierter Kommunen wegen angeblicher Korruption abgesetzt wurden, erhielt die AKP für dieses Vorgehen gegen die HDP bzw. die DBP die Unterstützung der CHP, die auch die im Verbund mit islamistischen Milizen ausgeführten militärischen Operationen des türkischen Militärs in Syrien gegen das Autonomieprojekt Rojava mittrug. Die Verschärfung der Repression und die militärische Intervention basierten auf einem breiten Konsens, in den auch die MHP eingeschlossen war. Die Repression gegen die kurdische Bewegung und der Krieg in Syrien bildeten vielmehr die Basis für eine Annäherung zwischen islamistischen und rechts-kemalistischen Kräften nach 2016. In diesem Zuge wurden auch die wegen angeblicher Putschplanung vor Gericht gestellten Offiziere und Zivilisten rehabilitiert (Ergenekon- und Balyoz-Verfahren, siehe S. 44). 
Einbindung von liberalen Intellektuellen, die die Vertiefung des neoliberalen Akkumulationsregimes und die Herstellung exekutiver Kontrolle über die Justiz und andere Behörden zur Bekämpfung des Kemalismus als Demokratisierung interpretierten, während das Gegenteil geschah. Das im Polizei-, Justiz- und Militärapparat organisierte Netzwerk der Gülen Gemeinschaft, das sich der AKP angeschlossen hatte, verlieh ihr eine starke Operationsbasis in den staatlichen Institutionen. Mit ihrer Hilfe intensivierte sie nach der 2007 gewonnenen Präsidentschaftswahl den Machtkampf gegen oppositionelle Akteure im Staat, die sich sukzessive der CHP angenähert hatten (Saraçoğlu/Yeşilbağ 2015: 928ff.). ${ }^{38}$ Die AKP etablierte sich in der Folge als Attraktivitätszentrum der türkischen Rechten und verhinderte ein Auseinandersplittern des rechten Lagers wie in den 1990er Jahren. Während die zweite, nach dem Verbot der FP im Jahr 2001 ebenfalls neu gegründete islamistische SP (Saadet Partisi - Partei der Glückseligkeit) sowie konservative Parteien nur noch am Rande der Bedeutungslosigkeit fortexistierten, absorbierte die AKP alternative islamistische Formierungen wie die HAS (»Halkın Sesi Partisi« - Partei der Volksstimme). Sie kooptierte Personal aus der MHP, die als einzige Partei des rechten Lagers neben ihr bestehen blieb, sich der AKP allerdings sukzessive annäherte und nach 2015 eine informelle Koalition mit ihr einging.

Die ökonomische Grundlage für den Zusammenhalt des rechten Lagers bildete die Kontrolle, die die AKP über die staatlich vermittelten Verteilungsmechanismen des gesellschaftlichen Mehrwerts herstellen konnte. Voraussetzung war das vom IWF angeleitete Privatisierungs- und Kommodifizierungspaket, das nach der 2000er Krise installiert worden war. Durch die Erschließung neuer Akkumulationsfelder und vertiefte Finanzialisierung rückte der seit Jahrzehnten bestehende Konflikt zwischen den Kapitalfraktionen, auf dessen Grundlage sich der politische Islam gebildet hatte, in den Hintergrund (vgl. Babacan 2014a). Die systematisch vorangetriebene Privatisierung und die schrittweise Aufhebung von Investitionshemmnissen stellten ein günstiges Investitionsumfeld für in- und ausländisches Kapital her. ${ }^{39}$ Ein Blick auf den Verkauf staatlicher Unternehmen und Infrastruk-

38 Die Gülen Gemeinschaft kann als ein hierarchisch organisiertes soziales Netzwerk bezeichnet werden, das nach 1980 eine religiös artikulierte »zivilgesellschaftliche« Struktur mit einem assoziierten kapitalistischen Firmennetz aufgebaut hatte und dessen Besonderheit darin bestand, eine systematische Infiltrierung der Bürokratie über 30 Jahre betrieben zu haben. Da die Gemeinschaft jedoch über keine eigenständige politische Organisation verfügte, bildete sie über die Zeit informelle Koalitionen mit verschiedenen politischen Parteien. Auf die Rolle der Gemeinschaften wird in Kapitel 6.6 näher eingegangen. Unter der AKP ist die Türkei noch stärker als zuvor für internationale Investoren geöffnet worden. Ein Indikator, der die Internationalisierung anzeigt, ist die Anzahl ausländischer Unternehmen, die in der Türkei einen Firmensitz angemeldet haben. Sie stieg von $15.000 \mathrm{im}$ Jahr 2006 auf 53.000 im Jahr 2016. Knapp die Hälfte dieser Unternehmen stammte aus der EU und den USA, davon allein 6.876 aus Deutschland (UDY 2016). 
turen zeigt die Besonderheit der AKP-Periode auf: 86 Prozent aller Privatisierungserlöse in der Geschichte der Türkei wurden in den ersten zehn Jahren ihrer Regierungszeit erzielt (Saraçoğlu/Yeşilbağ 2015: 876).

Mit der offensiven Fortführung des neoliberalen Akkumulationsregimes wurde die Entwicklungsdynamik der mit der islamistischen Bewegung assoziierten Bourgeoisie, für die die Neoliberalisierung nach 1980 die Basis ihrer Entwicklung gebildet hatte, weiter angetrieben (vgl. Kap. 3.4.1). Während diese Bourgeoisie vor 2002 an kleineren Privatisierungsmaßnahmen öffentlicher Güter und Dienstleistungen zumeist auf kommunaler Ebene beteiligt war, erhielt sie unter der AKP die Chance, einen Entwicklungssprung zu machen (Doğan 2011: 73; Sönmez, M. 2009: 180ff.). Sie erhielt auf Anweisung der Regierung günstige Kredite von den verbliebenen staatlichen Banken (Ertuğrul 2009), profitierte ebenso von den relativ günstigen internationalen Krediten und der Geldpolitik in den kapitalistischen Zentren, die insbesondere nach der globalen Wirtschaftskrise von 2008 eine Liquiditätsschwemme entfesselte. ${ }^{40}$ Der Verkauf von öffentlichem Land, der von der zentralen staatlichen Behörde TOKİ gelenkte Bau von Wohnsiedlungen und die Privatisierung öffentlicher Infrastrukturen ermöglichten der Regierung steuernde Eingriffe in die Kapitalakkumulation zugunsten bestimmter Firmen. Über Ausschreibungsverfahren und Veränderungen im Baurecht konnten mit der AKP assoziierte Firmen bevorzugt werden (Balaban 2011; Gülhan 2011). Bei großen Infrastrukturprojekten wie Flughäfen, Brücken, Häfen, Atomkraftwerken und Autobahnen, die die AKP intensiv als Wahrzeichen vermeintlich wieder errungener osmanischer Größe bewarb, befreite sie die protegierten Unternehmer von Risiken. Sie garantierte langfristige Miet- und Abnahmepreise für die zu erbringenden Dienstleistungen (Sönmez 2013). Die AKP erzwang in besonderen Bereichen der Kapitalakkumulation durch Einschüchterung und Kriminalisierung den Eigentümerwechsel zugunsten der mit ihr assoziierten Bourgeoisie, so bei oppositionellen Medienkonzernen, wodurch sie auch stärkere Medienkontrolle erreichte (Eres/Yüksel 2018; Sözeri 2015).

Unternehmen, die einst in Opposition zur Dominanz der in TÜSİAD organisierten großen Bourgeoisie standen und sich mit dem politischen Islam verbunden hatten, konnten so unter der politischen Protektion der AKP enorm wachsen. Öztürk spricht in diesem Zusammenhang von einem »konservativen Großkapital«, das organische Beziehungen zur AKP unterhält. So waren etwa zehn Mitglieder von MÜSİAD gleichzeitig Gründungsmitglieder der AKP, zwanzig Mitglieder zogen bei den Parlamentswahlen 2002 als Abgeordnete der AKP ins Parlament ein. ${ }^{41}$

40 Die Gesamtsumme ausländischen Kapitals, das zwischen 2003 und 2018 in der Türkei investiert wurde, betrug in etwa $600 \mathrm{Mrd}$. \$, während im wesentlich längeren Zeitraum zwischen 1980 und 2002 »nur « 35 Mrd. \$ an ausländischem Kapital in die Türkei flossen (zusammengestellt aus Daten der türkischen Zentralbank).

41 Organische Beziehungen sind auch aus früheren Zeiten bekannt. Als Istanbuler Bürgermeister war Recep Tayyip Erdoğan Teilhaber einer Distributionsfirma der konservativ-islami- 
Als der Verband MÜSİAD 1990 gegründet wurde, waren nur acht seiner Mitglieder in der Liste der 500 größten Unternehmen mit einem Firmensitz in der Türkei zu finden, 2007 waren es 23 und 2009 schon 31 (Öztürk 2015). ${ }^{42}$ Insgesamt lag die Anzahl gelisteter Firmen, die eine Verbindung zu islamistischen Netzwerken aufwiesen, bei 80. Diese Entwicklung und die Übereinstimmung zwischen der AKP und MÜSİAD bei der Frage der Regimeform sowie in der ideologischen und kulturellen Ausrichtung des Hegemonieprojekts lassen den Schluss zu, dass mit der AKP auch die mit ihr assoziierte beziehungsweise durch sie organisierte Bourgeoisie an die politische Herrschaft gelangt ist (Saraçoğlu/Yeşilbağ 2015: 882ff.; Yıldırım 2018).

Doch trotz Verschiebungen in den Relationen zwischen den Kapitalverbänden ist die seit den 1950er Jahren entstandene Hierarchie auch unter der AKP nicht erodiert. Die mit Abstand umsatzstärksten sowie international am stärksten verflochtenen Firmen sind nach wie vor im Verband TÜSİAD organisiert. Neben und oftmals in Form von Joint-Ventures mit ausländischen Direktinvestoren profitierten auch sie im großen Maßstab von neoliberalen Maßnahmen (Öztürk 2010: 177). Diese Firmen unterstützten anfangs klar die AKP, doch nach 2007 nahmen die Reibungen zwischen TÜSİAD und MÜSİAD wieder zu (Savran 2015). Zwar können die politischen Grenzen zwischen den Fraktionen in der AKP-Periode nicht mehr so eindeutig an der Verbandsmitgliedschaft festgemacht werden, denn einige Mitgliedsfirmen von TÜSİAD haben sich auch nach 2007 auf Seiten der AKP positioniert. Dennoch wurden Reibungen sichtbar anlässlich der Benachteiligung von TÜSİAD-Firmen gegenüber MÜSİAD-Firmen bei öffentlichen Ausschreibungsverfahren und der Verteilung von Subventionen. Sie betrafen ebenso aber die Geldpolitik der Zentralbank, die Regimefrage, die Außenpolitik und die Frage der Rolle der Religion in der Gesellschaft. Die Reibungen nahmen jedoch zu keinem Zeitpunkt die Form einer grundsätzlichen Opposition von TÜSİAD zur Regierung an, wie es Ende der 1970er Jahre der Fall gewesen war, als TÜSİAD gegen die sozialdemokratische CHP-Regierung offen Position bezogen hatte und in einen Investitionsstreik getreten war (Saraçoğlu/Yeşilbağ 2015: 884ff.).

Die AKP wahrte das Gesamtinteresse aller Kapitalverbände, indem sie Kontrolle über die Arbeiterschaft, auf deren Lage noch genauer eingegangen wird, herstellte. Dass Friktionen im Machblock nicht zu einem politischen Auseinandersplittern führten, hing schließlich damit zusammen, dass von neoliberalen Maßnahmen auch kleinere Firmen und das Kleinbürgertum profitierten. Maßnahmen wie der Abbau juristischer Schranken für die Privatisierung von Gemeinbesitz - von

schen Ülker Cruppe, die zum Monopolkapital gehört und lange vor 1980 gegründet wurde. Siehe http://haber.sol.org.tr/ekonomi/en-zengin-daha-da-zengin-ulker-hepsinden-zengin-haberi-61290 vom 22.10.2012 (Abruf am 12.10.2018).

42 In der Liste werden auch ausländische Konzerne mit einem Firmensitz in der Türkei aufgeführt. 
fließenden Gewässern, Waldbeständen, gemeinschaftlich genutzten Flächen -, die (Wieder-)Verwertung des städtischen Raums mittels Gentrifizierung oder die Öffnung der Gesundheitsversorgung für private Investoren haben die Aufnahme von Krediten auch für kleinere Unternehmer rentabel gemacht (Akbulut/Adaman 2013; Duru 2009: 792ff.). Bei Rückzahlungsschwierigkeiten griff die AKP zehntausenden überschuldeten Kleinunternehmen, aber auch einigen Großunternehmen unter die Arme, indem sie Kreditrestrukturierungsmaßnahmen ergriff, die staatlichen Garantien gegenüber den Gläubigern gleichkamen (Akçay 2018: 25). Doch bildet der Verschuldungsstand privater Unternehmen in der AKP-Periode ein beträchtliches Krisenpotential, das auch den Zusammenhalt des Machtblocks gefährdet. Die Schulden des Privatsektors haben sich innerhalb von fünfzehn Jahren (2002-2016) von etwa 43 auf 282 Milliarden $\$$ nahezu versiebenfacht. ${ }^{43}$

Auf mittlere Sicht haben die Privatisierung, die Erschließung neuer Akkumulationsfelder und der Zugang zu Krediten einen Investitionsboom befördert, der den Konsum ankurbelte und die Arbeitslosenrate über lange Zeit relativ stabil hielt, allerdings auf einem relativ hohen Niveau von etwa 14 Prozent bei gleichzeitig einer im internationalen Vergleich sehr niedrigen Beschäftigungsquote von 46 bis 49 Prozent in den $2000 e r$ Jahren (Yeldan/Voyvoda 2011). Selbst Privathaushalte mit unregelmäßigen, geringen und stagnierenden Löhnen konnten ihren Lebensstandard halten, indem sie Kredite erhielten. Auf lange Sicht haben auch die Privathaushalte enorme Schulden akkumuliert. Ihre Verschuldung stieg zwischen 2003 und 2017 von 13,4 auf 564 Milliarden TL, das Verhältnis der Verbindlichkeiten zu den Privatvermögen von 5 auf 45 Prozent im selben Zeitraum (CBRT 2017). Die Erwerbstätigenhaushalte hielten 2010 an den Gesamtschulden einen Anteil von 42 Prozent, was vor dem Hintergrund informeller und prekärer Beschäftigung einen enormen Druck auf sie entfaltet (Karacimen 2015). Eine weitere Statistik verdeutlicht die Dimension der Schuldenentwicklung: 2002 lag das Verhältnis der Schulden zu den verfügbaren Haushaltseinkommen bei 4,7 Prozent, 2015 war dieses Verhältnis um das Zwölffache auf 52 Prozent gestiegen (Güngen 2017). Die Verschuldung tritt als ein historisch neuartiger Inklusionsmechanismus der subalternen Klassen in das ökonomische Entwicklungsmodell auf.

Eine grundlegende Verschiebung in der wirtschaftspolitischen Ausrichtung aufgrund politischer oder kultureller Charakteristika des politischen Islam hat in der Regierungszeit der AKP nicht stattgefunden. Die AKP-Regierungen sahen von der Lenkung des Kapitals etwa in den Aufbau konkurrenzfähiger Produktionskapazitäten oder in die technologische Entwicklung ab. Investoren suchten sich den 
schnellsten Weg der Verwertung, den sie in Finanzwerten fanden, die maßgeblich an den Bau- und Konsumboom gebunden waren. Entgegen einer gelegentlich von islamistischen Politikern vorgebrachten Zins- und Finanzkritik stieg der Anteil von Finanzprodukten am Bruttoinlandsprodukt von $8,9 \%$ im ersten Regierungsjahr der AKP auf 13,2\% im Jahr 2014. Investitionen in die Produktion dienten der Modernisierung, aber nicht dem Aufbau neuer Sektoren (Öztürk 2010: 173). Die semi-periphere Einbindung der Türkei in globale Finanz- und Warenströme und die damit verbundenen strukturellen Probleme - Unterlegenheit der Produktionsstruktur, Abhängigkeit von technologischem Input und Energieimporten, Leistungsbilanzdefizit, Devisenmangel und Auslandsverschuldung - bestehen somit fort (Yeldan 2006; Boratav 2009). Die strukturelle Abhängigkeit des Wachstums inländischer Unternehmen vom internationalen Kapital ist vertieft, die ökonomische Anbindung der Türkei an die EU und die USA ungeachtet eines zeitweise verstärkten anti-westlichen Diskurses fortgesetzt worden. ${ }^{44}$ Das Aufbrechen von Differenzen innerhalb des Machtblocks, die in der Vergangenheit zu massiven Zerwürfnissen geführt hatten, konnte dank einer globalen Liquiditätsschwemme moderiert beziehungsweise in die Zukunft verschoben werden.

\subsubsection{Hegemonie und paternalistisches Armutsregime}

Im Kapitel zur Klassenkampfthese wurde dargelegt, dass die Bourgeoisie in der Türkei verschiedene Mittel und Wege ausgebildet hat, über die sie Hegemonie herstellen und ausüben konnte. Aus der Forschung geht hervor, dass nicht nur die dominanten, sondern auch subalterne Fraktionen der Bourgeoisie - Rentiers, kleine Händler und Unternehmer - ein dichtes Netz der ideologischen und kulturellen Kontrolle gewoben haben, das es ihnen ermöglicht, materielle Kompromisse in einem informellen und individualisierten Rahmen auszuhandeln und dadurch auch die Erwartungen der ArbeiterInnen gering zu halten. Als historische Grundlage für die Wirksamkeit dieses Netzes tritt die Desorganisierung der ArbeiterInnen durch massenhafte Verfolgung ihrer Intellektuellen begleitet von restriktiven Gesetzen gegen gewerkschaftliche Organisierung mit dem 1980er Militärputsch hervor, der die Zurückdrängung kollektiver Handlungsfähigkeit der ArbeiterInnen erwirkte. Die Privatisierung öffentlicher Unternehmen und Dienstleistungen 
nach dem Putsch trieb die Informalisierung und Flexibilisierung von Lohnarbeitsverhältnissen an und weitete die Möglichkeiten der Implementierung informeller Beziehungen zwischen Unternehmern und Arbeitern aus. Obgleich nach wie vor größere Fabriken mit formellen Beschäftigungsverhältnissen vorhanden sind, der sozialdemokratisch geprägte Klassenkompromiss nicht restlos erodiert ist, ist die Produktionsstruktur zunehmend dezentralisiert worden.

Unter Einwirkung der Wirtschaftskrisen von 1998 und 2000-2001 und dem Druck internationaler Gläubigerinstitutionen wurde die Proletarisierung von Kleinbauern nochmals verstärkt. Sie waren in informelle und prekäre Beschäftigungsverhältnisse gedrängt worden, in denen sie keine kollektive Verhandlungsmacht mittels Gewerkschaften ausgebildet hatten (Aydın 2010; Gürel 2014: 343-351, 368ff.; Ercan/Oğuz 2015: 123f.). Zwischen 2002 und 2011 stieg der Anteil von »working class households« (»Erwerbstätigenhaushalte«) an allen Haushalten von 54 auf $62 \%$, während der Anteil von kleinbäuerlichen Haushalten im selben Zeitraum von 3,2 auf 0,97\% und der der Subsistenzbauern von 8,5 auf 5,8\% fiel (Bahçe/Köse 2017: 583). ${ }^{45}$ Die von der AKP im Vollzug der Forderungen des IWF gleich im ersten Regierungsjahr umgesetzte Flexibilisierung des Arbeitsmarkts und die Privatisierung öffentlicher Unternehmen, die zu den letzten gewerkschaftlichen Hochburgen gehörten, trieben diese Entwicklung voran (Çelik 2015; Özdemir/Yücesan-Özdemir 2006). Werkverträge, kurze Kündigungsfristen, Subunternehmertum und Zeitarbeit, die für das Prekariat in den urbanen Zentren schon seit längerem die Normalität bildeten, wurden gesetzlich sanktioniert (Durak 2011: 72f.).

1980 lag der gewerkschaftliche Organisierungsgrad der formellen Beschäftigten noch bei 46,5\%, 2005 nur noch bei 14,9\%. In der AKP-Periode sind Arbeitskämpfe auf einzelne Betriebe begrenzt geblieben und waren in der Regel durch einen defensiven Charakter gezeichnet. Lediglich vereinzelte Aktionen wie der Widerstand von ArbeiterInnen der letzten TEKEL-Betriebe (ehemals staatliches Monopol für Tabak und Alkohol), die Ende 2009 für drei Monate eine Straße in Ankara vor ihrer Gewerkschaftszentrale besetzt hielten, lösten anhaltende Aufmerksamkeit aus. Im Rückblick unterstreicht die Straßenbesetzung allerdings den Niedergang der organisierten Arbeiterbewegung. Die ArbeiterInnen des bereits privatisierten Unternehmens protestierten gegen den Willen ihrer im größten Gewerkalle Erwerbstätigen, die vom Verkauf ihrer eigenen Arbeitskraft leben, also auch Angestellte. Auf der Gegenseite war der Anteil von urbanen Kapitalbesitzern an der Cesamtbevölkerung von 6,45 auf 6,01\% und der der Croßagrarier von 2,79 auf 1,86 \% gesunken. Unter Hinzuzählung der Rentiers und Kleinunternehmer betrug der Anteil der besitzenden Klassen an der Cesamtbevölkerung 2002 18,91 \% und 2011 noch 14,35 \% (Bahçe/Köse 2017: 583). Offenbar bedingt durch den Konzentrationsprozess des Kapitals schrumpfte die Bourgeoisie in der AKP-Periode zahlenmäßig. 
schaftsverband TÜRK-İ̧̧ organisierten Gewerkschaft, die bereit war, die Überführung ihrer sicheren Arbeitsverträge in ein prekäres Beschäftigungsverhältnis mitzutragen. Die ArbeiterInnen ließen sich von dem AKP-nahen Gewerkschaftsvorsitzenden überzeugen, den Widerstand aufzugeben und beendeten ihre Aktion ohne konkretes Ergebnis (Yalman/Topal 2017).

In der AKP-Periode sind einzig die Mitgliederzahlen von Gewerkschaften des öffentlichen Dienstes gestiegen, die mit der islamistischen Bewegung assoziiert sind (Saraçoğlu/Yeşilbağ 2015: 776, 893). Die organisatorische Verfasstheit der ArbeiterInnen in den 2000er Jahren ist also vor dem Hintergrund einer seit mehr als zwei Jahrzehnten andauernden Entwicklung zu sehen, die die Arbeiterbewegung sukzessive geschwächt, zugleich der Bourgeoisie Möglichkeiten eröffnet hat, neue Führungsmuster zu etablieren. Als charakteristisch für die mit der islamistischen Bewegung assoziierte Bourgeoisie tritt hervor, dass diese in den Produktions- und Wohnstätten durch persönliche Präsenz im Alltag der ArbeiterInnen sowie durch biographische Nähe zu den Arbeitern über eine genaue Kenntnis ihrer Lage verfügt, damit auf Sorgen und Nöte direkt reagieren und motivierend eingreifen kann (Cengiz 2013: 311ff.). Balaban berichtet aus seiner Feldstudie in einem Arbeiterviertel Istanbuls, dass Arbeitgeber und Hauseigentümer, die er der Faubourgeoisie zurechnet, entweder selbst an den Freizeitaktivitäten ihrer Beschäftigten und Mieter teilnehmen oder Aktivitäten organisieren beziehungsweise finanzieren, für die sie Mittelspersonen engagieren. Ein dichtes Netz ermöglicht die Kontrolle über Gesprächsthemen und Aktivitäten der ArbeiterInnen außerhalb des Betriebs (Balaban 2013: 12). Tuğal hatte im stark islamisch-konservativ geprägten Istanbuler Arbeiterviertel Sultanbeyli beobachtet, dass die mit der Krise von 2001 verarmten beziehungsweise erwerbslos gewordenen ArbeiterInnen zwar gegen den IWF protestierten, ihren Protest aber nationalistisch artikulierten. Ein Diskurs der Behinderung des türkischen Unternehmertums durch ausländische Mächte als Erklärung für die Misere dominierte. Da linke Akteure an den Protesten nicht teilnahmen, wurde dieser Diskurs, der Ausdruck der Hegemonie der Bourgeoisie war, nicht herausgefordert (Tuğal 2009: 97). Unter den Arbeitern war bereits eine »islamische Imagination « von Armut verbreitet, die auf Genügsamkeit beruhte und ökonomische Hierarchien für legitim hielt. Viele hatten einen Habitus der Notwendigkeit entwickelt (Bourdieu 1987: 594), akzeptierten die Unerreichbarkeit abgesicherter Arbeitsverhältnisse, sicherer Einkommen und begnügten sich mit dem, was sie zur Verfügung hatten (»wir brauchen keinen Reichtum«). Sie bejahten ihre ärmlichen Lebensbedingungen, glaubten an harte Arbeit und ein frommes Leben als Ausweg. Informelle Arbeiter positionierten sich gegen formelle Arbeiter, die sie als überbezahlt ansahen, sogar als Verursacher für das eigene Elend ausmachten, da sie dem Staat auf der Tasche lägen. Die Privatisierung staatlicher Betriebe thematisierten sie als Aufhebung von Ungerechtigkeit und wünschten sich mehr Unternehmer, die Arbeitsplätze schaffen sollten (Tuğal 2009: 129ff.). Durak berichtet aus seiner Un- 
tersuchung in der mittelanatolischen Stadt Konya in Übereinstimmung mit Tuğal, dass innerhalb der Arbeiterschaft die Vorstellung hegemonial geworden war, dass das unternehmerische Interesse dem Allgemeininteresse entspreche. Die ArbeiterInnen folgten der Selbstauffassung der Unternehmer, dass sie der Entwicklung der Nation dienten, indem sie Steuern zahlten, investierten, exportierten, Devisen einbrächten und für Arbeit sorgten (Durak 2011: 35ff.).

Duraks Untersuchung kleiner und mittlerer Betriebe in der mittelanatolischen Stadt Konya, die eine Hochburg des politischen Islam darstellt, verleiht einen exemplarischen Einblick, wie islamisch-konservative Weltauffassungen und Praktiken in den Beziehungen zwischen den Arbeitern und Unternehmern bei Abwesenheit von Gewerkschaften und Versicherungsschutz, unter der Bedingung flexibilisierter Arbeitsverhältnisse und geringer Löhne wirken. Die ideologische Grundlage des Wirkens ist, dass Arbeiter Frömmigkeit als Rechtschaffenheit und Pflichterfüllung begreifen. Gegenüber frommen Unternehmern sehen sich die Arbeiter verpflichtet, eine Haltung des harten Arbeitens einzunehmen, die sie zugleich als Rechenschaftspflicht gegenüber Gott begreifen. Sie akzeptieren grundsätzlich ihre Position, sehen die Härten des Lebens als eine durch Geduld zu bestehende Prüfung Gottes an und verschieben die Aussicht auf ein »besseres Leben« ins Jenseits. Neben dieser ideologischen Artikulation ist für die hegemonietheoretische Diskussion von besonderer Bedeutung, wie die Religion in die Gestaltung des materiellen Kompromissrahmens eingebettet ist. Für die Arbeiter tritt die Annahme einer islamisch-konservativen Weltauffassung und Sprache als Voraussetzung auf, einen Arbeitsplatz zu erhalten, legitime Anliegen formulieren und in Konfliktsituationen Solidarität von anderen Arbeitern erfahren zu können. Selbst Auseinandersetzungen um Arbeitspausen sind in Konya religiös artikuliert. Pausen werden durch Gebetszeiten, die dreimal am Tag in die Arbeitszeit fallen, eingelöst beziehungsweise von den Arbeitern beansprucht. Unternehmer akzeptieren sie widerwillig, da sie die Ausübung des Gebets als religiöse Pflicht nicht infrage stellen können, ohne den religiös artikulierten Beziehungsrahmen, der strukturell zu ihren Gunsten gestaltet ist, in Gänze infrage zu stellen.

Geringe Löhne und fehlender Versicherungsschutz bedingen, dass Unternehmer kleine Zuwendungen wie eine freiwillige Prämie oder Lohnfortzahlung bei Krankheit und Unfällen als großmütige Leistung lancieren können. Sie ermöglichen ihren Arbeitern ferner Zugang zu Darlehen und fungieren als persönliche Bürgen bei Mietverträgen. Neben solchen Praktiken der Patronage stehen sie in der Pflicht, an Hochzeiten und Beerdigungen teilzunehmen, Rituale wie das Fastenbrechen und religiöse Feiertage mit ihren Arbeitern zu verbringen, Zuwendungen auch bei solchen Anlässen beizusteuern. Dass die Vermittlung von Jobs zumeist über Verwandte und Bekannte verläuft, untermauert die Einlagerung der Arbeitsbeziehungen in ein Netz sozialer Beziehungen, das gegenseitige Verpflichtungen stabilisiert. Etablierte Sprachmuster, durch die Unternehmer als Teil der Familie 
erscheinen - über den Boss wird als großer Bruder oder Onkel gesprochen - spiegeln diese Einlagerung. Die Organisierung in Gewerkschaften gilt vor diesem Hintergrund als undenkbarer Vertrauensbruch. Sich den paternalistischen Praktiken einzufügen, bedeutet die Aussicht auf Jobs und informelle Zuwendungen. Ein Verstoß gegen diese Praktiken bedeutet dagegen nicht nur den Verlust dieser Aussicht, sondern auch ein Verstoß gegen die ebenfalls islamisch-konservativ geprägten Praktiken des sozialen Netzes, das Familie, Verwandtschaft, Nachbarn, Freunde umfasst und in das die Einzelnen auch außerhalb ihrer Erwerbstätigkeit eingebunden sind. Herausforderungen dieser paternalistischen Praxis entstehen, wenn Unternehmer ihre »Pflichten« nicht erfüllen oder ArbeiterInnen jenseits der Kontrolle des Unternehmers Erfahrungen untereinander austauschen können. Doch stellt auch Durak fest, dass solche Erfahrungen nicht die Chance erhalten, sich zu einem kollektiven Bewusstsein zu formieren. Das eng geflochtene soziale Beziehungsnetz lässt das Entstehen von »Freiräumen« nicht zu und bedingt das Verschieben von Besserung ins Jenseits (Durak 2011: 117) ${ }^{46}$

Die Zustimmung insbesondere der unteren Schichten der ArbeiterInnen zur AKP-Politik ist offensichtlich in diesen alltäglich reproduzierten sozialen Beziehungen verankert. Mit der dezentralisierten Produktionsstruktur, der Flexibilisierung und Informalisierung von Beschäftigungsverhältnissen geht auf der einen Seite die Entstehung eines Arbeitertyps einher, dessen Reproduktion in konservativ und religiös geprägte soziale Beziehungen eingebettet ist. Konservativ-religiöse Praktiken, in denen sich paternalistisch und patriarchal geprägte Beziehungen mit einer starken sozialen, auch über die Familie vermittelten Kontrolle sowie religiösen Ritualen verbinden, bilden den gesellschaftlichen Nährboden für den islamischen Konservatismus der AKP. Auf der anderen Seite steht ein Unternehmertyp, der mit seinen Arbeitern die gleichen konservativ-religiösen Praktiken teilt, die Kontrolle und Führung über die Arbeiterschaft ermöglichen und zugleich einen materiellen Kompromissrahmen vermitteln. Die genauere Bezeichnung für diesen in der Literatur als anatolischer Bourgeois bezeichneten Unternehmertyp ist die des konservativ-islamischen Bourgeois, der insbesondere auf kommunaler Ebene in den Leitungsgremien der Partei zusammen mit kleinen Händlern und Geschäftsinhabern, Bauherren und Immobilienhändlern sowie Mitgliedern der freien Berufe stark vertreten ist. Das islamisch-konservative Hegemonieprojekt der AKP ist folglich im Praxiswissen der kleinen und großen Unternehmerschaft, der Rentiers und des Kleinbürgertums verankert, die sich in und über die Partei organisieren (Balaban 2013; Doğan 2016: 73ff., 103ff.; Uysal/Topak 2010: 196ff.).

46 Cengiz und Doğan beschreiben unabhängig voneinander, dass im islamisch-konservativ geprägten Kayseri der Konformitätsdruck auch auf qualifizierte Fachkräfte und Unternehmer wirkt, die sich konservativ-islamischen Cepflogenheiten anpassen mussten (Cengiz 2013: 276ff. u. 415; Doğan 2009: 299, Fn. 5). 
Die Zerschlagung und Kooptation von Gewerkschaften, eine desorganisierte, fragmentierte, ideologisch und kulturell kontrollierte Arbeiterschaft sowie die kapitalfreundliche Politik der AKP bedeuten also nicht, dass keine materielle Kompromissbildung mehr stattfindet. Die Studie über Konya unterstreicht, dass unter den Bedingungen einer allgemeinen Tendenz zur Informalisierung auch die Mechanismen der Kompromissbildung stärker informell gestaltet werden. Schon zuvor hatte es - auf anderen Feldern - politisch vermittelte informelle Formen der Kompromissbildung gegeben, die ihre Vorreiter in der von der ANAP in den 1980er Jahren systematisch betriebenen Legalisierung beziehungsweise Integration der informellen Siedlungen (Gecekondu) in die kommunale Infrastruktur hatten. Während direkte Zugeständnisse durch Legalisierungen und Integration die informellen Wohnverhältnisse unmittelbar stabilisierten, war es der ANAP gelungen, die Zustimmung der Bevölkerung für langfristige neoliberale Weichenstellungen zu erhalten und zugleich für den Fortbestand verhältnismäßig geringer Wohnkosten, die sich als vorteilhaft für die Unternehmer erwiesen hatten, zu sorgen. Diese Form des Zugeständnisses wurde in den $2000 e r$ Jahren - häufig in Verbindung mit Kämpfen der Gecekondu-Bewohner - nicht nur in den islamistisch regierten Kommunen fortgeführt, sondern auch in Städten wie Izmir, die von der CHP regiert werden (Eğilmez 2010).

Eine ebenfalls politisch vermittelte Form der Zuwendung, in der die Religion und die religiösen Akteure eine vermittelnde Rolle spielen, besteht in der Verteilung informeller Transferleistungen durch den Ausbau eines "neoliberalen Armutsregimes« (Bahçe/Köse 2017: 576). Der landesweiten Etablierung dieses Regimes geht die Kapitulation sozialdemokratischer Regierungen in der ersten Hälfte der 1990er Jahre gegenüber der Neoliberalisierung voraus. Sie ebnete der islamistischen $\mathrm{Be}$ wegung den Weg in die Kommunen, wodurch sie ihre Mechanismen der Hegemonieausübung etablieren konnte. Wie angesprochen, hatte schon die Wohlfahrtspartei in den von ihr regierten Kommunen Zuwendungen an das Prekariat mit religiösen Zeremonien und einer islamischen Gerechtigkeits- und Gleichheitsrhetorik verwoben, die auf einer religiösen Ethik der Barmherzigkeit und der Armenabgabe beruhte, in der den Reichen eine Fürsorgepflicht gegenüber den Armen zugesprochen wurde (Bakırezer/Demirer 2009; Doğan 2007: 275). Zu ihrem Programm erkoren hatte diese Perspektive die mit der islamistischen Bewegung assoziierte Unternehmerschaft, die karitative Organisationen finanzierte und private Mechanismen der Armenhilfe etabliert hatte (vgl. Cengiz 2013). In einem Interview mit dem Gründungsvorsitzenden von MÜSİAD erklärte dieser seine Auffassung:

»Wenn ich meine Almosenabgabe zahle, kann mir niemand sagen, was ich zu tun habe. Der Gesandte Gottes hat es nicht erlaubt, sein gesamtes Vermögen zu spenden. [...] Von den Suren und Hadithen, die ich gelesen habe, weiß ich, dass die Ausgaben eines jeden so groß sind, wie Cott es ihm gegeben hat. [...] Ein jeder 
schuldet nur Gott Rechenschaft. [...] Wer soll mir denn Druck machen, gibt es einen größeren als Gott? «7

Die Unternehmerschaft hatte über die freiwillige Armenhilfe hinaus ein privates Netz sozialer Wohlfahrt - oftmals in Assoziation zu islamischen Gemeinschaften - aufgebaut, das Schulen und Wohnheime, die Vergabe von Stipendien und die Versorgung von Alten und Kranken umfasste. Sie hatte damit auch die Entscheidung inne, wem diese Hilfen zukommen sollten, wodurch sie zugleich ihren gesellschaftlichen Einfluss festigen konnte (Doğan 2009; Eder 2010: 179ff.).

Die AKP installierte das auf der kommunalen und privaten Ebene erprobte Wohlfahrtsregime auf der nationalen Ebene. Mit dem 2001 mit der ökonomischen Krise eingeleiteten »Projekt zur Eindämmung sozialer Risiken«, das zu den vom IWF geforderten Maßnahmen gehörte, wurde das auf die informellen und prekarisierten Arbeitskräfte zugeschnittene Wohlfahrtsregime institutionalisiert. Der IWF sah dieses Regime vor, um sozialen Konflikten vorzubeugen und die existentielle Not der proletarisierten Massen abzufedern, deren Einkommen zur Abdeckung ihrer physischen Bedürfnisse nicht ausreichte. Das auf selektiven, informellen, rechtlich nicht verbrieften Transfermechanismen bestehende Regime steht im Kontrast zum vorangehenden Regime, in dem soziale Leistungen Folge von Rechtsansprüchen beziehungsweise Versicherungsleistungen waren, die allerdings auf die Beschäftigten im formellen Sektor, Angestellte des öffentlichen Diensts und bestimmte selbständige Berufsgruppen begrenzt waren und die Grundlage für die sozialdemokratische Blockbildung gebildet hatten (vgl. Eder 2010: 157f.). Das neue Regime geht mit einer Deregulierung sozialer Wohlfahrt und der öffentlichen Gesundheitsversorgung einher. Es deckt einen Teil der Reproduktionskosten von Arbeitskräften durch öffentliche Transferleistungen, die somit nicht (mehr) von den Unternehmen durch Löhne getragen werden müssen. Seit der Installierung stiegen die informellen Transferleistungen, mit denen entweder direkt von der Regierung - über das Familien- und Sozialministerium und die von Provinz- und Bezirksgouverneuren verwalteten Stiftungen für Soziale Hilfe und Beistand - oder indirekt über islamische Wohlfahrtsorganisationen staatliche Gelder verteilt wurden, kontinuierlich (Bahçe/Köse 2017).

Wie stark die existenzielle Not der lohnabhängigen Klassen durch das neoliberale Regime und ihre Abhängigkeit vom neuen Wohlfahrtsregime geworden ist, zeigen Berechnungen von Bahçe und Köse (2017): 2011 fielen etwa 83 Prozent der Erwerbstätigenhaushalte durch die geringe Höhe eigenständiger Einkommen unter die Armutsgrenze (pro Kopf Tageseinkommen von weniger als 4,3 \$). Die Armutsrate stieg gegenüber 2002 um 14 Prozent. Dies bedeutete, dass 2011 die Ein-

47 Erol Yarar: Gerçek Burjuva Sınıfı Biziz [Erol Yarar: Wir sind die wahre Bourgeoisie], in: http://ekonomi.haber7.com/ekonomi/haber/421393-erol-yarar-gercek-burjuva-sinifi-biziz vom 20.07.2009 (Abruf am 12.10.2018). 
kommen von etwa der Hälfte aller Haushalte unter der Armutsgrenze lagen. Wenn jedoch die Transferleistungen, die sie - ohne Rechtsanspruch - zusätzlich zu ihren Einkommen erhielten, berücksichtigt werden, fiel die Armutsrate von 27,4\% für 2002 auf 7,4 \% für 2011. Bahçe und Köse zeigen ebenfalls auf, dass das Fehlen eines formalisierten Rechtsanspruchs eine Selektivität des neuen Wohlfahrtsregimes bedingt. Während die Summe der Transferleistungen gestiegen ist, ist die Anzahl der Haushalte, die Hilfen empfingen, gesunken. Aufgrund der allgemeinen Verschlechterung der Einkommenssituation von Erwerbstätigenhaushalten wäre das Gegenteil zu erwarten. Die Kriterien, die diese Selektivität gestalten, lassen sich aus quantitativen Erhebungen nicht erschließen. Eine naheliegende, durch einzelne Fälle informierte aber nicht systematisch untersuchte Hypothese ist, dass politische und kulturelle Nähe zur AKP eine Rolle spielen. Da die Verteilung von Hilfen nicht transparent gestaltet ist, eine öffentliche Instanz zur Kontrolle der Vergabe von Leistungen fehlt, ist es faktisch der Entscheidungsgewalt einzelner Behörden überlassen, wer solche Hilfen erhält und wer nicht. Patronage wird hierdurch begünstigt (vgl. Buğra/Candaş 2011: 518ff.; Eder 2010: 175ff.).

Anzunehmen ist, dass bei der Verteilung von Armenhilfe ähnliche und damit von persönlichen Entscheidungen abhängige Mechanismen greifen wie bei der privaten »Armenabgabe«, die in der islamischen Theologie als Pflicht der Reichen gegenüber den Armen thematisiert wird (vgl. Kuran 1995: 87). ${ }^{48}$ Der Empfänger muss die Nähe zu Wohltätern suchen und für sich werben. Er muss darlegen, warum gerade er Hilfe erhalten soll. Durch diese Form der persönlichen Bindung sozialer Hilfen wird die Mitgliedschaft in einer kulturellen Gemeinschaft attraktiv, hier also die Mitgliedschaft in einer islamisch-konservativen Glaubensgemeinschaft oder das Bekenntnis zu ihr, der sich im Falle staatlicher Verteilungsmechanismen die Mitglieder der Bürokratie angehörig fühlen. Offenkundig ist diese Selektivität, wenn allgemeine Steuern in die Finanzierung religiöser Aktivitäten wie den Bau theologischer Schulen oder von Pilgerfahrten gelenkt werden, die nur bestimmten, kulturell definierten Bevölkerungsgruppen offen stehen. Darüber hinaus ist die Teilnahme an einem religiösen Ritual wie dem Fastenbrechen erforderlich, um Hilfen zu erhalten. In den islamistisch regierten Kommunen wird die Verknüpfung von Armenhilfe mit religiösen Zeremonien schon seit den 1990er Jahren offensiv betrieben. Die islamistische Partei nutzt solche Zeremonien, um für ihre politischen Ziele zu werben. Die kritische Berichterstattung durch Mainstream-Medien

48 Die Armenabgabe ist ein weiteres Beispiel dafür, dass der Islam oder der Islamismus kein kohärentes politisches oder ökonomisches System, sondern eine Ideologie ist, die nur in Verbindung mit konkreten Akteuren wirklich wird. Ob die Abgabe auf Freiwilligkeit beruhen oder verpflichtend durch eine Institution eingetrieben, nur von Privatpersonen oder auch von Unternehmen bezogen werden soll, welche Regeln bei der Verteilung gelten, sind Fragen, die in jedem Land, das dieses Modell anwendet, unterschiedlich beantwortet werden. Indes behauptet jedes Land, es habe das ideale Modell gefunden (Kuran 1995). 
über die Verknüpfung öffentlicher Hilfen mit politischer Werbung hat über die Zeit deutlich abgenommen. Grund dafür ist nicht allein Gewöhnung, sondern auch verstärkte politische Kontrolle der Medien oder - mitunter erzwungene - Anpassung. 2010 wurde noch skandalisiert, dass in der Hauptstadt Ankara die AKP-geführte Kommune beim Fastenbrechen im Monat Ramadan Zelte aufstellte, in denen über vier Wochen täglich Verköstigung für angeblich mehrere hunderttausend Personen ausgegeben wurde. ${ }^{49}$ Während der Verköstigung wurde Werbung für ein »Ja « beim anstehenden Verfassungsreferendum gemacht. Das Aufstellen solcher Zelte, in denen Bürgermeister der AKP in Begleitung von Geistlichen, die das Ritual des Fastenbrechens anleiten, Ansprachen halten, die auf die jeweilige politische Tagesordnung eingehen, ist regelhafte Praxis. In den 2000er Jahren wurden sie zum festen Bestandteil organisierter Armenhilfe durch die Einrichtung kommunaler Fonds, die maßgeblich aus Spenden lokaler Unternehmer gespeist wurden (Eder 2010: 178). In Izmir, wo die AKP nicht den Bürgermeister stellt, beobachtete ich, dass die Ausgabe von Essen am Ramadan über die Moscheen stattfand. Da die Moscheen der nationalen Regierung unterstehen, konnte die AKP diese unter Umgehung der Kommunalverwaltungen mobilisieren. In Diyarbakır beobachtete ich, dass das lokale Büro der AKP als Anlaufstelle für potentielle Hilfsempfänger fungierte. Eine ehrenamtliche Parteifunktionärin war für diesen Zweck abgestellt, bot Beratungsgespräche an und vermittelte die Bittsteller an karitative Organisationen weiter. Letztere verteilten neben unregelmäßigen Hilfen in Form von Lebensmitteln und Heizmaterial auch regelmäßige Hilfen an ältere Menschen, Waisen und Pflegebedürftige.

Kutlu hat in seiner Studie über die staatliche Armenhilfe herausgearbeitet, dass für viele Arme diese Hilfen zum »fürsorglichen Gesicht« der Partei geworden sind (Kutlu 2015: 355). Sie erscheinen ihnen nicht als steuerfinanzierte öffentliche Hilfen, sondern als unmittelbare Zuwendungen dieser Partei, die dieses Image nachdrücklich pflegt und an politische Konditionen knüpft. Der von der AKP gestellte Parlamentspräsident formulierte diesen Zusammenhang im Vorfeld der Parlamentswahlen im Jahr 2015 folgendermaßen:

»Wenn ihr dieses Land von Koalitionsregierungen abhängig macht, dann wird es schwer, Arbeit für eure Kinder zu finden. Es wird schwer, sich um die Behinderten zu sorgen. Es wird sehr schwer, Kohle an unsere Armen zu verteilen. Dem Inhaber einer Grünen Karte ${ }^{50}$ seine Medikamente zu geben, wird sehr schwer.« (zit.n. Kutlu 2015: 355)

49 Siehe www.milliyet.com.tr/70-bin-kisiye-evet-li-iftar-siyaset-1284444/ vom 03.09.2010 (Abruf am 16.10.2018).

50 Die Crüne Karte wurde 1992 eingeführt, um nicht-versicherten Bevölkerungsgruppen den Zugang zu Gesundheitsleistungen zu ermöglichen beziehungsweise zu vereinfachen. Die AKP weitete diese Leistungen stark aus. Das Modell wurde 2008 beendet und durch ein Allgemei- 
Die Armenhilfe stärkt, so Kutlu, bei den Empfängern das konservativ-bewahrende Image der Partei und wirkt auf die Wahrnehmung von Religion zurück, die mit Hilfsbereitschaft assoziiert sowie mit Dankbarkeit und Schuldgefühlen verwoben wird. Im Gegenzug wird die Partei politisch unterstützt, beispielsweise durch eine Wahlstimme. Ein längeres Zitat zur Situation von Haselnussbauern vermittelt einen Eindruck wie diese Lebenslage der subalternen Klassen sich politisch niederschlägt:

»Nach Gesprächen mit etwa 20 Haselnussarbeitern habe ich Folgendes begriffen: Nachdem die Haselnuss kein Geld mehr einbrachte, sind die Bauern in die Städte migriert. In der Stadt arbeiten sie auch nicht, sie haben es aber geschafft, in den Randvierteln in lausigen Kellerwohnungen sich ein neues Leben mit der Grünen Karte, Nudeln und Kohlen einzurichten. Dieser neuen städtischen Schicht gelingt es, irgendwie Geld für die Ausbildung ihrer Kinder zu organisieren. Mit kommunalen und sonstigen Hilfen, die von irgendjemand dort oben verteilt werden, kommen sie über die Runden. Nach Gelegenheit verdingen sie sich für einen Tageslohn in nicht versicherten, prekären Jobs. Wie viele Jahre das noch gut geht, ob ein solches Leben auf Dauer gut gehen kann, sei dahingestellt. [...] Die neuen Städter kompensieren den materiellen Verlust aus der Haselnuss durch Hilfen, die ein konstantes Armutsniveau ermöglichen. [...] Diejenigen, die eine Angabe zu ihrer Wahlentscheidung machten, gaben alle an, die AKP zu wählen. [...] Danach gefragt, warum sie die AKP wählen, lauteten die Antworten und die dazugehörigen Erklärungen wie folgt: >Die Kinder gehen zur Schuleく (Die AKP gibt uns Geld für die Schulkosten); >Die Cesundheitsversorgung ist besser geworden< (Ich erhalte Pflegegeld für die Alten und Behinderten zu Hause); >Die Straßen sind besser geworden, eine Menge Dienste werden geleistet` (Kohle und andere Hilfen werden verteilt).«(Ince 2012, zit.n. Gürel 2014: 373, Übersetzung E.B.)

Indem die lohnabhängige Bevölkerung massenhaft zu Hilfsempfängern gemacht wurde, sind Patronage und paternalistische Beziehungen zwischen der Bevölkerung und denjenigen Instanzen entstanden, die Hilfen verteilen. Unter den Bedingungen existenzieller Armut haben die Nehmenden kaum eine Möglichkeit, paternalistischen Praktiken zu entkommen. Untersuchungen zeigen, dass sie sich in diesen Beziehungen einrichten. Die Armenhilfe lässt einen Kreislauf des Gebens und Nehmens entstehen, in dem Materielles (Hilfen), Politisches (Partei, Behörde, Organisation) und Kulturelles (Konservatismus, Religion) ineinander verwoben sind. Die Aufrechterhaltung dieses Kreislaufs trägt schließlich zur Erklärung bei, warum die AKP insbesondere die Zustimmung der prekarisierten und informalisierten ArbeiterInnen erhält, diese Zustimmung selbst unter ökonomisch krisen-

nes Versicherungssystem für Bevölkerungsgruppen, die nicht in das soziale Versicherungssystem integriert sind, ersetzt. 
haften Bedingungen, wie sie seit der globalen Krise von 2008/2009 in der Türkei vorherrschen (Akçay 2018), weitgehend erhalten geblieben ist. Andere Regierungsparteien in der Geschichte der Türkei hatten in Folge ökonomischer Krisen massiv an Zustimmung verloren oder wurden, wie nach der Krise von 2000/2001, sogar ganz von der politischen Bühne hinweggefegt.

Resümierend lässt sich festhalten, dass die historische Konjunktur, in der die Religion in der Regulierung sozialer Verhältnisse an Bedeutung gewinnt, einer Erosion des institutionalisierten Klassenkompromisses nachfolgt. Nicht staatsbürgerliche Rechte auf der Grundlage organisierter Klassenlagen, sondern kulturelle Bindung und Nähe werden in der Regulierung der Klassenverhältnisse bestimmend. Die Religion offeriert einen Deutungsrahmen und stellt Praktiken zur Verfügung, mit denen informalisierte, paternalistische Beziehungen als moralisch-richtiges Handeln legitimiert werden können in einer historischen Situation, in der Alternativen - Gewerkschaften, verbriefte Ansprüche und Rechte - gegenüber dieser Form informalisierter Sozialpolitik zurückgedrängt worden und kaum noch durchsetzungsfähig waren. Hegemonietheoretisch kann das Almosenregime als materieller Baustein eines »informellen« Klassenkompromisses gefasst werden, der die sozio-politische Blockbildung unter der praktischen Führung der islamistischen Bewegung ermöglicht. Aus dieser Perspektive zeigt sich, dass der Bedeutungsgewinn der Religion aus ihrer Rolle als kulturelle Vermittlungsform in der Ausübung von Hegemonie erwächst, die in den alltäglich reproduzierten sozialen Beziehungen zwischen den Klassen verankert ist. Die AKP hat die Verknüpfung der Informalisierung und Prekarisierung mit konservativ-religiösen Praktiken, die einen zentralen Baustein ihres Hegemonieprojekts bilden, von der kommunalen und betrieblichen auf die nationale Ebene getragen.

\subsubsection{Kulturkampf in der AKP-Periode}

Aus der Diskussion der Forschungsliteratur ging bereits hervor, dass die Auseinandersetzung mit seinen Widersachern die Formierung des islamistischen Projekts erheblich beeinflusst hat. Die islamistische Partei musste sich gegen die gesellschaftlichen Träger konkurrierender Hegemonieprojekte, die Machtzentren im Staat gebildet hatten, durchsetzen. Der Kulturkampf war die Form, die dieses Sich-Durchsetzen in den gesellschaftlichen Auseinandersetzungen angenommen hatte. Die Türkei der 2000er Jahre war Schauplatz eines stark zugespitzten Kulturkampfs konkurrierender Hegemonieprojekte, bei dem alle symbolischen Waffen ins Feld geführt wurden, die die sozialen Träger der Projekte über Jahrzehnte akkumuliert hatten. Unter Einbezug meiner Beobachtungen in Izmir und Diyarbakır werde ich im Folgenden einen Einblick vermitteln, mit welchen Mitteln dieser Kampf geführt wurde. Da der Kulturkampf sich neben der Frage der Laizität an der »kurdischen Frage« entzündete, habe ich eine Bestimmung des 
kurdisch-säkularen Hegemonieprojekts beziehungsweise der »kurdischen Frage« vorangestellt. Sie ist bislang unterbestimmt geblieben.

\section{Die »Kurdische Frage»}

Die »kurdische Frage« wird in der Literatur als ein aus der Leugnung der kurdischen Ethnie durch den Türkismus hervorgehender Problemzusammenhang diskutiert (Saraçoğlu/Yeşilbağ 2015: 941ff.). Durch den bewaffneten Guerillakampf der PKK ab den 1980er Jahren erhielt die »kurdische Frage« über die kulturelle Anerkennung des Kurdischen hinaus eine politische Dimension. ${ }^{51}$ Die PKK verfolgte die Gründung eines eigenständigen kurdischen Nationalstaats in Verbindung mit sozialistischen Zielen. In den $2000 e r$ Jahren wandelte sie dieses Ziel angesichts geringer Aussicht auf Durchsetzbarkeit in die Forderung politischer Selbstverwaltung mit kultureller Gleichstellung innerhalb der bestehenden Grenzen der Türkei um. Die Selbstverwaltung sollte zusammen mit einer umfassenden Amnestieregelung für die Guerilla und die kriminalisierten zivilen Akteure des kurdischen Projekts erreicht werden. In Assoziation mit der PKK hatten sich eine legale Partei und eine zivile Bewegung entwickelt, die sich sukzessive in allen gesellschaftlichen Bereichen organisierte. Ab den 1990er Jahren konnte die Bewegung Mehrheiten unter der kurdischen Bevölkerung im Südosten der Türkei herstellen und in vielen Kommunen trotz Rückschlägen aufgrund von Repressionswellen und Militärkampagnen Regierungserfahrungen sammeln.

Dass die kurdische Bewegung in der Region führend wurde, stand im Zusammenhang mit der Abwendung von sozialistischen Zielen schon in den 1990er Jahren und der Formulierung einer kapitalistischen Entwicklungsperspektive für die wirtschaftlich zurückgebliebenen südöstlichen Regionen der Türkei. In nationalen Programmen formulierte die legale parteiförmige Organisation der kurdischen $\mathrm{Be}$ wegung, die sich aufgrund von Verboten mehrfach neu gründen musste, ein Programm nachholender kapitalistischer Entwicklung und forderte Subventionen für mittelständische Unternehmen. Führende Parteimitglieder appellierten an große Unternehmen, in der kurdischen Region stärker zu investieren. ${ }^{52}$ Zaghafte sozialdemokratische Zielsetzungen in den von kurdischen Parteien regierten Kommunen wichen in den $2000 e r n$ einer neoliberal geprägten Kommunalpolitik, die sich auf der Basis einer Allianz des städtischen Kleinbürgertums realisierte, das sich

51 Der Gründung der PKK ging die Organisierung einer vorwiegend sozialistisch geprägten Bewegung im Osten der Türkei ab den 1960er Jahren voraus, die auf Seiten der sozialistischen Bewegung der Türkei für ein Ende der Assimilation und Leugnung, für kulturelle Anerkennung und Gleichheit stritt. Die Bewegung wurde in den 1970er Jahren auf höchst brutale Weise militärisch bekämpft (Atılgan 2015: 598f.; Ozan 2015: 710ff.).

52 Siehe www.hurriyet.com.tr/ekonomi/tusiad-diyarbakir-a-gidecek-bdp-yatirima-gelin-cagrisi-yapacak-16151223 vom 28.10.2010 (Abruf am 12.10.2018). 
einer durch intensivierten Handel im Nahen Osten gestärkten Bourgeoisie angliederte. Die Partei formulierte die Erwartung, dass Armut durch Überwindung kapitalistischer Unterentwicklung bekämpft werden könne (Yarkın 2011: 83ff.). Die von ihr regierten Kommunen näherten sich neoliberalen Stadtentwicklungszielen - investorenfreundliche Politik, Markenbildung - an und bedienten eine Nachfrage nach Wohnraum für die einkommensstärkeren Schichten, die Gentrifizierung und Betonwüsten nach sich zog. Diese Politik verband sie mit einem Diskurs, der kulturelle Diversität als Vorteil im Wettbewerb konkurrierender Städte thematisierte (Yüksel 2012: 76ff.).

Auf nationaler Ebene ging die kurdische Bewegung in den 2000ern zwar Bündnisse mit kleineren sozialistischen Kräften ein und formulierte auch hier sozialdemokratische Ziele. Deren Einfluss blieb jedoch gering, wie es sich in einer indifferenten Haltung zu Kämpfen der Arbeiterbewegung und in der kommunalpolitischen Ausrichtung der von der kurdischen Partei regierten Städte niederschlug. Eine deutliche Differenz zu islamistisch regierten Städten lag in einer nicht gewerkschaftsfeindlichen Haltung sowie in zaghaften Versuchen einer Organisierung von unten, die von Stadtteilinitiativen getragen wurden. Eine nachhaltige Initiative zur Verbesserung der Lebenslage des von den Kriegsfolgen besonders betroffenen, extrem verarmten kurdischen Prekariats ergriffen die kurdischen Kommunen jedoch nicht (Değirmen 2013). Eine zweite Differenz zu islamistischen Kommunen bestand darin, dass die kurdische Partei die neoliberal geprägte kapitalistische Entwicklungsperspektive mit einem kulturellen Liberalismus verband, der Anerkennung kultureller Diversität und die Gleichstellung der Geschlechter förderte. Die von der kurdischen Partei ausgehende politische Herausforderung ging nicht primär aus ökonomischen Differenzen hervor. Meine Beobachtungen und Gespräche in der Parteizentrale der AKP in Diyarbakır legten lediglich nahe, dass das islamistische Hegemonieprojekt im kurdischen Südosten sich - in Kontinuität zu den konservativen Parteien - auf die überregional aktive kurdische Bourgeoisie und religiöse Akteure stützen konnte (vgl. Atılgan 2015a: 484f.). Die Leitungsebene der AKP war mit Unternehmern besetzt, die von ihren überregionalen Investitionen berichteten. Ihre Nähe zum nationalen Machtzentrum war schon aus Opportunitätsgründen konsequent, insofern hier die für die Entwicklung der Unternehmer relevanten Entscheidungen getroffen wurden. Während die Basis anderer Parteien im kurdischen Südosten in den 200oern komplett erodiert war, diese sich zu mehr oder weniger kurdenfeindlichen Parteien entwickelt hatten, formulierte die islamistische Partei ein ideologisches Integrationsangebot an die kurdische Bevölkerung. Es bestand aus einem islamischen Konservatismus, der die ethnisch-türkische Definition der Nation zu einer religiös-konservativen Fundierung verschob und dabei auf die osmanische Vergangenheit rekurrierte, in der »Türken « und »Kurden" innerhalb eines Staatsgebiets gleichberechtigt nebeneinander existiert hätten. Durch die Hervorhebung einer gemeinsamen Unterdrückungsgeschichte 
durch den Kemalismus und den Rekurs auf eine verbindende islamische Identität sollte die ethnische Spaltung zwischen Türken und Kurden überwunden werden. Der islamische Konservatismus kündigte eine Abwendung der islamistischen Partei von der Türkisch-Islamischen Synthese an. Doch die starke und effektive Organisierung der kurdischen Bewegung sowohl im zivilen als auch im militärischen Bereich begrenzte die Wirkungsmöglichkeiten des islamistischen Hegemonieprojekts. Sie setzte ihm ein säkulares, auf ethnischer und nicht religiöser Identität beruhendes Hegemonieprojekt entgegen, für das sie Mehrheiten in der Region generieren konnte und das sie in Form eines inklusiven Anerkennungs- und Gleichstellungsversprechens auf die nationale Ebene trug (Saraçoğlu 2011). Die Forderung nach Selbstverwaltung, die die kurdische Bewegung auf der nationalen Ebene durch Transformation des zentralistischen Staates in einen Föderalstaat umsetzen wollte, war gleichbedeutend mit einer Dezentralisierung der politischen Macht. Damit stand sie im diametralen Widerspruch zu der von der AKP betriebenen Monopolisierung der Staatsapparate, die auch die Grundlage für den Zusammenhalt des rechten Lagers bildete.

Nichtsdestotrotz schien die AKP mit der »Demokratische Öffnung genannten Initiative die Realität einer kurdisch-säkular artikulierten Hegemonie anzuerkennen. Sie offerierte politische Verhandlungen und ein Ende der Militärkampagnen. Zwar widersprach die gleichzeitig betriebene Kriminalisierung ziviler Akteure der kurdischen Bewegung durch eine im Frühjahr 2009 eingeleitete massive Repressionswelle der »Demokratischen Öffnung«. Die Repression ließ erkennen, dass die "Öffnung« unter dem Primat der Einhegung des kurdisch-säkularen Hegemonieprojekts stand (vgl. Saraçoğlu/Yeşilbağ 2015: 932f.). Doch interpretierte die kurdische Bewegung die Repressionswelle als nachgeordnetes, vorübergehendes Element. Die rechts-kemalistischen und türkistischen Bewegungen, die sich in der CHP beziehungsweise der MHP organisierten, sahen dagegen in erster Linie die Grundlage des Nationalstaats erodieren. ${ }^{53}$ Sie beharrten auf einer rigorosen $\mathrm{Ab}$ lehnung von politischen Verhandlungen und Kompromissen mit der kurdischen Bewegung und mobilisierten gegen sie auf nationalistischer Grundlage.

53 Die kurdische Bewegung interpretierte die Repressionswelle als nachgeordnetes, vorübergehendes Element, indem sie die Durchführung zuerst den kemalistisch-türkistischen Oppositionszentren im Staat, nach deren offensichtlicher Zurückdrängung der Cülen Cemeinschaft zuschrieb, die sie nicht als integralen Bestandteil der AKP begriff. Einige Jahre später wurde bekannt, dass die AKP über die gesamte Zeit geheime Verhandlungen mit der PKK in Kenntnis führender ziviler politischer Akteure der kurdischen Bewegung geführt hatte, die deren verzerrte Wahrnehmung des Ceschehens beeinflussten, wie aus Stellungnahmen beteiligter kurdischer Politiker hervorgeht. Siehe https://anfturkce.net/guncel/aydar-bath-muzakereci-ocalan-dyr-12005 vom 06.12.2012; www.hurriyet.com.tr/gundem/oglumun-cesedi-balkondaydi-21646964 vom 08.10.2012; http://sehirmedya.com/genel/tugluktan-carpici-mit-yorumu/vom 09.02.2012, (alle abgerufen am 12.10.2018). 


\section{Neo-Kemalismus und das islamisch-konservative Hegemonieprojekt}

Eine Hochburg der kemalistischen Mobilisierung bildete Izmir, eine der wenigen Großstädte, in der der Kemalismus nach 2000 noch eine dominante öffentliche Präsenz durch Stadtviertel- und Straßennamen, Bilder, Büsten und (Straßen-)Ausstellungen entfaltete, die den Symbolen und Themen des Kemalismus - Rolle Izmirs im Befreiungskrieg 1919-22, modernistische Reformen, Verehrung von Atatürk - gewidmet waren. Die Verehrung konnte kultische Gestalt annehmen, wie beispielsweise ein in der Stadtbibliothek angekündigter Vortrag über die Mund- und Zahnhygiene von Atatürk nahelegte. Auf den Kundgebungen der CHP in Izmir traten die Konstitutionsmerkmale des Neo-Kemalismus (vgl. S. 168f.) auf prägnante Weise hervor (vgl. Yıldırım/Haspolat 2010: 312ff.). Eine dieser Kundgebungen während meines Aufenthalts richtete sich gegen die »Öffnungspolitik« der AKP in der »kurdischen Frage«. Auf dem großen Kundgebungsplatz am Meer hatten sich Zehntausende versammelt, die sich mit nationalistischen Parolen, Militärmärschen und einem immer wieder gespielten Popsong einstimmten, der große Sehnsucht nach »Meinem Blondhaarigen und Blauäugigen « - gemeint war Atatürk - ausdrückte. ${ }^{54}$ Veteranen und Witwen gefallener Soldaten der Zyperninvasion aus den 1970ern, die von der damaligen CHP geleitet worden war, waren vor Ort. Sie gaben sich durch Uniformen zu erkennen, während zehntausende Nationalflaggen, mit denen sich manche Teilnehmer gänzlich umhüllt hatten, ein rot-weißes Meer entstehen ließen. Flammende Reden wurden gehalten, die die Einheit des Landes beschworen, die sie durch die »Öffnungspolitik« der AKP gefährdet sahen.

Nach der Kundgebung stieg ich in einen Omnibus, der sich rasch mit anderen TeilnehmerInnen füllte. Während wir losfuhren, begann ein älterer Mann, augenscheinlich über siebzig Jahre alt, einfach, ärmlich gekleidet, sehr aufgeregt zu schimpfen: »Erdoğan bereichert nur sich selbst. Schuld sind aber die Menschen, die den wählen. Nicht die in Izmir aber die in den anderen Provinzen. Die sind ein bisschen dumm.« Eine Frau im mittleren Alter, der Kleidung nach zu urteilen auch eher arm, vielleicht eine kleine Angestellte, fiel ein: »Ja wirklich, das passiert eben, wenn man denen aus den Bergen das Recht gibt, zu wählen. In Europa ist das anders, jemand mit Universitätsabschluss hat dort vier Stimmen, also nein zwei, jemand mit Universitätsabschluss hat zwei Stimmen.« Ich war drauf und dran zu widersprechen, fragte mich, wie viele der MitfahrerInnen wohl einen Universitätsabschluss vorzuweisen hatten. Ich hielt mich zurück und wartete, ob jemand anderes etwas sagen würde. Die, die etwas sagten, stimmten ein. Die meisten MitfahrerInnen waren dem Aussehen nach ärmere Leute, einige waren an ihren Mützen als 
Arbeiter erkennbar, die im Gewerkschaftsverband DİSK organisiert waren. ${ }^{55}$ Ein älterer Mann, mit Atatürk-Rosette, ergriff das Wort: »Ich bin 82. Guckt euch den Erdoğan an. Was soll man von jemandem halten, der kein Respekt vor der Armee hat? Ein Lump ist das."

In Izmir war es nicht unüblich, auf solche Äußerungen zu stoßen, die Ungebildetsein, dörfliches Leben und eine Herkunft aus der Osttürkei - »die aus den Bergen« konnte für all das einzeln oder zusammen stehen - mit der AKP assoziierten. Die Äußerungen waren verknüpft mit einem Bekenntnis zum Militär. An eine bestimmte soziale Position waren sie augenscheinlich nicht gebunden. Sie verwiesen auf konkrete Biographien wie die Teilnahme an der Zyperninvasion, die in Izmir durch kulturelle Aktivitäten erinnerungspolitisch lebendig gehalten und gewürdigt wurde. Sie zeigten, dass quer zu den sozialen Positionen Weltauffassungen geteilt wurden, Identifikationen entstanden waren, die von der kemalistischen Hegemoniestrategie zusammengeführt und verstärkt wurden.

Eingebettet war die kemalistisch-urbane Form der Abgrenzung gegenüber »denen aus den Bergen « in einen Modernismus, der auf der Aneignung einer kapitalistisch artikulierten Fortschrittlichkeit seitens bestimmter Teile der Bevölkerung beruhte, die einem anderen Teil vorwarf, er halte die nationale Entwicklung durch borniertes Festhalten an Traditionen auf. Cihan Tuğal schreibt in seiner Studie solche Distinktionspraktiken urbanen Bevölkerungsgruppen $\mathrm{zu}$, die sich damit von der ländlichen Bevölkerung beziehungsweise den in die Städte hinzuziehenden BinnenmigrantInnen abgrenzten, indem sie sie als rückständige, kulturlose, unanständige Masse stigmatisierten (2009: 40, 123). Dieses Stigma mit Gläubigkeit und »vormoderner « Traditionalität gleichzusetzen, beschrieb er als das Werk der »säkularen Elite«. An diese Stigmatisierung konnten die AKP und die assoziierte Bourgeoisie anknüpfen, indem sie sich den Ausgegrenzten als ihre Repräsentantin anboten. Die Repräsentationsbeziehung funktionierte, nicht weil die AKP die soziale Lage der Ausgegrenzten entscheidend verbesserte, sondern indem sie die kulturellen Stigmata - Religiosität, Traditionalität und provinzielle Herkunft aufgriff und positiv bewertete. Während dieses Angebot in zahlreichen Städten angenommen wurde, wirkte die Distinktionspraxis in Izmir und einigen anderen in der ägäischen Region gelegenen Städten offenbar stärker in die entgegensetzte Richtung. Sie stabilisierte den kemalistischen Block. Die Abgrenzung fand sich hier nicht nur bei »Eliten« oder den »Bessergestellten«, die sich nach unten abgrenzten. Sie durchzog alle sozialen Klassen und bildete eine Konstituente des sozio-politischen Blocks, den die kemalistische Bewegung gebildet hatte. Die Anwesenheit von Gewerkschaftern auf der Kundgebung im Jahr 2009 zeigte an, dass die CHP trotz 
Anpassung an neoliberale Stadtentwicklungsmodelle (Eğilmez 2010: 626) und ausbleibender Opposition gegen neoliberale Politik (Doğan 2009b: 130) die formellen und gewerkschaftlich organisierten ArbeiterInnen, die landesweit allerdings nur noch etwa 5 Prozent der gesamten Arbeiterschaft stellten, auf ihrer Seite halten konnte (Saraçoğlu/Yeşilbağ 2015: 893). Gewerkschaftsmützen und ärmliche Kleidung, die in Izmir neben Angehörigen des wohlhabenderen Kleinbürgertums auf jeder kemalistischen Großdemonstration vorzufinden waren, waren Ausdruck eines Festhaltens an einer städtisch-sozialdemokratisch artikulierten Lebensweise, die sich in einen neo-kemalistisch dominierten sozio-politischen Block eingliederte. So konnte es paradoxerweise geschehen, dass Werktätige ohne Universitätsabschluss andere aufgrund eines fehlenden Universitätsabschlusses für dumm und unmündig erklärten, weil sie deren soziale Lage und Lebensweise als Bedrohung für die eigene Position ansahen.

Dass Izmir nicht schon immer von der CHP regiert wurde, sprach dafür, dass die Ursachen für die Entstehung dieser Konfrontation in der jüngeren Geschichte liegen mussten. Izmir war bis in die frühen 1970er Jahre eine Hochburg konservativer Parteien gewesen. Erst auf der Grundlage industrieller Entwicklung und der sozialdemokratischen Blockbildung wandte sich die Bevölkerung mehrheitlich der (damaligen) CHP zu. Entgegen des landesweiten Trends hatte sich die Izmirer Bevölkerung auch nach 1980 eher links-kemalistischen Parteien zugewandt, nach dem Zusammenbruch des Links-Kemalismus (der DSP) der neo-kemalistischen CHP. Die Forschungsliteratur bietet keine detaillierte Erklärung für das Fortwirken der sozio-politischen Blockbildung in Izmir. Doch neben der »Verteidigung der Lebensweise« gegen religiöse Vorgaben (Tosun 2010: 289) erscheint es plausibel, dass die CHP von der herausragenden Stellung Izmirs in der importsubstituierenden Industrialisierungsphase zehrte. Nach 1980 setzte in Izmir ein relativer sozio-ökonomischer Niedergang ein, der einen sozialen Abstieg des Izmirer Kleinbürgertums und der traditionellen Arbeiterschaft auslöste. Mit der Streichung landwirtschaftlicher Subventionen erodierten auch die Reproduktionsgrundlagen der Kleinbauern im ägäischen Hinterland von Izmir, die in die Städte migrierten. Ausbleibende staatliche Fördermittel in die Produktionsstruktur und den Ausbau öffentlicher Infrastrukturen, neue ökonomische Präferenzen unter den neoliberalen ANAP-Regierungen lösten auch eine Distanzierung der Izmirer Industrie- und Handelsbourgeoisie von den konservativen Parteien aus. Der Abstieg und der Bedeutungsverlust Izmirs verbanden sich zu einer allgemeinen Unzufriedenheit, die sich nach 1990 als kemalistische Nostalgie artikulierte. Die Binnenmigrationswellen aus dem kurdischen Osten infolge des Krieges verstärkten nochmals den Konkurrenzdruck innerhalb der durch Landflucht ohnehin stark angewachsenen Arbeiterschaft. Auf der Grundlage verstärkter Konkurrenz und des Abstiegs des Kleinbürgertums bildete sich nach 1990 ein anti-kurdischer Rassismus (Ylldırım/Haspolat 2010: 312f.). Dem »Elitendünkel« auf den Kundgebungen der 
CHP quer zu den sozialen Positionen lag diese Konstellation zugrunde, die durch Abstiegs- und Konkurrenzerfahrungen gekennzeichnet war. Dass die Zustimmung zur AKP in Izmir mehrheitlich aus den Vierteln der späten ArbeitsmigrantInnen kam, in denen die untersten Schichten der informellen ArbeiterInnen lebten, stützt diese These (Uyar 2010: 242ff.).

Die AKP reagierte auf das kemalistische Hegemonieprojekt in Izmir mit oberflächlicher Anpassung. Ihr öffentliches Auftreten war dominiert von einem Diskurs des toleranten Miteinanders verschiedener Identitäten und dem Bemühen, keinesfalls den Eindruck einer »ideologischen « Agenda zu erwecken. Sie betonte, die Partei sei nicht religiös, sie privilegiere niemanden und diene allen gleichermaßen. Auf ganz Izmir bezogen konnte sich die AKP mit etwa 35 Prozent der Stimmen auf eine starke Minderheit stützen, in einigen Stadtbezirken stellte sie die Bürgermeister. Ein AKP-Bürgermeister ließ an einer Hauptverkehrsstraße eine gigantische Büste von Atatürk errichten. Die AKP organisierte Veranstaltungen, die eine Nähe zum kemalistischen Modernismus demonstrierten, was an der Parteibasis zwar Befremden hervorrief, aber als Notwendigkeit akzeptiert wurde, sich den lokalen Bedingungen anzupassen. Ein Begebnis, das sich zu einem frühen Zeitpunkt meines Feldaufenthalts abspielte, vermittelt einen Eindruck, welche Formen diese Anpassung annahm. Im Büro der AKP lagen mit einem Porträt von Atatürk versehene Einladungen zu einem Konzert - einem »Republik Symphonie Orchester « aus, das am 29. Oktober, dem Gründungstag der Republik stattfinden sollte. Ein Mitglied der AKP-Jugend fragte mich, ob wir zusammen hingehen wollten. Ich antwortete überrascht, dass er solche »republikanischen Sachen« doch sonst ablehne. »Ja klar«, sagte er, »aber das hier ist eine Veranstaltung der Partei.« Ein zweiter erklärte mir daraufhin, dass die AKP in Izmir nicht repräsentativ sei:

Wir versuchen, die Reichen zu gewinnen. In Anatolien funktioniert das, da die Reichen dort eine anatolische Kultur haben. Hier nicht. Taha Aksoy hat Hundefutter verteilt im Wahlkampf. Das ist sogar Thema im nationalen Parlament geworden. Die Armenviertel werden hier von uns nicht so umworben. Deswegen diese Symphonie. Wir versuchen, zu zeigen, dass wir dazu gehören.

Von dieser Aktion des AKP-Oberbürgermeisterkandidaten Aksoy, Unternehmer und Mitglied von TÜSİAD, also des Unternehmerverbands, der in der staatszentristischen Literatur auf der Gegenseite der AKP positioniert wird, hatte ich schon bei meinen ersten Erkundungen gehört, als ich mich auf der Suche nach Verteilung von Armenhilfe durch die Partei befand. Ich konnte keine Anzeichen von Armenhilfe ausfindig machen, stieß stattdessen auf diese Aktion und war baff. Die politischen Werbekampagnen der AKP zielten nach der Gewinnung von 35 Prozent der Izmirer Bevölkerung nicht mehr auf die Armen, wie ich aufgrund der Literatur erwartet hatte, sondern auf die »Reichen«. Das Ungewöhnliche am Verteilen von Hundefutter war, dass Hunde in türkischen Städten als Wach-, 
aber kaum als Haustiere gehalten wurden. Hunde als Haustiere, ausgestattet mit eigener Versorgungsindustrie - Läden, die Tierfutter und anderes Zubehör verkaufen, Hundefriseurläden, Tierkliniken etc. -, verbreiteten sich nur in gehobenen Vierteln von Izmir, wo mittlere und obere Einkommensgruppen lebten, nicht jedoch in den ärmeren Vierteln. Die »Reichen« ist hier folglich als Synonym für die wohlhabendere Bevölkerung zu verstehen.

Es weist zugleich auf eine kulturelle Praxis hin, die als nicht-anatolisch markiert wurde und die es der AKP erschwerte, sich attraktiv zu machen, da die Praktiken der Adressierten den »eigenen« fremd erschienen. Im Sprachgebrauch konservativer Akteure war Anatolien eine Chiffre für eine bestimmte Kultur, die in ihrer Praxis jedoch erst hergestellt, vereinheitlicht, definiert und verändert wurde. Die Konstruktion entfaltete eine starke Wirkung über die konservativen Akteure hinaus. Wie dargestellt, trat sie bei den VerfechterInnen der Kulturkampfthese als Grundlage für die Behauptung auf, es habe immer-schon ein frommes Volk gegeben, das mit der AKP seine politische Repräsentantin fand. In Izmir sprachen auch AlevitInnen, die selbst aus Ostanatolien in den Westen migriert waren, von »anatolischer« Bigotterie oder Frömmlerei, die die AKP repräsentiere und von der Izmirer Bevölkerung abgelehnt werde. Tatsächlich existierten in Anatolien trotz der Bemühungen kultureller Homogenisierung, die in den vergangenen Jahrzehnten intensiviert worden waren, noch immer kulturell verschiedene Bevölkerungsgruppen, zu denen auch die AlevitInnen selbst gehörten. In Izmir hatten sie eine Lage vorgefunden, in der ihre kulturellen Praktiken anders als in vielen zentral- und ost-anatolischen Städten keine direkte Verfolgung auslösten. Als Gegenüber des islamisch-konservativen Konformitätsdrucks konnte die neo-kemalistische CHP in Izmir zur Bewahrerin einer relativ freiheitlichen Kultur werden, die auch AlevitInnen Schutz bot. Doch die andere Seite der neo-kemalistischen Medaille war eine Borniertheit, die rassistische Formen annahm, sich über kemalistische Symbole rückwärtsgewandt an einem sozialdemokratisch artikulierten Status festhielt und nach unten abgrenzte. Die Konstellation in Izmir trat so als eine Langzeitfolge der militärischen Zerschlagung der organisierten Werktätigen auf, die immer weniger in der Lage gewesen waren, den neoliberalen Angriff abzuwehren, geschweige denn die Ausweitung sozialer Errungenschaften auf alle Werktätigen zu fordern. Sie grenzten sich stattdessen gemeinsam mit Teilen des Kleinbürgertums zunehmend chauvinistisch gegen die BinnenmigrantInnen ab. Umgekehrt erschienen die bereits stark eingeschränkten sozialen Errungenschaften der formellen Werktätigen den Ausgegrenzten als Privilegien, von deren Teilhabe sie ausgeschlossen waren. Die Neoliberalisierung war auf diese Weise mit einer chauvinistisch aufgeladenen Polarisierung in den Städten verbunden.

Das »Gewinnen der Reichen« durch die AKP griff bewusst Zugeständnisse an die Träger der kulturellen Praktiken auf, die in Izmir hegemonial waren. Während mir erzählt wurde, worum es mit dem Symphonie-Orchester ging, kamen andere 
hinzu. Sie waren sich einig, dass die Veranstaltung eine Vortäuschung sei. Sie waren sicher, dass ihr Theater von allen als solches erkannt werde und zugleich waren sie davon überzeugt, dass auf die Izmirer Realitäten reagiert werden müsse. Aus ihrer Sicht war der Wahlslogan der AKP im Kommunalwahlkampf - „Veränderung ist geboten « (Değişim şart) - ein Fehler gewesen. Mit ihm sei die Befürchtung verstärkt worden, die die Izmirer Bevölkerung ohnehin hegte: dass die AKP den Status quo verändern werde. Der Toleranzdiskurs der AKP stand im Konflikt mit der Praxis der Partei in anderen Orten des Landes, in denen sie die konservativ-islamische Kontrolle des öffentlichen Raums verstärkt hatte. Während im ganzen Land um die Verbannung von Alkohol aus der Öffentlichkeit und Geschlechtersegregation gestritten wurde, betonte der AKP-Kandidat Aksoy, dass es in Izmir auch im Falle seines Wahlsiegs möglich bleiben werde, Alkohol zu trinken, Geliebte weiterhin händchenhaltend auf der Promenade spazieren gehen könnten.

Um zu veranschaulichen, wie sich die Anpassungsbemühungen der Partei in ihrem Inneren auswirkten, gebe ich einen Ausschnitt aus dem Vorbereitungstreffen für das Symphonieorchester wieder, das die AKP-Jugend einberief und an dem ich teilnahm. Anwesend waren 20 TeilnehmerInnen etwa im Alter zwischen 20 und 30. Es war abends und wir saßen an einem runden Konferenztisch. Der Leiter des Treffens (L) eröffnete die Runde.

L: Freunde, wir müssen alle dort hingehen, es muss voll werden, es ist natürlich kein Zwang, aber eine Veranstaltung unserer Partei.

A: Ja, es muss noch was gesagt werden, bei einem Symphonie-Orchester gibt es ein System. Es gibt Regeln. Zum Beispiel wird in der ersten Pause nicht geklatscht.

L: Ja, Freunde, die Regeln solcher Konzerte sind anders. Wir dürfen uns noch nicht mal bewegen, unsere Handys müssen aus sein, der Beifall folgt einem System. [Das Handy von A klingelt] Also, sogar das Handy von A muss aus sein [Gelächter]. Wir setzen uns hin, alles klar? Und passen uns an. Also, selbst aufstehen ist nicht angesagt.

Z: [steht auf, hebt beide Hände gen Himmel und ruft dazwischen] Stellt euch vor, einer steht aufund ruft: Das war göttlich Chef, spiel's noch mal [Gelächter].

E: Also ich möchte jetzt doch mal was fragen. Warum wird das überhaupt gemacht?

L: Keine Ahnung. Ich weiß nur, dass die Leitung das organisiert.

A: Also, wir müssen aufpassen. Nicht dass wir ein Auge ausstechen, während wir eine Augenbraue zupfen wollen. ${ }^{56}$

$Y$ [redet aufgeregt, dozentenhaft aber mit Selbstironie]: Ich schließe mich an. Also, obwohl das so eine intellektuelle Sache ist, hatte selbst ich keine Ahnung, wie kompliziert das sein kann [Celächter].

E: Also mir kommt das alles aufgesetzt vor.

L: Ja, wer nicht möchte, kommt nicht. 
E: Ist ja alles schön und gut, aber was ist die Erklärung hierfür? Wir werden uns blamieren. Was haben wir damit am Hut? Kann mir das mal einer sagen oder ist das geheim?

L: Republik-Konzerte halt. Passt auf: Die Republik ist nicht das Eigentum von irgendwem. Die tun so, als ob sie ihnen gehören würde. Die Republik gehört uns allen. Diese Veranstaltung muss so verstanden werden. Und wir müssen uns den Gepflogenheiten anpassen.

Deutlich trat aus der Diskussion das Gefühl kultureller Fremdheit der Veranstaltung, die von der eigenen Partei geplant wurde, hervor. Auch wenn sie der Situation zunächst mit Humor begegneten, um sie handhabbar zu machen, wurde ihnen doch gewahr, dass Fehlverhalten eine »Blamage« wäre: ein Beweis von Nicht-Können und Nicht-Eingeweiht-Sein. Während sich in der Diskussion eine Stimmung entwickelte, die dahin tendierte, sich auf das Eigene zu besinnen und solch »intellektuelle Sachen « zu ignorieren, um nicht am Ende selbst Schaden zu erleiden beziehungsweise Authentizität zu verlieren, wurde durch die Erklärung des Leiters am Ende deutlich, dass es darum ging, die Republikkonzerte als Symbol, mit dem die Republik gefeiert wurde und das ihr zugleich ein Gesicht verlieh, das über fast ein Jahrhundert mit bestimmten kulturellen Symbolen assoziiert war, zu besetzen. Indem die AKP die Veranstaltung durchführte - das wird in der Szene erkennbar - wurde die Republik angeeignet. Die Anpassung war nur der erste Schritt.

Ähnliches geschah Ende 2009 im Rahmen der sogenannten Öffnungspolitik. In Izmir und in anderen größeren Städten wurden Bildungsseminare durchgeführt, die sich in erster Linie an Parteimitglieder richteten, jedoch auch Außenstehenden offen standen. Die Seminare wurden mit einem Poster angekündigt, das Erdoğan zeigte, wie er auf einer Schultafel den Satz »Die Schulglocke läutet zur Akademie« unterschrieb. Das Poster weckte Assoziationen zu einem sehr bekannten Bild von Atatürk aus den 1920er Jahren, wie er an einer Tafel das neu eingeführte lateinische Alphabet vorstellte. Damit wurde Erdoğan als Lehrer in eine Reihe mit Atatürk gestellt, dem in der republikanischen Tradition der informelle Titel »Oberlehrer« verliehen worden war. Das Poster mit Erdoğan signalisierte Kontinuität und Ablösung zugleich.

Die Auftaktveranstaltung fand im Saal eines Fünf-Sterne-Hotels in der Innenstadt von Izmir statt. Sie war als öffentliche Veranstaltung beworben worden, zu der die Presse eingeladen war. Während ein Jingle, der aus einer Aneinanderreihung von gesprochenen Sätzen durch Erdoğan bestand, in Dauerschleife gespielt wurde, füllte sich der mit Spruchbändern geschmückte Saal mit etwa 350 Personen. Auf den Bändern waren die üblichen Parteislogans - Keine Rast, wir schreiten voran; Alles für die Türkei, alles für Euch; Eine Nation, eine Fahne, eine Heimat, ein Staat - neben besonderen Botschaften an die Izmirer Öffentlichkeit zu lesen: 
Können diejenigen, die Angst haben vor dem Volk, volksnah sein? Können diejenigen, die Angst haben vor der Nation, nationalistisch sein?

Nach etwa 15 Minuten Beschallung durch den Jingle wurde die Nationalhymne gespielt, zu der alle aufstanden und mitsangen. Anschließend wurde eine Schweigeminute für »Gazi Mustafa Kemal Atatürk« eingelegt. Das Singen der Nationalhymne war kein unübliches Ritual auf politischen Veranstaltungen. Sie verlieh der Veranstaltung die Atmosphäre eines Staatsakts. Sehr unüblich war die Schweigeminute, ein besonderer Anlass wie ein Jahrestag lag nicht vor. Gazi ist eine Bezeichnung für Veteranen. Bei Atatürk ist sie zu einem Ehrentitel gemacht worden, der immer dann angeführt wird, wenn seine soldatische Seite betont werden soll. In Izmir, wo das Militär und der Befreiungskrieg, wie beschrieben, in hohen Ehren gehalten wurden, erschien es besonders ausgetüftelt, diesen Bezug herzustellen. Der Izmirer Öffentlichkeit wurde nicht nur demonstriert, dass Atatürk in Ehren gehalten wurde, vielmehr zielte der Akt darauf, Atatürk zu vereinnahmen und der CHP streitig zu machen, die von Atatürk gegründet worden war und dessen politisches Erbe weiterhin für sich beanspruchte. Denn mit denjenigen, deren Angst vor dem Volk und der Nation auf den Spruchbändern angeprangert wurde, waren die Republikaner beziehungsweise die CHP gemeint. In einem Akt vereinte der Vorgang ein Bekenntnis zu und die Vereinnahmung von republikanischen Symbolen mit der Verhöhnung der Republikaner als unpatriotische Volksfremde.

Als Hauptredner der Veranstaltung war Privatdozent Dr. Hüseyin Çelik, Parlamentsabgeordneter und ehemaliger Bildungsminister der AKP, der als Architekt der Öffnungspolitik galt, angekündigt. Die Anführung des akademischen Titels betonte Wissenschaftlichkeit. Çelik entstammte der konservativen Parteientradition, war in den 1970ern Mitglied in der AP, danach in der DYP, bis er zur AKP wechselte. Er hielt eine lange, mit Anekdoten und Bonmots gespickte Rede, bei der er die ZuhörerInnen auf eine Reise in die Geschichte der Demokratie mitnahm. Von internationalen Gefilden kam er schließlich auf die Türkei zu sprechen:

In der Türkei steht die Demokratie nur auf dem Papier. Den Namen zu ändern, ändert die Wahrheit nicht. Allein zwischen 1950 und 1960 hat die Türkei mal durchatmen können. [...] Verschiedene Cruppen sind in der Republik fortwährend unterdrückt worden. Die Bauern, die nicht in die Städte gelassen wurden, weil man sich gegenüber den Europäern für ihr Aussehen schämte, Nicht-Muslime, Kurden, Aleviten und Fromme.

Dieser Zustand, so Çelik, werde nun beendet. Alle würden befreit und vereint in Verschiedenheit leben dürfen, so wie einst im Osmanischen Reich, das er mit einem Orchester verglich: 
Der Staat ist wie ein Orchesterchef, der die Instrumente dirigiert, damit sie zusammen spielen und keine Kakophonie entsteht. Das Osmanische Reich war ein gut dirigiertes Orchester. Alle konnten verschieden sein und trotzdem in Harmonie miteinander leben. [...] Die DNA eines jeden ist einzigartig, das beweist, dass Gott jeden verschieden geschaffen hat.

Wie sich der Staat zusammensetze, beschrieb er folgendermaßen:

Ein Staat ist wie eine Zwiebel. Das Innerste der Zwiebel ist das Individuum, darüber legt sich die Familie, darüber die Cemeinschaft [cemaat] und der Stamm [aşiret], darüber die Nation, darüber die Religion und über alles die Menschheit. Alle zusammen machen die Persönlichkeit aus.

Schließlich ging Çelik noch darauf ein, dass die Gendarmerie und die »CHP-Bürokratie« nie freie Wahlen in der Türkei zugelassen hätten. Er erzählte Anekdoten, wie 1960 nach dem Sturz der DP durch das Militär Wahlen manipuliert und bei der Verfassungsabstimmung von 1982, nach dem 1980er Militärputsch, Druck auf die Wähler ausgeübt worden sei.

Çelik betrieb eine raffinierte Demagogie. Auf die Kräfteverhältnisse in Izmir abgestimmt konstruierte er eine Weltauffassung, die konservativ, zugleich inklusiv (gegenüber den Unterdrückten) und nach vorne gerichtet erschien. Nichtsdestotrotz war es eine Geschichte der Verzerrungen und Ent-Nennungen von historischer Täterschaft und Initiative. Das Bekenntnis zur Demokratie mit freien Wahlen und die Idealisierung des monarchisch verfassten Osmanischen Reichs, dirigiert von einem »Orchesterchef«, stellte er unvermittelt nebeneinander. Die Türkei machte er zu einer von der »CHP-Bürokratie« unterdrückten Opfergemeinschaft, die "nur einmal durchatmen« konnte. Die Unterdrückung von Aleviten schob er ebenso der CHP zu wie den Putsch von 1980, der sich auch gegen die sozialdemokratische Politik der damaligen CHP gerichtet hatte, während es seine damalige Partei (die AP) gewesen war, die die Repression verschärft und schließlich das Militär auf den Plan gerufen hatte. Seine Rede umriss die Referenzen des konservativen Narrativs, das von den Verfechtern der Kulturkampfthese, die in der AKP eine demokratisch-liberale Partei zu erkennen meinten, über wissenschaftliche und journalistische Medien international verbreitet worden war. In diesem Narrativ erschien die Periode zwischen 1950 und 1960 als eine der Freiheit, während die 1960er Verfassung, mit der Gewaltenteilung, Bürger- und Arbeiterrechte verfassungsrechtlich verbrieft worden waren, als ein Rückfall in die Unterdrückung auftauchte.

Einige Wochen später hörte ich auf einer Parteiveranstaltung in Diyarbakır nochmals eine in ihren Grundzügen identische Rede von Çelik, jedoch angepasst an die dortigen Kräfteverhältnisse. Die Nationalhymne wurde angesichts der virulenten Kämpfe um die Anerkennung kurdischer Selbstbestimmung nicht gespielt. 
Die Hymne war in Diyarbakır, anders als in Izmir, kein Symbol der Befreiung, sondern eines der Unterdrückung. Vom türkischen Militär war sie als Instrument der Erniedrigung und Unterwerfung eingesetzt worden. Im Foltergefängnis von Diyarbakır waren kurdische und sozialistische Gefangene in den 1980ern gezwungen worden, sie zu singen, um ihnen ein Bekenntnis zum türkischen Nationalstaat abzuzwingen (vgl. Zeydanlıoğlu 2009). Auch eine Schweigeminute für Atatürk wurde nicht eingelegt. Referenzen auf die republikanischen Symbole wurden unterlassen. Der Saal eines Hochzeitsveranstalters war außer den üblichen, neutralen Slogans (Keine Rast...) und vielen Erdoğan-Bildern mit Spruchbändern geschmückt, die Einheit und Demokratie betonten:

Wir zusammen sind die Türkei

Die Geschichte wird die Helden der Demokratie nicht vergessen

Der AKP-Vorsitzende von Diyarbakır hielt eine Vorrede, in der er feststellte, dass die Unterdrückung und die Leugnung der Kurden von der AKP beendet worden sei. Die AKP werde das von den Jungtürken ethnisch gespaltene Volk in der islamischen Gemeinschaft wieder zusammenführen. Çeliks anschließende Rede war gespickt mit kurdischen Zitaten. Er versprach Diyarbakır ein Ende des Krieges, durch das - so kündigte er an - der Nährboden für die spalterischen »nationalistischen « Parteien - die MHP, die CHP und die kurdische Partei stellte er dabei in eine Reihe - trockengelegt werde.

Abgestimmt auf die lokalen Kräfteverhältnisse legte die AKP in Izmir und in Diyarbakır gegensätzliche Schwerpunkte. In Izmir trat sie gegen einen kemalistisch, in Diyarbakır gegen einen kurdisch-säkular geprägten Status quo an. An beiden Orten wurde das politische Feld von kulturkämpferischen Strömungen dominiert, die unterschiedliche Artikulationen des Neoliberalismus mit kulturellen Fragen hervorgebracht hatten. Die Strategie der AKP zielte darauf, in die Kasematten ihrer politischen Gegner einzudringen, ihnen ihre Waffen aus der Hand zu nehmen, zugleich die eigenen Truppen $\mathrm{zu} »$ bilden«, ihnen diskursive Mittel an die Hand zu geben und sie mit einer islamisch-konservativen Geschichtsauffassung auszustatten, deren Rückgrat die Konstruktion der Republikaner als Unterdrücker des Volkes bildete. Da die CHP die gesellschaftlichen Konfliktlinien ebenfalls über kulturelle Elemente konstruierte, stellte sie den komplementären Gegenpart zur AKP. Die von Kemalisten reproduzierte alltägliche Erniedrigung bestimmter Teile der Bevölkerung als kulturell rückständig und ungebildet bildete eine zentrale Voraussetzung für die Plausibilität des auch in staatszentristischen Interpretationen affirmativ aufgegriffenen Diskurses, wonach die AKP die »authentischen « Interessen des Volkes gegenüber den »kemalistischen Eliten« verteidige.

Der im Rahmen der Kulturkampfthese als auslösendes Ereignis für die »autoritäre Wende« der AKP thematisierte Juni-Aufstand im Jahr 2013 stellte einen poten- 
tiellen Einschnitt in die Reproduktion des Kulturkampfs dar. Anfängliche Vorstöße kemalistischer Organisationen, den Aufstand zu vereinnahmen und kurdische Organisationen aus dem Protest auszuschließen, stießen auf breite Ablehnung. Anders als bei den kemalistischen Demonstrationen wurden weder nationalistische Parolen noch die Armee auf den Plan gerufen, während die AKP und ihr nahestehende Medien die Spaltungslinien zwischen »elitären Laizisten« und »unterdrückten Gläubigen« zu aktivieren versuchten. Die vorherrschende Praxis während des Aufstands bestand in der gegenseitigen Anerkennung verschiedener kultureller Identitäten, die bislang nicht miteinander, sondern neben- oder gegeneinander protestiert hatten. Indem sich diese Tendenz mit dem Protest gegen die kapitalistische Landnahme und den politischen Autoritarismus der AKP verband, sich zugleich der Aufbau eines Netzwerks an der gesellschaftlichen Basis abzeichnete, öffnete sich für kurze Zeit ein Fenster für die Formierung einer politischen Alternative zu den kulturkämpferisch artikulierten bürgerlichen Hegemonieprojekten (vgl. Babacan 2013). Mit der Niederschlagung des Aufstands, der Versandung basisnaher Organisierung, der ambivalenten Positionierung der kurdischen Bewegung zum Aufstand, der Eskalation des Bürgerkriegs mit der PKK und der nationalistischen Positionierung der CHP wurde die kulturkämpferische Praxis jedoch erneut dominant.

Nach diesem Einblick in den Status quo des Kulturkampfs soll zum letzten offenen Diskussionspunkt, der Ergründung der Rolle der theologisch geschulten Intellektuellen, übergegangen werden. Auf die Intellektuellen wurde bisher nur bruchstückhaft und teils im Rahmen der Partei eingegangen. Eine Erfassung der islamistischen Bewegung, die sich auf die politische Partei und die assoziierte Bourgeoisie beschränkt, bleibt jedoch unvollständig. Sie tendiert dazu, die Bedeutung der institutionalisierten Reproduktionsstätten der Intellektuellen und ihre Gruppeninteressen zu übersehen, die dem Kulturkampf eine besondere Dynamik verleihen. Im zweiten empirischen Teil der Arbeit werden daher die Reproduktionsmechanismen und Wirkungsstätten in den Blick genommen, in denen sich das islamistische Kollektiv in Abgrenzung zu den konkurrierenden Hegemonieprojekten formiert. 



\section{Teil IV - Religiöse Infrastruktur und Praxis}





\section{Religiöse Wirkungsstätten}

In den Interviews mit Mitgliedern der AKP während des Kommunalwahlkampfs im März 2009 betonten diese unisono, dass Politik und Religion strikt voneinander zu trennen seien. Im Einklang mit dem Parteiprogramm wurde hervorgehoben, die AKP sei eine konservative Partei auf der Grundlage nationaler und ideeller Werte, die in gleicher Distanz zu allen Religionen stehe. Die Aufstellung alevitischer Kandidaten wurde als Beleg für Pluralismus angeführt. Einen ersten empirischen Fingerzeig, dass diese die Außenwahrnehmung der Partei prägende und sogar unter AlevitInnen einen gewissen Anklang findende Darstellung grundverkehrt war, erhielt ich bei einem Treffen mit einem jungen Islamisten an der Theologischen Fakultät von Izmir. Er studierte Philosophie und ging nebenher an die Fakultät, »als Zusatzausbildung«, wie er mir mitteilte. Er war ein Mittzwanziger und stellte sich als ehemaligen radikalen Islamisten vor, der zu einer pragmatischen Linie gewechselt war. Im Gymnasium sei er ein Radikaler gewesen, Radikalismus bringe aber nichts, die Umsetzung alter Regeln sei nicht möglich in einer modernen Welt: »Was nicht umsetzbar ist, ist falsch«. Deswegen nähere er sich immer mehr der Gülen Gemeinschaft an, denn die würde Praktikabilität betonen. ${ }^{1}$ Er berichtete mir, dass die meisten Studenten an der Fakultät von einer Imam Hatip Schule kämen, er selbst aber nicht. Zu Beginn dieses Lehrjahrs seien 400 neue Studenten an die Fakultät gekommen. Die Zahl der Erstsemester habe sich verdoppelt, nachdem die Regierung beschlossen habe, die Budgets für die theologischen Fakultäten zu erhöhen. Die eine Hälfte der Fakultät bestehe aus Türkisten, die andere aus Islamisten. Zur Unterstreichung der gestiegenen Bedeutung der Religion erzählte er, dass manche Moscheen mittlerweile mit zwei Imamen doppelbesetzt seien. Einige islamische Gemeinschaften seien dazu übergegangen, eigene Moscheen zu unterhalten. Die AKP toleriere das.

Unser Interview auf dem Campus wurde unterbrochen durch einen zu uns stoßenden Dozenten, mit dem er mich bekannt machte. Der Dozent war Izmirer Vor- 
sitzender des ältesten türkistischen Vereins, des bereits erwähnten Vereins Türk Ocakları (S. 142), der 1912 gegründet wurde. In der frühen Republik waren die führenden nationalistischen Intellektuellen Mitglied dieses Vereins, der Anfang der 1930er Jahre geschlossen und 1949 wieder eröffnet wurde. Der Vorsitzende stand der ultra-nationalistischen Splitterpartei BBP (Partei der Großen Einheit) nahe, deren Wirken weitgehend auf die mittelanatolische Provinz Sivas begrenzt ist. Die BBP bildete in den 2000 er Jahren bei verschiedenen Anlässen Bündnisse mit der AKP, auf deren Wahllisten sie ihre Kandidaten platzierte. Sie propagiert das Ziel, ein pan-türkisches Reich auf der ideologischen Grundlage der Türkisch-Islamischen Synthese zu errichten.

Über das Treffen an der Fakultät erfuhr ich, dass die theologischen Wirkungsstätten sich im Schatten der damals aktuellen Auseinandersetzungen zwischen der AKP und dem Militär in einem starken Aufwind befanden. Die politische Förderung der theologischen Ausbildungsstätten, Finanzierung doppelbesetzter Moscheen, die prominente Präsenz der Türkisch-Islamischen Synthese an der Izmirer Fakultät stellten einen Widerspruch zur behaupteten laizistischen Agenda der AKP dar, durch den mein Blick auf die Ausbildungs- und Wirkungsstätten der Theologen gelenkt wurde, die ich im Folgenden gestützt auf meine Feldstudie diskutieren werde.

\subsection{Die Diyanet und das Prinzip der Laizität}

Die zentrale institutionelle Wirkungsstätte von Theologen ist die Diyanet, bei der eine sehr große Zahl der intellektuellen Trägerschicht der islamistischen Bewegung angestellt ist. Die 1924 gegründete Diyanet organisiert religiöse Dogmen und Aktivitäten, sie definiert den legalen Rahmen religiöser Praxis. Die Aufgaben und Funktionen der Diyanet haben sich im Laufe der Zeit stark verändert und ausdifferenziert. Mit Ausnahme einer Phase zwischen 1931 und 1950 obliegt der Behörde die Verwaltung von allen Moscheen und Gebetsstätten des Landes. Die Zentrale in Ankara entsendet Muftis in die Provinzen, die dort über die religiöse Praxis wachen sollen.

Seit ihrem Bestehen gibt es politischen Streit über die Frage, wie sich eine staatliche religiöse Institution mit dem Prinzip der Laizität vertragen kann. Als Folge der tiefen Skepsis der staatsgründenden Republikaner gegenüber der Loyalität der osmanischen Geistlichen zu den Zielen der jungen Republik herrschte in den Anfängen der Republik ein Antiklerikalismus vor. Die CHP unter der Direktion von Atatürk übte bis in die 1940er Jahre eine bremsende Wirkung auf religiöse Aktivitäten aus. Wie bereits beschrieben, rangen schon vor der Abspaltung der DP im Jahr 1946 zwei Positionen in der CHP miteinander. Die erste Strömung sah in der Diyanet einen Widerspruch beziehungsweise in ihrer Förderung eine Gefahr für die 
Laizität. Die zweite Strömung sah dieselbe Institution als ein Instrument an, das entweder als neutral vorgestellte religiöse Dienstleistungen erbringen oder die Religion kontrollieren sollte: um die nationale Einheit, den Türkismus und die »ideellen Werte der Nation« zu fördern; um eine unkontrollierte Entwicklung und Politisierung religiöser Aktivitäten und den »Aberglauben « zu unterbinden; um die »ungebildeten Massen zu indoktrinieren«; oder um kemalistische Inhalte zu transportieren. Ferner bestand die Auffassung, dass ohne staatliche Kontrolle der Religion ein Krieg zwischen verschiedenen religiösen Strömungen ausbrechen könnte (Gözaydın 2009: 204ff., 275ff., 284ff.; Mertcan 2012: 73ff.). Konservative und islamistische Parteien sahen in der Diyanet unterdessen ein Instrument, den Wirkungsbereich des konservativen Islam unter der Führung von Geistlichen auszubauen. Sie verbanden mit der Diyanet keinen geringeren Erziehungsanspruch als die Kemalisten, auch ihnen ging es um die Kontrolle der religiösen Praxis, allerdings viel stärker vermittelt durch eine integrale Anbindung der sunnitischen Geistlichen in ihre politischen Projekte, als dies bei der CHP der Fall war. Mit der zur politischen Priorität erhobenen Bekämpfung des Kommunismus nach dem Zweiten Weltkrieg setzten sich die konservativen Parteien und die zweite Strömung in der CHP mit der Zielsetzung durch, die Diyanet auszubauen.

Die Behörde orientiert sich in Kontinuität zu den Institutionen der Ulema im Osmanischen Reich an einer sunnitischen Auslegung des Koran (Gözaydın 2009: 135,153 ). Sie agiert nichtsdestotrotz mit dem Ziel, für die Gesamtheit der »muslimischen« Bevölkerung religiöse »Dienste« auf der Grundlage der »laizistischen Prinzipien« zu leisten, »über den politischen Auffassungen und Meinungen stehend die nationale Einheit und Solidarität zu fördern«, so in der weiterhin aktuellen Aufgabendefinition der 1982er Verfassung. Sie stützt sich hierbei auf die Ansicht, dass 99 Prozent der Bevölkerung Muslime seien. Wie sich die einzelnen BürgerInnen selbst begreifen, wer einen Glauben in welcher Form praktizieren will, sind Fragen, die sich im Lichte dieser Überzeugung nicht stellen. In der Praxis formuliert die Behörde den Anspruch, die Bevölkerung über die »echten« Regeln und Prinzipien des Islam aufzuklären, sie vor »Aberglauben«, »Heidentum«, »Subversion «, »Separatismus«, »moralischer Degeneration« und "geistigen Krankheiten« zu schützen. ${ }^{2}$ Auf dieser Grundlage wurde auch der sunnitische Religionsunterricht in den staatlichen Schulen ab 1950 zunächst als Wahlfach und nach dem 1980er Putsch als obligatorischer Unterricht ohne Rücksicht auf familiär verankerte Religion oder Nicht-Religiosität eingeführt. Alevitische LehrerInnen, so auch meine Grundschullehrerin, wurden gezwungen, Kindern die sunnitische Religionsauffassung beizubringen. metleriGenelMudurlugu/Sayfalar/DHCM.aspx (Abruf am 12.10.2018). 
Die grundlegende Behauptung der Diyanet besteht darin, dass die Religion unverzichtbar sei, alles Gute und Höherwertige der Religion entspringe und diese Religion der Islam sei. Fest verankert ist die Überzeugung, dass es nur einen Islam geben kann. Außerhalb der sunnitischen Auslegung Stehende gelten als abtrünnig oder ungläubig, werden mitunter als pervers und amoralisch bezeichnet. AlevitInnen wird nicht selten angelastet, dass sie den Islam im Auftrag von äußeren Feinden von innen zerstörten. In Publikationen der Behörde werden ferner Atheismus und die Evolutionstheorie als von ausländischen Mächten betriebene Verschwörungen »enttarnt«, Kommunisten, Materialisten, Missionare, Imperialisten, Zionisten, Kreuzritter als Feinde bestimmt (Mertcan 2012: 147ff.).

Das Wirken der Behörde ist nicht auf Publikationen noch durch die Mauern der Moschee begrenzt. Es ist unvermeidbar, dass theologisch ausgebildetes Personal überall dort wirkt, wo es sich bewegt. Einblicke in dieses Wirken konnte ich bei einer als Tefsir angekündigten Veranstaltung der Ismailağa Gemeinschaft, die auch als Mahmut Hoca Gemeinschaft bekannt ist, gewinnen. Die Ismailağa Gemeinschaft ist eine Strömung innerhalb des Nakschibendi Ordens, der historisch eng mit der Milli Görüş Bewegung assoziiert ist. Als Tefsir werden von Gelehrten durchgeführte Koranexegesen bezeichnet. Die Veranstaltung der Ismailağa Gemeinschaft fand im Stadtzentrum von Izmir statt, von ihr erfuhr ich durch meine Kontaktperson an der Izmirer Fakultät. Mein Interesse an seiner Geschichte und der islamistischen Bewegung bewog ihn, mich auf diese Veranstaltung mitzunehmen.

In einem Salon befanden sich etwa 25 Zuhörer, die meisten Stühle waren frei geblieben. Die Größe des Salons ließ die Teilnehmerzahl gering erscheinen. Indes empfand ich die relativ geringe Zahl inmitten des kemalistischen Izmir als nicht überraschend. Auf einem Podium saßen drei Personen, von denen einer sich als Moderator und die anderen beiden als Gelehrte (Hoca) vorstellte, die außerhalb von Izmir bei einer Moschee angestellt seien. Das Thema des Tefsir wurde angekündigt als Missgunst (»haset «) und begann mit einer Lesung aus dem Koran. Auf das Lesen eines Abschnitts, das zuerst auf Arabisch ${ }^{3}$ erfolgte und dann für die Zuhörerschaft übersetzt wurde, folgte die Exegese des Hoca:

Missgunst heißt, dass ein anderer, was ich nicht habe, auch nicht haben soll. Neid bedeutet, etwas haben zu wollen, was ein anderer hat. Missgunst, dem anderen etwas nicht zu gönnen, heißt, den Segen und die Caben Gottes zu hinterfragen. Wenn einer reich ist, dann ist das als Cottes Gabe anzuerkennen. Gott hat das

3 Es besteht ein Konsens unter türkischen Theologen, der Koran müsse auf Arabisch rezitiert werden, da eine Übersetzung nicht mehr »die Worte Cottes« seien. Die Frage der Übersetzung ist verknüpft mit der Frage der Auslegung, insofern jede Übersetzung notwendigerweise eine Interpretation ist. Da allerdings jedes verstehende Lesen ebenfalls interpretieren heißt, dreht sich die theologische Diskussion an dieser Stelle im Kreis. 
erschaffen und er hat gegeben. Wer bist du? Hast du es etwa erschaffen, dass du geben willst?

Der zweite Gelehrte ergänzte:

Wer reich ist und sein Vermögen auf dem Weg Cottes ausgibt, dem sei es gegönnt. Im Anschluss an dieses Thema, das durch weitere Zitate ausgeführt wurde, leiteten die Gelehrten das Gespräch auf das Gebet (»namaz ${ }^{4}$ ) und die Armenabgabe (»zekat«). Sie stellten die Frage, warum diese im Koran nebeneinander stehen und gaben selbst die Antwort, indem sie aus dem Koran zitierend mit ihrer Interpretation fortfuhren:

Zur Zeit des Propheten haben viele Christen und Juden im selben Landstrich gelebt. Um den neugebackenen Muslim vom rechten Weg abzubringen, versuchten sie, ihn zu verwirren. Um ihn von der Religion abzubringen, behaupteten sie, dass nur sie ins Paradies kämen. Mit der Zeit ist der Druck der Christen immer größer geworden. Sie haben selbst die Muslime bedrängt, von denen sie nur das Beste erfahren hatten. Irgendwann hatten die Muslime die Schnauze voll, sie hätten beinahe die Christen umgebracht. Aber, angesichts dieser Situation sprach Cott, habt etwas Ceduld, lasst uns stark werden, dann kommt unsere Zeit. [...] Hierfür ist das Cebet, der Muslim betet, um stark zu werden. Mit dem Cottesdienst wirst du zur Reife gelangen, denn du wirst in der Zukunft in große Kriege ziehen.

Der zweite Gelehrte fiel erneut ein:

Das Gebet ist wichtig, um nicht den Juden auf den Leim zu gehen. Denn die Juden können es nicht verkraften, dass der Prophet nicht aus ihren Reihen kommt. Mit dem Gebet bereitet ihr euch für den Dschihad vor. Deswegen ist es wichtig. Lasst sie im Moment noch in Ruhe.

Der erste Gelehrte ergriff wieder das Wort:

Wenn das Gebet dafür gut ist, den Willen zu stärken, dann ist die Armenabgabe dafür da, den Cemeinschaftssinn zu stärken. Früher gab es dieses Bewusstsein, in der Republikzeit haben wir es vergessen, jetzt kommt es zurück.

Der zweite Gelehrte übernahm das Wort, dieses Mal in einem lauteren Ton:

Es gibt eine Bürokratie im Staat, die nicht will, dass die Religion des Islam erlernt wird. Das ist der Versuch der Laizisten, diejenigen, die in Gott vertrauen [mümin] soll, ist ein hochgradig strukturiertes Ritual, das Körper und Geist reglementiert. Es enthält vorgeschriebene Sequenzen mit Gesten, Aussprachen und Gebeten. Im Mittelpunkt des körperlichen Akts steht die Verbeugung vor Gott in Richtung Mekka. 
in Gottesleugner [kâfir] zu verwandeln. Die, die keinen Religionsunterricht wollen, wollen das Volk vom Islam abbringen.

Nach einer Reihe weiterer Zitate aus dem Koran kam einer der Gelehrten auf die Aleviten zu sprechen:

Zwischen Süleyman Ateş [ehemaliger Leiter der Diyanet] und einem marxistischen Aleviten findet im Fernsehen ein Disput statt.

Der Gelehrte betonte das Wort Marxist sehr stark:

Der marxistische [!] Alevit sagt: >Einer nimmt die Laute [saz], ein anderer singt, und der Rest tanzt<. Was ist denn das für ein Cottesdienst? Sollen wir uns etwa auf den Weg des Teufels begeben?

An dieser Stelle endete die Rezitation und Interpretation, deren verkürzte Wiedergabe den Eindruck von Sprunghaftigkeit erwecken könnte. Das Leitthema zog sich jedoch wie ein roter Faden durch: Was macht einen Muslim aus und wie soll er sich korrekt verhalten angesichts verschiedener Herausforderungen, die ihm im realen Leben begegnen? Der Moderator erteilte dem Publikum, das bis dahin geduldig zugehört hatte, das Wort. Ein Mann im mittleren Alter, der sich als Ladenbesitzer im Basar vorstellte, meldete sich:

Ich blicke nicht mehr durch. Die USA wollen von uns, dass wir keine Beziehung zu einem muslimischen Land, dem Iran, unterhalten und gleichzeitig wollen sie, dass wir für sie Soldaten in ein muslimisches Land, nach Afghanistan, schicken. Wie soll man da durchblicken? Man sagt, wir sollen tolerant sein. Toleranz, ja gut, aber bis wohin?

Einer der Gelehrten antwortete sichtlich erregt:

Die Muslime waren im 18., 19., 20. Jahrhundert nicht herrschend, sondern gefangen. Wir müssen die Bedingungen unserer Zeit kennen, die Schlüsselpositionen werden immer noch von Laizisten gehalten. Man muss vorsichtig sein und sich nicht der Aufregung hingeben. Ein Muslim ist so viel Wert wie zwei Gottesleugner, das sagt unser Prophet. Er hat sogar zuerst gesagt, so viel wie 100 Cottesleugner, glaube ich. Aber er hat auch gesagt: Bis du eine gewisse Stärke erreicht hast, halte dich bedeckt, sei nicht laut.

Wieder wurde er vom zweiten Gelehrten ergänzt:

Kann denn jemand, der sich in der Lage eines Sklaven befindet, tolerant gegenüber dem Herrn sein? Die Muslime sind wie Sklaven. Tolerant kann nur jemand sein, der überlegen ist. Wer bist du denn, dass du tolerant sein willst? Du wirst unterdrückt, du bist Sklave. 
Nochmals brachten die Gelehrten das Wort darauf, dass die Muslime Geduld haben müssen:

Wer sich Cott verpflichtet, kommt ins Paradies. Es gibt aber viele, die keine ordentliche religiöse Ausbildung haben. Wenn ich nach den Namen der Cefährten des Propheten frage, seine vier Stellvertreter ausgenommen, seine Mutter und Weiber ausgenommen, wie viele könnt ihr dann aufzählen? Aber Fußballer und Popstars könnten alle jede Menge aufzählen. Man muss die Gehirne neu formatieren, um die Ordnung, die von den Cottesleugnern zerstört wurde, wieder herzustellen.

Mertcan konstatiert über die Diyanet, dass sie in jüngerer Zeit eine bedachtsamere Sprache gegenüber Gruppen wähle, die außerhalb der von ihr vertretenen Orthodoxie stehen (Mertcan 2012: 193f.). Dies trifft wohl auf Auftritte zu, die stark im Licht der Öffentlichkeit stehen. Die von mir besuchte Veranstaltung wurde nicht von der Diyanet durchgeführt, sondern von Vertretern eines Seitenarms des sunnitischen Islam. Nichtsdestotrotz waren sie bei der Behörde angestellt, sie beaufsichtigten als verbeamtete Imame Moscheen. Ihre Sprache war brüsk und drastisch. Sie traten mit dem für die Behörde charakteristischen Selbstverständnis auf, eine Allgemeinheit zu repräsentieren, die sich über die Erschaffung von Gefahren und Feindbildern, durch Erniedrigung von Anders- und Nichtgläubigen bestätigt. Die Bevölkerung imaginierten sie als eine Gemeinschaft, die seit zwei bis dreihundert Jahren einer Zersetzung anheimgefallen war und ihren Zusammenhalt verloren hatte. Anders als der von Islamisten verbreitete Diskurs über die 99 Prozent Muslime, aus denen die Bevölkerung der Türkei bestehe, impliziert, sahen sie den Muslim nicht als gegeben, sondern als etwas an, das wiederhergestellt werden muss. Diese Ansicht begegnete mir bei Gesprächen mit islamistischen Funktionären und Aktivisten regelmäßig. Der durchschnittliche Staatsbürger wurde keineswegs als Muslim angenommen, dem bestimmte, neutrale Dienste geleistet werden, wie es zur Aufgabendefinition der Diyanet offiziell heißt, sondern als eine Gestalt, die es zu formen gilt. Ich selbst wurde mit meinem offensichtlich begrenzten Wissen über die religiöse Praxis als »Standardmuslim« oder als »Nullkilometermuslim« bezeichnet und galt darin als durchschnittlich. Im vorliegenden Fall nahmen die 99 Prozent Muslime die Gestalt einer ungebildeten Masse an, die falschen Göttern - Fußballern und Popstars - huldigte und umerzogen werden musste.

Solch drastischen Ausdrücken wie bei den Gelehrten der Ismailağa Gemeinschaft, die die erzieherische Aufgabe in der Computersprache als ein Formatieren von Gehirnen fassten - als Zurückversetzen in einen unbeschriebenen Zustand, auf null setzen -, bin ich selten begegnet. Den zugrundeliegenden Anspruch fand ich jedoch regelmäßig vor, er macht auch das Selbstverständnis der Diyanet aus. Dass sich diese Umerziehung in der Auffassung von Islamisten als eine Befreiung von Unterdrückung darstellt, erscheint folgerichtig, wenn von einer "gefangenen« Gegebenheit, einem Kern ausgegangen wird, dessen Entfaltung behindert wird. 
Da »die Muslime« über Jahrhunderte nicht herrschend waren, wird zu Geduld gemahnt, bis die Zeit zum selbständigen Handeln wiedergekommen sei, "große Kriege« nicht nur geführt, sondern gewonnen werden könnten. Befreiung von Unterdrückung und Streben nach totaler Herrschaft präsentieren sich hier als zwei Seiten derselben Medaille. Das Streben wird mal offen und drastisch, mal vorsichtig und schmuckvoll verpackt ausgedrückt, wie Mertcan es über die Diyanet feststellt. Es konstituiert sich immer durch ein Gegenüber: Die »Laizisten«, Neider und Abweichler, die Gottesleugner, worin Angehörige anderer Religionen und Konfessionen inbegriffen sind, die den falschen und gefährlichen Weg beschreiten.

Wie selbstverständlich wurde dem Streben soziale Ungleichheit vorausgesetzt. Die Gelehrten verteidigten den Unterschied zwischen Arm und Reich als gottgegeben: »Wer bist du, dass du geben willst?« Diese Positionierung zu hinterfragen, wurde mit der höchsten Autorität zurückgewiesen, das Denken von Eingriffen in Ungleichheit auf die Ebene der Gotteslästerung gehoben: "Hast du es etwa erschaffen, dass du geben willst? « Einen unmittelbaren Anlass für diese Offensive gleich zu Beginn der Veranstaltung gab es nicht, die Gelehrten hielten sie ungefragt und kamen auch nicht wieder auf das Thema zurück. Ich interpretiere es als eine vorsorgende Maßnahme, Kritik vor dem Hintergrund von zwei Entwicklungen $\mathrm{zu}$ verunmöglichen. Zum einen waren viele Islamisten, die Kritik an einem »unrechtmäßig erworbenen Reichtum« geübt hatten, zu sichtbarem Reichtum gelangt, während die Masse der Bevölkerung in Armut verharrte. Zum anderen hatte zum Zeitpunkt des Tefsir gerade die globale Wirtschaftskrise die Türkei erreicht und $\mathrm{zu}$ einem massiven wirtschaftlichen Einbruch geführt. Auch wenn nicht danach gefragt wurde, das Thema lag in der Luft, es wurde allerorten über die Folgen der Krise diskutiert, von der viele Privathaushalte und Geschäftsinhaber negativ betroffen waren, während die AKP-Regierung sie zu bagatellisieren suchte.

Die Entsendung von Soldaten in ein muslimisches Land, um den USA, also »den Christen« beizustehen, widersprach dem Selbstverständnis, sich gegen Christen und Juden behaupten zu müssen. Der Widerspruch wurde durch den Verweis auf ein höheres Ziel entkräftet. Obwohl klar zum Ausdruck gebracht wurde, was zu tun sei - die Ungläubigen bekämpfen -, wurde dieses Ziel in die Zukunft verschoben. Der Diskurs über die Notwendigkeit, sich zu verstellen, bis man als Stärkster auf die Bühne treten kann, nahm in diesem Fall eine über bloße Vorsicht oder Opportunismus hinausreichende Funktion an. Nach meiner Beobachtung gab es keine Zugangsbeschränkung zur Veranstaltung inmitten des kemalistischen Izmir, es wurde keine besondere Vorsicht an den Tag gelegt, während Ziele wie das Formatieren von Hirnen offen ausgesprochen wurden. Der halb-öffentliche Charakter der Veranstaltung, an der jeder teilnehmen konnte, relativierte das Verstecken der »eigentlichen« Absichten als zentrales Motiv. Die erweiterte, vielleicht sogar primäre Funktion des Diskurses bestand in dem Verhältnis, das er zwischen den Gelehrten und der Gemeinde herstellte. Prinzipiell lässt sich jede Aktion, wie sehr 
auch immer sie im Widerspruch zu etablierten »Wahrheiten« steht, rechtfertigen, indem sie einer höheren "Wahrheit« - in diesem Fall der geeignete Zeitpunkt untergeordnet wird. Die religiöse Autorität, die vom Podium sprach, gab deutlich zu erkennen, dass sie und nicht die Zuhörer - die Gemeinde der Gläubigen - die Autorität besaß, den geeigneten Zeitpunkt zu bestimmen, selbständig aktiv zu werden. Die indirekte Botschaft lautete, dass nur die religiöse Autorität in der Lage ist, die Zeichen zu deuten. Sie erfüllte die Voraussetzungen, da sie den Koran kannte, ihn auf Arabisch lesen und interpretieren, damit auch den Willen Gottes bestimmen konnte. Sie wusste ferner, wer die Gefährten des Propheten waren. Die Zuhörer wurden als Subalterne adressiert, die unwissend sind und der Führung bedürfen. Es lässt sich erkennen, dass der Umerziehungsanspruch - das Formatieren der Hirne - gekoppelt war an einen bevormundenden Führungsanspruch der Imame, der durch die Akzeptanz der Grenzen des Sag- und Fragbaren durch die Zuhörer durchgesetzt wurde.

Die Flexibilität im islamistischen Diskurs, die Fähigkeit, bei wechselnden Bezügen neue Bedeutungen zu kreieren und somit Widersprüche zu entkräften, könnte als politische Trivialität angesehen werden, die den islamistischen zu einem austauschbaren populistischen Diskurs macht. Zweierlei ist in diesem Zusammenhang zu bedenken: Zum einen kann sich der islamistische Diskurs auf eine eigene, institutionell festgefügte und tradierte Autorität stützen, wodurch eine enorme Akkumulation von Ressourcen zur Einflussnahme auf das kollektive Bewusstsein ermöglicht wird. Zum anderen erfordert das Kitten von Widersprüchen innerhalb eines Diskurszusammenhangs einen hohen Aufwand. Die Islamisten haben diesen nicht alleine aufgebracht. Sie hatten zahlreiche Freunde, Unterstützer und selbst ihre Gegner arbeiteten ihnen zu, um auftretende Widersprüche zu kitten und Argumente abzudichten.

Ein schillernder Widerspruch im Diskurs über die Diyanet besteht in der offen zu Tage liegenden Tatsache, dass die Diyanet als Institution, die durch bestimmte religiöse Auffassungen geformt ist, die Reproduktion und Expansion dieser Auffassungen zum Ziel hat, nicht nach den Prinzipien der Gleichheit aller Staatsbürger und der Äquidistanz, denen sie auch verfassungsgemäß verpflichtet ist, funktionieren kann. Um Laizität herzustellen, müssten bestimmte Kriterien erfüllt sein: eine institutionelle Trennung von Staat und Religion; die Abwesenheit einer offiziellen Religion des Staates; die Neutralität des Staates gegenüber allen Religionen; keine Privilegierung einer Religion und Bereitstellung religiöser Dienstleistungen durch den Staat; die Entfernung des obligatorischen Religionsunterrichts und der Religion als Legitimationsquelle des Staates (vgl. Mertcan 2012: 201). Da die Begriffe oft miteinander vertauscht werden, möchte ich an dieser Stelle eine Definition einfügen. Mit Laizismus soll in Abgrenzung zu Laiziät im Rahmen dieser Studie eine Weltauffassung bezeichnet werden, die verschiedenartige und gegensätzliche Bedeutungen - Kontrolle oder Bekämpfung der Religion oder ihre Zu- 
rückdrängung ins Private - annehmen kann. Mit Säkularisierung soll dagegen ein Prozess bezeichnet werden, durch den das Gewicht der Religion als handlungsanleitendes Deutungssystem abnimmt. In der Türkei liegen keine Laizität, aber eine laizistische Weltauffassung sowie ein historischer Säkularisierungsprozess vor.

Um die Diskrepanz zwischen der Realität und dem in der Verfassung verankerten Prinzip der Laizität zu verwischen, ist in der Türkei ein Legitimationsdiskurs entwickelt worden, an dem auch das Verfassungsgericht, eine der »Schlüsselpositionen «, die von den Gelehrten der Ismailağa Gemeinschaft als Institution des Feindes angesprochen wurde, mitgewirkt hat. In einem maßgebenden Urteil aus dem Jahr 1971 wird behauptet, dass die Diyanet keine religiöse Institution, sondern ein Verwaltungsorgan sei, das dem Bedürfnis der Mehrheit der Bevölkerung nach einer religiösen Dienstleistung nachkomme. Um die Unverzichtbarkeit der Behörde $\mathrm{zu}$ begründen, wird das Argument ins Feld geführt, es gebe im Islam keine Kirche wie im Christentum, die das religiöse Bedürfnis bedienen könne. Dass das Personal aus Beamten besteht, bedeute nicht, dass der Staat sich in die Religion einmische (Gözaydın 2009: 179, 279, 283). Der Auffassung unterliegt die Annahme, dass eine religiöse Dienstleistung eine neutrale, verwaltungstechnische Angelegenheit sein kann. Geflissentlich übergangen wird, dass mit der Ausführung notwendigerweise auch Inhalte verbunden sind. Entsprechend werden die Angestellten der Behörde im Gesetz als Klasse der religiösen Dienstleister bezeichnet, womit die Bezeichnung Geistliche oder Theokratie eloquent umgangen wird. Ein Spiegelbild dieser Verwirrung ist das klare Bekenntnis der AKP zur Laizität in ihrem Parteiprogramm wie auch die Diskussion unter den türkischen Theologen. Letzteren zufolge soll die Diyanet religiöse Dienste leisten, aber keine religiöse Autorität beanspruchen, weil dies aufgrund ihrer Anbindung an die Exekutive bedeuten würde, dass eine religiöse politische Herrschaft bestehe, eine Art Kirche beziehungsweise Theokratie installiert werde, die im Islam nicht vorgesehen sei (ebd.: 103). Tatsächlich liegt in der Türkei aber genau dies vor: Der Diyanet wird die Rolle einer religiösen Repräsentanz der Türkei zugesprochen, sie vertritt die offizielle Religion der Türkei. Zum Ausdruck gebracht wird dies auch durch das Auftreten des mit dem höchsten Beamtenstatus ausgestatteten Behördenleiters in religiösen Gewändern bei Staatsbesuchen und offiziellen Zeremonien.

Die Existenz einer aus allgemeinen Steuermitteln finanzierten »Staatskirche« macht Einverständnis von Islamisten mit dem »Prinzip der Laizität« möglich. Als der türkische Ministerpräsident Erdoğan 2011 auf einer Tour durch nordafrikanische Staaten, in denen politische Aufstände ausgebrochen und islamistische Regierungen an die Macht gespült worden waren, für das türkische Modell warb, konnte er dies tun, ohne in einen praktischen Widerspruch zur eigenen islamistischen 
Agenda zu geraten. ${ }^{5}$ In den Worten des islamistischen Intellektuellen Mehmet Şevket Eygi heißt es zum Status der Diyanet im Jahr 1990:

»Ich persönlich bin der Meinung, dass der Status quo bewahrt werden sollte. Denn die Zeit arbeitet zugunsten des Islam und der Muslime. Ja, alles sollte so bleiben, wie es ist, und die Muslime sollten mit aller Kraft danach streben, fähige, hervorragende, zielstrebige Kader zu erziehen. Der Tag wird kommen, an dem sich Gerechtigkeit einfinden wird. Da es im sunnitischen Islam keine Trennung von Religion und Welt gibt, ist die Bewahrung des bestehenden Modells der klügste Weg, es ist das kleinere Übel.« (Eygi, zit.n. Gözaydın 2009: 278, Übersetzung E.B.)

Hier wird die Erwartung ausgedrückt, dass der Ausbau der Diyanet das Ziel, einen theokratisch geführten Staat zu errichten, auf lange Sicht näher bringen wird, dafür hingenommen werden muss, dass diese Institution zeitweise unter der formalen Kontrolle von »Laizisten« steht. ${ }^{6}$ Der Begriff »Welt« ist in diesem Zusammenhang ein Synonym für Politik. Das kemalistische Ziel, eine eigenständige Organisierung von Gläubigen zu verhindern, fällt in der Praxis zusammen mit dem islamistischen Ziel, eine theokratische Institution aufzubauen, die eine Organisierung von Gläubigen außerhalb der Orthodoxie und damit ein Auseinanderlaufen religiöser Auslegungen unterbinden soll.

\subsubsection{Institutioneller Aufbau}

Dass der Staat als eine abgeschlossene Entität begriffen wird, die entweder laizistisch oder religiös ist, hat in der Türkeiforschung zu einer systematischen Fehleinschätzung der Religionspolitik und der Rolle staatlich-religiöser Institutionen beigetragen (bspw. Kuru 2009; Ozgur 2012). Offensichtlich können sich unterschiedlich verfasste, durchaus auch zueinander feindlich gesinnte Gruppen innerhalb der Institutionen eines Staates organisieren und nebeneinander existieren. Die Organisierung der Theologen im türkischen Staat zeigt jedenfalls, dass dieser von An-

5 Von den frischgebackenen islamistischen Machthabern in Nordafrika wurde dieses Werben allerdings als Einmischung in die Innenpolitik ihrer Länder aufgefasst und zurückgewiesen. Siehe https://www.jpost.com/Middle-East/Brotherhood-angry-at-Erdogan-call-forsecular-Egypt-238021 vom 14.09.2011 (Abruf am 12.10.2018).

6 Ferner wurde von manchen Islamisten und Theologen die Auffassung vorgebracht, die religiösen Institutionen sollten autonom sein und gänzlich vom Staat separiert werden. Diese Auffassung wurde meist allerdings nicht konsequent oder in Abhängigkeit von der politischen Konjunktur vorgebracht, wenn gerade keine konservative oder islamistische Partei an der Regierung war. Die Gülen Gemeinschaft brachte das Ansinnen in den 200oern aufgrund der Rivalität zwischen ihrem privaten religiösen Netz und den staatlichen Institutionen vor. Eine Sammlung unterschiedlicher Meinungen zur Diyanet, die ein breites bürgerliches Spektrum umfasst, findet sich bei Çakır und Bozan (2005). 
fang an nicht als eine laizistische Entität gefasst werden kann, auch wenn diese in der Verfassung festgeschrieben ist.

Im Laufe eines Jahrhunderts sind die Aufgaben und Funktionen der Diyanet enorm ausgeweitet worden. 1929 verfügte die Behörde über 6.029 Angestellte. Noch unter einer CHP-Regierung wurde die Behörde 1950 reorganisiert, sie erhielt die Aufsicht über die Moscheen, die ihr 1931 entzogen worden war, zurück. Ihr Personal wurde um 940 Stellen, also um 14 Prozent aufgestockt. 1965 wurden der Behörde bereits 19.693 und 197031.149 Stellen zugewiesen. 1984 erreichte die Behörde die Schwelle von 50.000 Angestellten, 1997 waren es über 80.000. Nach der 1997er Intervention des Militärs sank das Personal auf etwa 74.000 im Jahr 2003. Einen besonderen Anstieg des Personals verzeichnete die Behörde mit den AKP-Regierungen. Die Behörde wurde um knapp 46.000 neue Stellen, auf über 120.000 Angestellte im Jahr 2013 aufgestockt. Wahrscheinlich bedingt durch die Ausstoßung der Gülen Gemeinschaft aus der Bürokratie sank das Personal danach auf 109.000 im Jahr 2017. Auf etwa 800 Einwohner des Landes fällt damit ein professioneller Geistlicher. Ein Vergleich mit den beiden großen Kirchengemeinden in Deutschland, das ungefähr die gleiche Einwohnerzahl wie die Türkei hat, verdeutlicht die Dimension. Die Katholische Kirche beschäftigte 2017 13.560 Priester, von der Evangelischen Kirche wurden etwa 18.000 PfarrerInnen beschäftigt, zusammengenommen also etwa ein Viertel gegenüber der Türkei. ${ }^{7}$

Tabelle 1: Entwicklung des Personals der Diyanet 1929-2017

\begin{tabular}{|l|l|l|l|l|l|l|l|l|}
\hline & 1929 & 1965 & 1981 & 1991 & $2002^{\mathrm{a}}$ & 2007 & 2013 & 2017 \\
\hline $\begin{array}{l}\text { Per- } \\
\text { sonal }\end{array}$ & 6.029 & 19.693 & 43.197 & 74.789 & 74.368 & 84.195 & 121.845 & 109.332 \\
\hline
\end{tabular}

a Bildung der ersten AKP-Regierung

Das fest angestellte Personal der Diyanet besteht zu einem kleinen Teil aus Verwaltungsangestellten und Hausmeistern, größtenteils aus verbeamteten Geistlichen, die hauptsächlich den Moscheen zugeteilt und als Koranlehrer tätig sind. Ihr Anteil an allen Beamten der Republik ist von 3,5\% im Jahr 2007 auf 4,22 \% im Jahr 2017 gestiegen. ${ }^{8}$ Das Personal bezieht ein monatliches Gehalt, Sachleistungen, bezahlte Überstunden, es erwirbt Ansprüche auf Sozialversicherungsleistungen, eine Rente und verfügt über eigenständige Interessenvertretungen wie Gewerkschaften. Etwa 80 Prozent der Ausgaben der Diyanet gehen an das Personal, zu inhalte/142490/06-03-2017/evangelische-kirche-sucht-den-kommenden-jahren-tausendepfarrer vom 06.03.2017 (beide abgerufen am 23.12.2018).

8 Siehe Finanzministerium und Schatzamt der Türkei: www.bumko.gov.tr/TR,908/kadro-istatistikleri.html (Abruf am 23.10.2018). 
dem ab Mitte der 2000er Jahre auch eine wachsende Zahl von Frauen zählt. Sie sollen »über die Religion aufklären und Familienberatung leisten« (Gözaydın 2009: 107). Für den Bau von Moscheen wendet die Diyanet in der Regel keine Mittel auf, dieser wird hauptsächlich durch Spenden finanziert. Dennoch kommen auch für den Bau öffentliche Mittel zum Einsatz über die Kommunen, die Grundstücke zur Verfügung stellen können. Seit 1998 besteht eine gesetzliche Regelung, bei der Planung neuer Stadtviertel einen Platz für Moscheen zu reservieren.

Parallel zum Personal ist das Budget der Behörde kontinuierlich gestiegen. Der durchschnittliche Anteil am öffentlichen Haushalt stieg in den 1950er Jahren von $0,2 \%$ auf etwa $0,7 \%$, in den 1990ern auf etwa $0,8 \%$ und in den $2010 e r n$ (bis 2018) auf etwa 1,1 \% (ebd. 222ff.). ${ }^{9}$ Zwischen 2003 und 2018 wurde das Budget um durchschnittlich 15 Prozent pro Jahr erhöht. Beeindruckend ist die Erhöhung in absoluten Zahlen: Von 2002 auf 2018 ist das Budget um das vierzehnfache, von 0,55 Mrd. auf 7,77 Mrd. YTL, erhöht worden. Parallel zum Wachstum des Personals ist die Anzahl der Moscheen von 42.744 im Jahr 1971 auf 76.445 im ersten Regierungsjahr der AKP (2003) gestiegen. Unter der AKP kamen bis 201711.576 neue Moscheen hinzu, wodurch die Gesamtzahl auf 88.021 stieg. Dies bedeutet, dass pro Jahr durchschnittlich 827 Moscheen neu eröffnet worden sind. ${ }^{10}$

Die Expansion der Diyanet lässt sich besonders deutlich ablesen an der Anzahl der Korankurse, die unter ihrer Obhut durchgeführt werden. Die Kurse, die in Form von 32 Wochen-Kursen oder Intensivkursen in den Sommerferien angeboten werden, werden teils vom fest angestellten Personal, teils durch Werkverträge mit Externen durchgeführt. 1980 wurden 2.610 Kurse durchgeführt, 1996 wurde ein erster Höhepunkt mit 5.421 Kursen erreicht. Nach dem Ende der Erbakan-Regierung und den anti-islamistischen Maßnahmen des Nationalen Sicherheitsrats sank die Zahl. Sie lag 2002 jedoch immer noch bei 3.664 Kursen. Mit der AKP setzte ein rapider Anstieg ein: Pro Jahr kamen durchschnittlich 850 neue Kurse hinzu. 2016 wurden 15.796 Kurse mit 674.703 TeilnehmerInnen durchgeführt. Auffallend ist der hohe weibliche Anteil an den Teilnehmenden, der 2016 bei etwa 84 Prozent lag, wofür zwei Gründe infrage kommen könnten. Zum einen können Frauen kaum über das Gebetsritual erreicht werden, da sich in den Moscheen traditionell eine männliche Gemeinschaft konstituiert. Möglicherweise richten sich die Kurse im besonderen Maße an Frauen, um die dadurch entstehende Lücke zu schließen. Zum anderen ist die Beschäftigungsquote von Frauen in der Türkei sehr niedrig, so dass ihre Erreichbarkeit wahrscheinlich weniger durch regelmäßige Lohnarbeit yonetim-butcesine-dahil-kurumlarin-yillar-itibariyle-odenek-a-cetveli-icmalleri-20062018.html (Abruf am 23.10.2018).

10 Siehe Website der Diyanet: http://stratejigelistirme.diyanet.gov.tr/sayfa/57/istatistikler (Abruf am 23.10.2018). 
eingeschränkt ist. Ein auffallender Sprung ist im Schuljahr 2012/2013 zu verzeichnen: Die Teilnehmerzahl an den Korankursen verdreifachte sich in diesem Jahr im Vergleich zum Vorjahr von 290.818 auf 908.589 und blieb danach auf dem hohen Niveau. ${ }^{11}$ Der massive Anstieg der Korankurse bedingt schließlich den Anstieg des weiblichen Personals. Nach Angaben des Behördenleiters arbeiteten 2018 etwa 40.000 Frauen als Koranlehrerinnen für die Diyanet, davon 20.000 bis 25.000 als Festangestellte oder mit Werkverträgen und die restlichen ehrenamtlich. ${ }^{12}$

Tabelle 2: Entwicklung von Korankursen 1980-2016

\begin{tabular}{|l|l|l|l|l|l|l|l|l|}
\hline & 1980 & 1990 & 1996 & 2002 & 2005 & 2011 & 2012 & 2016 \\
\hline Kurse & 2.610 & 4.998 & 5.241 & 3.664 & 5.654 & 14.676 & 15.457 & 15.796 \\
\hline $\begin{array}{l}\text { Teil- } \\
\text { neh- } \\
\text { mer }\end{array}$ & 25.513 & 51.852 & 47.291 & 9.363 & 11.680 & 8.963 & 43.010 & 107.012 \\
\hline $\begin{array}{l}\text { Teil- } \\
\text { neh- } \\
\text { mer- } \\
\text { innen }\end{array}$ & 34.293 & 94.744 & 111.155 & 70.473 & 116.037 & 281.855 & 865.579 & 567.691 \\
\hline
\end{tabular}

Das Jahr 2012 markiert einen Sprung hinsichtlich der Bildungsaktivitäten der Diyanet, die eigentlich dem Bildungsministerium obliegen, in das die Behörde mehrere tausend Geistliche transferiert hat. ${ }^{13}$ In das Jahr 2012 fällt die Bildungsreform, mit der die AKP das Schulsystem mit der Zielsetzung reformierte, eine »fromme und zürnende ${ }^{14}$ Generation zu erziehen, auf die ich im Zusammenhang mit den Imam Hatip Schulen noch eingehen werde. Seit 2013/2014 hat die Diyanet ihre Bildungsaktivitäten auf Vorschulkinder (4-6 Jahre) erweitert. ${ }^{15} 2017$ befanden sich unter den Teilnehmenden an den Korankursen etwa 88.000 Vorschulkinder,

11 Zusammengestellt aus Daten der Statistikbehörde der Türkei (tuik.gov.tr) und des Nationalen Bildungsministeriums der Türkei (sgb.meb.gov.tr).

12 Siehe Website der Diyanet: https://www.diyanet.gov.tr/tr-TR/Kurumsal/Detay/11507/diyanetisleri-baskani-erbas-islam-ve-kadin-calistayinin-acilisina-katildi vom 25.04.2018 (Abruf am 24.10.2018).

13 Siehe www.mebpersonel.com/meb/diyanet-ten-milli-egitim-e-5-bin-50-kisi-gecti-h217620.html vom 01.11.2017 (Abruf am 24.10.2018).

14 Auf Türkisch heißt es »dindar ve kindar«. Kindar kann auch als »gehässig«, »rachsüchtig«oder »einer Sache hartnäckig nachgehen« übersetzt werden.

15 Als allgemeines Ziel des Programms für Vorschulkinder ist definiert: »Den Koran und seine Buchstaben kennenlernen, kurze Suren und Gebete auswendig lernen, die grundlegenden Werte des Islam internalisieren« (Öztürk 2018: 13). 
2018 soll die Zahl nach Angaben der Behörde auf 150.000 gestiegen sein. ${ }^{16}$ Dies bedeutet, dass Kinder im Alter von 4 Jahren damit anfangen, den Koran auswendig zu lernen. ${ }^{17}$ In welchem Geist diese Kurse durchgeführt werden, erklärte der Behördenleiter im Zusammenhang mit dem Einmarsch der türkischen Armee nach Afrin in Syrien. Die bisweilen vorgenommene Trennung zwischen einem zivilen und militärischen Dschihad negierend brachte der Behördenleiter Erbaş auf den Punkt, dass der Dschihad ein umfassendes Konzept ist:

»Unseren Märtyrern erbitte ich Gottes Gnade, unseren Versehrten rasche Heilung. Sie kämpfen dort, wir eröffnen hier Korankurse. Sie dort, wir hier führen den Dschihad. Möge Gott unseren Dschihad annehmen. ${ }^{18}$

Die Diyanet initiiert ferner Gebetsrituale und Koranlesewettbewerbe in Schulen, organisiert Ausflüge von Kindergärten und Schulen in Moscheen. Die Aktivitäten ergreifen auch die Sonderschulen. Seit 2010 erhalten "autistische Kinder« verpflichtend religiöse Unterrichtung, als Maßnahme gegen Atheismus, wie es von Seiten der Betreiber heißt. ${ }^{19}$ Den Sonderstatus, der den Institutionen der sunnitischen Religion gewährt wird, unterstreicht ein Schwerpunktprojekt der Diyanet, das in der Ausbildung von »hafiz« besteht. »Hafiz« werden Personen genannt, die den gesamten Koran auswendig gelernt haben und rezitieren können. Es handelt sich um mehrere hundert Seiten auf Arabisch. Seit 2014 können auf Wunsch ihrer Eltern Kinder ab der fünften Klasse - etwa im Alter von zehn Jahren - für ein Jahr von der Schulpflicht entbunden werden, um den Koran auswendig zu lernen. ${ }^{20}$ Die Diyanet fordert vom Bildungsministerium, dass der Zeitraum auf zwei Jahre erhöht wird, da ein Jahr nicht ausreiche. Für das Erlernen einer anderen Religion, einer Weltanschauung oder des Atheismus gibt es in der Türkei keine Freistellung von der Schulpflicht.

Darüber hinaus sind die Moscheen für die AKP Orte, an denen sie für politische Ziele und Wählerstimmen wirbt. ${ }^{21}$ Im kurdischen Südosten der Türkei streitet die

16 Siehe https://tr.sputniknews.com/turkiye/201809061035084131-diyanet-isleri-baskani-ku -ran-kur-su-pro-gra-mi/ vom 06.09.2018 (Abruf am 24.10.2018).

17 Siehe www.haber7.com/guncel/haber/900706-6-yasinda-hafiz-olan-zeynep-sinavda-aglatti vom 10.07.2012 (Abruf am 24.10.2018).

18 Siehe www.cumhuriyet.com.tr/haber/turkiye/915263/Diyanet_isleri_Baskani_Erbas_tan_Af-rin_yo-ru-mu_Onlar_orada_biz_burada_cihada_devam_ediyoruz.html vom 29.01.2018 (Abruf am 13.02.2018).

19 Siehe http://egitimsen.org.tr/wp-content/uploads/2015/12/Eğitimin-Dinselleştirilmesive-Şura-Kararları.pdf (Abruf am 3.10.2017).

20 Siehe http://dinogretimi.meb.gov.tr/proje/OrgunEgitimleBirlikteHafizlik.pdf vom März 2018 (Abruf am 23.10.2018).

21 Siehe Pinar Tremblay: How Erdogan uses Turkey's mosques to push syes vote, AlMonitor, 12.04.2017, https://www.al-monitor.com/pulse/originals/2017/04/turkey-erdoganuses-mosques-to-win-referendum.html (Abruf am 23.10.2018). 
Diyanet gegen die kurdische Bewegung, um sich als religiöse Autorität durchzusetzen. Der Streit ist immer wieder eskaliert, so auch im Vorfeld der Parlamentswahlen im Juni 2013, als Prediger instruiert wurden, gegen die kurdische Opposition $\mathrm{zu}$ agitieren. Die Regierung stellte Mittel für den Neubau von 1.362 Moscheen im kurdischen Gebiet und für Vergünstigungen der dort Dienst leistenden Prediger bereit. Neu gebildeten religiösen »Aufklärungsteams« wurde eine aktive Rolle in der »Terrorbekämpfung « erteilt. ${ }^{22}$ Zur gleichen Zeit wurde ein groß dimensioniertes Projekt beworben, das die Großstadt Diyarbakır, deren Bevölkerung mehrheitlich für Parteien der kurdischen Bewegung stimmt, zu einem religiösen Ausbildungszentrum mit Ausstrahlungskraft in die Nachbarstaaten machen sollte. ${ }^{23} \mathrm{Als}$ die kurdische Bewegung auf diese Maßnahmen reagierte, indem sie eigene Geistliche mobilisierte und das Freitagsgebet ${ }^{24}$ von der Moschee auf die Straße verlagerte, handelte sie sich den Vorwurf des "Separatismus« und »Kommunismus« ein: »Sie tragen den Separatismus in unsere heilige Religion. (...) Deren marxistisch-leninistische Auffassung hat nichts mit Religion zu tun«, so der damalige Ministerpräsident Erdoğan. ${ }^{25}$ Seine Aussage brachte zum Vorschein, dass die Rhetorik des Kalten Krieges, als Islamismus und Antikommunismus miteinander verwoben wurden, immer noch eingesetzt wird, obgleich die kurdische Bewegung sich schon in den 1990er Jahren von sozialistischen Zielen distanziert hatte.

\subsubsection{Relative Autonomie und Demokratieverständnis der Diyanet}

Es ist nicht verwunderlich, dass die Diyanet politische Positionen einnimmt. Sie ist eine politische Institution, ihr Personal wird politisch ernannt. Bis 2018 war sie dem Ministerpräsidenten unterstellt, nach dem Übergang in das Präsidialsystem wurde sie dem Staatspräsidenten unterstellt. Doch trotz enger Anbindung an die politischen Ziele der AKP verfügt die Behörde über eine relative Autonomie gegenüber Regierungen. Sie ergibt sich aus ihrem spezifischen Charakter, institutionalisierte Reproduktionsstätte von Geistlichen zu sein, denen sie organisiertes Handeln ermöglicht. Als 1963 von einer CHP-Regierung der Vorschlag erfolgte, eine Abteilung für Konfessionen in der Diyanet einzurichten, opponierten in der Diyanet organisierte Geistliche gegen das Vorhaben. Sie führten die Unteilbarkeit des

22 Siehe www.milliyet.com.tr/bolucu-akimlara-karsi-irsat-ekipleri/guncel/haberdetayarsiv/12.11.2010/1313418/default.htm vom 12.11.2010 (Abruf am 12.10.2017).

23 Siehe https://www.birgun.net/haber-detay/diyarbakir-akp-ile-kutsal-lasacakmis-58289. html vom 06.05.2011 (Abruf am 23.10.2018).

24 Das Freitagsgebet, bei der die Gemeinschaft in der Moschee zusammenkommen soll, wird im sunnitischen Islam als das wichtigste Gebet der Woche angesehen.

25 Siehe http://t24.com.tr/haber/basbakan-erdogan-devlette-yeni-bir-yapilanmaya-gidiyoruz ,144165 vom 10.05.2011 und https://bianet.org/bianet/diger/129098-demirtas-imamlari-terorle-mucadelede-kullanmak-cok-tehlikeli vom 06.04.2011, (beide abgerufen am 23.10.2018). 
Islam und das Bedrohungsszenario ins Feld, es werde eine künstliche Spaltung zwischen Sunniten und Schiiten auferweckt, dadurch die nationale und religiöse Einheit gefährdet. Parallel initiierte die rechte Presse eine Diffamierungskampagne gegen AlevitInnen. Angesichts solch organisierter Proteste wurde das Projekt eingestellt, die Diyanet verteidigte erfolgreich ihre Position als Autorität des Islam (Mertcan 2012: 157f.). Die Behörde widerstand auch jahrzehntelang politischem Druck, eine Fatwa ${ }^{26}$ zu veröffentlichen, die das Kopftuch zur Entscheidungssache Einzelner deklariert, anstatt es als islamisches Prinzip anzuerkennen (Lord 2018).

Bereits in diesen beiden Beispielen tritt die Diyanet als eigenständige und normativ wirkende Institution auf, die sich politischen Entscheidungen widersetzt. Verknüpft ist dieses Wirken mit einer eigenwilligen Auslegung von Laizität. Die Diyanet interpretiert die Trennung zwischen staatlichen und religiösen Angelegenheiten dergestalt, dass religiöse Angelegenheiten allein der Behörde obliegen müssten, die Politik sich nicht in die Religion einmischen dürfe. ${ }^{27}$ Laizität bedeutet für sie institutionelle Autonomie als Staatsapparat beziehungsweise Nichteinmischung der gewählten politischen Entscheidungsträger. Die Auslegung ist Teil des kritisierten Verwirrspiels um den Begriff Laizität. Camoufliert wird der grundlegend politische Charakter der Behörde als Teil des Staates ebenso wie ihr konkretes politisches Wirken: die Parteinahme der Behörde in den gesellschaftlichen Auseinandersetzungen. Dass politische Entscheidungsträger nicht über die Religion befinden sollen, bedeutet, dass sie nicht über die Religionsauffassung der Behörde bestimmen sollen, etwa indem sie darüber befinden, dass der Islam mehr als nur eine Konfession kennt.

Obgleich die Angestellten der Behörde laut Beamtengesetz sich jeglicher politischer Tätigkeit enthalten müssten, ist die Behörde in Kernbereichen des Politischen aktiv. Sie erhebt Anspruch auf die Formung der nationalen Identität, die als konservativ, sunnitisch und türkisch definiert wird. Sie ist zunehmend an einer Bildungspraxis beteiligt, der diese Einschränkungen zugrunde liegen. Ausgestattet mit der politischen Autorität, den wahren und einzigen Islam zu repräsentieren, nimmt sie sich heraus, $\mathrm{zu}$ allen erdenklichen Angelegenheiten des gesellschaftlichen Lebens - Kleidung, Essen, Moral, Ästhetik, Sexualität, Arbeitsteilung, Geschlechterrollen, soziale Hierarchien, Krieg und Frieden, Feind und Freund - eine Auffassung im Namen der Allgemeinheit zu vertreten. Sie gestaltet den Geltungsbereich der Religion umfassend, aber die Repräsentantin der Allgemeinheit - »die Politik« - soll

Als Fatwa wird das Cutachten einer religiösen Autorität bezeichnet, ob eine bestimmte Angelegenheit religionsrechtlich legitim ist. Die Diyanet veröffentlicht zumeist auf Anfrage täglich Fatwas zu allen Angelegenheiten. Eine Zeitlang betrieb sie eine telefonische Hotline und stieg dann auf das Medium Internet um.

27 Siehe https://www.sabah.com.tr/gundem/2010/10/18/basortusu_muslumanligin_on_sarti_ degil vom 08.10.2010 (Abruf am 10.10.2018). 
sich nicht einmischen. Prinzipiell bedeutet dies, dass die Behörde über dem politischen Willensbildungsprozess stehen, eine in demokratischen Prozessen hergestellte politische Legitimation nicht anerkennen will. Nochmals sei die Tragweite vor Augen geführt: Eine öffentliche Behörde befindet, dass die gewählten Vertreter der Öffentlichkeit nicht über sie bestimmen sollen.

Angesichts dieser Anmaßung, die sich auf eine reale Praxis stützen kann, ist die Bezeichnung Behörde für die Diyanet unzureichend. Es handelt sich zweifellos um einen theokratischen Beamtenapparat, eine »Staatskirche«, das ist gegen den Legitimationsdiskurs, der die Behörde als neutrale Dienstleisterin darstellt, zu betonen. Der Apparat ist zugleich funktionaler Bestandteil einer gesellschaftlichen Partei - der islamistischen Partei der Bourgeoisie - und verfügt ferner über eine relativ eigenständige Agenda, die in der Ausweitung seines Wirkungsbereichs basierend auf dem Anspruch auf Autonomie besteht. Die Bezeichnung Behörde deckt diese parteilich-autonome Seite, die in die sozio-politische Blockbildung im Rahmen des islamistischen Hegemonieprojekts eingelassen ist, nur unzureichend $\mathrm{ab}$.

Ferner zeigt sich die Diyanet in Anbetracht eines schwächer werdenden laizistischen Widerstands bestrebt, in den Rechtsbereich vorzudringen. So hat die CHP einen strategischen Wechsel vollzogen und mobilisiert nicht mehr offensiv auf laizistischer Grundlage. ${ }^{28}$ Sie hat sich sukzessive dem islamischen Konservatismus angenähert, beispielsweise durch Adaption eines islamischen Diskurses und durch die Aufstellung eines türkischen Islamisten (Ekmeleddin İhsanoğlu) als gemeinsamen Kandidaten mit der MHP gegen den AKP-Kandidaten Erdoğan bei den Präsidentschaftswahlen 2014 (Babacan 2014b). ${ }^{29} 2017$ konnte so ohne nennenswerten Protest per Gesetzgebung die Ermächtigung von Muftis erfolgen, zivile Ehen schließen zu dürfen. Gefordert hatte diese Ermächtigung seit 2007 die Gewerkschaft der Angestellten bei der Diyanet (Diyanet-Sen). ${ }^{30}$ Seit der Einführung der

28 Das letzte einschneidende Ereignis, bei dem die CHP sich deutlich gegen die Islamisierungspolitik stellte, war die Bildungsreform von 2012, mit der die AKP das Schulsystem mit der Zielsetzung reformierte, eine »fromme und zürnende« Ceneration zu erziehen.

29 Ein Beispiel für diese Anpassung ist die Kritik des CHP-Vorsitzenden an Importfleisch aus Osteuropa, weil es angeblich nicht nach islamischen Prinzipien zubereitet wurde. Siehe https://www.milligazete.com.tr/haber/1265012/kemal-kilicdaroglu-sirbistandan-gelecek-etler-besmelesiz-kesildi vom 17.10.2017 (Abruf am 12.10.2018). Ein weiteres Beispiel ist die Legitimation eigener Handlungen sowie die Kritik an Handlungen des politischen Gegners durch Bezugnahme auf religiöse Vorschriften wie »helal« (von Cott erlaubt, der Religion gemäß) und »haram« (von Gott verboten, der Religion widersprechend). Siehe http://t24.com.tr/haber/chpden-cumhurbaskani-erdogana-yanit-harama-alismis-olanlar-helal-gelirle-yasamasini-anlayamaz,601421 vom 09.04.2018 (Abruf am 12.10.2018).

30 Siehe https://www.muftulukhaber.com/diyanet-sen-in-teklifi-mecliste-muftuler-de-nikahkiyabilecek/1523/vom 26.07.2017 (Abruf am 12.10.2018). 
Bürgerlichen Gesetzgebung und des Zivilrechts im Jahr 1926 hatten Kommunalbeamte diese Funktion inne. Die Inanspruchnahme der Eheschließung durch einen Mufti ist zwar eine optionale und freiwillige »Dienstleistung «. Sie kann jedoch als erster Schritt interpretiert werden, das Befugnis der Ulema aus dem Osmanischen Reich, Recht zu sprechen, wiederherzustellen. Unabhängig davon, erweitert die neue Regelung das sunnitische Sonderrecht, bestimmten Bevölkerungsgruppen aus allgemeinen Steuermitteln finanzierte Dienste exklusiv zur Verfügung zu stellen.

\subsubsection{Intellektuelle Führungspraxis - Diyanet im Alltag}

Unter der AKP hat die Religion eine enorme Aufwertung erfahren, ohne dass dies einen scharfen Bruch mit der vormaligen »laizistischen « Praxis notwendig werden ließ, weshalb die Entwicklung schleichend vonstattengehen konnte. Die Aufmerksamkeit für konservativ-islamische Praktiken - wie das Verbot von Alkohol in staatlichen Kantinen und bei öffentlichen Anlässen, die Erklärung von Nichtkopftuchträgerinnen zu Feinden des Islam, Berührungsverbote zwischen den Geschlechtern und Legitimierung der Polygamie - war in der ersten Regierungsperiode aufgrund der liberalen Flankierung der AKP weitgehend auf kemalistische Kräfte begrenzt. Nach 2012 sind die Aktivitäten, die sunnitische Religion ins kulturpolitische Zentrum der Bevölkerungspolitik zu heben, sichtbar beschleunigt worden. Der Anspruch, das alltägliche Leben nach den Richtlinien eines »wahrhaft islamischen Lebens« zu gestalten, wurde auch vom Ministerpräsidenten Erdoğan offener formuliert. Im Kontext einer Gesetzesinitiative seiner Partei zur Verbannung alkoholhaltiger Getränke aus dem öffentlichen Sichtfeld gab er auf einer Fraktionssitzung an die säkulare Opposition gerichtet kund:

»Egal welche, eine Religion gebietet nicht das Falsche, sondern das Richtige. Wenn sie das Richtige gebietet, stellst du dich dagegen, nur weil es die Religion gebietet? Ein Cesetz, das von zwei Säufern gemacht wurde, ist für euch verbindlich, aber einer Wahrheit, einer Gegebenheit, die der Glauben gebietet, stellt ihr euch entgegen. ${ }^{31}$

Die zentrale Institution für die Umsetzung der »Wahrheit« ist die Diyanet, die in den Bereich der Sozialhilfe, der Kinder- und Altenbetreuung, der Krankenversorgung und der Familienberatung vorgerückt ist (Göker 2013). Seit 2011 sollen sogenannte Familienprediger aus den Mauern der Moschee hinaus auf die Straße und in die Häuser gehen, um dort Sozial- und Konfliktberatung für alle Lebenslagen zu 
leisten. ${ }^{32}$ Im selben Zuge wurden auf Bezirksebene »Aufklärungs- und Beratungsbüros für Familien« eröffnet, die an das Amt des Muftis angebunden sind.

Die offizielle Systematisierung von »Hausdiensten« stellt eine neue Qualität dar, das Wirken in privaten Räumen an sich ist jedoch nicht neu. Ein Geistlicher sitzt nicht seine Lebenszeit in der Moschee ab und wartet, bis die Gläubigen zu ihm kommen. Er wirkt im alltäglichen Leben ebenso wie in politischen Auseinandersetzungen. Das Tefsir mit den Gelehrten der Ismailağa Gemeinschaft war eine Form dieses Wirkens, einer weiteren begegnete ich in Izmir, wo ein bei der Diyanet angestellter Prediger Studenten privat unterrichtete. Die Studenten, die mich für einige Zeit in ihrer Wohngemeinschaft als Gast aufgenommen hatten, waren Mitte Zwanzig und studierten verschiedene Fächer der Naturwissenschaften, Ökonomie und Erziehungswissenschaften. Zwei von ihnen wollten eine feste Diskussionsgruppe bilden, hatten sich dafür mit weiteren Studenten zusammengetan und befanden sich auf der Suche nach einer systematischen Unterrichtung in der Koranexegese. Sie hatten sich, nachdem sie zum Studieren nach Izmir gekommen waren, an der Universität kennengelernt, sich weitgehend selbständig mit islamischer Theologie auseinandergesetzt und Sympathien $\mathrm{zu}$ militanten Strömungen entwickelt. Sie hörten Musik, die sich um den Dschihad drehte, diskutierten über die Anwendbarkeit islamischen Rechts, bewunderten den bewaffneten Kampf der Mudschaheddin und der Hamas, lasen querbeet Koranexegesen verschiedener türkischer Theologen. Eine ihrer Auseinandersetzungen stiftete der Kontakt zu einem Grundschullehrer in Izmir, den ich ebenfalls kennenlernte. Er vertrat die Ansicht, der Koran müsse wortgetreu ausgelegt werden und nahm damit in Diskussionen eine Position ein, die zumeist aneckte und isoliert war, weil die meisten anderen die Position vertraten, das Buch müsse im Lichte kontemporärer Bedingungen interpretiert werden. Die AKP und die Diyanet kritisierte er dafür, dass sie sich nicht an die Regeln des Koran hielten, sie seien nicht aufrichtig. Die Studenten teilten letztere Ansicht mit ihm, die AKP hielten sie für handzahm. Sie kokettierten mit der »dava«, eine Formel, die für die islamistische Missionierungstätigkeit steht, die sie sehr kämpferisch auslegten. ${ }^{33}$ "Entweder bist du einer von uns oder du bist gegen uns«, war ein Spruch, den sie mal ernst, mal spaßhaft selbst beim Fußballspielen auf den Lippen führten. Nur einer der Studenten hatte eine theologische Ausbildung in seiner Heimat im Norden der Türkei an einer informellen Schule, die sie mit der alten osmanischen Bezeichnung als Medrese bezeichneten, erhalten. Einige brachten Vorwissen über islamische Theologie aus ihren Elternhäusern

32 Siehe https://www.yenisafak.com/gundem/aile-imamligi-uygulamasi-basliyor-298073 vom 15.01.2011 und http://m.bianet.org/biamag/toplum/128498-catkapi-imam-gelebilir vom 10.03.2011, (beide abgerufen am 10.10.2018).

33 Dava (türkische Schreibweise, ins Englische eher als dawa oder dawa übertragen) heißt in etwa »Aufruf zum wahren Islam«oder »Verkündung des wahren Islam« (vgl. Mahmood 2005: $57 \mathrm{ff}$.$) .$ 
mit und einer hatte ganz neu sein Interesse für den Islam entdeckt. Gemeinsam wollten sie ihr Wissen synchronisieren und waren dabei auf einen Koranlehrer gestoßen, der ihnen wöchentlichen Unterricht anbot. Sie hatten es vorher mit dem erwähnten Grundschullehrer versucht, waren jedoch unzufrieden, da dessen Lehre ihnen nicht systematisch und zielführend genug war.

Als Gast war ich eingeladen, an der konstituierenden Sitzung des Studienkreises teilzunehmen, die in einer anderen studentischen Wohngemeinschaft stattfinden sollte. Auf halbem Weg dorthin trafen wir den Koranlehrer, der schätzungsweise um die 40 war und uns in seinem Auto den Rest der Strecke mitnahm. Zu fünft trafen wir in einer Hochhaussiedlung ein. Im Aufzug zur Wohnung fragte mich der Koranlehrer, ob es stimmt, was man über Deutschland so hört. Ich fragte zurück, was man so hört. Der moralische Verfall sei dort fortgeschritten. Ich sagte, dass ich mich darin nicht so gut auskenne. Er sagte, er habe gehört, dass dort viel »zina« - sexuelle Beziehungen außerhalb der Ehe - betrieben werde. Ich antwortete, das kann stimmen und fragte zurück, ob das in türkischen Städten anders ist? Er nickte, es sei nicht anders.

Gemeinsam betraten wir die Wohnung und gingen in ein Wohnzimmer, das in drei Ecken mit Sofas bestückt war. Überall lagen oder standen Bücher verschiedener Theologen, Koranexegesen, Enzyklopädien des Islam, Bücher über den Kemalismus, Wörterbücher verschiedener Sprachen. Wir setzten uns alle auf den Boden um einen kleinen Tisch, nur der Koranlehrer blieb auf dem Sofa sitzen und meinte: »Lehrer sitzen erhöht«. Alle lachten. Sogleich ergriff er das Wort und erzählte von sich, dass er in den 1990ern in der Stiftung Nationaler Jugend (MGV), einer mit der Wohlfahrtspartei RP assoziierten islamistischen Jugendorganisation, organisiert war. Einige Anekdoten, in denen es darum ging, dass er damals viele Leute mit seiner Radikalität vor den Kopf gestoßen habe, folgten. Wie zur Betonung seiner damaligen Wildheit benutzte er eine derbe Sprache. Mittlerweile habe er aber gelernt, dass es darauf ankomme, Streitereien innerhalb der muslimischen Gemeinde zu vermeiden. Er gab den Studenten die Empfehlung, die Studienzeit gut zu nutzen, sie zeichne sich dadurch aus, dass sie nicht nur unter Muslimen seien. Nach dem Studium, im Berufs- und Familienleben trete dies ein, das sei ein Nachteil, denn einem Muslim müsse man das Muslimsein nicht mehr erklären. Jetzt jedoch hätten sie Gelegenheit, anderen das Muslimsein näher zu bringen.

Als eine Pause entstand, ergriff einer der Studenten die Gelegenheit, einen anderen zu necken, indem er in die Runde erzählte, die Frauen an der Uni würden auf ihn fliegen. Immer noch witzelnd wandte er sich an den Lehrer, was man denn da tun könne. Der Lehrer reagierte reserviert: »Möge Gott ihn vor solch einer Versuchung schützen.« Anschließend kam der Lehrer zum Anlass des Treffens und gab direkt kund, dass alle Bücher außer dem Koran überflüssig seien. Zumindest für den Anfang müsse dies so sein. Zuallererst müsse der Koran studiert werden, dann könne man sich mit Auslegungen von anderen auseinandersetzen: »Nur drei 
Bücher haben im Regal zu stehen: der Koran, das Leben des Propheten und die Hadithen $^{34}$.«Er ließ sich die verschiedenen Bücher in der Wohnung zeigen und lehnte sie nacheinander alle als ungeeignet $\mathrm{ab}$. Während er weiter sprach, blätterte er wie zufällig im Koran und fand immer die Stelle, von der er gerade sprach. Unvermittelt nannte er dann seine Bedingungen:

Ich erwarte Kontinuität, die anfängliche Gruppe wird nicht erweitert, wir treffen uns einmal in der Woche für zwei bis drei Stunden. Es gibt keine Diskussion über unterschiedliche Auffassungen. Jeder kann seine Argumente darlegen, aber es wird keine Diskussion geben, keinen Versuch, die anderen zu überzeugen. Entweder überzeugt das bessere Argument oder mehrere Meinungen werden nebeneinander existieren.

Bevor er die erste Sitzung beendete, gab der Lehrer den Studenten eine Aufgabe für das nächste Treffen. Sie sollten die Namen der ersten Koranverse auswendig lernen.

Die Sitzung war geprägt von dem Bemühen des Koranlehrers, sich als Kumpel, der nützliche Ratschläge erteilt, und zugleich als Autorität, die über Erfahrung und Wissen verfügt, $\mathrm{zu}$ behaupten. Indem er alle Koranexegesen und sonstigen Bücher, die die Studenten ihm vorlegten, zurückwies, räumte er andere Autoritäten beiseite und konstituierte sich als Brücke zur einzigen Autorität: dem Koran. Durch die Erhebung des Koran zur absoluten Referenzquelle etablierte er eine Hierarchie, mit der ein spezielles Buchwissen aufgewertet und alles andere Wissen abgewertet wurde. Zugleich schuf er sozio-kulturelle Nähe zu den Studenten durch die Erzählung von Anekdoten aus seiner Jugend. Dieselben Studenten, die die AKP und die Diyanet als nicht aufrichtig und handzahm ansahen, nahmen ihn nicht als handzahmen Beamten wahr, der ihnen ein Berufs- und Familienleben an den Horizont malte - dem Gegenteil ihrer Begeisterung für militante Kämpfe. »Für die Sache kämpfen« (dava) wurde in eine bestimmte Richtung gelenkt: Den Koran studieren, auswendig lernen, keine Diskussion, die Reihen nach innen schließen, nach außen agitieren, bevor das Berufs- und Familienleben beginnt.

Offenkundig hält die Diyanet Personal für verschiedene Lebenslagen bereit, auch für radikalisierte Studenten, die nach Orientierung suchen. ${ }^{35}$ Sie tritt als zentrale Institution auf, die die notwendigen Mittel für diese Praxis zur Verfügung stellt, in der maßgeblich ein Buch zur Referenzquelle des gesellschaftlichen Zusammenlebens erhoben wird. Die Ausstattung mit einem Gehalt und der Infrastruktur

34 Als Hadithe werden überlieferte Aussprüche und Handlungen bezeichnet, die entweder von Mohammed selbst stammen sollen oder von ihm gebilligt worden seien. Sie gelten in der sunnitischen Auslegung des Islam als verbindlich.

35 In ihrer Forschung über Imam Hatip Schulen stellt Ozgur fest, dass es eine große Zahl privater Tutoren gibt, die in der Regel entweder als Lehrer an den Imam Hatip Schulen ober bei der Diyanet angestellt sind (Ozgur 2012: 112f.). Meine Begegnung war also kein Einzelfall. 
gestattet es dem Koranlehrer, sich als konservative Autorität, die religiöse Anleitungen erteilt, (re-)produzieren zu können. Tatsächlich könnte im vorliegenden Fall die Mäßigung von jugendlichem Radikalismus nach vorne gestellt und die Schlussfolgerung gezogen werden, bürgerliche Lebensziele - Beruf, Familie, Auto - wirkten mäßigend auf (religiösen) Radikalismus, der in einen spezifischen Wertekonservatismus - Beklagen eines moralischen Verfalls, kein Sex vor der Ehe, Distanz zum anderen Geschlecht - verwandelt wird. Aus dieser Perspektive könnte das Begebnis sogar Assoziationen zur Jugendarbeit christlicher Kirchen in Deutschland wecken, so wie die AKP ja auch lange Zeit als konservativ-demokratische Partei nach christlichem Vorbild dargestellt wurde. ${ }^{36}$ Einer solchen Einschätzung sind drei Bedenken entgegenzubringen. Erstens entsteht hier ein ausgesprochen autoritäres Verhältnis, das, zweitens, bei einer anderen Gelegenheit genauso gut in eine andere Richtung wirken, beispielsweise auf den bewaffneten Kampf und den Dschihad einschwören kann, wie es auf höchster Ebene im Zusammenhang mit Kriegseinsätzen der türkischen Armee geschieht. ${ }^{37}$ Drittens handelt es sich nicht um Jugendarbeit, sondern um eine zwar autoritäre aber doch auf studentisches Lernen gerichtete Beziehung, die die Suche nach Orientierung und Zusammenhalt als Lernprozess gestaltet, durch den spezifische Praktiken mit spezifischem Wissen verbunden werden.

\subsection{Theologische Bildungsstätten}

Die zweite zentrale Wirkungsstätte der Theologen sind ihre originären Ausbildungsinstitutionen, die Imam Hatip Schulen und die theologischen Fakultäten. Die Imam Hatip Schulen wurden 1924 anstelle der geschlossenen osmanischen Medrese zur Ausbildung von Vorbetern (Imam) und Predigern (Hatip) eröffnet, wobei beide Funktionen in einer Person vereint sind, für die die geläufige Bezeichnung Imam lautet. Die primäre Aufgabe eines Imam in der Türkei besteht darin, religiöse Rituale anzuleiten und Ansprachen an die Gemeinde zu halten, die regelmäßig an Freitagen sowie zu besonderen Anlässen wie religiösen Feiertagen stattfinden.

36 »Political Islam has transformed in Turkey and accepted to function in a secular environment. The Turkish model can inspire Islamist movements in other countries to become Muslim democratic movements like the Christian Democrats in Europe«, so beispielsweise der Politikwissenschaftler Cengiz Aktar in The Guardian (Egypt: Doubts cast on Turkish claims for model democracy, https://www.theguardian.com/world/2011/feb/13/egypt-doubtturkish-model-democracy vom 13.02.2011, Abruf am 13.10.2018).

37 Ein jüngeres Beispiel stellt der Einmarsch der türkischen Armee nach Syrien dar, zu dem die Diyanet aus allen Moscheen das »Eroberungsgebet« aus dem Koran predigen ließ. Siehe www.cumhuriyet.com.tr/haber/turkiye/910385/Diyanet_ten_Afrin_aciklamasi_Camilerde_Fetih_Suresi_okunacak.html vom 22.01.2018 (Abruf am 10.10.2018). 
Doch schon die Wortbedeutung verweist auf einen weiteren Zusammenhang: Die wörtliche Bedeutung des arabischen Wortes Imam ist Vorsteher, Vorbild, Richtschnur oder Führer. Augenfällig ist die Analogie zum griechischen Wort Hegemon, das die gleichen Bedeutungen trägt (Haug 2004: 4). In der islamischen Theologie ist Imam entsprechend auch eine Bezeichnung für das politische und religiöse Oberhaupt einer Gemeinschaft. Imam kann dementsprechend sinngemäß als Hegemon der islamischen Gemeinschaft übersetzt werden.

Die ersten Schulen vermittelten eine rein theologisch-sunnitische Ausbildung. Sie wurden 1929 wieder geschlossen, nachdem die Nachfrage für die Ausbildung sank, weil Stellen und Fördermittel knapp gehalten wurden. Durch die Einschränkung seiner materiellen Reproduktionsgrundlagen wurde der Beruf des religiösen Intellektuellen in der frühen Republik unattraktiv. Vor dem beschriebenen Hintergrund einer wahrgenommenen kommunistischen Bedrohung nach dem Zweiten Weltkrieg und den Auseinandersetzungen innerhalb der CHP, wie dieser Bedrohung zu begegnen sei, wurden 1949 noch von der CHP Imam Hatip Kurse eröffnet, die insgesamt 50 Imame ausbildeten, die in Dörfer entsendet wurden. Vorausgegangen war die Schließung der Dorfinstitute, die eine aufgeklärt-kemalistische Weltauffassung in die bis dahin vernachlässigten Dörfer tragen sollten. Ebenfalls 1949 wurde eine theologische Fakultät in Ankara eröffnet, für die öffentliche Stipendien vergeben und Wohnplätze eingerichtet wurden. Mit der Regierungsübernahme durch die DP wurden die Imam Hatip Kurse 1951 wieder in eine Schulform überführt. Die Schulform legte den Schwerpunkt auf die theologische Ausbildung in der sunnitischen Tradition des Islam und der arabischen Sprache. Arabisch gilt, wie bereits erwähnt, als unabdingbar für die islamische Praxis. Einzelne Fächer an den Schulen sind bis heute die Koranexegese, die islamische Rechtsprechung und Theologie, das Leben des Propheten und die Hadithe, die eine Sammlung handlungsanleitender Aussprüche und Praktiken darstellen, die auf Mohammed zurückgeführt werden. Geübt wird die rhetorische Praxis, die Ansprache des Predigers, durch die Imam Hatip-Schüler praktische Führungsfertigkeiten erwerben (vgl. Ozgur 2012: 68ff.).

Den ersten Schülern wurden an 7 theologischen Schulen von der sechsten bis zur zwölften Klasse auch allgemeine Bildungsinhalte vermittelt. 1968 war die Anzahl der Schulen bereits auf 68 gestiegen. Das rapide Wachstum führte dazu, dass Ende der 1950er Fachhochschulen (Yüksek İslam Enstitüleri - Hohe Islam Institute) eröffnet wurden, um Lehrer für die Imam Hatip Schulen (IHS) auszubilden. Mit dem Militärputsch von 1960 erfuhren die Schulen einen neuen Schub. Entgegen der vom Militär gepflegten Behauptung, die kemalistischen Werte gegen die reaktionäre Gefahr verteidigen zu wollen, wurden unter der kurzen Militärregierung sieben weitere IHS eröffnet. Auch im Militär setzte sich ein Flügel durch, der bei der Bekämpfung des Kommunismus auf die Förderung der Religion setzte. Als das Militär 1971 erneut mit der Begründung intervenierte, die laizistische 
Ordnung schützen $\mathrm{zu}$ wollen, ging es tatsächlich gegen die Schulen vor, indem es die Mittelstufen schließen und die Ausbildung auf drei Jahre begrenzen ließ. ${ }^{38}$ Von inzwischen 48.475 Schülern an 72 IHS im Jahr 1971 sank die Zahl auf etwa ein Drittel. Eine schnelle und qualitativ entscheidende Wendung erfuhr dieser Einschnitt mit den Regierungsbeteiligungen der islamistischen Partei MSP zwischen 1973 und 1980. Die MSP legte einen Schwerpunkt auf die Förderung der Schulen, die in Imam Hatip Lyzeen umbenannt wurden. ${ }^{39}$ Der Umbenennung entsprach, dass der Schulabschluss ab 1973 zum Hochschulstudium berechtigte, allerdings mit der Einschränkung auf sozial- und geisteswissenschaftliche Fächer. Entsprechend der Vorbereitung auf ein Hochschulstudium nahm das Gewicht nicht-religiöser Fächer in den Lehrplänen der Schulen zu. ${ }^{40} 1974$ wurden die Mittelstufen wieder eröffnet, die 1976 zum ersten Mal auch Mädchen aufnahmen (Çakır u.a. 2004: 57ff.).

Den Durchbruch zur vollen Gleichstellung mit anderen Schulformen erzielten die Schulen 1983 noch unter der Militärjunta, die 1980 geputscht hatte. Der Schulabschluss berechtigte nun zum uneingeschränkten Hochschulzugang. Die Junta hob erneut die Wahrung der Laizität aufs Schild, während sie den Islam zur kohäsiven Kraft und die Türkisch-Islamische Synthese zur Erziehungsdoktrin erhob. In diesem Zusammenhang wurden auch die theologischen Fachhochschulen in die Universitäten als theologische Fakultäten integriert (Ozgur 2012: 48f.). Einen vorläufigen Höhepunkt mit mehr als 500.000 eingeschriebenen SchülerInnen, mit einem Frauenanteil von etwa 40 Prozent, erreichte die Entwicklung der Schulen 1996, zeitgleich mit der Bildung der Koalitionsregierung unter Führung der Wohlfahrtspartei RP. Bis dahin hatten kumulativ, über mehr als vier Jahrzehnte, etwa 1,5 Millionen Schüler und Schülerinnen eine IHS absolviert. Der Anteil von IHS-SchülerInnen an der Gesamtzahl aller SchülerInnen war von 2,6\% im Jahr 1965 auf 8 \% im Jahr 1985 und $10 \%$ im Jahr 1991 gestiegen.

38 Bis zur Bildungsreform im Jahr 1998 bestand eine Unterteilung der Schulzeit in die obligatorische Crundstufe (1.-5. Klasse) sowie die Mittelstufe (6.-8. Klasse) und Oberstufe (9.-12. Klasse). Danach wurden Grund- und Mittelstufe auf 8 Jahre obligatorische Schulzeit zusammengefasst, wodurch die Mittelstufen wegfielen. 2012 wurde das System erneut verändert. Um die LeserInnen nicht zu verwirren, behalte ich die Bezeichnung Imam Hatip Schulen und das Kürzel IHS bei.

40 Der Zeitanteil der religiösen Fächer sank von etwa 55 \% auf $40 \%$. Die Schüler und Schülerinnen haben längere Schulzeiten als an anderen Schulen, da sie die religiösen Fächer gewissermaßen als Zusatzunterricht erhalten. 
Tabelle 3: Entwicklung von Imam Hatip Schulen 1950-1998, zusammengestellt nach Çakır u.a. (2004)

\begin{tabular}{|l|l|l|l|l|l|l|l|}
\hline & 1951 & 1962 & 1970 & 1981 & 1990 & 1996 & $1998^{\mathrm{a}}$ \\
\hline $\begin{array}{l}\text { Schu- } \\
\text { len }\end{array}$ & 7 & 26 & 72 & 710 & 761 & 1202 & 1224 \\
\hline $\begin{array}{l}\text { Schü- } \\
\text { lerln- } \\
\text { nen }\end{array}$ & 876 & 7.040 & 48.475 & 216.864 & 309.553 & 511.502 & 192.786 \\
\hline
\end{tabular}

${ }^{a}$ Schließung der Mittelstufen und Einführung des Koeffizienten; die Jahresangaben beziehen sich auf den Beginn eines Schuljahres, 1951 ist entsprechend das Schuljahr 1951/52. Ich habe die Anzahl der Schulen nach Mittel- und Oberstufe getrennt gezählt. Meine Angaben weichen deshalb von anderen Quellen ab, in der die Mittel- und Oberstufe zusammen - als eine Schule - gezählt wurden, wodurch die Zahl sich in etwa halbiert. Das Problem bei der statistischen Darstellung ist, dass es nicht über die gesamte Zeit Mittelstufen gegeben hat.

Einen Einschnitt in der Entwicklung der IHS stellte die militärische Intervention von 1997 dar. Auf Betreiben des Militärs wurden die Mittelstufen ein weiteres Mal geschlossen, der Hochschulrat YÖK führte ein Punktesystem ein, wodurch die AbsolventInnen von allen Berufsschulen, als die auch die IHS nach wie vor nominell firmierten, bei der Aufnahmeprüfung zur Universität stark benachteiligt wurden. Die IHS verloren an Attraktivität. Eine unbeabsichtigte Folge dieses zweiten Einschnitts nach 1997 war, dass der Anteil der Schülerinnen den der Schüler stark überstieg. Mädchen wurden trotz erheblich eingeschränkter beruflicher Aussichten weiterhin auf eine IHS geschickt. Offenbar waren konservativ-religiöse Familien eher bereit, auf eine Berufslaufbahn für ihren weiblichen Nachwuchs zu verzichten. Der Beruf des Imam, für den die Schulen ohne Einschränkungen weiter ausbilden durften, blieb weiterhin Männern vorbehalten. Als paradoxaler Effekt der Benachteiligung von Frauen durch ihre Familien nahm der Anteil von Frauen in der Ausbildung religiöser Intellektueller stark zu. Nach 1997 stieg auch der Anteil von Frauen in den theologischen Fakultäten, deren Zugang anders als bei anderen Fakultäten nicht durch einen Koeffizienten eingeschränkt wurde. Wie angesprochen, schlägt sich diese Tendenz einer Öffnung des theologischen Berufs für Frauen bereits bei der Diyanet nieder. Zwar sind Frauen noch weit davon entfernt, mit Männern gleichgestellt zu sein, doch ist die Diyanet seit den 2010er Jahren nicht mehr eine exklusive Organisation von Männern. Obgleich sich die Entwicklung noch in ihren Anfängen befindet, lässt sich konstatieren, dass die professionellen Geistlichen - die Ulema - sich einer Beteiligung von Frauen öffnen.

Mit der Regierungsübernahme Ende 2002 versprach die AKP, die IHS wieder gleichzustellen. Nachdem ihr Kandidat Abdullah Gül 2007 zum Staatspräsidenten gewählt wurde und einen neuen Vorsitzenden des Hochschulrats ernannte, konnten erste Maßnahmen zur Einlösung dieses Versprechens ergriffen werden. 2009 
hob der Hochschulrat den Koeffizienten-Faktor für alle Schulen auf. Der Kassationshof revidierte diese Regelung umgehend. Als Zwischenlösung führte die AKP eine neue Regelung ein, die den Faktor nicht aufhob, aber stark abschwächte, wogegen kein juristischer Widerspruch geltend gemacht wurde. Mithilfe des Verfassungsreferendums 2010, durch das die Regierung die Möglichkeit erhielt, die Justizbehörden mit neuem Personal zu besetzen, wurde weiterer juristischer Widerspruch unterbunden und der Faktor konnte ganz aufgehoben werden. Mit der Bildungsreform im Jahr 2012 wurden schließlich die 1997 geschlossenen Mittelstufen wieder eröffnet. Die Zahl der Schulen und SchülerInnen schnellte innerhalb kürzester Zeit in die Höhe. Im ersten Regierungsjahr der AKP 2003 lag der Anteil von IHS-SchülerInnen an allen SchülerInnen bei $2,4 \%$. Im Jahr der Bildungsreform 2012 lag er bei 4,5\%. Im Jahr 2017 war er auf $12 \%$ gestiegen. Um sich die Dimensionen dieser Entwicklung zu vergegenwärtigen, hilft eine Übertragung. Es ist sich vorzustellen, dass etwa 12 Prozent aller Schüler und Schülerinnen in Deutschland $\mathrm{zu}$ Geistlichen ausgebildet würden. Nur ein kleiner Teil würde einen Beruf des Geistlichen schlussendlich ausüben, der größere Teil verteilte sich auf andere Berufe, doch alle hätten die Ausbildung zum/zur Geistlichen durchlaufen.

Tabelle 4: Entwicklung von Imam Hatip Schulen 1999-2017, zusammengestellt aus Daten des Erziehungs- und Bildungsministeriums der Türkei (meb.gov.tr)

\begin{tabular}{|l|l|l|l|l|l|l|l|}
\hline & 1999 & 2003 & 2011 & $2012^{\mathrm{a}}$ & 2013 & 2015 & 2017 \\
\hline $\begin{array}{l}\text { Schu- } \\
\text { len }\end{array}$ & 504 & 450 & 490 & 1.807 & 2.215 & 3.116 & 4.891 \\
\hline $\begin{array}{l}\text { Schü- } \\
\text { lerIn- } \\
\text { nen }\end{array}$ & 134.224 & 71.100 & 235.000 & 475.238 & 714.111 & 1.201 .500 & 1.350 .611 \\
\hline
\end{tabular}

${ }^{a}$ Wiedereröffnung der Mittelstufen

Die theologischen Schulen wurden also sukzessive mit anderen Schulen gleichgestellt. Ferner wurden unter der AKP nicht-theologische Schulen der theologischen Schulform angenähert. 2012 wurde an nicht-theologischen Schulen zusätzlich zum seit 1982 bestehenden obligatorischen sunnitischen Religionsunterricht ein neues Wahlfach zum Koranstudium und zum Leben des Propheten $\mathrm{ab}$ dem fünften Schuljahr eingeführt. ${ }^{41}$ Ende 2014 beschloss der Nationale Bildungsrat Empfehlungen, wonach der obligatorische Religionsunterricht zukünftig

412012 kann insgesamt als ein Jahr bestimmt werden, in dem die Islamisierung offener artikuliert wurde. Ein Jahr darauf formierte sich spontaner Protest, der mit der Besetzung des Gezi-Parks im Sommer 2013 begann und in einem landesweiten Aufstand gegen das islamistische Hegemonieprojekt kulminierte. 
bereits mit der ersten Klasse beginnen soll, zugleich die Vermittlung »religiöser und nationaler Werte« in den Vorschulen systematisiert werden soll.

Noch vor der Bildungsreform im Jahr 2012 hatte der Hochschulrat beschlossen, die Kapazitäten der theologischen Fakultäten zu erhöhen. 1999 existierten 22 Fakultäten, die jährlich etwa 1.000 neue Studenten und Studentinnen aufnahmen. Die Zahl der IHS-AbsolventInnen lag zu dieser Zeit aber bei 100.000 pro Jahr. Auf Druck von Abgeordneten der AKP wurde 2008 das Kontingent auf 2.700 nahezu verdreifacht (Ozgur 2012: 140). Etwa ein Jahr darauf führte ich mein Interview auf dem Campus der Izmirer Fakultät, das mich auf diese Entwicklung aufmerksam machte. 2014 wurde eine Regelung getroffen, mit der der Abschluss eines Studiums an den Fakultäten den Weg zum Beruf des Religionslehrers eröffnete, wodurch die Attraktivität der Fakultäten erhöht wurde. Ein Büroleiter innerhalb der Diyanet warb zu diesem Zeitpunkt für die IHS, die einen privilegierten Zugang zum Lehrerberuf eröffneten, der 40.000 neue Stellen bereithalte. ${ }^{42} 2017$ war die Zahl der theologischen Fakultäten auf 92 angewachsen, die 14.528 Erstsemester aufnahmen und damit auf insgesamt 92.744 eingeschriebene StudentInnen kamen. Die $\mathrm{Zu}$ nahme der Fakultäten geht mit einer zunehmenden Hierarchisierung innerhalb der Gruppe der Theologen einher, bei der die universitäre Bildung wichtiger wird, um den Beruf ausüben und hohe Positionen erreichen zu können.

\subsubsection{Entwicklung des islamistischen Kollektivwillens}

Die Bedeutung der Imam Hatip Schulen für die islamistische Bewegung wird in vielen Arbeiten auf der Grundlage eines rationalisierungstheoretischen Verständnisses begriffen, in der die Religion als weltabgewandt, idealistisch oder kulturalistisch konzipiert wird. Obwohl der tiefgreifend islamisierende Effekt der Schulen auf die nationale Kultur und die Institutionalisierung der Religion herausgearbeitet wird, werden die Schulen als säkularisierender Faktor eingeschätzt (Tuğal 2009: 48, 143; Ozgur 2012: 148). Aus der hegemonietheoretischen Perspektive dieser Studie besteht die zentrale Rolle der theologischen Schulen in der Konstruktion eines islamistischen Kollektivwillens. Das Kollektiv der Imam Hatip-Absolventen wird dazu erzogen, sich moralisch-intellektuell überlegen und berufen zu fühlen, die Nation anzuführen. In der ersten Ausgabe einer Zeitschrift aus dem Umfeld der Schulen heißt es im Jahr 1995:

»Diese Generation ist gekommen, um die Jugend zu retten, die ihre Ceschichte vergessen hat, ihre nationalen und humanen Werte nicht achtet, in Dunkelheit

42 Siehe https://t24.com.tr/haber/ilahiyat-fakultesi-17den-100e-cikti-imam-hatip-ogrencisi60-binden-15-milyona-yukseldi,340767 vom 17.05.2016 (Abruf am 12.10.2018). 
versunken, ihr Clück im Westen gesucht hat, mit ausgestreckter Hand.« (zit.n. Ozgur 2012: 10, Übersetzung E.B.)

Wie schon dargelegt, kann die Entwicklung des Kollektivwillens auf eine lange intellektuelle Tradition zurückblicken. Das Zitat könnte dem Inhalt und Duktus nach einer Schrift von Necip Fazıl Kısakürek entnommen sein, der die Leitlinie für die islamistische Bewegung, eine "fromme und zürnende« Generation zu erziehen, in einem Appell an die Jugend, das als Gegenmanifest zur Ansprache Atatürks an die Jugend aufgefasst werden kann, formulierte. ${ }^{43}$ Ozgur hat festgestellt, dass aus den Reihen der islamistischen Intellektuellen des 20. Jahrhunderts Kisakürek neben Mehmet Akif Ersoy in den Gebäuden der IHS eine herausragende symbolische Präsenz durch Spruchbänder, Schaukästen und andere Hinweise zuteilkommt $(\mathrm{Oz}-$ gur 2012: 89). Der Schriftsteller und Dichter Kisakürek (1905-1983) ist eine zentrale Figur in der Phase des Aufbaus kulturpolitischer Institutionen der Religion nach dem Zweiten Weltkrieg. Bei ihm nimmt ein auf der Basis der Religion definierter Nationalismus einen Inhalt an, der in eine Reihe mit den faschistischen Ideologien des 20. Jahrhunderts gestellt werden kann. ${ }^{44}$ Kisakürek bekämpfte den Laizismus, der der nationalen Kultur schade, da er den Lehren des Islam keinen ausreichenden Platz einräume. ${ }^{45}$ In Auseinandersetzung mit der ethnischen Frage formulierte er, dass Muslime anderer ethnischer Abstammungen so lange toleriert werden sollten, wie sie einerseits dem Islam treu blieben und andererseits keine separatistischen Absichten hegten. Sobald sie aber solche Absichten hegten, müsse das Türkentum

43 Die Ansprache trägt den gleichen Titel wie die von Atatürk, nämlich Gençliğe Hitabe (Ansprache an die Jugend). Sie appelliert an eine »kämpferische«, »stolze«, »echte«, »türkisch-muslimische« Jugend, die die durch Laizismus hervorgerufenen »Krankheiten« - die Verweichlichung und Unterlegenheit gegenüber dem Westen - überwinden, die weltbeherrschende Stellung der Osmanen wiederherstellen, nicht das Volk, sondern Gott ehren soll.

44 Zum Werdegang des Intellektuellen Kısakürek siehe Ayşe Hür: Necip Fazıl Kısakürek'in >öteki< portresi [Das sandere www.radikal.com.tr/yazarlar/ayse-hur/necip-fazil-kisakurekin-oteki-portresi-1115579/ (Abruf am 13.09.2018). Für einen Vergleich ideologischer Positionen von Kısakürek mit dem deutschen und italienischen Faschismus siehe Çoban (2015).

Kısaküreks schriftstellerische und verlegerische Aktivitäten wurden zum Teil aus der Staatskasse bezahlt, so wie er auch lange Zeit ein Cehalt als Angestellter einer staatlichen Bank bezog (Ayşe Hür 2013, siehe Fn. 44). Dieser Sachverhalt ist beispielhaft für viele islamistische Intellektuelle. Es gab bestimmte Gruppen, die ein Interesse hatten, dass die Ideen dieser Intellektuellen in Akademien und Medien produziert wurden, auch indem sie Posten im öffentlichen Dienst bereitstellten. Die Nähe zur DP und den konservativen Nachfolgeparteien legt offen, dass sie aus den Reihen der besitzenden Klassen finanziert wurden. Gleichzeitig waren viele islamistische Intellektuelle, so auch Kısakürek, von Zeit zu Zeit Repressionen ausgesetzt, insbesondere wenn sie in starken Widerspruch mit den aktuell dominanten Klassenfraktionen und ihren Entwicklungszielen gerieten. 
nach vorne gestellt und durchgesetzt werden (vgl. Bora 1998: 130). Aleviten bezeichnete er als primitive Abweichler vom wahren Islam, die bekämpft und assimiliert werden müssten. ${ }^{46}$

Der Ruf nach einem starken Führer und der Herstellung einer absolutistischen Ordnung, in der eine Theokratie über das gesellschaftliche Leben wacht, eine klare Ablehnung der parlamentarischen Demokratie und des politischen Liberalismus durchziehen Kısaküreks Werk. ${ }^{47}$ Kennzeichnend ist ein Opferdiskurs, in dem Themen des Sufismus - das Leiden und sich ganz Gott verschreiben - mit dem Verlust des Osmanischen Reichs und den Zerstörungen der »Moderne« - kodiert als Dekadenz des Stadtlebens und Verfall der Familie durch westliche Einflüsse - zu einer großen Erzählung leidvoller Unterdrückung verbunden werden. In einem seiner bekannteren Gedichte beschwört Kisakürek einen schlummernden Geist aus den Tiefen der Geschichte, der dem osmanischen Sturmreiter (»akınc1«) gleich auferstehen, die historische Ungerechtigkeit, die den Muslimen durch den Westen und den Laizismus widerfahren sei, beenden, verlorenes Land wiedererobern, Leid und Fremdheit im eigenen Land überwinden und die verlorene Heimat zurückholen soll (vgl. Açıkel 1996: 166ff.). ${ }^{48}$ Ein zentrierendes Thema seiner Schriften sind Verschwörungen, die von Juden, Freimaurern, Materialisten und anderen fiktiven Gruppen ausgehen, die als Verantwortliche für das Leiden ausgemacht werden. Wie in einem Brennglas verdichtet Kisakürek eine partikulare (Gefühls-)Lage, die den Verlust der gesellschaftlich führenden Stellung des sunnitischen Intellektuellen mit dem Niedergang des Osmanischen Reichs literarisch zur leidvollen, schmerzhaften Erfahrung des gesamten Volkes erhebt.

Die Anrufung der Vergangenheit sollte das ideologische Fundament für einen politischen Akteur legen und die Themen vorgeben, über die dieser sich konstituiert. Kısakürek avancierte in den 1950ern zu einem Stichwortgeber für Adnan Menderes, Großgrundbesitzer und Vorsitzender der DP, dem er sich unter der Prämisse andiente, dass »die Türkei ein muslimischer Staat ist und bleibt « (zit.n. Yücekök 1977: 93). Heute gehören Zitate aus Kisaküreks Ansprache an die Jugend zum rhetorischen Standardrepertoire islamistischer Politiker, mit dem sie für ihr Erziehungsprogramm werben. Der prominenteste Verehrer von Kisakürek ist Staats-

46 Siehe Kazım Ateş: Necip Fazıl'ın Dersim'i [Necip Fazıls Dersim], in: Birikim, 11.12.2011, www.birikimdergisi.com/guncel-yazilar/575/necip-fazil-in-dersim-i\#.XDjBRNPQgnQ (Abruf am 12.10.2018).

47 Kısakürek, Necip Fazıl: İdeoloçya Örgüsü [Ideologia Flechtwerk]. Das Werk ist eine Schriftensammlung ohne Jahresangabe. »Ideoloçya « ist eine Wortschöpfung von Kısakürek, für die es eigentlich keine Übersetzung gibt. 
präsident Recep Tayyip Erdoğan, der selbst an einer IHS zum Imam ausgebildet wurde. ${ }^{49}$

In ihrer Forschung über Imam Hatip Schulen nennt Ozgur deren Leistung als Vermittlung eines Habitus. Unter Bezug auf Bourdieu, der darunter »ein System dauerhafter und übertragbarer Dispositionen, die vergangene Erfahrungen integrierend in jedem Moment als eine Matrix von Wahrnehmungen, Geschmäckern und Praktiken funktioniert (Bourdieu 1977: 82f., Hervorhebung im Original) begreift, fasst sie den Habitus als Kultivierung religiöser Sensibilitäten der SchülerInnen (Ozgur 2012: 64). Sie führt aus, wie der Schulbesuch eine kollektive Identität, das Bewusstsein, ein Imam-Hatipli zu sein, hervorbringt. Ein Imam-Hatipli ist jemand, der die Schule besucht hat und beruht auf der Vorstellung, einer Generation anzugehören, die vom Geist des Islam und des Koran beseelt ist. Vereine, Zeitschriften sowie ein soziales Umfeld bestehend aus Familien, Peer-Groups und Lehrern sorgten meist dafür, dass das kollektive Bewusstsein über die Schulzeit hinaus perpetuiert werde. Das Kollektiv sanktioniere Abweichungen, übe sozialen Druck auf Mitglieder aus, insbesondere wenn sie sich entfernten und den »Laizisten« annäherten, die als feindliches Lager markiert seien.

Tatsächlich organisieren die Schulen nicht nur religiöse Weltauffassungen, sondern zugleich eine Perspektive auf gesellschaftliche und individuelle Entwicklung als kulturelle Entfaltung einer überlegenen islamischen Identität (vgl. Tuğal 2009: 117). Der indoktrinierende Charakter ist zwar auch bei rechts-kemalistischen Bildungskonzepten gegeben, die Bindung an eine türkisch-kemalistische Identität mit Atatürk als Kultfigur herzustellen suchen. Die Besonderheit von Imam Hatip Schulen besteht aber darin, wie keine andere Schulform in der Türkei ein spezifisches und konzentriertes Kollektivbewusstsein in Anbindung an eine politische Bewegung entwickelt zu haben.

In den Interviews mit Mitgliedern der AKP-Parteijugend, die eine IHS besucht hatten, treten als grundlegende Orientierungen der Koran, das Leben des Propheten sowie das Osmanische Reich hervor. ${ }^{50}$ Seine eigene Position reflektierend erzählte ein Parteimitglied:

Als ich nach Izmir kam, war einer meiner ersten Freunde einer aus Çorum, er war auch Kurde, aber assimiliert. Ich nannte ihn einen Zwangsbekehrten [devşirme] ${ }^{51}$.

49 Siehe https://www.sabah.com.tr/gundem/2015/12/25/necip-fazil-odulleri-sahiplerine-verildi vom 25.12.2015 und https://www.sabah.com.tr/gundem/2018/05/11/cumhurbaskanierdogan-necip-fazilin-o-siirini-okudu vom 11.05.2018, (beide abgerufen am 12.09.2018). Die Bezeichnung Parteijugend könnte zur Annahme führen, dass es sich um Jugendliche handelte. Dies ist nicht der Fall. Wie auch bei anderen Parteien setzte die »]ugend « sich aus jungen Erwachsenen etwa im Alter zwischen 20 und 30 zusammen. Manche studierten, andere übten Berufe wie die des Anwalts oder des Firmenmanagers aus.

51 Als »devşirme« wird die im Osmanischen Reich praktizierte Aushebung beziehungsweise Zwangsrekrutierung und -bekehrung bezeichnet, bei der christliche, vorwiegend männliche 
$\mathrm{Na}$ ja, zur damaligen Zeit war ich selbst auch ein Zwangsbekehrter. Das liegt an der klassischen Erziehung, die wir in der Schule erhalten haben. Wir tragen eine Begeisterung für die Osmanen in uns. Wenn die anderen die Revolutionen von Atatürk verteidigen, dann haben wir aus Anatolien die Osmanen, das ist vielleicht der einzige Unterschied zwischen uns. Es heißt ja auch `Erhabener Staat der Osmanen<. Diesem heiligen Gebilde erbieten wir Respekt, seine unteilbare Einheit verteidigen wir. Solange die Fahne über uns weht, diese heilige Fahne, sterben wir für sie, Hauptsache die Fahne weht für immer. [...] Über Fatih Sultan Mehmet [Sultan in der expansivsten Phase des Reichs] denken wir wie über einen Heiligen. [...] Wir sind so erzogen worden, in solch einer Struktur, dass wir für den Staat im Ceiste Murad IV. [Sultan, der im Alter von elf ]ahren den Thron bestieg und der mit autoritären Tugenden assoziiert wird] alle unsere Glieder opfern. Die anderen empfinden das für Atatürk, uns ist das für das Osmanische Reich eingeprägt worden.

Die kritische Distanzierung von der eigenen Sozialisation, die andeutungsweise erkennbar wird und im Laufe des Interviews deutlicher zu Tage tritt, blieb in meinen Interviews eine Ausnahme. Der Interviewpartner führte sie auf eigenständige Studien an der Universität und die Konfrontation in Izmir mit Nicht-Anerkennung seiner für ihn unumgänglichen kurdischen Identität zurück, die ihn zur Reflektion drängte. Auf die Distanzierung von der »osmanischen« Erziehung aufgrund der kurdischen Identität werde ich an späterer Stelle noch eingehen. Der Interviewpartner reflektiert, dass die Begeisterung für das Osmanische den »vielleicht einzigen «Unterschied zu den »Anderen« ausmache. Er thematisiert die nationalistische Begeisterung als Ergebnis einer erzieherischen Anstrengung, der er an einer Imam Hatip Schule unterworfen war und von der er sich $\mathrm{zu}$ emanzipieren suchte. Zugleich verallgemeinert er diese Erfahrung als »anatolische« Erfahrung, worin sich die Überzeugung spiegelt, über die relativ kleine Gruppe der Imam Hatip Absolventen hinaus Teil einer größeren Gemeinschaft zu sein. Bei anderen Interviewpartnern, die eine Imam Hatip Schule besucht hatten, trat der geteilte Bildungshintergrund über die Sprache, durch Allegorien und Geschichten hervor. Formeln wie »Selam-ün aleyküm« (»Friede sei mit dir«, klingt neutral, hat aber eine religiöse Konnotation), »hamdolsun« und »Allah'a şükür« (beides »Gott sei Dank«), »eyvallah« (»im Namen Gottes, so soll's sein«), »Allah vergisi« (»Gottes Gabe«) wurden oft gebraucht.

Auf die Frage, nach welchen Kriterien er sein Team auswählt, holte der Vorsitzende der Forschungs- und Entwicklungsabteilung der AKP-Jugend in Izmir, der zugleich als Manager eines Familienunternehmens arbeitete, weit aus:

Jugendliche aus ihren Familien verschleppt und islamisiert wurden, um sie im Militär und der Verwaltung einzusetzen. 
Haben wir Zeit? Ja? Dann lass mich dir eine schöne Geschichte erzählen. Es begibt sich in der Kanuni-Periode. Da ist Mimar Sinan, der von allen Architekten der Welt bewundert wird. ${ }^{52}$ Eines Tages ruft Kanuni Sinan zu sich und spricht: Baue mir eine Moschee, sie soll in aller Munde sein, sie soll viele Botschaften enthalten, diese von Generation zu Ceneration überliefern. Sie soll unverwüstlich sein, jedem Erdbeben widerstehen. Mit diesen Worten schickt er Sinan fort. Es vergehen vier Jahre und das Volk verlangt nach der Moschee. Sinan ist im Volk sehr beliebt, es verfolgt seine Werke aufmerksam. Nach vier Jahren ist gerademal das Fundament der Moschee gelegt und das Volk wird ungeduldig. Eines Tages tritt es versammelt vor Kanuni, den Padischah. Mein Cebieter, spricht es, Ihr habt befohlen, aber es sind jetzt schon vier Jahre, die wir auf unsere Moschee warten, Mimar Sinan nimmt uns wohl auf den Arm, er hat uns wohl vergessen. Der Padischah wird ärgerlich: Ruft mir sofort den Sinan. Sinan erscheint vor dem Padischah: Komm mal her du großer Architekt, ich hatte dir doch befohlen, eine Moschee zu bauen. Ja, sagt Sinan. Und, was hast du getan? Du hast die Grube ausgehoben und das Fundament gelegt, seitdem ist nichts weiter geschehen. Woran liegt das? Mein Gebieter, spricht Sinan, wenn etwas Generationen überdauern soll, muss das Fundament stabil sein. Ich warte seit vier Jahren, dass das Fundament sich setzt. Cebt mir noch zwei Monate. Was soll der Padischah tun, es ist der große Mimar Sinan. Gut, spricht er und schickt Sinan fort. Nach zwei Monaten wird der Bau fortgesetzt und nach nur einem Jahr steht die Süleymaniye Moschee. Könige aus aller Welt, die wichtigen Staatsmänner und Architekten kommen in Scharen, besichtigen die Moschee. Sie ist noch nicht ganz fertiggestellt, kleinere Arbeiten an der Gartenmauer sind noch im Gange. Ein Architekt wendet sich an Sinan: Wie wählst du dein Team aus? [an mich gewendet] ]etzt sind wir bei Deiner Frage. Komm, ich zeig's dir, spricht Sinan. Sie gehen in den Innenhof der Moschee zur Cartenmauer, wo gearbeitet wird. Frag, wen du willst, spricht Sinan, hier sind die Lehrlinge, die Gesellen, die Meister. Mein Kernteam wird sich dir zu erkennen geben. Sie gehen zu einem Meister und der Architekt fragt ihn, was machst du, Meister? Siehst du doch, ich haue Steine. Gut, sie gehen zum nächsten: Was machst du? Ich haue Steine für diese Mauer. Sie gehen zu einem dritten: Und du? Ich haue Steine für eine Moschee, für die Süleymaniye Moschee, die Generationen überdauern wird.

Der erste Meister haut nur Steine, erfüllt seine Aufgabe, der zweite ist sich der Bedeutung seiner Arbeit schon bewusster, er baut eine Mauer, der dritte weiß

52 Kanuni bedeutet »Der Gesetzgebende« und meint den Sultan Süleyman, der in der Hochphase des Reichs regierte. Den Beinamen Kanuni erhielt er aufgrund von Gesetzen und Kodifizierungen, die unter seiner Regentschaft erlassen wurden. Mimar Sinan war ein Architekt, unter dessen Leitung einige der heute noch bestehenden osmanischen Großbauten errichtet wurden. Mimar heißt Architekt. 
genau, was er tut und wem er dient, er haut Steine nicht nur für eine Mauer und eine Moschee, sondern für ein unvergängliches Werk. So suche ich mein Team aus.

Das Heranziehen der Geschichte verweist zunächst darauf, wie präsent das Osmanische Reich für Mitglieder des islamistischen Kollektivs ist. Der Interviewpartner zog sie heran, ohne dass es in den vorausgegangenen Abschnitten des Interviews oder im anbahnenden Gespräch einen Bezug auf die osmanische Geschichte gegeben hatte. Ferner transportiert sie bestimmte Vorstellungen sozialer Ordnung, die den islamistischen Kollektivwillen charakterisieren. Im Zentrum der Geschichte steht die Moschee, die die Gemeinschaft zusammenhält und ihr Kontinuität verleiht. Sie ist für die Ewigkeit gemacht, übermittelt Botschaften über Generationen und zeigt an, wem zu dienen ist. Die Konstituenten der Gemeinschaft, der Regent, das Volk und der Baumeister, werden über die Moschee zusammengeführt. Die Beziehungen zwischen ihnen sind geregelt, jeder hat seinen Platz und festgelegte Bedürfnisse: Das Volk verlangt nach der Moschee, um zu beten, der Padischah, um seine Größe der Welt zu demonstrieren, der Baumeister will sein Können unter Beweis stellen. Das Volk bildet eine Einheit, es tritt versammelt vor den Padischah und spricht mit einer Stimme. Es ist klar konturiert als fromme, sunnitische Gemeinschaft, die genau weiß, an wen sie sich, wie und mit welchen Erwartungen wenden muss. Mit Anerkennung der Ordnung wird den Subalternen Zugehörigkeit zu einer erfolgreichen und aufstrebenden Gemeinschaft versprochen, die die Bewunderung der gesamten Welt genießt und Neid hervorruft. Wenn sie ihre Position akzeptieren, dürfen sie erwarten, dass die Herrschenden sich für die Erfüllung ihrer Bedürfnisse einsetzen. Nicht Aushandlungen und Ausgleich in demokratischen Verfahren, sondern die gegenseitige Anerkennung von ungleichen Bedürfnissen einer als fromm gekennzeichneten Gemeinschaft konstituiert aus dieser Perspektive die politischen Beziehungen zwischen den Herrschenden und den Beherrschten.

Ein wiederkehrendes Thema, mit dem sich nicht nur Imam Hatip-Absolventen, sondern auch meine islamistischen Mitbewohner in der Wohngemeinschaft, die auf keiner Imam Hatip Schule gewesen waren, auseinandersetzten, war die Frage der Bestrafung der Frau bei »Ehebruch«. Ein Interviewpartner, Imam Hatip-Absolvent und Mitglied der AKP-Jugend, reflektierte, dass es im laizistisch geprägten Izmir kaum möglich sei, die in der islamischen Rechtsauslegung vorgesehene Strafe bestehend aus achtzig Peitschenhieben auf den Rücken der Frau öffentlich anzuwenden. In diesem Fall müsse eine Alternative gefunden werden, denn

das Familienglück steht für uns an oberster Stelle. Eine Beziehung außerhalb der Heirat bedroht die Cesellschaft. Es geht darum, dass moralischer Verfall sich wie ein Virus verbreiten kann, deshalb muss es eine Strafe geben.

Die Auffassung, dass die Familie heilig und Heiraten eine religiöse Pflicht sei, ist nach Ozgur (2012: 59) eingebettet in die Überzeugung unter Absolventen und Leh- 
rern, dass die Schulen Festungen gegen moralischen Verfall, Kriminalität und Prostitution seien. Çakır u.a (2004: 125ff.) legen dar, dass diese Auffassung mit einer Abgrenzung verbunden ist, die Außenstehende als schmutzig (im übertragenen Sinne) markiert.

Es zeigt sich, dass die Imam Hatip Schulen auf besondere Weise materielle Manifestationen der Türkisch-Islamischen Synthese sind, in denen eine bestimmte nationale Identität über eine gemeinsame Sprache, Symbole und Wahrnehmungsweisen (re-)produziert wird. Sie bilden das intellektuelle Fundament des islamischen Konservatismus der AKP. Nicht nur der Lehrplan, auch die mit religiösen Symbolen durchwirkte Ästhetik und Architektur der Gebäude sind darauf ausgelegt, starke Bindungen an islamische Ideen und Praktiken herzustellen (Ozgur 2012: 84). Aus Ozgurs Untersuchung geht hervor, dass die SchülerInnen die Überzeugung vorbringen, ihr Leben müsse in Übereinstimmung mit dem Koran und dem Leben des Propheten stehen, dem sie in ihren religiösen Praktiken, sozialen Interaktionen, in der Körperpflege wie auch in ihrem Aussehen nacheifern. Sie würdigen islamische Führungsfiguren wie Kaliphen, die sie zur Orientierung und Erklärung von eigenen Verhaltensweisen heranziehen.

Tatsächlich bleibt das Heranziehen religiöser Weltbilder nicht auf Verhaltensweisen begrenzt, es erstreckt sich auf politische Themen, wie schon in der Geschichte über den Moscheebau sichtbar wurde, und ist mit der Interpretation sozialer Themen verwoben. In einem weiteren Interview mit einem Mitglied der Parteijugend lenkte ich das Gespräch auf das Thema soziale Ungleichheit. Wir saßen in einem Straßencafé und schauten beim Reden der Müllabfuhr zu, wie sie die Straße reinigte. Ich brachte ein, dass die Ungleichheit zwischen einem Straßenkehrer und einem Fabrikbesitzer durch Vererbung über Generationen hinweg auf Dauer gestellt wird. Mein Interviewpartner, der Wirtschaftswissenschaften studierte, antwortete:

E: Das System ist von vornherein verkehrt, aber es ist kaum möglich, einen Fabrikbesitzer zu enteignen und seinen Besitz zu verteilen.

I: Das heißt, Ungleichheit reproduziert sich unvermeidlich?

E: Zur Zeit des Propheten waren der Heilige Ebubekir und der Heilige Osman sehr reich. Sie waren reich, bevor sie zu Muslimen wurden. Der Heilige Osman verteilt dann die Hälfte seines Reichtums im Namen Cottes, am Ende seines Lebens bleibt ihm selbst nichts mehr. So auch Ebubekir, was bleibt ihm, was seinen Kindern? Wir haben Cott und wir haben seinen Gesandten, sagt er. Sie verteilen ihren Reichtum, ohne dass der Prophet sie dazu auffordert. Um die Gesellschaft zu verbessern, geben sie alles aus. Auf der anderen Seite gibt es Gefährten des Propheten, die immer reicher wurden, die egoistisch waren, ein Menschentyp, der unaufhörlich seinen Besitz mehrte. Salebe, zum Beispiel, will sehr reich werden, fängt mit ein-zwei Schafen an und wird sehr reich. Der Cesandte Gottes spricht zu ihm: Es gibt eine Armenabgabe, Gott hat dir so viel Besitz gegeben, andere haben das nicht. 


\section{I: Das ist ja interessant. Er sagt, Cott hat dir das gegeben?}

E: Mit Cott hat gegeben ist gemeint, dass er es besitzt. Also jeder Atemzug ist uns ja von Cott gegeben, das sagen wir so, das ist eine Sprachgewohnheit. Es ist natürlich nicht so, dass Cott von oben gibt. Du hast dich angestrengt, Tag und Nacht gearbeitet, Salebe, du hast diesen Besitz erworben, hast deine religiösen Pflichten aber nicht erfüllt. Das so zu sagen, das ist unserer Sprache fremd. Weil es uns immer in einer anderen Sprache erzählt wurde, erzähle ich es aus Gewohnheit so.

Mein Interviewpartner diskutierte soziale Fragen entlang eines richtigen Verhaltens, für das er Vorbilder aus dem Gründungsmythos des Islam heranzog. Die »andere« (ihm eigene) Sprache hatte er auf einer Imam Hatip Schule und in seinem sozialen Umfeld, das er als sehr fromm beschrieb, erworben. Indem er sagte, »es ist kaum möglich, einen Fabrikbesitzer zu enteignen und seinen Besitz zu verteilen«, positionierte er sich zu den von mir angesprochenen realen Verhältnissen, die er für »verkehrt« hielt, aber doch akzeptierte. Sein Rückgriff auf die »Zeit des Propheten« führte dazu, dass er das Thema der Reproduktion sozialer Ungleichheit von den ungleichen Ausgangslagen, die Akteure für ihre Reproduktion vorfinden, löste und stattdessen Ausgleichshandlungen thematisierte, die dem erfolgreichen Wirtschaften folgen sollten: das Verteilen von Reichtum und die Armenabgabe. Schon in der Geschichte der Heiligen wird eine Adaption der überlieferten Geschichte an kapitalistische Verhältnisse vollzogen: Reichtum muss produktiv eingesetzt werden, um sich zu vermehren, andernfalls wird er einfach nur aufgebraucht, wenn auch für einen "guten« Zweck. Es bleibt weder etwas zum Verteilen, noch etwas für die eigene Reproduktion. Das Verschenken erweist sich als idealistische Sackgasse und eine zweite Geschichte zeichnet das Bild vom fleißigen Unternehmer, der durch seigene harte Arbeit< aus seinem Besitz ein Vermögen macht, mutmaßlich viel und lange Almosen verteilen können wird, auch wenn er auf seine »Pflicht « hingewiesen werden muss. In der Interpretation meines Interviewpartners ist eine betriebswirtschaftliche Perspektive mit einer religiösen Botschaft für den politischen Umgang mit den »Reichen« verwoben. Selbst wenn es sich um sehr unangenehme, »egoistische« Zeitgenossen handelt, sollen sie nicht kritisiert werden, sondern "freundlich« auf ihre Almosenpflicht hingewiesen werden. Erkennbar wird die Artikulation von Islam und egoistischen Wirtschaftens, mit der soziale Ungleichheit und zugleich die Akzeptanz der Folgen konkurrenzkapitalistischen Wirtschaftens reproduziert wird.

Die Adaption der religiösen Überlieferung an die kontemporäre Ausprägung der Klassenverhältnisse in der Türkei blieb in dem Interview implizit. Das paternalistische Armutsregime, das das islamistische Hegemonieprojekt kennzeichnet, wurde nicht ausdrücklich angesprochen und doch prägte dessen Rechtfertigung die Erzählung. Ferner wurde eine Kongruenz des religiösen Diskurses zum »me- 
thodologischen Individualismus« erkennbar (vgl. Yalman 2002: 39ff.), der eine Gemeinsamkeit der staatszentristischen Auffassungen von der Bourgeoisie bildet. In inhaltlicher Übereinstimmung zu polit-ökonomischen Analysen, die individuelle Einstellungen als Grundlage erfolgreichen Wirtschaftens bestimmen, wird dem tüchtig-selbstlosen der egoistisch-pflichtvergessene Geschäftsmann entgegengestellt. Ausgangspunkt für gesellschaftliche Dynamiken können aus dieser Perspektive nur die Handlungsmotive des einen der beiden »Menschentypen« sein, die legitimiert werden: Das egoistische Handeln bringt Güter hervor, die am Ende auch den Reichtum der Gesellschaft erhöhen und Ausgleichshandlungen ermöglichen können.

Sunnitische Intellektuelle haben eine kollektive Weltauffassung ausgebildet, durch die sie sich überlegen und zur Führung berufen fühlen. Artikuliert ist die Weltauffassung mit einem kapitalistischen Entwicklungsprogramm, das den subalternen Klassen die Position von Bittstellern und Hilfsempfängern zuweist. Durch den Bezug auf eine osmanisch-islamische Tradition wird eine historisch-bewährte Ordnung konstruiert, deren Stabilität vorbildhaft herangezogen wird. Zugehörigkeit $\mathrm{zu}$ einer erfolgreichen und aufstrebenden Gemeinschaft, die Bewunderung der gesamten Welt und Erfüllung ihrer Bedürfnisse sind die an die Subalternen gerichteten Versprechen im Rahmen dieser autoritären Ordnung, in der die politischen Beziehungen nicht durch Aushandlungen und Ausgleich in demokratischen Verfahren, sondern durch gegenseitige Anerkennung ungleicher Bedürfnisse zwischen Herrschenden und Beherrschten gekennzeichnet sind.

\subsubsection{Sunniten als Diskriminierte}

Die für den Kollektivwillen charakteristische Überzeugung, sich in der Position eines Unterdrückten zu befinden, ist historisch bedingt durch die Niederlage, die sunnitische Intellektuelle im Übergang zur kapitalistischen Produktionsweise erfuhren. Die Gründung der Republik war für sie kein Neubeginn, sondern die Besiegelung ihrer Ablösung aus der Position der Intellektuellen, die eine privilegierte Stellung in der Ausübung von Hegemonie innehatten. Zur Zeit meines Feldaufenthalts war die Auffassung, Opfer und unterdrückt worden zu sein, von der Erfahrung einer verhinderten Karriere in Folge des 1997er Eingriffs des Militärs überzeichnet. Einige Mitglieder der AKP-Jugend gingen 1997-1998 auf eine IHS und mussten mit der Schließung der Mittelstufen auf eine andere Schule wechseln. Andere machten trotz Einschränkungen ihren Abschluss an einer IHS und nahmen ein Studium auf. Sie berichteten, dass ihnen bei Bewerbungsgesprächen für die Aufnahme in den öffentlichen Dienst von einer Auswahlkommission Fragen gestellt wurden, die ihren islamischen Hintergrund offen legen sollten, sie selbst ohne Nachweis einer Verstrickung in islamistische Aktivitäten ausgesiebt wurden. 
Als ich nach Abschluss meines Jura-Studiums im Jahr 2002 mich zum Staatsexamen anmeldete, hatte ich den Beruf Richter vor Augen. Die schriftliche Prüfung bestand ich mit einer guten Note. Ich war unter den ersten Hundert meines Jahrgangs. Das mündliche Vorsprechen im Anschluss bereitete mir allerdings schon im Vorfeld Kopfzerbrechen. Nun sollte ich vor eine Kommission treten, die mich auf meine politische Tauglichkeit für den Staatsdienst abklopfte. Auf die Frage, was den Laizismus ausmacht, war ich vorbereitet, denn der 1997er Prozess war damals noch in vollem Gange. Die Antwort eines Juristen ist hier deutlich vorgegeben, die Trennung von Staat und Religion ist ein Staatsprinzip. Als ich dann gefragt wurde, welche Schule ich vor meinem Studium besucht hatte, wurde klar, dass das Gespräch einen anderen Lauf nehmen würde. Ich sagte, ich habe eine staatliche Schule für Religionsgelehrte besucht. Die Stimmung schlug sofort um. Ich merkte, wie mir in hohen Wellen Misstrauen entgegenschlug. Die Antwort auf die nächste Frage, was denn der Beruf meines Vaters sei, hatte ich mir bereits zurechtgelegt: Er ist Staatsbediensteter in einer Moschee, sagte ich. Er ist also ein Imam, bekam ich zurück. Ab da war besiegelt, dass ich keine Chance mehr hatte.

Der Interviewpartner, der in der Partei eine Leitungsfunktion einnahm und zugleich den Beruf des Anwalts ausübte, erfuhr, dass sein Fachwissen nicht ausreichte, um nach der Intervention in das Feld des öffentlichen Diensts eintreten zu können. Es bedurfte zusätzlich eines glaubwürdigen Nachweises einer laizistischen Weltauffassung, die mit einem Aufwachsen in einem Milieu explizit islamischer Institutionen - der Familie eines Imam und der IHS - schwer zu erbringen war. Seine angestrengt zurechtgelegten Antworten auf erwartete Prüfungsfragen, mit denen er sich als Diener des Staates zu kennzeichnen versuchte, spiegeln dies. Nach 1997 ging es vielen Imam Hatip-Absolventen ähnlich. Aus der biographischen Perspektive waren sie Opfer eines repressiven Eingriffs in einen Lebensplan, in den sie hineinsozialisiert wurden. Qualifikationen, die zum Eintritt in den öffentlichen Dienst befähigten, wurden durch die Verkopplung mit der Erziehung als sunnitischer Muslim nach der Intervention abgewertet.

Der biographisch erfahrenen Diskriminierung war indes der Sonderstatus vorausgesetzt, durch den sunnitische Muslime exklusive Förderung in eigenen Bildungsinstitutionen und Wirkungsstätten erhielten und in denen sie die Auffassung ausbildeten, einem moralisch überlegenen Kollektiv anzugehören, dem Führungsaufgaben zukommen. Meine Interviewpartner thematisierten den Sachverhalt, qua kultureller Merkmale über andere Gruppen in der Gesellschaft gestellt worden zu sein, nicht als Privileg, sondern als selbstverständliches Grundrecht. Auch wenn keine biographisch nachvollziehbare Diskriminierung wie die Abwertung eines Fachwissens vorhanden war, begriffen sich Islamisten als benachteiligt und herabgesetzt. Im Nachgang an die Sitzung, die den Auftakt zum Koranunterricht durch den bei der Diyanet angestellten Imam bildete (Kap. 6.1.3), fragte ich 
meine Mitbewohner, wie es zusammenpasst, dass sie sich einerseits radikal nennen und die Diyanet dafür kritisieren, nicht radikal genug zu sein, andererseits von einem Beamten der Diyanet Unterricht nehmen. Einer entgegnete, er sei kein Radikaler, sondern ein Muslim und führte aus, dass Muslime immer vom türkischen Staat unterdrückt worden seien. Ich antwortete, der türkische Staat unterdrücke doch nicht die Muslime, sondern bestimmte Auslegungen des Islam wie das Alevitentum. Er fragte empört zurück, an welcher Stelle er als Muslim vom türkischen Staat profitiere. Ich antwortete, dass er gerade von einem alimentierten Beamten des türkischen Staates Unterricht im Muslimsein in Anspruch genommen hatte. Diesen Einwand überging er und erklärte, dass Aleviten keine Muslime seien. 99 Prozent der Bevölkerung seien bestenfalls werdende Muslime, ich sei noch nicht mal das. Das Gespräch war durch meinen Einwand eskaliert und ich brach es ab. Die Überzeugung, einer diskriminierten Gruppe anzugehören, perspektivierte die Wahrnehmung meines Gesprächspartners so stark, dass er offenkundig Widersprüchliches nicht wahrnahm und auf einen konkreten Einwand mit Exkommunikation aus der Gruppe der (werdenden) Muslime reagierte.

\subsection{Netzwerk der religiösen Infrastruktur}

Die Diyanet und die theologischen Bildungsinstitutionen bilden die zentralen Reproduktionsstätten der sunnitischen Intellektuellen, die in ein umfassendes materielles Netzwerk eingebettet sind, das fördernde und unterstützende Funktionen ausübt. Die Diyanet, deren Personal überwiegend aus Imam Hatip-Absolventen besteht, ist selbst organisierendes Zentrum eines Netzwerks, das weit über die Verwaltung der Moscheen und Gebetsräume hinaus verschiedene Aktivitäten umfasst. Sie erstrecken sich von der Publikation religiöser Schriften und Zeitschriften, dem Betreiben von Radio- und Fernsehsendern, über die Supervision von Schulbüchern und Ausübung von Zensur, die gesetzlich verankerte Repräsentation des Imam im Ältestenrat eines Dorfes bis zur Organisierung von Pilgerfahrten nach Mekka und Vergabe von Stipendien an Schüler, um qualifizierten Nachwuchs zu fördern. Seit der militärischen Intervention von 1971 agiert die Behörde als kulturpolitische Vertretung der Türkei im Ausland mit dem Ziel, die Kontrolle über das religiöse Leben der Staatsbürger im Ausland zu behalten und die türkisch-sunnitische Auslegung des Koran zu verbreiten (Gözaydın 2009: 137ff., 147).

An die Behörde angegliedert ist die Diyanet Stiftung der Türkei (Türkiye Diyanet Vakfi), die Spenden sammelt, um Gesundheitsleistungen für Arme anzubieten, Moscheen zu bauen und auszustatten, Sozialhilfe zu leisten sowie »religiöse Aufklärungsteams « zu bilden und auszusenden. Die Stiftung ist verlegerisch tätig, unterhält ein islamisches Forschungszentrum und gründete 2010 eine Universität 
in Istanbul. ${ }^{53}$ Sie betreibt mehrere Krankenhäuser und Wohnheime, ein Versicherungsunternehmen sowie eine Holding, die ähnlich wie die Holding des Militärs (OYAK) Sonderrechte wie die Befreiung von Steuern genießt. Die Einnahmen der Holding, deren Höhe unbekannt ist, da die Stiftung keiner öffentlichen Rechenschaftspflicht unterzogen wird, fließen ebenfalls in den Haushalt der Diyanet. Damit existiert eine Art Schattenhaushalt der Diyanet, der aus den Einnahmen einer kapitalistischen Holding gespeist wird..$^{54}$

Die theologischen Ausbildungsstätten stehen dagegen im Zentrum eines Netzwerkes, zu dem Stiftungen, Verbände, Vereine, Medien sowie Parteien und Jugendorganisationen gehören. Es gibt kein vergleichbares Netzwerk in der Türkei, das so viele Einzelpersonen über Jahrzehnte und Generationen hinweg zu integrieren, mit einer gemeinsamen Sprache und Weltauffassung auszustatten vermochte. Zwar unterhalten auch andere Parteien Jugendorganisationen und Netzwerke, aber keine steht in so enger Verbindung mit einer bestimmten Schulform. Als die RP 1996 als stärkste Partei ins Parlament einzog, hatten 54 von insgesamt 84 Abgeordneten, die sie stellte, einen IHS-Hintergrund (Ozgur 2012: 155ff.). Für die Imam Hatip-Absolventen ist ihre religiöse Identität ausschlaggebend für ihre politischen Präferenzen. ${ }^{55}$ Bei einer Befragung wurde die CHP durchgehend abgelehnt, während der größte Teil mit der AKP, ein kleinerer mit anderen rechten Parteien sympathisierte (ebd.: 131f.). In einer Studie über das sozio-kulturelle Profil von AKP-WählerInnen gaben 28 Prozent ihrer WählerInnen bei der Parlamentswahl von 2002 an, mindestens ein Familienmitglied sei auf einer IHS (gewesen). ${ }^{56}$ Es kann gefolgert werden, dass ein wesentlicher mit den Schulen verbundener Erfolg darin besteht, kulturelle Identität hergestellt und als verbindliche politische Richtschnur etabliert zu haben.

Etwa 70 Prozent der nach 1970 erbauten IHS wurden von Nichtregierungsorganisationen finanziert, weitere 20 Prozent sind durch öffentlich-private Partnerschaften gebaut worden. ${ }^{57}$ Nach dem Bau wird das Eigentum zumeist dem Staat

53 Siehe Website der Diyanet Stiftung: https://www.tdv.org.

54 Siehe Çiğdem Toker: Peki ya Fetva Makamının Hesapları? [Was ist mit den Bilanzen des Fatwaamts?], in: Cumhuriyet, 20.11.2013, www.cumhuriyet.com.tr/koseyazisi/11233/Peki_ya_Fetva_Makaminin_Hesaplari_.html (Abruf am 23.10.2018).

55 Von dieser Regel sind wenige Ausnahmen bekannt, zu deren prominenteren Alper Taş gehört, der einer sozialistischen Partei vorsitzt (Ozgur 2012: 133).

56 Siehe www.milliyet.com.tr/yuzde----de-harem-selamlik-protokolu/siyaset/haberdetayarsiv/20.06.2005/120806/default.htm vom 20.06.2005 (Abruf am 12.10.2018).

57 Zu den größeren und landesweit tätigen NCOs, die auch Stipendien vergeben und Wohnheime bauen, zählen Ensar Vakfı, ÖNDER, Ilim Yayma Cemiyeti, der Unternehmerverband MÜSIAD sowie die IHH. Die Beteiligung von MÜSiAD gibt einen Hinweis, wer für den Zeitraum nach 1990 die Spender sind, die den Bau der Schulen finanzieren. In der Literatur werden häufig pauschal »die konservativen Schichten« als Spender genannt, ohne die soziale Zusammensetzung der Spender zu hinterfragen (Çakır u.a. 2004: 17). 
überschrieben, der die Kosten für den Betrieb und das Lehrpersonal trägt. Besonders aktiv in der Förderung mit 100 Imam Hatip Schulen und 50 Wohnheimen ist die »Vereinigung zur Verbreitung von Wissenschaft« (İY - İlim Yayma Cemiyeti), die 1951 mit dem Ziel gegründet wurde, »fromme Generationen« zu erziehen, die den »nationalen und spirituellen Werten des Landes« dienen (Ozgur 2012: 157ff.).

Zwei islamistische Jugendorganisationen, die für sehr viele IHS-Schüler attraktiv waren und in direkter Verbindung zu islamistischen Parteien stehen, sind die »Stiftung Nationaler Jugend « (MGV) und der »Verein Nationaler Türkischer Schüler« (MTTB). Der Verein MTTB wurde 1916 bereits vor Gründung der Republik ins Leben gerufen und war zunächst eine Organisation, die sozialistische Ideen favorisierte. Nachdem der Verein 1936 verboten worden war, wurde er 1946 von neuem Personal mit antikommunistischer Ausrichtung wieder eröffnet. Doch erst in den 1960ern wurde er zu einem breitenwirksamen Forum für konservativ-religiöse Gymnasiasten und Studenten, warb offen für einen Islamischen Staat und die Scharia und rief zur Ermordung von Linken auf. Der Verein wurde mit dem Putsch von 1980 geschlossen und erst 2006 wieder eröffnet. $\mathrm{Zu}$ dieser Zeit gaben mehr als hundert Abgeordnete der AKP, darunter die drei führenden Figuren dieser Zeit Tayyip Erdoğan, Abdullah Gül und Bülent Arınç -, an, mit dem MTTB assoziiert gewesen zu sein (At1lgan 2015b: 593f.).

In den 1970ern hieß die mit der damaligen islamistischen Partei MSP assoziierte Jugendorganisation Akıncılar, die Bezeichnung für den osmanischen Sturmreiter, der im erwähnten Gedicht von Kisakürek als historischer Hoffnungsträger auftaucht. Ihre Mitglieder warben für einen Islamischen Staat und die Einführung der Scharia. Zahlreiche Gründer der AKP waren Mitglied der Akıncılar. Nach 1980 wird als Nachfolgeorganisation die Stiftung MGV gegründet, zu der sich der neue Koranlehrer meiner studentischen Mitbewohner bekannt hatte. Die MGV bekam in den 1990ern großen Zulauf und stand in enger Verbindung zur Wohlfahrtspartei RP. Sie bot unter anderem Gesundheitsleistungen an, vermittelte Unterkünfte und Nachhilfe, organisierte Wettbewerbe und Konferenzen mit islamistischen Intellektuellen und trug wesentlich zur Bildung des Nachwuchses bei. Sie wurde 2004 geschlossen (Ozgur 2012: 123ff.). ${ }^{58}$

Schließlich fördern Mitglieder von MÜsİAD die Schulen. Nach Angaben des Verbands sollen etwa ein Drittel der Verbandsmitglieder Imam Hatipli sein (ebd.: 168). Dass die Schulen als Sozialisationsinstanz für die "anatolische Bourgeoisie« fungierten, geht auch aus Interviews mit Unternehmern hervor (Yankaya 2014:

58 Als die Organisation MCV 2004 geschlossen wurde, unterhielt sie 900 Büros und hatte 350.000 Mitglieder, von denen 2/3 auf eine IHS gingen (Ozgur 2012: 125). Die 2002 gegründete Organisation ACD (Verein Anatolischer Jugend) führt die Tradition der Milli Cörüş Bewegung fort. Sie ist mit der SP (Partei der Clückseligkeit) assoziiert, die eine marginale Partei des islamistischen Spektrums ist. 
38ff.). Anatolische Kleinunternehmer schickten ihren Nachwuchs auf Imam Hatip Schulen und legten damit einen intellektuellen Grundstein für die spätere Gründung von MÜSİAD. Einschlägige Publikationen des Verbands, in deren Mittelpunkt der mit einer islamischen Ethik auszustattende Mensch, der sogenannte homo islamicus steht, der in der "muslimischen Familie« und in den Imam Hatip Schulen erzogen werden soll, legen die Anbindung des Erziehungsprogramms der Schulen an den Unternehmerverband offen (MÜSİAD 1994; Yarar 1997).

\subsubsection{Verlagerung des islamistischen Netzwerks in den Staat}

Nach der 1997er Intervention des Militärs und dem Verbot der Wohlfahrtspartei erlahmte die Organisierung und Bildung der islamistischen Jugend in relativ selbständigen Massenorganisationen. Sie wurde zum einen auf eine größere Anzahl privater Organisationen verteilt. Schulen privater islamistischer Netzwerke übernahmen Bildungsaufgaben. Zum anderen wurde mit Gründung der AKP die Organisierung und Bildung der Jugend in die Parteistrukturen und noch stärker als zuvor in die staatlichen Institutionen verlagert. Die Reichweite der Diyanet, der Imam Hatip Schulen und der theologischen Fakultäten erhöhte sich enorm. Da islamistische Intellektuelle inzwischen in allen staatlichen Institutionen organisiert waren, waren Massenorganisationen außerhalb des Staates und der Partei für die Bewegung nicht mehr ausschlaggebend. Die Intellektuellen kämpften nicht mehr gegen die Institutionen, sondern innerhalb der Institutionen um die Übernahme der gesellschaftlichen Führungsaufgabe.

Eine Station dieses Kampfs bildete die Verfassungsreform von 2010 (vgl. S. 37f.). Nachdem sie die Polizeibehörden bereits übernommen hatten und sich auch im Militär in der Offensive befanden, ermöglichte die Reform die Verdrängung kemalistischer Kräfte aus den höheren Justizbehörden. Mit der stetigen Expansion der theologischen Fakultäten wurden die islamistischen Intellektuellen zusätzlich in die Lage versetzt, an den Hochschulen um Führung zu kämpfen. Eine konkrete Form dieses Kampfes war die Kriminalisierung und Entlassung von hunderten WissenschaftlerInnen aus den türkischen Universitäten unter dem Vorwand der »Terrorbekämpfung«. Anfang 2016 unterzeichneten mehr als 2.000 WissenschaftlerInnen, die sich »Akademiker für den Frieden« nannten, eine Stellungnahme ${ }^{59}$, in der von der AKP-Regierung die Beendigung der damaligen militärischen Belagerung kurdischer Städte sowie die Wiederaufnahme von Friedensverhandlungen mit der kurdischen Bewegung gefordert wurden. In Reaktion auf diese Stellungnahme verfasste eine zweite Gruppe Hochschulangehöriger,

59 Siehe Stellungnahme der »Akademiker für den Frieden«: We will not be a party to this crime! 10.01.2016, https://www.barisicinakademisyenler.net/node/63 (Abruf am 12.10.2018). 
die sich »Akademiker für die Türkei« nannte, eine Gegenstellungnahme ${ }^{60}$, in der Kritik an der Regierung zurückgewiesen und ihr Unterstützung im »Kampf gegen den Terrorismus« zugesagt wurde. Ebenfalls mehr als 2.000 Unterzeichner, die sich als »Türkei-Verliebte« bezeichneten, die die »echten Gefühle und Gedanken der türkischen Nation« ausdrücken wollten, stellten sich gegen die Kritik ihrer KollegInnen, die sie als »Gesindel« bezeichneten, »das noch gefährlicher und niederträchtiger als die Banditen in den Bergen ist «.

Die Gegenstellungnahme verlieh einen unikalen Einblick in die universitäre Organisierung und Zusammensetzung der intellektuellen Führungsschicht des islamistischen Hegemonieprojekts. Der namentlich verantwortlich zeichnende Verfasser war Leiter einer theologischen Fakultät. Die mit Abstand größte Einzelgruppe unter den Unterzeichnern, die zu $99 \%$ an türkischen Universitäten beschäftigt waren, wurde mit $20 \%$ von Theologen gebildet, gefolgt von Ingenieuren (12\%) und Medizinern (9\%). ${ }^{61}$ Der Frauenanteil betrug $10 \%$, unter denjenigen mit Professur oder Dozentur betrug er sogar nur $5 \%$. Bei den "Akademikern für den Frieden« lag der Frauenanteil bei 54 \%, die größte Gruppe wurde von ÖkonomInnen (19\%) gebildet, gefolgt von Politik- und ErziehungswissenschaftlerInnen (14 und $9 \%$ ). Sie waren zu einem Drittel an Universitäten außerhalb der Türkei beschäftigt. Die geographische Verteilung der UnterzeichnerInnen bildete die politischen Kräfteverhältnisse ab. Die reaktionären Akademiker dominierten in den türkisch-islamistisch regierten Städten sowie in den unter der AKP neu gegründeten Universitäten, an denen sie durch die Ernennung von Rektoren und über den von ihr kontrollierten Hochschulrat YÖK Dominanz herstellen konnte. Mittels Disziplinarverfahren, Strafprozessen und anderer Druckmittel wurde nachfolgend ein großer Teil der regierungskritischen WissenschaftlerInnen von ihren regierungstreuen Kollegen aus den Universitäten entfernt beziehungsweise aus türkisch-islamisch kontrollierten Städten vertrieben. Mit dem islamistischen Hegemonieprojekt hat sich an den Universitäten eine Gruppe von Intellektuellen etabliert, die männlich dominiert sind und von Theologen angeführt werden. Auch bei anderen politischen Streitthemen meldeten sich die Theologen geschlossen zu Wort. Als die Diyanet wegen Überschreitung ihres stetig anwachsenden Budgets und der Leiter der Behörde wegen luxuriöser Dienstwagen kritisiert wurden, wiesen 66 Dekane theologischer Fakultäten in einer gemeinsamen Erklärung diese Kritik zurück, indem sie auf die In-

60 Siehe Stellungnahme der »Akademiker für die Türkei«: https://www.sabah.com.tr/gundem/ 2016/01/12/akademisyenlerden-terore-karsi-operasyonlara-destek vom 12.01.2016 (Abruf am 12.10.2018).

61 Für eine statistische Auswertung der Zusammensetzung beider Gruppen siehe Efe Kerem Sözeri: Evrensel değerler ve milli yalnızlık: iki akademi, iki bildiri [Universelle Werte und nationale Einsamkeit: Zwei Akademien, zwei Stellungnahmen], in: Platform24, 28.01.2016, http://platform24.org/guncel/1320/evrensel-degerler-ve-milli-yalnizlik-iki-bildiri--iki-akademi (Abruf am 12.10.2018). 
tegrität der Diyanet als respektable Autorität in religiösen Fragen verwiesen. ${ }^{62}$ Die Theologen demonstrierten ein weiteres Mal, dass sie in der Lage waren, organisiert zu handeln und sich als Teil eines Kollektivs begriffen, dessen Ziele sie unter Zugriff auf ihre religiösen Ressourcen legitimierten.

\subsection{Materielle Attraktivität der religiösen Infrastruktur}

Die IHS hatten lange Zeit »nur« den Status von Berufsschulen inne. Bei ihrer Etablierung mussten einige Rückschläge wie die 1971er und die 1997er Interventionen des Militärs hingenommen werden. Nichtsdestotrotz waren sie über die gesamte Zeit Gegenstand eines besonderen Förderns und Werbens durch islamistische und konservative Politiker und das Militär. Mit dem Putsch von 1980 wurde verstärkt die Strategie verfolgt, die Bürokratie mit islamisch-konservativem und türkistischem Personal zu besetzen (Ahmad 1993: 194; Tuğal 2009: 91; White 2008: 363). Absolventen der IHS rückten dadurch in die Gruppe der bevorzugten Kandidaten auf. ${ }^{63}$ Die Attraktivität für Eltern, ihren Nachwuchs auf eine theologische Schule zu schicken, stieg. Es sprach sich herum, dass diese Schulen Karrieren ermöglichten. $\mathrm{Zu}$ den Förderpraktiken, die die Schulen attraktiv machten, gehörte, dass das Bildungsministerium den IHS pro SchülerIn mehr Mittel als anderen Schulen zur Verfügung stellte. Das Schüler-Lehrer-Verhältnis an den IHS lag in den 1990ern bis Ende der 2000er bei 10:1, an anderen Oberstufen dagegen bei 20:1. 2009 waren 17 Prozent der Heime, die unter der Aufsicht des Bildungsministeriums standen, für IHS reserviert, obwohl diese im Durchschnitt weniger als 5 Prozent der SchülerInnen stellten. In den 1990er Jahren lag der Anteil von IHS-SchülerInnen mit einem Stipendium durchschnittlich doppelt so hoch wie an anderen Berufsschulen (Ozgur 2012: 48ff., 142ff.). Nach Çakır u.a. (2004: 73) sind dies Gründe, die die IHS für Kinder aus ärmeren Familien attraktiv gemacht haben. ${ }^{64}$

Islamistisch regierte Kommunen stellten ebenfalls besondere Fördermittel zur Verbesserung der Ausstattung aber auch Stipendien und Preise für IHS-SchülerInnen zur Verfügung, wie zum Beispiel im Rahmen von Koranrezitationswettbewer-

62 Siehe Çiğdem Toker: Illahiyat Fakültesi Dekanına Çağrı [Aufruf an den Dekan der Theo-lo-gi-schen Fakultät], in: Cumhuriyet, 13.05.2015, www.cumhuriyet.com.tr/koseyazisi/275191/66_ilahiyat_fakultesi_dekanina_cagri.html, (Abruf am 12.10.2018).

63 Als die Wohlfahrtspartei RP Mitte der 1990er Jahre an die Regierung kam, sollen etwa $50 \%$ der Studenten, die eine Anstellung im öffentlichen Dienst erhielten, Absolventen von IHS gewesen sein, obwohl ihr Anteil an allen Schülern bei etwa 5 \% lag (Ozgur 2012: 51).

64 Einzelne Erhebungen indizieren, dass einkommensstärkere Familien ihre Kinder überwiegend auf von religiösen Gemeinschaften betriebene private Schulen schicken, sicherlich aus Prestigegründen, primär aber wegen der besseren Ausstattung gegenüber öffentlichen Schulen (Cengiz 2013: 301, 377). 
ben. Islamistische Politiker werteten die Frömmigkeit von Schülern, etwa religiös inspirierte Hilfsbereitschaft, wertebasierte Nähe zum »Volk « und den Willen, diese "Werte« in allen Feldern zu fördern, als besondere Qualitäten und versprachen Anstellungen. Sie halfen Absolventen bei Bewerbungen und vermittelten ihnen Stellen in der Verwaltung auf kommunaler und nationaler Ebene. $\mathrm{Zu}$ seiner Zeit als Bürgermeister von Istanbul in den 1990ern sagte Recep Tayyip Erdoğan:

»In Anbetracht meiner Erfahrungen in der Verwaltung und im Lichte des Ceistes, den ich von meiner Schule vermittelt bekam, kann ich in Bezug auf Bildung und menschlichen Umgang mit voller Überzeugung sagen, dass ich immer einen Imam Hatipli vorziehen werde, wenn ich nach einer qualifizierten Person Ausschau halte.« (zit.n. Ozgur 2012: 145, Übersetzung E.B.)

In den 1960ern bildete die Aussicht auf eine Anstellung bei der Diyanet noch einen wesentlichen Faktor für Eltern, ihren Nachwuchs auf eine theologische Schule zu schicken. Die Beamtenlaufbahn wurde mit einem relativ sicheren Einkommen verbunden (Çakır u.a. 2004: 17). Seit Mitte der 1970er ergriff die Mehrheit der AbsolventInnen jedoch andere Berufe. ${ }^{65} 2010$ erhielten nur noch 15 Prozent der IHS-Absolventen eine Anstellung bei der Diyanet. Es ist davon auszugehen, dass die Aufhebung der Restriktionen und die Vervielfachung der Schülerzahlen nach 2012 dazu führen werden, dass dieser Anteil sehr viel stärker fallen wird. Gegen Ende der 200oer Jahre, mit der AKP an der Regierung, befanden sich IHS-Absolventen auf allen Verwaltungsebenen in leitenden Positionen, so auch in den Behörden, die die allgemeinen Lehrpläne für alle Schulformen bestimmen (Ozgur 2012: 147). Der Leiter der Stiftungsbehörde Yusuf Beyazıt, mit dem ich die Entwicklungsgeschichte der islamistischen Bewegung eingeleitet habe, war keine Ausnahmeerscheinung mehr.

Der Erwerb einer religiösen Erziehung hatte also an Attraktivität gewonnen, indem sich die beruflichen Möglichkeiten, die sich mit ihr eröffneten, vervielfachten. Auf diese Weise wurde eine kulturelle Inklusion verstärkt, die schon durch die Etablierung und den Ausbau der Diyanet, die ausschließlich »Sunniten« offenstand, gegeben war. Die Kehrseite der Inklusion ist die Exklusion von »NichtSunniten« aus den staatlichen Institutionen. In den gesellschaftlichen Auseinandersetzungen tritt diese Exklusion als Ausgrenzungspraxis in Erscheinung, von

65 Der Anteil der Absolventen, die ein Hochschulstudium aufnahmen, lag in den 1990ern zwischen 15 und $20 \%$ und damit gleichauf mit anderen Gymnasien. Nach 1998 stieg der Anteil trotz Restriktionen auf über $22 \%$. Von diesen Absolventen, die ein Studium aufnahmen, wählten 2/3 Jura oder Verwaltungswissenschaften, beides Fächer, die auch den Weg in die Bürokratie ebnen. 1992 sollen 60 \% der Studenten an der Fakultät für Politikwissenschaften der Ankara Universität IHS-Absolventen gewesen sein (Ozgur 2012: 46, 50). 
der verschiedene Gruppen betroffen sind. In der Diskussion der vorliegenden empirischen Forschungsergebnisse wurde erkennbar, dass diese Gruppen nicht als politische Gegner, sondern als religiös definierte Gefahr kodiert werden, die die Gemeinschaft der »Muslime« von innen wie von außen bedrohen. Angehörige anderer Religionen und Atheisten werden als Bedrohung von außen konstruiert, ihre Exklusion ist damit festgelegt. Die Grenzziehung gegenüber »Laizisten « und Aleviten blieb weniger eindeutig. Aus der Perspektive islamistischer Intellektueller waren sie vom richtigen Weg abgekommen, auf den sie durch Umerziehung wieder zurückgeführt werden sollten. Sie wurden als werdende Muslime bezeichnet, denen eine Chance zuerkannt wurde, in das Kollektiv aufgenommen zu werden, sofern sie bereit waren, sich der Umerziehung zu unterwerfen.

Da die Förderung von IHS-Absolventen eine offen ausgesprochene Priorität darstellt und die sich an der Zentralregierung befindende AKP über die Besetzung öffentlicher Stellen entscheiden kann, besteht die Kehrseite der Förderpraxis aus der Benachteiligung von Absolventen anderer Schulen sowie - pauschaler der Gruppe der »Nicht-Muslime«, der Laizisten und Atheisten. Es ist zu erwarten, dass die Förderpraxis eine gesamtgesellschaftliche Verschiebung zugunsten einer religiösen Erziehung und der Aneignung einer türkisch-islamischen Weltauffassung weiter verstärken wird. Während diese Konstellation schon in anderen Feldern sichtbar wurde, so in Duraks Untersuchung in Konya, wo die Aneignung einer konservativ-islamischen Weltauffassung in einem Bedingungsverhältnis zur Reproduktion als Arbeitskraft stand (vgl. S. 180), wird ein Effekt dieser Verschiebung in quantitativen Studien sichtbar, die eine Zunahme der politischen Selbstzuschreibung als »religiös« belegen. ${ }^{66}$ Quantitative Untersuchungen zu dieser Entwicklung im Feld der beruflichen Opportunitäten liegen noch nicht vor. Der explosionsartige Anstieg der Schülerzahlen an den IHS stellt einen weiteren Fingerzeig dar. Einen konkreten Hinweis auf die Breitenwirkung der Aussicht auf (erhöhte) Chancen durch den Erwerb einer religiösen Erziehung erhielt ich bei einer Unterhaltung mit einem Kind, die ich 2013 in einem südanatolischen Dorf führte. Der elfjährige Schüler der fünften Klasse äußerte den Wunsch, auf eine IHS zu wechseln. Seine Familie zeichnete sich nicht durch besondere Frömmigkeit aus, auch gab es in seinem Dorf keine IHS. So wurde ich neugierig und fragte, warum er wechseln wolle. »Ich möchte Polizist werden«, war seine Antwort. »Warum musst du auf eine Imam Hatip Schule gehen, wenn du Polizist werden willst?«, fragte

66 Der Studie zufolge stieg der Anteil derjenigen, die ihre politische Identität als »religiös« angaben, zwischen 2015 und 2017 von 14,7 auf 27,6\%. Neben »religiös« gab es die Möglichkeiten, »konservativ«, »nationalistisch«, »republikanisch-kemalistisch«, »sozialdemokratisch«, »völkisch« oder »sozialistisch« anzugeben. Außer einer leichten Steigerung bei »nationalistisch« wiesen alle anderen eine sinkende Tendenz auf (TSSEA 2018: 11). 
ich ihn. "Wenn man Polizist werden will, muss man auf eine Imam Hatip Schule gehen«, antwortete er. Der Junge gab für seine Präferenz weder ideologische noch familiäre Gründe an, wie das Erlernenwollen der Religion oder Druck der Familie, die in Umfragen als Beweggründe ausgemacht werden (Çakır u.a. 2004: 19; Ozgur 2012: 107ff.), sondern den pragmatischen Wunsch, Polizist zu werden. ${ }^{67}$ Wie der Junge dazu kam, diese Verbindung herzustellen, habe ich von ihm nicht erfahren. Eine formale Verbindung zwischen den IHS und dem Polizeiberuf gab es nicht. Doch war der Wunsch keine ausgefallene Idee. Er spiegelte die Annahme von Wahrscheinlichkeiten, die Folge der Förderung und der Werbekampagnen waren, die für die Schulen betrieben wurden. In der Kampagne einer IHS in Istanbul, die in einer Broschüre mit dem Versprechen warb, IHS-Absolventen würden einen Vorzug bei der Aufnahme in die Polizei- und Militärschulen erhalten, wurde der Zusammenhang sogar explizit hergestellt. ${ }^{68}$ Der Vorgang verweist auf die Herausbildung eines auch von anderen Autoren beobachteten Bewusstseins, wonach die Zugehörigkeit zur gesellschaftlichen Partei des Islamismus sich in berufliche Chancen ummünzen lassen sollte (Tuğal 2009: 220f.). Hegemonietheoretisch lässt sich feststellen, dass das islamistische Projekt Hegemonie organisiert, indem es der subalternen Anhängerschaft »reale Vorteile« mittels Zugang zu beruflichen Chancen verspricht. In Abgrenzung $\mathrm{zu}$ anderen kulturellen Affiliationen wird die Annahme der türkisch-sunnitischen Identität attraktiv gemacht.

Während meines Feldaufenthalts bin ich einigen Ausnahmen begegnet, die diese kulturellen Grenzziehungen herauszufordern schienen und den Anschein erweckten, dass das Projekt auch für abweichende kulturelle Identitäten Attraktivität entfaltete. So waren in der AKP vereinzelt Aleviten vertreten, deren Dabeisein in Izmir besonders betont wurde, um den pluralen Charakter der Partei hervorzuheben. Aleviten nahmen auch politische Funktionen für die Partei in Parlamenten ein. Die AKP entschied sich in einem überwiegend alevitisch besiedelten Bezirk sogar für einen alevitischen Bürgermeisterkandidaten. Der Vorsitzende eines alevitischen Vereins in Izmir erklärte mir diese Aufstellung durch die AKP folgendermaßen:

Wenn dieser Freund sich in einem Bezirk bewerben würde, in dem die AKP eine Aussicht auf eine Mehrheit hat, dann würde er niemals als Kandidat ins Rennen geschickt werden. Dass ein Alevit in einem nicht-alevitischen Bezirk von der AKP

67 Der Konflikt mit der Gülen Bewegung, die ihre eigenen Schulen unterhielt, daher wohl kaum mit den IHS in Berührung kam, lässt annehmen, dass die IHS weiter im Ansehen gestiegen sind, um die Sicherheitsapparate, die einen besonders sensiblen Bereich bilden, mit loyalem Personal zu besetzen. 
als Kandidat aufgestellt wird, das ist unmöglich, dafür gibt es kein einziges Beispiel. Aber hier, wo die AKP keine Chance hat, stellen sie ihn auf, um möglichst viele Stimmen für das Oberbürgermeisteramt zu sammeln.

Der politische Pragmatismus der AKP ließ Ausnahmen zu, ohne dass sich dadurch der kulturelle Charakter des von ihr getragenen Hegemonieprojekts entscheidend veränderte. ${ }^{69}$ In den Leitungsgremien der Partei erhielten Aleviten kein politisches Gewicht (vgl. Doğan 2016: 151ff.). Vielmehr wirkte die Nicht-Zugehörigkeit zur Gruppe der Sunniten beziehungsweise des türkisch-islamischen Kollektivs als Ausschlussmechanismus, auf den ich an späterer Stelle nochmals eingehen werde.

\subsection{Zwischenresümee: Privilegienstruktur und Gruppeninteresse}

Der Wiederaufbau der in der Phase der Republikgründung konservierten religiösen Institutionen der osmanischen Ulema nach dem Zweiten Weltkrieg auf Betreiben bestimmter Fraktionen der besitzenden Klassen, die im Grundbesitz, im Handel sowie in der kleinen Bourgeoisie lokalisiert wurden, stellt eine Privilegierung einer kulturell bestimmten Gruppe bei der Zuteilung von Ressourcen und Dienstleistungen dar: Der sunnitisch ausgebildeten Geistlichen auf der einen und derjenigen Bevölkerungsgruppe, die deren »Dienste« in Anspruch nimmt, auf der anderen Seite. Im Widerspruch zum in der Verfassung verankerten Prinzip der Laizität und der staatsbürgerlichen Gleichheit ist mit der Diyanet und den Imam Hatip Schulen der Diskriminierung nicht-sunnitischer BürgerInnen eine institutionelle Form verliehen und ein Sonderstatus für die sunnitische Religion geschaffen worden. Der Ulema repräsentiert als professioneller Geistlicher eine Seite des Sonderstatus, die des Ausführenden, der Zugang zu einer aus allgemeinen Steuermitteln finanzierten öffentlichen Anstellung erhält, um bestimmte Dienste zu erbringen. Er ist in gewisser Weise der Archetyp des religiösen Intellektuellen, da seine materielle Reproduktion ausschließlich an die Ausübung einer religiösen Funktion gebunden ist. Die Ulema verfügen über Institutionen, die ihnen die Entwicklung eines Kollektivwillens, organisiertes Handeln und damit die Artikulation eines Gruppeninteresses auch im Widerspruch zu politischen Regierungen ermöglicht. Ihr Gruppeninteresse besteht im Erhalt und im Ausbau ihrer Infrastruktur, deren Verknüpfung mit exklusiven ökonomischen Opportunitäten sie zu einer Pri-

69 Auch die personelle Integration ehemaliger Mitglieder der CHP kam vor. Während meines Feldaufenthalts war ein prominenter Fall ein Bürgermeisterkandidat in einem laizistisch geprägten Stadtbezirk von Izmir, der sich von der AKP aufstellen ließ, nachdem er zwei Wahlperioden für die CHP dieses Amt ausgeübt hatte. 
vilegienstruktur macht. Die Geschichte der islamistischen Bewegung ist auch die Geschichte des Voranbringens dieser Privilegienstruktur.

In der theoretischen Diskussion wurde dargelegt, dass der Zugang zu den Privilegien für die Geistlichen auf der Ebene von Verteilungsverhältnissen zweiten Grades angesiedelt ist (vgl. Kap. 4.3). Er erfolgt durch Einkommen, Sachleistungen und Fördermittel. Ressourcentheoretisch reformuliert heißt dies, dass der Zugang zu den ökonomischen Mitteln durch den Erwerb religiöser Ressourcen - ein bestimmtes Wissen über die Auslegung und Ausführung der Religion - erfolgt. Das religiöse Wissen erhält durch diese privilegierte Stellung den Charakter einer exklusiven kulturellen (Bildungs-)Ressource. Da der Erwerb des Wissens zudem an die Voraussetzung geknüpft ist, einer bestimmten religiösen Gruppe anzugehören, konstituiert die Zugehörigkeit zu dieser Gruppe eine exklusive soziale Ressource. Die erste Erweiterung, die aus der hegemonietheoretischen Rekonstruktionsarbeit erfolgt, besteht folglich in der Feststellung, dass die religiösen Intellektuellen ein relativ eigenständiges Gruppeninteresse gekoppelt an exklusive kulturelle und soziale Ressourcen herausgebildet haben, durch die sie Zugang zu ökonomischen Mitteln erhalten. Diese Erweiterung ist bereits orientierend in die Darstellung der Entwicklungsgeschichte der islamistischen Bewegung eingegangen, mit der die einzelnen Stationen ihrer Formierung in Anbindung an die bürgerlichen Klassen der Republik nach ihrer partiellen Ablösung von den besitzenden Klassen des Osmanischen Reichs nachgezeichnet wurde.

Dass der kulturelle Charakter des Hegemonieprojekts für seine Vermittler eine ökonomische Seite aufweist, ließ die hegemonietheoretische Rekonstruktionsarbeit an eine zweite Grenze stoßen, die durch die Differenzierung der ressourcentheoretischen Erweiterung erfasst werden konnte. Die islamistische Bewegung vermochte es, eingelassen in gesellschaftliche Kämpfe um Hegemonie, religiöse Ressourcen auch zur Voraussetzung für gesellschaftliche Positionen zu machen, die bis dahin durch von der Religion unabhängige kulturelle Bildungsressourcen und soziale Ressourcen zu erreichen waren. In diesem Prozess avancierte die Stellung der sunnitischen Intellektuellen in der Gesellschaft von der ideologischen Ausübung von Hegemonie zur Position der Ausbilder und Vermittler kultureller und sozialer Ressourcen, die Zugänge in alle Hochschulfächer und Berufe eröffnen. Damit erreichte die islamistische Bewegung zum einen eine breite gesellschaftliche Streuung der in den Schulen ausgebildeten türkisch-sunnitischen Weltauffassungen. IHS-Absolventen können als Journalisten, Redakteure, Schriftsteller, Wissenschaftler, Politiker, Verwalter, Behördenleiter etc. wirken und werden sukzessive bevorzugt. Sie können damit praktische intellektuelle Funktionen des islamistischen Hegemonieprojekts in allen gesellschaftlichen Bereichen einnehmen. Zum anderen macht die besondere Förderung und Bevorzugung türkisch-sunnitischer Weltauffassungen bei der Besetzung von Stellen im gesamten öffentlichen Dienst die religiöse Erziehung über die Privilegienstruktur hinaus materiell attraktiv. In- 
dem die Verbesserung beruflicher Aussichten in eine direkte Verbindung mit einer theologischen Ausbildung gebracht wird, durch die ein bestimmter Kollektivwille gebildet wird, der in den gesellschaftlichen Kämpfen für ein bestimmtes kapitalistisches Entwicklungsprogramm Partei ergreift, werden beruflich-materielle Opportunitäten in ein Bedingungsverhältnis zur Bildung dieses Willens gesetzt. Bildungsabschlüsse, Fachwissen und die Verfügung über soziale Netzwerke werden ökonomisch aufgewertet, wenn sie sich mit einer türkisch-islamischen Weltauffassung verbinden. Auf diese Weise wird eine kulturelle Inklusivität hergestellt, die den relativen Tauschwert kultureller und sozialer Ressourcen, die mit der »Religion« beziehungsweise dem islamistischen Hegemonieprojekt verknüpft sind, erhöht. Diese Aufwertung von religiösen Ressourcen in Verschränkung mit dem Hegemonieprojekt kann als ein kulturell vermittelter materieller Inklusionsmechanismus bestimmt werden. Der Mechanismus ist informell gestaltet, sofern es keinen rechtlich festgeschriebenen Anspruch auf exklusive Förderung gibt und doch wird vermittelt über den Erwerb von religiösem Wissen und einer islamisch-konservativen Weltauffassung der Zugang zu realen ökonomischen Vorteilen hergestellt.

\subsection{Private islamistische Institutionen - Islamische Gemeinschaften}

Die bisher thematisierten zentralen Institutionen der sunnitischen Intellektuellen waren die Diyanet, die theologischen Bildungsinstitutionen und die politische Partei. Eine vierte Institution, die für die Entwicklung der islamistischen Bewegung eine besondere Rolle spielt, bilden die islamischen Gemeinschaften. Sie verleihen der islamistischen Bewegung und den assoziierten Intellektuellen eine noch größere gesellschaftliche Reichweite und stellen ebenfalls Institutionen kulturell vermittelter Inklusion beziehungsweise Exklusion dar.

Die Gemeinschaften haben sich sowohl in Assoziation mit der Milli Görüş Bewegung als auch außerhalb von ihr entwickelt. Sie verfolgen ebenfalls das Ziel, einen neuen Menschen zu erziehen, organisieren sich aber nicht in Form von eigenständigen politischen Parteien, weshalb sie auch nicht in der Lage sind, massenhafte Anhängerschaft zu mobilisieren. Sie konstituieren sich als besonderer Typus einer Intellektuellenbewegung. So propagierte die vom Geistlichen Fethullah Gülen angeführte Bewegung die Erziehung einer geistigen Elite, einer »Goldenen Generation«. Deren Aufgabe sollte sein, das mit dem Islam vereinte Türkentum weltweit führend zu machen (Şen 2007; Turam 2007). Auf den Treffen der AKP-Jugend nahm ich wahr, dass sehr viele aktive Mitglieder mit der Gülen Gemeinschaft assoziiert waren. Einige redeten mit Hochachtung vom »Hoca Efendi«, dem »Hohen Gelehrten«, ein informeller Titel, der Fethullah Gülen von seiner Gefolgschaft verliehen worden war. Andere erzählten von Rekrutierungspraktiken, Zusammen- 
künften und brachten verschiedenste Personen und Gegenstände - Wohnungen, Heime, Zeitungen, Läden - in einen Zusammenhang mit den Gemeinschaften.

Nach einem Treffen in der großen Gruppe, in der die Sprache wieder mal auf die Gülen Gemeinschaft gekommen war, fragte ich meinen Begleiter, mit dem ich das Treffen gemeinsam verlassen hatte:

I: Worum geht es eigentlich bei diesen Cemeinschaften?

A: Nur ums Geschäft. Du hast es doch gehört. Er fährt von einem Ende der Stadt zum anderen, um Essen zu gehen, nur weil der Restaurantbesitzer ein Muslim ist. Du musst dir das wie MÜSIAD oder TÜSIAD vorstellen. Sie machen untereinander Ceschäfte. Das ist die Die-Unsrigen-Denke.

Dass mein Begleiter die religiösen Gemeinschaften mit dem »Geschäftemachen« in Verbindung brachte, hatte nachvollziehbare Gründe. Die Gemeinschaften wurden im Verlauf der Studie bereits als Träger der Türkisch-Islamischen Synthese und als kleinkapitalistische Investitionsgemeinschaften benannt. In der Besprechung der Klassenkampfthese wurde dargelegt, dass sie im Zusammenhang mit dem islamischen Unternehmertum als Organisationsformen hervortreten, die Netzwerke zum Zwecke der Kapitalbildung bilden sowie Multiplikatoreneffekte bereithalten. Schon in den 1990er Jahren war der Nexus zwischen islamischen Gemeinschaften und ihren ökonomischen Investitionen derart ausgeprägt, dass sie zu einem gewichtigen politischen Faktor geworden waren. Die Gemeinschaften sollen zusammengenommen über einen Milliardendollarfonds verfügt haben, dessen Mittel sie über Vereine und Stiftungen in parteipolitische und sozio-kulturelle Aktivitäten wie den Bau von Moscheen, Schulen, Universitäten, Repetitorien, Schülerheime und die Armenhilfe lenkten (Doğan 2009a: 297).

Indes ranken sich viele Gerüchte um das innere Funktionieren der Gemeinschaften und ihren tatsächlichen Einfluss. Allein die Assoziierten der Nurcu, die in der Türkei mutmaßlich den zahlenmäßig größten Korpus stellen, werden mitunter auf mehrere Millionen (Ozgur 2012: 118) und die einzelnen Zellen der Bewegung, die Häuser des Lichts (»nur« oder »1şık evleri«) genannt werden, auf 20.000 (Atasoy 2009: 129) geschätzt. Die Angaben müssen jedoch spekulativ bleiben. Es gibt viele Gründe, weshalb Gemeinschaftsmitglieder aber auch Außenstehende die Zahlen hoch oder niedrig hängen könnten, beispielsweise um Stärke oder Schwäche, Gefahr oder Harmlosigkeit zu demonstrieren. Die Nurcu-Bewegung geht auf Said Nursi (ca. 1876-1960) zurück. Nach seinem Tod entwickelten sich mehrere separate Seitenarme. Die affirmative Haltung zu Technologie und Entwicklung bildete die Basis für die Attraktivität seiner Ideen, die insbesondere von kleineren Gewerbetreibenden - Händler, Handwerker und aufsteigende Unternehmer - aufgegriffen wurden. Ein sichtbares und greifbares Tätigkeitsfeld der Nurcu seit den frühen 1980ern, nach der Öffnung des Schulsystems für private Investoren, ist der Aufbau eigener Bildungsinstitutionen. Die Gülen Gemeinschaft ist die prominenteste 
unter den Seitenarmen der Nurcu, die über ein Netzwerk von hunderten Bildungseinrichtungen - Schulen, Repetitorien ${ }^{70}$, Wohnheime für SchülerInnen und StudentInnen - neben Krankenhäusern, Wohlfahrtsorganisationen und Medien verfügte, bis sie teilweise zerschlagen wurde (Balc1 2005; Şen 2007) ${ }^{71} 2011$ unterhielt die Gülen Gemeinschaft 300 Schulen in der Türkei und über 1.000 im Ausland. Eine Besonderheit der Gülen Gemeinschaft bestand darin, dass sie über ein internationales Netzwerk an Unternehmen verfügte, die in einem eigenen Verband (TUSKON) organisiert waren (Öztürk 2015). ${ }^{72}$ Die Vielseitigkeit ihres Netzwerks und die gezielt betriebene Infiltrierung der Bürokratie ließ sie als einen »Staat im Staate« bezeichnen. ${ }^{73}$ In den Gülen-Schulen wurde der religiösen Unterrichtung mit einer Wochenstunde ein sehr geringes Gewicht beigemessen. Insbesondere in den Auslandsschulen lag auf der Unterrichtung der türkischen Sprache ein wesentlich größeres Gewicht als auf der Religion. Dass diese Schulen trotzdem als islamistisch bezeichnet werden können, liegt daran, dass die privaten Stifter bei der Auswahl des Lehrkorpus besonders darauf achteten, dass diese sich den türkisch-islamistischen Lehren des Predigers Gülen verpflichtet sahen und eine interne Ausbildung durchlaufen hatten (Ozgur 2012: 29; Şen 2007).

In einer Sammlung seiner Recherchen legt der Journalist Atay (2017) über weitere Gemeinschaften dar, wie sie als vernetzte Konglomerate mit Fernsehsendern, Zeitungen, Supermarktketten, privaten Krankenhäusern und zum Teil international operierenden Finanzunternehmen auftreten. Aus Hakan Yavuz Arbeiten über

70 Insbesondere die Repetitorien (»dershane«) nahmen eine herausragende Rolle in der Netzwerkbildung ein, da sie Millionen Schülerlnnen erreichten, die in den privaten Repetitorien aufgrund der Mängel des staatlichen Bildungssystems sowie der starken Konkurrenz Nachhilfestunden erhielten und auf Aufnahmeprüfungen für höhere Schulen und Hochschulen vorbereitet wurden. Die Gülen Cemeinschaft war in diesem Bereich besonders aktiv, sie betrieb etwa ein Drittel aller Repetitorien, bis sie nach 2013 schrittweise zerschlagen wurde.

71 Fethullah Gülen floh 1999 in die USA, nachdem Tonband-Aufnahmen veröffentlicht worden waren, in denen er seine Anhänger zur Infiltrierung wichtiger Behörden wie der Justiz, der Polizei und des Militärs aufgerufen hatte. Die Veröffentlichung sorgte für erheblichen Aufruhr und Empörung. Eine Strafermittlung wegen Aufruf zum Sturz der Regierung und der laizistischen Ordnung wurde eingeleitet. 2006 wurde er frei gesprochen, blieb aber in den USA. Er wird von der AKP beschuldigt, den Putschversuch gegen sie im Jahr 2016 angeleitet zu haben. Hierzu liegen jedoch keine Beweise, lediglich Indizien vor.

72 Die Abkürzung steht für Türkiye İ̧̧ Adamları ve Sanayiciler Konfederasyonu (Konföderation von Geschäftsleuten und Industriellen der Türkei). Die Mitgliedsunternehmen sind überwiegend in den gleichen Wirtschaftssektoren wie die von MÜSIAD - Textil, Bauwirtschaft, Handel - tätig. Nach Ausstoßung der Cülen Cemeinschaft aus der AKP und der Verfolgung ihrer Mitglieder hat die Bedeutung des Verbands TUSKON abgenommen. Bemerkenswert bleibt, dass ein einzelnes Netzwerk einen eigenständigen Unternehmerverband gegründet hat.

73 Nach der Herauslösung der Cemeinschaft aus der AKP, deren Hintergründe hier nicht erörtert werden können, wurden Massenverfahren gegen zehntausende mutmaßlich Assoziierte der Bewegung eingeleitet, verstärkt nach dem Putschversuch von 2016. 
die Gemeinschaften geht hervor, dass die Nakschibendi und Nurcu federführend in der kulturellen Verbreitung kapitalistischer Entwicklungsideale waren, indem sie den Islam als eine Religion rationalen Fortschritts interpretierten (Yavuz 2003). Er zitiert einen Ordensführer, der betont, dass die Grundlage einer gerechten Gesellschaft in einer starken Ökonomie bestehe, die wiederum nur durch eine Arbeits- und Geschäftsethik hergestellt werden könne, die allein der Islam zur Verfügung stelle. Wie die Puritaner im England des 17. Jahrhunderts sähen auch die Nakschibendi weltlichen Erfolg als Zeichen für Anerkennung durch Gott an. Eine ältere ethnographische Studie in einer Kleinstadt an der Schwarzmeerküste gelangt zu einem ähnlichen Schluss (Vergin 1985). Ihr zufolge entstand das religiöse Bedürfnis dort als Reaktion auf die Industrialisierung, die eine soziale Krise provoziert habe. Die Hinwendung zur religiösen Gemeinschaft der Nakschibendi sei als Kompensation für die Auflösung tradierter sozialer Beziehungen aufgetreten und habe sich mit einer Skepsis gegenüber der Republik verbunden, die als Urheberin der Industrialisierung und ihren negativ erlebten Auswirkungen identifiziert wurde. Die Studie verweist auf die Ambivalenz dieses Ausdrucks des bereits diskutierten Konservatismus. Die Nakschibendi begrüßten technologischen Fortschritt, lehnten aber die Modernisierungsideologie des Kemalismus ab. Aus der Studie lässt sich schließen, dass sie der Bevölkerung nicht die Bewahrung tradierter sozialer Beziehungen, sondern alternative kulturelle Deutungen und Praktiken anboten, die die Industrialisierung ebenso bejahend begleiteten wie der modernistische Kemalismus. Während sie symbolisch für Traditionalität standen, befürworteten sie die sozio-ökonomische Umwälzung, durch die Reproduktionsmuster - Familien-, Wohn- und Konsumformen - Veränderungen durchliefen.

Yavuz legt in einer weiteren Studie am Beispiel von Textilfirmen, die Modeartikel für Muslime produzieren, dar, dass diese Firmen ihre Entwürfe von geistlichen Autoritäten im Hinblick auf Konformität zum Islam prüfen lassen. Die geprüfte Ware diene muslimischen Frauen dazu, sich und ihren Wohlstand zu präsentieren, ohne in Konflikt mit ihrer religiösen Identität zu geraten (Yavuz 2004). Er formuliert auch die These, die Nurcu und andere Gemeinschaften, die dem Sufismus zugeordnet werden, hätten durch Lese- und Diskussionsgruppen, über die Kontakte hergestellt und Vertrauen aufgebaut worden seien, strategische Verbindungsorte für Unternehmer geschaffen. Diese dienten dazu, ein Gegengewicht zu den in Marktwirtschaften auftretenden Unsicherheiten herzustellen, wie die Schwierigkeit, Investitionen verlässlich kalkulieren zu können oder Zugang zu Material und Arbeitskräften zu erhalten.

Es ist schwierig, Aussagen über den Charakter ökonomischer Beziehungen zwischen Mitgliedern einer Gemeinschaft zu überprüfen. Die Gemeinschaften sind informelle Organisationen, sie führen kein einsehbares Buch, sie unterliegen keiner Datenerfassung, zumindest keiner, die öffentlich zugänglich ist. Offiziell sind alle religiösen Gemeinschaften seit 1925 verboten. Sie organisieren sich 
deshalb in Vereinen und Stiftungen, die bestimmten legalen Zwecken gewidmet sind, sowie auf informelle Weisen. Dass sie über eine sehr lange Zeit klandestin tätig waren und, wie sich im Fall der Gülen Gemeinschaft gezeigt hat, auch unter einer islamistischen Regierung nicht sicher vor Verfolgung sind, erschwert den Zugang zu Informationen. Einsichten, die über die Interpretation von Schriften und Interviews hinausgehen, sind daher selten. In seiner Fallstudie in der Stadt Kayseri-Hacilar rekonstruiert Cengiz auf der Grundlage von Interviews, dass die Gemeinschaften dort erst in den 1990ern an Popularität gewannen. Zwar gehe aus Erzählungen die Existenz einer ersten Gemeinschaft in den späten 1940ern hervor, in der Assoziierte Said Nursis Schriften gelesen und interpretiert hätten. Sie seien von der Gendarmerie kritisch beäugt aber nicht verfolgt worden. Bis in die 1980er Jahre seien solche Aktivitäten auf kleine Gruppen begrenzt geblieben, ohne dass sie eine besondere Wirkung in der Bevölkerung entfalten konnten. In den späten 1980ern hätten sie begonnen, sich verstärkt $\mathrm{zu}$ organisieren, Frauentreffen, Korankurse für Erwachsene und Kinder zu veranstalten. In den 1990ern seien sie zum ersten Mal in Form von Vereinen, Stiftungen und privaten Schulen aufgetreten. Unternehmer der Stadt seien erst nachdem sie erfolgreich waren, gezielt von Gemeinschaften umworben worden. In den zoooern habe etwa die Hälfte der Unternehmer von Kayseri ihm gegenüber bekundet, einem Nakschibendi-Orden oder der Gülen Gemeinschaft anzugehören, die regelmäßige Zusammenkünfte in kleineren Gruppen organisierten (Cengiz 2013: 362ff.). Cengiz bezweifelt, dass die »Die-Unsrigen-Denke«, womit der Zusammenhalt auf der Grundlage einer gemeinsamen Affiliation gemeint war, im geschäftlichen Bereich tatsächlich das Zentrale an den Gemeinschaften bildet. Er stieß in seiner Studie auf eine sehr begrenzte Solidarität zwischen Unternehmern, die Mitglieder der gleichen Gemeinschaft waren. Die Grenze werde von der ökonomischen Rationalität gesetzt. Geschäftsbeziehungen richteten sich nach Regeln des Profits, nicht nach kultureller Nähe oder ideologischem Bekenntnis. Die breite Partizipation der Unternehmer in Kayseri an Zusammenkünften islamischer Gemeinschaften lässt indes den Schluss zu, dass die Gemeinschaften neben den IHS eine bedeutsame Rolle in der religiösen Bildung der Unternehmerschaft einnehmen. Denn nach Cengiz entwickelten die Unternehmer erst ausgeprägte religiöse Weltauffassungen, nachdem sie mit den Gemeinschaften in Kontakt getreten waren.

Die bisher präsentierten Einsichten zu den Gemeinschaften ergeben, dass ihre Attraktivität für die Unternehmer in der Netzwerkbildung und Möglichkeit der Einflussnahme auf die Politik auch auf der Grundlage personeller Verschränkungen liegen. Sie bieten eine Plattform oder Börse für geschäftliche Kontakte, treten als Zusammenschluss von Quasiaktionären und Unternehmern in Erscheinung, verleihen kapitalistischen Waren religiöse Prüfsiegel. Sie fungieren ebenso wie andere religiöse Instanzen als Mittler, die Widersprüche zwischen religiösen Überzeugungen und zuwiderlaufenden alltäglichen Praktiken befrieden. Zugleich stat- 
ten sie die Unternehmerschaft mit religiösen Weltauffassungen aus, die sie in den Beziehungen zu ihren ArbeiterInnen einsetzen, um Hegemonie auszuüben. Über die Studie von Vergin wird deutlich, dass sie Zustimmung der Arbeiter- und Bauernschaft zur kapitalistischen Industrialisierung mobilisierten, indem sie alternative Deutungsangebote entwickelten, wenn der Kemalismus an Grenzen oder auf Ablehnung stieß. Im Beispiel der Ismailağa Gemeinschaft (Kap. 6.1.3) tritt hervor, dass sie als Organisationen agieren, die den Widerspruch zwischen Kapital und Arbeit befrieden, indem sie Reichtum mit einem religiösen Panzer versehen und gegen Kritik abzuschirmen versuchen. Angesichts auftretender Widersprüche in der politischen Praxis, wie das Entsenden von Soldaten in Kooperation mit den "Feinden« der Muslime, die sie als eine Gemeinschaft herstellen, deren Führung sie zugleich beanspruchen, arbeiten sie an der Aufrechterhaltung der Identität der Gemeinschaft.

\subsubsection{Intellektuelle Führungs- und Distinktionspraxis}

Während meines Feldaufenthalts erhielt ich besondere Einblicke in die bildende und organisierende Rolle der religiösen Gemeinschaften. Im Folgenden werde ich diese Einblicke aus der Perspektive der Konstituierung von Führungs- und Distinktionspraktiken thematisieren und mit der Diskussion über die Herstellung exklusiver kultureller und sozialer Ressourcen verknüpfen.

Ein Aktivitätsfeld von Gemeinschaften sind Sohbet. Damit werden Konversationsrunden bezeichnet, die in der Regel nach Geschlechtern getrennt an nicht-öffentlichen, privaten Orten aber auch in Moscheen unter der Anleitung von religiösen Akteuren stattfinden können. Diese Akteure sind häufig ausgebildete Imame oder Lehrer an theologischen Schulen, was jedoch nicht zwingend ist. Während solcher Konversationen werden Koranverse diskutiert, es wird über das Leben religiöser Autoritäten reflektiert, beides wird in Verbindung zu alltäglichen Ereignissen gebracht, von denen die Teilnehmer berichten. Zur Teilnahme an einer Konversationsrunde eines Seitenarms der Nurcu wurde ich von einem Mitglied der AKP-Jugend, der an der Universität Verwaltungswissenschaften studierte, eingeladen. Er berichtete mir, es gebe in jedem Stadtviertel von Izmir zwei oder drei Privatwohnungen, in denen regelmäßig Treffen stattfänden.

Gemeinsam betraten wir das Parterre eines Wohnhauses, wo ein Treffen bereits im Gange war. In einem großen, mit einem Teppich ausgelegten Raum standen Sofas an allen vier Wänden. Die Mitte war frei. Auf einem Sofa saß ein älterer Mann. Vor ihm befand sich ein Tischchen mit mehreren Büchern. Im Raum waren weitere drei Personen, junge Erwachsene in ihren Zwanzigern, von denen einer gerade vorlas. Die anderen verfolgten das Gelesene aus jeweils eigenen Büchern. Wir setzten uns dazu und nahmen uns auch je ein Buch. Gelesen wurden die Risale-i Nur (Botschaft des Lichts), die eine mehrere tausend Seiten umfassende Koran- 
interpretation von Nursi ist. Auf Koranverse, die auf Arabisch vorgelesen wurden, folgte das Vorlesen der Exegese. Der ältere Mann korrigierte, wenn etwas falsch vorgelesen wurde. Für mich war es schwierig, $\mathrm{zu}$ folgen, ich verstand viele der arabischen und osmanischen Wörter nicht. Ich bekam mit, dass es um die Schöpfung ging, die Existenz Gottes an einzelnen Schöpfungsbeispielen nachgewiesen wurde.

Die Lesereihe wurde in Intervallen weiter gegeben. Nach und nach kamen weitere Personen hinzu, ohne dass die Vorleser unterbrochen wurden. Nach etwa einer halben Stunde wurde eine Pause gemacht und Tee gereicht. Inzwischen war die Gruppe auf zehn Teilnehmer gewachsen, von denen die meisten nicht älter als 25 gewesen sein dürften. Der ältere Mann verabschiedete sich, nachdem er sich nach mir erkundigt hatte und mir den Tipp gab, ich könnte bei Interesse auch in Frankfurt an einer Runde teilnehmen. Den Vorsitz übernahm nun einer, den die anderen als Abi bezeichneten. ${ }^{74}$ Er las eine kurze Passage vor, anschließend wurde in einem Alltagstürkisch diskutiert, sodass ich die Konversation mitverfolgen konnte. Es ging um die Einzigartigkeit der Schöpfung am Beispiel der Honigbiene. Der Vorleser leitete ein mit der Frage:

Wie kann eine solch sensible Balance an einem so kleinen Tier Zufall sein?

Im Raum herrschte Konsens, dass es kein Zufall sein konnte. Er führte weiter aus:

Stellt euch vor, ihr wisst gar nichts über Honig und man würde euch fragen, was ihr denkt, wo der herkommt? Ihr würdet vielleicht an eine Kuh denken oder an ein Schaf. Eine Biene würde euch als letztes einfallen. Denn die Biene hat Gift, sie sticht. Auf die Idee, dass ein giftiges Wesen so etwas Süßes wie Honig hervorbringt, kämt ihr nicht.

Ein zweiter ergänzte:

Ja, und stellt euch vor, beides in einem, Gott platziert dieses Gift in die Biene, ohne die Biene selbst zu vergiften.

Die Anwesenden staunten und murmelten Beifall. Ein dritter übertrug die Frage auf eine Kuh:

Wie kommt es, dass eine Kuh Milch gibt? Wenn du eine Nadel in ihren Euter stichst, kommt Blut heraus, nur von der Spitze des Euters kommt Milch.

74 Abi ist eine Kurzform für »Ağabey« und heißt älterer Bruder. Die Bezeichnung verweist auf eine Verwandtschaftsbeziehung, wird jedoch sehr häufig auch als Ansprache für nicht allzu viel Ältere benutzt. Während sie primär eingesetzt wird, um eine Rangfolge nach Alter zu bezeichnen oder Respekt gegenüber Älteren auszudrücken, verweist sie im Zusammenhang mit religiösen Gemeinschaften auf einen Status, der mit dem Durchlaufen einer Ausbildung erworben wird und dazu berechtigt beziehungsweise verantwortet, Andere anzuleiten. Das weibliche Pendant zu Abi ist Abla. 
Es folgte erneut gemurmeltes Staunen. Schließlich meinte der Abi, man solle sich nicht verwirren lassen, wenn andere Gründe angeführt würden:

Es werden schon irgendwelche Gründe gefunden, die sind alle Nonsens. Gott gibt, ohne sich zu zeigen, dafür hat er die Kreaturen geschaffen.

Einer brachte das Beispiel des Apfelbaums ein:

Damit Gott sich nicht zeigen muss, gab er den Apfel über den Baum.

Der Vorsitzende ergänzte:

Ja, der Cottesfürchtige zweifelt nicht, er staunt, aber zweifelt nicht.

Daraufhin erzählte wieder ein anderer eine Anekdote:

Ich bin mal in Van [Stadt im Osten der Türkei] gewesen und habe, so wie hier heute, an einem Sohbet teilgenommen. Plötzlich hat die Erde gebebt. Alles hat gewackelt, die Bücher, was heißt gewackelt, das Buchregal ist umgeflogen. Ein richtig starkes Erdbeben war das. Panik ist ausgebrochen, alle sind aus den Häusern gerannt. Auch ich wollte rennen, habe aber gesehen, dass einer der Älteren nicht rennt, sondern nur da sitzt und >Allah Allah< ruft. Am liebsten wäre ich losgerannt, soviel Angst hatte ich. Ich bin nur sitzen geblieben, weil der Ältere auch sitzen blieb.

Alle schmunzelten oder lachten. Mein Begleiter meinte:

Es ist sowieso gefährlich, loszurennen.

»Ja«, sagte der Erzähler,

das auch. Aber was ich sagen will ist, dass der Ältere genau diese Gelassenheit an den Tag gelegt hat, von der wir gerade gesprochen haben. Er hatte Cottvertrauen und staunte.

Das Ritual gewährte mir einen - ziemlich überraschenden - Einblick in eine der vielen Verästelungen der islamistischen Bewegung, die im Privaten verborgen sind. Die Exegesegruppe studierte den Koran in der kreationistischen Auslegung von Said Nursi. Die Gruppe verfügte über zwei Sprachen: eine, die der gemeinsamen Aneignung einer distinkten Weltanschauung diente und eine zweite, die sie im Alltag benutzte. Die Teilnehmer erlernten unter der Anleitung eines Älteren die Sprache eines Intellektuellen aus der osmanischen Zeit und eine Art des vorwissenschaftlichen Denkens, die mir, der wie der größte Teil der Bevölkerung im säkularen türkischen Schulsystem sozialisiert wurde, fremd war. Die Sitzung stellte eine sich vermittels der alten Sprache nach außen abgrenzende Welt her, deren Grenzen durch die Warnung verstärkt wurden, sich nicht durch »Gründe«, gemeint waren offensichtlich naturwissenschaftliche Erklärungen, verwirren zu lassen. Das 
türkische Schulsystem sieht weiterhin in allen Schulen, auch in den privaten und den theologischen, verpflichtend naturwissenschaftliche Fächer vor. Es konnte also kaum sein, dass die Teilnehmer diese Unterrichtung nicht erhalten hatten. Indem sie sich in die Lage von Unwissenden versetzten - »stellt euch vor, ihr wisst gar nichts« - , legten sie die Grundlage, sich die Welt von neuem zu erschließen. Kulturelle Anstrengungen seit der Gründungszeit der Republik, aufklärerische und naturwissenschaftlich fundierte Bildungsinhalte und eine neue Sprache zu etablieren, wurden in diesem Raum aufgehoben.

Das Ritual gab eine Struktur zu erkennen, bei der die Führung von älteren, erfahrenen Personen ausgeübt wurde, die korrigierend eingriffen und anleiteten. Wie bei der Sitzung mit den radikalisierten Studenten und dem Koranlehrer stützte sich die Führung auf das Beherrschen einer Quelle, die den »richtigen« Weg wies. Eingeübt wurde die Auffassung, dass diese Quelle letztgültiges Wissen berge. Die Teilnehmer bestätigten sich zugleich gegenseitig in ihrer Bereitschaft, sich in diesem Bereich führen zu lassen. Die Erzählung über das Erdbeben bekräftigte zum einen die Aneignung der naiven Perspektive, zum anderen die Überlegenheit des religiösen Wissens über das säkulare in Verknüpfung mit der Vorbildfunktion des Älteren, dem zugesprochen wurde, in Situationen großer Angst durch Gefahren $\mathrm{zu}$ leiten, durch Gottvertrauen Sicherheit zu vermitteln, gerade wenn das säkulare Wissen in eine andere Richtung zieht. Indem sie das Staunen und Vertrauen als würdevolle Erhabenheit gegenüber dem säkularen Wissen praktizierten, stellten sie Distinktion her.

Nachdem die Sitzung beendet war und wir die Gruppe verlassen hatten, befragte ich meinen Begleiter nach den Teilnehmern. Der Ältere, der den Raum vorzeitig verlassen hatte, sei ein Hoca (Gelehrter), zwei arbeiteten als Schullehrer, einer für Mathematik und einer für Literatur, die anderen seien Studenten. Er selbst war, wie erwähnt, Student der Verwaltungswissenschaften und strebte eine Beamtenlaufbahn an. Wäre ich den einzelnen Mitgliedern an einem anderen Ort begegnet, hätte ich von ihrem Äußeren vielleicht auf einen studentischen oder bildungsbürgerlichen, ganz sicher aber nicht auf einen islamistischen Hintergrund schließen können. Ich hätte nicht einmal ahnen können, dass sie zu den Anwärtern einer intellektuellen Führungsschicht gehörten, die die islamistische Bewegung ausbildet und ausgestattet mit einer distinkten Weltauffassung und eingeübten Loyalitäten in allen Bereichen der Gesellschaft ansiedelt.

Die ausgeübten und angestrebten Berufe der Teilnehmer verweisen darauf, dass die Aneignung von religiös-kreationistischem »Wissen «, das in ausdrücklicher Abgrenzung zu säkular-naturwissenschaftlichem Wissen steht, Karrierechancen in allen Berufsfeldern nicht im Wege steht. Die Bedeutung dieser Einsicht lässt sich noch besser begreifen, wenn sie in Beziehung zur Bildungs- und Wissenschaftspolitik der AKP gesetzt wird. Die Aufwertung religiösen »Wissens« ist, wie bereits thematisiert, ein durchschlagendes Kennzeichen der AKP-Regierung, und kommt 
nicht nur in der Förderung der theologischen Ausbildungsstätten, sondern an allen Bildungseinrichtungen zum Tragen. Seit der Regierungsübernahme betreibt die AKP eine Politik, durch die naturwissenschaftlich-säkulares Wissen schrittweise durch konservativ-religiöse Weltauffassungen ergänzt wurde. ${ }^{75}$ Verstärkt wurde diese Politik nach dem Verfassungsreferendum von 2010. 2011 wurde das leitende Gremium im Wissenschafts- und Technologieforschungsrat der Türkei (TÜBİTAK), die zentrale nationale Einrichtung für die Organisation von Forschung und Entwicklung, personell neu besetzt. ${ }^{76}$ Die Wissenschaftspolitik des neu besetzten Rats ist seitdem vom Bestreben gezeichnet, evolutionstheoretisch fundierte Inhalte zu zensieren. ${ }^{77} 2017$ sollte die Evolutionstheorie aus den Lehrplänen einiger Schulklassen entfernt und durch das Thema Dschihad ersetzt werden, ein Vorstoß, der nach Protesten abgeschwächt wurde. ${ }^{78}$

Vor dem Hintergrund dieser Entwicklung und des gerade präsentierten empirischen Falls, der als radikale Negation nicht-theologischen Wissens erscheint, stellt sich die Frage, ob diese Tendenz sich verallgemeinern lässt, eine komplette Negation nicht-theologischen Wissens angestrebt wird, administrative und wirtschaftspolitische Prozesse durch religiöse Textauslegung angeleitet werden sollen. Wie im Laufe der Arbeit bereits aufgezeigt wurde, ist das islamistische Projekt nicht darauf gerichtet, sich von naturwissenschaftlichem und ökonomischtechnischem Wissen zu verabschieden. Die vorherrschende Strategie, deren Herausbildung sich seit der Spätphase des Osmanischen Reichs nachzeichnen lässt (vgl. S. 125ff.), ist die Herstellung von Vereinbarkeit zwischen Theologie und nicht-theologischen Wissensformen (vgl. Atasoy 2009: 44ff., 254 Fn. 6; Tuğal 2009: 218). ${ }^{79}$ An den Imam Hatip Schulen wie auch den zahllosen privaten islamistischen Bildungsinstitutionen der religiösen Gemeinschaften (Privatschulen und -universitäten) wird Allgemeinbildung mit theologischer Bildung artikuliert. Aus

75 Siehe auch https://www.dw.com/de/türkische-schulbücher-weniger-frauen-mehr-religion/a-45921288 vom 17.10.2018 (Abruf am 20.10.2018).

76 Die Amtszeit des gewählten Vorstands wurde per Dekret kurzerhand beendet, der neue Vorstand durch den vom Ministerpräsidenten und Staatspräsidenten dominierten Hochschulrat (YÖK) besetzt.

77 Siehe http://sendika63.org/2011/08/tubitak-da-akpye-baglandi-57194/ vom 27.08.2011 und http://sendika63.org/2014/02/iktidar-catismasi-tubitakta-tubitakin-evrimini-yeniden-ha tirlamak-169369/ vom 22.02.2014, (beide abgerufen am 12.10.2018).

78 Siehe Samuel Osborne: Turkey's new school curriculum drops evolution and will teach concept of jihad, in: Independent, 19.07.2017, https://www.independent.co.uk/news/world/ europe/turkey-school-curriculum-teach-jihad-concept-drop-evolution-science-muslimislam-a7848176.html (Abruf am 12.10.2018).

79 Die Auffassung, Religion sei Ursprung allen Wissens, spiegelt sich auch in der theologischen These (Kapitel 3.2, »islamischer Calvinismus«), in der ökonomische Entwicklung mit Tugenden aus dem Koran begründet, unternehmerischer Erfolg und Rationalität aus dem Koran abgeleitet werden. 
den Schulen gehen nicht nur Theologen hervor, sondern mit religiösen Weltauffassungen, Loyalitäten, (Führungs-)Wissen und (Führungs-)Praktiken ausgestattete AbsolventInnen, die alle möglichen Berufslaufbahnen einschlagen können. Dabei wird die Besonderheit religiösen Wissens durch seine Überordnung hergestellt, verbunden mit der Herausforderung, Unvereinbarkeiten mit säkularen Wissensbeständen »auszuhalten«. Als Sonderwissen, das die säkulare Wissenschaft wie ein Schirm überspannt, erhält das Religiöse durch seine Nicht-Erklärbarkeit den Charakter des Besonderen, der es ermöglicht, säkulare, naturwissenschaftlichtechnische Wissensbestände beizubehalten und ihr Erlernen und Anwenden als ein für das religiöse Weltbild affirmatives Handeln zu begreifen. Mit anderen Worten, die Geschichte der Re-Artikulation der Religion mit den herrschenden Klassen ist auch die Geschichte der Artikulation mit der vorherrschenden Wissenschaft bei gleichzeitiger Etablierung der Theologie als eine Art übergeordnetes Wissen oder Sonder-Wissen. In diesem Zuge wird säkulare Wissenschaft als affirmatives Wissen zugerichtet. ${ }^{80}$ Wird die angeführte Beobachtung in diesen Zusammenhang gestellt, dann verweist sie auf die Besonderung, die durch die Einsozialisation in Führungsstrukturen entsteht, die mit dem gemeinsam praktizierten Aussetzen säkularen Wissens Gemeinschaft und Distinktion herstellt, während dieses Wissen in der separierten Berufswelt seine Geltung behalten kann.

Eine weitere große und weitverzweigte Gemeinschaft, die ein Netzwerk an privaten Institutionen betreibt, ist die Süleyman Efendi Gemeinschaft. Die Assoziierten oder Gefolgsleute werden nach ihrem Begründer Süleyman Hilmi Tunahan (1888-1959) auch kurz Süleymancı genannt. ${ }^{81}$ Tunahan entstammte der Ulema-Tradition. Er arbeitete im Osmanischen Reich als Medrese-Lehrer, später in der Republik zeitweise für die Diyanet, bis er 1950 ein privates Koran-Internat und wenig später Korankurse eröffnete, die von der Diyanet beaufsichtigt wurden. Ende der 1950er soll die Anzahl der Kurse auf 1.000 und Mitte der 1960er auf 3.000 gestiegen sein. Die Kurse bildeten Imame für die Diyanet aus, bis die Behörde 1965 per Gesetz reorganisiert wurde. Fortan wurden Absolventen von Imam Hatip Schulen und theologischen Fakultäten den Süleymancı vorgezogen, wodurch ein Zwist mit der Diyanet und den Imam Hatip Schulen entstand. Nach 1971 verlagerten die Süleymancı ihren Schwerpunkt. Sie gründeten Vereine, die Internate für SchülerInnen und StudentInnen betreiben, denen sie zusätzlich Koranunterricht anbieten. Die Verlagerung des Schwerpunkts bedingte, dass sie an das Bildungsministerium

80 Eine Artikulationsstrategie, die Said Nursi, dessen Werk in der Cruppe gelesen wurde, zugewiesen wird, besteht in der Auffassung, dass alles Wissen bereits im Koran enthalten und die »wissenschaftliche« Forschung ein Mittel sei, dieses Wissen offenzulegen (Atasoy 2005: 47). 
angebunden wurden. ${ }^{82}$ Jüngere Recherchen von Tageszeitungen beschreiben expandierende Aktivitäten der Süleymancı im privaten Bildungsbereich. Demzufolge betreiben sie mehr als 1.000 Wohnheime mit etwa 100.000 Schüler und Schülerinnen, verfügen ferner über eigene Publikationsorgane, Stiftungen sowie assoziierte Firmen. ${ }^{83}$ Indes zeichnen sich die Süleymancı gegenüber anderen religiösen Gemeinschaften dadurch aus, dass sie schon vor der neoliberalen Wende von 1980 ein privates Bildungsnetz etabliert hatten (Aydın, M. 2005).

Auf der Suche nach einer Unterkunft für meinen Forschungsaufenthalt im kurdischen Südosten wurde ich über die AKP an ein Heim der Süleymancı vermittelt, die mich für eine Woche als Gast aufnahmen. Das Heim war ein mehrstöckiges Gebäude, das seit den 1970ern bestand. Aktuell beherbergte es 130 Schüler etwa im Alter zwischen 7 und 16 Jahren. Im Mittelpunkt des Heimalltags stand das Lernen. Die Schüler gingen tagsüber zur Schule, am Nachmittag machten sie Hausaufgaben, anschließend lernten sie Arabisch und erhielten Koranunterricht. Die Betreuer berichteten, dass unterschiedliche Familien ihre Kinder wegen der Bildung, die sie im Heim erhielten, dort unterbrachten, auch solche, die in der Nachbarschaft wohnten. Die Kinder wurden von sechs Betreuern beaufsichtigt, die zwischen 20 und 25 Jahre alt waren und Abi genannt wurden. Sie hatten selbst keine staatliche, sondern eine private Ausbildung nach den Regeln der Gemeinschaft durchlaufen. Da sie erzieherische Aufgaben erfüllten, werde ich sie im Folgenden nicht mehr Betreuer, sondern Erzieher nennen. Die Gemeinschaft grenzte sich nach außen durch verschiedene kleine und große Praktiken ab, so durch das Verbot von Jeans, da diese zu eng am Körper anlägen und dessen Konturen sichtbar machten, oder einen Handschlag, bei dem die Hand des Gegenüber mit beiden Händen berührt wurde. ${ }^{84}$ Klare Distanzierung äußerten die Erzieher gegenüber »dem Volk«, das

82 Etwa zeitgleich mit der Diyanet gründeten die Süleymancı 1973 zuerst in Deutschland, später auch in anderen Ländern Islamische Kulturzentren, die sich an die MigrantInnen aus der Türkei richten. In Deutschland soll es etwa 300 Vereine und Moscheegemeinden, sowie 19 Wohnheime geben, die von den Süleymancı betrieben werden. Sie verfügen in Konkurrenz zur DITIB, dem an die Diyanet angeschlossenen Moscheeverband in Deutschland, über einen eigenen Dachverband.

83 Siehe İsmail Saymaz: Kurslar ve yurtlar imparatorluğu Süleymancılar [Das Imperium aus Kursen und Internaten der Süleymancı], 11.12.2016, in: www.hurriyet.com.tr/gundem/kurslar-veyurtlar-imparatorlugu-suleymancilar-40303192. Siehe auch https://www.birgun.net/haberdetay/bilinmeyen-gercekleriyle-suleymancilik-nedir-137657.html vom 30.11.2016, (beide abgerufen am 23.10.2018).

84 Mir wurde erklärt, dass diese Geste aus den Überlieferungen von Mohammed, den Hadithen, stamme. Der Handschlag unter Muslimen werde dort als eine Art des Cottesdiensts beschrieben. Nach meinen Recherchen gibt es keine Einigkeit, ob dies mit einer oder mit zwei Händen geschehen soll. Es ist, wie immer, Auslegungssache. 
sie für ungebildet/unwissend (»cahil«) hielten. ${ }^{85}$ Nachdem ich von meinem Aufenthaltszweck und meiner Herkunft aus Deutschland berichtet hatte, äußerte ein Erzieher seine Sorge über das Bild, das durch das »ungebildete Volk« nach außen entstehen könne: »Die Europäer denken bestimmt, dass wir alle dumm sind«. Die Distanzierung passte nicht zu der in der Forschungsliteratur verankerten Annahme, konservativ-religiöse Akteure seien volksnah. Gerade von den Süleymancı hieß es, sie seien ein Sprachrohr der unteren Volksschichten (Aydın, M. 2005: 309). Die Süleymanc1, denen ich begegnete, brachten ein Selbstverständnis als Bildungselite zum Ausdruck, die sich für diejenigen, die keinen Zugang zu Bildung hatten, gegenüber Europäern schämte, deren imaginäres Urteil sie als Maß heranzogen. ${ }^{86}$

Ein weiteres Element, durch das die Süleymancı sich als distinkte Gruppe konstituierten, bestand in der Betonung von Reinlichkeit. Das Heim war sehr reinlich. Es gab einen Eingangsbereich, wo die Straßenschuhe ausgezogen und Hausschuhe angezogen wurden. Da das gesamte Gebäude inklusive der Treppen mit Teppich ausgelegt war, war es alternativ möglich, sich mit Socken zu bewegen, ohne kalte Füße zu bekommen. Vor den Waschräumen befanden sich Plastiklatschen zum Überstülpen. Es handelte sich jedoch nicht nur um eine pragmatische Reinlichkeit, wie mir durch eine der ersten Unterhaltungen deutlich wurde. Am Tag meiner Ankunft wurde ich von Erziehern und Besuchern des Heims nach meiner Herkunft befragt. Als sie erfuhren, dass ich aus Deutschland kam, versicherten sie sich zunächst, dass ich kein Schweinefleisch esse, und bemerkten dann halb feststellend halb fragend: »Die Europäer sind doch sauberer als wir, oder?« Als ich antwortete, sie achteten etwas mehr auf ihre Umgebung, entgegnete einer: »Na ja, aber sie wischen sich mit Papier ab, das ist nicht sauber. ${ }^{87}$ Die Reinlichkeit war Teil ihrer Identität und Bestandteil der Distinktionspraxis. Sie manifestierte sich auch über die Sprache. In einem Gruppeninterview mit Schülern des Heims, auf das ich nachfolgend noch eingehen werde, antworteten diese auf meine Frage, was das Heim für sie bedeutet, an erster Stelle mit der Freundschaft untereinander und an zweiter mit der Sprache. Sie fühlten sich unter ihren Klassenkameraden in der Schule, die in keinem Heim waren, unbehaglich, da diese häufig »schmutzige« Schimpfwörter gebrauchten.

Die Abgrenzung zum »Volk« wurde durch den Umstand verstärkt, dass die Erzieher keine Kurden waren, während die Schüler, die sie betreuten, aus kurdi-

85 In der islamischen Theologie wird »Unwissenheit« auch als eine Phase (»cahiliyet dönemi«) bestimmt, mit der die Zeit vor dem Islam bezeichnet wird. Das Studium des Koran führt demzufolge zum richtigen Wissen, es steht für die Aufklärung, die Licht ins Dunkel bringt.

Die Abgrenzung gegenüber dem »unwissenden« Volk und die Konstitution eines elitären Bewusstseins ist von Cihan Tuğal auch unter Imam Hatip Absolventen festgestellt worden (Tuğal 2009: 117).

87 Gemeint ist die Säuberung nach dem Toilettengang. Sie erfolgte nicht mit Papier, sondern durch eine Waschung. 
schen Familien stammten. Die Erzieher verfolgten die damaligen Verhandlungen zwischen der Regierung und der PKK, die unter dem Namen »Öffnung « geführt wurden, mit Skepsis. $\mathrm{Zu}$ dieser Zeit hatte die PKK gerade in Absprache mit der AKP eine Guerilla-Delegation aus dem Irak in die Türkei geschickt, um die Nachhaltigkeit der Verhandlungen zu testen, wie es hieß. Die Delegation wurde von hunderttausenden KurdInnen euphorisch auf der Straße empfangen. ${ }^{88}$ Einige Erzieher befürchteten, die kurdische Bewegung würde immer mehr verlangen, nur der Leiter des Heims war sich sicher, dass die AKP den Konflikt, den er auf Provokationen des »tiefen Staats« zurückführte, lösen und die Türkei aus der Lösung gestärkt hervorgehen werde. Er zitierte aus der Zeitung Taraf, die diese Position vertrat und zu dieser Zeit in vielen Cafés und Büros auslag und an vielen Kiosken die sichtbarste Zeitung war.

Die Einschätzung der Schüler des Heims wich stark von dieser Haltung ab. Eine vierköpfige Gruppe von Schülern des Heims im Alter von 13-15 beispielsweise, die von sich aus um Erlaubnis baten, mit mir ein Gespräch führen zu dürfen, äußerte sich sehr skeptisch gegenüber der AKP. Zugleich waren sie überzeugt, dass die kurdische Bewegung gestärkt aus der »Öffnung« hervorgehen werde. »Die in den Bergen haben unseren größten Respekt «, sagten sie, und meinten damit die PKK-Guerilla, die die Berge zu ihrer Operationsbasis gemacht hatte. Sie distanzierten sich zwar von der damaligen kurdischen Partei DTP und auch vom bewaffneten Kampf. Doch sie sprachen von »denen in den Bergen«, als seien sie mit ihnen identisch: „Wir wären nicht in die Berge gegangen, wenn wir nicht unterdrückt würden.« Auf meine Frage, welche Entwicklung sie erwarteten, äußerten sie: »Ein kurdischer Staat wird gegründet.« Die Schüler berichteten von Gewalt und Folter, die ihre Eltern vollkommen grundlos vom Militär erfahren hätten, und von Diskriminierung, die ihnen aufgrund ihrer kurdischen Identität durch Lehrer in der Schule widerfahre. Sie betonten nachdrücklich, dass alles, was sie erzählten, tatsächlich geschehen sei. Es sei kein Bücherwissen, sondern selbst Erlebtes oder von den Eltern und Brüdern überliefert. Während sie Glaubwürdigkeit durch Bezug auf die Eltern herstellten, grenzten sie sich gleichzeitig von ihnen ab. Die Eltern seien von der AKP mit »religiösen Formeln« leicht hinters Licht zu führen, das liege am begrenzten Horizont des dörflichen Lebens und mangelnder Bildung.

In Kurdistan konstituierten sich die Erzieher des Heims als türkisch-islamische Bildungselite, die über das Gebildetsein und bestimmte Distinktionspraktiken eine bewusste Linie zwischen sich und dem »Volk«zog. Die Linie wurde verstärkt vom

88 Die Euphorie auf kurdischer Seite löste heftige türkisch-nationalistische Reaktionen in vielen Landesteilen der Türkei aus, die von der MHP und Teilen der CHP geschürt wurden. Die AKP rückte danach schrittweise von der »Öffnung « ab, zumal diese auch in ihren Reihen von Anfang auf nationalistische Reaktionen gestoßen war. 
Bezug auf ethnische Identität beziehungsweise der Ablehnung und Skepsis gegenüber der kurdischen Bewegung. Unter den Schülern fand sich ein widersprüchlicher Widerschein dieser Abgrenzung. Zwischen ihnen und der Außenwelt war zum einen eine Grenze durch die Aneignung der religiös gezeichneten Sprache entstanden. Sie hatten das Selbstbewusstsein "gebildeter Städter« übernommen und unterschieden sich aus ihrer Sicht von den Weltauffassungen »ungebildeter Dörfler«. Zum anderen begriffen sie sich zwar als angehende Intellektuelle, die die meiste Zeit Bücher lasen und einmal an der Universität studieren wollten, doch sie grenzten sich gleichzeitig von einem bloßen Bücherwissen $a b$, betonten ihre Erfahrungen ethnischer Diskriminierung und Unterdrückung, die sie wiederum anders verarbeiteten als ihre Eltern und auch anders als die Erzieher im Heim.

Trotz der Abgrenzungspraktiken der Süleymancı schickten kurdische Familien ihre Kinder in das Heim. Das Bedürfnis, dem die Süleymancı mit dem Heim nachkamen, bestand nach Angaben der Kinder nicht in der religiösen Bildung, sondern darin, dass auserwählten Kindern aus kinderreichen Familien - ich traf auf Schüler mit 7 und mehr Geschwistern - die Chance eröffnet wurde, sich auf einen guten Schulabschluss in einem ruhigen Lernumfeld konzentrieren zu können. Die Eltern, so berichteten mir die Erzieher, zahlten einen kleinen Anteil an den Heimkosten, etwa ein Viertel, der größere Teil werde durch Spenden gedeckt. Die Süleymancı ermöglichen somit Kindern aus ärmeren Familien eine Bildungslaufbahn, die sozialen Aufstieg verspricht. Nebenbei vermitteln sie religiöse Praktiken und Weltauffassungen und versuchen dadurch, ihren Einfluss in der Gesellschaft - in diesem Fall in der kurdischen Bevölkerung - auszubauen.

Als politisch entstandene, kulturell unterlegte Grenze für diese Aktivitäten wurde der Krieg gegen die kurdische Bewegung erkennbar. Ihr Kampf zielte auf politische Selbstverwaltungsrechte und ethnische Anerkennung beziehungsweise Gleichstellung. Mit diesem Kampf war in langen Jahren der Auseinandersetzungen ein kurdisch-säkulares Hegemonieprojekt entstanden, das auch die spontane - in ihre sozialen Beziehungen eingelassene - Verarbeitung der überlieferten und erlebten Gewalt durch die Schüler prägte und zugleich im Widerspruch zur Auffassung der nicht-kurdischen Erzieher im Heim stand. Zwar grenzten sich die älteren Schüler gegenüber der legalen Partei DTP der kurdischen Bewegung und dem bewaffneten Kampf ab. Dennoch übernahmen sie nicht die Verachtung des »Volks« und die Indifferenz gegenüber erlittener Unterdrückung, die in die islamische-konservative Perspektive der Erzieher eingelassen war, sondern begriffen die PKK als Ausdruck notwendiger Selbstverteidigung. Sie hatten die kurdische Befreiungsperspektive durch Gründung eines Staates übernommen. Das Angebot der AKP, das den Familien der kurdischen Schüler die Integration in ihr Hegemonieprojekt auf der Grundlage einer islamisch-konservativen Identität versprach, wurde nicht angenommen - obwohl die AKP in Diyarbakır anders als der Orden der Süleymancı nicht von Türken, sondern maßgeblich von kurdisch- 
islamischen Akteuren getragen wurde. Die Perspektive der Schüler hatte sich vor dem Hintergrund der Erfahrungen von Unterdrückung, Diskriminierung und den Kämpfen der kurdischen Befreiungsbewegung herausgebildet. Sie spiegelte, dass ein großer Teil der kurdischen Bevölkerung davon ausging, dass das Kurdische im AKP-Projekt zwar als "folkloristisches Element« akzeptiert, aber weder mit Selbstverwaltungsrechten noch mit vollständiger Gleichstellung verbunden war (vgl. Saraçoğlu 2011).

Die Schüler hatten durch Bildung die Hoffnung auf einen sozialen Aufstieg und ein spezifisches intellektuelles Bewusstsein erworben, ohne jedoch die kulturelle (konservativ-islamische) Einbettung des Aufstiegs vollständig zu übernehmen. Auf der Grundlage ihrer sozialen Ressourcen - der Einbettung in ein »kurdisches« Netz in Kombination mit Erlebnissen, die von der kurdischen Bewegung politisch artikuliert wurden - hofften sie auf einen Transfer der Bildungsressourcen in ein kurdisches Projekt: »Ein kurdischer Staat wird gegründet«. Obgleich das Angebot von Bildung den Islamisten einen Zugang zur Bevölkerung verschaffte, indem sie als Vermittler von Chancen auftraten, konnten die Schüler die religiösen Elemente, die ihnen bei den Süleymancı vermittelt wurden, aus ihrer Einbettung in das konservativ-islamische Hegemonieprojekt lösen. Sie eigneten sich Bildung als kulturelle Ressource an, doch ließ ihre bereits bestehende soziale Einbindung - die ebenfalls als potentielle Ressource in einem noch nicht existierenden Staatsprojekt erkennbar wird - eine bloße Übernahme des Wissens nicht zu. Trotzdem vermittelten die Islamisten ihnen die Haltung von Intellektuellen, denen Führungsaufgaben zukommen. Die Schüler begriffen Bildung als Zugang zu Wissen, dessen Erwerb sie, anders als ihre Eltern, davor bewahrte, Geführte zu sein. Die Unterwerfung als Ungebildete, die nach Wahrnehmung der Schüler das Verhältnis der Eltern zur AKP prägte, war für sie nicht mehr denkbar. Zugleich formulierten sie eine tiefe Verbundenheit zur Familie, die sie in die intellektuelle Aufgabe transformierten, diese $\mathrm{zu}$ führen und von der durch »religiöse Formeln« perpetuierten Unterdrückung zu befreien. Unter den gegebenen Bedingungen eines langanhaltenden kurdischen Befreiungskampfs - »die in den Bergen haben unseren größten Respekt« - war die intellektuelle Aufgabe selbstbestimmt-kurdisch und nicht paternalistisch-konservativ-islamisch artikuliert.

Jede Verschiebung der Machtbalance, wie sie sich entgegen der Erwartungen der Schüler schon bald nach unserem Zusammentreffen zuungunsten der kurdisch-nationalen Selbstbestimmungsziele ereignete und deren Umsetzung unwahrscheinlich werden ließ, ging mit der Drohung einher, die angeeigneten kulturellen Ressourcen zu entwerten und den erhofften sozialen Aufstieg zu verunmöglichen. Die Verbindung der kurdischen Identität mit der Perspektive eines teil-autonomen oder nationalen Projekts wurde repressiv unterdrückt, wodurch sich die Chancen für die Realisierung der kulturellen Ressourcen in der Form eines Bildungsaufstiegs ohne Verknüpfung mit dem AKP-spezifischen islamischen 
Konservatismus erheblich verringerten. Den Schülern fehlte das »Türkischsein« oder zumindest die Internalisierung der Überlegenheit des Islamisch-Konservativen gegenüber dem Kurdischen. ${ }^{89}$ Sichtbar wird in diesem Geschehen die Verschränkung von Hegemoniebildung und Kräfteverhältnissen mit der Inwertsetzung von Ressourcen. Die notfalls auch mit Gewalt durchgesetzte Dominanz des islamischen Konservatismus, die gegenüber den kurdischen Autonomiezielen durch die Unterstützung von Neo-Kemalisten und Türkisten gestärkt wurde, in letzter Instanz jedoch auf der Fähigkeit basierte, die gesellschaftliche Führung der Bourgeoisie zu organisieren, bestimmte über die Auf- und Abwertung von Ressourcen. ${ }^{90}$

\subsubsection{Kompromissbildung und Integration}

Von der Diskussion über die Inwertsetzung von Ressourcen möchte ich nun zu einer abschließenden Einschätzung der Gemeinschaften im Verhältnis zu den politischen Institutionen und dem islamistischen Hegemonieprojekt in der AKP-Periode überleiten. Zunächst ließ mich eine weitere Beobachtung, die ich bei den Süleymancı machte, die Autorität der Diyanet über die religiöse Praxis neu bewerten. Die Süleymancı zelebrierten in ihrem Heim einen eigenen Gottesdienst. Der Tag begann durch den Gebetsruf eines Erziehers über die interne Lautsprecheranlage des Hauses. ${ }^{91}$ Kurz darauf folgte der Ruf aus der Moschee, die wenige Meter entfernt auf der gegenüberliegenden Straßenseite stand. Dem Ruf der Moschee folgte jedoch niemand aus dem Heim, sie versammelten sich in einem großen Raum und beteten dort gemeinsam. $\mathrm{Zu}$ anderen Tageszeiten beteten sie einzeln oder in Kleingruppen in Aufenthaltsräumen, wo sie sich gerade zufällig aufhielten. Nur gelegentlich zum Freitagsgebet gingen sie in die Moschee, erzählten mir die Erzieher, um in der großen Gemeinschaft zu beten, ansonsten unterhielten sie ihr eigenes System. Das Heim wurde von den Behörden offensichtlich als autonome Gebetsstätte neben der Diyanet geduldet. Solche Ausnahmen wurden mir auch über andere sunnitische Gemeinschaften wie die Menzil-Gruppe und die Gülen

89 Als Bestätigung dieses Zusammenhangs erscheint mir die Cegebenheit, dass »die in den Bergen«, also Mitglieder der PKK, zu einem signifikanten Teil über einen studentischen Bildungshintergrund verfügen, wie politisch verschiedentlich positionierte Akteure, mit denen ich in Diyarbakır sprach, auch Mitglieder der AKP und der Süleymancı, explizit hervorhoben. Im Anschluss an einen mehrjährigen »Friedensprozess«, mit dem Verhandlungen zwischen der AKP-Regierung und der PKK bezeichnet wurden, eskalierte der bewaffnete Konflikt ab 2015 auf eine qualitativ neuartige Weise. Bereits zuvor hatte sich ein Stellvertreterkrieg in Syrien zwischen islamistischen Milizen, die auch von der Türkei unterstützt wurden, und den militärischen Einheiten des Autonomieprojekts Rojava, die mit der PKK assoziiert waren, entwickelt (Babacan 2016; Yilmaz 2016).

91 Tatsächlich begann der Tag noch 15 Minuten früher durch die Handywecker meiner Nachbarn im Gästezimmer, die als individuelles Wecksignal den Cebetsruf eingestellt hatten. 
Gemeinschaft berichtet. Offensichtlich existierten größere Spielräume für sunnitische Gemeinschaften, sich als relativ autonome Institutionen zu etablieren, wie ich ja auch schon durch meinen Kontakt auf dem Campus der theologischen Fakultät in Izmir erfahren hatte.

Aus der Literatur geht hervor, dass die Grenzen dieser Autonomie politisch bestimmt sind. Über den 1980er Putsch wird berichtet, die Süleymancı hätten mit der Junta verhandelt, dass ihre Heime unangetastet blieben, sie im Gegenzug die Ziele der Putschisten aktiv unterstützten (Aydın, M. 2005). Zu dieser Zeit fungierte ein gemeinsames Feindbild als Kitt: Ein sehr weit definierter Kommunismus, der den sozialdemokratischen Linkskemalismus in den Reihen der CHP, die von Bülent Ecevit angeführt wurde, einbegriff. In Gesprächen zwischen den Erziehern kam die Sprache auch auf diese Periode:

R: Wenn Ecevit in den Siebzigern die Wahlen gewonnen hätte, dann wäre der Kommunismus in die Türkei eingezogen. Der hat das mit nur drei Abgeordneten verpasst.

K: Der Kommunismus hat 100 Millionen Opfer gefordert.

R: Nein, 50 Millionen waren es. So viele Menschen sind verhungert. Cott sei Dank gibt es keinen Kommunismus.

Die Süleymancı haben über die Zeit verschiedene konservative und türkisch-islamistische Parteien unterstützt, für die einzelne Mitglieder als Parlamentsabgeordnete und sogar als Minister tätig waren. Sie standen in Opposition zur Milli Görüş Bewegung wie auch später zur AKP, allem Anschein nach bedingt durch den Zwist mit den Imam Hatip Schulen, die als Domäne der Milli Görüş Bewegung beziehungsweise der mit ihr eng assoziierten anderen Gemeinschaften gelten. Die Erhebung der Türkisch-Islamischen Synthese zur Staatsdoktrin, die Förderung religiöser Aktivitäten und die Integration von Islamisten und Türkisten in die Bürokratie erweiterten die Grundlage für Kompromisse zwischen den Gemeinschaften. Çakır und Bozan stellen in diesem Zusammenhang fest, dass die Opposition seitens der Süleymancı gegenüber der Diyanet und den Schulen nach 1980 stark abgenommen hat (Çakır/Bozan 2005: 261ff.).

Obgleich manche Gemeinschaften in der Diyanet stärker als andere repräsentiert zu sein scheinen, bildet sie ein integratives Zentrum für die Gemeinschaften. Fethullah Gülen wie auch viele andere geistliche Oberhäupter islamischer Gemeinschaften, darunter der Mentor von Necmettin Erbakan, Mehmet Zahid Kotku, waren bei der Diyanet als Prediger angestellt. In einzelnen Ortschaften können bei der Diyanet angestellte Imame aus einem lokal verankerten Orden stammen, wie im Fall der Menzil-Gruppe, die im Südosten der Türkei ihre Basis hat und dort für die Restauration der Umma - der internationalen Gemeinschaft der Muslime - wirbt (Ozgur 2012: 118). Ein zweites integratives Zentrum für die Gemeinschaften ist die politische Partei, über die bürokratische und politische Posten sowie öffentliche Fördermittel verteilt werden. Schon in den 1970er Jahren wurde diese Form der In- 
tegration offensiv betrieben. ${ }^{92}$ Umstandslos belegen lässt sich der Nexus über die personelle Verflechtung, die auf der lokalen wie der nationalen Ebene keine Ausnahme, sondern die Regel ist (ebd.: 176). ${ }^{93}$ Die Gemeinschaften fungieren so wie die IHS als Rekrutierungsfeld für den öffentlichen Dienst. Als neue Qualität unter der AKP erscheint, dass einzelne Gemeinschaften ganze Ministerien besetzen oder dominieren und dort ihre gesellschaftliche Stellung auszubauen und abzusichern versuchen. Zum Zeitpunkt meiner Feldforschung nahm die Gülen Gemeinschaft eine hervorgehobene Position ein. Sie wurde nicht nur von Mitgliedern der Parteijugend als Türöffnerin in den öffentlichen Dienst gehandelt. Ein geflügeltes Wort bei Stammtischrunden war, dass in der Bürokratie die Ära der Mandelschnurrbärte angebrochen sei. Gemeint war ein Schnurrbarttyp, der mit der islamischen Identität assoziiert wurde.

Ein assoziierter Mechanismus der Integration ist die Allokation von öffentlichen Fördermitteln. Der Leiter des Süleymancı Heims berichtete, dass sie Projektgelder im Rahmen eines sozialen Unterstützungsprogramms erhielten. ${ }^{94}$ In einer Studie über Aktivitäten von Gemeinschaften im Bildungssektor wird eine Systematisierung von Allokationsmechanismen festgestellt. ${ }^{95}$ Demzufolge werden über verschiedene Wege wie die Unterstützung von Stiftungsuniversitäten und Wohnheimen Fördermittel aus dem Staatshaushalt an die Gemeinschaften transferiert. Die Stiftungen werden von Steuern befreit, bekommen öffentliche Immobilien überschrieben, Unternehmer werden gezielt zu Spenden an Einrichtungen der Gemeinschaften angehalten. ${ }^{96}$ Die Höhe der transferierten Mittel ist schwer zu bestimmen, da die Gemeinschaften jeweils ein Netz an Stiftungen, Vereinen und

92 Ein prominentes Beispiel ist Korkut Özal, der Bruder von Turgut Özal, der die prägende politische Figur der 1980er Jahre war. Korkut Özal war in den 1970ern wie auch sein Bruder Turgut Mitglied der islamistischen MSP, für die er Innenminister wurde. Er war Assoziierter des Nakschibendi-Ordens und platzierte Assoziierte im Sicherheitsapparat. In den 1980ern war er Teilhaber einer sogenannten islamischen Finanzinstitution aus Bahrain. Siehe Hakkı Özdal: Korkut Özal: Yeni rejimin kilit taşıydı [Korkut Özal war der Angelpunkt des neuen Rejimes], in: Gazete Duvar, 02.11.2016, https://www.gazeteduvar.com.tr/gundem/2016/11/02/ korkut-ozal-yeni-rejimin-kilit-tasiydi/ (Abruf am 23.10.2018).

93 Führende Mitglieder von Gemeinschaften haben höchste Posten erklommen. So war das Oberhaupt der Süleymancı Gemeinschaft Arif Ahmet Denizolgun in den späten 1990ern Minister in einer ANAP-Regierung. Siehe https://m.bianet.org/bianet/siyaset/ 181379-nokta-dergisi-30-yil-once-suleymancilari-neden-kapak-yapmisti vom 04.12.2016 (Abruf am 23.10.2018).

94 Es handelte sich um SODES (Sosyal Destek Programı). Siehe: www.sodes.gov.tr.

95 Siehe https://sendika63.org/2018/03/akp-tarikatlar-el-ele-egitimde-2023-hedefi-cihatci-nesiller-yetistirmek-479003/ vom 08.03.2018 (Abruf am 11.10.2018).

96 Siehe Serbay Mansuroğlu/Can Uğur: Eğitimde tarikat sisteminin şifreleri [Das Sektensystem in der Bildung], in: Birgün, 02.04.2016, https://www.birgun.net/haber-detay/egitimdetarikat-sisteminin-sifrelerini-anlamak-icin-yazi-dizisinin-tamami-107990.html (Abruf am 12.10.2018). 
Initiativen unterhalten, die unter verschiedenen Namen firmieren, die in der Regel keinen Hinweis auf die Gemeinschaft enthalten. Nach Recherchen und Schätzungen belaufen sich die aus dem zentralen Staatshaushalt transferierten Mittel in einer Höhe von mehreren Hundert Millionen US-Dollar. ${ }^{97}$ Insgesamt unterstreicht die Expansion islamischer Gemeinschaften, die auch über ihre Unternehmensnetzwerke Mittel in Infrastrukturen und »zivilgesellschaftliche« Aktivitäten transferieren und somit Einkommensmöglichkeiten schaffen, die materielle Attraktivität religiöser Weltauffassungen.

Indes ist das einst von Befürwortern der Diyanet ins Feld geführte Ziel, mit dem Ausbau der Behörde einen Krieg zwischen den verschiedenen religiösen Strömungen zu unterbinden, vor dem Hintergrund der Expansion der Gemeinschaften hinfällig geworden. Die Gemeinschaften konkurrieren um Einfluss und Zugang zur staatlichen Bürokratie. Nach 2013 ist mit der Ausstoßung der Gülen Bewegung diese Konkurrenz zum ersten Mal großflächig innerhalb der Bürokratie ausgebrochen. ${ }^{98} \mathrm{Zu}$ den Auslösern des Machtkampfs mit der Gülen Gemeinschaft, die mit der Zurückdrängung von Kemalisten in den Justiz- und Militärapparaten ihren Einfluss stark ausbauen konnte, zählten die regionalpolitische Positionierung der Türkei und die Politik in der »kurdische Frage«. Ferner deuten Indizien auf ökonomische Verteilungskämpfe, sofern mit der Gülen Gemeinschaft assoziierte Unternehmen bei der Vergabe staatlicher Ausschreibungen benachteiligt worden seien (Akçay 2018: 20ff.). Nach Ausstoßung der Gülen Gemeinschaften häufen sich journalistische Recherchen, wonach andere Gemeinschaften sich die staatliche Bürokratie untereinander aufteilen. ${ }^{99}$

Vor diesem Hintergrund kann die Bestimmung islamischer Gemeinschaften erweitert werden: Islamische Gemeinschaften sind informelle Parteien, die Machtzentren im Staat mit eigenen ökonomischen Aktivitäten und zivilgesellschaftlichen Elementen - Wissensstrukturen, Führungspraktiken, Loyalitäten - bilden. Verquickt mit religiösen Praktiken bilden sie informelle Herrschaftsknoten mit eigener Anhängerschaft, die sich auf die Partei(en) und Bürokratie verteilt. Sie kon-

97 Siehe https://t24.com.tr/haber/sayistay-acikladi-devletin-kasasindan-37-milyar-lira-kayip ,716145 vom 05.10.2018 und https://www.birgun.net/haber/yandas-vakiflara-4-5-milyardestek-180373.html vom 20.09.2017, (beide abgerufen am 12.10.2018).

Eine der ersten Ankündigungen dieser Rivalität erfolgte auf der Crundlage von Beobachtungen in den »]ustizkorridoren « durch den Richter Orhan Gazi Ertekin (2011). Er bestimmte die Kontrolle der Islamisten über die Justizapparate infolge des Verfassungsreferendums von 2010 als Schwelle. Nachdem der Machtkampf gegen die Kemalisten in diesem Bereich entschieden war, begannen die Auseinandersetzungen innerhalb des islamistischen Lagers. Siehe Deniz Coşan/Can Uğur: İşte Gülenciler sonrası ülkeyi saran tarikat ağları [Die landesweiten Sektennetzwerke nach den Cülenisten], in: Birgün, 29.10.2016, https://www. birgun.net/haber-detay/iste-gulenciler-sonrasi-ulkeyi-saran-tarikat-aglari-133401.html (Abruf am 23.10.2018). 
stituieren neben den staatlichen Institutionen eine private Reproduktionsstätte von professionellen Geistlichen - den Ulema - und erweitern deren Gruppeninteresse, das im Erhalt und im Ausbau ihrer Institutionen besteht, in den Bereich privater Organisationen.

\subsection{Grenzen des Kollektivs und integrative Mechanismen an seinen Rändern}

Religion wird in dieser Studie als ein besonderes Element thematisiert. Obgleich es bei verschiedenen Gelegenheiten wie dem Verhältnis zwischen Islamismus und Nationalismus oder der Verknüpfung religiöser Erziehung mit kulturellen und sozialen Ressourcen schon diskutiert wurde, sei nochmals explizit betont, dass Religion nur auf einer analytischen Ebene als separates Element thematisiert werden kann. In der Realität ist dieses Element in einen gesamtgesellschaftlichen Zusammenhang eingebettet. Religion tritt nicht als stets gleichbleibendes und isoliertes Element, sondern immer in historisch-kulturellen Artikulationen auf. Als kulturelle Praxis, die in ein Hegemonieprojekt eingebunden ist, ist sie ferner Bestandteil eines relationalen Feldes, in dem sie sich behaupten muss.

Eine Grenze für das Wirken der Religion trat in Izmir in der Form des Kemalismus auf. Ins Innere der islamistischen Bewegung wirkte die kemalistische Praxis der Grenzziehung dagegen vereinigend. Ein Parteimitglied aus dem kurdischen Osten, der dort einer radikalen islamistischen Gruppe angehört hatte, dann zum Studieren nach Izmir gekommen war, schilderte den Hintergrund für seine Mitgliedschaft in der AKP:

In meiner Klasse war ich der einzige Student aus dem Osten, von 29 war ich der einzige, und auch der einzige, der am Ramadan fastete. [...] Ich wurde gefragt, ob es in X [seine Herkunftsstadt] einen Puff gibt. Ich wusste damals nicht, was ein Puff sein soll, hatte bloß eine Vermutung und antwortete, dass es ein paar Nachtclubs gibt. Ein Schüler hat mich dann mitten im Unterricht blamiert, als einen der direkt aus einem Puff aus X kommt. [...] Der Lehrer hat nicht eingegriffen. [...] Ein anderes Mal bin ich im Englisch-Unterricht aufgefordert worden, ich soll mal was von $X$ erzählen. Ich habe mich abgemüht mit meinem miserablen Englisch, bis dann andere sich eingemischt haben. Sie haben das Bild eines primitiven Dorfes gezeichnet. Da habe ich realisiert, was es heißt, aus dem Osten in den Westen zu migrieren. Ich war erst total überrumpelt, dann habe ich gefragt, ob denn irgendwer je im Osten gewesen ist. Die Antwort: Nein. Ob denn jemand sich mal bewusst auseinandergesetzt hat, versucht hat, etwas zu erfahren über den Osten, über Bücher vielleicht. Die Antwort: Nein. Ich habe dann gesagt, dass sie kein 
Recht haben über den Osten zu urteilen. Dass sie hier alles haben, während im Osten alles fehlt. Danach bin ich nicht mehr in den Unterricht gegangen.

Dass die Erfahrung in Izmir wie auch in anderen nicht-kurdischen Städten der Türkei (vgl. Doğan 2016: 127ff.; Tuğal 2009: 216), aufgrund der Herkunft aus dem Osten, die hier auch für eine kurdische Identität steht, ausgegrenzt zu werden, als typisch angesehen werden kann, habe ich schon thematisiert. Zwei zentrale Faktoren, mit denen sich ein ausgrenzender Nationalismus verstärkt hat, der alles Östliche und Kurdische mit Primitivität, Dummheit und Unanständigkeit assoziierte, waren die bürgerkriegsbedingte Migration nach Izmir in den 1990er Jahren aus dem Osten der Türkei und die extreme Armut, in der Hunderttausende landeten. Sie wurden nicht wie frühere Migrationswellen von den Fabriken absorbiert, mussten sich stattdessen auf Dauer in informellen Behausungsformen einrichten, die kriminalisiert wurden. Sie wurden in informelle Beschäftigungsverhältnisse gedrängt, die in der Hierarchie zwischen den LohnarbeiterInnen auf der untersten Stufe standen. Der westtürkische Rassismus machte für das Verharren in Armut nicht die sozio-ökonomischen Verhältnisse und den Krieg, sondern die kurdischen BinnenmigrantInnen selbst verantwortlich, gegenüber denen herabwürdigende Ausgrenzungspraktiken entwickelt wurden. Die Konkurrenz zwischen den Arbeitskräften wurde zunehmend nationalistisch und rassistisch aufgeladen (Saraçoğlu 2010; Yıldırım/Haspolat 2010: 321f.).

Die AKP führte Kampagnen, die die Aufhebung dieser Diskriminierung und Ausgrenzung versprach, so auch die Kampagne mit der Überschrift »Demokratische Öffnung« in den Jahren 2009/2010, die im Laufe der Zeit in »Öffnung für Nationale Einheit und Zusammenhalt « umgeändert wurde. Die AKP stellte die staatsbürgerliche Identität zur Diskussion. Ein Effekt war die Eskalation des alltäglichen Rassismus. Die CHP und die MHP lehnten die Infragestellung der türkischen Identität empört ab. Nationalistische Mitglieder dieser Parteien ergriffen das Wort, die eine internationale Verschwörung, die Republik zu spalten, am Werk sahen. Sie sahen die Büchse der Pandora geöffnet, durch die alle neuralgischen Themen der Republik auf den Tisch kommen würden. Die Strategie der AKP bestand darin, möglichst wenig konkret zu werden, bei Andeutungen zu bleiben. Sie ließ die »links-liberalen« Intellektuellen über Fragen wie den Genozid an den Armeniern und Verbrechen wie das Massaker an den alevitischen Kurden in Dersim 1937/38 diskutieren, stellte ihnen mediale Mittel zur Verfügung und schaute zu, wie sich die CHP und die MHP in reaktionärer Abwehr nationalistisch verhärteten.

In der Lokalität von Izmir ging diese Strategie der AKP nur bedingt auf, sie sorgte für Reibungen und Irritationen. An der Basis machte sich der türkische $\mathrm{Na-}$ tionalismus bemerkbar. Die jungen Erwachsenen, die sich den Nurcu angeschlossen hatten und sich in der Partei organisierten, waren sich einig, dass Türkischsein und Muslimsein sich gegenseitig bedingten. Kurdische Mitglieder der AKP protes- 
tierten gegen diese Gleichsetzung. Die Differenz blieb bestehen, führte aber nicht zur Spaltung, da sich der türkisch-islamische Nationalismus innerhalb der Partei nicht unmittelbar gegen Kurden als ethnische Gruppe richtete. Prägend war eher eine Feindschaft, die sich gegen die kurdische Bewegung richtete und diese als kriminellen Organisationszusammenhang denunzierte. Die kurdische Bevölkerung stand dieser Ansicht nach außerhalb dieses Zusammenhangs, von dem sie unter Druck gesetzt und terrorisiert wurde. Auch die Kurden in der Partei standen in deutlicher Distanz zur kurdischen Bewegung. Sie begriffen sie jedoch eher als ein Symptom der Leugnung der kurdischen Ethnie und nicht als Ursache des Problems, wie es unter türkischen Islamisten Konsens war.

Kritik und sich widersprechende Ansichten zwischen kurdischen und nicht-kurdischen Islamisten in der AKP transformierten die Differenz während meines Feldaufenthalts nicht in eine Spaltung, obgleich es eine Reihe prekärer Situationen gab. Von einer solchen Situation berichtete ein Mitglied, das große Hoffnungen in die Lösung der kurdischen Frage durch die AKP setzte:

Letzten Monat hat das landesweite Treffen der AKP-Jugend in Izmir stattgefunden. Auch Erdoğan ist gekommen. Zur Vorbereitung haben wir ein Komitee gebildet, in dem ich, ein zweiter und unser Jugendvorsitzender Mitglied waren. Wir haben eine Begrüßungsrede für Erdoğan vorbereitet, dazu ein kleines Video und ein Transparent, auf dem ein Ende des Sterbens unserer Kinder in den Bergen gefordert wurde. Es wurden Städte aufgezählt, Städte im Osten und im Westen, in denen es Tote zu beklagen gab. [...] Am Abend vor Erdoğans Ankunft ist einer seiner Berater vorbei gekommen, um sich die Vorbereitungen anzuschauen. Als er das Transparent gesehen hat, hat er es abhängen lassen. Wir waren verärgert, auf dem Transparent stand nicht mehr, als an anderer Stelle schon von Parteigrößen gesagt wurde. Unser Jugendvorsitzender wollte es in der Partei thematisieren, er hat es dann aber gelassen, weil die Veranstaltung insgesamt ein voller Erfolg gewesen ist und dies nicht überschattet werden sollte. Das hat mich überzeugt.

Der Spruch auf dem Transparent war in eine Kampagne der AKP eingebettet, zu der auch der Slogan »Unsere Mütter sollen nicht weinen« gehörte. Mit Kindern war nicht eine Altersgruppe gemeint. Die Kinder der Mütter waren die Gefallenen im Krieg. Die Berge benannten den Ort des Geschehens unter Vermeidung des Wortes Kurdistan. In Phasen der Verhandlungsführung zwischen der Regierung und der PKK wurde eine Sprachregelung aktiviert, die die in den Phasen der offenen Kriegsführung benutzten Wörter - Krieg, gefallene Soldaten, Terroristen - ersetzte. Die Bevölkerung wurde als eine große Familie konzipiert, die am gleichen Übel litt, dessen Verursachung dem Kemalismus zugeschoben wurde (vgl. Saraçoğlu 2011). Der Kurs der AKP in der kurdischen Frage folgte - wie auch schon bei den Vorgängerregierungen - taktischen Richtlinien. Auch während der Verhandlungsphasen konnte es zu plötzlichen Diskurswechseln kommen, die nicht 
mit den einzelnen Gliederungen der Partei abgesprochen wurden. Die Parteijugend, die einen erheblichen Teil der Kampagnenarbeit vor Ort schulterte, stand vor der Herausforderung, der Izmirer Bevölkerung diese Wechsel zu vermitteln, eine Aufgabe, die schwieriger wurde, wenn Verhandlungen geführt und Zugeständnisse gemacht wurden. Als die PKK, wie schon erwähnt (S. 266), eine Delegation in die Türkei schickte, die die Grenze vom Irak über den Grenzort Habur passieren durfte, ohne dass eine strafrechtliche Verfolgung eingeleitet wurde, war diese Delegation von hunderttausenden KurdInnen auf der Straße euphorisch empfangen worden. In der Parteijugend sorgte der Vorgang für erhebliche Unruhe:

E: Es gibt Probleme in der Organisation. Es gibt Unruhe wegen Habur. Ich habe an einem Bezirkstreffen teilgenommen und das Thema angesprochen. Der Bezirksvorsitzende meinte, das Thema soll nicht diskutiert werden. Niemand kenne den Inhalt der Demokratischen Öffnung, deshalb sollten wir nicht an Diskussionen teilnehmen. Diskussionen sollten nur innerhalb des Parteivorstands stattfinden. Dagegen gab es Proteste, es soll diskutiert werden, warum denn keine Diskussion?

L: Ja, genau das ist das Problem.

E: Es wird zu einem Problem innerhalb der Organisation.

L: Das Thema ist heikel. Ein falsches Wort kann in jede Richtung ausgelegt werden. Ihr müsst genau darauf achten, was ihr sagt. Informiert, aber bleibt sehr oberflächlich. Fordert das Niveau des Gegenübers nicht heraus.

E: Ja aber, die in der Leitung sind sehr unruhig geworden.

L: Im Endeffekt ist es unsere Politik. Aber bei solchen Sachen läuft es manchmal nicht so, wie geplant. Das müssen wir zuerst in der Organisation klären. Bei den Wahlen wird es das bestimmende Thema sein. Schaut, es heißt Demokratische Öffnung. Das hat nicht nur mit den Kurden zu tun.

E: Wir müssen diskutieren, warum wir ein solches Paket benötigen.

$X$ : Das Thema wird überall diskutiert, sogar beim Tee trinken im Teehaus. Es heißt, draußen sticht einer einen anderen mit einem Messer ab und bekommt vier Monate Gefängnisstrafe und die PKKler werden zwei Minuten befragt und dann laufen gelassen. Wie sollen wir das erklären?

L: Eben, ohne die Details zu kennen, ist es besser, nicht zu diskutieren.

$X$ : Wir müssen erklären, dass es eine Systemfrage ist, kein Türken-Kurden-Problem.

L: Ja, deshalb müssen wir an der Politischen Akademie teilnehmen. Die Demokratische Öffnung wird dort erklärt. Ohne Wissen, mit Informationen aus den Medien, nur mit Hörensagen können wir nicht diskutieren.

Inwiefern die Politische Akademie, die eine Reihe von Bildungsseminaren darstellte, die die AKP veranstaltete, dazu verhalf, das Problem in den Griff zu bekommen, werde ich an späterer Stelle diskutieren. Die Parteijugend einigte sich, sich nicht auf Diskussionen einzulassen. Ähnlich wie beim Republik SymphonieOrchester (vgl. S. 194ff.) wurde akzeptiert, dass von der Parteileitung Taktiken an- 
gewendet werden, die nicht ganz durchschaubar waren. In der kurdischen Frage führte der Wechsel zwischen einem nationalistisch-ausgrenzenden und einem versöhnend-eingrenzenden Diskurs jedoch zu stärkeren Ärgernissen und Verwirrungen. In Abgrenzung zum kemalistischen Gegenüber, das vereinigend nach innen wirkte, sorgten drei miteinander verschränkte Mechanismen dafür, dass Differenzen sich nicht in Spaltungen transformierten und das Hegemonieprojekt angesichts diverser Herausforderungen und Widersprüche nicht an seinen Rändern zerbröckelte: Die Gateholder, die bewegungsgeschichtliche Bindung und die gemeinschaftsbildende Praxis in der Gruppe.

\subsubsection{Gateholder}

Ein starker und zugleich prekärer Mechanismus des Zusammenhalts nach innen bestand darin, dass immer eine »integre« Person in den Reihen der Partei gefunden wurde, durch die Zusammenhalt wieder hergestellt wurde. Ich möchte diese Personen als Gateholder bezeichnen. Sie erkannten Probleme oder Widersprüche an und sprachen dies aus. Sie traten ebenso als Personen auf, die Ideale der Partei wie Aufrichtigkeit, Bindung an Programme, Demokratie und Menschenrechte verkörperten. Sie hielten damit Türen offen und moderierten. ${ }^{100}$

Ein Mitglied der Parteijugend aus dem kurdischen Osten, wie die meisten ein Student an der Izmirer Universität, erzählte:

Bei einem Bildungscamp der Partei habe ich Aksu [damaliger Innenminister von der AKP] nach der Ungerechtigkeit gefragt, die wegen den Terrorbekämpfungsgesetzen entsteht. Hunderte kurdische Kinder werden wegen Bagatellen eingesperrt. Ich habe keine Antwort, wenn wir deshalb kritisiert werden, habe ich gesagt. Aksu wich aus. Ein anderes Parteimitglied aus Yozgat [mittelanatolische Stadt] meldete sich zu Wort: >Die schmeißen mit Steinen auf meine Polizei, ich bring die alle um<. Aksu sagte daraufhin nur, >löst das unter euch <. [...] Am selben Tag ist abends Arslan [kurdisch-islamischer Parlamentsabgeordneter der AKP] gekommen, morgens war Aksu, abends Arslan da. Er hat auch über die Demokratische Öffnung gesprochen. Wir müssen einen Kompromiss mit den Institutionen finden, um das Problem zu lösen, sagte er. Daraufhin habe ich mich gemeldet: Okay, habe ich gesagt, ich sehe das Problem, der Hochschulrat, das Militär tragen nicht annähernd so viel zur Lösung des Problems bei wie wir. Aber ich sehe auch, dass wir in der Partei ein Problem haben. Mal angenommen, wir

100 Das Konzept des »Gateholders«schließt an das von Kurt Lewin (1943: 40ff.) entwickelte Konzept des Gatekeepers an, mit dem er am Rande einer Studie Vermittlungs- und Kontrollaktivitäten von Akteuren in Bezug auf Entscheidungsprozesse beschrieb. Der Gateholder zielt auf Aktivitäten, die die Verbindung zu einer Verhaltensweise oder einer Organisation auch dann noch aufrechterhalten, wenn Zweifel an ihr entstanden sind. 
haben einen Kompromiss mit den Institutionen gefunden, was machen wir mit der Partei? Er hat nur gelacht. Später haben wir uns privat unterhalten und er hat zugestanden, dass es ein manifestes Problem in der Partei und auch an der Basis gibt. Da konnte ich nur beipflichten. Ich habe es dir ja schon erzählt, auf dem Camp wurde ich angemacht, ob ich denn von der TKP [Kommunistische Partei der Türkei] bin, was ich denn für ein Muslim sei.

Das kurdische Parteimitglied bewegte sich am Rande der Ausgrenzung aus der Partei. Er hatte auf dem Treffen den türkischen Nationalismus des Militärs kritisiert, dieses für die Unterdrückung der kurdischen Bevölkerung und das Antreiben des Kriegs verantwortlich gemacht. Daraufhin hatten Parteimitglieder aus den mittel- und nord-anatolischen Provinzen sich gegen ihn gestellt und selbst offensiv den türkischen Nationalismus vertreten. Den Anwurf, Kommunist zu sein, setzten sie als Stigma gegen ihn ein, mit dem sie Kritik am türkischen Nationalismus, den sie mit Muslimsein gleichsetzten, unmöglich machen wollten. Sein Fall gibt zugleich zu erkennen, dass kurdische Mitglieder der AKP aufgrund ethnischer Zugehörigkeit mit der virulenten Gefahr der Abwertung ihrer sozialen Ressourcen, die sich über die Mitgliedschaft im islamistischen Kollektiv und den assoziierten Chancen herstellte, konfrontiert waren. Doch trotz scharfer Konfrontation blieb das kurdische Mitglied in der Partei. Der kurdisch-islamische Abgeordnete vermittelte ihm, dass er nicht alleine war. Seine Hoffnungen in die Partei wurden aufrechterhalten durch eine Person, deren Einfluss durch den hohen Rang als Abgeordneter unterstrichen wurde.

Der Mechanismus wirkte auf verschiedenen Ebenen. Das gleiche Mitglied der Parteijugend bewunderte Erdoğan. Erdoğan stand für Integrität und die AKP für »besseres Regieren«. Sich selbst bezeichnete er als Idealisten, was er mit einer Kritik verband. Es gab »Probleme«, »in jeder Organisation gibt es Menschen, die aus unterschiedlichen Gründen da rein gehen«. Er war nicht einverstanden, dass die Bürgermeisterkandidaten nach der »Dicke ihres Portemonnaies« ausgewählt wurden. Für die Kandidatur seien Ausgaben zu bestreiten, die nur durch erhebliche Spenden oder eigenes Geld beglichen werden könnten. Der Wahlkampf sei eine noch viel größere finanzielle Herausforderung. Das bereite Opportunisten den Weg, sich in der Partei breit zu machen. Trotz Kritik war er überzeugt, dass bei der Auswahl Qualifikation und Bindung an das Parteiprogramm überwiegen würden. Die letzte Entscheidung über die Kandidaten treffe Erdoğan, der schon korrigierend eingreifen werde. Ein Jahr später, im Winter 2010, war sein Idealismus einer Ernüchterung gewichen. Ereignisse wie das bereits erwähnte Parteijugendtreffen, bei dem ein Mitarbeiter von Erdoğan das Transparent, auf dem ein Ende des Sterbens gefordert worden war, hatte abhängen lassen, und der lauter werdende türkische Nationalismus in der Partei hatten seine Zweifel verstärkt. Seine Kritik war deutlicher geworden, er äußerte sie auf den Treffen der Parteijugend, brachte zu- 
meist als einziger Bedenken zur Parteipolitik an. Dem Jugendvorsitzenden gelang es, die Kritik zu moderieren und ihn einzubinden: "Du kannst etwas verändern «, habe er ihm gesagt, »wenn du nicht dabei bist, bist du verantwortlich, dass die anderen sich durchsetzen. « Der Vorsitzende fand Erklärungen wie »den vollen Erfolg des nationalen Jugendtreffens, der nicht überschattet werden sollte«, die ihn bis zum nächsten Konflikt versöhnten.

Zweifler und Idealisten innerhalb der Partei konnten selbst als Gateholder nach außen wirken. Sie vermittelten das Bild einer pluralen Partei, in der Ideale vorhanden sind. Als die AKP die Abstimmung über die Verfassungsreform von 2010 in die Wege leitete und hierfür gesellschaftliche Unterstützung mobilisierte, hielten Gateholder in Izmir den Kontakt zu (links-)liberalen Akteuren außerhalb der Partei und organisierten mit ihnen die Wahlkampagne »Ja, aber nicht genug« (vgl. S. 37f.). Die Kampagne wurde von der Kritik am Militär und türkischen Nationalismus beziehungsweise den Kemalisten als Träger dieses Nationalismus zusammen gehalten, während zum gleichen Zeitpunkt, wie dargestellt, kritische Diskussionen zum türkischen Nationalismus innerhalb der Partei und zur Anerkennung der kurdischen Identität unterdrückt wurden.

Einem weiteren Beispiel für das Wirken des Mechanismus des Gateholders durch regelhafte Einbindung von Nichtmitgliedern begegnete ich in Diyarbakır. Nachdem mir der Provinzvorsitzende des islamischen Menschenrechtsvereins in Diyarbakır dargelegt hatte, dass die AKP nach Aufnahme der EU-Beitrittsgespräche im Jahr 2005 alle Liberalisierungen im Straf- und Polizeirecht zurückgenommen, sogar über den Status quo ante hinausgehende Verschärfungen vorgenommen habe, schränkte er auf meine Bemerkung, dass es jetzt also schlimmer war als zuvor, sogleich ein:

Ich denke, dass es in der Regierung sehr aufrichtige Menschen gibt, die kämpfen, die für Menschenrechte und die Demokratie einstehen wollen, damit sie sich in der Türkei etablieren. Aber es gibt einen nationalistischen Flügel, der von innen Widerstand leistet. Das zeigt sich von Zeit zu Zeit. Der Schlingerkurs der Regierung hängt meiner Meinung nach damit zusammen.

Der Vorsitzende berichtete, dass sie in Treffen und Beratungsrunden mit der Regierung eingebunden seien, dass die Regierung sie in die Lösung der kurdischen Frage einbeziehe. Die Treffen verliefen sehr offen, Probleme würden angesprochen. Er begründete die Einschränkung seiner Kritik mit dem Verweis auf einzelne Parteimitglieder, denen er auf diesen Treffen begegnete und die er aufgrund ihrer Verwurzelung in der islamischen Menschenrechtsbewegung für integer hielt.

Einzelne Personen wurden zu Gateholdern, weil Diskrepanzen zwischen Idealen und realen Entwicklungen auftauchten. Der Gateholder fachte Hoffnungen an, dass es genug Widerspruchsträger in der Partei geben könnte, um verhinderte Auseinandersetzung, ausbleibende Diskussion innerhalb der Partei irgendwann in der 
Zukunft mal führen zu können. Er hielt entweder selbst an den Idealen fest und wirkte dadurch integrierend oder er integrierte Personen, die an den Idealen festhielten, während die Partei in der realen Politik sich von den Idealen entfernte, indem sie Krieg führte, nationalistisch agitierte und ihre Kandidaten opportunistisch rekrutierte.

\subsubsection{Bewegungsgeschichtliche Bindung}

Die Breite der islamistischen Bewegung, die seit den 1970ern sich sukzessive in allen gesellschaftlichen Bereichen organisiert hatte, bildete die Grundlage für den zweiten Mechanismus: die bewegungsgeschichtliche Bindung, die über Kämpfe mit einem »Außen« hergestellt wurde. Der gerade erwähnte islamische Menschrechtsverein war Anfang der 1990er von einem sehr breiten Spektrum sunnitischer Intellektueller gegründet worden. Den initialen Schwerpunkt seiner Tätigkeiten bildeten Kämpfe, die zunächst auf der Grundlage der Erweiterung des als Grundrecht begriffenen sunnitischen Sonderstatus und dann für dessen Verteidigung und gegen kemalistische Diskriminierung (Kopftuchverbot) geführt wurden. Der 1997er Prozess, der mit diversen Verboten und der Verhinderung von Karrieren einherging, hatte ein starkes Notwendigkeitsbewusstsein geschaffen, die religiösen Reihen geschlossen zu halten. In den späten 2000ern hatten mit der kurdischen Frage verbundene Kämpfe eine Erweiterung des Tätigkeitsfelds des Vereins und damit auch eine relative Ablösung von den allein auf die sunnitische Identität bezogenen Kämpfen initiiert. Doch trotz inzwischen manifester Widersprüche, entstanden in der siebenjährigen Regierungstätigkeit der AKP, schätzte der Vorsitzende des Vereins in Diyarbakır die Wirksamkeit menschenrechtlicher Ideale in der Partei weiterhin als hoch ein, zumal die Kämpfe um die Wiederherstellung des sunnitischen Sonderstatus und Aufhebung der Diskriminierung durch das pauschale Kopftuchverbot noch nicht ausgefochten waren. ${ }^{101}$ Die Einbindung in das soziale Netzwerk, das bewegungsgeschichtlich gekennzeichnet war, ließ ihn einen nationalistischen Flügel bestimmen, um die Verzerrung der integren Absichten der Bewegung, der er sich angehörig fühlte, zu begreifen.

Die bewegungsgeschichtliche Bindung integrierte auch radikale Islamisten wie den Grundschullehrer, der die Studenten unterwiesen hatte, bevor sie sich an den Koranlehrer der Diyanet wendeten (vgl. Kap. 6.1.3), sowie Mitglieder eines islamistischen Vereins in Izmir, die die AKP für nicht islamisch genug hielten. Der Verein

101 Der Menschenrechtsverein spaltete sich zu einem späteren Zeitpunkt an der Frage der Niederschlagung des Juni-Aufstands durch die AKP im Jahr 2013. Einige Gründungsmitglieder des Vereins schlossen sich der HDP und einige der CHP an. Die bewegungsgeschichtliche Bindung überdauerte in diesem Fall nicht die Kämpfe um den sunnitischen Sonderstatus, der durch die Schulreform von 2012 wieder weitgehend hergestellt worden war. 
engagierte sich besonders für die Gleichstellung der Imam Hatip Schulen und Aufhebung des Kopftuchverbots. Im Umfeld des Vereins bewegte sich auch eine kleine Gruppe von Studenten, die im Koran nach Anhaltspunkten für eine "Alternative zum Kapitalismus« suchten. Islamistische Weggefährten vor Augen, die ehemals für eine gerechte Gesellschaft gestritten, nun aber Reichtum angehäuft hatten, wurden sie von einem Unbehagen mit dieser Entwicklung angetrieben. Sie leisteten jedoch keine angeleitete Begriffsarbeit, die eine Kritik der kapitalistischen Produktionsweise ermöglicht hätte, verloren sich stattdessen in der Vielfalt möglicher Interpretationen des Koran. Ihr konkretes politisches Wirken blieb auf Aktivitäten begrenzt, die innerhalb des von der AKP vorgegeben Möglichkeitsraums, in die Behauptung des sunnitischen Sonderstatus, eingebettet blieben. Unter der Regierung der AKP konnten sie frei agieren, während sie von den »Laizisten« Repressionen erwarteten, die ihre Laufbahnen bedrohten und die Abwertung der mit der religiösen Erziehung assoziierten kulturellen Ressource Bildung fortsetzen würden, die durch den 1997er Prozess eingeleitet worden war. Der Bezug auf eine Geschichte der Ausgrenzung aus den staatlichen Institutionen durch das kemalistische Gegenüber in Kombination mit einem religiösen Idealismus überbrückte Differenzen innerhalb des Kollektivs, bevor sie zu Spaltungen werden konnten.

\subsubsection{Gemeinschaftsbildende Praxis}

Als drittes Element trat die gemeinschaftsbildende Praxis in der Gruppe hervor. Für das Wirken dieses Mechanismus, der durch gemeinsames Lernen und Aneignung von Weltauffassungen, durch praktizierte Religion gruppenbildend wirkte, stehen bereits exemplarisch der Koranunterricht (Kap. 6.1.3), das Sohbet der Nur$\mathrm{cu}$ (Kap. 6.6.1) oder die AKP-Jugendtreffen, obgleich bei letzteren der religiöse Aspekt nicht immer im Vordergrund stand. Voraussetzung für das Wirken war die Bereitschaft der Teilnehmer, die Regeln der Gruppe zu befolgen und sich in die autoritären Strukturen einzufügen. War diese Bereitschaft nicht vorhanden, kam es zu Ausschlüssen, so bei einem Studenten, der nach seiner ersten Ankunft in Izmir notgedrungen, weil über keine ausreichenden finanziellen Mittel verfügend, in einem Wohnheim einer islamischen Gemeinschaft untergekommen war, das offenbar auch Akteuren Unterkunft bot, die keine Assoziierten der Gemeinschaft waren. Schon nach wenigen Wochen habe er vor dem Rauswurf gestanden, weil er gerne diskutierte, wie er sagte. Dass er Meinungen vertrat, die von denen der Gemeinschaft abwich, sei zum Problem geworden, als er die Differenzen ausdiskutieren wollte. Er sei dem Rat eines Abi (»Älteren«) gefolgt, sich solange zurückzuhalten, bis er sich nach einem Jahr eine andere Unterkunft leisten konnte. Seine Erzählung fügt sich in meine Beobachtung ein, dass islamistische Akteure, die keiner religiösen Gemeinschaft angehörten, die nicht in von religiösen Autoritäten angeleitete Rituale eingebunden waren, die die Diskussion lenkten und ihr enge 
Grenzen steckten, weniger festgelegt und offener gegenüber Einflüssen von außen waren. Ihnen fehlte die geregelte paternalistische Praxis der Mitglieder der islamischen Gemeinschaften. Ihre Integration in das islamistische Hegemonieprojekt wurde in erster Linie durch die Mechanismen des Gateholder und der bewegungsgeschichtlichen Bindung in Konfrontation mit dem Kemalismus aufrechterhalten. Sie wurden jedoch auch durch eine gemeinschaftsbildende Praxis integriert, die durch Bildungsaktivitäten der Partei unter der Bezeichnung Politische Akademie hergestellt wurde. Im Folgenden gebe ich meine Einblicke in diese Bildungsaktivität als Aushandlungsprozess einer Gruppenidentität wieder, bei dem Abweichungen zurückgeholt und Konsens wiederhergestellt wurde.

Hale und Özbudun schreiben in ihrem Buch über die AKP, dass »der Unterschied zwischen einer Massenpartei und einer Kader- beziehungsweise Volkspartei über den Stellenwert parteiinterner Bildung und Indoktrination « (2010: 48, Übersetzung E.B.) festgestellt werden könne. Im Unterschied zu anderen Parteien in der Türkei stufen sie die AKP auf der Grundlage ihrer gezielten und umfangreichen Bildungsaktivitäten als Kaderpartei ein. Die ersten Interviews, die ich mit AKP-Mitgliedern in Izmir führte, stützten diese Einschätzung. Es hieß, seit 2004 fänden in allen Provinzen regelmäßig Seminarreihen gegen eine geringe Teilnahmegebühr statt, die auch für Nichtmitglieder offen seien. Die Rede war von der Politischen Akademie. Insbesondere die Parteijugend, auch der Parteivorstand seien aufgefordert, an der Akademie teilzunehmen, verpflichtend sei die Teilnahme für diejenigen, die für ein politisches Amt kandidierten. Als Themen vergangener Seminarreihen wurden »Good Governance in der Kommunalverwaltung« und "Self-Improvement « genannt, wofür die Partei auch Professoren engagiert habe, die auf Hochschulniveau unterrichteten. Bei der letzten Runde hätten $18.000 \mathrm{Ab}$ solventen ein Zertifikat erhalten. Durch die Interviews entstand bei mir der Eindruck reger Bildungsaktivitäten. Im Laufe der Zeit erfuhr ich durch Gespräche, dass es erhebliche Probleme bei der Teilnahme gab. Anfangs seien zu den Seminaren, die für 60-70 Leute konzipiert waren, nur 6-7 gekommen. Als die Teilnahme daraufhin verpflichtend gemacht wurde, hätten viele zwar die Teilnehmerliste unterschrieben, aber nicht teilgenommen.

Die Veranstaltung mit Hüseyin Çelik, die ich in einem früheren Kapitel über die Formen des Kulturkampfs in der AKP-Periode geschildert habe (S. 197ff.), war die Eröffnung einer solchen akademischen Bildungsreihe im Zuge der sogenannten Demokratischen Öffnung. Die Eröffnungsveranstaltung endete ohne Diskussion. In den folgenden beiden Monaten wurden Seminare angeboten, die in der Izmirer Parteizentrale abgehalten wurden. Die ersten beiden Seminare bestanden aus Vorträgen von Parlamentsabgeordneten und blieben ohne kontroverse Diskussion. In Vortragsform wurden die Säulen des Konservatismus - die Familie, die Tradition, die Nation und die Religion - sowie Eckpunkte der konservativen Geschichtsauffassung umrissen. Diese möchte ich nochmals in Erinnerung rufen: Das Ende 
des Osmanischen Reichs als Beginn einer Unterdrückungsgeschichte des religiösen Volks und die DP-Periode als Phase der Entwicklung des »kulturell Authentischen «, die durch einen »bürokratischen« Putsch beendet wurde. Redner und Teilnehmer einigten sich mühelos darauf, dass Symbole der »DP-Freiheit « in der Wiedereinführung des arabischen Gebetsrufs und der »Befreiung der Religion aus der Klandestinität« bestanden.

Die Teilnehmerzahl der ersten beiden Seminare lag bei etwa 20 und war fast ausschließlich auf die Parteijugend begrenzt. Aus dem Parteivorstand kamen keine Teilnehmer. Erst die dritte Veranstaltung unterschied sich, sie war mit etwa 50 Teilnehmern, überwiegend junge Männer aber auch ein paar junge Frauen, die sich separat setzten, gut besucht. Es wurde rege diskutiert. Der eingeladene Redner war ehemaliger landesweiter Vorsitzender der gleichen islamischen Menschenrechtsorganisation, deren Provinzvorsitzenden von Diyarbakır ich schon zitiert habe. Sein Vortragsthema hieß Menschenrechte. Er begann mit einer internationalen Geschichte der Menschenrechte, der er keine islamische Interpretation zur Seite stellte, wie vielleicht aufgrund des islamischen Kontexts zu erwarten gewesen wäre. Stattdessen betonte er die Universalität von Menschenrechten und grenzte sie gegen eine kulturelle Relativierung ab. Akzeptanz von Differenz sei zentrales Prinzip von Menschenrechten, die nur in einem Rechtsstaat mit Gewaltenteilung und Bürgerrechten garantiert werden könnten, weshalb Menschenrechte und Rechtsstaatlichkeit sich gegenseitig bedingten. Auf die zu dieser Zeit im Rahmen der »Demokratischen Öffnung« diskutierten Themen des Rechts auf muttersprachlichen Unterricht in Kurdisch und der Anerkennung alevitischer Gebetsstätten Bezug nehmend befand er, dass diese als Menschenrechte anzuerkennen und rechtlich zu garantieren seien.

Nachdem er seinen Standpunkt dargelegt hatte, ließ der Redner die TeilnehmerInnen zu Wort kommen. In einer Reihe von Kommentaren hoben diese hervor, dass Menschenrechte vor allem gegenüber Afrikanern und Muslimen nicht eingehalten würden. Warum nicht über die dahinterstehenden Ursachen, den Kolonialismus und die Doppelzüngigkeit des Westens, gesprochen werde, wurde gefragt. Implizit war mit diesen Fragen ein Perspektivwechsel verbunden, indem nicht die inländische (Rechts-)Lage, sondern die »eigene« Diskriminierung durch das westliche Ausland thematisiert wurde. Der Redner stimmte der Benennung dieser Ursachen zu, betonte aber zugleich, dass die Praxis der Anderen keine Ausrede für die Nichtthematisierung eigener Praxis sein dürfe. Er thematisierte erneut die Problematik der Nichtanerkennung von Differenz und führte aus, dass in der Türkei die Ursache ausbleibender Anerkennung beim Staat liege, der Angst vor den Bürgern habe. Infolge der Gründungsgeschichte und des Befreiungskrieges lebe der Staat in einer permanenten Psychologie der Angst, von außen wie von innen angegriffen und zersetzt zu werden. Differenz werde vorschnell als Separatismus wahrgenommen. Erneut auf die »Demokratische Öffnung« Bezug nehmend befand er, dass die 
Menschenrechte eingelöst werden könnten, wenn die Staatsgewalt ihre Angst ablege. Durch die Regierung der AKP sei dies erstmals in den Bereich des Möglichen gerückt.

Auf diese Problembestimmung, die den Staat als Eigenwesen begriff, das sich vom »Volk« entfremdet hatte, folgte eine zweite Reihe von Kommentaren. Sie suchte die Tanzimat-Reformen im 19. Jahrhundert als Beginn eines Auseinanderlaufens von Staat und Volk im Osmanischen Reich zu erinnern. Da die Republik sich in dieser Tradition entwickelt habe, habe sich die Türkei nicht demokratisieren können. In den Kommentaren ausdrücklich ausgeklammert wurde die DP-Periode, in der eine demokratische Entwicklung - ein Zusammenrücken von Staat und Volk eingeleitet aber durch den Putsch unterbrochen worden sei. Diese Kommentare griffen zwar die These der Verselbständigung staatlicher Aktionen aus »Angst vor dem Volk« auf. Doch sie verlegten deren Ursprung um einige Jahrzehnte weiter zurück und betonten erneut als Ursache der Problementstehung eine »westlich« beeinflusste Politik, mit der die Tanzimat-Reformen (S. 126f.) angezeigt wurden. Auf der von den TeilnehmerInnen neu bestimmten thematischen Grundlage handelten der Redner und die TeilnehmerInnen in der Folge einen Konsens aus, bei dem sich der Redner den TeilnehmerInnen annäherte. Hergestellt wurde eine Perspektive auf das Osmanische Reich, durch die es zum positiven Bezugspunkt für Menschenrechte und Anerkennung von Differenz wurde. Obwohl der Redner damit begonnen hatte, Rechtsstaatlichkeit und Gewaltenteilung als Bedingung für die Umsetzung von Menschenrechten zu erläutern, gab er diese Position auf. Er unterstrich sogar, dass das Osmanische Reich in seiner Hochphase, also weit vor dem 19. Jahrhundert, einem menschenrechtlichen Ideal sehr nahegekommen sei. Damit akzeptierte er, dass ausgerechnet die Tanzimat-Periode, in der erstmals rechtsstaatliche Voraussetzungen für die Gleichstellung ethnisch-religiös verschiedener Gruppen geschaffen wurden, zum Ausgangspunkt der Unterdrückung von Menschenrechten gemacht wurde. Der Konsens, dass die Probleme mit dem Niedergang des Osmanischen Reichs begonnen hatten, von der Tanzimat-Periode über die Jungtürken in die heutige Zeit fortgetragen wurden, war hergestellt. Damit verbunden war, dass die Abdülhamit-Periode, in der die Verfassung und erste rechtsstaatliche Versuche aufgehoben, die Dominanz der sunnitischen Gruppe wiederhergestellt und der Genozid eingeleitet wurde, implizit zu einem positiven Bezugspunkt avancierte. Die explizite Ausklammerung der DP-Periode als demokratische Zwischenphase unterstrich den Konsens, dass die »eigentliche« Unterdrückung sich gegen Muslime richtete. Während sich der Redner den TeilnehmerInnen annäherte, beharrten diese auf ihrer Position, dass Menschenrechte vor allen Dingen ein Vorwand für westliche Interventionen seien.

Die Gruppe vermochte es, den türkisch-sunnitischen Führungsanspruch, wie er in der Türkisch-Islamischen Synthese zum Ausdruck kommt, durch die Konstruktion einer notwendigen Selbstbehauptung gegen die vermeintliche Infiltrati- 
on von Konzepten und Regeln für das gesellschaftliche Zusammenleben aus dem Westen zu legitimieren. Die Abgrenzung, die der Redner gegenüber einer kulturellen Relativierung von Menschenrechten als universales Konzept vorgenommen hatte, war aufgehoben. Die Gruppe entzog sich einer Thematisierung aktiver Verantwortung für historisches und aktuelles Geschehen, indem sie sich in die Kontinuität einer konstruierten Gruppe der Muslime stellte, die als unterdrückt und passiv erschien, obwohl sie realiter einen privilegierten Status innehatte. Die Gruppe wollte nicht über die Rechte von Kurden oder Aleviten, sondern über ihre eigenen Rechte als unterdrückte Gruppe sprechen. Dafür war sie angewiesen auf eine Opferidentität. Der Redner des Menschenrechtsvereins, der aus der Gruppe ausgebrochen war, indem er eine rechtsstaatlich-universale Perspektive eingenommen hatte, wurde von der Mehrheit wieder zurückgeholt.

\subsubsection{Resümee der Integrationsmechanismen}

In den Praktiken des Kollektivs fand eine bestimmte Vermittlung von Widersprüchen statt. Sie stieß an Grenzen, wenn Diskrepanzen zwischen Idealen und realen Entwicklungen virulent wurden, wie im Zusammenhang mit Opportunismus, der Frage des Kriegs, der Anerkennung von kultureller Selbstbestimmung und Differenz. Da die Widersprüche nicht bearbeitet, sondern verdeckt beziehungsweise temporär überbrückt wurden, Auseinandersetzung verhindert wurde, blieben die Diskrepanzen als Sollbruchstellen des Kollektivs bestehen. Sie wurden insbesondere in den Fällen zu Herausforderungen, wenn es kämpfende Gruppen wie die kurdische Bewegung gab, die auf die Einlösung der Ideale drängten beziehungsweise diese als Täuschungen erkennbar machen konnten, während der Bezug auf eine Geschichte der Ausgrenzung aus den staatlichen Institutionen durch das kemalistische Gegenüber in Kombination mit einem religiösen Idealismus Differenzen innerhalb des Kollektivs zu überbrücken verhalf, bevor sie zu Spaltungen werden konnten.

\subsection{Resümee der Konstitutionsmerkmale der intellektuellen Führungsgruppe}

Ein übergreifendes Charakteristikum meiner Beobachtungen religiöser Praxis besteht darin, dass die religiösen Intellektuellen keine Trennlinie zwischen Glauben und Wissen zogen. Mit Blick auf eine Gesellschaft, in der aufgeklärtes Wissen und religiöse Erziehung nebeneinander zu stehen lernen mussten und ein Kompromiss gefunden wurde, indem Religion als »Glaube « neben das aufgeklärte Wissen gestellt wurde, ist es wichtig, sich zu vergegenwärtigen, dass die religiösen Intellektuellen ihrem Selbstverständnis nach nicht einen Glauben praktizierten, son- 
dern den Weg des Wissens beziehungsweise der Wahrheit beschritten, die sie teils sehr offensiv als die einzig mögliche und legitime vertraten. Da die religiösen Akteure im Sichtfeld meiner Feldstudie nicht an Gott glaubten, sondern »wussten«, dass Gott - zudem einzig in der von ihnen aufgefassten Form - existiert, ist es auch irreführend, die Aktivitäten dieser Akteure mit dem Konzept der »faith-based politics« (Ozgur 2012) zu analysieren. Die religiösen Akteure machten keine Politik auf der Grundlage des Glaubens, sondern nach den Richtlinien richtigen Wissens. Selbst wenn sie das Wort Glauben benutzten, was nur als Ausnahme vorkam, verwendeten sie es gleichbedeutend mit richtigem Wissen. Vor dem Hintergrund, dass sie sich für wissend hielten, begriffen sie andere als unwissend und dumm oder als Gottesleugner. Ein gleichberechtigtes Nebeneinander verschiedener Religionen, unterschiedlicher Konfessionen oder Weltauffassungen ist aus dieser Perspektive undenkbar. Bestenfalls denkbar ist ein Tolerieren aus der Position des Überlegenen. ${ }^{102}$

Diese Einsicht in die Selbstauffassung der religiösen Intellektuellen, die ich aus meiner Feldforschung gewann, hatte auch Konsequenzen für die sprachliche Analyse und Übersetzung des religiösen Vokabulars. Anfangs übersetzte ich in durchaus üblicher Weise das Wort »mümin« als »Gläubiger« und »kâfir« als »Ungläubiger«. Mit dieser Übersetzung unterstellte ich religiösen Akteuren jedoch, dass sie sich über den Glauben definierten und von anderen unterschieden. Die religiösen Akteure, denen ich begegnete, unterschieden sich aber nicht bloß von anderen, sondern begriffen das Muslimsein als eine Wahrheit, die alle Bereiche des Lebens, auch die der Wissensproduktion integrierte. Ein »mümin« war für sie kein »Gläubiger «, sondern jemand, der die Wahrheit über die Existenz Gottes anerkannt oder erworben hatte und nach den »Regeln des Islam« lebte. Mit »kâfir« wurde so nicht ein »Ungläubiger«, sondern jemand bezeichnet, der diese Wahrheit (noch) nicht erkannt hatte oder leugnete. Die Aufgabe, das Wissen über die Wahrheit weiterzutragen, wurde damit zugleich zu einer Aufgabe, der Gesellschaft den »richtigen« Weg aufzuzeigen: eine Führungsaufgabe. In der Aufgabendefinition der Diyanet ist diese Führungsaufgabe mit dem Begriff »Aufklärung « umschrieben. Aufklärung bedeutet allerdings gerade nicht Aufklärung des Volkes über den Glauben, sondern Aufklärung darüber, was das richtige Wissen ist.

Die Konstitutionsmerkmale der intellektuellen Führungsgruppe des islamistischen Hegemonieprojekts lassen sich vor diesem Hintergrund in fünf Unterpunk-

102 Wie dargelegt, haben die Theologen Auslegungsstrategien entwickelt, durch die sie in die Lage versetzt werden, nicht-theologisches Wissen als untergeordnetes Wissen zu akzeptieren und in ihren Schulen zu vermitteln. Diese Vermittlungsfähigkeit öffnete ihnen den Weg zurück zur Übernahme der gesellschaftlichen Führungsfunktion, die sie in der Spätphase des Osmanischen Reichs verloren hatten, in Abstimmung mit den Erfordernissen des kapitalistischen Entwicklungswegs. 
ten zusammenfassen. In der Ausführung der Führungsaufgabe und in ritualisierter Praxis (Sohbet, Tefsir, Beten) reproduzierten die religiösen Intellektuellen bestimmte Selbst- und Weltauffassungen sowie Distinktionspraktiken, durch die sie sich als besondere Gruppe konstituierten. Als grundlegendes Element tritt, erstens, die Formierung eines paternalistischen Führungsverhältnisses zwischen Gebildeten und Ungebildeten hervor. Dieser Formierung unterliegt die Arbeitsteilung in der bürgerlichen Gesellschaft. ${ }^{103}$ Als allgemeine Intellektuelle reproduzieren und rechtfertigen die islamistischen Intellektuellen die hierarchische Arbeitsteilung, indem sie sich gegenüber dem »Volk« als geistig erhaben begreifen. Zweitens erheben sie sich als besondere Intellektuelle über die Gesamtheit der Intellektuellen. Sie sind der Überzeugung, über ein spezielles Wissen zu verfügen, das den wahren und richtigen Weg aufzeigt. Über das Bewusstsein, wissender oder aufgeklärter als alle anderen zu sein, nahmen sie sich im drastischsten empirischen Fall, der in dieser Studie angeführt wurde, heraus, »Gehirne zu formatieren«. Im Rahmen konservativ-islamischer Auffassungen sind sie, drittens, überzeugt, die Gesellschaft am besten schützen zu können. Sie fühlen sich moralisch überlegen, die Anderen werden als verirrt, fehlgeleitet und schmutzig markiert, mit Kriminalität und Praktiken in Verbindung gebracht, die die Gesellschaft von innen zerrütteten. Die Praktiken des Kollektivs der Intellektuellen im Umgang untereinander sind, viertens, autoritär geprägt. Diskussionen sind nicht erwünscht, der Handlungsspielraum für Abweichler ist eng und nur auf der Grundlage einer gemeinsamen islamischen Identität oder besonderer Konstellationen gegeben, die im Rahmen strategischer Notwendigkeiten und in Auseinandersetzung mit anderen Hegemonieprojekten auftreten. In den Praktiken der Intellektuellen findet, fünftens, eine paternalistische Vermittlung gesellschaftlicher Widersprüche statt, die jedoch nicht immer klappt, weil die Praxis von Widersprüchen durchzogen bleibt, Diskrepanzen zwischen Idealen und realen Entwicklungen auftauchen, die insbesondere in den Fällen eine Herausforderung darstellen, wenn es kämpfende Gruppen gibt, die ein anderes Wissen vertreten.

103 Intellektuelle Tätigkeiten setzen die Verfügung über materielle Ressourcen voraus. Mit ihnen verbunden ist in der Regel eine Besonderung und in der Folge oftmals das Privileg, sich der intellektuellen Tätigkeit - insbesondere der Bildung und dem Studium - zuwenden zu können. Die gesellschaftliche Arbeitsteilung bedingt, dass andere die körperliche Arbeit verrichten müssen, die in der Regel nicht oder nicht gleichermaßen über entsprechende Ressourcen - weder Geld und Zeit, noch das kulturelle Wissen - zur Ausübung der intellektuellen Tätigkeit verfügen. Intellektuelle Praxis, die nicht auf die Aufhebung solcher gesellschaftlicher Arbeitsteilung, die ungleiche Positionen festlegt, drängt, konstituiert sich daher als Herrschaftspraxis, durch die HandarbeiterInnen strukturell zu Beherrschten werden. 


\section{Fazit: Hegemonie, Kulturkampf und sunnitische Privilegien - Was ist Islamismus?}

Die in dieser Studie verfolgte Forschungsfrage lautete, wie die Rolle der Religion im politischen Projekt der AKP aus einer hegemonietheoretischen Perspektive begriffen werden kann. Die theoretische Rekonstruktionsarbeit aufgreifend sollen im Folgenden die Ergebnisse zusammengefasst werden und die Antworten auf die aus der Diskussion der Forschungsliteratur gewonnenen Fragen nach der räumlichen und zeitlichen Reichweite von Hegemonietheorie, den Antriebskräften der Islamisierung und des Kulturkampfs sowie der Rolle der intellektuellen Trägerschaft des islamistischen Hegemonieprojekts zugespitzt wiedergegeben werden.

Im Verlauf der Rekonstruktion des Hegemonieprojekts konnten fünf Entwicklungsstationen ausgemacht werden. Deren Einteilung ist orientiert an der Position der sunnitischen Intellektuellen - die als intellektuelle Träger des Projekts identifiziert wurden - innerhalb der Klassenmatrix des untersuchten Raums. Die Stationen verlaufen von der Ablösung der sunnitischen Intellektuellen von den besitzenden Klassen in der Spätphase des Osmanischen Reichs und der jungen Republik über die Wiederanbindung, die Verselbständigung als politische Partei und soziale Bewegung, das ideologische Vorrücken ins politische Zentrum bis zur schrittweisen Monopolisierung der Staatsapparate.

Während der Einparteienherrschaft der CHP wirkten die religiösen Intellektuellen trotz massiver Einschränkung ihrer Reproduktionsgrundlagen fort. Mit dem Übergang in ein Mehrparteiensystem unter den Bedingungen des Kalten Krieges setzte der Wiederaufbau ihrer Infrastruktur ein. Die relativ schwachen sunnitischen Intellektuellen waren in dieser Phase in die Strömung des Konservatismus eingebunden, der sich auf den Großgrundbesitz und die Handelsbourgeoisie stützte. Gleichzeitig förderten Teile der kleinen Bourgeoisie und des Kleinbürgertums die Ausbildung der intellektuellen Trägerschicht des Islamismus im Lokalen durch den Bau von Moscheen und theologischen Schulen. Die Beschleunigung des Industrialisierungsprozesses in den 1950er Jahren, mit der die Industriebourgeoisie zur dominanten Fraktion aufstieg und innerhalb kurzer Zeit Monopolstrukturen ausbildete, ging der Verselbständigung der islamistischen Bewegung und der Abspaltung von der konservativen Partei voraus. Die komplexe Zusammensetzung einer 
zunehmend kapitalistisch dominierten Gesellschaft widerspiegelnd kulminierten Reibungen zwischen den Monopolen und anderen Kapitalfraktionen gegen Ende der 1960er Jahre in der Herausbildung des politischen Islam als eigenständige Partei eines Teils der kleinen Bourgeoisie und des Kleinbürgertums. Trotz entwicklungspolitischer Differenzen ließen der Antikommunismus und die Bekämpfung beziehungsweise Kontrolle von Bewegungen der subalternen Klassen die islamistische Bewegung, die sich mit der kleinen Bourgeoisie verbunden hatte, auf einer Seite mit der großen Bourgeoisie kämpfen. Auch im Militär und in den Reihen der Kemalisten fand die Bewegung in dieser Phase Bündnispartner. Angesichts einer Hegemoniekrise in den 1970ern ebnete nach Aufforderung aus der Bourgeoisie das Militär mit dem 1980er Putsch den Trägern des türkisch-islamischen Hegemonieprojekts den Weg ins politische Zentrum. Im Aufstieg der Wohlfahrtspartei RP zunächst in den Kommunen und schließlich auf nationaler Ebene schlug sich die Symbiose des islamistischen Hegemonieprojekts mit einer sich rapide entwickelnden kleinindustriellen Bourgeoisie nieder. Mit der AKP stieg die islamistische Bewegung schließlich in Folge des Zusammenbruchs der tragenden Parteien des neoliberalen Regimes zur dominanten politischen Kraft im Machtblock auf, die zwischen den bürgerlichen Klassen moderiert und schrittweise Kontrolle über die staatlichen Institutionen herstellen konnte.

Als Grundlage für die Zustimmung der ArbeiterInnen zum islamistischen Hegemonieprojekt konnten konservativ und religiös geprägte soziale Beziehungen in den Produktions- und Wohnstätten der expandierenden Städte identifiziert werden. Diese so gestalteten Beziehungen waren jedoch nicht immer-schon gegeben. Sie konnten erst vor dem Hintergrund der Neoliberalisierung und der Kapitulation der Sozialdemokratie hergestellt, verändert, stabilisiert und in der Breite wirksam werden. Konservativ-religiöse Praktiken, in denen sich paternalistisch und patriarchal geprägte Beziehungen mit einer starken sozialen Kontrolle sowie religiösen Ritualen verbinden, bilden den gesellschaftlichen Nährboden für den islamischen Konservatismus der AKP, der mit der Etablierung eines Schulden- und Almosenregimes auf nationaler Ebene weitere ideologisch-kulturelle Wirkkraft entfaltet. In einer historisch-spezifischen Situation, in der Gewerkschaften, verbriefte soziale Ansprüche und Rechte zurückgedrängt worden sind, offeriert die Religion einen alternativen Deutungsrahmen und stellt Praktiken zur Verfügung, mit denen paternalistische Beziehungen als moralisch-richtiges Handeln legitimiert werden können.

Mit fortschreitender Neoliberalisierung sind in der Regulierung der Klassenverhältnisse nicht staatsbürgerliche Rechte auf der Grundlage organisierter Klassenlagen, sondern kulturelle Bindung und Nähe dominant geworden. Unter den Bedingungen einer allgemeinen Tendenz zur Informalisierung von Arbeitsverhältnissen sind auch die Mechanismen der Kompromissbildung stärker informell gestaltet. In Auseinandersetzung mit der in der Forschungsliteratur aufgeworfenen 
Frage nach der Reichweite hegemonietheoretischer Annahmen unter neoliberalen beziehungsweise semi-peripheren Verhältnissen konnte so die These formuliert werden, dass der materielle Kompromissrahmen unter den Bedingungen einer flexibilisierten und dezentralisierten Produktionsstruktur stärker durch informelle und kulturell artikulierte Zugeständnisse gebildet wird. Das Almosenregime steht im Zentrum eines informellen Klassenkompromisses, der die sozio-politische Blockbildung - ein Begriff, der im Rahmen dieser Studie eingeführt wurde, um Hegemoniebildungsprozesse differenzierter erfassen zu können - unter der praktischen Führung der islamistischen Bewegung ermöglicht.

An diesen Befund schließt die zweite zentrale These dieser Studie an, die die Frage aufgreift, wie die Position und Bedeutung der intellektuellen Träger des Hegemonieprojekts, die eine vermittelnde und konsensstiftende Rolle einnehmen, bestimmt werden kann. Um die Rolle der Trägerschaft zu erfassen, konnte zunächst auf die hegemonietheoretische Definition des Intellektuellen zugegriffen werden. Dargelegt wurde aus dieser Perspektive, dass die Stellung des Intellektuellen in die Gesamtheit der gesellschaftlichen Arbeitsteilung eingelassen ist. Die Intellektuellen bilden keine »eigenständige Klasse« (Yıldızoğlu 2016), sondern eine mit bestimmten Aufgaben befasste Gruppe auf der Grundlage eines in den gesellschaftlichen Widersprüchen angelegten Bedarfs an Organisierung von Hegemonie. Im Hinblick auf die Positionierung der Intellektuellen des islamistischen Hegemonieprojekts bedeutete dies, dass sie nicht unbedingt aufgrund ihrer Klassenposition, sondern aufgrund der von ihnen wahrgenommenen Aufgabe integrierender Bestandteil der bürgerlichen Klasse sind. Sie sind nicht unbedingt Inhaber der Hegemonie, aber ihre Vermittler. Der religiöse oder islamistische Intellektuelle kann vielmehr objektiv verschiedenen Klassen angehören. Entscheidend für seine Bestimmung sind die Assoziation mit dem islamistischen Projekt und die übernommene Aufgabe, über religiös artikulierte Ideen und Praktiken die Führung der Bourgeoisie zu organisieren. Herausgearbeitet wurde auf dieser Grundlage, dass der Nexus zwischen islamisch-konservativen Weltauffassungen und dem kapitalistischen Entwicklungsprogramm über die Herstellung eines Kollektivwillens durch diese Intellektuellen vermittelt wird. In diesen Kollektivwillen eingelassen ist eine bestimmte Auffassung gesellschaftlicher Verhältnisse, mit der den subalternen Klassen die Position von Hilfsempfängern zugewiesen, paternalistische Beziehungen, soziale Ungleichheit und Reichtum legitimiert werden. Als Orte der Bildung des Kollektivwillens wurden Schulen, Heime, Moscheen, Korankurse, Sohbet, öffentliches Fastenbrechen oder Gebete in Betrieben bestimmt. In ihnen geben religiöse Intellektuelle ein die von Widersprüchen durchzogene Gesellschaft durch Religion verbindendes Wissen, eine bestimmte Sicht auf und Haltung zur Gesellschaft weiter.

Im Zuge der Diskussion der intellektuellen Aufgaben wurden verschiedene Gruppen in den Blick genommen. Als erstes ist eine Gruppe zu nennen, die eine 
Doppelstellung einnimmt. Sie ist Inhaberin und Vermittlerin von Hegemonie zugleich. Sie besteht aus Rentiers und Mitgliedern der Bourgeoisie, die sich in Verbänden und in der politischen Partei organisieren, religiös artikulierte intellektuelle Führungsaufgaben finanzieren, aber auch selbst wahrnehmen, so im direkten Kontakt mit ihren ArbeiterInnen oder indirekt über Medien. Diese Gruppe wurde als islamische Bourgeoisie und Rentiers gefasst. Die anderen Gruppen, die intellektuelle Führungsaufgaben wahrnehmen, konnten dem Kleinbürgertum zugerechnet werden. Sie sind in dieser Studie als Journalisten, Schriftsteller, Anwälte, Wissenschaftler, Manager, professionelle Politiker, Lehrer, Erzieher, Bürokraten und Funktionäre in Erscheinung getreten. Als besonderer Typ des religiösen Intellektuellen tritt aus dieser Gruppe der Religionsgelehrte - der Ulema - hervor, der in der Bürokratie, in Schulen, Universitäten sowie Gemeinschaften organisiert ist. Die Ulema bilden die maßgebliche Gruppe, die dem Projekt eine besondere Dynamik verleiht, indem sie sich einen Sonderstatus und Privilegien erkämpft hat. Ihre Institutionen sind über die Jahrzehnte stark expandiert, wodurch ihre Interventionsmöglichkeiten in die Regulierung des gesellschaftlichen Zusammenlebens erweitert und inzwischen zur Grundlage für Forderungen nach Ausweitung auch in den Rechtsbereich geworden sind.

Als Besonderheit der Ulema im Unterschied $\mathrm{zu}$ anderen intellektuellen Gruppen, die die bürgerliche Vergesellschaftung hervorgebracht hat, manifestiert sich, dass ihre Reproduktion nicht nur an eine spezifische Ideologie und Profession, sondern auch an die Ausbildung einer relativ eigenständigen Infrastruktur gekoppelt ist, die durch die Verknüpfung mit exklusiven Einkommensmöglichkeiten zu einer Privilegienstruktur wird. Der Erhalt und der Ausbau dieser Privilegienstruktur, die maßgeblich über die Diyanet, die theologischen Ausbildungsstätten und die Organisationen der religiösen Gemeinschaften hergestellt wird, konnte als ein objektives Gruppeninteresse der Ulema bestimmt werden. Durch die Identifizierung dieses Gruppeninteresses entstand die Notwendigkeit, die Reproduktion der Intellektuellen theoretisch neu $\mathrm{zu}$ fassen. Sie ist erfolgt durch eine ressourcentheoretische Erweiterung der Hegemonietheorie unter Rückgriff auf Bourdieus Kapitaltheorie, die für diese Studie adaptiert wurde. Diese Erweiterung erwies sich insbesondere als entscheidend, da die Ulema nicht nur über relativ eigenständige Institutionen verfügen, die ihnen exklusive Reproduktionsmöglichkeiten eröffnen und organisiertes Handeln ermöglichen. Eingelassen in gesellschaftliche Kämpfe um Hegemonie und in (zum Teil instrumenteller) Allianz mit der Bourgeoisie sind sie vielmehr zu Ausbildern und Vermittlern kultureller und sozialer Ressourcen avanciert, die privilegierte Zugänge für Positionen in allen gesellschaftlichen Feldern eröffnen. Der sukzessiven Übernahme der Position von Ausbildern durch die Ulema folgt eine breite gesellschaftliche Streuung der für das islamistische Hegemonieprojekt charakteristischen islamisch-konservativen Weltauffassungen in alle Bereiche der Kultur- und Wissensproduktion. Umso häufiger sie ihre Schüler 
in die staatlichen Behörden sowie in die »zivilgesellschaftlichen« Verästelungen der Gesellschaft entsenden, desto wertvoller werden die religiösen Ressourcen, die sie vermitteln.

Mit Blick auf diesen Vorgang ermöglichte die ressourcentheoretische Erweiterung, die Dynamik hinter dem Aufstieg des politischen Islam genauer zu bestimmen und begrifflich zu fassen: Der Aufstieg des politischen Islam beruht auf Kämpfen, durch die kulturelle Ressourcen wie theologisches Wissen, Wissen über religiöse Praktiken und soziale Ressourcen wie die Zugehörigkeit zu einer religiösen Gruppe oder einem islamischen Netzwerk - Gemeinschaften, Imam Hatip Kollektiv, politische Partei - zu Voraussetzungen für den Zugang zu gesellschaftlichen Positionen und ökonomischen Praktiken werden. Mit der Identifizierung dieses Zusammenhangs wird eine Entwicklung begreifbar, die parallel zur auf der politischen Ebene stattfindenden schrittweisen Monopolisierung der Staatsapparate durch die AKP verläuft. Ausgestattet mit einem strategischen Bewusstsein streiten die religiösen Intellektuellen entschieden um die Vorrangstellung in der Ausübung gesellschaftlicher Führung. Quantitativ erfassbarer Entwicklungsstand dieses Strebens ist die Expansion von Korankursen, theologischen Schulen und Fakultäten sowie die Zunahme der politischen Selbstzuschreibung in der Bevölkerung als »religiös«. Qualitativ erfassbar ist dieses Streben im Vordringen in allen Bildungs- und Erziehungsinstitutionen der Gesellschaft, in der Förderung und Bevorzugung türkisch-sunnitischer Intellektueller im gesamten öffentlichen Dienst, im allgemeinen Konformitätsdruck oder dadurch, dass der Erwerb religiöser Ressourcen als Voraussetzung für eine erfolgreiche Bildungslaufbahn angesehen wird.

Als Antwort auf die Frage nach den Antriebskräften der Islamisierungsdynamik und des Kulturkampfs kann so ein Ringen um gesellschaftliche Positionen ermittelt werden, das die Allokation ökonomischer Mittel zugunsten von Intellektuellen, die mit dem islamistischen Hegemonieprojekt assoziiert sind, umschließt. Folglich kämpfen islamistische Intellektuelle auch nicht nur anstelle einer Fraktion oder Bourgeoisie. Sie kämpfen ebenso für die Reproduktion ihrer eigenen Positionen, die unter Verhältnissen ungleicher Verteilung die Form von Privilegien annehmen. Die Islamisierungsdynamik ist somit Resultat der Bipolarität des Kulturkampfs als Ausübung von Hegemonie und Inwertsetzung von Ressourcen beziehungsweise Voranbringen des objektiven Gruppeninteresses. Diese Dynamik bewirkt im Umkehreffekt die Abwertung säkular und nicht-sunnitisch artikulierter Ressourcen. Sie schlägt sich in den gesellschaftlichen Auseinandersetzungen als Ausgrenzungspraxis gegenüber säkularen und nicht-sunnitischen Praktiken beziehungsweise in der Verfolgung und Verdrängung säkularer, atheistischer und nichtsunnitischer Kultur- und Wissensproduzenten nieder. Gerechtfertigt wird diese Praxis mit der Behauptung eines überlegenen Wissens, einer überlegenen Wahrheit und Moral. Der Kulturkampf, so lässt sich zusammenführend formulieren, 
zeichnet sich durch Exklusions-, Diskriminierungs- und Assimilationspraktiken aus, die politische, kulturelle und ökonomische Aspekte in sich vereinen.

Indem die materielle Reproduktion gesellschaftlicher Gruppen und die Allokation des gesellschaftlich produzierten Reichtums auch auf der Ebene von Verteilungsverhältnissen zweiten Grades in den Blick genommen wird, kann der Kulturkampf also als Konkurrenzkampf bestimmt werden, der mit ökonomischen Allokationsmechanismen verknüpft ist. In diesem Kampf befinden sich die religiösen Intellektuellen seit etwa 70 Jahren wieder in der Offensive. Doch obgleich sich das islamistische Projekt auf das Osmanische Reich beruft, geht die Reichweite der bereits etablierten islamistischen Infrastruktur weit über die Wirkungsmöglichkeiten der sunnitischen Intellektuellen im Osmanischen Reich hinaus. Die religiösen Intellektuellen haben ein wesentlich feingliedriger gestaltetes »zivilgesellschaftliches« Netz gesponnen. Über die Bildungsinstitutionen erreichen sie die gesamte Gesellschaft, Institutionen anderer Glaubensgruppen, die ihre Reichweite im Osmanischen Reich begrenzt hatten, sind nicht (mehr) oder kaum noch vorhanden. Sie verfügen über materielle Mittel auf der Grundlage fortgeschrittener Produktivkräfte, vermittels derer sie auf allen Felder gestaltend auf die Beziehungen zwischen den sozialen Klassen einwirken können. Der Kompromiss, der in der Türkei vor einem Jahrhundert unter der Bezeichnung Laizität eingeführt und durch den aufgeklärtes Wissen und religiöse Erziehung nebeneinander gestellt wurden, ist jedenfalls weitgehend erodiert. Konzepte wie »Säkularisierung des Islam« (Tuğal 2009) und »Post-Islamismus« (Bayat 2013) haben die Sicht auf diese Erosion und die Entwicklungstendenzen des islamistischen Projekts verstellt.

Abschließend bleibt zu fragen, welche Grenzen des islamistischen Hegemonieprojekts erkennbar geworden sind und mit welchen Aussichten für die weitere politische Entwicklung diese verbunden sein können. Als ökonomische Achillesferse des islamistischen Hegemonieprojekts tritt der hohe Verschuldungsstand privater Unternehmen und Haushalte hervor. Über ihn kommt die Fragilität des neoliberalen Entwicklungsmodells an der Peripherie kapitalistischer Zentren zum Ausdruck. Im Fall einer ökonomischen Krise sind eine Verschärfung von Kämpfen im Machtblock und eine Zunahme von Machtkämpfen zwischen den einzelnen Konstituenten des islamistischen Projekts - den islamischen Gemeinschaften - zu erwarten. Durch das Fehlen einer organisierten politischen Alternative zum kapitalistischen Almosenregime fehlt allerdings eine gesellschaftliche Kraft, durch die das islamistische Hegemonieprojekt herausgefordert und das ökonomische Krisenpotential in eine Hegemoniekrise transformiert werden könnte. Damit sind auch die Aussichten auf den (Wieder-)Aufbau einer Grenze des Projekts, die aus seiner historischen Entwicklungsgeschichte bestimmt werden kann, gering. Sie bestand im sozialdemokratisch institutionalisierten Klassenkompromiss, der mit den sozialistischen Initiativen der 1960er und 1970er Jahre interagierend emanzipative Bewegungen der Subalternen ermöglicht hatte. Das Potential einer sozialdemokratischen Bewe- 
gung bestünde darin, die prekarisierten Massen aus der paternalistischen Führung der religiösen Intellektuellen zu lösen. Noch in den 1990er Jahren war ein solches Potential erkennbar, als die EinwohnerInnen der heutigen islamistischen Hochburgen mehrheitlich sozialdemokratisch agierten. Doch hat die weitere Entwicklung die Grenzen der sozialdemokratischen Politik aufgezeigt. Ihre TrägerInnen ließen die emanzipativen Bewegungen der subalternen Klassen zugunsten neoliberaler Politik fallen, während die Bourgeoisie sich umorientierte und Bündnisse mit den kulturkämpferischen Intellektuellen einging. Der sozialdemokratische Kurswechsel trug objektiv dazu bei, dass das paternalistische Armutsregime expandieren, die Beschäftigten in ein konservativ-islamisch geprägtes soziales Netz eingebunden werden konnten und die Bewegungsspielräume für eine emanzipative Formierung der Arbeiterschaft geringer geworden sind.

In säkular geprägten Kommunen treten als Grenzen des islamistischen Hegemonieprojekts der Neo-Kemalismus und mancherorts der völkische Türkismus auf. Sie versprechen jedoch keine demokratisch artikulierte soziale Emanzipation, sondern eine Verschärfung des Kulturkampfs unter neoliberalen Bedingungen. Letztendlich stabilisieren beide Strömungen das islamistische Projekt sogar, da sie mit einer rassistischen Ausgrenzungspraxis gegenüber KurdInnen artikuliert sind und das Entstehen einer politischen Alternative behindern, die auch für diejenigen attraktiv werden kann, die in die islamistische Bewegung integriert waren, jedoch Zweifel entwickelt haben, von ihr abgerückt oder abgestoßen worden sind.

Als Ausblick lässt sich hinzufügen, dass in jüngerer Zeit konturenhaft ein widersprüchlicher Wandel in der kemalistischen Artikulation des Kulturkampfs erkennbar geworden ist. Die CHP hat sich einerseits dem islamischen Konservatismus angenähert und verteidigt den Laizismus nicht mehr offensiv. Während sie die Repression gegen die kurdische Bewegung auf der nationalen Ebene mitträgt, hat sie sich andererseits auf kommunaler Ebene wahltaktischen Arrangements mit der Bewegung geöffnet. Abzuwarten bleibt, inwiefern die hierauf erfolgte Niederlage der AKP gegenüber CHP-Kandidaten in den Großstädten Ankara und Istanbul bei den Kommunalwahlen von 2019 auch mit einer Transformation der alltäglichen kemalistischen Ausgrenzungspraxis einhergehen sowie die expansive Dynamik der islamistischen Intellektuellen und ihrer Institutionen aufhalten wird. Hervorzuheben ist in diesem Zusammenhang, dass die einzelnen politischen Parteien des islamistischen Projekts bisher alle an bestimmte Grenzen gestoßen sind, während die Reproduktionsstätten der sunnitischen Intellektuellen erhalten geblieben und ausgebaut worden sind. Der kemalistische Wandel ist bislang jedenfalls nicht verbunden mit einer politisch artikulierten Alternative zur neoliberalen Politik und zum paternalistischen Armutsregime, das die sozio-ökonomische Reproduktionsbasis des islamistischen Projekts bildet. Eine Loslösung der Werktätigen von der religiösen Führung bleibt damit auf lange Sicht auch bei Verschärfung ihrer sozialen Lage infolge ökonomischer Krisen fraglich. 
Eine partielle, weil auf das kulturelle Feld begrenzte Herausforderung für das islamistische Hegemonieprojekt besteht in der kurdischen Bewegung. Die Bewegung hat durch ihre Kämpfe ein säkulares Hegemonieprojekt und eine Perspektive hervorgebracht, die der paternalistischen Integration Grenzen setzt, Befreiung nicht in ein Jenseits verschiebt und trotz aller Rückschläge von großen Teilen der kurdischen Bevölkerung getragen wird. Schließlich ließ der Juni-Aufstand im Jahr 2013 eine potentielle Grenze nicht nur des islamistischen Projekts erkennbar werden. Mit dem Aufstand zeichnete sich die Entstehung einer libertären und kapitalismuskritischen Bewegung ab, die sich jedoch nicht zu einem stabilen politischen Projekt formieren konnte, womit sie das uneingelöste Gegenstück zur kulturkämpferischen Reproduktion des neoliberalen Akkumulationsregimes verblieb. 


\section{Literatur- und Quellenverzeichnis}

Açıkel, Fethi (1996): Kutsal Mazlumluğun Psikopatolojisi [Psychopathologie des Heiligen Unterdrücktseins]. In: Toplum ve Bilim, Bd. 20, Nr. 70, 153-198.

Adas, Emin Baki (2003): Profit and the Prophet: Culture and Politics of Islamic Entrepreneurs in Turkey. Unveröffentlichte Dissertation an der University of Illinois at Urbana-Champaign.

Adolphs, Stephan; Karakayali, Serhat (2007): Die Aktivierung der Subalternen. Gegenhegemonie und passive Revolution. In: Buckel \& Fischer-Lescano 2007, 121140, https://doi.org/10.5771/9783845201849-121.

Ahmad, Feroz (1993): The Making of Modern Turkey. London.

Akbulut, Bengi; Adaman, Fikret (2013): The Unbearable Appeal of Modernization: The Fetish of Growth. In: Perspectives, Nr. 5, 14-17.

Akça, İsmet (2014): Hegemonic Projects in Post-1980 Turkey and the Changing Forms of Authoritarianism. In: Akça, İsmet; Bekmen, Ahmet; Özden, Barış Alp (Hg.): Turkey Reframed. Constituting Neoliberal Hegemony. London, 1346, https://doi.org/10.2307/j.ctt183p72x.4.

Akçay, Ümit (2012): 2011 Krizinin Gölgesinde Yeni Sanayi Politikaları Üzerine Bir Not [Eine Anmerkung zur neuen Industriepolitik im Schatten der Krise]. In: Praksis, Nr. 27, 145-166.

Akçay, Ümit (2018): Neoliberal Populism in Turkey and Its Crisis. Institute for International Political Economy Berlin. Working Paper Nr. 100.

Akdoğan, Yalçın (2004): AK Parti ve Muhafazakâr Demokrasi [AK Partei und Konservative Demokratie]. Istanbul.

Akkaya, Yüksel (2002): Türkiye'de İşçi Sınıfı ve Sendikacılık - I [Arbeiterklasse und Gewerkschaftsbewegung in der Türkei - I]. In: Praksis, Nr. 5, 131-176.

Akpınar, Nazlı; Araman, Sinan (2011): Din ve Kapitalizm Sarmalında Milli Görüş Hareketi [Die Milli Görüş Bewegung in der Spirale von Kapitalismus und Religion]. In: Praksis, Nr. 26, 77-99.

Akşit, Bahattin; Şentürk, Recep; Küçükural, Önder; Cengiz, Kurtuluş (2012): Türkiye'de Dindarlık. Sosyal Gerilimler Ekseninde İnanç ve Yaşam Biçimleri [Religiosität in der Türkei. Glaubens- und Lebensweisen im sozialen Spannungsfeld]. Istanbul. 
Aladağ, Aras (2013): Hegemonya Yeniden Kurulurken Sol Liberalizm ve Taraf [LinksLiberalismus und die Taraf in der Rekonstitution von Hegemonie]. Istanbul. Alpkaya, Faruk (2001): Bir 20. Yüzyıl Akımı: »Sol Kemalizm« [Eine Strömung des 20. Jahrhunderts: Links-Kemalismus]. In: Bora \& Gültekingil 2001, 477-500. Anderson, Benedict (1993): Die Erfindung der Nation: Zur Karriere eines folgenreichen Konzepts. Frankfurt a.M..

Anderson, Perry (1979): Antonio Gramsci. Eine kritische Würdigung. Berlin. Arslan, Emre (2014): Siyasal İslam ve Sinıflar: Utku Balaban'ın Faburjuvazi Kavramı Hakkında [Politischer Islam und Klassen: Über den Begriff Faubourgeoisie bei Utku Balaban]. In: Praksis, Nr. 35-36, 203-207.

Atasoy, Ylldız (2005): Turkey, Islamists and Democracy: Transition and Globalization in a Muslim State. London/New York.

Atasoy, Ylldız (2009): Islam's Marriage with Neoliberalism: State Transformation in Turkey. London/New York, https://doi.org/10.1057/9780230246669.

Atay, Tayfun (2017): Parti, Cemaat, Tarikat. 2000'ler Türkiye'sinde Dinbaz Politik Seyir Defteri [Partei, Gemeinschaft, Orden. Kursbuch religionistischer Politik in der Türkei der 2000er Jahre]. Istanbul.

Atılgan, Gökhan (2015a): Tarımsal Kapitalizmin Sancağı Altında [Unter der Flagge des agrarischen Kapitalismus]. In: Atılgan \& Saraçoğlu \& Uslu 2015, 387-514.

Atılgan, Gökhan (2015b): Sanayi Kapitalizmin Sancağı Altında [Unter der Flagge des industriellen Kapitalismus]. In: Atılgan \& Saraçoğlu \& Uslu 2015, 515-656.

Atılgan, Gökhan; Saraçoğlu, Cenk; Uslu, Ateş (Hg.) (2015): Osmanlı'dan Günümüze Türkiye'de Siyasal Hayat [Das politische Leben in der Türkei vom Osmanischen Reich bis in die Gegenwart]. Istanbul.

Aydın, Mustafa (2005): Süleymancılık [Süleymanismus]. In: Bora \& Gültekingil $2005,308-322$.

Aydın, Oya (2012): Hukuk Devleti Nerede Biter, Polis Devleti Nerede Başlar? [Wo hört der Rechtsstaat auf, wo beginnt der Polizeistaat?]. In: Birikim, Nr. 273, 24-29.

Aydın, Zülküf (2005): The Political Economy in Turkey. London.

Aydın, Zülküf (2010): Neo-Liberal Transformation of Turkish Agriculture. In: Journal of Agrarian Change, Bd. 10, Nr. 2, 149-187, https://doi.org/10.1111/j.14710366.2009.00241.x.

Aydınkaya, Fırat (2015): Bir başka açıdan Kürtlerin Ermeni Soykırımı'ndaki rolü [Die Rolle der Kurden im Genozid an den Armeniern aus einem anderen Blickwinkel]. In: AGOS, 27.04.2015, www.agos.com.tr/tr/yazi/11405/bir-baskaacidan-kurtlerin-ermeni-soykirimindaki-rolu (Abruf am 12.10.2018).

Ayengin, Tevhit (2005): Çalışmanın Dinî Temelleri: Kalvinizm ve İslâm Örneği [Die religiösen Fundamente des Arbeitens: Das Beispiel Calvinismus und Islam]. In: İslâmi Araştırmalar, Bd. 18, Nr. 4, 463-472. 
Aytekin, E. Attila (2015a): Başlangıç Nağmesi [Auftakt]. In: Atılgan \& Saraçoğlu \& Uslu 2015, 11-38.

Aytekin, E. Attila (2015b): Kapitalistleşme ve Merkezileşme Kavşağında [Am Kreuzungspunkt kapitalistischer Entwicklung und Zentralisierung]. In: Atılgan \& Saraçoğlu \& Uslu 2015, 39-87.

Aytekin, E. Attila; Uslu, Ateş (2015): Burjuva Devriminin ve Savaşın Belirsiz Sınırlarında [An den diffusen Grenzen der bürgerlichen Revolution und des Kriegs]. In: Atılgan \& Saraçoğlu \& Uslu 2015, 89-193.

Babacan, Errol (2012): Akkumulation und Krise. Eine kritische Betrachtung des Wirtschaftswachstums in der Türkei. Arbeitspapiere der Forschungsgruppe Europäische Integration an der Universität Marburg Nr. 32.

Babacan, Errol (2013): Der Juni-Aufstand in der Türkei. In: PROKLA, Nr. 173, 631650, https://doi.org/10.32387/prokla.v43i173.253.

Babacan, Errol (2014a): Die finanzialisierte Akkumulationsstrategie der Türkei und ihre Risiken. In: Nölke, Andreas; May, Christian; Claar, Simone (Hg.): Die großen Schwellenländer - Ursachen und Folgen ihres Aufstiegs in der Weltwirtschaft. Wiesbaden, https://doi.org/10.1007/978-3-658-02537-3_13.

Babacan, Errol (2014b): Eine Packung Nudeln, ein Bekenntnis und einige Verprellte - Formeln zur Präsidentschaftswahl in der Türkei. In: Infobrief Türkei, 26.07.2014, http://infobrief-tuerkei.blogspot.com/2014/07/eine-packungnudeln-ein-bekenntnis-und.html (Abruf am 30.10.2018).

Babacan, Errol (2016): Unauflösbare Widersprüche: Die Kurdische Bewegung und die AKP. In: Wissenschaft und Frieden, Dossier 82, 6-9.

Babacan, Errol; Gehring, Axel (2013): Hegemonie in Zeit und Raum. Zur Dekonstruktion des Zentrum/Peripherie-Gegensatzes in der Hegemonietheorie am Beispiel Türkei. In: Peripherie, Nr. 130/131, 178-200.

Bahçe, Serdal; Köse, Ahmet Haşim (2017): Social Classes and the Neo-Liberal Poverty Regime in Turkey, 2002-2011. In: Journal of Contemporary Asia, Bd. 47, Nr. 4, 575-595, https://doi.org/10.1080/00472336.2017.1325919.

Bakırezer, Güven; Demirer, Yücel (2009): AK Parti'nin Sosyal Siyaseti [Die Sozialpolitik der AKP]. In: Uzgel \& Duru 2009, 153-178.

Balaban, Osman (2011): İnşaat sektörü neyin lokomotifi? [Was treibt der Bausektor voran?]. In: Birikim, Nr. 270, 19-26.

Balaban, Utku (2013): Faburjuvazi ve İktidar: Yakın Türkiye Tarihinde Sınıf ve Siyasal İslam [Fabourgeoisie und Herrschaft: Klasse und Politischer Islam in der jüngeren Geschichte der Türkei]. In: Praksis, Nr. 32, 11-63.

Balcı, Bayram (2005): Orta Asya'da İslâm Misyonerleri: Fethullah Gülen Okulları [Missionare des Islam in Mittelasien: Die Fethullah Gülen Schulen]. Istanbul.

Balkan, Neşecan; Savran, Sungur (Hg.) (2002): The Ravages of Neoliberalism. Economy, Society, and Gender in Turkey. New York. 
Balkan, Neşecan; Balkan, Erol; Öncü, Ahmet (Hg.) (2015): The Neoliberal Landscape and the Rise of Islamist Capital in Turkey. New York/Oxford.

Baran, Zeyno (2008): Turkey Divided. In: Journal of Democracy, Bd. 19, Nr. 1, 55-69, https://doi.org/10.1353/jod.2008.0018.

Barnes, John Robert (1987): An Introduction to Religious Foundations in the Ottoman Empire. Leiden.

Bayat, Asef (2007): Islam and Democracy. What is the Real Question? In: ISIM, Paper 8, Leiden, https://doi.org/10.5117/9789053569832.

Bayat, Asef (2013): Introduction. Post-Islamism at Large. In: Ders. (Hg.): PostIslamism: The Changing Faces of Political Islam. Oxford, 3-33, https://doi. org/10.1093/acprof:0so/9780199766062.003.0001.

Becker, Joachim (2008): Der kapitalistische Staat in der Peripherie: politökonomische Perspektiven. In: Journal für Entwicklungspolitik, Bd. 24, Nr. 2, 10-32, https://doi.org/10.20446/JEP-2414-3197-24-2-10.

Bein, Amit (2006): The Ulema, Their Institutions, and Politics in the Late Ottoman Empire. Unveröffentlichte Dissertation an der Princeton University, New Jersey.

Belge, Murat (1983): Sivil Toplum ve Türkiye [Zivilgesellschaft und die Türkei]. In: Cumhuriyet Dönemi Türkiye Ansiklopedisi [Enzyklopädie der republikanischen Periode der Türkei], Bd. 7. Istanbul.

Belge, Murat (1998): Sivil Toplum Örgütleri [Organisationen der Zivilgesellschaft]. In: Ulaş, Taciser (Hg.): Merhaba Sivil Toplum [Hallo Zivilgesellschaft]. Istanbul, 23-37.

Berlinski, Claire (2017): Guilty Men. How Democracies Die. In: The American Interest, 24.04.2017, https:/www.the-american-interest.com/2017/04/24/guiltymen/(Abruf am 12.10.2018).

Boone, Catherine (1994): States and Ruling Classes in Postcolonial Africa: The Enduring Contradictions of Power. In: Migdal, Joel Samuel; Kohli, Atul; Shue, Vivienne (Hg.): State Power and Social Force. Domination and Transformation in the Third World. Cambridge, 108-140, https://doi.org/10.1017/ CBO9781139174268.008.

Bora, Tanıl (1998): Türk Sağı'nın Üç Hâli: Milliyetçilik, Muhafazakârlık, İslâmcılık [Drei Zustände der türkischen Rechten: Nationalismus, Konservatismus, Islamismus]. Istanbul.

Bora, Tanıl; Gültekingil, Murat (Hg.) (2001): Modern Türkiye'de Siyasi Düşünce: Cilt 2 Kemalizm [Politische Ideen in der modernen Türkei: Band 2 Kemalismus]. Istanbul.

Bora, Tanıl; Gültekingil, Murat (Hg.) (2005): Modern Türkiye'de Siyasi Düşünce: Cilt 6 İslâmcilık [Politische Ideen in der modernen Türkei: Band 6 Islamismus]. Istanbul. 
Boratav, Korkut (1987): Die türkische Wirtschaftspolitik (1908-1980). Frankfurt a.M..

Boratav, Korkut (2003): Türkiye İktisat Tarihi 1908-2002 [Wirtschaftsgeschichte der Türkei 1908-2002]. Ankara.

Boratav, Korkut (2005): 1980'li Yıllarda Türkiye'de Sosyal Sınıflar ve Bölüşüm [Soziale Klassen und Verteilung in der Türkei der 1980er Jahre]. Ankara.

Boratav, Korkut (2009): Bir Çevrimin Yükseliş Aşamasında Türkiye Ekonomisi [Die Ökonomie der Türkei im Aufwärtstrend eines Zyklus]. In: Mütevellioğlu \& Sönmez 2009, 1-75.

Boratav, Korkut (2017): Emperyalizm Türkiye'de. AKP'li Yıllar [Der Imperialismus ist in der Türkei: Die AKP Jahre]. In: Monthly Review Türkiye, Bd. 1, Nr. 1, 19-34. Bortz, Jürgen; Döring, Nicola (2006): Forschungsmethoden und Evaluation für Human- und Sozialwissenschaftler. Heidelberg, https://doi.org/10.1007/978-3540-33306-7.

Bourdieu, Pierre (1977): Outline of a Theory of Practice. Cambridge, https://doi. org/10.1017/CBO9780511812507.

Bourdieu, Pierre (1983): Ökonomisches Kapital, kulturelles Kapital, soziales Kapital. In: Kreckel, Reinhard (Hg.): Soziale Ungleichheiten. Soziale Welt Sonderband 2. Göttingen, 183-198.

Bourdieu, Pierre (1985): The Social Space and the Genesis of Groups. In: Theory and Society, Bd. 14, Nr. 6, 723-744, https://doi.org/10.1007/BFoo174048.

Bourdieu, Pierre (1987): Die feinen Unterschiede. Kritik der gesellschaftlichen Urteilskraft. Frankfurt a.M..

Bozarslan, Hamit (2003): The Kurdish Nationalism in Turkey: From the Tacit Contract to Rebellion (1919-1925). In: Vali, Abbas (Hg.): Essays on the Origins of Kurdish Nationalism. Costa Mesa, Mazda Pub, 163-190.

Bozarslan, Hamit (2008): Kurds and the Turkish State. In: Kasaba 2008, 333-356, https://doi.org/10.1017/CHOL9780521620963.013.

Brand, Ulrich; Görg, Christoph (2000): Die Regulation des Marktes und die Transformation der Naturverhältnisse. In: PROKLA, Nr. 118, 83-106, https://doi. org/10.32387/prokla.v30i118.785.

Breidenstein, Georg; Hirschauer, Stefan; Kalthoff, Herbert; Nieswand, Boris (2018): Ethnographie. Die Praxis der Feldforschung. Konstanz.

Buci-Glucksmann, Christine (1981): Gramsci und der Staat. Für eine materialistische Theorie der Philosophie. Köln.

Buckel, Sonja; Georgi, Fabian; Kannankulam, John; Wissel, Jens (2017): The European Border Regime in Crisis. Theory, Methods and Analyses in Critical European Studies. Study commissioned by the Rosa-Luxemburg-Stiftung, Berlin.

Buckel, Sonja; Fischer-Lescano, Andreas (Hg.) (2007): Hegemonie gepanzert mit Zwang. Zivilgesellschaft und Politik im Staatsverständnis Antonio Gramscis. Baden Baden. 
Buğra, Ayşe (1994): State and Business in Modern Turkey: A Comparative Study. State University of New York Press.

Buğra, Ayşe (1998): Class, Culture, and State: An Analysis of Interest Representation by Two Turkish Business AssociationIn: International Journal of Middle East Studies, Bd. 30, Nr. 4, 521-539, https://doi.org/10.1017/S0020743800052545.

Buğra, Ayşe; Candaş, Ayşen (2011): Change and Continuity under an Eclectic Social Security Regime: The Case of Turkey. In: Middle Eastern Studies, Bd. 47, Nr. 3 , 515-528, https://doi.org/10.1080/00263206.2011.565145.

Burawoy, Michael (1998): The Extended Case Method. In: Sociological Theory, Bd. 16, Nr. 1, 4-33, https://doi.org/10.1111/0735-2751.00040.

Çağlar, Gazi (2000): Staat und Zivilgesellschaft in der Türkei und im Osmanischen Reich. Frankfurt a.M..

Çağlar, Gazi (2003): Die Türkei zwischen Orient und Okzident. Eine politische Analyse ihrer Geschichte und Gegenwart. Münster.

Çakır, Ruşen; Bozan, İrfan (2005): Sivil, Şeffaf ve Demokratik bir Diyanet İşleri Başkanlığı Mümkün mü? [Ist eine zivile, transparente und demokratische Diyanet möglich?]. TESEV Yayınları, Istanbul.

Çakır, Ruşen; Bozan, İrfan; Talu, Balkan (2004): İmam Hatip Liseleri: Efsaneler ve Gerçekler (Imam Hatip Lyzeen: Legenden und Tatsachen]. TESEV Yayınları, Istanbul.

Calhoun, Craig; Juergensmeyer, Mark; VanAntwerpen, Jonathan (2011): Introduction. In: Dies. (Hg.): Rethinking Secularism. NewYork, 3-30.

Candeias, Mario (2004): Neoliberalismus, Hochtechnologie, Hegemonie. Grundrisse einer transnationalen kapitalistischen Produktions- und Lebensweise. Eine Kritik. Hamburg.

Candeias, Mario (2007): Gramscianische Konstellationen. Hegemonie und die Durchsetzung neuer Produktions- und Lebensweisen. In: Merkens \& Diaz 2007, 15-32.

Candeias, Mario (2008): Von der Dialektik des Neoliberalismus zu den Widersprüchen der Bewegungen. In: Butterwegge, Christoph; Lösch, Bettina; Ptak, Ralf (Hg.): Neoliberalismus. Wiesbaden, 301-317, https://doi.org/10.1007/978-3-53190899-1_17.

Çarkoğlu, Ali; Toprak, Binnaz (2000): Türkiye'de Din, Toplum ve Siyaset [Religion, Gesellschaft und Politik in der Türkei]. TESEV Yayınları, Istanbul.

Çavdar, Gamze (2006): Islamist New Thinking: A Model for Political Learning? In: Political Science Quarterly, Bd. 21, Nr. 3, 477-497, https://doi.org/10.1002/j.1538165X.2006.tboo579.x.

Cavuldak, Ahmet (2013): Die Legitimität der hinkenden Trennung von Staat und Kirche in der Bundesrepublik Deutschland. In: Pickel, Gert; Hidalgo, Oliver (Hg.): Religion und Politik im vereinigten Deutschland. Was bleibt von der 
Rückkehr des Religiösen? Wiesbaden, 307-335, https://doi.org/10.1007/978-3531-94181-3_13.

CBRT (2017): Financial Accounts Report. 2017 - III. Central Bank of Turkey.

Çelik, Aziz (2015): Turkey's New Labour Regime under the Justice and Development Party in the First Decade of the Twenty-First Century: Authoritarian Flexibilization. In: Middle Eastern Studies, Bd. 51, Nr. 4, 618-635, https://doi.org/10.1080/ 00263206.2014.987665.

Cengiz, Kurtuluş (2013): »Yav İşte Fabrikalaşak«. Anadolu Sermayesinin Oluşumu: Kayseri-Hacılar Örneği [»Ey, lass uns eine Fabrik gründen«. Die Entstehung des anatolischen Kapitals: Das Kayseri-Hacilar Beispiel]. Istanbul.

Ciddi, Sinan (2011): Turkey's September 12, 2010, Referendum. In: Middle East Review of International Affairs (Online), Bd. 15, Nr. 4.

Cinar, Menderes (2006): Turkey's Transformation Under the AKP Rule. In: The Muslim World, Bd. 96, Nr. 3, 469-486, https://doi.org/10.1111/j.1478-1913.2006. 00138.x.

Cizre, Ümit (Hg.) (2008): Secular and Islamic Politics in Turkey: The Making of the Justice and Development Party. Oxon, https://doi.org/10.4324/9780203937334.

Cizre, Ümit (2017): Fear and Loathing in Turkey: The Backstory to Erdoğan's Referendum. In: MERIP, 26.04.2017, https://merip.org/2017/04/fear-and-loathingin-turkey/(Abruf am 12.10.2018).

Çoban, Funda (2015): İslamcılığın Fikri Taşıyıcısı Olarak Türkiye Siyasi Hayatında Necip Fazıl [Necip Fazıl als intellektueller Träger des Islamismus im politischen Leben der Türkei]. In: Mülkiye Dergisi, Bd. 39, Nr. 3, 59-87.

Copeaux, Etienne (2000): Tarih ders kitaplarında (1931-1993) Türk tarih tezinden Türk-İslam sentezine [Von der türkischen Geschichtsthese zur TürkischIslamischen-Synthese in Schulbüchern für Geschichte (1931-1933)]. Türk Tarih Vakfi Yayınları, Istanbul.

Çoşar, Simten; Yücesan-Özdemir, Gamze (Hg.) (2012): Silent Violence. Neoliberalism, Islamist Politics, and the AKP Years in Turkey. Ottawa.

De Leon, Cedric; Desai, Manali; Tuğal, Cihan (2009): Political Articulation: Parties and the Constitution of Cleavages in the United States, India, and Turkey. In: Sociological Theory, Bd. 27, Nr. 3, 193-219, https://doi.org/10.1111/j.1467-9558. 2009.01345.x.

Değirmen, Ufuk (2013): Neoliberalizm-İslamcılık Hegemonyası ve Kürdi Belediyeler [Hegemonie des Neoliberalismus-Islamismus und Kurdische Kommunen]. In: Sol Bakış, Nr. 13, 30.03.2013, Beilage der Tageszeitung Sol.

Demirović, Alex (1992): Regulation und Hegemonie. Intellektuelle, Wissenspraktiken und Akkumulation. In: Demirović, Alex; Krebs, Hans-Peter; Sablowski, Thomas (Hg.): Hegemonie und Staat. Kapitalistische Regulation als Projekt und Prozess. Münster, 128-157. 
Demirović, Alex (2001): Hegemoniale Projekte und die Rolle der Intellektuellen. In: Das Argument, Heft 239, 59-65.

Demirović, Alex (2006a): Neoliberalismus und Hegemonie. In: Filipič, Ursula (Hg.): Neoliberalismus und Globalisierung. Wien, 17-33, https://doi.org/10.1007/9783-531-90899-1_2.

Demirović, Alex (2006b): Volkes Herrschaft? Demokratie und kapitalistischer Staat bei Nicos Poulantzas. In: Bretthauer, Lars; Gallas, Alexander; Kannankulam, John; Stützle, Ingo (Hg.): Poulantzas lesen. Zur Aktualität marxistischer Staatstheorie. Hamburg.

Demirović, Alex (2007a): Nicos Poulantzas. Aktualität und Probleme materialistischer Staatstheorie. Münster.

Demirović, Alex (2007b): Politische Gesellschaft - zivile Gesellschaft. Zur Theorie des integralen Staates bei Antonio Gramsci. In: Buckel \& Fischer-Lescano 2007, 21-41, https://doi.org/10.5771/9783845201849-19.

Demirpolat, Anzavur (2002): The Rise of Islamic Economic Ethic, Rationality and Capitalism in Modern Turkey: the Case of Konya. Unveröffentlichte Dissertation an der Middle East Technical University, Ankara.

Dinler, Demet (2003): Türkiye'de Güçlü Devlet Geleneği Tezinin Eleştirisi [Kritik der These vom Starken Staat in der Türkei]. In: Praksis, Nr. 9, 17-54.

Doğan, Ali Ekber (2004): Sosyal Demokrat Vaatlerden Neoliberal Rövanşçllı̆a: 1990'lar Ankara'sinda Belediyecilik [Vom sozialdemokratischen Versprechen zum neoliberalen Revanchismus: Kommunalpolitik im Ankara der 1990er]. In: Praksis, Nr. 12, 103-128.

Doğan, Ali Ekber (2007): Eğreti Kamusallık. Kayseri Örneğinde İslâmcı Belediyecilik [Oberflächliche Kommunalität. Islamische Kommunalpolitik am Beispiel von Kayseri]. Istanbul.

Doğan, Ali Ekber (2009a): İslamcı Sermayenin Gelişme Dinamikleri ve 28 Şubat Süreci [Die Entwicklungsdynamiken des islamischen Kapitals und der Prozess des 28. Februars]. In: Uzgel \& Duru 2009, 283-306.

Doğan, Ali Ekber (2009b): 29 Mart 2009 Seçimleri ve AKP: Türkiye'nin Siyasal Coğrafyası Açısından bir Değerlendirme [Die Wahlen vom 29. März 2009 und die AKP: Eine Bewertung hinsichtlich der politischen Landschaft der Türkei]. In: Praksis, Nr. 21, 113-134.

Doğan, Ali Ekber (2011): »1994'ten Bugüne Neoliberal İslamcı Belediyecilikte Süreklilik ve Değişimler« [Kontinuiäten und Veränderungen in der neoliberal-islamischen Kommunalpolitik von 1994 bis heute]. In: Praksis, Nr. 26, 55-75.

Doğan, Sevinç (2016): Mahalledeki AKP. Parti İşleyişi, Taban Mobilizasyonu ve Siyasal Yabancılaşma [Die AKP im Bezirk. Funktionsweise der Partei, Mobilisierung der Basis und Politische Entfremdung]. Istanbul. 
Dörre, Klaus (2009): Die neue Landnahme. Dynamiken und Grenzen des Finanzmarktkapitalismus. In: Dörre, Klaus; Lessenich, Stephan; Rosa, Hartmut (Hg.): Soziologie - Kapitalismus - Kritik. Eine Debatte. Frankfurt a.M., 21-86.

Dufner, Ulrike (1998): Militär kontra Islamismus. In: Wissenschaft und Frieden, Bd. 16, Nr. 4.

Durak, Yasin (2011): Emeğin Tevekkülü. Konya'da İşçi-İşveren İlişkileri ve Dindarlık [Die Schicksalsergebenheit der Arbeitskraft. Arbeitnehmer-Arbeitgeber Beziehungen und Religiosität in Konya]. Istanbul.

Duru, Bülent (2009): Modern Muhafazakârlık ve Liberal Politikalar Arasında Doğal Varlıklar: AKP'nin Çevre Politikalarına bir Bakış [Natürliche Ressourcen zwischen modernem Konservatismus und liberaler Politik: Ein Blick auf die Umweltpolitik der AKP]. In: Uzgel \& Duru 2009, 783-802.

Duzgun, Eren (2012): Review: Islam's Marriage with Neoliberalism: State Transformation in Turkey, Yıldız Atasoy. In: Historical Materialism, Bd. 4, Nr. 3, 181-200, https://doi.org/10.1163/1569206X-12341262.

Eder, Mine (2010): Retreating State? Political Economy of Welfare Regime Change in Turkey. In: Middle East Law and Governance, Bd. 2, Nr. 2, 152-184, https:// doi.org/10.1163/187633710X500739.

Eğilmez, D. Burcu (2010): İzmir'de Kentsel Dönüşüm ve Dönüştürülemeyen Zorunlu Yoksulluk Halleri [Städtische Transformation und gleichbleibende Armutszustände in Izmir]. In: Yıldırım \& Haspolat 2010, 601-638.

Elfferding, Wieland (1983): Klassenpartei und Hegemonie: zur impliziten Parteientheorie des Marxismus. In: Das Argument, Sonderband 91: Marxismus und Theorie der Parteien, 7-35.

Ercan, Fuat (2002): The Contradictory Continuity of the Turkish Capital Accumulation Process: A Critical Perspective on the Internationalization Process of the Turkish Economy. In: Balkan \& Savran 2002, 21-37.

Ercan, Fuat; Oğuz, Şebnem (2015): Form Gezi Resistance to Soma Massacre: Capital Accumulation and Class Struggle in Turkey. In: Socialist Register, Bd. 51, 114135.

Ercan, Fuat; Tuna, Ş. Gürçağ (2006): İç Burjuvazinin Gelişimi: 1960'lardan Günümüze Bakış [Entwicklung der inneren Bourgeoisie: Eine Sichtung von 1960 bis heute]. In: Ülman, Burak; Akça, İsmet (Hg.): İktisat, Siyaset, Devlet Üzerine Yazılar: Prof. Dr. Kemali Saybaşılı'ya Armağan [Schriften über Wirtschaft, Politik, Staat: Widmung an Prof. Dr. Kemali Sayıbaşıl1]. Istanbul, 141-173.

Erden, M. Suphi (2004): The exchange of Greek and Turkish populations in the 1920 s and its socio-economic impacts on life in Anatolia. In: Crime, Law \& Social Change, Bd. 41, Nr. 3, 261-282, https://doi.org/10.1023/ B:CRIS. 0000024437.30463 .84$.

Erdoğan, Necmi (2001a): »Kalpaksız Kuvvacılar«: Kemalist Sivil Toplum Kuruluşları [»Streiter ohne Filzmütze«: Kemalistische Zivilgesellschaftsorganisatio- 
nen]. In: Türkiye'de Sivil Toplum ve Milliyetçilik [Zivilgesellschaft und Nationalismus in der Türkei]. Istanbul, 235-263.

Erdoğan, Necmi (2001b): Neo-Kemalizm, Organik Bunalım ve Hegemonya [NeoKemalismus, Organische Krise und Hegemonie]. In: Bora \& Gültekingil 2001, 584-591.

Eres, Beran; Yüksel, Hakan (2018): AKP Döneminde Türkiye'de Değişen Medya Sermayesi [Wechsel von Medieneigentum in der AKP-Periode]. In: Hâlâ Gazeteciyiz, 10.05.2018, https://halagazeteciyiz.net/2018/05/10/akp-donemindeturkiyede-degisen-medya-sermayesi/(Abruf am 12.10.2018).

Ertekin, Orhan Gazi (2011): Yarg1 Meselesi Hallolundu [Die Justizfrage ist erledigt]. Ankara.

Ertuğrul, İlker N. 2009: AKP ve Özelleştirme [AKP und Privatisierung]. In: Uzgel \& Duru 2009, 522-555.

Esen, Berk; Gumuscu, Sebnem (2016): Rising Competitive Authoritarianism in Turkey. In: Third World Quarterly, Bd. 37, Nr. 9, 1581-1606, https://doi.org/10. 1080/01436597.2015.1135732.

Esen, Berk; Gumuscu, Sebnem (2017): Turkey: How the Coup Failed. In: Journal of Democracy, Bd. 28, Nr. 1, 59-73, https://doi.org/10.1353/jod.2017.0006.

ESI (2005): Islamische Calvinisten. Umbruch und Konservatismus in Zentralanatolien. Berlin/Istanbul. In: https://www.esiweb.org/index.php?lang=en\&id=156 \&document_ID=71 vom 19.09.2005 (Abruf am 10.12.2018).

Evans, Peter B.; Rueschemeyer, Dietrich (1985): The State and Economic Transformation. Toward an Analysis of the Conditions Underlying Effective Intervention. In: Evans \& Rueschemeyer \& Skocpol 1985, 44-77, https://doi.org/10.1017/ CBO9780511628283.004.

Evans, Peter B.; Rueschemeyer, Dietrich; Skocpol, Theda (Hg.) (1985): Bringing the State Back In. Cambridge.

Fisahn, Andreas (2016): Die Saat des Kadmos. Staat, Demokratie und Kapitalismus. Münster.

Gerlach, Christian (2002): Nationsbildung im Krieg: Wirtschaftliche Faktoren bei der Vernichtung der Armenier und beim Mord an den ungarischen Juden. In: Kieser, Hans-Lukas; Schaller, Dominik J. (Hg.): Der Völkermord an den Armeniern und die Shoah. Zürich, 347-422.

Göçek, Fatma Müge (1993): Ethnic Segmentation, Western Education, and Political Outcomes: Nineteenth-Century Ottoman Society. In: Poetics Today, Bd. 14, Nr. 3, 507-538, https://doi.org/10.2307/1773283.

Göker, Emrah (2013): Emme-basma tulumba olarak cami [Die Moschee als Saugund Druckpumpe]. In: Express, Nr. 135, 10-11.

Göktaş, Kemal (2012): Yeni Yargı: Kurumsallaşma ve Pratik [Die neue Justiz: Institutionalisierung und Praxis]. In: Birikim, Nr. 275, 18-22. 
Göle, Nilüfer (1997): Secularism and Islamism in Turkey: The Making of Elites and Counter-Elites. In: Middle East Journal, Bd. 51, Nr. 1, 46-58.

Göle, Nilüfer (2004): Die sichtbare Präsenz des Islam und die Grenzen der Öffentlichkeit. In: Dies.; Ammann, Ludwig (Hg.): Islam in Sicht. Der Auftritt von Muslimen im öffentlichen Raum. Bielefeld, 11-44, https://doi.org/10.14361/ 9783839402375-001.

Göle, Nilüfer (2012): Post-Secular Turkey. In: New Perspectives Quarterly, Bd. 29, Nr. 1, 7-11, https://doi.org/10.1111/j.1540-5842.2012.01290.x.

Gözaydın, İştar (2009): Diyanet. Türkiye Cumhuriyet'inde Dinin Tanzimi [Diyanet. Die Regulierung der Religion in der Republik Türkei]. Istanbul.

Gramsci, Antonio (1986): Einige Gesichtspunkte der Frage des Südens. In: Zamis, Guido (Hg.): Zu Politik, Geschichte und Kultur: ausgewählte Schriften. Frankfurt a.M., 188-215.

Gramsci, Antonio (1991ff.): Gefängnishefte. Kritische Gesamtausgabe. Hamburg/Berlin.

Guha, Ranajit (1997): Dominance without Hegemony. History and Power in Colonial India. Cambridge/London.

Gülalp, Haldun (1997): Modernization Policies and Islamist Politics in Turkey. In: Kasaba \& Bozdoğan 1997, 52-63.

Gülalp, Haldun (1999): Political Islam in Turkey: The Rise and Fall of the Refah Party. In: The Muslim World, Bd. 89, Nr. 1, 22-41, https://doi.org/10.1111/j.1478-1913. 1999.tbo3667.x.

Gülalp, Haldun (2005): Enlightenment by Fiat: Secularization and Democracy in Turkey. In: Middle Eastern Studies, Bd. 41, Nr. 3, 351-372, https://doi.org/10. 1080/00263200500105984.

Gülhan, Sinan T. (2011): Devlet müteahhitlerinden gayrimenkul geliştiricilerine. Türkiye'de kentsel rant ve bir meta olarak konut üreticiliği. Konuta hücum [Von staatlichen Bauträgern zu Immobilienentwicklern. Wohnungsbau als urbaner Profit und Ware in der Türkei. Run auf die Immobilien]. In: Birikim, Nr. 270, 27-33.

Güney, Murat (2009): AKP ve Türkiye'de Yeni İktidar [Die AKP und die neue Herrschaft in der Türkei]. In: Ders. (Hg.): Türkiye'de İktidarı Yeniden Düşünmek [Herrschaft in der Türkei Neu Denken]. Istanbul.

Güngen, Ali Riza (2017): Financial Inclusion and Policy-Making: Strategy, Campaigns and Microcredit a la Turca. In: New Political Economy, Online, https:// doi.org/10.1080/13563467.2017.1349091.

Güngen, Ali Rıza; Erten, Şafak (2005): Approaches of Şerif Mardin and Metin Heper on State and Civil Society in Turkey. In: Journal of Historical Studies, 3/2005, 1-14. 
Gürel, Burak (2014): Türkiye'de Kırda Sınıf Mücadelelerinin Tarihsel Gelişimi [Die historische Entwicklung von Klassenkämpfen auf dem Land in der Türkei]. In: Savran \& Tanyılmaz \& Tonak 2014, 303-385.

Güveloğlu, Nazım (2004): Demokrasinin Neoliberal Çağda Geçirdiği Dönüşümün Siyasal Partiler Üzerindeki Etkileri [Auswirkungen der Transformation der Demokratie im neoliberalen Zeitalter auf die politischen Parteien]. In: Praksis, Nr. 12, 11-36.

Hale, William (2006): Christian Democracy and the JDP. Parallels and Contrasts. In: Yavuz, M. Hakan (Hg.): The Emergence of a New Turkey: Democracy and the AK Parti. Salt Lake City, 66-87.

Hale, William; Özbudun, Ergun (2010): Islamism, Democracy and Liberalism in Turkey. The Case of the AKP. Oxon, https://doi.org/10.4324/9780203873359.

Hastings, Adrian (1997): The Construction of Nationhood. Ethnicity, Religion and Nationalism. Cambridge.

Haug, Frigga (2007): Mit Gramsci die Geschlechterverhältnisse begreifen. In: Merkens \& Diaz 2007, 33-53.

Haug, Wolfgang Fritz (2004): Hegemonie. In: Haug, Wolfgang Fritz (Hg.): Historisch-Kritisches Wörterbuch des Marxismus Band 6/I. Hamburg, 2-25.

Heper, Metin (1985): The State Tradition in Turkey. Walkington.

Heper, Metin (1987): The State and Public Bureaucracies: A Comparative Perspective. London.

Heper, Metin (1992): The Strong State as a Problem for the Consolidation of Democracy: Turkey and Germany Compared. In: Comparative Political Studies, Bd. 25, Nr. 2, 169-194, https://doi.org/10.1177/0010414092025002002.

Hill, Christopher (1961): Protestantism and the Rise of Capitalism. In: Fisher, Frederick J. (Hg.): Essays in the Economic and social History of Tudor and Stuart England. London, 15-39.

Hillebrandt, Frank (2009): Praxistheorie. In: Kneer, Georg; Schroer, Markus (Hg.): Handbuch Soziologische Theorien. Wiesbaden, 369-394, https://doi.org/10. 1007/978-3-531-91600-2_18.

Hirsch, Joachim (2005): Materialistische Staatstheorie. Transformationsprozesse des kapitalistischen Staatensystems. Hamburg.

Hobsbawm, Eric (1968): Industry and Empire. London.

Hoşgör, A. Evren (2008): AKP, State and Capital. A Class-theoretical ReInterpretation of the Conflict between the >Centre Turkey. Unveröffentlichte Dissertation an der Lancaster University.

Hoşgör, Evren (2015): Islamic Capital. In: Balkan \& Balkan \& Öncü 2015, 142-165. Hoşgör, Evren; Özel, Bülent (2010): Tracing >Center-Periphery< Paradigm: Critical Literature Review via Network Analysis. Präsentation an der Duke University Political Networks Conference, Juli 2010. 
Huntington, Samuel (1993): The Clash of Civilizations? In: Foreign Affairs, Bd. 72, Nr. 3, 22-49, https://doi.org/10.2307/20045621.

Iğsız, Aslı (2013): Brand Turkey and the Gezi Protests: Authoritarianism, Law, and Neoliberalism. In: Jadaliyya, 12.07.2013, www.jadaliyya.com/Details/29078 (Abruf am 14.02.2017).

Inalcik, Halil (1969): Capital Formation in the Ottoman Empire. In: The Journal of Economic History, Bd. 29, Nr. 1, 97-140, https://doi.org/10.1017/ So022050700097849.

Insel, Ahmet (2003): The AKP and Normalizing Democracy in Turkey. In: The South Atlantic Quarterly, Bd. 102, Nr. 2/3, 293-308, https://doi.org/10.1215/00382876102-2-3-293.

İnsel, Ahmet (2014): Bir devir daha kapanırken [Während eine weitere Ära zu Ende geht]. In: Birikim, Nr. 297, 8-10.

İnsel, Ahmet (2015): Putinizm pençesinde Türkiye [Die Türkei im Würgegriff des Putinismus]. In: Cumhuriyet, 29.09.2015.

İnsel, Ahmet (2016a): Özgürlükçü Laiklik [Libertärer Laizismus]. In: Cumhuriyet, 03.05 .2016 .

İnsel, Ahmet (2016b): Otoriterizm ötesine gidiş [Über den Autoritarismus hinaus]. In: Cumhuriyet, 17.05.2016.

Isik, Damla (2014): Vakıf as Intent and Practice: Charity and Poor Relief in Turkey. In: International Journal of Middle East Studies, Bd. 46, Nr. 3. 307-327, https:// doi.org/10.1017/S0020743814000129.

Jäger, Michael (2007): Die Partei, die ein Ziel hat. In: Merkens \& Diaz 2007, 126-140. Jessop, Bob (1982): The Capitalist State. Marxist Theories and Method. Oxford.

Jessop, Bob (1990): State Theory. Putting the Capitalist State in its Place. Cambridge. Kalaycıoglu, Ersin (2015): Turkish Popular Presidential Elections: Deepening Legitimacy Issues and Looming Regime Change. In: South European Society and Politics, Bd. 20, Nr. 2, 157-179, https://doi.org/10.1080/13608746.2015.1046264.

Kannankulam, John; Georgi, Fabian (2012): Die Europäische Integration als materielle Verdichtung von Kräfteverhältnissen. Hegemonieprojekte im Kampf um das `Staatsprojekt Europar. Arbeitspapier Nr. 30 der Forschungsgruppe Europäische Integration an der Phillips-Universität Marburg. Marburg.

Karacimen, Elif (2015): Interlinkages between credit, debt and the labour market: evidence from Turkey. In: Cambridge Journal of Economics, Bd. 39, Nr. 3, 751767, https://doi.org/10.1093/cje/beuo16.

Karakas, Cemal (2007): Türkei: Islam und Laizismus zwischen Staats-, Politik- und Gesellschaftsinteressen. HSFK-Report 1/2007. Frankfurt a.M..

Karaömerlioglu, M. Asim (1998): The village institutes experience in Turkey. In: British Journal of Middle Eastern Studies, Bd. 25, Nr. 1, 47-73, https://doi. org/10.1080/13530199808705654. 
Kasaba, Reşat (1988): The Ottoman Empire and the World Economy: The Nineteenth Century. State University of New York Press.

Kasaba, Reşat (Hg.) (2008): The Cambridge History of Turkey. Volume 4: Turkey in the Modern World. Cambridge.

Kasaba, Reşat; Bozdoğan, Sibel (Hg.) (1997): Rethinking Modernity and National Identity in Turkey. Seattle/London.

Kazancigil, Ali (1981): The Ottoman-Turkish State and Kemalism. In: Özbudun, Ergun; Kazancıgil, Ali (Hg.): Atatürk, Founder of a Modern State. London, 37-56.

Keyder, Çağlar (1987): State and Class in Turkey. A Study in Capitalist Development. London/New York.

Keyder, Çağlar (1997): Whither the Project of Modernity? Turkey in the 1990s. In: Kasaba \& Bozdoğan 1997, 37-51.

Kieser, Hans-Lukas (2000): Der verpasste Friede. Mission, Ethnie und Staat in den Ostprovinzen der Türkei 1839-1938. Zürich.

Kisakürek, Necip Fazıl (ohne Jahr): İdeoloçya Örgüsü [Ideologia Flechtwerk].

Koçak, Orhan (2001): 1920'lerden 1970'lere Kültür Politikaları [Kulturpolitiken von den 1920ern bis in die 1970er]. In: Bora \& Gültekingil 2001, 370-424.

Köse, Ahmet Haşim; Öncü Ahmet (1998): Dünya ve Türkiye ekonomisinde Anadolu imalat sanayii: Zenginleşmenin mi yoksa yoksullaşmanın mı eşiğindeyiz? [Die anatolische Herstellerindustrie in der globalen und türkischen Ökonomie: Befinden wir uns an der Schwelle zum Reichtum oder zur Armut?]. In: Toplum ve Bilim, Nr. 77, 135-159.

Küçükömer, İdris (1994): Sivil Toplum Yazıları [Schriften zur Zivilgesellschaft]. Istanbul.

Kuran, Timur (1995): Islamic Economics and the Islamic Subeconomy. In: Journal of Economic Perspectives, Bd. 9, Nr. 4, 155-173, https://doi.org/10.1257/jep.9.4.155.

Kuran, Timur (2001): The Provision of Public Goods under Islamic Law: Origins, Impacts, and Limitations of the Waqf System. In: Journal of the Law and Society Association, Bd. 35, Nr. 4, 841-898, https://doi.org/10.2307/3185418.

Kuru, Ahmet (2009): Secularism and State Policies Toward Religion. Cambridge, https://doi.org/10.1017/CBO9780511815096.

Kutlu, Denizcan (2015): Türkiye'de Sosyal Yardım Rejiminin Yapısal Boyutları, Disiplin Oluşumu ve Yardım Alan Yoksul Tipolojisi [Strukturelle Dimensionen des Wohlfahrtsregimes in der Türkei, Disziplinierung und Typologie der hilfsempfangenden Armen]. Einreichung auf dem 14. Kongress der Türkischen Vereinigung der Sozialwissenschaften.

Laclau, Ernesto; Mouffe, Chantal (1985): Hegemony and Socialist Strategy. Towards a Radical Democratic Politics. London.

Lauggas, Ingo (2007): Empfindungsstrukturen und Alltagsverstand. Implikationen der materialistischen Kulturbegriffe von Antonio Gramsci und Raymond Williams. In: Merkens \& Diaz 2007, 85-97. 
Lewin, Kurt (1943): Forces Behind Food Habits and Methods of Change. In: Bulletin of the National Research Council, Nr. 108, 35-65.

Lewis, Bernhard (1961): The Emergence of Modern Turkey. London.

Lord, Ceren (2018): The Story Behind the Rise of Turkey's Ulema. In: MERIP, 02.04.2018, https://merip.org/2018/02/the-story-behind-the-rise-ofturkeys-ulema/(Abruf am 12.10.2018).

Mahmood, Saba (2005): Politics of Piety: The Islamic Revival and the Feminist Subject. Princeton.

Mardin, Şerif (1980): The Transformation of an Economic Code. In: Özbudun, Ergun; Ulusan, Aydın (Hg.): The Political Economy of Income Distribution in Turkey. New York, 23-53.

Mardin, Şerif (1991): Türkiye'de Din ve Siyaset. Makaleler 3 [Religion und Politik in der Türkei. Schriften 3]. Istanbul.

Mardin, Şerif (2006a): Center-Periphery as a Concept for the Study of Social Transformation. In: Ders. 2006, 298-315.

Mardin, Şerif (2006b): Religion in Modern Turkey. In: Ders. 2006, 225-242.

Mardin, Şerif (2006c): Cultural Change and the Intellectual: Necip Fazil and the Nakşibendi. In: Ders. 2006, 243-259.

Mardin, Şerif (Hg.) (2006): Religion, Society, and Modernity in Turkey. Syracuse.

Marx, Karl (1977): Das Kapital. Kritik der politischen Ökonomie. In: Marx Engels Werke, Bd. 23. Berlin.

Marx, Karl; Engels, Friedrich (1981): Die deutsche Ideologie. In: Marx Engels Werke, Bd. 3. Berlin.

Mecham, R. Quinn (2004): From the ashes of virtue, a promise of light: the transformation of political Islam in Turkey. In: Third World Quarterly, Bd. 25, Nr. 2, 339-358, https://doi.org/10.1080/0143659042000174842.

Merkens, Andreas; Diaz, Victor Rego (Hg.) (2007): Mit Gramsci arbeiten. Texte zur politisch-praktischen Aneignung Gramscis. Hamburg.

Mertcan, Hakan (2012): Bitmeyen Kavga Laiklik. Türkiye'de Din-Devlet-Diyanet [Der andauernde Kampf um die Laizität. Religion-Staat-Diyanet in der Türkei]. Ankara.

Morton, Adam David (2011): The Limits of Sociological Marxism? In: Historical Materialism, Bd. 21, Nr. 1, 129-158, https://doi.org/10.1163/1569206X-12341284.

MÜSİAD (1994): İş Hayatında İslâm İnsanı (Homo Islamicus) [Der islamische Mensch im Geschäftsleben (Homo Islamicus)]. Istanbul.

Mütevellioğlu, Nergis; Sönmez, Sinan (Hg.) (2009): Küreselleşme, Kriz ve Türkiye'de Neoliberal Dönüşüm [Globalisierung, Krise und neoliberale Transformation in der Türkei]. Istanbul.

Mutlu, Kayhan (1990): Toplumların Gelişmesinde Dini Değer Yargılarının Önemi (İslâm ve Protestan Ahlâkının Karşılaştırılması) [Die Bedeutung religiöser 
Werturteile bei der Entwicklung von Gesellschaften (Vergleich der islamischen und protestantischen Ethik]. In: İslâmi Araştırmalar, Bd. 4, Nr. 2, 99-104.

Odman, Emine Asl (2000): Informalisierung und Staat: die Türkei seit der neoliberalen Wende 1980. In: PROKLA, Bd. 30, Nr. 3, 449-468.

Odman, Aslı (2006): 1929 Büyük Buhran Sonrası Meksika'da Korporatist Populizm ve Türkiye'de Solidarist Devletçilik Karşılaştırması: Küçükkuyu ile Yoğrulan Tezler [Vergleich des korporatistischen Populismus in Mexiko mit dem solidaristischen Etatismus in der Türkei nach der Großen Depression: Mit Küçükkuyu gereifte Thesen]. In: Yllmaz, Demet u.a. (Hg.): Türkiye'de Kapitalizmin Gelişimi [Die Entwicklung des Kapitalismus in der Türkei]. Ankara.

Oğurlu, Anita; Öncü, Ahmet (2015): The Laic-Islamist Schism in the Turkish Dominant Class and the Media. In: Balkan \& Balkan \& Öncü 2015, 272-285.

Öncü, Ahmet (2003): Dictatorship Plus Hegemony: A Gramscian Analysis of the Turkish State. In: Science \& Society, Bd. 67, Nr. 3, 303-328, https://doi.org/10. 1521/siso.67.3.303.21243.

Öniş, Ziya (2009): Conservative Globalism at the Crossroads: The Justice and Development Party and the Thorny Path to Democratic Consolidation in Turkey. In: Mediterranean Politics, Bd. 14, Nr. 1, 21-40, https://doi.org/10.1080/ 13629390902747376.

Öniş, Ziya (2015): Monopolising the Centre. The AKP and the Uncertain Path of Turkish Democracy. In: The International Spectator. Italian Journal of International Affairs, Bd. 50, Nr. 2, 22-41, https://doi.org/10.1080/03932729.2015. 1015335.

Opratko, Benjamin (2012): Hegemonie. Politische Theorie nach Antonio Gramsci. Münster.

Ozan, Ebru Deniz (2012): Gülme Sırası Bizde. 12 Eylül'e Giderken Sermaye Sınıfı, Kriz ve Devlet [Jetzt sind wir mit dem Lachen an der Reihe. Kapitalistische Klasse, Krise und Staat auf dem Weg zum 12. September]. Istanbul.

Ozan, Ebru Deniz (2015): İki Darbe Arasında Kriz Sarmalı [Krisenspirale zwischen zwei Putschs]. In: Atılgan \& Saraçoğlu \& Uslu 2015, 657-746.

Özbudun, Ergun (2006): From Political Islam to Conservative Democracy: The Case of the Justice and Development Party in Turkey. In: South European Society and Politics, Bd. 11, Nr. 3, 543-557, https://doi.org/10.1080/13608740600856561.

Özbudun, Ergun (2014): AKP at the Crossroads: Erdogan's Majoritarian Drift. In: Southeast European Society and Politics, Bd. 19, Nr. 2, 155-167, https://doi. org/10.1080/13608746.2014.920571.

Özçelik, Pınar Kaya (2015): İlk Birikim Sorunsalı Bağlamında ve Türk Ulus Devletinin Kurulma Sürecinde Gayrimüslim Azınlıklar [Nicht-muslimische Minderheiten im Kontext der Frage der primitiven Akkumulation und des Prozesses der Gründung des türkischen Nationalstaats]. In: Praksis, Nr. 39, 45-102. 
Özdalga, Elisabeth (2000): Worldly Asceticism in Islamic Casting: Fethullah Gülen's Inspired Piety and Activism. In: Critique: Critical Middle Eastern Studies, Bd. 9, Nr. 17, 83-104, https://doi.org/10.1080/10669920008720169.

Özdalga, Elisabeth (2006): The Hidden Arab: A Critical Reading of the Notion of >Turkish Islamく. In: Middle Eastern Studies, Bd. 42, Nr. 4, 551-570.

Özdemir, Ali Murat; Yücesan-Özdemir, Gamze (2006): Labour Law Reform in Turkey in the 2000s: The Devil is Not Just in the Detail but Also in the Legal Texts. In: Economic and Industrial Democracy, Bd. 27, Nr. 2, 311-331, https:// doi.org/10.1177/0143831X06060592.

Ozgur, Iren (2012): Islamic Schools in Modern Turkey. Faith, Politics, and Education. Cambridge, https://doi.org/10.1017/CBO9781139176026.

Öztürk, Naciye (2018): Okul Öncesi Dini Eğitim: »Kur'an Kursları Okul Öncesi Dini Eğitim Projesi« ve Öneriler [Religiöse Bildung in der Vorschule: »Projekt Korankurse in der religiösen Vorschulbildung« und Vorschläge]. SETA Yayınları, Istanbul.

Öztürk, Özgür (2010): Türkiye'de Büyük Sermaye Grupları. Finans Kapitalin Oluşumu ve Gelişimi [Die großen Kapitalgruppen in der Türkei. Entstehung und Entwicklung des Finanzkapitals]. Istanbul.

Öztürk, Özgür (2015): Islamist Big Bourgeoisie in Turkey. In: Balkan \& Balkan \& Öncü 2015, 117-141.

Özuğurlu, Metin (2008): Anadolu'da Küresel Fabrikanın Doğuşu. Yeni İşcilik Örüntülerinin Sosyolojisi [Die Genese der globalen Fabrik in Anatolien. Soziologie des neuen Arbeitertypus]. Ankara.

Poulantzas, Nicos (1967): Marxist Political Theory in Great Britain. In: New Left Review, Nr. 43, 57-74.

Poulantzas, Nicos (1973): Faschismus und Diktatur. München.

Poulantzas, Nicos (1978): Political Power and Social Classes. London.

Poulantzas, Nicos (2002): Staatstheorie. Politischer Überbau, Ideologie, Autoritärer Etatismus. Hamburg.

Quataert, Donald (2006): The Age of Reforms, 1812-1914. In: Inalc1k, Halil; Quataert, Donald (Hg.): An Economic and Social History of the Ottoman Empire, Volume Two 1600-1914. New York, 759-943.

Reyhan, Cenk (2008): Jön Türk Hareketi Üzerine Kavramsal Bir Çerçeve [Theoretischer Rahmen zur Erfassung der jungtürkischen Bewegung]. In: Akademik Bakış, Bd. 1, Nr. 2, 121-138.

Röttger, Bernd (2007): Passive Revolution und Gewerkschaften. Aufstieg und Niedergang korporatistischer Politik. In: Merkens \& Diaz 2007, 54-70.

Saraçoğlu, Cenk (2010): The changing image of the Kurds in Turkish cities: middleclass perceptions of Kurdish migrants in Izmir. In: Patterns of Prejudice, Bd. 44, Nr. 3, 239-260, https://doi.org/10.1080/0031322X.2010.489735. 
Saraçoğlu, Cenk (2011): İslami-Muhafazakar Milliyetçiliğin Millet Tasarımı: AKP Döneminde Kürt Politikası [Der Entwurf der Nation des islamisch-konservativen Nationalismus: Die Kurdenpolitik in der AKP-Periode). In: Praksis, Nr. 26, 31-54.

Saraçoğlu, Cenk (2015): Tank Paletiyle Neoliberalizm [Neoliberalismus mit Panzerketten]. In: Atılgan \& Saraçoğlu \& Uslu 2015, 747-869.

Saraçoğlu, Cenk; Yeşilbağ, Melih (2015): Minare ile İnşaat Gölgesinde [Im Schatten von Moschee und Bau]. In: Atılgan \& Saraçoğlu \& Uslu 2015, 871-957.

Savran, Sungur (1985): Osmanlı'dan Cumhuriyete: Türkiye'de Burjuva Devrimi Sorunu [Vom Osmanischen Reich zur Republik: Die Frage der bürgerlichen Revolution in der Türkei]. In: 11. Tez, Nr. 1, 172-214.

Savran, Sungur (1986): Sol Liberalizm: Maddeci bir Eleştiriye Doğru [LinksLiberalismus: In Richtung einer materialistischen Kritik]. In: 11. Tez, Nr. 2, 1040.

Savran, Sungur (2002): The Legacy of the twentieth Century. In: Balkan \& Savran 2002, 1-20.

Savran, Sungur (2010): Türkiye'de Sinif Mücadeleleri Cilt I: 1908-1980 [Klassenkämpfe in der Türkei Band I: 1908-1980]. Istanbul.

Savran, Sungur (2014): Sinıfları Haritalandırmak: Sinıflar Birbirinden Nasıl Ayrilır? [Die Klassen kartographieren: Wie unterscheiden sich Klassen voneinander?] In: Savran \& Tanyılmaz \& Tonak 2014, 25-67.

Savran, Sungur (2015): Class, State and Religion in Turkey. In: Balkan \& Balkan \& Öncü 2015, 41-88.

Savran, Sungur; Tanyılmaz, Kurtar; Tonak, E. Ahmet (Hg.) (2014): Marksizm ve Siniflar. Dünyada ve Türkiye'de Sinıflar ve Mücadeleleri [Marxismus und Klassen. Klassen und ihre Kämpfe auf der Welt und in der Türkei]. Istanbul.

Sayari, Sabri (2007): Towards a New Turkish Party System? In: Turkish Studies, Bd.

7, Nr. 2, 197-210, https://doi.org/10.1080/14683840701312286.

Saymaz, İsmail (2013): Sözde Terörist [Sogenannter Terrorist]. Istanbul.

Scherrer, Christoph (1998): Neo-gramscianische Interpretationen internationaler Beziehungen. Eine Kritik. In: Hirschfeld, Uwe (Hg.): Gramsci-Perspektiven. Hamburg/Berlin, 160-174.

Schütz, Alfred (1972): Der Fremde. Ein sozialpsychologischer Versuch. In: Schütz, Alfred: Gesammelte Aufsätze. Band 2 Studien zur soziologischen Theorie. Den Haag, 53-69, https://doi.org/10.1007/978-94-010-2849-3_3.

Şen, Mustafa (2007): A Background for Understanding the Gulen Community. In: Wohlrab-Sahr, Monika; Tezcan, Levent (Hg.): Konfliktfeld Islam in Europa. Soziale Welt, Sonderband 17, 327-346, https://doi.org/10.5771/9783845203263-327.

Şener, Mustafa (2015): Burjuva Uygarlığının Peşinde [Der bürgerlichen Zivilisation auf der Spur]. In: Atılgan \& Saraçoğlu \& Uslu 2015, 195-339. 
Singer, Amy (2000): A note on Land and Identity: From Ze'amet to Waqf. In: Owen, Roger (Hg.): New Perspectives on Land and Property in the Middle East. Cambridge, 161-173.

Skocpol, Theda (1985): Bringing the State Back In: Analyses and Strategies in Current Research. In: Evans \& Rueschemeyer \& Skocpol 1985, 3-37, https://doi. org/10.1017/CBO9780511628283.002.

Solty, Ingar (2009): Trägt Gramscis Begriff des organischen Intellektuellen noch? In: Das Argument, Bd. 51, Nr. 1/2, 110-115.

Somer, Murat (2007): Moderate Islam and Secularist Opposition in Turkey: implications for the world, Muslims and secular democracy. In: Third World Quarterly, Bd. 28, Nr. 7, 1271-1289, https://doi.org/10.1080/01436590701604888.

Sönmez, Mustafa (2009): 2000'ler Türkiye'sinde AKP, Hâkim Sınıflar ve İç Çelişkileri [Die AKP und die inneren Widersprüche der herrschenden Klassen in der Türkei der 2000er Jahre]. In: Uzgel \& Duru 2009, 179-191.

Sönmez, Mustafa (2013): Ten Years of Turkish Capitalism and Tendencies. In: Perspectives, Nr. 5, 18-21.

Sönmez, Sinan (2009): Türkiye Ekonomisinde Neoliberal Dönüşüm Politikaları ve Etkileri [Wirkung der neoliberalen Transformationsmaßnahmen in der Ökonomie der Türkei]. In: Mütevellioğlu \& Sönmez 2009, 25-75.

Sözeri, Ceren (2015): Türkiye'de Medya-İktidar İlişkileri. Sorunlar ve Öneriler [Beziehungen zwischen Regierung und Medien in der Türkei. Probleme und Vorschläge]. Istanbul.

Steckner, Anne (2012): Antonio Gramscis Auseinandersetzung mit Religion im Spannungsfeld zwischen Unterwerfung und Widerständigkeit. In: Grundrisse, Nr. 44, 11-20.

Suciyan, Talin (2015): The Armenians in Modern Turkey: Post-Genocide Society, Politics and History. London.

Taşkın, Yüksel (2001): 12 Eylül Atatürkçülüğü ya da Bir Kemalist Restorasyon Projesi olarak 12 Eylül [12. September Atatürkismus oder der 12. September als kemalistisches Restaurationsprojekt]. In: Bora \& Gültekingil 2001, 570-583.

Therborn, Göran (1977): The Rule of Capital and the Rise of Democracy. In: New Left Review, Nr. 103, 3-41.

Thomas, Peter D. (2009): The Gramscian Moment. Philosophy, Hegemony, and Socialism. Leiden/Boston, https://doi.org/10.1163/ej.9789004167711.i-478.

Thompson, Edward P. (1987): Die Entstehung der englischen Arbeiterklasse. Erster Band. Frankfurt a.M..

Tok, Evren (2011): Varieties of Communitarianism in the Cities of Anatolia Region: A Comparison of Kayseri, Gaziantep and Eskisehir. Unveröffentlichte Dissertation an der Carleton University of Ottawa, Ontario.

Toprak, Binnaz (2005): Islam and Democracy in Turkey. In: Turkish Studies, Bd. 6, Nr. 2, 167-186, https://doi.org/10.1080/14683840500119494. 
Toprak, Binnaz; Bozan, Irfan; Morgül, Tan; Şener, Nedim (2009): Being Different in Turkey. Religion, Conservatism and Otherization. Research Report on Neighbourhood Pressure. Boğaziçi University, Open Society Foundation.

Toprak, Zafer (1982): Türkiye'de Milli İktisat 1908 - 1918 [Nationale Wirtschaft in der Türkei: 1908 - 1918]. Ankara.

Tosun, Tanju (2010): 1950'lerden 2000'lere İzmir'de Seçimler [Wahlen in Izmir von den 1950ern bis in die 2000er]. In: Yildırım \& Haspolat 2010, 251-289.

Traunmüller, Richard (2012): Zur Messung von Staat-Kirche-Beziehungen: Eine vergleichende Analyse neuerer Indizes. In: Zeitschrift für Vergleichende Politikwissenschaft, Sonderheft 1, 207-231, https://doi.org/10.1007/s12286-012-0127-4.

Trimberger, Ellen Kay (1978): Revolution From Above: Military Bureaucrats and Development in Japan, Turkey, Egypt and Peru. New Brunswick.

Tröndle, Dirk (2007): Das Verhältnis von Islam und Demokratie in der Türkei zwischen Islamisierung der Politik und Politisierung des Islam. In: KAS-AI 12/07, 66-90.

TSSEA (2018): Türkiye Sosyal-Siyasal Eğilimler Araştırması [Türkei Studie zu SozioPolitischen Tendenzen]. Kadir Has University Center for Turkish Studies.

Tuğal, Cihan (2007): The Hand of the Market \& the Boot of the Army. In: ISIM Review 20.

Tuğal, Cihan (2009): Passive Revolution. Absorbing the Islamic Challenge to Capitalism. Stanford, California.

Tuğal, Cihan (2011): The Islamic Making of a Capitalist Habitus: The Turkish Subproletariat's Turn to the Market. In: Brady, David (Hg.): Comparing European Workers Part A. Research in the Sociology of Work, Bd. 22, Part 1, 85-112, https://doi.org/10.1108/S0277-2833(2011)0000022006.

Tuğal, Cihan (2012): Pasif Devrimlerde Toplum, Siyaset ve Bloklar [Gesellschaft, Politik und Blöcke in passiven Revolutionen]. In: Praksis, Nr. 27, 41-54.

Tuğal, Cihan (2013): Islam and the Retrenchment of Turkish Conservatism. In: Bayat, Asef (Hg.): Post-Islamism: The Changing Faces of Political Islam. Oxford, 109-133, https://doi.org/10.1093/acprof:oso/9780199766062.003.0004.

Tuğal, Cihan (2016): The Fall of the Turkish Model: How the Arab Uprisings Brought Down Islamic Liberalism. London.

Tuna, Ş. Gürçağ; Güneş, Bayram (2012): Munzur'dan Şirket Yaratmak: Munzur A.Ş Üzerinden Dersim'de Sermaye Birikiminin Dinamikleri [Aus Munzur ein Unternehmen erschaffen: Dynamiken der Kapitalakkumulation am Beispiel von Munzur A.Ş.]. In: Praksis, Nr. 28, 99-119.

Turam, Berna (2007): Between Islam and the State: The Politics of Engagement. Stanford, California.

Türk, Duygu (2004): Adaletin ve Kalkınmanın Üçüncü Yolu [Der Dritte Weg der Gerechtigkeit und Entwicklung]. In Praksis, Nr. 12, 63-84. 
Türkay, Mehmet (1998): Türkiye'de Kapitalist Sermaye Birikiminin »Ulusal« Dönüşümü [Die »nationale« Transformation der kapitalistischen Kapitalakkumulation in der Türkei]. In: Yllmaz, Demet u.a. (Hg.): Türkiye'de Kapitalizmin Gelişimi [Die Entwicklung des Kapitalismus in der Türkei]. Ankara, 19-36.

UDY (2016): Uluslararası Doğrudan Yatırımlar 2016 Yılı Raporu, T.C. Ekonomi Bakanlığ1 [Bericht über internationale Direktinvestitionen für 2016, Wirtschaftsministerium der Republik Türkei].

Ulus, Özgür Mutlu (2011): The Army and the Radical Left in Turkey - Military Coups, Socialist Revolution and Kemalism. London.

Uslu, Ateş (2015): >Hür Dünya'nın Saflarında [Auf der Seite der >freien Welt‘]. In: Atılgan \& Saraçoğlu \& Uslu 2015, 341-386.

Uyar, Hakkı (2010): Erken Cumhuriyet Döneminden Bugünümüze İzmir'de Siyasal Partiler, Seçimler ve Seçmen Eğilimleri [Politische Parteien und Wählerbewegungen in Izmir von der frühen Republik-Periode bis heute]. In: Yıldırım \& Haspolat 2010, 215-249.

Uysal, Ayşen; Topak, Oğuz (2010): Particiler. Türkiye'de Partiler ve Sosyal Ağların İnşası [Die Parteileute. Parteien und Aufbau sozialer Netzwerke in der Türkei]. Istanbul.

Uzgel, İlhan (2009): AKP: Neoliberal Dönüşümün Yeni Aktörü [AKP: Neuer Akteur der neoliberalen Transformation]. In: Uzgel \& Duru 2009, 11-39.

Uzgel, İlhan; Duru, Bülent (Hg.) (2009): AKP Kitabı. Bir Dönüşümün Bilançosu [Das AKP Buch. Bilanz einer Transformation]. Ankara.

van Bruinessen, Martin (1989): Vom Osmanismus zum Separatismus: Religiöse und ethnische Hintergründe der Rebellion des Scheich Said. In: Blaschke, Jochen; van Bruinessen, Martin (Hg.): Islam und Politik in der Türkei. Berlin, 109-165.

van Bruinessen, Martin (1992): Agha, Shaikh and State: On the Social and Political Organization of Kurdistan. London.

van Bruinessen, Martin (2000): Religion in Kurdistan. In: Ders. (Hg.): Mullas, Sufis and Heretics: The Role of Religion in Kurdish Society. Istanbul, 15-36.

Vergin, Nur (1985): Toplumsal değişme ve dinsellikte artış [Sozialer Wandel und Zunahme an Religiosität]. In: Toplum ve Bilim, Nr. 29-30, 9-28.

Weber, Max (1986): Die Protestantische Ethik und der »Geist « des Kapitalismus. In: Weber, Max: Gesammelte Aufsätze zur Religionssoziologie. Band 1. Tübingen, 17-206.

White, Jenny B. (2002): Islamist Mobilization in Turkey. A Study in Vernacular Politics. Seattle.

White, Jenny B. (2008): Islam and Politics in Contemporary Turkey. In: Kasaba 2008, 357-380, https://doi.org/10.1017/CHOL9780521620963.014.

Yalman, Galip (2002): The Turkish State and Bourgeoisie in Historical Perspective: A Relativist Paradigm or a Panoply of Hegemonic Strategies? In: Balkan \& Savran 2002, 21-54. 
Yalman, Galip (2009): Transition to Neoliberalism. The Case of Turkey in the 1980s. Istanbul.

Yalman, Galip; Topal, Aylin (2017): Labour Containment Strategies and Working Class Struggles in the Neoliberal Era: The Case of TEKEL Workers in Turkey. In: Critical Sociology Online, August 2017, https://doi.org/10.1177/ 0896920517711489.

Yankaya, Dilek (2014): Yeni İslâmî Burjuvazi. Türk Modeli [Die neue islamische Bourgeoisie. Türkisches Modell]. Istanbul.

Yarar, Erol (1997): A New Perspective of the World at the Threshold of the 21st century. MUSIAD, Istanbul.

Yarkın, Güllistan (2011): Dünyada Dönüşen Toplumsal Mücadeleler Ekseninde Türkiye'deki Kürt Hareketinin Ekonomi Politiği [Die Politische Ökonomie der Kurdischen Bewegung im Zusammenhang mit dem globalen Wandel sozialer Kämpfe]. In: Toplum ve Kuram, Nr. 5, 63-91.

Yavuz, M. Hakan (1997): Political Islam and the Welfare (Refah) Party in Turkey. In: Comparative Politics, Bd. 30, Nr. 1, 63-82, https://doi.org/10.2307/422193.

Yavuz, M. Hakan (2003): Islamic Political Identity in Turkey. Oxford.

Yavuz, M. Hakan (2004): Opportunity Spaces, Identity and Islamic Meaning in Turkey. In: Wiktorowicz, Quintan (Hg.): Islamic Activism. A Social Theory Approach. Indiana, 270-288.

Yavuz, M. Hakan (2005): Milli Görüş Hareketi: Muhalif ve Modernist Gelenek [Die Milli Görüş Bewegung: Oppositionelle und Modernistische Tradition]. In: Bora \& Gültekingil 2005, 591-603.

Yavuz, M. Hakan (Hg.) (2006): The Emergence of a New Turkey: Democracy and the AK Parti. Salt Lake City, https://doi.org/10.1093/jis/etmo63.

Yavuz, M. Hakan (2009): Secularism and Muslim Democracy in Turkey. Cambridge, https://doi.org/10.1017/CBO9780511815089.

Yavuz, M. Hakan; Koç, Rasim (2016): The Turkish Coup Attempt: The Gulen Movement vs. the State. In: Middle East Policy, Bd. 23, Nr. 4, 20-39, https://doi. org/10.1111/mepo.12239.

Yeldan, Erinç (2006): Neoliberal Global Remedies: From Speculative-Led Growth to IMF Led-Crisis in Turkey. In: Review of Radical Political Economics, Bd. 38, Nr. 2, 193-213, https://doi.org/10.1177/0486613405285423.

Yeldan, Erinç (2007): Patterns of Adjustment under the Age of Finance. The Case of Turkey as a Peripheral Agent of Neoliberal Globalization. Political Economy Research Institute, Working Paper Series Number 126.

Yeldan, Erinç; Voyvoda, Ebru (2011): Derinleşen Küresel Kriz ve Türkiye Ekonomisine Yansımaları: Ücretli Emek ve Sermaye [Vertiefte globale Krise und Auswirkungen auf die Ökonomie der Türkei: Lohnarbeit und Kapital]. Istanbul. 
Yıldırım, Deniz (2009): AKP ve Neoliberal Popülizm [AKP und Neoliberaler Populismus]. In: Uzgel \& Duru 2009, 66-107.

Yıldırım, Deniz; Haspolat, Evren (2010): Bir Liman Kentinin Siyasal Dönüşümünün Ekonomi-Politik Fay Hatları [Politisch-Ökonomische Bruchlinien der politischen Transformation einer Hafenstadt]. In: Yıldırım \& Haspolat 2010, 291-333.

Yıldırım, Deniz; Haspolat, Evren (Hg.) (2010): Değişen İzmir'i Anlamak [Izmir im Wandel Verstehen]. Ankara.

Yıldırım, Kansu (2018): OHAL-16 Nisan-24 Haziran: AKP-MHP iktidarı mı? Yeni bir tarihsel blok mu? [Ausnahmezustand-16. April-24. Juni: Eine AKP-MHP Regierung? Ein neuer historischer Block?]. In: https://devletvesiniflar.blogspot.de/ 2018/04/ohal-16-nisan-24-haziran-akp-mhp_20.html vom 20.04.2018 (Abruf am 25.04.2018).

Yıldızoğlu, Ergin (2009): AKP ve Liberal Entellektüellerin Yavaş İntiharı [Die AKP und der schleichende Suizid der liberalen Intellektuellen]. In: Uzgel \& Duru 2009, 108-125.

Yıldızoğlu, Ergin (2016): Laiklik Savunulmalıdır [Die Laizität muss verteidigt werden]. Istanbul.

Yilmaz, Arzu (2016): Friedensweg mündet im Krieg - Die Internationalisierung der kurdischen Frage. In: Wissenschaft und Frieden, Dossier 82, 3-6.

Yücekök, Ahmet N. (1977): Türkiye'de Örgütlenmiş Dinin Sosyo-Ekonomik Tabanı (1946-1968) [Die sozio-ökonomische Basis der organisierten Religion in der Türkei (1946-1968)]. Ankara Üniversitesi Siyasal Bilgiler Fakültesi Yayın Nr. 323.

Yüksel, Ayşe Seda (2012): Ölçek Literatürü ve Yereli Anlamak: Türkiye'nin Güneydoğusunda Neoliberal Deneyim ve Sınıf İlişkileri [Raum-Literatur und Verstehen des Lokalen: Neoliberale Erfahrung und Klassenbeziehungen im Südosten der Türkei]. In: Praxis, Nr. 29, 65-86.

Zander, Michael (2003): »Kulturelles Kapital« und Klassengesellschaft. Zu den Arbeiten Pierre Bourdieus und ihrem Nutzen für die Psychologie. In: Forum Kritische Psychologie, Bd. 46, 101-124.

Zencirci, Gizem (2015): From Property to Civil Society: The Historical Transformation of Vakıfs in Modern Turkey (1923-2013). In: International Journal of Middle East Studies, Bd. 47, Nr. 3, 533-554, https://doi.org/10.1017/S0020743815000537. Zeydanlığlu, Welat (2009): Torture and Turkification in Diyarbakır Prison. In: Zeydanlıoglu, Welat; Parry, John T. (Hg.): Rights, Citizenship \& Torture: Perspectives on Evil, Law and the State. Oxford, 73-92.

Zürcher, Erik J. (2004): Turkey. A Modern History. London/New York. 


\title{
Zeitungen
}

Birgün

Cumhuriyet

Frankfurter Allgemeine Zeitung

Hürriyet

Independent

Jerusalem Post

Le Monde diplomatique

Milliyet

Sabah

Star

The Guardian

Washington Post

Yeni Şafak

Yeniçağ

\section{Websites}

\author{
al-monitor.com \\ anfturkce.net \\ barisicinakademisyenler.net \\ bianet.org \\ birikimdergisi.com \\ bumko.gov.tr \\ diyanet.gov.tr \\ dw.com \\ egitimsen.org.tr \\ gazeteduvar.com.tr \\ haber7.com \\ ilerihaber.org \\ meb.gov.tr \\ mebpersonel.com \\ muftulukhaber.com \\ platform24.org \\ radikal.com.tr \\ sehirmedya.com \\ sendika63.org \\ t24.com.tr
}


tdv.org

timeturk.com

tr.sputniknews.com

tuik.gov.tr 


\section{Politikwissenschaft}



Extinction Rebellion Hannover

"Hope dies - Action begins":

Stimmen einer neuen Bewegung

2019, 96 S., kart.

7,99€ (DE), 978-3-8376-5070-9

E-Book: kostenlos erhältlich als Open-Access-Publikation, ISBN

978-3-8394-5070-3

EPUB: $0,00 €$ (DE), ISBN 978-3-7328-5070-9

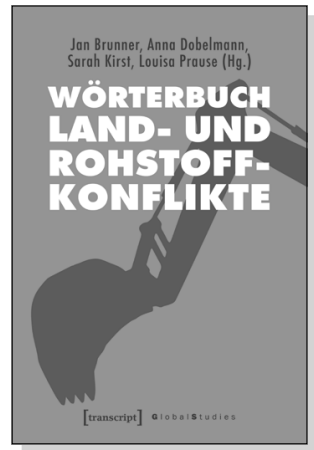

Jan Brunner, Anna Dobelmann,

Sarah Kirst, Louisa Prause (Hg.)

\section{Wörterbuch Land- und Rohstoffkonflikte}

2019, 326 S., kart., Dispersionsbindung, 1 SW-Abbildung 24,99€ (DE), 978-3-8376-4433-3

E-Book: 21,99 € (DE), ISBN 978-3-8394-4433-7

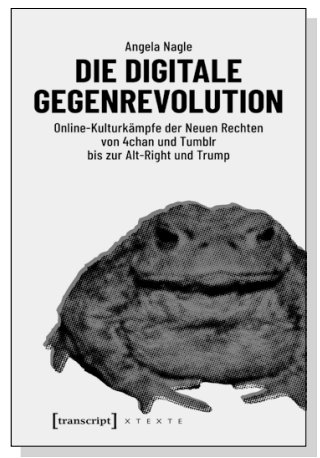

Angela Nagle

Die digitale Gegenrevolution

Online-Kulturkämpfe der Neuen Rechten

von 4chan und Tumblr bis zur Alt-Right und Trump

2018, 148 S., kart.

$19,99 €(D E), 978-3-8376-4397-8$

E-Book: 17,99€ (DE), ISBN 978-3-8394-4397-2

EPUB: $17,99 €$ (DE), ISBN 978-3-7328-4397-8 


\section{Politikwissenschaft}

Ines-Jacqueline Werkner Gerechter Frieden Das fortwährende Dilemma militärischer Gewalt

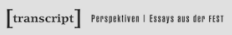

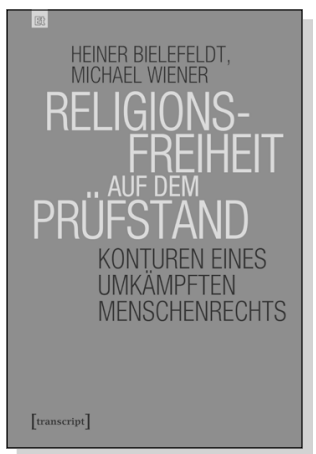

Judith Vey, Johanna Leinius, Ingmar Hagemann ( $\mathrm{Hg}$. )

Handbuch

Poststrukturalistische

Perspektiven auf

soziale Bewegungen

Ansätze, Methoden

und Forschungspraxis
Ines-Jacqueline Werkner

\section{Gerechter Frieden}

Das fortwährende Dilemma militärischer Gewalt

2018,106 S., kart.

$14,99 €$ (DE), 978-3-8376-4074-8

E-Book: 12,99 € (DE), ISBN 978-3-8394-4074-2

Heiner Bielefeldt, Michael Wiener

\section{Religionsfreiheit auf dem Prüfstand}

Konturen eines umkämpften Menschenrechts

Februar 2020, 278 S., kart.

$32,99 €(D E), 978-3-8376-4997-0$

E-Book: 32,99€ (DE), ISBN 978-3-8394-4997-4

Judith Vey, Johanna Leinius, Ingmar Hagemann (Hg.)

Handbuch Poststrukturalistische Perspektiven auf soziale Bewegungen

Ansätze, Methoden und Forschungspraxis

2019, 306 S., kart., Dispersionsbindung,

2 SW-Abbildungen, 2 Farbabbildungen

24,99€ (DE), 978-3-8376-4879-9

E-Book: kostenlos erhältlich als Open-Access-Publikation, ISBN 978-3-8394-4879-3 
